\title{
PRODUCTION OF HIGH VALUE FLUORINE GASES FOR THE SEMICONDUCTOR INDUSTRY
}

\author{
U.S. Department of Energy \\ Small Business Innovation Research Program \\ Phase II Final Report \\ Grant No. DE-FG02-99ER82894
}

October 23,2003

Principal Investigator John B. Bulko

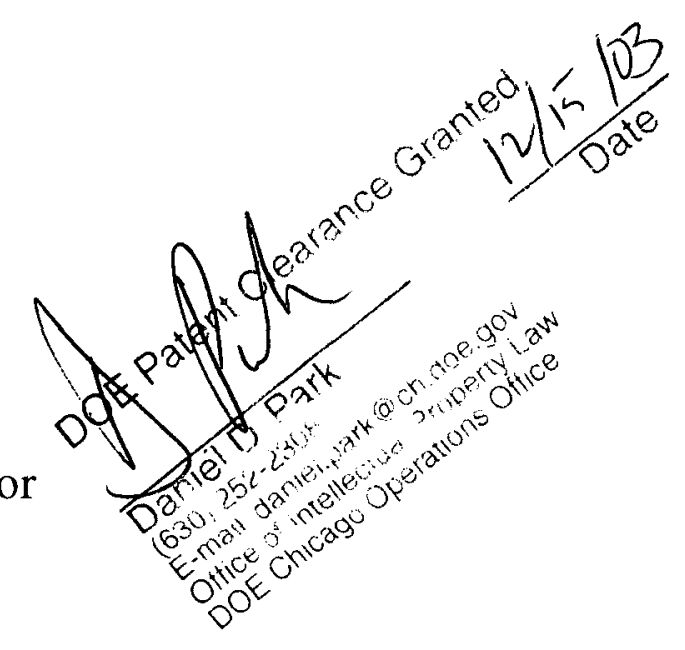

ST $\neg M M E T$

STARMET CORPORATION

2229 Main Street

Concord, MA 01742 


\section{DISCLAIMER}

This report was prepared as an account of work sponsored by an agency of the United States Government. Neither the United States Government nor any agency thereof, nor any of their employees, makes any warranty, express or implied, or assumes any legal liability or responsibility for the accuracy, completeness, or usefulness of any information, apparatus, product, or process disclosed, or represents that its use would not infringe privately owned rights. Reference herein to any specific commercial product, process, or service by trade name, trademark, manufacturer, or otherwise does not necessarily constitute or imply its endorsement, recommendation, or favoring by the United States Government or any agency thereof. The views and opinions of authors expressed herein do not necessarily state or reflect those of the United States Government or any agency thereof. 


\section{DISCLAIMER}

Portions of this document may be illegible in electronic image products. Images are produced from the best available original document. 


\section{SBIR RIGHTS NOTICE (JUN 1987)}

These SBIR data are furnished with SBIR rights under Grant No. DE-FG02-99ER82894. For a period of 4 years after acceptance of all items to be delivered under this grant, the Government agrees to use these data for Government purposes only, and they shall not be disclosed outside the Government (including disclosure for procurement purpose) during such period without permission of the grantee, except that, subject to the foregoing use and disclosure prohibitions, such data may be disclosed for use by support contractors. After the aforesaid 4-year period the Government has a royalty-free license to use, and to authorize others to use on its behalf, these data for Government purposes, but is relieved of all disclosure prohibitions and assumes no liability for unauthorized use of these data by third parties. This Notice shall be affixed to any reproductions of these data in whole or in part. 


\section{INTRODUCTION}

The US DOE is responsible for managing over 700,000 metric tons of depleted uranium hexafluoride $\left(\mathrm{DUF}_{6}\right)$. This material represents the so-called "tails" from the several gaseous diffusion enrichment plants located in Paducah, KY, Portsmouth, OH and Oak Ridge, TN. This material, stored as a solid in carbon steel cylinders, has accumulated over a period of 50 years. Originally, it was thought that the tails would be used as a feed material for the fast breeder reactor fuel cycle. However, with the national policy abandoning that use, this material has grown to be the largest amount of nuclear material in DOE inventory without significant application. Legislation enacted by Congress has led to the development of a Depleted Uranium Hexafluoride Materials Use Roadmap ${ }^{1}$ which details potential pathways in which the $\mathrm{DUF}_{6}$ resource may be converted to useful products in the future.

$\mathrm{DOE}$ has evaluated numerous management options for the $\mathrm{DUF}_{6}$ inventory in their Programmatic Environmental Impact Statement (PEIS) ${ }^{2}$. The strategy, based on the published Record of Decision for Long-Term Management and Use of Depleted Uranium Hexafluoride ${ }^{3}$, is to extract as much value as possible through beneficial re-use in order to reduce the costs of managing the $\mathrm{DUF}_{6}$ surplus and ultimately convert the uranium into uranium oxide, uranium metal or a combination of both. This strategy also includes converting the 225,000 metric tons of fluorine contained in the $\mathrm{DUF}_{6}$ stockpile into valuable fluorine products and using the uranium oxide by-product in applications such as radiation shielding ${ }^{4}$.

Several companies ${ }^{5}$ have demonstrated various hydrolysis methods for converting DUF $_{6}$ into uranium oxide $\left(\mathrm{U}_{3} \mathrm{O}_{8}\right)$ and recovery of hydrogen fluoride $(\mathrm{HF})$ as an anhydrous gas or aqueous mixture. This technology, while well known, produces a commodity chemical which has a market value of $\$ 0.40-\$ 0.50 / \mathrm{lb}^{2}$ for $70 \%$ aqueous $\mathrm{HF}$ and $\$ 0.70-\$ 0.90 / \mathrm{lb}^{2}$ for anhydrous hydrogen fluoride Consequently, while such "salvage value" will reduce the cost of conversion to the DOE, it has a minor impact.

This body of work presented here describes a new technology that can convert the fluorine in $\mathrm{DUF}_{6}$ into high-value, semiconductor specialty gases such as $\mathrm{SiF}_{4}, \mathrm{BF}_{3}, \mathrm{GeF}_{4}, \mathrm{SF}_{6}$ and $\mathrm{WF}_{6}$. These specialty gases are used extensively in the electronics industry. Detailed sales volumes of such gases are held proprietary by existing vendors. However, some indication of the market potential for these gases can be deduced from the data in Figure 1. 


\section{TABLE OF CONTENTS}

1 EXECUTIVE SUMMARY

2 TABLE OF CONTENTS

iii

3 LIST OF FIGURES

V

4 LIST OF TABLES

ix

7.2 Tasks For Producing $\mathrm{WF}_{6}$

$8 \mathrm{GeF}_{4}$ PRODUCTION

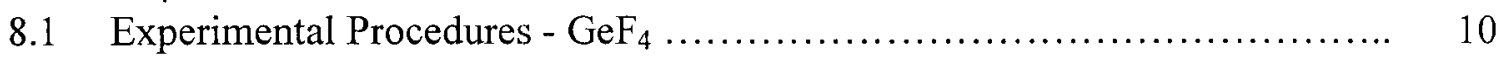

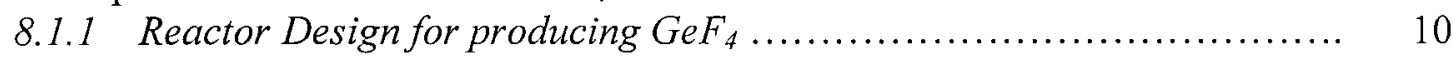

8.1.2 Materials of construction for production of $\mathrm{GeF}_{4} \ldots \ldots \ldots \ldots \ldots \ldots \ldots . . \ldots$

8.1.3 Optimization of product yield ...................................... 17

8.1.4 Development of analytical technology for identifying trace $U$ in $G_{e} F_{4} \ldots \quad 20$

8.1 .5 Particulate filtration ...................................................... 22

8.1.6 Process scale-up ..................................................... 22

8.1 .7 Gas ultrapurification ................................................. 26

8.1 .8 Product qualification .......................................... 28

8.1.9 Design and construction of low production-rate equipment .............. 28

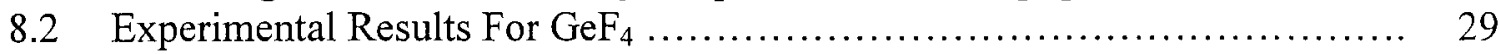

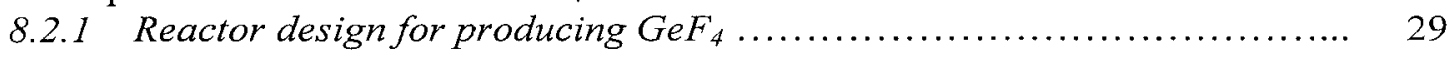

8.2.2 Materials of construction for production of $\mathrm{GeF}_{4} \ldots \ldots \ldots \ldots \ldots \ldots \ldots \ldots . . \ldots \ldots$

8.2 .3 Optimization of product yield ...................................... 67

8.2.4 Development of analytical technology for identifying trace $U$ in $G e F_{4} \ldots \quad 84$

8.2 .5 Particulate filtration .................................................. 90

8.2.6 Process scale-up ..................................................... 92

8.2 .7 Gas ultrapurification ........................................... 98

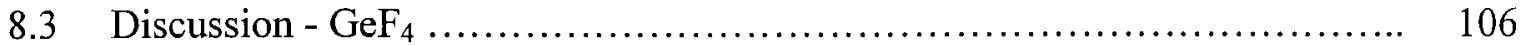

8.3.1 Producing the gas ................................................. 106

8.3.2 Quality of the gas ................................................. 108

8.3.3 Mechanistic considerations ....................................... 109

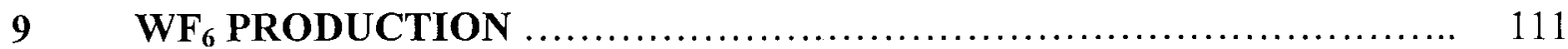

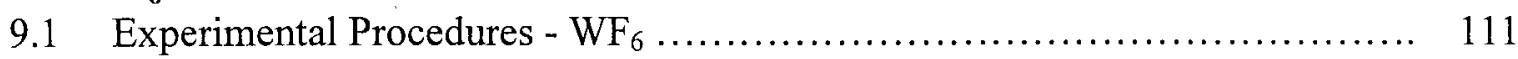

9.1.1 Bench-scale process development for $W_{6}$ from $W_{0 F} \ldots \ldots \ldots \ldots \ldots \ldots . \ldots 111$

9.1.2 Selection of suitable materials of construction for producing $W F_{6} \ldots \ldots \ldots 132$ 
$9.1 .3 \quad$ Reactor design ................................................... 132

9.1.4 WF $W_{6}$ product characterization ...................................... 132

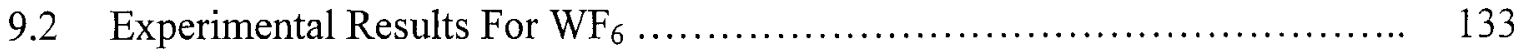

9.2.1 Bench-scale process development for $W_{6}$ from $W_{0 F} \ldots \ldots \ldots \ldots \ldots \ldots \ldots . \ldots 133$

9.2.2 Selection of suitable materials of construction for producing $W_{6} \ldots \ldots \ldots \quad 186$

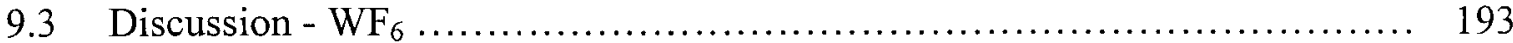

9.3.1 Producing the $\mathrm{WOF}_{4}$ intermediate ............................... 193

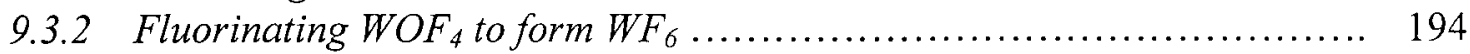

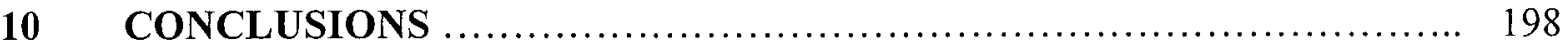

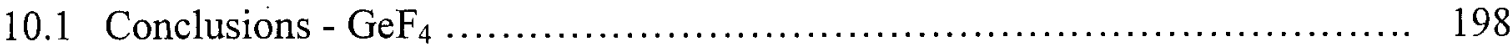

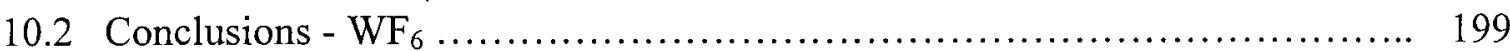

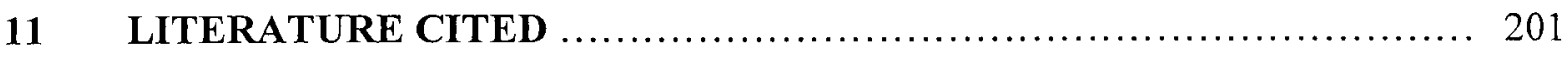

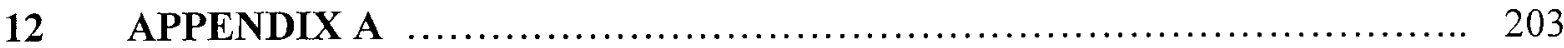

"Ultratrace Determination Of Uranium In Germanium Tetrafluoride"

March 12, 2001 Progress Report

October 23, 2001 Progress Report

May 11, 2002 Progress Report

March 17, 2003 Progress Report 


\section{LIST OF FIGURES}

Figure 1: Market Data on Semiconductor Specialty Gases (EMCON 98). $\ldots \ldots \ldots \ldots .2$

Figure 2: Schematic of crucible reactor setup with gas cylinder attached to collect $\mathrm{GeF}_{4}$.

Figure 3: Schematic of crucible reactor with copper cup and 'chimney' insert used in GeFusn-22.

Figure 4: Schematic of the Ni tube reactor setup with gas cylinder attached to collect $\mathrm{GeF}_{4}$.

Figure 5: New cylinder configuration and gas flow pathway used in collecting $\mathrm{GeF}_{4} . \quad 18$

Figure 6: Schematic representation of the temperature probe within the Ni tube reactor.

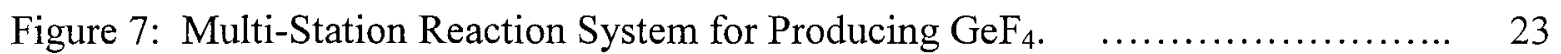

Figure 8: Gas collection system for trapping and packaging $\mathrm{GeF}_{4} . \quad \ldots \ldots \ldots \ldots \ldots \ldots .24$

Figure 9: $\mathrm{X}$-ray diffraction patterns for materials recovered from crucible reactor experiments GeFusn-19, $-20,-21,-22$ and -23 and reference patterns for $\mathrm{UF}_{4}$ (pdf\# 32-1401), $\mathrm{UGeO}_{4}$ (pdf\# 13-0588) and $\mathrm{UO}_{2}$ (pdf\# 41-1422). .......

Figure 10: X-ray diffraction pattern for residue recovered from GeFusn-24 and reference pattern for $\mathrm{UO}_{2}$ (pdf\# 41-1422).

Figure 11: X-ray diffraction patterns for the solids recovered from GeFusn-25 and -26 and the reference pattern for $\mathrm{UO}_{2}$ (pdf\# 41-1422).

Figure 12: X-ray diffraction patterns for the residues recovered from GeFusn-27, -30 and -31 and reference patterns for $\mathrm{UF}_{4}$ (pdf\# 32-1401), $\mathrm{UGeO}_{4}$ (pdf\# 13-0588) and $\mathrm{UO}_{2}$ (pdf\# 41-1422).

Figure 13: X-ray diffraction patterns for the residues recovered from GeFusn-28, -29 and -32 and reference patterns for $\mathrm{U}_{3} \mathrm{O}_{8}$ (pdf\# 47-1493) and $\mathrm{UO}_{2} \mathrm{~F}_{2}$ (pdf\# 25-1115).

Figure 14: Infrared spectra of gas samples produced in GeFusn-19, -20 and 23 and reference spectra for $\mathrm{GeF}_{4}, \mathrm{SiF}_{4}$ and $\mathrm{BF}_{3}$.

Figure 15: Enhanced view of the spectral region between $4000-2200 \mathrm{~cm}^{-1}$ for samples collected in GeFusn-19, -20 and -23 and reference spectrum for $\mathrm{GeF}_{4}$. .....

Figure 16: Infrared spectrum of gaseous product collected in GeFusn-24 and reference spectra for $\mathrm{GeF}_{4}, \mathrm{BF}_{3}$ and $\mathrm{SiF}_{4}$.

Figure 17: Infrared spectra for gases made in GeFusn-25 and -26 and reference spectra for $\mathrm{SiF}_{4}, \mathrm{BF}_{3}$ and $\mathrm{GeF}_{4}$.

Figure 18: Enhanced view of the spectral region between $4000-2200 \mathrm{~cm}^{-1}$ for GeFusn-25 and -26 samples and reference spectrum for $\mathrm{GeF}_{4}$.

Figure 19: Infrared spectra for gas samples taken from GeFusn-27, -30 and -31 and reference spectra for $\mathrm{GeF}_{4}$ and $\mathrm{BF}_{3}$.

Figure 20: Enhanced view of the spectral region between $4000-2200 \mathrm{~cm}^{-1}$ for GeFusn-27, -30 and -31 and reference spectrum for $\mathrm{GeF}_{4}$.

Figure 21: Infrared spectra for gas samples taken from GeFusn-28, -29 and -32 and reference spectra for $\mathrm{GeF}_{4}$ and $\mathrm{BF}_{3}$.

Figure 22: Enhanced view of the spectral region between $4000-2200 \mathrm{~cm}^{-1}$ for GeFusn-28, -29 and -32 and reference spectrum for $\mathrm{GeF}_{4}$.

Figure 23: EDS pattern from the inside surface of the Ni boat. 
Figure 24: EDS pattern from the outside surface of the Ni boat.

Figure 25: Backscattered image of Monel coupon after being embedded in the reaction mixture.

Figure 26: Backscattered image of Inconel 600 coupon after exposure to the reaction mixture.

Figure 27: Cross section of Haynes 242 coupon exposed to dry $\mathrm{GeF}_{4}$.

Figure 28: Haynes $\mathrm{HR} 160^{\circledR}$ coupon exposed to the reaction mixture.

Figure 29: Type 304 Stainless Steel coupon after being embedded in the reaction mixture.

Figure 30: Summary of the examination of the internal surface of the Copper chimney tube used in GeFusn-22.

Figure 31: Summary of the examination of the external surface of the Copper chimney tube used in GeFusn-22.

Figure 32: Copper coupon exposed to $\mathrm{GeF}_{4}$ gas in the crucible reactor outlet.

Figure 33: X-ray diffraction pattern for the residue recovered from GeFusn-33 and reference patterns for $\mathrm{UF}_{4}, \mathrm{UO}_{2}$ (pdf\# 41-1422) and $\mathrm{UGeO}_{4}$ (pdf\# 13-0588).

Figure 34: Infrared spectrum of $\mathrm{GeF}_{4}$ collected from GeFusn-33 and a reference spectrum of $\mathrm{GeF}_{4}$ supplied by Voltaix, Inc.

Figure 35: Infrared spectra of gas samples taken during GeFusn-35 at various temperatures between ambient and $350^{\circ} \mathrm{C}$.

Figure 36: Infrared spectra of gas samples from GeFusn -35 at $350^{\circ} \mathrm{C}, 650^{\circ} \mathrm{C}, 700^{\circ} \mathrm{C}$ and $725^{\circ} \mathrm{C}$.

Figure 37: X-ray diffraction pattern for reaction residue from GeFusn-35 and reference patterns for $\mathrm{UF}_{4}, \mathrm{UO}_{2}$ (pdf\# 41-1422) and $\mathrm{UGeO}_{4}$ (pdf\# 13-0588).

Figure 38: TGA result showing the weight gain when $\mathrm{Ge}^{\circ}$ metal was heated to $1000^{\circ} \mathrm{C}$ in dry air.

Figure 39: TGA result showing the weight loss when a mixture of $\mathrm{UF}_{4}$ and $\mathrm{Ge}^{\circ}$ metal was heated to $850^{\circ} \mathrm{C}$ in dry air.

Figure 40: X-ray diffraction pattern for residue recovered from the TGA reaction performed at $850^{\circ} \mathrm{C}$ and reference patterns for $\mathrm{U}_{3} \mathrm{O}_{8}$ (pdf $47-1493$ ) and $\mathrm{Ge}^{\circ}$ metal (pdf\# 04-0545).

Figure 41: Infrared spectra of gas samples generated in GeFusn-39 taken at a temperature of $600^{\circ} \mathrm{C}$ and $700^{\circ} \mathrm{C}$.

Figure 42: TGA results showing the temperature at which the reaction between $\mathrm{UF}_{4}$ and $\mathrm{GeO}_{2}$ starts producing $\mathrm{GeF}_{4}$.

Figure 43: X-ray diffraction patterns for the black and green residues from GeFusn-36 and reference patterns for $\mathrm{UO}_{2}$, (pdf\# 41-1422), $\mathrm{U}_{3} \mathrm{O}_{8}$ (pdf\# 47-1493), $\mathrm{UGeO}_{4}$ (pdf\# 13-0588) and $\mathrm{UF}_{4}$.

Figure 44: Description and illustration of the TEM- 800 Series Gas Filter. ........... 91

Figure 45: Revised design of the multi-station reaction system. $\ldots \ldots \ldots \ldots \ldots \ldots \ldots \ldots . . \ldots 4$

Figure 46: Revised design of the condensation zone in the collection system. ....... 95

Figure 47: X-ray diffraction patterns for the solids recovered from GeFusn-37 and -38 and reference pattern for $\mathrm{U}_{3} \mathrm{O}_{8}$ (pdf\# 47-1493). 
Figure 48: Infrared spectrum of the gas stream leaving the collection cylinder in GeFusn- 38 with the furnace at $800^{\circ} \mathrm{C}$ and a reference sample of $\mathrm{GeF}_{4}$ at 10 torr. Peaks due to known impurities such as $\mathrm{CO}_{2}, \mathrm{BF}_{3}, \mathrm{SiF}_{4}$ and $\mathrm{H}_{2} \mathrm{O}$ have been marked.

Figure 49: Infrared spectra for $\mathrm{GeF}_{4}$ produced at Starmet in GeFusn-37\&38 and two samples obtained from other vendors.

Figure 50: Comparison of reaction conversions using either $100 \%$ helium or a mixture of helium + air as the sweep gas at $700^{\circ} \mathrm{C}$ and $750^{\circ} \mathrm{C}$.

Figure 51: Reaction conversion charted as a function of temperature for the series of tube reactor experiments where pure helium and helium/air sweep streams were employed.

Figure 52: Schematic diagram of the reaction system used for conducting WFusn-18 and -19 .

Figure 53: TGA results showing the weight change during the reaction between $\mathrm{UF}_{4}$ and $\mathrm{WO}_{2}\left[\mathrm{UF}_{4}: \mathrm{WO}_{2}=1.014: 1\right]$ in air at $600^{\circ} \mathrm{C}$ and the oxidation of $\mathrm{WO}_{2}$ in air at $600^{\circ} \mathrm{C}$.

Figure 54: TGA result comparing the weight change during the reaction between $\mathrm{UF}_{4}$ and $\mathrm{WO}_{2}\left[\mathrm{UF}_{4}: \mathrm{WO}_{2}=1.014: 1\right]$ at $600^{\circ} \mathrm{C}$ and $700^{\circ} \mathrm{C}$ in air.

Figure 55: $\mathrm{X}$-ray diffraction pattern of the residue from $\mathrm{UF}_{4}+\mathrm{WO}_{2}\left[\mathrm{UF}_{4}: \mathrm{WO}_{2}=1.014: 1\right]$ reacted at $700^{\circ} \mathrm{C}$ in air and the reference pattern for $\mathrm{UO}_{2} \mathrm{~F}_{2}$ (pdf\# 27-0933). .

Figure 56: X-ray diffraction pattern of the residue from $\mathrm{UF}_{4}+\mathrm{WO}_{2}\left[\mathrm{UF}_{4}: \mathrm{WO}_{2}=1.014: 1\right]$ reacted at $600^{\circ} \mathrm{C}$ in air and reference patterns for $\mathrm{WO}_{2.96} \mathrm{O}_{0.04}$ (pdf\# 22-0960) and $\mathrm{UF}_{4}$ (pdf\# 32-1401).

Figure 57: TGA results showing the weight change during the reaction between $\mathrm{UF}_{4}$ and $\mathrm{WO}_{2}\left[\mathrm{UF}_{4}: \mathrm{WO}_{2}=1.844: 1\right]$ at $700^{\circ} \mathrm{C}$ and $800^{\circ} \mathrm{C}$ in air.

Figure 58: $\mathrm{X}$-ray diffraction patterns for the residues from $\mathrm{UF}_{4}+\mathrm{WO}_{2}$

[UF $\left.\mathrm{UF}_{4}: \mathrm{WO}_{2}=1.844: 1\right]$ reacted at $700^{\circ} \mathrm{C}$ and $800^{\circ} \mathrm{C}$ in air and reference patterns for $\mathrm{UO}_{2} \mathrm{~F}_{2}$ (pdf\# 27-0933), $\mathrm{UF}_{4}$ (pdf\# 32-1401) and $\mathrm{U}_{3} \mathrm{O}_{8}$ (pdf\# 47-1493)...

Figure 59: TGA result showing weight change during reaction between $\mathrm{UF}_{4}$ and $\mathrm{WO}_{2}$ $\left[\mathrm{UF}_{4}: \mathrm{WO}_{2}=2.013: 1\right]$ at $700^{\circ} \mathrm{C}$ in air.

Figure 60: X-ray diffraction pattern for the residue from $\mathrm{UF}_{4}+\mathrm{WO}_{2}$

$\left[\mathrm{UF}_{4}: \mathrm{WO}_{2}=2.013: 1\right]$ and reference patterns for $\mathrm{UO}_{2} \mathrm{~F}_{2}$ (pdf\# 27-0933) and $\mathrm{U}_{3} \mathrm{O}_{8}$ (pdf\# 47-1493).

Figure 61: TGA result showing the weight change during the reaction between $\mathrm{UF}_{4}$ and $\mathrm{WO}_{3}\left[\mathrm{UF}_{4}: \mathrm{WO}_{3}=1: 1.025\right]$ at $700^{\circ} \mathrm{C}$ in air.

Figure 62: X-ray diffraction patterns for the residue from $\mathrm{UF}_{4}+\mathrm{WO}_{3}$ $\left[\mathrm{UF}_{4}: \mathrm{WO}_{3}=1: 1.025\right]$ reacted in air at $700^{\circ} \mathrm{C}, \mathrm{WO}_{3}$ reagent from Alfa Aesar and the reference pattern for $\mathrm{UO}_{2} \mathrm{~F}_{2}$ (pdf\# 27-0933).

Figure 63: TGA results showing weight change during the reaction between $\mathrm{UF}_{4}$ and $\mathrm{WO}_{3}\left[\mathrm{UF}_{4}: \mathrm{WO}_{3}=1.908: 1\right]$ at $700^{\circ} \mathrm{C}, 750^{\circ} \mathrm{C}$ and $800^{\circ} \mathrm{C}$ in air.

Figure 64: $\mathrm{X}$-ray diffraction patterns for the residues from the reactions between $\mathrm{UF}_{4}+\mathrm{WO}_{3}\left[\mathrm{UF}_{4}: \mathrm{WO}_{3}=1.908: 1\right]$ and reference patterns for $\mathrm{UO}_{2} \mathrm{~F}_{2}$ (pdf\# 27-0933), $\mathrm{U}_{3} \mathrm{O}_{8}$ (pdf\# 47-1493) and $\mathrm{UF}_{4}$ (pdf\# 32-1401).

Figure 65: TGA results showing weight loss and temperature difference for three stoichiometric mixtures of $\mathrm{UF}_{4}$ with $\mathrm{WO}_{2}$ heated to $700^{\circ} \mathrm{C}$ in air. 
Figure 66: TGA results showing weight loss and temperature difference for two stoichiometric mixtures of $\mathrm{UF}_{4}$ with $\mathrm{WO}_{3}$ heated to $700^{\circ} \mathrm{C}$ in air. .........

Figure 67: TGA results showing the weight change during reactions between mixtures of $\mathrm{UF}_{4}$ with $\mathrm{WO}_{2}$ and $\mathrm{WO}_{3}$ at $700^{\circ} \mathrm{C}, 750^{\circ} \mathrm{C}$ and $800^{\circ} \mathrm{C}$ in air.

Figure 68: X-ray diffraction patterns for several residues from reactions between $\mathrm{UF}_{4}$ with $\mathrm{WO}_{2}$ and $\mathrm{WO}_{3}$ at $700^{\circ} \mathrm{C}$ and $800^{\circ} \mathrm{C}$ and the reference pattern for $\mathrm{UO}_{2} \mathrm{~F}_{2}$ (pdf\# 27-0933).

Figure 69: X-ray diffraction pattern for residue from Wfusn-8 and the reference pattern for $\mathrm{UO}_{2} \mathrm{~F}_{2}$ (pdf\# 27-0933).

Figure 70: X-ray diffraction patterns for the hydrolyzed residue causing the blockage in the tube, the hydrolyzed solid captured in the flask and residue in the boat from WFusn-9 and reference patterns for $\mathrm{WO}_{3} \cdot 2 \mathrm{H}_{2} \mathrm{O}$ (pdf\# 18-1419), $\mathrm{WO}_{3} \cdot \mathrm{H}_{2} \mathrm{O}$ (pdf\# 43-0679), $\mathrm{UF}_{4}$ (pdf\# 32-1401) and $\mathrm{UO}_{2} \mathrm{~F}_{2}$ (pdf\# 270933). .

Figure 71: X-ray diffraction patterns for the residue recovered after WFusn-10, the hydrolyzed residue from the condensation tube and reference patterns for $\mathrm{UO}_{2} \mathrm{~F}_{2}$ (pdf\# 27-0933) and $\mathrm{WO}_{3} \cdot \mathrm{H}_{2} \mathrm{O}$ (pdf\# 43-0679).

Figure 72: X-ray diffraction patterns for the residue recovered after WFusn-11, the residue produced by the reaction between $\mathrm{UF}_{4}$ and $\mathrm{WO}_{3}$ at $800^{\circ} \mathrm{C}$ in the TGA apparatus and the reference pattern for $\mathrm{UO}_{2} \mathrm{~F}_{2}$ (pdf\# 27-0933).

Figure 73: X-ray diffraction patterns for hydrolyzed samples of condensed solid produced in WFusn-10 and WFusn-11 and reference patterns for $\mathrm{WO}_{3} \cdot 2 \mathrm{H}_{2} \mathrm{O}$ (pdf\# 18-1419) and $\mathrm{WO}_{3} \bullet \mathrm{H}_{2} \mathrm{O}$ (pdf\# 43-0679).

Figure 74: X-ray diffraction patterns for the bulk reaction residue recovered from WFusn-12 and reference patterns for $\mathrm{UO}_{2} \mathrm{~F}_{2}$ (pdf\# 27-0933) and $\mathrm{UF}_{4}$ (pdf\# 32-1401).

Figure 75: X-ray diffraction patterns for the residue recovered from WFusn-13 and untreated $\mathrm{UF}_{4}$ and the reference pattern for $\mathrm{UO}_{2} \mathrm{~F}_{2}$ (pdf\# 27-0933).

Figure 76: $\mathrm{X}$-ray diffraction patterns for the residue recovered after heating the $\mathrm{UF}_{4} / \mathrm{WOF}_{4}$ mixture to $196^{\circ} \mathrm{C}$ in air, untreated $\mathrm{UF}_{4}$ and the reference pattern for $\mathrm{UO}_{2} \mathrm{~F}_{2}$ (pdf\# 27-0933).

Figure 77: X-ray diffraction pattern for the residue from WFusn-14 and the reference pattern for $\mathrm{UO}_{2} \mathrm{~F}_{2}$ (pdf\# 27-0933).

Figure 78: X-ray diffraction pattern for the WFusn-14 residue and reference patterns for two hydrated analogs of $\mathrm{UO}_{2} \mathrm{~F}_{2}$ formed by adsorption of moisture from the air, $\mathrm{UO}_{2} \mathrm{~F}_{2} \bullet 1.5 \mathrm{H}_{2} \mathrm{O}$ (pdf\# 24-1154) and $\mathrm{UO}_{2} \mathrm{~F}_{2} \bullet 2 \mathrm{H}_{2} \mathrm{O}$ (pdf\# 24-1153)...

Figure 79: X-ray diffraction pattern for the green powder coating the interior walls of the reaction tube and reference pattern for untreated $\mathrm{UF}_{4}$.

Figure 80: X-ray diffraction pattern for the pale yellow solid recovered from WFusn-15 and reference patterns for $\mathrm{UO}_{2} \mathrm{~F}_{2}$ (pdf\#27-0933) and $\mathrm{UO}_{2} \mathrm{~F}_{2} \bullet 1.5 \mathrm{H}_{2} \mathrm{O}$ (pdf\# 24-1154).

Figure 81: $\mathrm{X}$-ray diffraction pattern for the residue reclaimed from WFusn-16 and reference patterns for $\mathrm{UO}_{2} \mathrm{~F}_{2}$ (pdf\# 27-0933), $\mathrm{UO}_{2} \mathrm{~F}_{2} \bullet 1.5 \mathrm{H}_{2} \mathrm{O}$ (pdf\# 24-1154) and unreacted $\mathrm{UF}_{4}$.

Figure 82: Post-reaction residue in the nickel boat after WFusn-17 showing many pieces of scale scattered across the surface of the $\mathrm{UO}_{2} \mathrm{~F}_{2}$ powder. 
Figure 83: X-ray diffraction pattern for the green-tinted portion of residue from WFusn-17 and reference patterns for $\mathrm{UO}_{2} \mathrm{~F}_{2}$ (pdf\# 27-0933), $\mathrm{UO}_{2} \mathrm{~F}_{2} \cdot 2 \mathrm{H}_{2} \mathrm{O}$ (pdf\# 24-1153) and unreacted $\mathrm{UF}_{4}$.

Figure 84: $\mathrm{X}$-ray diffraction pattern for the pale yellow residue from WFusn-17 and reference patterns for $\mathrm{UO}_{2} \mathrm{~F}_{2}$ (pdf\# 27-0933) and $\mathrm{UO}_{2} \mathrm{~F}_{2} \cdot 2 \mathrm{H}_{2} \mathrm{O}$ (pdf\# 24-1153).

Figure 85: TGA Plot showing the weight change during reaction between $\mathrm{TiF}_{4}$ and $\mathrm{WO}_{2}$ at $500^{\circ} \mathrm{C}$ in air.

Figure 86: FT-IR spectra of gaseous samples collected at various reactor temperatures during the WFusn-19 reaction.

Figure 87: FT-IR spectra of the gas aliquot collected at $185^{\circ} \mathrm{C}$, the same sample after diluting with helium and reference spectra for $\mathrm{WF}_{6}$ and $\mathrm{HF}$.

Figure 88: X-ray diffraction pattern for the hydrolyzed residue recovered from the underside of the reactor lid and the reference pattern for $\mathrm{TiOF}_{2}$ (pdf\# 08-0060).

Figure 89: Image of nickel boat used in the high temperature fusion reactions between $\mathrm{UF}_{4}$ and $\mathrm{WO}_{2} / \mathrm{WO}_{3}$ mixtures.

Figure 90: Side view image of the nickel boat showing the green-brown corrosion layer covering the exterior and interior walls. The arrow shows where a piece of scale was removed from the exterior wall.

Figure 91: A close-up image of the nickel boat showing the corrosion of the interior walls.

Figure 92: X-ray diffraction patterns for the outward and inward facing sides of the scale removed from the side of the nickel boat shown in Figure 88.

Figure 93: X-ray diffraction pattern for the outward facing side of the scale and reference patterns for $\mathrm{NiO}$ (pdf\# 47-1049), $\mathrm{NiF}_{2}$ (pdf\# 24-0791) and $\mathrm{NiWO}_{4}$ (pdf\# 15-0755).

Figure 94: X-ray diffraction pattern for the inward facing side of the scale and reference patterns for $\mathrm{NiO}$ (pdf\# 47-1049), $\mathrm{NiWO}_{4}$ (pdf\# 15-0755) and $\mathrm{NiF}_{2}$ (pdf\# 24-0791).

\section{LIST OF TABLES}

Table 1: Retail Pricing of Specialty Gases from BOC Edwards (2003). ............ 2

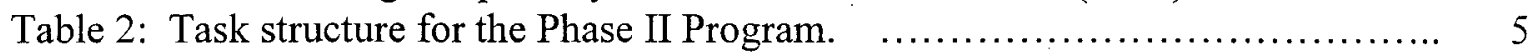

Table 3: Experiments Performed in the Crucible Reactor Setup. $\quad \ldots \ldots \ldots \ldots \ldots \ldots \ldots . . . \ldots 11$

Table 4: Heating Profile for the Crucible Reactor Experiments. $\quad \ldots \ldots \ldots \ldots \ldots \ldots \ldots \ldots \ldots$

Table 5: Experiments Performed in the Tube Reactor Setup. $\quad \ldots \ldots \ldots \ldots \ldots \ldots \ldots \ldots \ldots . . \ldots \ldots$

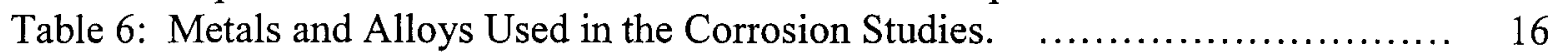

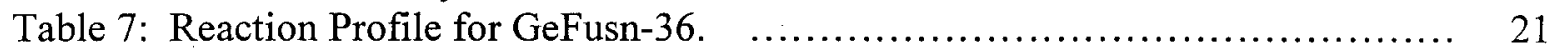

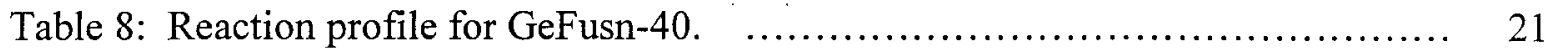

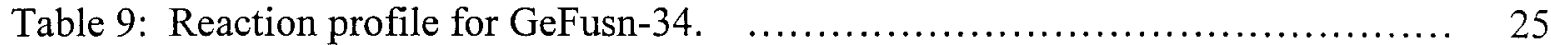

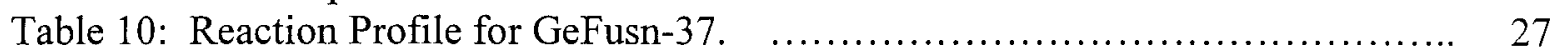

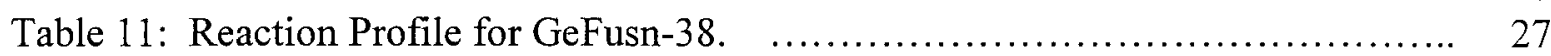

Table 12: Experiments performed in the crucible reactor setup. $\ldots \ldots \ldots \ldots \ldots \ldots \ldots \ldots . . . \ldots$ 
Table 13: Results showing analyses for Ge by ICP for aqueous wash solutions collected during recovery of $\mathrm{GeF}_{2}$ residue from reactor hardware. $\quad \ldots \ldots \ldots . \quad 32$

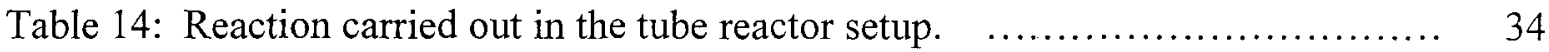

Table 15: Recovery of $\mathrm{GeF}_{2}$ deposits from reactor hardware. $\quad \ldots \ldots \ldots \ldots \ldots \ldots \ldots \ldots . . \ldots \ldots$

Table 16: Reaction Profile for GeFusn-33. ................................ 67

Table 17: Internal temperature profile in the nickel tube reactor. $\ldots \ldots \ldots \ldots \ldots \ldots \ldots . . . \ldots 9$

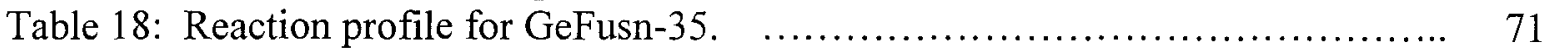

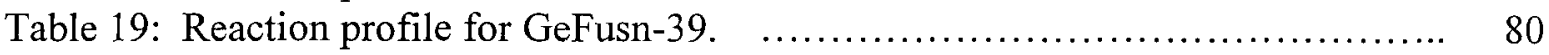

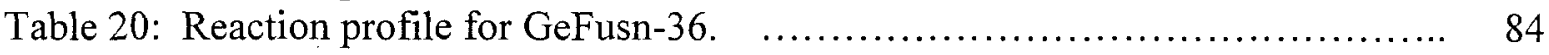

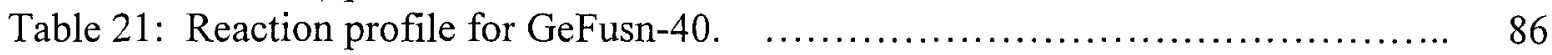

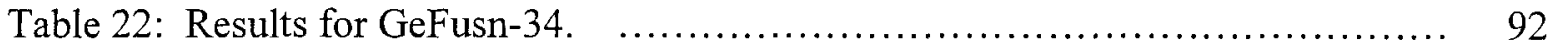

Table 23: Process Hazards Review for $\mathrm{GeF}_{4}$ Production. $\quad \ldots \ldots \ldots \ldots \ldots \ldots \ldots \ldots \ldots . . \ldots 6$

Table 24: Profile and results for GeFusn-37 and 38. ......................... 98

Table 25: Results for ICP-MS analysis of 'as-produced' $\mathrm{GeF}_{4}$ received from Voltaix,

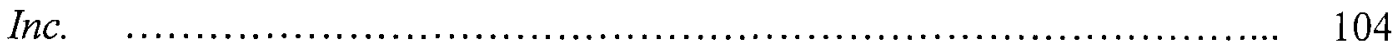

Table 26: Specifications for UHP grade - 99.99\% $\mathrm{GeF}_{4}$ established by Voltaix, Inc. ... 105

Table 27: Micro-scale experiments performed using the thermogravimetric analyzer. .. 111

Table 28: Experiments performed in the bench-scale reaction system. $\ldots \ldots \ldots \ldots \ldots \ldots, 112$

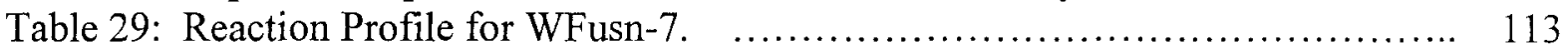

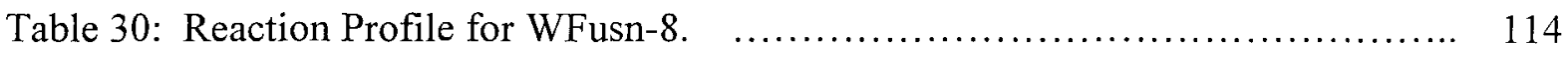

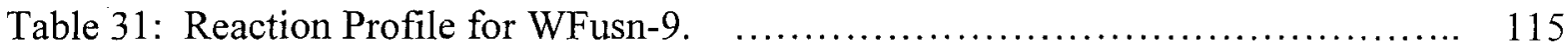

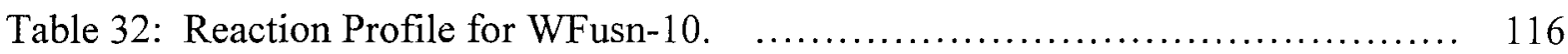

Table 33: Reaction Profile for WFusn-11. .................................. 117

Table 34: Reaction Profile for WFusn-12. ................................ 118

Table 35: Reaction Profile for WFusn-13. ................................. 119

Table 36: Thermodynamic calculations for reacting $\mathrm{UF}_{4}$ with $\mathrm{WOF}_{4} . \quad \ldots \ldots \ldots \ldots \ldots . \ldots$

Table 37: Reaction Profile for WFusn-14. ................................. 121

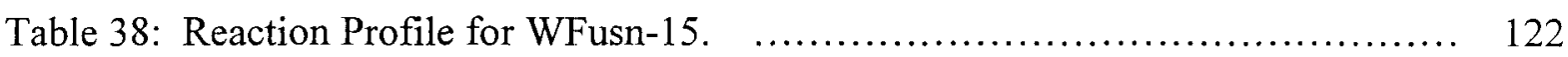

Table 39: Thermodynamic calculations for reacting $\mathrm{WOF}_{4}$ with $\mathrm{SiO}_{2} . \quad \ldots \ldots \ldots \ldots \ldots . \ldots 123$

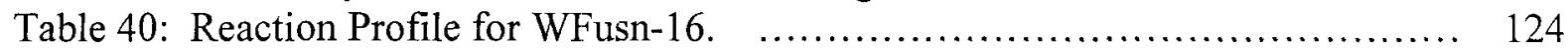

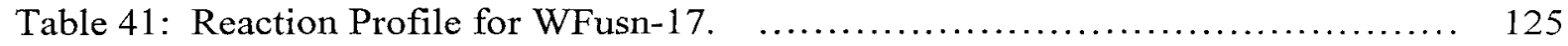

Table 42: Thermodynamic calculations for reacting $\mathrm{WOF}_{4}$ with $\mathrm{TiF}_{4} . \quad \ldots \ldots \ldots \ldots \ldots . . .126$

Table 43: Thermodynamic calculations for reaction $\mathrm{WO}_{2}$ with $\mathrm{TiF}_{4} . \quad \ldots \ldots \ldots \ldots \ldots \ldots$

Table 44: Reaction Profiles for WFusn-18 and WFusn-19. $\ldots \ldots \ldots \ldots \ldots \ldots \ldots \ldots \ldots \ldots$

Table 45: TGA results for the reactions using $\mathrm{UF}_{4}+\mathrm{WO}_{2}\left[\mathrm{UF}_{4}: \mathrm{WO}_{2}=1.014: 1\right] . \quad \ldots \ldots \ldots 136$

Table 46: Thermodynamic calculations for the reaction between $\mathrm{UF}_{4}$ and $\mathrm{WO}_{3} . \ldots \ldots, 141$

Table 47: Weight loss results for the reactions between $\mathrm{UF}_{4}+\mathrm{WO}_{3}\left[\mathrm{UF}_{4}: \mathrm{WO}_{3}=1.908: 1\right]$. 144

Table 48: Summary of results for trials WFusn-7 to WFusn-12. $\quad \ldots \ldots \ldots \ldots \ldots \ldots \ldots \ldots \ldots$

Table 49: Summary of results for WFusn-13 to WFusn-17. $\ldots \ldots \ldots \ldots \ldots \ldots \ldots \ldots \ldots \ldots$

Table 50: Thermodynamic calculations describing the two-step corrosion process occurring on the surface of nickel. 


\section{Phase II Final Report}

\section{PRODUCTION OF HIGH VALUE FLUORINE GASES FOR THE SEMICONDUCTOR INDUSTRY}

\section{EXECUTIVE SUMMARY}

The chemistry to manufacture high purity $\mathrm{GeF}_{4}$ and $\mathrm{WF}_{6}$ for use in the semiconductor industry using Starmet's new fluorine extraction technology has been developed. Production of $\mathrm{GeF}_{4}$ was established using a tube-style reactor system constructed of nickel 200 alloy in which conversion yields as high as $98.1 \%$ were attained. Collection of the fluoride gas improved to $97.7 \%$ when the reactor sweep gas contained a small fraction of dry air (10-12 vol\%) along with helium. The quality of fluoride gas produced throughout the program was analyzed by FT-IR spectroscopy. The $\left(\mathrm{UF}_{4}+\mathrm{GeO}_{2}\right)$ reaction was shown to begin above $400^{\circ} \mathrm{C}$. The lab-synthesized product was shown to contain the lease amount of infrared-active and elemental impurities when analyzed at contracted and independent analytical laboratories and compared with a reference material certified at $99.99 \%$ purity. Analysis of the "as-produced" gas using ICP-MS showed that uranium could not be detected at a detection limit of 0.019ppm-wt. Argonne National Laboratory was subcontracted to develop two new methods to detect trace uranium in $\mathrm{GeF}_{4}$. Samples of lab-synthesized gas were analyzed by ultraviolet optical absorption spectroscopy for determining the level of $\mathrm{U}_{\text {as }} \mathrm{UF}_{6}$ in $\mathrm{GeF}_{4}$. In two separate trials, no absorbance due to $\mathrm{UF}_{6}$ could be detected in either the unfiltered or the filtered batch of fluoride at their respective detection limits of 0.75 and $0.64 \mathrm{ppm}$-vol. The second analytical technique for trace uranium determination involved laser-induced photoluminescence spectroscopy. Trials to detect luminescence of uranyl species in glassy $\mathrm{GeO}_{2}$ were unsuccessful due to the formation of impurity species whose luminescence decay overlapped that of the uranyl ions in the glassy matrix. Alternative techniques involving the conversion of hydrolyzed $\mathrm{GeO}_{2}$ to $\mathrm{GeCl}_{4}$ were unsuccessful in producing a residue containing $\mathrm{UO}_{2} \mathrm{Cl}_{2}$ species for quantitative analysis by laser induced phosphorescence. Finally, conceptual drawings of a production-scale reaction system were made for generating up to $2 \mathrm{~kg}$ of $\mathrm{GeF}_{4}$ per day using six tube-style reaction stations. Construction of the production apparatus was postponed to a later date as a result of a global slump in the electronics and semiconductor sectors over the previous 18 months.

Development of a process to make $\mathrm{WF}_{6}$ from $\mathrm{WOF}_{4}$ was also pursued during the later half of the SBIR program. Results from milligram-scale reactions showed that the oxyfluoride compound could be made using either $\mathrm{WO}_{2}$ or $\mathrm{WO}_{3}$ in reaction with $\mathrm{UF}_{4}$ in the $700^{\circ} \mathrm{C}-800^{\circ} \mathrm{C}$ temperature range. When conducted in a bench-sized nickel tube reaction system, capture efficiency for the white crystalline residue ranged from $48.5 \%$ to $67.1 \%$ of the theoretical yield. After determining suitable reactants and conditions, focus shifted to probing the reactivity of $\mathrm{WOF}_{4}$. The oxyfluoride intermediate did not appear to react with either $\mathrm{UF}_{4}$ or $\mathrm{SiO}_{2}$ up to a temperature of $196^{\circ} \mathrm{C}$, contrary to prediction by thermodynamic calculations of the spontaneous Gibbs free energy change. When $\mathrm{WOF}_{4}$ was reacted with $\mathrm{TiF}_{4}$, there were some indications of a gaseous product being released. Investigation was broadened to study the reaction between $\mathrm{WO}_{2}$ and $\mathrm{TiF}_{4}$. When staged in a bench-top apparatus, gaseous reaction products released around $185^{\circ} \mathrm{C}$ showed a component whose infrared absorbance bands emerging at frequencies consistent with those for $\mathrm{WF}_{6}$. Further experimentation is required to determine if the $\left(\mathrm{WO}_{2}+\mathrm{TiF}_{4}\right)$ pathway is feasible for producing $\mathrm{WF}_{6}$ of high purity. 


\section{Semiconductor Specialty Gas Market (1997)}

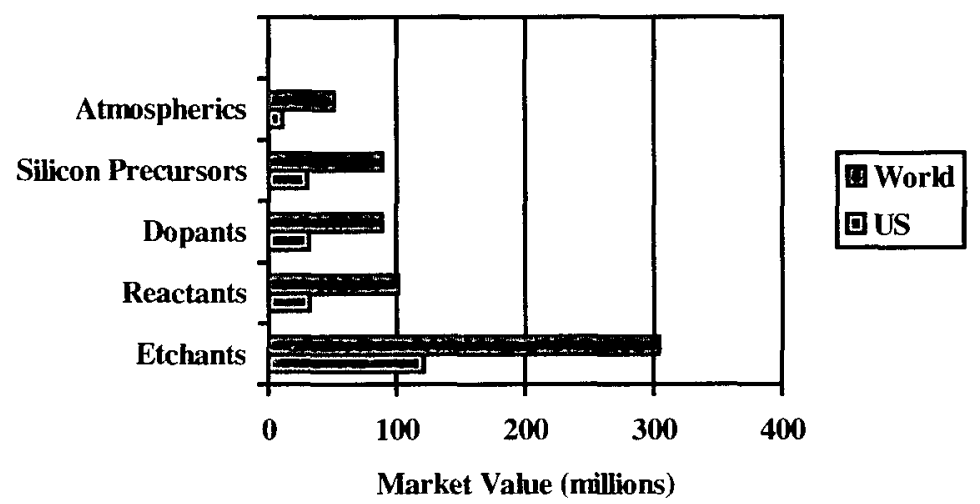

Figure 1. Market Data on Semiconductor Specialty Gases (EMCON 98).

These gases are used for ion-implantation, chemical vapor deposition (CVD), cleaning, and as starting materials for some other processes including the production of high purity silicon. Retail prices for some of the gases from BOC Edwards are shown in Table 1. Purchase price for such gases from producers was stated to be about $25 \%$ to $30 \%$ of retail values.

Table 1.

Retail Pricing of Specialty Gases from BOC Edwards (2003).

\begin{tabular}{|c|c|c|c|c|c|}
\hline Gas & Grade & $\begin{array}{c}\text { Purity } \\
\boldsymbol{\%}\end{array}$ & $\begin{array}{c}\text { Container } \\
\text { Size (lbs.) }\end{array}$ & $\begin{array}{c}\text { Cost } \\
\mathbf{\$}\end{array}$ & $\begin{array}{c}\text { Price } \\
\mathbf{( \$ / l b . )}\end{array}$ \\
\hline $\mathrm{BF}_{3}$ & Electronic & 99.5 & 1.6 & 186 & 116.25 \\
\hline & VLSI & 99.99 & 1 & 518 & 518.00 \\
\hline $\mathrm{WF}_{6}$ & Electronic & 99.9 & 204 & 29,328 & 143.76 \\
\hline & ULSI & 99.999 & 90 & 18,078 & 200.87 \\
\hline $\mathrm{SiF}_{4}$ & Electronic & 99.99 & 50 & 7,293 & 145.86 \\
\hline & VLSI & 99.999 & 40 & 8,946 & 223.65 \\
\hline $\mathrm{SF}_{6}$ & Electronic & 99.8 & 95 & 1,611 & 16.96 \\
\hline & VLSI & 99.996 & 100 & 2,030 & 20.30 \\
\hline
\end{tabular}

In addition to considering higher value products than HF, it is also important to develop technology that can produce a number of different high value fluorine gases. For example, if all of the $\mathrm{DUF}_{6}$ were converted to $\mathrm{SiF}_{4}$, this would produce about 32 million pounds per year based on a 20 -year conversion campaign. This quantity far exceeds known demand. Consequently, any successful conversion effort for fluorine products other than $\mathrm{HF}$, must use the $\mathrm{DUF}_{6}$ to produce a variety of end products in quantities consistent with market demands. 
Traditionally, the problem with extracting fluorine using hydrolysis reactions from $\mathrm{DUF}_{6}$ (a gas at temperatures above about $56^{\circ} \mathrm{C}$ ) is that uranium will readily carry over to the product, lowering value and limiting commercial usage. Consequently, to minimize the uranium carryover, an alternate approach using $\mathrm{DUF}_{4}$ - a nonvolatile solid - has been developed and higher valued fluorine products have been identified. Depleted uranium hexafluoride is readily converted to $\mathrm{DUF}_{4}$ in a hydrogen reduction process operated by Starmet Corporation at its South Carolina site. The advanced technology presented in this report reacts crystalline $\mathrm{DUF}_{4}$ $\left(\mathrm{T}_{\mathrm{m}}=960^{\circ} \mathrm{C}\right.$ ) with a solid metal oxide (such as $\mathrm{GeO}_{2}$ or $\mathrm{WO}_{2}$ ) in a high temperature fusion process above $700^{\circ} \mathrm{C}$ to form a gaseous product (such as $\mathrm{GeF}_{4}$ or $\mathrm{WF}_{6}$ ) that readily separates as a high purity gas and leaves a uranium oxide residue. Starmet has used this same technology to produce $\mathrm{SiF}_{4}$ from $\mathrm{SiO}_{2}{ }^{6}$ in a pilot-scale demonstration plant as well as high-purity $\mathrm{BF}_{3}$ from $\mathrm{B}_{2} \mathrm{O}_{3}$ in laboratory production trials.

Current cost estimates from the DOE UF 6 PEIS $^{2}$ project the cost of conversion of $\mathrm{UF}_{6}$ using hydrolysis technology at $\$ 3.00$ per $\mathrm{kg}-\mathrm{UF}_{6}$. The total cost to the DOE for the inventory conversion is near $\$ 2$ billion with credits for aqueous or anhydrous HF sale. Starmet has estimated that by converting the $\mathrm{UF}_{6}$ to higher value fluorine products, a reduction in conversion cost to DOE of $\$ 1.5$ to $\$ 2.00$ per $\mathrm{kg}-\mathrm{UF}_{6}$ is possible. Thus, a cost savings for DOE of over $\$ 1$ billion for conversion of the $\mathrm{UF}_{6}$ inventory is possible ${ }^{7}$.

A traditional process for manufacturing either $\mathrm{GeF}_{4}$ or $\mathrm{WF}_{6}$ involves the direct fluorination of the respective base metal with fluorine gas. This method is expensive due to the cost of fluorine gas and requires special safety and handling considerations due to the extreme reactivity of this reagent. In the case of $\mathrm{GeF}_{4}$, it has also been manufactured by several alternative processes $\mathbf{s}^{\mathbf{8 , 9}, 10,11}$ including the reaction of a finely powdered suspension of $\mathrm{GeO}_{2}$ in sulfuric acid with $\mathrm{UF}_{6}{ }^{12}$.

As mentioned above, the traditional process for producing $\mathrm{WF}_{6}$ reacts the metal with fluorine. Here the metal is first obtained by reduction of $\mathrm{WO}_{2}$, which also adds to the downstream production costs of the fluoride. Typical impurities in the tungsten oxide can include uranium and thorium oxides that are easily fluorinated and carry over as gaseous contaminants requiring additional purification steps to insure their concentrations remain below the $50 \mathrm{ppb}$ and $10 \mathrm{ppb}$ limits (respectively) often specified by the semiconductor industry. In comparison, the new Starmet process has the advantage that $\mathrm{WF}_{6}$ is formed by a fusion reaction where all uranium and thorium (if present) remain as stable oxides. If needed, the $\mathrm{WF}_{6}$ gas may be subjected to another purifying step that involves another phase change, further ensuring excellent gas purity. For the electronics industry, process gas purity of $99.9 \%$ to $99.995 \%$ is generally required.

The new technology being developed by Starmet will

- demonstrate a relatively simple and robust process for producing high purity fluoride gases,

- utilize a highly refined source of fluorine, $\mathrm{UF}_{4}$, which can be recovered from the immense inventory of $\mathrm{UF}_{6}$ surplus

- virtually eliminate the potential for uranium carryover into the gas phase by reacting two solids to produce the desired high-value gaseous fluoride products and 
- provide more downstream economic value and beneficial reuse of the fluorine bound to uranium compared to commodity grade HF and uranium oxide. 


\section{OBJECTIVES OF THE PHASE II PROGRAM}

The primary objectives of the Phase II SBIR program for producing high purity fluorine gases for use by the semiconductor industry are shown below.

The objectives for $\mathrm{GeF}_{4}$ are:

- to develop a production process including reactor design and processes for generation, capture and purification to the point that the end product is market-ready for existing semiconductor applications at the completion of PhaseII;

- to develop higher purity GeF4 than is currently available on the market, tailored for photovoltaic applications.

The objectives for $\mathrm{WF}_{6}$ are:

- to develop and scale-up the process for manufacturing $\mathrm{WF}_{6}$ from the reaction between $\mathrm{DUF}_{4}$ and $\mathrm{WO}_{2}$;

- to design and develop a reactor system for producing $\mathrm{WF}_{6}$ via a two-stage reaction wherein the suitable mixing, contact and control of the second stage reaction between the tungsten oxyfluoride intermediate $\left(\mathrm{WOF}_{4}\right)$ and $\mathrm{DUF}_{4}$ can be achieved.

\section{PHASE II WORK PLAN}

The work plan to accomplish the Phase II objectives was structured in two subdivisions consisting of separate plans for $\mathrm{GeF}_{4}$ and $\mathrm{WF}_{6}$ due to the inherent differences in the chemistry and process requirements for making each gas. The scope of work associated with $\mathrm{GeF}_{4}$ was divided into nine tasks whereas the effort on $\mathrm{WF}_{6}$ was parceled among four tasks. The list of tasks for each product is shown in Table 2. The plan was carried out by focusing first on the development of a marketable $\mathrm{GeF}_{4}$ product during the first year of the program followed by the pursuit of a pathway to $\mathrm{WF}_{6}$ during the second year.

\section{Table 2.}

\section{Task structure for the Phase II Program.}

Task structure for producing $\mathrm{GeF}_{4}$.

Task 1: Reactor design for producing $\mathrm{GeF}_{4}$

Task 2: Materials of construction for production of $\mathrm{GeF}_{4}$

Task 3: Optimization of product yield

Task 4: Development of analytical technology for identifying trace $\mathrm{U}$ in $\mathrm{GeF}_{4}$

Task 5: Particulate filtration

Task 6: Process scale-up

Task 7: Gas ultrapurification

Task 8: Product qualification

Task 9: Design and construction of low production rate equipment 


\section{Task structure for producing $\mathrm{WF}_{6}$.}

Task 1: Bench-scale process development for $\mathrm{WF}_{6}$ from $\mathrm{WOF}_{4}$

Task 2: Selection of suitable materials of construction for producing $\mathrm{WF}_{6}$

Task 3: Reactor design

Task 4: $\mathrm{WF}_{6}$ product characterization

A summary of each task as it was performed for each of the fluoride gases is presented below.

\subsection{Tasks for Producing $\mathrm{GeF}_{4}$.}

\section{Task 1: Reactor design for producing $\mathrm{GeF}_{4}$.}

Production of $\mathrm{GeF}_{4}$ was studied using two different reactor designs in a batch operation. Experiments conducted in the crucible reactor showed high reaction conversions $(\sim 95 \%)$ between $\mathrm{DUF}_{4}$ and $\mathrm{GeO}_{2}$ but raised issues conceming product purity. Trials conducted using a tube reactor yielded even better performance ( $>98 \%$ conversion) especially when suitable materials were found from which to fabricate the reaction hardware and favorable reactions conditions established.

\section{Task 2: Materials of construction for production of $\mathrm{GeF}_{4}$.}

A search for suitable materials from which to fabricate a production scale reactor was undertaken. A range of materials including a Haynes HR $160^{\circledR}$ alloy and nickel were subjected to gaseous reaction products and reaction mixtures under simulated and actual reaction conditions and examined in detail using scanning electron microscopy (SEM) and $x$-ray diffraction (XRD) to follow the formation of corrosion products. Several materials were found that offer greater resistance to attack by $\mathrm{GeF}_{4}$ when pretreated first and could be used to build a reaction system to manufacture the gas.

\section{Task 3: Optimization of product yield.}

Experimentation focused on producing larger quantities of fluoride gas in each batch reaction. Reaction hardware was fabricated to hold larger amounts of $\mathrm{DUF}_{4} / \mathrm{GeO}_{2}$ mixtures and gas collection hardware was modified to achieve greater capture efficiency. Issues concerning liberation of moisture in the product stream led to exploration of an alternative pathway for producing $\mathrm{GeF}_{4}$ using powdered germanium metal. Further testing at the milligram scale using the thermogravimetric analyzer was performed to better define the onset of reaction in order that moisture adsorbed on the reagents not compromise the purity of the final $\mathrm{GeF}_{4}$ product.

\section{Task 4: Development of analytical technology for identifying trace $\mathrm{U}$ in $\mathrm{GeF}_{4}$.}

Routine analysis of $\mathrm{GeF}_{4}$ produced by the reaction between $\mathrm{DUF}_{4}$ and $\mathrm{GeO}_{2}$ using standard indirect analytical techniques such as inductively coupled plasma (ICP) and kinetic phosphorescence analysis (KPA) has shown no evidence of uranium carryover into the final 
product beyond background levels. However, direct analysis for $U$ in the fluoride gas is necessary in order to demonstrate what can be achieved using the new process technology and to qualify the material for use in semiconductor applications. A program to explore the applicability of two analytical methods involving laser-induced photoluminescence and optical absorption spectroscopy was established in collaboration with Dr. James V. Beitz at Argonne National Laboratory (Argonne, IL). Samples of $\mathrm{GeF}_{4}$ produced in lab-scale trials were analyzed using these techniques. Quantitative determination of uranyl species in glassy $\mathrm{GeO}_{2}$ using photoluminescence was found to be unsuitable for ultratrace analysis due to interferences introduced during the formation of the glassy $\mathrm{GeO}_{2}$ matrix. An alternative technique to convert hydrolyzed $\mathrm{GeF}_{4}$ to volatile $\mathrm{GeCl}_{4}$ that is removed before measuring the luminescence of uranyl species was also found to be ineffective due to the formation of unreactive hexagonal $\mathrm{GeO}_{2}$ during the hydrolysis step that was resistant to chlorination. Luminescence measurements performed on hydrolyzed $\mathrm{GeO}_{2}$ particulate dissolved in HF solution were also compromised due the presence of impurities leached from the walls of the fluoropolymer container used to contain the dissolved material. Analysis of lab synthesized $\mathrm{GeF}_{4}$ by ultraviolet absorption spectroscopy for the presence of $\mathrm{DUF}_{6}$ was also performed at $A N L$. No absorbance attributable to $\mathrm{DUF}_{6}$ gas was detected.

\section{Task 5: Particulate filtration.}

Although no evidence of uranium carryover in the gas phase was observed, contamination by solid phase uranium particulate created during formation and release of $\mathrm{GeF}_{4}$ from the reaction zone, was of potential concern. For laboratory trials, a $0.45 \mu$ stacked PTFE $^{\circledR}$ membrane filter enclosed in a polypropylene shell (Osmonics, Westborough, MA) was incorporated into the line at the entrance to each gas cylinder to remove any entrained particulate. Information about gas filtration technology was also supplied by Starmet's development partner, Voltaix, Inc., regarding the filtering devices they use for removing particulate from other semiconductor grade materials they sell.

\section{Task 6: Process scale-up.}

Based on what was learned during the bench-scale trials to produce $\mathrm{GeF}_{4}$, a multi-station reaction manifold and gas collection station were designed with capacity to process multikilogram quantities of reagents per batch. A prototype of the closed-end, vertical tube reactor was fabricated and tested. The gas collection station consisted of a pass-through condensation cylinder for cryogenically trapping $\mathrm{GeF}_{4}$ prior to final packaging. Both the reactor and gas collection segments of the production apparatus were redesigned using results gathered from the prototype reactor trial and technical recommendations made by Voltaix for improving gas production and handling.

\section{Task 7: Gas ultrapurification.}

As part of the collaborative effort to develop and market germanium tetrafluoride, Voltaix was subcontracted to characterize the purity of the 'as-produced' gas. Material produced in laboratory trials was subjected to analyses by Fourier transform infrared spectroscopy (FT-IR) to determine IR-acitve impurities such as $\mathrm{HF}, \mathrm{CO}_{2}, \mathrm{H}_{2} \mathrm{O}, \mathrm{SiF}_{4}$ and gaseous organic species and by 
ICP-MS to measure the concentration of 37 elemental impurities including uranium. Similar tests were performed on a purchased material with certified purity of $99.99 \%$, providing a standard to which the Starmet product could be compared. The gas produced by the new fusion chemistry was found to contain less elemental impurities than the reference and no uranium could be detected at the detection limit of $19 \mathrm{ppb}$-wt. From all the analytical testing performed on laboratory synthesized $\mathrm{GeF}_{4}$, the quality of the 'as-produced' gas was of sufficient purity to qualify for use in the semiconductor industry.

\section{Task 8: Product qualification.}

Laboratory trials have shown that $\mathrm{GeF}_{4}$ can be produced at a purity sufficient to meet current market specifications. As development moves forward to production, the quality of gas produced in the production-scale equipment must also be verified that it also meets or exceeds current specifications for entry into the marketplace.

\section{Task 9: Design and construction of low production rate equipment.}

A process flow diagram for the $\mathrm{GeF}_{4}$ production process was drawn and costs based on making $100 \mathrm{~kg} / \mathrm{yr}$ were calculated. Designs of a multi-station gas manifold and gas collection station were completed as part of Task 6 above. However, due to the weak economic performance and stalled growth seen in both the electronic and semiconductor markets over the last 18 months, the demand for fabrication materials has fallen off, forcing a delay in construction of the production-scale reaction system.

\subsection{Tasks for Producing $\mathrm{WF}_{6}$.}

\section{Task 1: Bench-scale process development for $\mathrm{WF}_{6}$ from $\mathrm{WOF}_{4}$.}

Investigation into the chemistry to produce $\mathrm{WF}_{6}$ from $\mathrm{WOF}_{4}$ started with milligram-scale experiments to determine effective reaction parameters such as temperature, reagent stoichiometry and form of tungsten oxide reactant. The same solid by-product, $\mathrm{UO}_{2} \mathrm{~F}_{2}$, was produced using either $\mathrm{WO}_{2}$ or $\mathrm{WO}_{3}$ in the fusion reactions at temperatures in the range between $700^{\circ} \mathrm{C}-800^{\circ} \mathrm{C}$. Bench trials were conducted using a nickel tube reactor where larger samples of $\mathrm{WOF}_{4}$ were collected. Several two-stage reactions were performed to explore the reactivity of $\mathrm{WOF}_{4}$ with probe molecules such as $\mathrm{UF}_{4}, \mathrm{SiO}_{2}$ and $\mathrm{TiF}_{4}$. A new pathway to $\mathrm{WF}_{6}$ was explored encompassing the reaction of $\mathrm{TiF}_{4}$ with $\mathrm{WO}_{2}$, first using milligram quantities followed by reactions involving gram quantities in a $100 \mathrm{ml}$-benchtop reaction vessel. Analysis of the product from this reaction by $\mathrm{FT}$-IR spectroscopy showed the first indication of $\mathrm{WF}_{6}$ formation.

\section{Task 2: Selection of suitable materials of construction for producing $\mathrm{WF}_{6}$.}

Much of the bench-scale experimentation performed to develop a pathway to $\mathrm{WF}_{6}$ was accomplished using a 1" diameter tube made of nickel as well as a nickel boat to hold the reactants. After observing large pieces of debris on the surfaces of reaction by-products and the progressive deterioration of the boat itself after many trials, an investigation into the corrosion 
occurring with nickel was conducted. It was determined that the surface of nickel was first oxidized to nickel oxide in the high temperature fusion environment followed by reaction of the fluoride intermediate, $\mathrm{WOF}_{4}$, and $\mathrm{NiO}$ to produce $\mathrm{NiF}_{2}$ and $\mathrm{NiWO}_{4}$. Passivation of the $\mathrm{Ni}$ surface with fluorine to form a tightly bound layer of unreactive $\mathrm{NiF}_{2}$ for guarding against oxidation was recommended. With this pretreatment, nickel could be an effective material from which to build the production system for $\mathrm{WF}_{6}$.

\section{Task 3: Reactor design.}

Design of a reaction system to accommodate the two-step conversion involving the evolution of $\mathrm{WOF}_{4}$ and subsequent transformation to $\mathrm{WF}_{6}$ was not completed since the investigation into determining a suitable fluorinating agent was not completed.

\section{Task 4: $\mathrm{WF}_{6}$ Product characterization.}

All issues dealing with the purity of $\mathrm{WF}_{6}$ could not be addressed since collection of useable quantities of material was not synthesized amongst the bench-scale trials performed during this investigation. 


\section{$8 \mathrm{GeF}_{4} \mathrm{PRODUCTION}$}

\subsection{Experimental Procedures $-\mathrm{GeF}_{4}$.}

\subsubsection{Reactor design for producing $\mathrm{GeF}_{4}$.}

Production of $\mathrm{GeF}_{4}$ was studied using two different reactor designs in a batch-type process for manufacturing material of exceptional purity. Due to the low volume (in the range of $100-200 \mathrm{~kg} / \mathrm{yr}$ ) and high value (\$3-\$5 per gram) of the product, a batch process was pursued since it is best suited for controlling reaction yield and product quality. The two system configurations examined in detail involved a crucible reactor and a tube reactor. Each design offered certain distinct advantages, which were examined as Task 1 was accomplished.

A schematic of the crucible reactor system used to produce $\mathrm{GeF}_{4}$ is shown in Figure 2. This design provided for easy material transfer and accommodated sufficient reagent volume to produce up to $1 \mathrm{~kg}$ of gas per batch. Characteristics of this design such as the large freeboard (internal void volume) above the heated zone and large internal surface area within the reaction chamber were issues of concern.

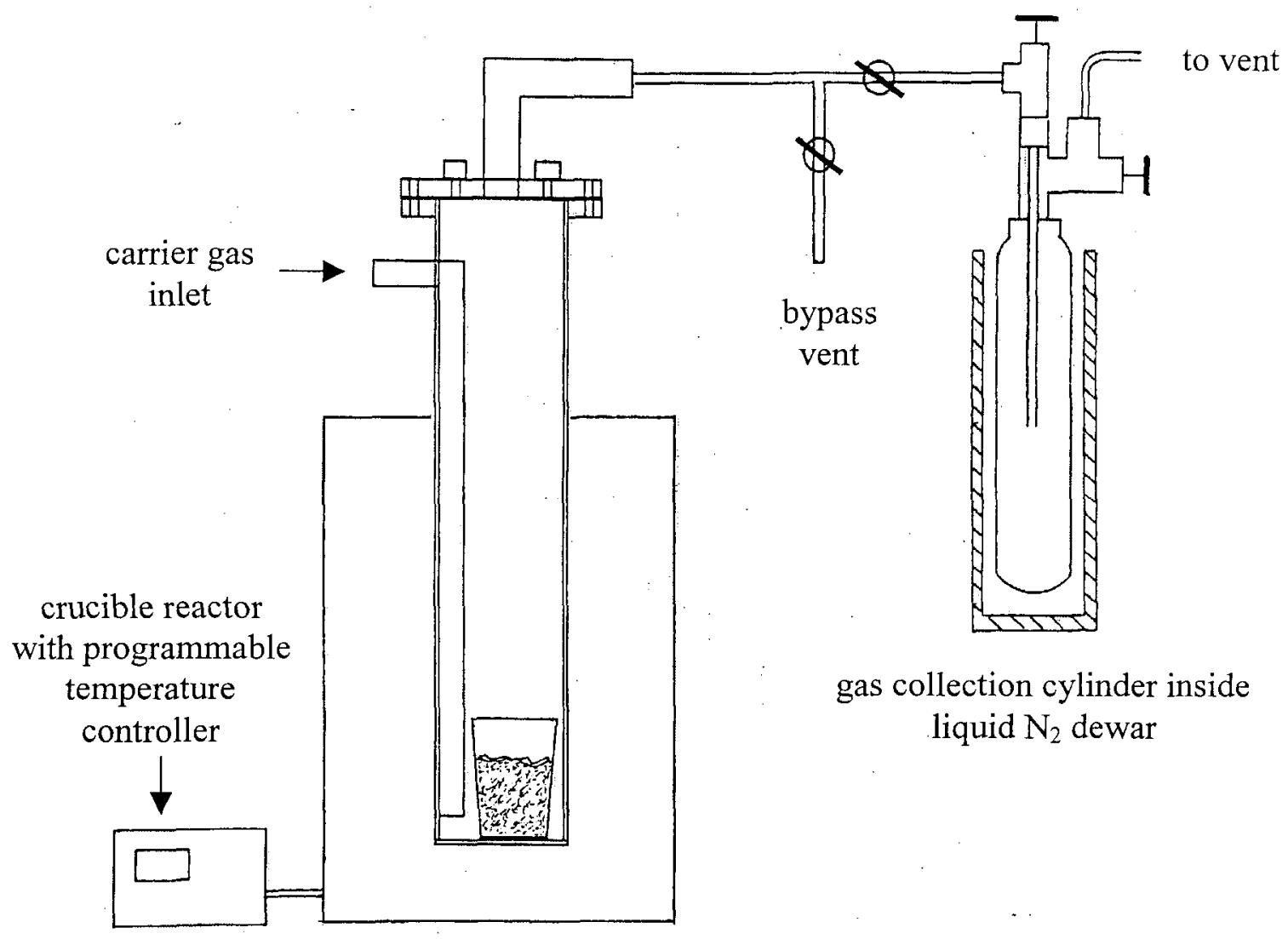

Figure 2. Schematic of crucible reactor setup with gas cylinder attached to collect $\mathrm{GeF}_{4}$. 
Five experiments were performed using the crucible reactor setup in order to assess the performance of this design with respect to conversion yield and gas capture efficiency. The list of trials is shown in Table 3, showing reaction time, temperature and reagent make-up.

Table 3.

Experiments Performed in the Crucible Reactor Setup.

\begin{tabular}{|c|c|c|c|c|c|}
\hline $\begin{array}{c}\text { Experiment } \\
\text { ID }\end{array}$ & $\begin{array}{c}\text { Reagent } \\
\text { Vessel }\end{array}$ & $\begin{array}{c}\text { Reaction } \\
\text { Temperature } \\
\left({ }^{\circ} \mathbf{C}\right)\end{array}$ & $\begin{array}{c}\text { Reaction } \\
\text { Time } \\
(\mathbf{h r})\end{array}$ & $\begin{array}{c}\text { Reagent } \\
\text { Weight } \\
(\mathbf{g m})\end{array}$ & $\begin{array}{c}\mathbf{G e O}_{2} \\
\text { Weight } \\
\text { Fraction } \\
\mathbf{( \% )}\end{array}$ \\
\hline GeFusn-19 & Ni beaker & 875 & 2 & 30.284 & 25.451 \\
\hline GeFusn-20 & Ni beaker & 875 & 2 & 30.842 & 23.977 \\
\hline GeFusn-21 & Ni beaker & 925 & 2 & 28.691 & 23.946 \\
\hline GeFusn-22 & Cu cup & 925 & 2 & 31.065 & 23.979 \\
\hline GeFusn-23 & Ni beaker & 925 & 3 & 32.444 & 23.999 \\
\hline
\end{tabular}

For each experiment, the reagent mixture of $\mathrm{UF}_{4}$ and $\mathrm{GeO}_{2}$ was contained in a $250 \mathrm{ml}$ beaker made of nickel. For the GeFusn-22 trial, the reagent container was switched to a copper cup along with a copper tube insert in an attempt to direct the gas product out of the reactor faster. This was done to reduce the effects that the large internal volume (freeboard) and surface area may have (i.e. possible side reactions) on the $\mathrm{GeF}_{4}$ produced in the hot zone of the reaction chamber. A schematic of the copper cup/'chimney' insert is shown in Figure 3.

Except for the first experiment, GeFusn-19, the composition of the reactant mixture was such that there was a slight molar excess $(\sim 5 \mathrm{wt} \%)$ of $\mathrm{UF}_{4}$ over $\mathrm{GeO}_{2}$ in order to promote complete reaction of all germania to gaseous product. The reaction parameters for each experiment are listed in Table 3. The approach was to find a set of conditions which maximized both conversion yield and capture efficiency. Chromatographic grade helium (specified as grade 5.5 from AirGas East, Salem, $\mathrm{NH}$ ) was used as the motive gas to convey the $\mathrm{GeF}_{4}$ out of the reaction vessel and through a small gas sample cylinder (150cc internal volume) used as the collection vessel. Each cylinder was made of type 316 stainless steel and was equipped with 2 valve closures and an outage tube to deliver the gas stream to about the midpoint of the cylinder interior. A partially filled dewar of liquid nitrogen was used to cool the cylinders for trapping the $\mathrm{GeF}_{4}$ within the cylinder volume. Prior to each experiment, the collection vessel was heated and out-gassed under vacuum to remove adsorbed moisture to prepare the sample cylinder to receive $\mathrm{GeF}_{4}$. It was weighed prior to and after collection to record the amount of volatile product captured. In addition to the weight change of the vessel, the weight of the container holding the reagents was recorded prior to and after reaction.

A step by step description of the procedure followed is included here as a representative example of the experimental process. The procedure started with the preparation of a fresh mixture of constituents for each experiment. Once prepared, the mixture was placed in the nickel beaker which was lowered to the bottom of the HR $160^{\oplus}$ alloy reactor (internal volume $\sim 4$ liters). The reaction chamber was sealed at the top flange opening using a teflon ${ }^{\circledR}$ gasket and a 
source of high purity helium connected via gas-tight compression fittings. To effectively purge the atmosphere of air inside the vessel, a vacuum was carefully established using a mechanical pump followed by back-filling with helium to ambient pressure. After completing three vacuum/backfill cycles, the flow of helium carrier was established at the desired rate. The gas stream exiting the reactor was sent through a tee where one branch led to the collection vessel and the other to a vent line. The crucible furnace (Blue M/Lindberg) was connected to a 16segment programmable controller. The heating profile followed is shown in Table 4. After maintaining the reaction for the desired period, the flow of gas from the reactor was allowed to continue through the collection vessel for 30 minutes following the start of the cooling segment to allow for collection of product entrained inside the reactor's freeboard. Once gas collection was terminated and the sample cylinder closed to flow, the gas stream was redirected through the vent line while the reactor cooled to ambient under a flow of helium. After cooling to ambient, the reaction vessel was opened to retrieve the nickel beaker containing reaction residue. In each case, the beaker was weighed and solid residue recovered.

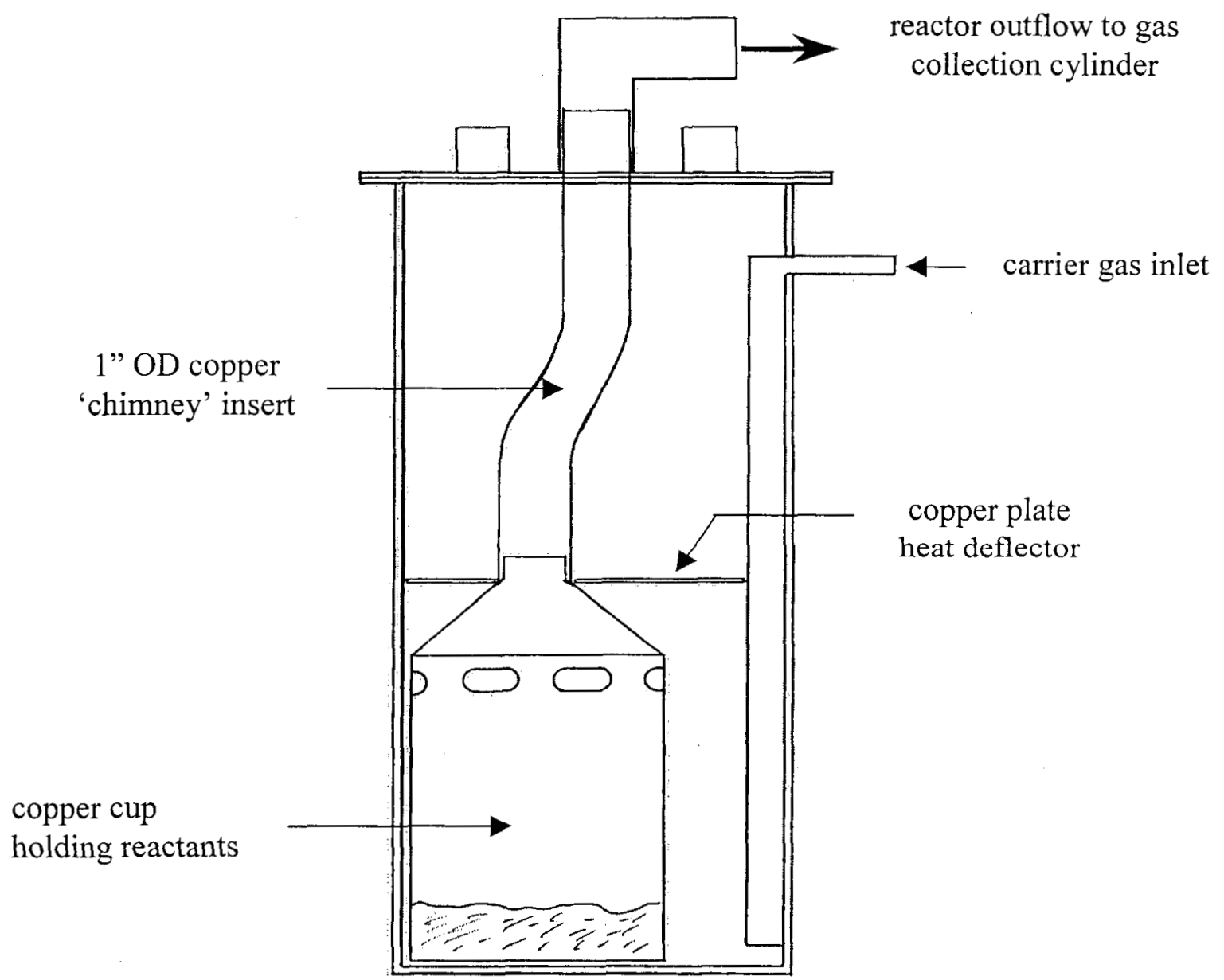

Figure 3. Schematic of crucible reactor with copper cup and 'chimney' insert used in GeFusn-22. 
Table 4.

Heating Profile for the Crucible Reactor Experiments.

\begin{tabular}{|c|c|}
\hline Segment & $\begin{array}{c}\text { Heating Rate } \\
{ }^{\circ} \mathrm{C} / \text { minute }\end{array}$ \\
\hline Ambient $\rightarrow 400^{\circ} \mathrm{C}$ & 15 \\
\hline Dwell @ $400^{\circ} \mathrm{C}$ & $60 \mathrm{~min}$ \\
\hline Ramp $400^{\circ} \mathrm{C} \rightarrow 800^{\circ} \mathrm{C}$ & 15 \\
\hline Dwell @ $800^{\circ} \mathrm{C}$ & 15 \\
\hline Ramp 800 $\mathrm{C} \rightarrow 875^{\circ} \mathrm{C}$ or $925^{\circ} \mathrm{C}$ & 120 or 180 min \\
\hline Dwell at reaction temperature & 10 \\
\hline Ramp $875^{\circ} \mathrm{C} \rightarrow 25^{\circ} \mathrm{C}$ & \\
\hline
\end{tabular}

The second type of reactor that was investigated for synthesizing $\mathrm{GeF}_{4}$ in a batch process was a tube reactor. The tube reactor offers a higher heat transfer rate in the high temperature zone and reduced freeboard downstream of the generation point. The first tube reactor constructed to evaluate this configuration was made of type $304 \mathrm{~L}$ stainless steel and consisted of a 27 " section of $2.75^{\prime \prime}$ OD pipe welded to an 11 " section of 1 " OD tube. The reduction in tube diameter was used to reduce void volume outside the heated reaction zone and convey the product gas out of the tube faster. The 2.75" diameter of the pipe allowed for larger amounts of reactants per batch. The tube furnace was a $3 "$ diameter, single zone unit (Lindberg) possessing a 10"-12" heated bed length. This reaction tube was used for only one experiment, GeFusn-24. In this trial, a high-density alumina boat was used to shuttle a mixture of $\mathrm{UF}_{4}$ and $\mathrm{GeO}_{2}$ to the center of the hot zone prior to heating. A $150 \mathrm{cc}$ gas cylinder was fixed to the reactor effluent stream similar to the setup used to collect gas in the crucible reactor experiments. A schematic of the tube reactor configuration is shown in Figure 4.

An additional eight experiments were performed in a second tube reactor constructed of nickel 200 alloy. The Ni tube reactor consisted of a 1" OD section of tube 43 " in length. The selection of a relatively small diameter tube for these experiments was made since it was readily available from various vendors, did not require additional fabrication techniques (welding, etc.) and used only standard compression fittings $\left(S w a g e l o k^{\circledR}\right)$ for connecting to the gas collection vessel. The complete list of experiments performed in the tube reactor configuration is compiled in Table 5. Reaction parameters and reagent specifications are listed here for each trial. In all experiments the stoichiometry of the $\mathrm{UF}_{4} / \mathrm{GeO}_{2}$ starting mixtures contained a slight excess of green salt. For the 1" OD Ni tube experiments, a small 4" long nickel boat was used to shuttle reagents into the central reaction zone. Output from the reactor was either diverted through a vent line or through a 316 stainless steel cylinder chilled using a partially filled dewar of liquid nitrogen. Starting with experiment GeFusn-28, type-K thermocouples were attached to the external surface of each collection cylinder to monitor its temperature in an effort to prevent stoppage of flow caused by $\mathrm{GeF}_{4}$ condensing in the 0.25 " diameter outage tube rather than in the cylinder interior.

Parameters investigated included temperature, reaction atmosphere (helium or helium + air) and flow rate of carrier gas. With the exception of the first two experiments (GeFusn-25 


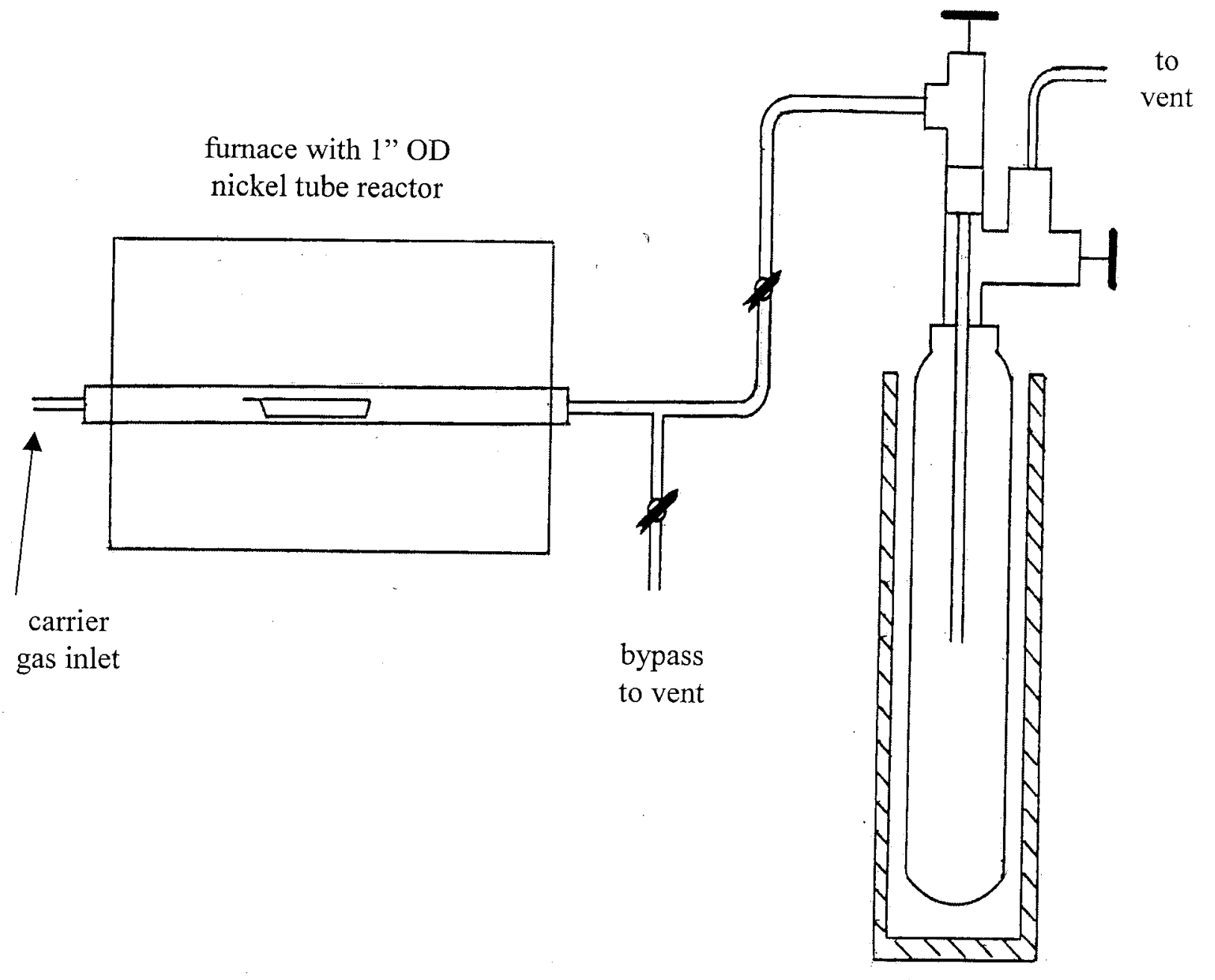

gas collection cylinder submerged in liq $\mathrm{N}_{2}$ dewar

Figure 4. Schematic of the $\mathrm{Ni}$ tube reactor setup with gas cylinder attached to collect $\mathrm{GeF}_{4}$. 
Table 5.

Experiments Performed in the Tube Reactor Setup.

\begin{tabular}{|c|c|c|c|c|}
\hline \multirow{3}{*}{$\begin{array}{c}\text { Experiment } \\
\text { ID } \\
\text { GeFusn - }\end{array}$} & $\begin{array}{c}\text { Reaction } \\
\text { Conditions }\end{array}$ & $\begin{array}{l}\text { Motive Gas } \\
\text { Flow Rate }\end{array}$ & \multirow{2}{*}{$\begin{array}{l}\text { Weight of } \\
\text { Reagents }\end{array}$} & \multirow{2}{*}{$\begin{array}{c}\text { Weight } \\
\text { Fraction } \\
\mathrm{GeO}_{2}\end{array}$} \\
\hline & \multirow{2}{*}{$\begin{array}{l}\text { Atm/Temp/Time } \\
\text { gas / }{ }^{\circ} \mathrm{C} / \mathrm{hr}\end{array}$} & \multirow{2}{*}{$\begin{array}{c}\mathrm{cc} / \mathrm{min} \\
(\mathrm{He} / \text { air })=\text { Total }\end{array}$} & & \\
\hline & & & (gms) & $(w t \%)$ \\
\hline \multicolumn{5}{|c|}{ Experiment performed in the 304L stainless steel tube reactor } \\
\hline 24 & $\mathrm{He} / 850 / 2.5$ & 100 & 31.1941 & 24.236 \\
\hline \multicolumn{5}{|c|}{ Experiments performed in the nickel tube reactor } \\
\hline 25 & $\mathrm{He} / 800 / 2.5$ & 67 & 15.6158 & 24.004 \\
\hline 26 & $\mathrm{He} / 800 / 2.5$ & 150 & 15.9473 & 24.004 \\
\hline 27 & $\mathrm{He} / 700 / 5$ & $150-67$ & 17.2200 & 23.991 \\
\hline 28 & $\mathrm{He}+\mathrm{air} / 700 / 5$ & $(67+9)=76$ & 16.0310 & 23.991 \\
\hline 29 & $\mathrm{He}+$ air $/ 725 / 5$ & $(67+9)=76$ & 14.9553 & 23.991 \\
\hline 30 & $\mathrm{He} / 750 / 5$ & 67 & 16.9337 & 23.991 \\
\hline 31 & $\mathrm{He} / 775 / 5$ & 67 & 15.7964 & 23.991 \\
\hline 32 & $\mathrm{He}+$ air $/ 750 / 5$ & $(67+15)=82$ & 17.1139 & 23.991 \\
\hline
\end{tabular}

and -26), a reaction period of five hours was employed. Three experiments were performed where a small flow of dry air was added to the helium stream (for GeFusn-28,-29 and -32) after the furnace temperature reached the desired mark. The heating profile was slightly different than that listed in Table 4. The temperature of the furnace was raised to $500^{\circ} \mathrm{C}$ at $15^{\circ} \mathrm{C} / \mathrm{minute}$ and maintained for 60 minutes to allow removal of adsorbed moisture from the reagents before ramping to the final reaction temperature at a rapid rate of $\sim 100^{\circ} \mathrm{C} /$ minute. Upon conclusion of the reaction, the furnace temperature was lowered at $10^{\circ} \mathrm{C} /$ minute but the actual temperature drop tailed off after 10-15 minutes from the programmed rate to a slower pace set by heat loss from the furnace. Passage of gas through the cylinder was continued for 30 minutes following the start of cooling to harvest residual $\mathrm{GeF}_{4}$ from the gas stream during the cool down. Data collection from the experiments was the same as that described for the crucible experiments.

Besides the gravimetric measurements collected after each reaction in both the crucible and tube reactor trials, characterization of the synthesized reaction products was also done. The powder materials recovered from the nickel beaker and boat were analyzed by $\mathrm{x}$-ray powder diffraction (XRD) to qualitatively document final composition and investigate possible reaction intermediates in the cases where conversion was incomplete. The XRD analyses were performed on a Shimadzu XRD-6000 diffractometer equipped with a copper radiation source. Data were collected over the range of $10^{\circ}-150^{\circ} 2$-theta. The experimental data were compared to the library of reference patterns contained in the Powder Diffraction File of the International Center for Diffraction Data, Volumes 1-47, Release 1997 (Newtown Square, PA) ${ }^{\mathbf{1 3}}$.

The gaseous product captured in the $150 \mathrm{cc}$ collection cylinders was analyzed by Fourier transform infrared spectroscopy (FT-IR) to verify the gas was indeed $\mathrm{GeF}_{4}$ and also to evaluate 
purity with respect to other foreign species such as $\mathrm{HF}$ and $\mathrm{H}_{2} \mathrm{O}$ which may have been liberated during the reaction. The measurements were made using a Nicolet Magna-IR 560 optical bench situated with a $\mathrm{KBr}$ beamsplitter and DTGS detector. Gas samples were contained in a gas-tight $10 \mathrm{~cm}$ cell (CIC Photonics, Inc., Albuquerque, NM) outfitted with zinc selenide windows and a programmable heater for maintaining the cell at $125^{\circ} \mathrm{C}$ to displace adsorbed moisture prior to data collection.

\subsubsection{Materials of construction for production of $\mathrm{GeF}_{4}$.}

Fluoride gases, especially at elevated temperatures, can be very corrosive. Therefore it was necessary that the materials of construction used in building a production system be as inert and unreactive toward $\mathrm{GeF}_{4}$ as possible when placed in demanding conditions including high temperature and strong oxidizing environments such as hydrogen fluoride vapor. Corrosion testing was performed on a number of metals and metal alloys compiled in Table 6 below. Table 6 also lists the constituents of the materials and their relative proportions. In the Phase II proposal task outline, Haynes Alloy $\mathrm{N}^{\circledR}$ was also selected as a potential candidate, however this alloy is being phased out by Haynes in favor of Alloy 242. Thus Haynes Alloy ${ }^{\circledR}$ was not studied, as this alloy is now difficult to obtain. In place of Haynes Alloy $\mathrm{N}^{\circledR}$, copper was tested for resistance to attack by $\mathrm{GeF}_{4}$ since some of the crucible reactor experiments used a $\mathrm{Cu}$ chimney over the reactor cup to minimize the freeboard within the reactor. One of the copper chimney inserts was dissected and studied for corrosion products. Monel was also included in the study since earlier work had shown that Monel reacted extensively with the product gases. Finally, 304 stainless steel (SS) was substituted for 316 SS since 304 SS was used for the tubing of the system.

\section{Table 6.}

Metals and Alloys Used in the Corrosion Studies.

\begin{tabular}{|l|l|}
\hline Material & Composition \\
\hline Ni sheet & $100 \% \mathrm{Ni}$ \\
\hline Monel & $70 \mathrm{Ni}-30 \mathrm{Cu}$ \\
\hline Inconel $600^{\circledR}$ & $72 \mathrm{Ni}-14 \mathrm{Cr}-6 \mathrm{Fe}-0.15 \mathrm{C}-1 \mathrm{Mn}-0.015 \mathrm{~S}-0.50 \mathrm{Si}-0.50 \mathrm{Cu}$ \\
\hline Haynes $242^{\circledR}$ & $65 \mathrm{Ni}-25 \mathrm{Mo}-8 \mathrm{Cr}-2.5 \mathrm{Co}-2 \mathrm{Fe}-0.8 \mathrm{Mn}-0.8 \mathrm{Si}-0.5 \mathrm{Al}-0.5 \mathrm{Cu}-0.03 \mathrm{C}-0.006 \mathrm{~B}$ \\
\hline Haynes HR-160 & 37Ni-29Co-28Cr-2.75Si-2Fe-0.5Mn-0.05C \\
\hline 304 Stainless Steel & Fe-18Cr-8Ni-2Mn-1Si-0.08C-0.045P-0.03S \\
\hline Cu tubing & $99 \% \mathrm{Cu}$ \\
\hline
\end{tabular}

The metal samples were prepared by removing rough edges and polishing with 600 grit $\mathrm{SiC}$ paper. Two major experiments were conducted. In the first, the metal samples were exposed to pure $\mathrm{GeF}_{4}$ gas from a commercial supplier in a tube furnace. In the second, metal samples were exposed to both the reaction mixture and the product gas produced in the crucible reactor. In addition to these experiments, materials used in other reactions that could be spared were examined. Analysis primarily consisted of scanning electron microscopy coupled with energy dispersive spectroscopy (SEM/EDS). In addition, x-ray diffraction (XRD) was used on some samples. 


\section{Corrosion Experiment 1}

This experiment was performed in a Mini Mite furnace (Blue M/Lindberg), using an 18" section of Monel tube as the chamber. Samples tested in this experiment included 304SS, Inconel 600 , Haynes 242, and $\mathrm{Cu}$. The procedure for the experiment was as follows:

1. Purge system with dry argon for $1 / 2$ hour

2. Shut off argon, and close off valves to argon side of assembly.

3. Open $\mathrm{GeF}_{4}$ tank. Allow to flow until bubbles seen in trap.

4. Close $\mathrm{GeF}_{4}$ tank, followed by closing each end of the reaction tube.

5. Begin heating to $900^{\circ} \mathrm{C}$ at $50^{\circ} \mathrm{C} / \mathrm{min}$.

6. Hold 1 hour

7. Cool to $300^{\circ} \mathrm{C}$. Shut off furnace

8. Open ends of reaction tube

9. Purge system for 2 hours with dry argon as it continues to cool.

10. Shut off argon.

11. Open furnace. Disconnect tube at both ends at 1"Swagelok $k^{\circledR}$ fitting.

12. Tilt tube to slide corrosion coupons out into beaker

13. Test coupons for $\mathrm{pH}$. Wash in water, test again. Neutralize with lime solution if necessary.

14. Proceed once neutralized with metallography/microscopy.

Some difficulties were encountered during the experiment. A leak occurred at the valve after the check valve, leading to a leak at the regulator connection, which was then tightened. At the end of the experiment, when the ball valve nearest the water trap was opened, water was sucked into the reaction tube. The system was at around $200^{\circ} \mathrm{C}$ when this occurred. The system was purged with argon overnight to try to dry the system. The coupons needed to be neutralized as they were highly acidic.

\section{Corrosion Experiment 2}

This reaction was performed in the Lindberg crucible furnace used in previous experiments. A reaction mixture consisting of $194.6 \mathrm{~g} \mathrm{UF}_{4}$ and $67.5 \mathrm{~g} \mathrm{GeO}_{2}$ was made, and $172.1 \mathrm{~g}$ of this mixture was placed into an alumina crucible. Coupons of all six metals were embedded in the reaction mixture. Additional coupons were placed in the outflow tube of the reactor. In this way, the performance of the materials in question could be studied simultaneously with exposure to the gas phase and in contact with the solids. The furnace was heated at $15^{\circ} \mathrm{C} / \mathrm{min}$ to $400^{\circ} \mathrm{C}$, held for 1 hour, ramped at $20^{\circ} \mathrm{C} / \mathrm{min}$ to $925^{\circ} \mathrm{C}$, held for 2 hours, and then cooled to room temperature. The gas produced was scrubbed out with water in a large Erlenmeyer flask.

\subsubsection{Optimization of product yield.}

A group of experiments was performed as part of the reactor design study in Task 1 which explored reaction parameters that directly affected the yield of $\mathrm{GeF}_{4}$. The parametric study included aspects such as reaction temperature, reaction atmosphere and length of reaction. As part of Task 3, several additional experiments were done to find conditions for maximizing both conversion and yield of $\mathrm{GeF}_{4}$. There was also a need to increase the amount of fluoride produced per batch reaction to make sufficient quantity for analytical characterization. In order to produce more gas from each experiment using the 1" OD tube reactor setup, a larger reagent 
vessel was fabricated in-house using an 8 " section of 1 " OD nickel 200 alloy tube. The tube was cut lengthwise, in half, and curled so that it would slide into the 0.834 " internal diameter reaction tube opening. End pieces of nickel were welded to the ends of the curled section, forming a boat with a capacity of about 50 grams of combined reactants.

The first experiment to use the larger reagent boat, GeFusn-33, also incorporated a change to the gas collection hardware as recommended by Voltaix, Inc. personnel. The revised gas collection configuration is shown in Figure 5. It was suggested that the $\mathrm{GeF}_{4}$ laden gas stream enter the cylinder through the top port and be vented through the outage tube which should be shortened to protrude into the vessel to a depth of $\sim 2$ inches. In previous trials, the outage tube delivered the incoming gas flow to the midpoint of the 9" cylinder before venting through the top port. The new gas flow pathway was instituted to reduce the likelihood of freeze-up and blockage caused by condensed product in the $1 / 4$ " outage tube. It was recommended that the coolant level remain 1-2" below the tip of the outage tube opening.

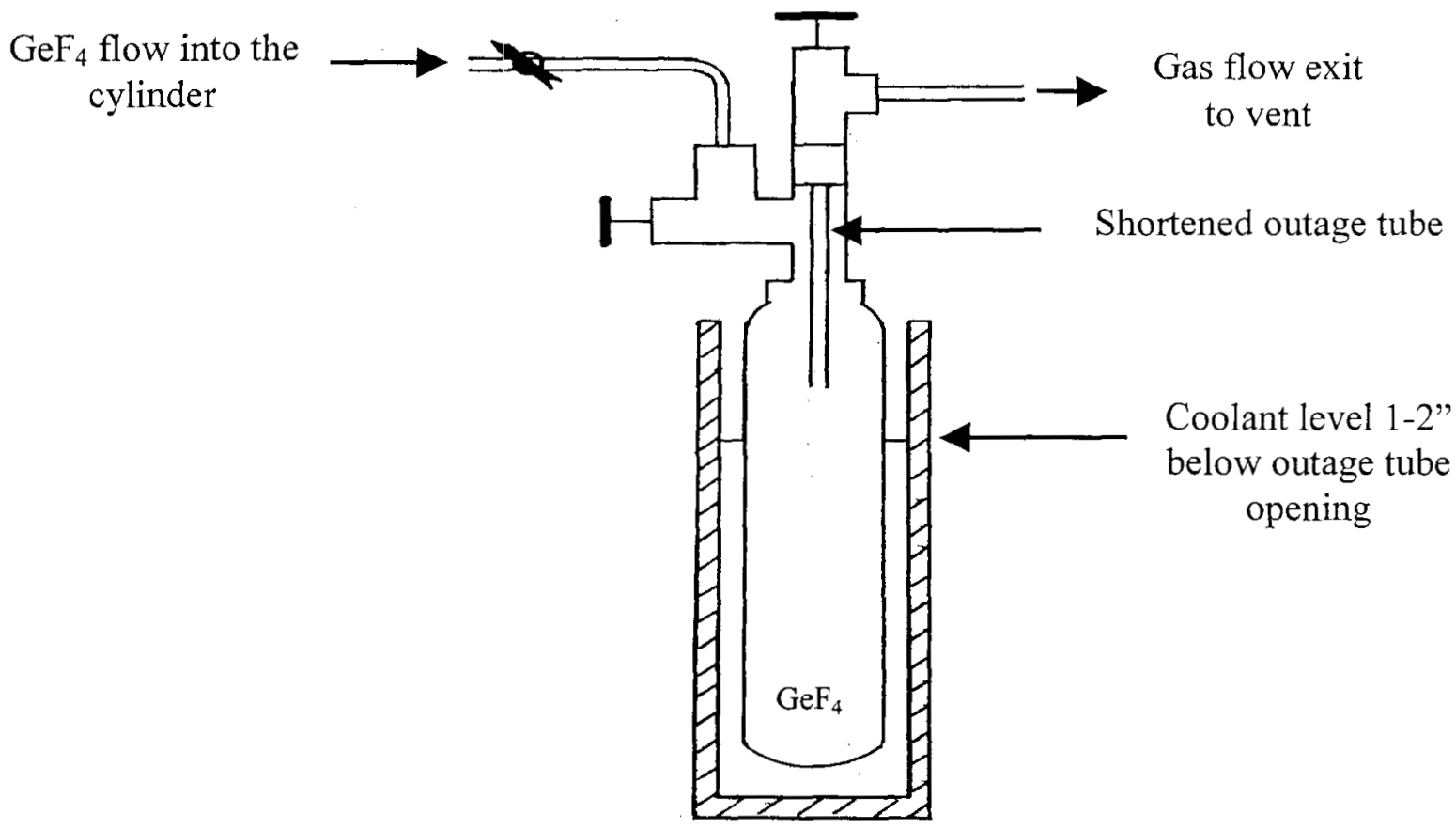

Figure 5. New cylinder configuration and gas flow pathway used in collecting $\mathrm{GeF}_{4}$.

After completing GeFusn-33, in which the reaction temperature was in the range between $700^{\circ}-775^{\circ} \mathrm{C}$ and total reaction time approached 7 hours, a significant fraction on the residue remaining in the $8^{\prime \prime}$ boat was green in color, indicative of unreacted green salt. As a result, a probe of the internal temperature inside the nickel reaction tube was conducted. The 1 " tube was 
outfitted with a thermocouple to probe the internal temperature over the 12 " section of heated area. A schematic of the temperature probe setup is shown in Figure 6 depicting the four points $(A, B, C$, and $D)$ along the center axis where the measurements were taken. Temperature data were recorded at five furnace set-points without the 8 " boat or reagents in the reactor.

Thermocouple probe

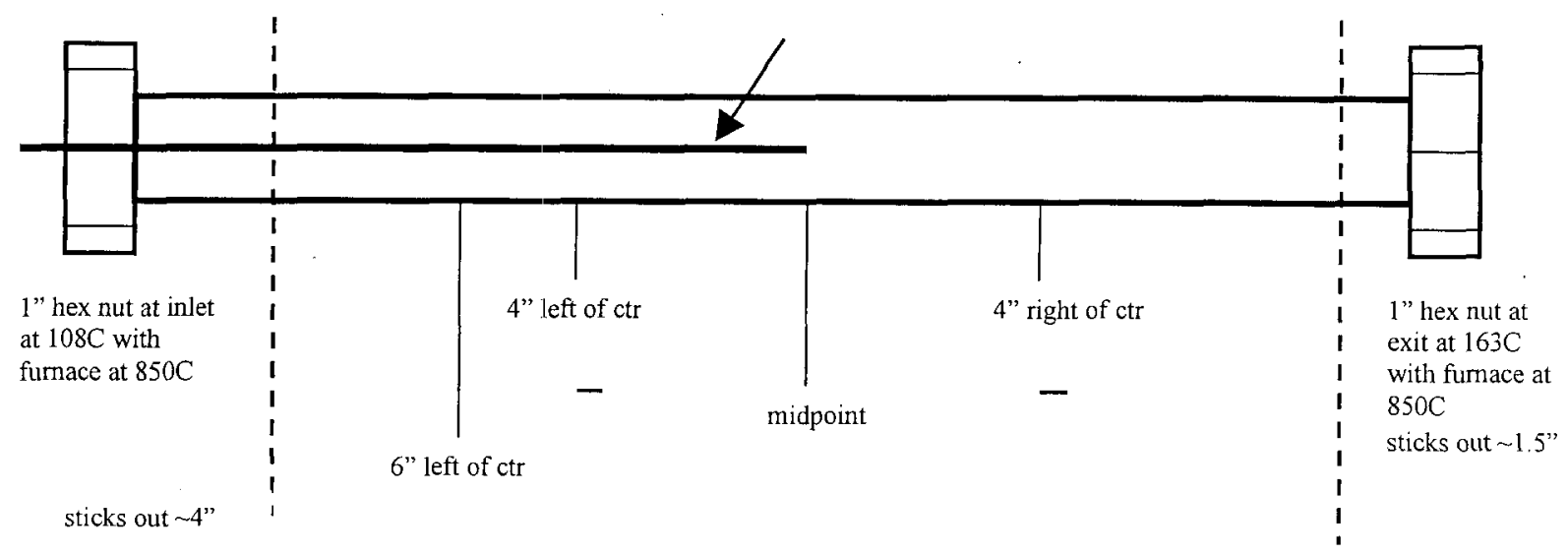

Figure 6. Schematic representation of the temperature probe within the Ni tube reactor.

A second experiment, GeFusn-35, was performed in the 1" tube reactor where the $\mathrm{GeF}_{4}$ product stream was analyzed directly by in-line FT-IR spectroscopy using the $10 \mathrm{~cm}$ gas cell maintained at $130^{\circ} \mathrm{C}$. Multiple aliquots of gas captured at various points along the reaction timeline were examined to catalog the quality of $\mathrm{GeF}_{4}$ with respect to moisture content and onset of gas evolution.

From the start of the experimental program, the primary germanium source to produce $\mathrm{GeF}_{4}$ was high purity $\mathrm{GeO}_{2}(99.999 \%)$. After developing the cost model for producing the gas, it became evident that there may be a competitive economic advantage to derive $\mathrm{GeF}_{4}$ using $\mathrm{Ge}^{\circ}$ metal as an alternative source. The alternative reaction pathway is given in equation (8.1)

$$
3 \mathrm{UF}_{4}+3 \mathrm{Ge}^{\circ}+4 \mathrm{O}_{2}(\mathrm{~g}) \longrightarrow 3 \mathrm{GeF}_{4}(\mathrm{~g})+\mathrm{U}_{3} \mathrm{O}_{8}
$$

This new chemistry is based on the in-situ oxidation of $\mathrm{Ge}^{\circ}$ to $\mathrm{GeO}_{2}$ and is analogous to the chemistry developed at Starmet for producing silicon tetrafluoride from the reaction between

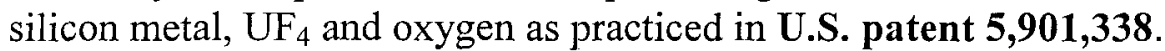

To test the feasibility of the chemistry shown in equation (1), two milligram-scale experiments were performed using the TA Instruments model 2960 Simultaneous TGA/DTA (ThermoGravimetric Analyzer/Differential Thermal Analyzer). In the first trial, a small sample of $\mathrm{Ge}^{\circ}$ metal was heated to $1000^{\circ} \mathrm{C}$ in a stream of dry air. In the second experiment, a mixture of $\mathrm{UF}_{4}$ and powdered $\mathrm{Ge}^{\circ}$ metal was heated to $850^{\circ} \mathrm{C}$ at $10^{\circ} \mathrm{C} / \mathrm{min}$ in a stream of dry air. In each trial the sample weight was measured as a function of time and temperature.

After completing the milligram-scale experiments, the same reaction was carried out on a larger scale using the 1" OD Ni tube reactor setup. In this trial, identified as GeFusn-39, 2.0558 grams of $99.9 \%$ pure $\mathrm{Ge}^{\circ}$ metal powder was combined with $\mathrm{UF}_{4}$ and reacted at temperatures in the range between $600^{\circ} \mathrm{C}-700^{\circ} \mathrm{C}$. The output from the reactor was connected to the gas-sampling 
cell and multiple aliquots of reactor offgas were analyzed by FT-IR spectroscopy to characterize the purity of the product. The post-reaction solid residues were analyzed by x-ray powder diffraction.

Finally, one micro-scale experiment was performed in order to better define the temperature at which the fluoride gas was first liberated. Experiments from the reactor design trials have shown that the reaction between green salt and germanium oxide is well underway at a temperature of $650^{\circ} \mathrm{C}$. A more refined determination of the reaction onset temperature is expected to impact both the purity and yield of the final product. Using the TGA instrument, a mixture of reagents was heated to $500^{\circ} \mathrm{C}$ at $15^{\circ} \mathrm{C} / \mathrm{min}$ in a stream of air or argon. The change in the weight of the mixture was monitored during three successive heating cycles.

\subsubsection{Development of analytical methodology for identifying trace uranium in $\mathrm{GeF}_{4}$.}

Analysis for uranium species, which may have carried into the $\mathrm{GeF}_{4}$ produced by solid state reaction between $U_{4}$ and $\mathrm{GeO}_{2}$, was investigated previously in the Phase I SBIR program using indirect methods such as kinetic phosphorescence (KPA) involving aqueous scrubber solutions. Those results showed $U$ content at background levels measuring in the single digit parts-perbillion (ppb) range. However, more sensitive measurements were sought employing direct methods to determine the $U$ concentration at levels called out in specifications of other important semiconductor gases such as tungsten hexafluoride, $\mathrm{WF}_{6}$. The value specified for uranium impurity in $\mathrm{WF}_{6}$ offered by Matheson Electronic Products Group / Semi $\cdot$ Gas Systems is listed at 0.05 ppbwt. The goal of this task was to develop the methods and procedures that have the sensitivity to measure uranium in the range that is appropriate for products intended for use in the semiconductor industry.

To assist with meeting that challenge, a collaborative effort was undertaken with Dr. James Beitz at Argonne National Laboratory (ANL) to explore the applicability of using two new techniques, optical absorption spectroscopy and laser-induced photoluminescence, to measure the very low levels of $\mathrm{U}$ in $\mathrm{GeF}_{4}$. The work carried out at $A N L$ is compiled in four quarterly progress reports that are included in Appendix A of this report. Details of the experimental program and results are included there.

Two samples of $\mathrm{GeF}_{4}$ produced at Starmet were sent to $A N L$ for characterization by the new techniques. The first sample was made as part of the GeFusn-36 trial and contained 5.3 grams of gas in a $300 \mathrm{cc}$ Monel gas cylinder equipped with a shortened outage tube made from $1 / 4$ " nickel tube. The reaction conditions for this run are compiled in Table 7 . The gas produced in this trial was collected without passing it through a filter and was considered as the most 'crude' form (worst case scenario) with regard to possible U contamination. 


\section{Table 7.}

\section{Reaction Profile for GeFusn-36.}

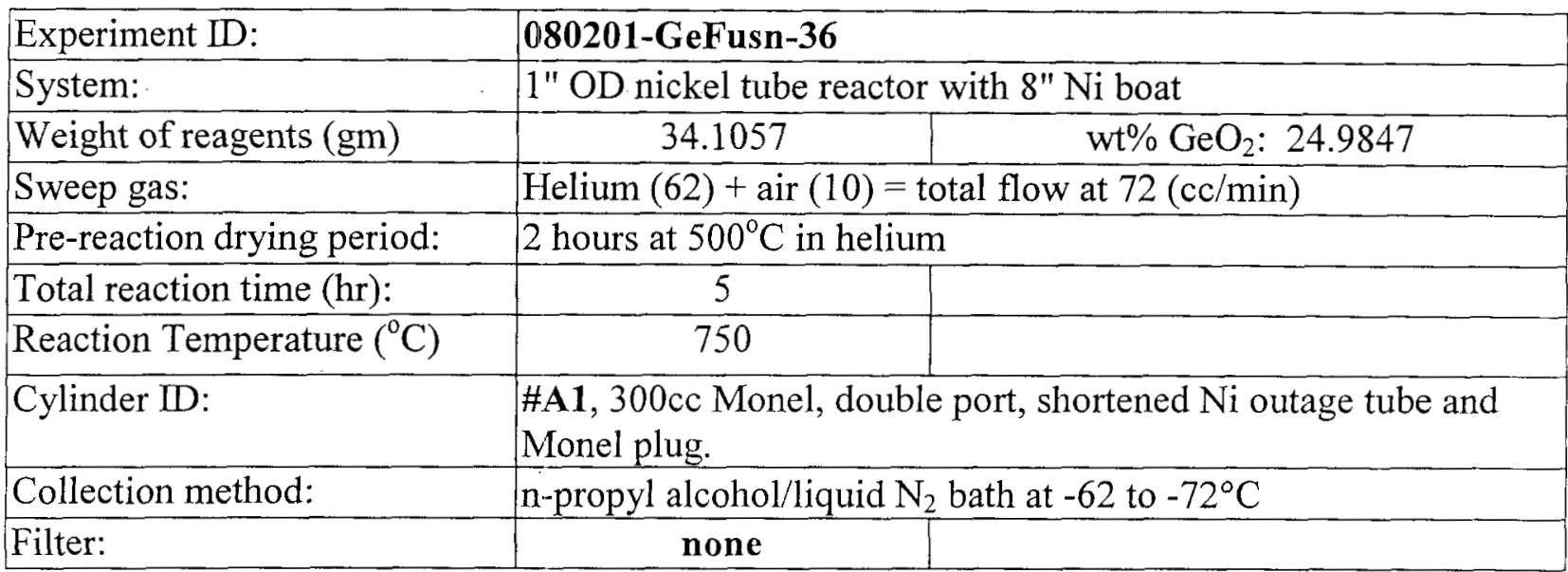

A second sample of $\mathrm{GeF}_{4}$ was prepared as part of GeFusn-40. In this experiment, the gas stream leaving the 1 " tube reactor was passed through a $0.45 \mu$ stacked PTFE $^{\circledR}$ membrane filter (Osmonics, Inc., Westborough, MA) before collection in the $300 \mathrm{cc}$ Monel cylinder. Reaction conditions for GeFusn-40 are given in Table 8. By making slight changes to the pre-reaction drying period and reaction temperature profile, 8.3 grams of gas was captured for shipment to $A N L$.

Table 8.

\section{Reaction profile for GeFusn-40.}

\begin{tabular}{|c|c|c|c|c|}
\hline Experiment ID: & \multicolumn{4}{|c|}{$011102-G e F u s n-40$} \\
\hline Reaction: & \multicolumn{4}{|c|}{$3 \mathrm{UF}_{4}+3 \mathrm{GeO}_{2}+\mathrm{O}_{2}(\mathrm{~g})=3 \mathrm{GeF}_{4}+\mathrm{U}_{3} \mathrm{O}_{8}$} \\
\hline System: & \multicolumn{4}{|c|}{ 1" OD Nickel tube reactor with 8 " nickel boat (including Ni foil spacer) } \\
\hline Weight of reagents (gm): & 36.4229 & \multicolumn{3}{|c|}{$\mathrm{wt} \% \mathrm{GeO}_{2}: 23.4819 \%$} \\
\hline Sweep gas: & \multicolumn{4}{|c|}{ Helium $(62)+$ air $(20)=$ total flow at $82(\mathrm{cc} / \mathrm{min})$} \\
\hline Pre-reaction drying period: & \multicolumn{4}{|c|}{1 hour at $450^{\circ} \mathrm{C}$ in helium } \\
\hline Total reaction time $(\mathrm{hr})$ : & 5.33 & & & \\
\hline \multirow[t]{5}{*}{ Reaction temperature profile } & & Time (hr) & at $\mathrm{T}\left({ }^{\circ} \mathrm{C}\right)$ & \\
\hline & & 0.33 & 725 & \\
\hline & & 0.50 & 750 & \\
\hline & & 3.33 & 775 & \\
\hline & & 1.17 & 800 & \\
\hline \multirow[t]{2}{*}{ Cylinder D: } & \multicolumn{4}{|c|}{ \#A2, 300cc Monel, double port, Monel plug and shortened Ni } \\
\hline & \multicolumn{4}{|c|}{ outage tube. } \\
\hline Collection method: & \multicolumn{4}{|c|}{ n-propyl alcohol/liquid $\mathrm{N}_{2}$ bath at $-85^{\circ} \mathrm{C}$ to $-80^{\circ} \mathrm{C}$} \\
\hline Filter: & \multicolumn{4}{|c|}{ Osmonics $0.45 \mu$ stacked $\mathrm{PTFE}^{(]}$membrane / polypropylene shell } \\
\hline
\end{tabular}


The post-reaction solids from both GeFusn- 36 and -40 were recovered and weighed to determine both reaction yield and conversion and then analyzed by $\mathrm{x}$-ray powder diffraction to characterize the composition of the leftover materials.

\subsubsection{Particulate filtration.}

During the reactor design trials, conducted as part of Task 1, filtering of the gas leaving the reactor was not done in order to maximize the total amount of product captured. However, when samples of $\mathrm{GeF}_{4}$ were made as part of the characterization of gas purity at facilities outside of Starmet, the gas was filtered through a $0.45 \mu$ stacked PTFE ${ }^{\circledR}$ membrane filter enclosed in a polypropylene shell (Osmonics, Inc., Westborough, MA). This included the material sent to Argonne National Laboratory and Voltaix, Inc. .

Information about gas filtration technology was also passed along from Voltaix, Inc. regarding what they used for removing particulate from other semiconductor grade materials they manufacture. One filter they have experience with and recommend is the Wafergard II F- 6 In-Line Gas Filter manufactured by Millipore Corporation (Bedford, MA). This unit features a teflon ${ }^{\circledR}$ membrane module rated for particulate removal of $\geq 0.003 \mu$. This type of modular filter can be placed directly in-line within a short distance of the gas cylinder inlet. Another filter, equivalent to the unit used by Voltaix, Inc., was purchased for use when the $\mathrm{GeF}_{4}$ productionscale reaction system was built. The filter, model \# TEM-811-P, was manufactured by the T.E.M. Filter Company (Santa Clara, CA) and purchased from Air Products (Allentown, PA).

\subsubsection{Process scale-up.}

Using what has been learned from reactor design and optimization trials (Tasks $\mathbf{1}$ and $\mathbf{3}$ ), production of $\mathrm{GeF}_{4}$ was demonstrated at high conversion levels and reasonably good capture efficiencies. Design of a production-scale apparatus was started and conceptual drawings of a multi-station reaction manifold and gas collection station were made. The two segments of the system are depicted in Figures $\mathbf{7}$ and $\mathbf{8}$. The reaction hardware consisted of six individual stations linked to a common manifold for conveying $\mathrm{GeF}_{4}$ to the collection station. The multiple reactor setup was adopted over a larger capacity single reactor apparatus to accommodate:

improved heat transfer to the reactant bed by keeping bed dimensions to a minimum; adding production capacity as needed over time;

greater control over batch purity and avoidance of lost production time;

lower cost and time to fabricate reaction hardware;

ease of handling reaction hardware by operators.

Each station joined to the manifold was designed to hold a reactant charge of $\sim 1 \mathrm{~kg}$ and produce $\sim 0.33 \mathrm{~kg}_{\text {of }} \mathrm{GeF}_{4}$. With all stations in operation at once, the system would deliver $\sim 2 \mathrm{~kg}$ of fluoride gas per day. Pertaining to operation, the gas produced by heating each reaction tube is carried into a central manifold by introducing a sweep stream of helium (or helium+air) above the reactor charge. The $\mathrm{GeF}_{4}$-laden stream is filtered using an in-line sintered metal (nickel) disc for snagging entrained particulate leaving the reaction zone. The combined gas flow is then directed to the collection apparatus shown in Figure 8, where $\mathrm{GeF}_{4}$ is condensed into a large volume cylinder surrounded by an appropriate coolant bath such as dry ice/alcohol. Once the 


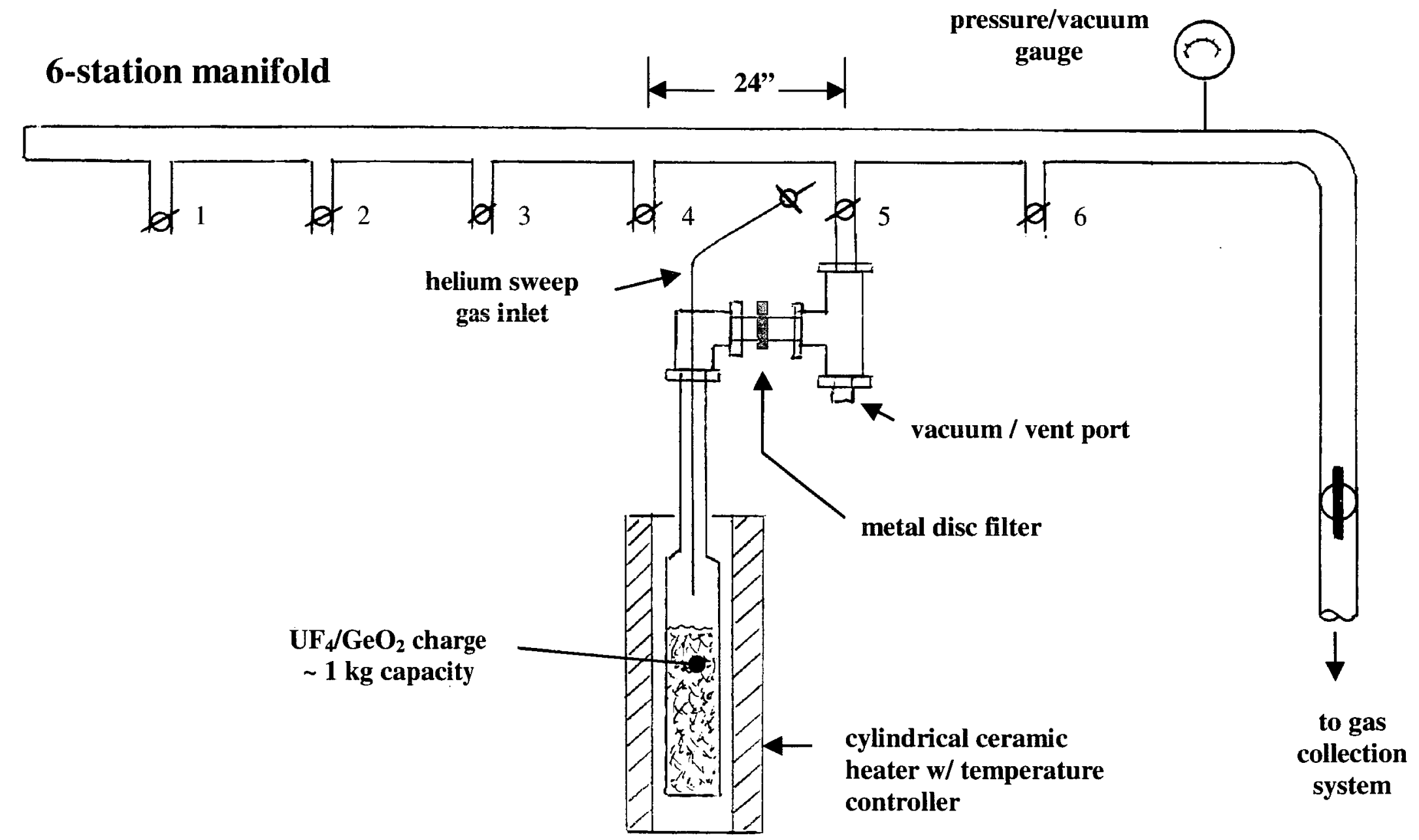

Figure 7. Multi-Station Reaction System for Producing $\mathrm{GeF}_{4}$. 


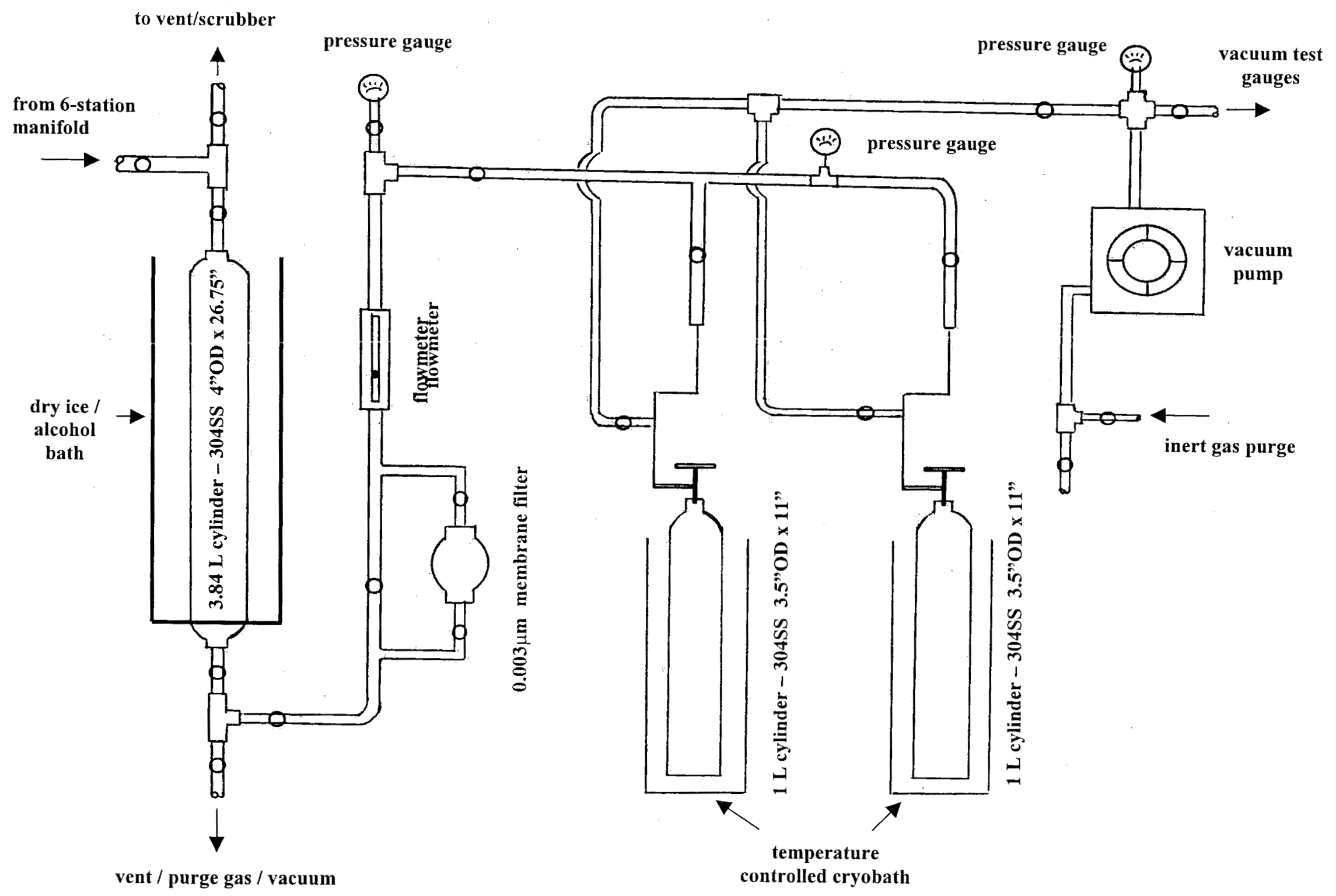

Figure 8. Gas collection system for trapping and packaging $\mathrm{GeF}_{4}$. 
capture of $\mathrm{GeF}_{4}$ is complete, the gas quality can be upgraded using fractional distillation procedures when transferring the product into transportable 1-liter (or larger) cylinders. It is possible to automate the transfer from the collection cylinder to the final package vessel but the automation hardware is costly and is not justified for a low production process such as this. In an effort to increase the amount of $\mathrm{GeF}_{4}$ produced per batch and also test the merits of the reactor design put forth in Figure 7, a small-scale prototype of the closed-end tube reactor was constructed from a 9" section of 1"OD nickel tube to hold the reactant mixture. The sweep gas was introduced via a $1 / 4$ " tube inserted through the wall of the $90^{\circ}$ union elbow used to cap the closed-end tube. The 1" elbow orifice was stepped down in size to a $1 / 4$ " tube connection and ultimately joined to a $300 \mathrm{cc}$ sample cylinder which had two ports and no outage tube. The cylinder was setup as a 'flow-through' condenser to capture $\mathrm{GeF}_{4}$ from the gas phase as the stream exiting the reactor passed through. The details of the reaction are given in Table 9 and the trial was identified as GeFusn-34. In this experiment, 87.84 grams of combined $U_{4}$ and $\mathrm{GeO}_{2}$ were loaded into the vertically oriented tube. A 6"OD x 6"long ceramic heater, controlled manually by variable potentiostat, was used to heat the tube. The 'flow-through' cylinder was positioned about 12 " to the side of the reaction tube and was outfitted with a container to hold bulk dry ice pellets around the circumference of the cylinder body.

Table 9.

Reaction profile for GeFusn-34.

\begin{tabular}{|c|c|c|c|c|}
\hline Experiment D: & \multicolumn{4}{|c|}{ 051501-GeFusn-34 } \\
\hline System: & \multicolumn{4}{|c|}{ Closed-end 1" OD nickel tube reactor } \\
\hline & \multicolumn{4}{|c|}{ 6" OD x 6" long ceramic heater (with manual control) } \\
\hline Weight of reagents $(\mathrm{gm})$ : & 87.84 & \multicolumn{3}{|c|}{$\mathrm{wt} \% \mathrm{GeO}_{2}: 24.1689$} \\
\hline Sweep gas: & \multicolumn{4}{|c|}{ Helium flow at $70(\mathrm{cc} / \mathrm{min})$} \\
\hline Total reaction time $(\mathrm{hr})$ & 5 & & & \\
\hline \multirow[t]{4}{*}{ Reaction temperature profile } & & Time (hr) & at $\mathrm{T}\left({ }^{\circ} \mathrm{C}\right)$ & \\
\hline & & 2 & $735-755$ & \\
\hline & & 1 & 775 & \\
\hline & & 2 & 800 & \\
\hline Cylinder ID: & \multicolumn{4}{|c|}{$\# 11,300 \mathrm{cc}$ volume, Monel, double port, no outage tube } \\
\hline Collection method: & \multicolumn{4}{|c|}{ dry ice bath, neat } \\
\hline
\end{tabular}




\subsubsection{Gas ultrapurification.}

As part of the Phase II program to harvest $\mathrm{GeF}_{4}$ from processing of uranium tetrafluoride, Voltaix, Inc. (North Branch, NJ) was subcontracted by Starmet to perform analytical testing of the gas to establish the purity of the "as-produced" material. Voltaix, Inc. agreed to partner with Starmet to assist with the development and commercialization of $\mathrm{GeF}_{4}$ since they currently market this material for ion implantation applications. The material produced by the FEP ${ }^{\mathrm{TM}}$ technology requires in-depth characterization to establish what must be done at either the crude production stage or with additional purification steps to insure that this gas will be pure enough to meet or exceed the current specifications.

Under the subcontract agreement with Voltaix, Inc. germanium tetrafluoride produced at Starmet was to be characterized using three techniques, FT-IR spectroscopy (FT-IR), gas chromatography-mass spectrometry (GC-MS) and inductively coupled plasma-mass spectrometry (ICP-MS). Infrared spectra were collected using a Nicolet Instruments MagnaIR560 optical bench, similar to the instrumentation at Starmet. Analysis of gas samples by GC-MS was attempted but abandoned after experiencing problems with identifying an acceptable separatory column that did not react with $\mathrm{GeF}_{4}$. ICP-MS analysis of Starmet material was accomplished at an independent laboratory, Applied Analytical Inc. (Austin, TX). For this evaluation, $\mathrm{GeF}_{4}$, produced in laboratory trials (GeFusn-37 and -38), was first hydrolyzed in deionized water at Voltaix, Inc. and the resultant solution, along with a similarly prepared reference sample and 'blank' specimen, were forwarded on to Applied Analytical Inc. . The source of the reference sample was derived using a purchased source of $\mathrm{GeF}_{4}$ claimed to have a purity of $99.99 \%$ (vendor certified). The 'blank' sample was prepared by bubbling a known amount of nitrogen ballast gas through a set volume of deionized water.

The $\mathrm{GeF}_{4}$ submitted for purity analysis was generated from two experiments, GeFusn-37 and GeFusn-38. The material collected in both trials totaled 15.61 grams. The reaction profile for each experiment is given in Table $\mathbf{1 0}$ and Table $\mathbf{1 1}$ showing reaction time and temperature information. 
Table 10.

\section{Reaction Profile for GeFusn-37.}

\begin{tabular}{|c|c|c|c|}
\hline Experiment ID: & \multicolumn{3}{|c|}{ 081601-GeFusn-37 } \\
\hline System: & \multicolumn{3}{|c|}{ 1" OD nickel tube reactor with 8 " Ni boat (including Ni foil spacer) } \\
\hline Weight of reagents $(\mathrm{gm})$ & 35.1592 & \multicolumn{2}{|c|}{$\mathrm{wt} \% \mathrm{GeO}_{2}: 24.9847$ (stoichiometric mixture) } \\
\hline Sweep gas: & \multicolumn{3}{|c|}{ Helium $(62)+\operatorname{air}(20)=$ total flow at $82(\mathrm{cc} / \mathrm{min})$} \\
\hline Pre-reaction drying period: & \multicolumn{3}{|c|}{1 hr at $300^{\circ} \mathrm{C}$ in helium } \\
\hline Total reaction time $(\mathrm{hr})$ : & 5.25 & & \\
\hline \multirow[t]{5}{*}{ Reaction temperature profile } & Time (hr) & at $\mathrm{T}\left({ }^{\circ} \mathrm{C}\right)$ & \\
\hline & 0.25 & 700 & \\
\hline & 1 & 750 & \\
\hline & 2.75 & 775 & \\
\hline & 1.25 & 800 & \\
\hline \multirow[t]{2}{*}{ Cylinder ID: } & \multicolumn{3}{|c|}{$\# 8,150 \mathrm{cc}$ stainless steel 304 , single port with shortened } \\
\hline & \multicolumn{3}{|c|}{ outage tube. } \\
\hline Collection method: & \multicolumn{3}{|c|}{ n-propyl alcohol/dry ice bath at $-72^{\circ} \mathrm{C}$} \\
\hline Filter: & \multicolumn{3}{|c|}{ Osmonics $0.45 \mu$ stacked PTFE ${ }^{\circledR}$ membrane/polypropylene shell } \\
\hline
\end{tabular}

Table 11.

Reaction Profile for GeFusn-38.

\begin{tabular}{|c|c|c|c|}
\hline Experiment ID: & \multicolumn{3}{|c|}{ 082101-GeFusn-38 } \\
\hline System: & \multicolumn{3}{|c|}{ 1" OD nickel tube reactor with 8 " Ni boat (including Ni foil spacer) } \\
\hline Weight of reagents $(\mathrm{gm})$ & 34.0237 & \multicolumn{2}{|c|}{$\mathrm{wt} \% \mathrm{GeO}_{2}: 24.9847$ (stoichiometric mixture) } \\
\hline Sweep gas: & \multicolumn{3}{|c|}{ Helium $(62)+$ air $(20)=$ total flow at $82(\mathrm{cc} / \mathrm{min})$} \\
\hline Pre-reaction drying period: & \multicolumn{3}{|c|}{$1 \mathrm{hr}$ at $400^{\circ} \mathrm{C}$ in helium } \\
\hline Total reaction time $(\mathrm{hr}):$ & 3.75 & & \\
\hline \multirow[t]{3}{*}{ Reaction temperature profile } & Time (hr) & at $\mathrm{T}\left({ }^{\circ} \mathrm{C}\right)$ & \\
\hline & 0.75 & $650-800$ & \\
\hline & 3 & 800 & \\
\hline \multirow[t]{2}{*}{ Cylinder ID: } & \multicolumn{3}{|c|}{$\# 8,150$ cc stainless steel 304 , single port with shortened outage } \\
\hline & \multicolumn{3}{|c|}{ tube containing $\mathrm{GeF}_{4}$ collected in $081601-\mathrm{GeFusn}-37}$. \\
\hline Collection method: & \multicolumn{3}{|c|}{ n-propyl alcohol/dry ice bath at $-77^{\circ} \mathrm{C}$} \\
\hline Filter: & \multicolumn{3}{|c|}{ Osmonics $0.45 \mu$ stacked PTFE $^{\circledR}$ membrane / polypropylene shell } \\
\hline
\end{tabular}


In brief, both reactions were carried out using a helium/air mixture as the sweep gas through the reactor. The material produced in both reactions was filtered using a $0.45 \mu$ stacked PTFE $^{\circledR}$ membrane filter (Osmonics, Westborough, MA) before condensation in the cylinder. FT-IR analysis of the gas stream exiting the $150 \mathrm{cc}$ collection cylinder was done during the GeFusn-38 trial to monitor how much product gas was escaping from the condensation zone while the cylinder was submerged in the coolant bath at $-77^{\circ} \mathrm{C}$. After concluding GeFusn-38, the helium/air residual was removed by vacuum processing before shipping the sample to Voltaix, Inc: Follow-up analysis of the reaction solids left behind after each trial was also performed using $\mathrm{x}$-ray powder diffraction.

\subsubsection{Product qualification.}

Germanium tetrafluoride produced in laboratory trials was analyzed by several different techniques described in Tasks 4 and 7. The crude product was determined to be equivalent in purity to the reference material with certified purity of $99.99 \%$ (UHP grade). Additional analytical testing is required to quantify the level of impurities specifically called out in the Voltaix, Inc. specification for UHP grade $\mathrm{GeF}_{4}$ such as $\mathrm{CF}_{4}, \mathrm{CO}, \mathrm{CO}_{2}, \mathrm{SO}_{2}, \mathrm{~N}_{2}, \mathrm{Ar}+\mathrm{O}_{2}$ and HF. Many if not all of these impurities can be measured by GC-MS, the one technique that presented the greatest challenge in obtaining useable data during the Phase II program.

However, the need for a material with higher purity than the current specification has not been established. No work was done to pursue what the next generation of electronic/semiconductor products may require with regard to material specifications.

\subsubsection{Design and construction of low production rate equipment.}

Due to the weak economic performance and global slump in the electronic and semiconductor sectors over the past 18 months, the decision to erect a production-scale plant for producing $\mathrm{GeF}_{4}$ was postponed. However, conceptual drawings of a multi-station reaction system and gas collection station were made and described in Task 6 . This system was configured to deliver up to $2 \mathrm{~kg}$ of fluoride gas per day when operated at full capacity, making it well suited to meet the projected $100 \mathrm{~kg}$ production plateau as forecasted by Voltaix, Inc. 


\subsection{Experimental Results for $\mathrm{GeF}_{4}$.}

\subsubsection{Reactor design for producing $\mathrm{GeF}_{4}$.}

Two designs for a batch-type reaction system were tested for producing $\mathrm{GeF}_{4}$ with good reaction yield and capture efficiency. Five experiments were performed using a crucible reactor while nine experiments were carried out using several tube reactor systems. The experimental setups and procedures were given in detail in section 8.1.1. Results for these two reactor configurations are arranged into two groups to help facilitate comparison of their performance as indicated by reaction conversion and capture efficiency values. After presenting the reaction data, results for the analyses of the reaction products (both solids and gas) by x-ray diffraction and FT-IR spectroscopy are also included.

Results for the five experiments in the crucible reactor setup are given in Table 12. In this table, both theoretical (calculated) and experimental (observed) values were used in deriving the "Reaction Conversion" and "Capture Efficiency" parameters. Calculations were based on gravimetric measurements collected for gaseous product and residues remaining after reaction. "Calculated" values in the table were based on $100 \%$ reaction conversion. The "Reaction Conversion" was calculated as a ratio of "Observed weight loss of reagents" to the "Calculated weight loss of reagents" expected upon complete reaction (x 100\%). The "Capture Efficiency" of $\mathrm{GeF}_{4}$ was compiled as the "Observed weight gain in cylinder" divided by the "Observed weight loss of reagents" ( $x$ 100\%). Among the five trials, the Reaction Conversion ranged from a low of $84.9 \%$ (for GeFusn-20) to $95.2 \%$ (for GeFusn-23) while the Capture Efficiency ranged from $20.9 \%$ (for GeFusn-19) to a high of $38.3 \%$ (for GeFusn-21).

The reaction parameters, i.e. reaction temperature, time and flow rate of carrier gas, were varied in order to find a set of conditions which maximized both conversion and capture efficiency in this reactor configuration. As expected, when the reaction temperature was increased from $875^{\circ} \mathrm{C}$ to $925^{\circ} \mathrm{C}$, a corresponding increase in conversion was noted. An increase in reaction time from 2 to 3 hours also helped to further conversion. It was anticipated that a faster flow of helium carrier gas would shorten the residence time of $\mathrm{GeF}_{4}$ in the reaction zone and result in higher capture efficiency. However, this scenario was not the case when results for GeFusn-21 are compared to those of GeFusn-23. What is clearly evident from the five trials is the poor collection efficiency experienced in all experiments. Although a majority of the reaction was completed and volatile product made, it did not wind up as desired product. The use of a copper container and 'chimney' in GeFusn-22 did not result in increased recovery by minimizing effects of reactor freeboard and residence time.

It is apparent that several factors contributed to the low recovery of $\mathrm{GeF}_{4}$. They include:

1. corrosive attack of the $\mathrm{GeF}_{4}$ laden atmosphere on the reactor material

2. formation of $\mathrm{Ni}_{2} \mathrm{GeO}_{4}$ on the nickel beaker walls

3. less than $100 \%$ reaction conversion

4. formation of crystalline condensate $\left(\mathrm{GeF}_{2}\right)$ on cooler section of the reaction system

5 . small condensing zone provided by the $150 \mathrm{cc}$ gas sample cylinder interior.

A more detailed explanation of factors 1-4 is provided below and is based on direct observations of similar findings during and after the disassembly of the reaction system following each experiment. 
Table 12.

Experiments performed in the crucible reactor setup.

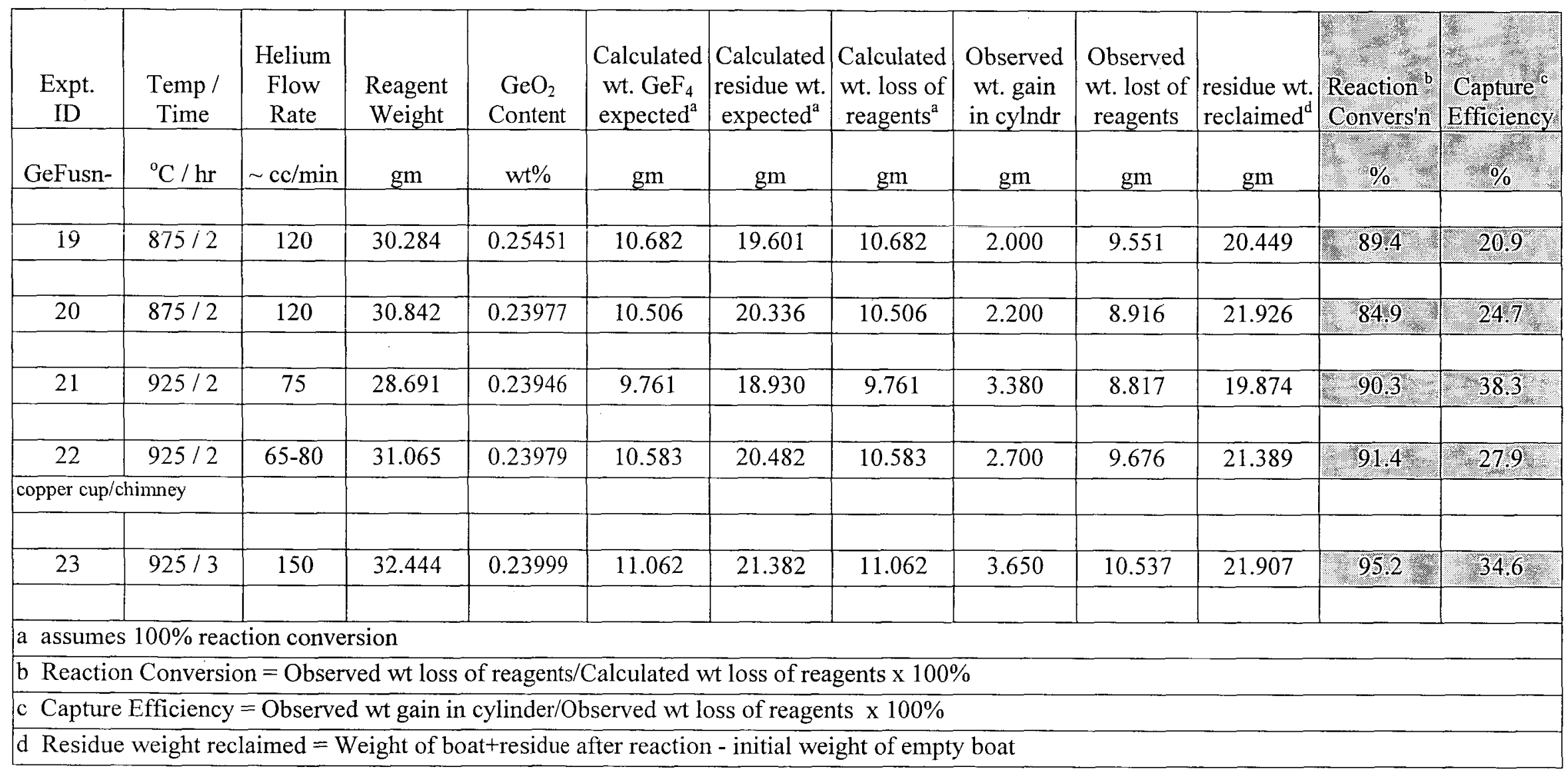


Factor 1: The inside surfaces of the reactor walls exposed to the heat of the furnace and $\mathrm{GeF}_{4}$ atmosphere were aqua blue-green in color with formation of peeling scale. Analysis of this scale by $\mathrm{x}$-ray powder diffraction showed a combination of mixed metal oxides of $\mathrm{Ni}-\mathrm{Cr}, \mathrm{Cr}-\mathrm{Co}$ and possible oxyfluoride compounds. It was clear the HR $160^{\circledR}$ alloy was being attacked at the reaction temperature in the presence of $\mathrm{GeF}_{4}$.

Factor 2: The interior wall of the nickel beaker above the solid residue was coated with a thin, flaky, light green skin which was removed easily with scraping. The light green substance was examined by both $x$-ray powder diffraction and energy dispersive $x$-ray analysis techniques in the scanning electron microscope (EDS/SEM). It was identified as $\mathrm{Ni}_{2} \mathrm{GeO}_{4}$ which obviously was produced by consuming some of the $\mathrm{GeF}_{4}$ in the surrounding atmosphere. The weight of the empty nickel beaker at the start of each experiment was progressively higher (by as much as 0.5 gram) compared to the trial coming immediately before it. The continued formation of this skin over the course of the trials may account for the steady weight increase but it is believed the loss of $\mathrm{GeF}_{4}$ from this interaction with the beaker represented only a small fraction of the amount not captured in the collection vessel.

Factor 3: The surface of the powder in the center of the container was varying shades of dark green and not fully blackened. The solid closer to the beaker walls was notably darker in appearance than at the center, indicative of how heat was penetrating to the vessel's core. The temperature in Table 12 for each experiment was the furnace set point temperature. Actual temperatures inside the $4.5^{\prime}$ " diameter reactor were not profiled but were estimated to be some $60^{\circ}-75^{\circ} \mathrm{C}$ lower than the set point temperature. The presence of color gradients in the residues is consistent with the gradients in heat transfer from the outside wall of the reactor to the center of the nickel beaker.

Factor 4: A deposit of white crystalline residue was found in varying amounts on the underside of the reaction vessel lid and sections of pipe downstream from the reaction chamber. Upon exposure to air, the solid residue became wet and eventually turned completely to liquid. A quick test of the liquid with $\mathrm{pH}$ test paper showed it to be extremely acidic at $\mathrm{pH}<1$. Because of the nature of this material to rapidly hydrolyze in air, efforts were made to quantify the amount of condensed residue by washing off reactor hardware with distilled water. When placed in water immediately following exposure to air, the surface layer turned bright yellow-orange. Over the course of 48 hours the residue was completely dissolved in water. Solutions containing dissolved residue collected after each experiment were analyzed by inductively coupled plasma (ICP) techniques to measure the amount of Ge distributed on the reactor hardware not in the form of $\mathrm{GeF}_{4}$. The amount of Ge lost to the buildup of this residue is summarized in Table 13. 


\section{Table 13.}

\section{Results showing analyses for Ge by ICP for aqueous wash solutions collected during recovery of $\mathrm{GeF}_{2}$ residue from reactor hardware.}

\begin{tabular}{|l|c|c|c|c|c|c|c|}
\hline Experiment No. & $\begin{array}{c}\text { Ge content } \\
\text { in wash soln }\end{array}$ & $\begin{array}{c}\text { Total soln. } \\
\text { volume } \\
\text { collected }\end{array}$ & $\begin{array}{c}\text { Total Ge } \\
\text { content }\end{array}$ & $\begin{array}{c}\text { Moles } \\
\mathrm{Ge}\end{array}$ & $\begin{array}{c}\text { equivalent } \\
\text { amt. GeO }\end{array}$ & $\begin{array}{c}\text { Amt. } \mathrm{GeO}_{2} \\
\text { in reaction } \\
\text { mixture }\end{array}$ & $\begin{array}{c}\text { Fraction of } \\
\mathrm{GeO}_{2} \text { charge } \\
\text { recov'd from } \\
\text { reactor hardware }\end{array}$ \\
\hline GeFusn-20 & $\mathrm{ug} / \mathrm{ml}$ & $\mathrm{ml}$ & $\mathrm{gm}$ & $\mathrm{n})$ & $\mathrm{gm}$ & $\mathrm{gm}$ & $\%$ \\
\hline GeFusn-21 & 350 & 3000 & 1.650 & 0.0227 & 2.377 & 7.3949 & 32.1 \\
\hline GeFusn-22 & 357 & 3000 & 1.071 & 0.0148 & 1.543 & 7.4491 & 20.7 \\
\hline GeFusn-23 lid & 314 & 3000 & 0.942 & 0.0130 & 1.357 & 7.7865 & 17.4 \\
\hline - exit tube & 550 & 50 & 0.0275 & 0.0004 & 0.040 & & 0.5 \\
\hline
\end{tabular}

The identity of the condensed crystalline residue (before exposure to moisture and water recovery) is not certain due to the lack of direct analysis. It is believed to be $\mathrm{GeF}_{2}$ based on properties of the difluoride being a low melting solid which is rapidly hydrolyzed by moisture. Further work is required to specifically isolate the residue where it can be handled without compromising its integrity during the analytical characterization process. As shown in Table 13, and estimated $32.1 \%$ of the Ge content put into the reactor as $\mathrm{GeO}_{2}$ for GeFusn- 20 was collected from the deposited residue on the reactor hardware. This is a conservative estimate since much of the cooler surface area beyond the reactor lid not easily accessible to washing, may have contained a thin coating of residue which was not recovered. This is a very significant fraction of $\mathrm{Ge}$ that does not get captured as $\mathrm{GeF}_{4}$. A clear understanding of how the condensed residue is formed, whether it be directly by parallel side reaction or by secondary reaction which consumes $\mathrm{GeF}_{4}$, is lacking and requires further investigation. Additional discussion concerning a possible mechanism will be included later in the discussion section of this report.

$\mathrm{By}$ far, it is the formation of the $\mathrm{GeF}_{2}$ condensate that contributes the most to the low capture yield of $\mathrm{GeF}_{4}$. To help understand the origin of this unwanted residue, one qualitative experiment was performed involving gaseous $\mathrm{GeF}_{4}$. Germanium tetrafluoride gas (purchased from Advanced Research Chemicals, Inc., Catoosa, OK) was added to a stream of helium and passed through the HR $160^{\circledR}$ alloy reactor heated at $925^{\circ} \mathrm{C}$ for a two-hour period. The reaction vessel contained the empty nickel beaker used in previous experiments and the same heating profile shown in Table 4 (page 13) was used. The $\mathrm{GeF}_{4} / \mathrm{He}$ stream was introduced into the reaction zone after the reaction temperature was reached. A preweighed gas sample cylinder chilled with a liquid nitrogen bath was used to recover $\mathrm{GrF}_{4}$ from the reactor exit stream. After completing the experiment, the cylinder contained 1.13 grams of condensed gas. Upon opening the reactor, the lid had the same crystalline residue deposited on the side exposed to the reactor interior. The residue became quickly hydrolyzed in the presence of air. Submerging the lid in a bath of distilled water produced the same yellow-orange colored solution. The inside walls of the reactor exposed to the high temperature had blue-green scale covering the surface. It is 
evident from these observations that the condensed $\mathrm{GeF}_{2}$ deposit is formed as a result of $\mathrm{GeF}_{4}$ interaction with the HR $160^{\circledR}$ alloy or nickel beaker. Additional discussion will be presented later after detailing experiments performed in the alternate reactor configuration, namely the tube reactor.

Investigation of the tube reactor configuration was performed by conducting nine experiments, the first using a 304L stainless steel reaction tube and eight using a nickel 200 alloy tube reactor. Results for the nine trials are given in Table 14, showing reaction parameters as well as "calculated" and experimental "observed" values. Again, the "Reaction Conversion" and "Capture Efficiency" values were calculated in a similar fashion to those reported for the crucible reactor experiments, thereby making it possible to compare the performance of the two reactor designs directly. 
Table 14.

Reaction carried out in the tube reactor setup.

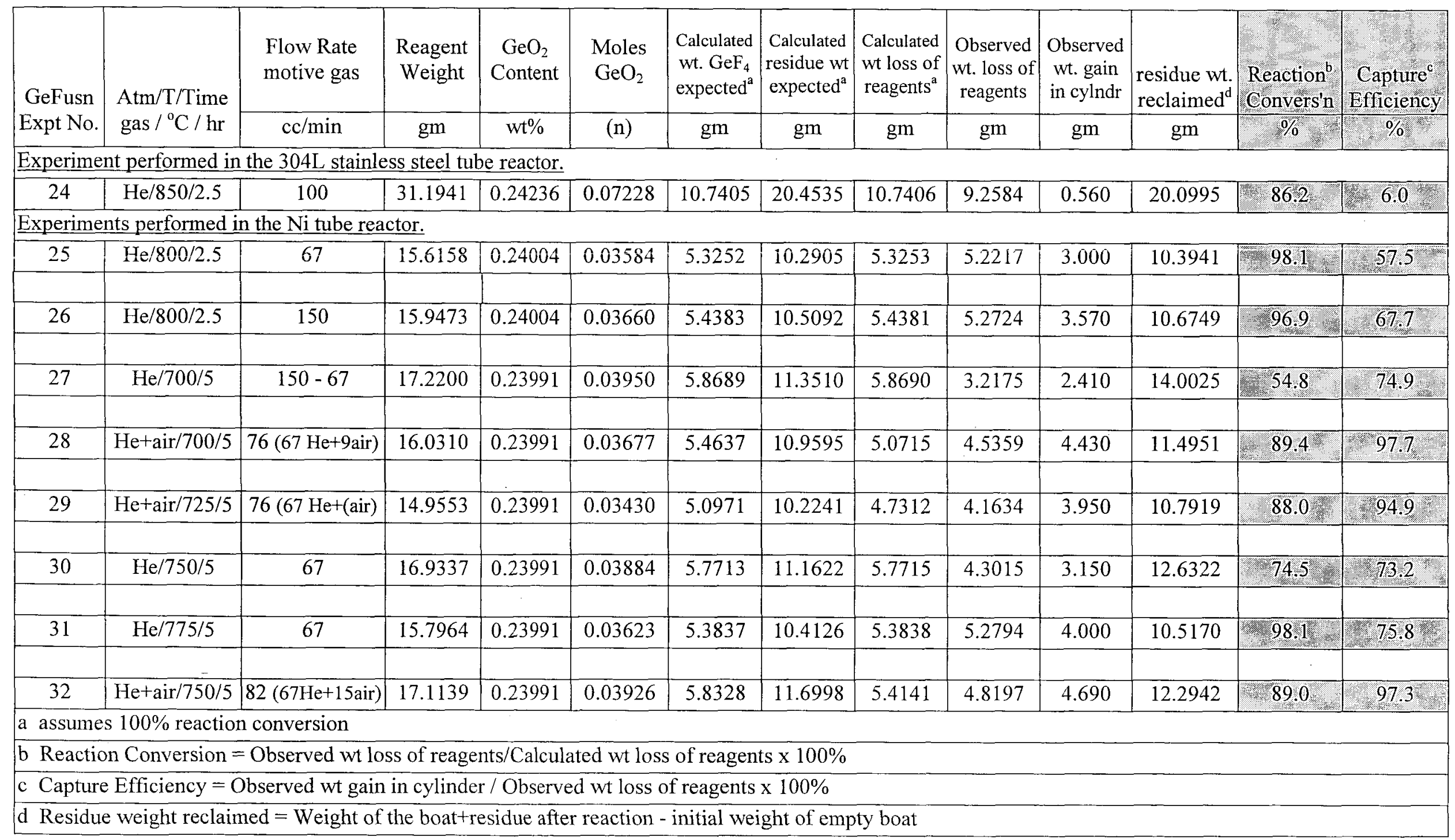


The first experiment carried out in a tube reactor was GeFusn-24. The reaction tube was constructed of type 304L stainless steel with a tube diameter of $2.75^{\prime \prime}$. The reaction parameters for this trial are given in Table 14. Upon concluding the run, the same set of gravimetric measurements was recorded as done in previous experiments. The residue left in the alumina boat was totally black in color indicative of a high degree of conversion. However, the weight of the boat was dramatically altered (1.8164 gram increase) by the growth of unremoveable scale on the bottom exterior surface where the boat came into contact with the stainless steel tube. Values for the "Observed weight loss of reagents" and the "residue weight reclaimed" include this artifact which compromised the accuracy of these data. Nonetheless, it is clearly evident that most of the volatile product created by the reaction never made it to the collection vessel, culminating in a capture efficiency of only $6 \%$. Upon disassembling the reactor sections downstream from the furnace, there was clear evidence of hydrolyzed $\mathrm{GeF}_{2}$ residue distributed on tube wall surfaces leading to the collection cylinder. From visual inspection of the heated section of the tube, most of the generated $\mathrm{GeF}_{4}$ reacted with the $304 \mathrm{~L}$ stainless steel. No further experimentation was performed in this apparatus due to the poor result.

A larger group of experiments was carried out using a 1" OD reaction tube constructed from nickel 200 alloy. Results for those trials are also posted in Table 14. In those trials, the reaction conversion ranged from a high of $98.1 \%$ (for GeFusn-25 and -31 ) to a low of $54.8 \%$ (for GeFusn-27). Likewise, the capture efficiency spanned a broad range from $97.7 \%$ (for GeFusn28) down to $57.5 \%$ (for GeFusn-25). Influence of various reaction parameters can also be seen amongst the eight experiments. The influence of reaction temperature can be followed by comparing GeFusn trials 27, 30 and 31, which showed a significant increase in reaction conversion as the temperature was stepped up from $700^{\circ} \mathrm{C}$ (GeFusn-27) to $775^{\circ} \mathrm{C}$ (GeFusn-31) in a helium atmosphere. More importantly, a significant increase in capture efficiency of more than $20 \%$ was seen when the reaction atmosphere was changed from pure helium to one containing a mixture of helium and air (for GeFusn-28, -29 and -32). The GeFusn-28 trial posted the highest capture efficiency at $97.7 \%$ combined with an $89.4 \%$ reaction conversion. It is of interest to note that in the trials where air was introduced to the carrier stream (GeFusn-28,-29 and -32) it appears that the reaction conversion reached an upper limit around $89 \%$, regardless of temperature. Additional results concerning the selection of optimum reaction parameters is included in a later section 8.2.3 dealing with optimization of product yield.

Overall, reactions conducted in the tube configuration yielded higher levels of conversion and capture efficiency. More importantly, the collection of $\mathrm{GeF}_{4}$ increased significantly with the use of nickel 200 alloy to fabricate the reaction tube. The better performance observed during the tube trials is supported further by several key observations seen routinely across the series of eight reactions. They include:

1. onset of gas evolution

2. formation of crystalline condensate $\left(\mathrm{GeF}_{2}\right)$.

In brief:

1. Evolution of $\mathrm{GeF}_{4}$ was confirmed by observing a stream of white vapor leaving the exit line from the reactor at a furnace temperature of $700^{\circ} \mathrm{C}$. Prior to the use of the nickel tube, the reaction between $\mathrm{UF}_{4}$ and $\mathrm{GeO}_{2}$ was not seen until the reaction temperature eclipsed the $775^{\circ} \mathrm{C}$ threshold. The ability to carry out the reaction at lower temperatures will reduce the corrosive attack of the reaction atmosphere on reactor hardware and decrease the loss of $\mathrm{GeF}_{4}$ through destructive side reactions. In all reactions prior to using the nickel material, the $\mathrm{GeF}_{4}$ being produced (at temperatures between $775^{\circ}-925^{\circ} \mathrm{C}$ ) most likely was consumed by reacting within 
the immediate vicinity of the hot zone with the vessel material. There is evidence of a fine, light green substance coating the interior surface of the nickel tube in the area of the intense heat. This is believed to be a coating of $\mathrm{Ni}_{2} \mathrm{GeO}_{4}$ generated by the reaction of $\mathrm{GeF}_{4}$ with nickel oxide that is present as a result of moisture desorbing before and during the reaction.

2. The deposition of a white, crystalline residue at the end of the tube, just outside the body of the furnace, was seen to some extent in all eight experiments. It appeared that the residue condensed to liquid first before solidifying since most of the deposit was situated along the tube floor especially in the area where the tube diameter was reduced to $1 / 2$ ", then to $1 / 4$ " via Swagelok ${ }^{\circledR}$ reducing unions. Upon exposure to air, the same hydroscopic behavior was observed where the solid quickly became wetted. In two experiments an attempt was made to estimate how much residue collected in the area where the tube diameter narrowed. Almost all the residue was deposited on the surfaces of the reducing unions so they were quickly submerged in distilled water after dismantling the reactor after each reaction. The parts were washed clean of deposits and the resultant solutions dried to recover hydrolyzed material. Those results are shown in Table 15. The identity of the hydrolyzed residue was confirmed as $\mathrm{GeO}_{2}$ by $\mathrm{x}$-ray powder diffraction analysis.

\section{Table 15.}

Recovery of $\mathrm{GeF}_{2}$ deposits from reactor hardware.

\begin{tabular}{|c|c|c|}
\hline $\begin{array}{c}\text { Experiment } \\
\text { ID }\end{array}$ & $\begin{array}{c}\text { Weight of material recovered } \\
\text { (grams) }\end{array}$ & $\begin{array}{c}\text { Fraction (\%) of initial charge of } \\
\mathbf{G e O}_{2} \text { used in the reaction }\end{array}$ \\
\hline GeFusn-26 & 0.4873 & 12.7 \\
\hline GeFusn-31 & 0.8800 & 23.2 \\
\hline
\end{tabular}

As found earlier in the crucible reactor study, a significant fraction on the order of $23.2 \%$ of the $\mathrm{GeO}_{2}$ put in as reactant for the GeFusn-31 trial was lost to the condensed $\mathrm{GeF}_{2}$ residue instead of being captured as $\mathrm{GeF}_{4}$. Quantitative results were not collected for all the reactions but two trends stand out. First, reactions carried out at lower temperature produced lesser amounts of residue downstream from the reactor hot zone. Secondly, reactions where air was included in the carrier gas stream tended to deposit lesser amounts of residue. It is clear that the formation of the Ge rich deposits is not exclusive to either of the reactor designs being evaluated. However, using suitable reaction parameters the amount of unwanted residue can be controlled and minimized.

Characterization of the reaction products synthesized during the reactor design trials was also done. The solid residues were examined using $x$-ray diffraction techniques while the reactor off-gas was analyzed by FT-IR spectroscopy. Results of the x-ray diffraction analyses are presented first followed by FT-IR analysis of the material collected in the 150cc gas sample cylinders.

\section{X-ray Diffraction Analyses of Reaction Residues.}

$\mathrm{X}$-ray diffraction patterns for each of the residues recovered during the crucible reactor investigation (GeFusn-19, -20, -21, -22 and -23) are compiled in Figure 9. Reference patterns for $\mathrm{UF}_{4}$ (pdf\# 32-1401), $\mathrm{UGeO}_{4}$ (pdf\# 13-0588) and $\mathrm{UO}_{2}$ (pdf\# 41-1422) are included above the 


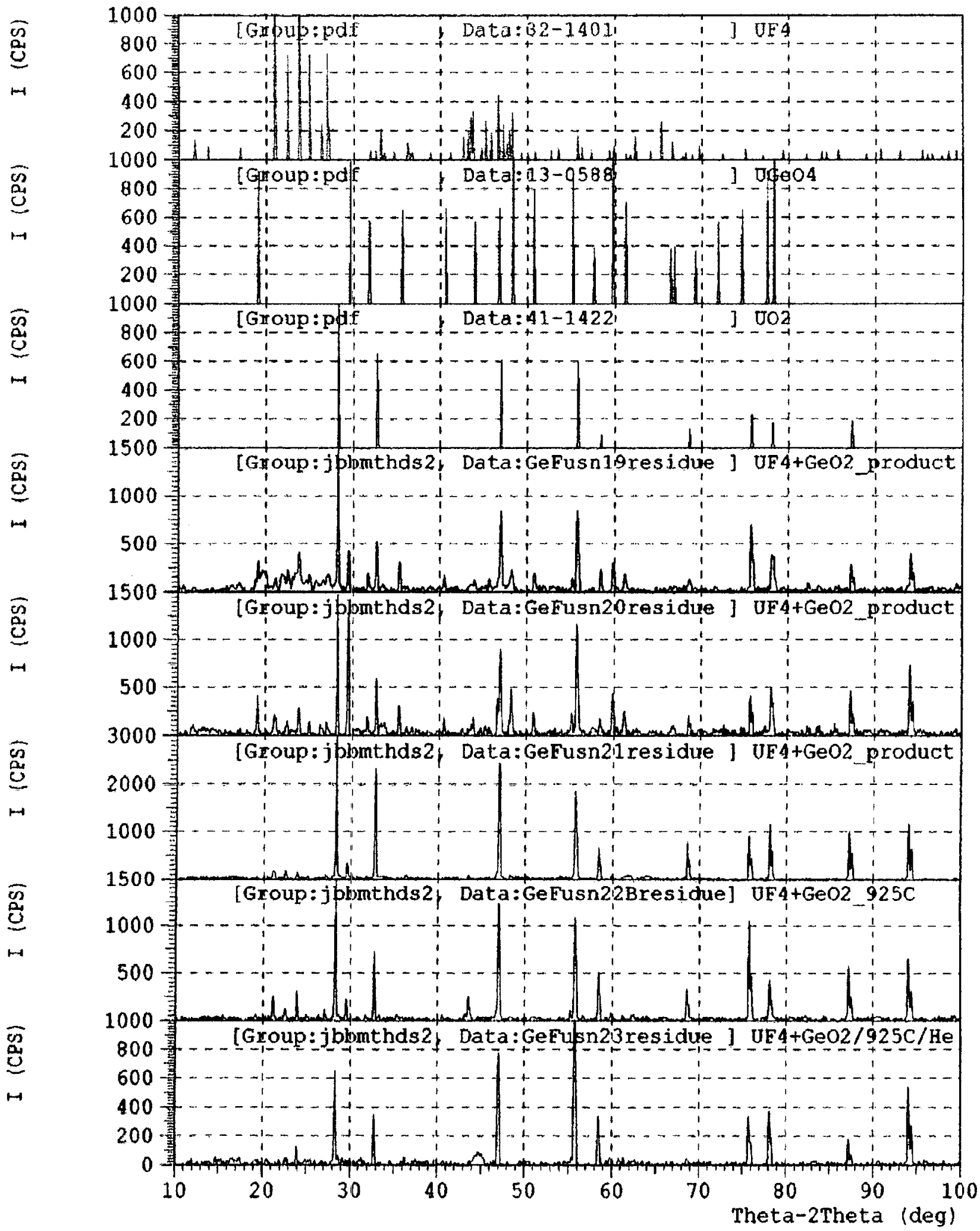

Figure 9. XRD patterns for materials recovered from crucible reactor experiments GeFusn-19, -20, -21, -22 and -23 and reference patterns for $\mathrm{UF}_{\mathbf{4}}$ (pdf\# 32-1401), $\mathrm{UGeO}_{4}$ (pdf\# 13-0588) and $\mathrm{UO}_{2}$ (pdf\# 41-1422). 
experimental patterns. The predominant phase in each of the patterns matched well with the reference for $\mathrm{UO}_{2}$. Evidence for unreacted $\mathrm{UF}_{4}$ and the presence of $\mathrm{UGeO}_{4}$ were detected in differing amounts among the group. Patterns for residues from GeFusn-21 and -23 , which were run at the $925^{\circ} \mathrm{C}$ temperature, showed only a trace of $\mathrm{UF}_{4}$ in GeFusn-21 or none at all as in GeFusn-23 where the conversion was $95.2 \%$. At the lower temperature of $875^{\circ} \mathrm{C}$, lower conversion was confirmed by the appearance of more $\mathrm{UF}_{4}$ and the formation of $\mathrm{UGeO}_{4}$ that was apparently formed by a reaction between $\mathrm{UO}_{2}$ and $\mathrm{GeO}_{2}$.

Analysis of the material recovered from the stainless steel tube apparatus, GeFusn-24, is shown in Figure 10. At $850^{\circ} \mathrm{C}$ it is clear the reaction went essentially to completion since no other phases could be identified other than $\mathrm{UO}_{2}$. The listed conversion of $86.2 \%$ (see Table 14) is remarkably low when taking into consideration the XRD result which has a limit of detection (LOD) on the order of $1-3 \mathrm{wt} \%$ for $\mathrm{UF}_{4}$.

The XRD results collected for the materials coming out of the nickel tube setup are sectioned into three groups. Analyses of samples collected from GeFusn-25 and -26 are shown in Figure 11. The patterns for each solid left in the reaction container matched well to $\mathrm{UO}_{2}$. No other phases could be detected indicating the reaction was essentially done after 2.5 hours at $800^{\circ} \mathrm{C}$.

Residues reclaimed from the reactions carried out using only helium as the sweep gas are shown in Figure 12 for GeFusn-27, -30 and -31. Included in the figure are reference patterns for $\mathrm{UF}_{4}, \mathrm{UGeO}_{4}$ and $\mathrm{UO}_{2}$ above those of the individual solids. It is clear that the pattern recorded for the GeFusn-31 residue showed only one phase present, namely $\mathrm{UO}_{2}$, which reinforces the observed conversion value of $98.1 \%$. Reactions carried out at lower temperature $\left(700^{\circ} \mathrm{C}\right.$ and $750^{\circ} \mathrm{C}$ ) revealed the presence of unreacted $\mathrm{UF}_{4}$ and $\mathrm{UGeO}_{4}$ in addition to $\mathrm{UO}_{2}$. The most predominant product identified in the GeFusn-27 material was not $\mathrm{UO}_{2}$ but rather $\mathrm{UGeO}_{4}$. This is significant since although the conversion was only slightly greater than $50 \%$, there was no evidence of any $\mathrm{GeO}_{2}$ present. This observation indicates the reaction that produces $\mathrm{GeF}_{4}$ is no longer between $\mathrm{UF}_{4}$ and $\mathrm{GeO}_{2}$ but instead controlled by

$$
\mathrm{UF}_{4}+\mathrm{UGeO}_{4} \longrightarrow \mathrm{GeF}_{4}(\mathrm{~g})+2 \mathrm{UO}_{2}
$$

Lastly, the XRD patterns for the materials produced from the reactions where air was introduced into the helium carrier, i.e. GeFusn-28, -29 and -32 , are shown in Figure 13. The multi-plot contains reference patterns for the two most abundant phases found, $\mathrm{U}_{3} \mathrm{O}_{8}$ and $\mathrm{UO}_{2} \mathrm{~F}_{2}$. Although the conversions determined from the gravimetric results were on the order of 88.0 $89.4 \%$, no evidence of unreacted $\mathrm{UF}_{4}$ was seen. Instead, the presence of air in the reaction atmosphere resulted in the formation of $\mathrm{U}_{3} \mathrm{O}_{8}$ as the dominant uranium oxide phase. The other phase identified in all three post reaction residues was $\mathrm{UO}_{2} \mathrm{~F}_{2}$. The presence of this compound provides evidence to support the synthesis of $\mathrm{GeF}_{4}$ may occur by a second reaction pathway given by

$$
2 \mathrm{UF}_{4}+\mathrm{GeO}_{2}+\mathrm{O}_{2}(\mathrm{~g}) \longrightarrow \mathrm{GeF}_{4}(\mathrm{~g})+2 \mathrm{UO}_{2} \mathrm{~F}_{2}
$$

The Gibbs free energy ${ }^{14}$ for this reaction at $700^{\circ} \mathrm{C}$ is $-19.496 \mathrm{kcal} / \mathrm{mol}$. It is also interesting to note that no $\mathrm{UGeO}_{4}$ was found in any of the post-reaction solids when air was included in the reactor sweep gas, irrespective of reaction temperature. 


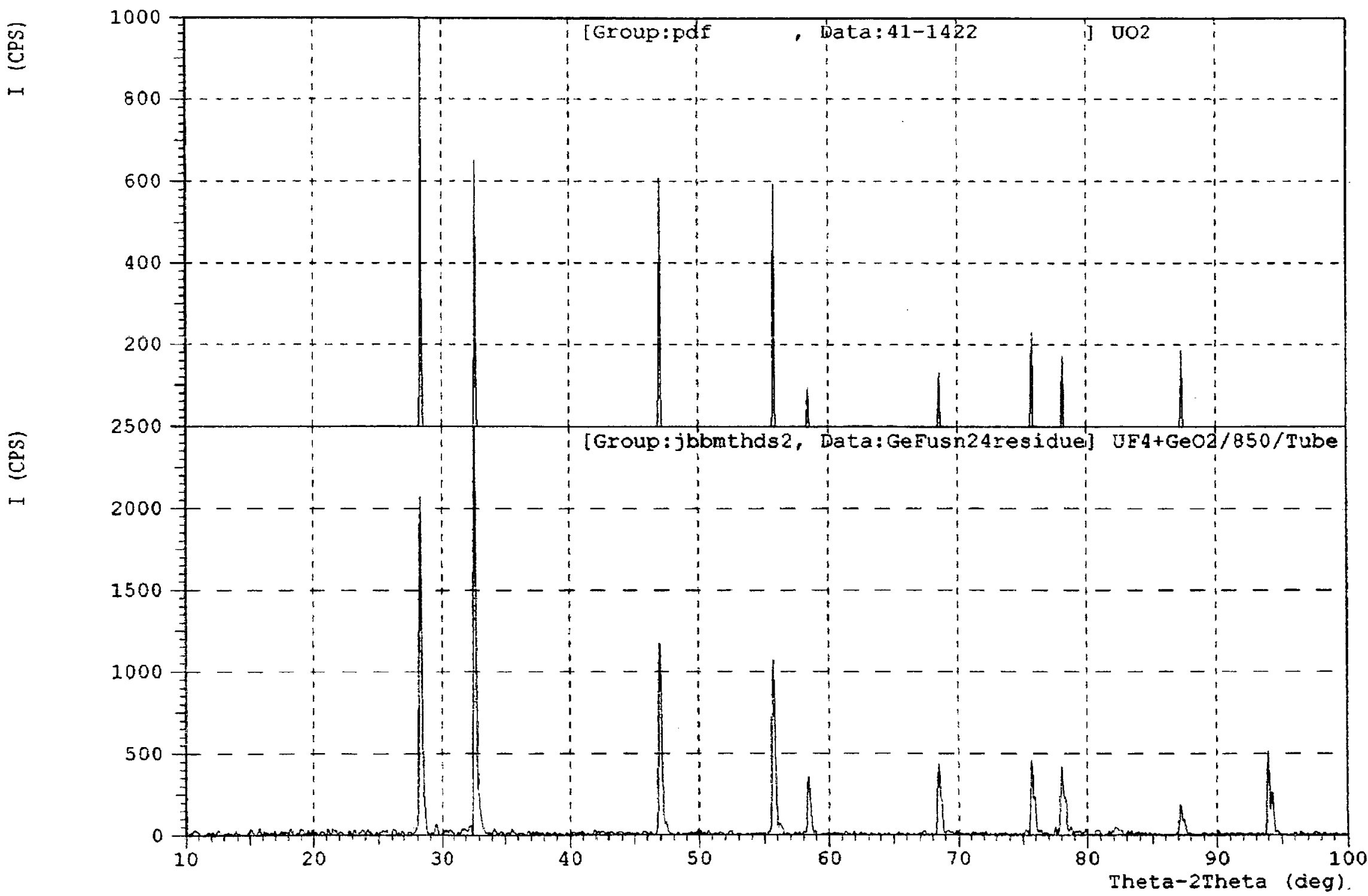

Figure 10. X-ray diffraction pattern for residue recovered from GeFusn-24 and reference pattern for $\mathrm{UO}_{2}$ (pdf\# 41-1422). 


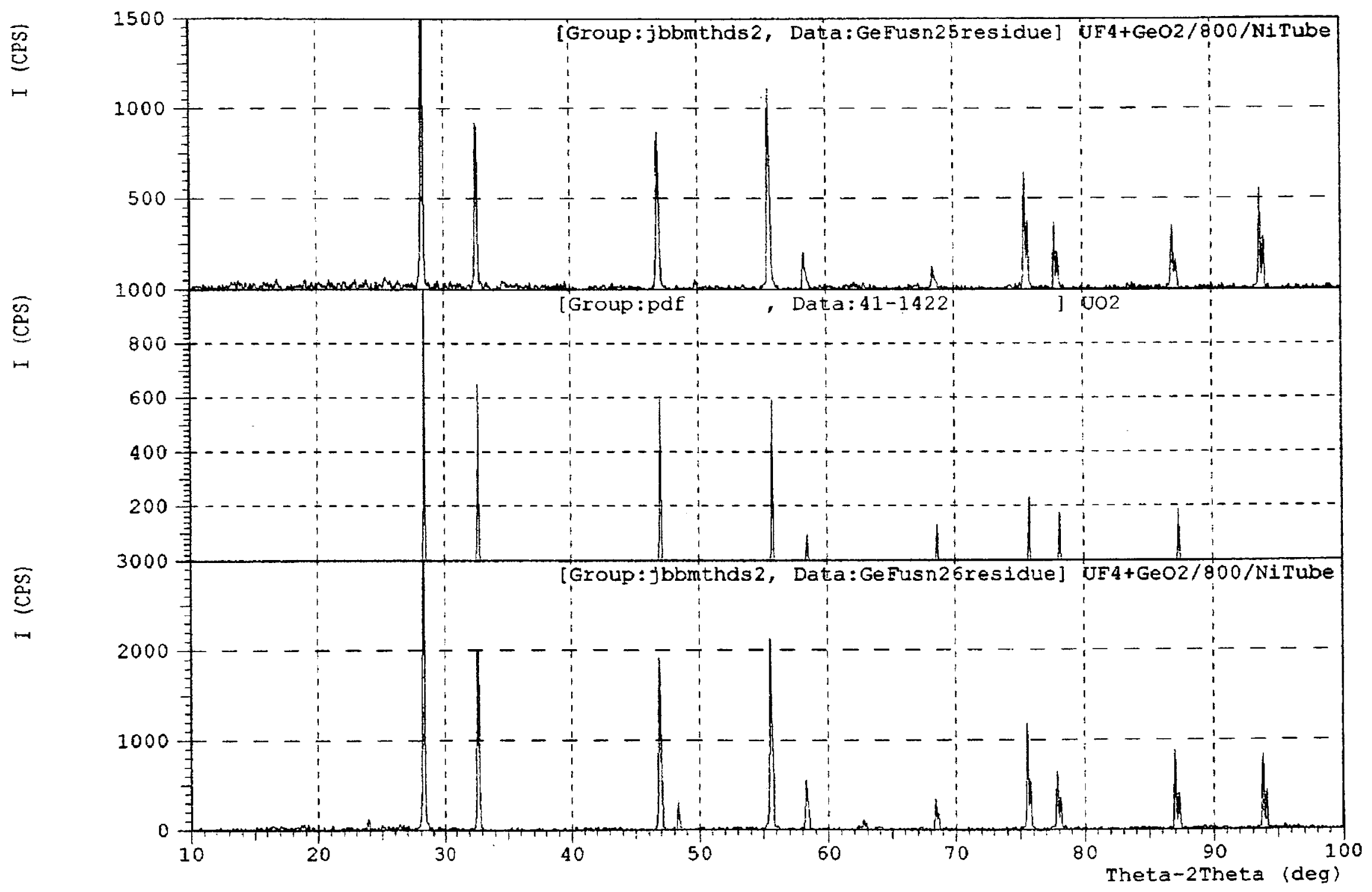

Figure 11. X-ray diffraction patterns for the solids recovered from GeFusn-25 and -26 and the reference pattern for $\mathrm{UO}_{2}$ (pdf\# 41-1422). 


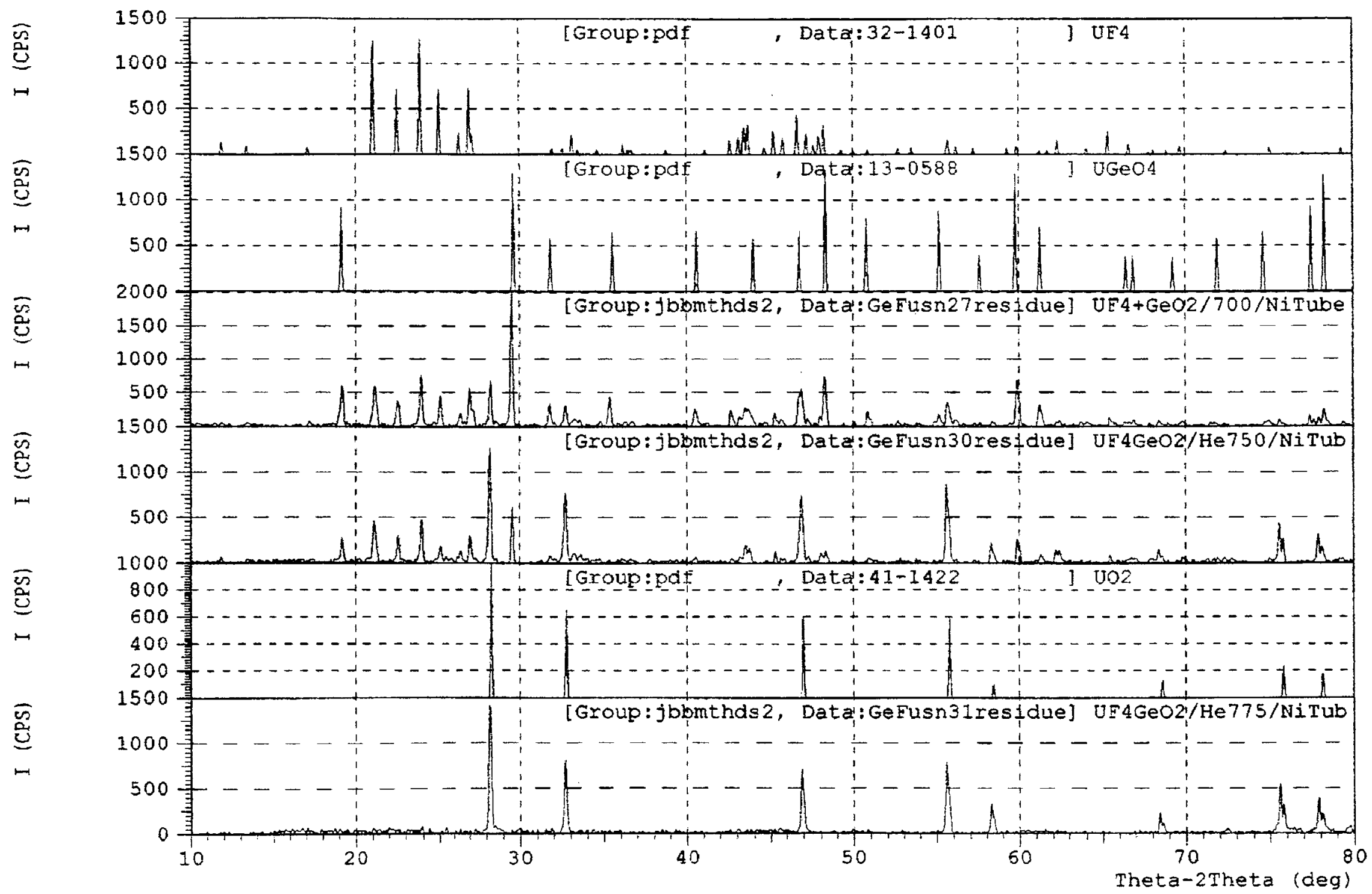

Figure 12. X-ray diffraction patterns for the residues recovered from GeFusn-27, -30 and -31 and reference patterns for $\mathrm{UF}_{4}$ (pdf\# 32-1401), $\mathrm{UGeO}_{4}$ (pdf\# 13-0588) and $\mathrm{UO}_{2}$ (pdf\# 41-1422). 


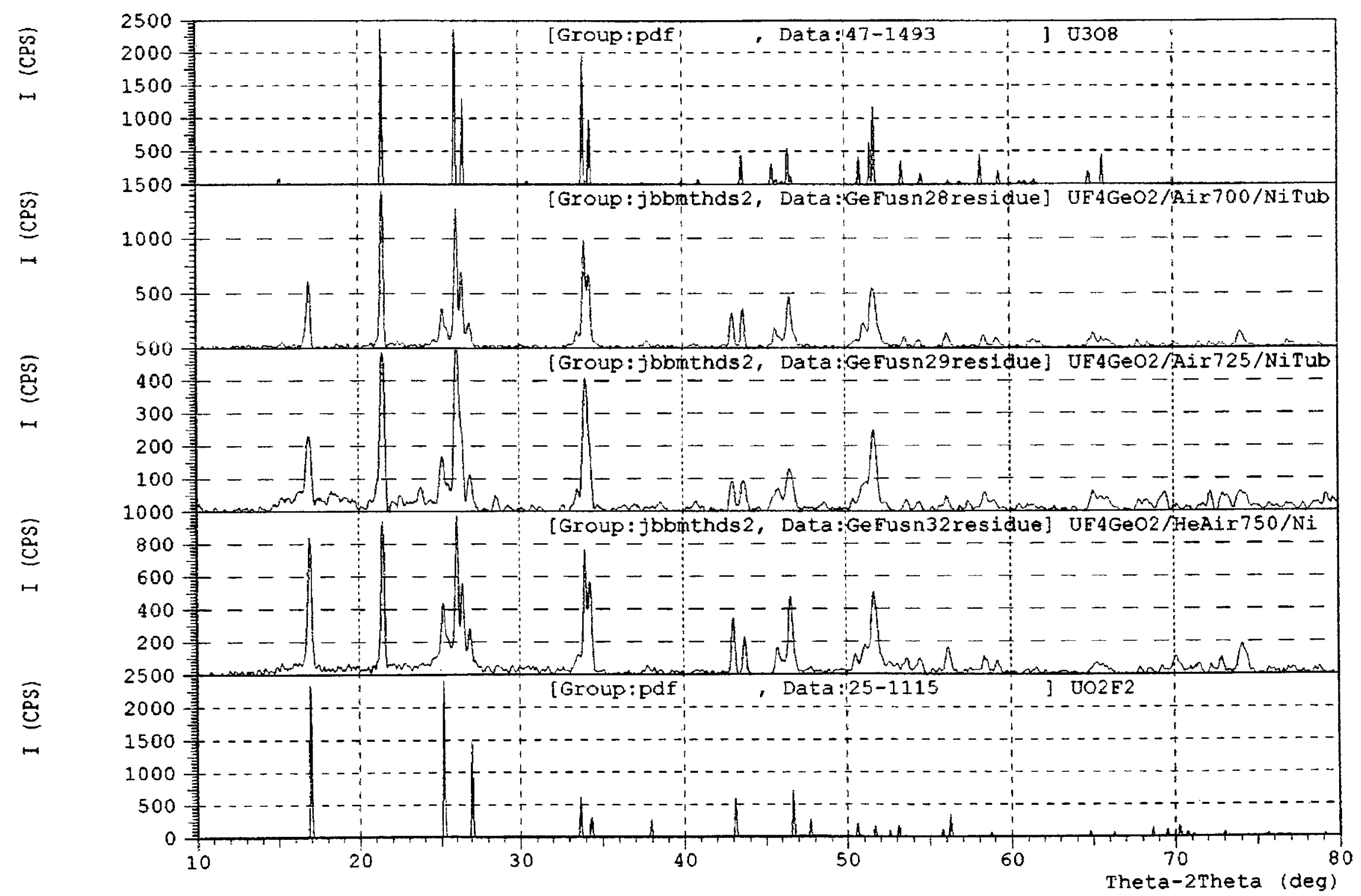

Figure 13. X-ray diffraction patterns for the residues recovered from GeFusn-28, -29 and -32 and reference patterns for $\mathrm{U}_{3} \mathrm{O}_{8}$ (pdf\# 47-1493) and $\mathrm{UO}_{2} \mathrm{~F}_{2}$ (pdf\# 25-1115). 


\section{FT-IR Analyses of Reaction Product Collected in the Gas Cylinder.}

Infrared analysis of the gas phase product produced in the crucible and tube reactor experiments was done to verify the gas was indeed $\mathrm{GeF}_{4}$ and also to comment on purity with respect to other foreign species such as $\mathrm{HF}$ and $\mathrm{H}_{2} \mathrm{O}$ which may have been liberated during the reaction. The measurements were made using a Nicolet Magna-IR 560 optical bench situated with a $\mathrm{KBr}$ beamsplitter and DTGS detector. Gas samples were contained in a gas-tight $10 \mathrm{~cm}$ cell outfitted with zinc selenide windows and a programmable heater for maintaining the cell at $125^{\circ} \mathrm{C}$ to displace adsorbed moisture prior to data collection.

Infrared spectra of the gases collected from three of the five reactions performed in the crucible reactor are shown in Figure 14 along with reference spectra for $\mathrm{GeF}_{4}$ and $\mathrm{SiF}_{4}$ to help with identification of constituent absorption bands. The infrared spectra for the GeFusn-19 sample and two reference materials were collected at Voltaix (High Springs, FL) using similar instrumentation. The data for the three trials shows that $\mathrm{GeF}_{4}$ was produced by the reaction between $\mathrm{UF}_{4}$ and $\mathrm{GeO}_{2}$. However, the gas leaving the reactor also contained a significant amount of $\mathrm{SiF}_{4}$ that was trapped in the gas cylinder. For the GeFusn-23 sample, the fraction of $\mathrm{SiF}_{4}$ may be greater then $50 \%$ of the gas mixture based on the ratio of intensities of each compound's major absorption band after diluting the cell contents with nitrogen to bring them onto the same absorbance scale. Figure $\mathbf{1 5}$ depicts a magnified view of the absorbance scale over the wavelength region between $4000-2200 \mathrm{~cm}^{-1}$ for the three gas samples. From this view it is evident the gases also contained small amounts of substances such as HF and other unknowns (see the C-H stretch@2970 cm-1). The peaks located between $3740-3570 \mathrm{~cm}^{-1}$ belonged to $\mathrm{CO}_{2}$ which was present as part of the ambient atmosphere inside the instrument chamber during data collection and not as a component of the gas coming from the cylinder.

The presence of $\mathrm{SiF}_{4}$ in all the gas generated using the $\mathrm{HR} 160^{\circledR}$ alloy crucible reactor can be traced back to the corrosion and scaling problem observed after each trial. Haynes HR $160^{\circledR}$ material contains up to $2.75 \mathrm{wt} \%$ silicon, which is evidently unstable in the $\mathrm{GeF}_{4}$ at the reaction temperatures employed. A reaction between the $\mathrm{Si}$ component and $\mathrm{GeF}_{4}$ to produce $\mathrm{SiF}_{4}$ can be written as

$$
\{\mathrm{Si}\}_{\text {alloy }}+\mathrm{GeF}_{4}(\mathrm{~g}) \longrightarrow\{\mathrm{Ge}\}_{\text {surface }}+\mathrm{SiF}_{4}(\mathrm{~g})
$$

Thermodynamic calculations ${ }^{\mathbf{1 4}}$, using elemental $\mathrm{Si}$ as a first approximation of reaction energetics in equation (3), show that the reaction at $900^{\circ} \mathrm{C}$ is notably spontaneous $(\Delta \mathrm{G}=-98.913 \mathrm{kcal} / \mathrm{mol})$.

The other elements making, up the alloy $(37 \mathrm{Ni}, 30 \mathrm{Co}, 28 \mathrm{Cr}, 3.5 \mathrm{Fe})$ with the exception of nickel, all show similar spontaneous reaction $\left(-\Delta \mathrm{G}\right.$ values) when contacted with $\mathrm{GeF}_{4}(\mathrm{~g})$ at such high temperatures. The $\mathrm{HR} 160^{\circledR}$ alloy is degraded during production of $\mathrm{GeF}_{4}$ and the purity of the gas liberated was diminished by unwanted $\mathrm{SiF}_{4}$. For these reasons, it is not feasible to construct the production scale reactor from this material. 


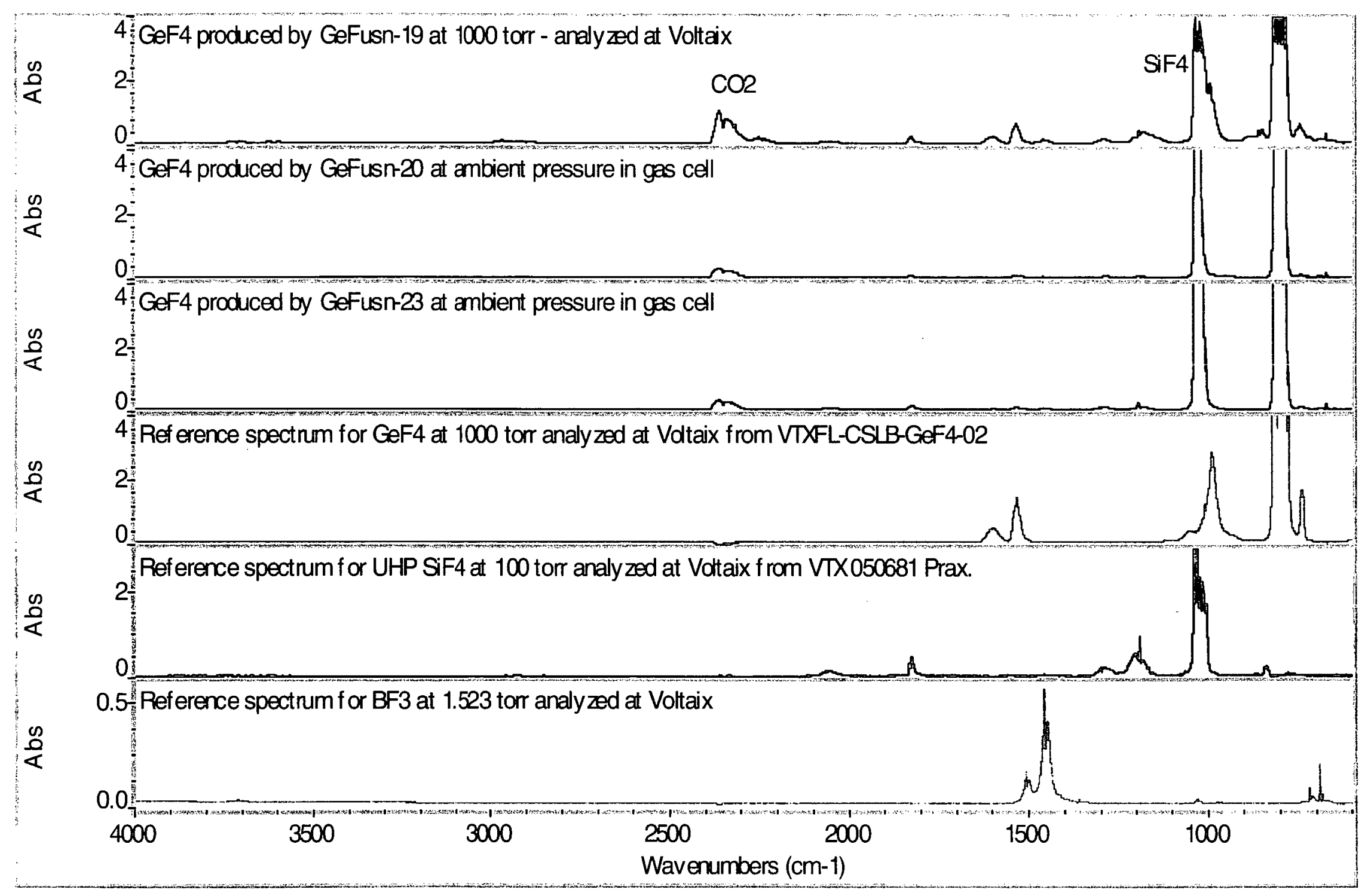

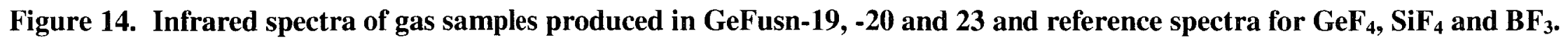




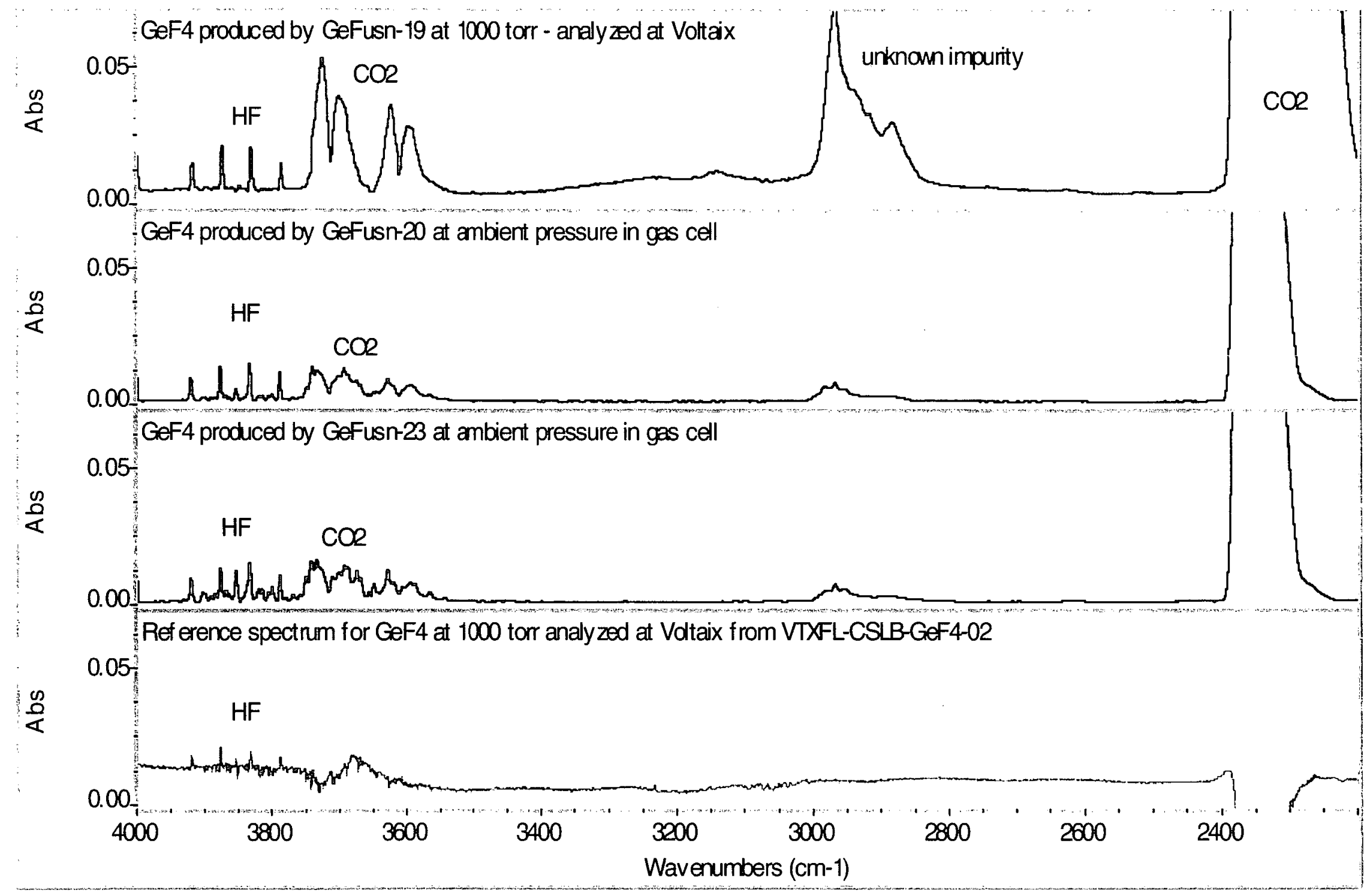

Figure 15. Enhanced view of the spectral region between $4000-2200 \mathrm{~cm}^{-1}$ for samples collected in GeFusn-19, -20 and -23 and reference spectrum for $\mathrm{GeF}_{4}$. 
Analysis of the gaseous product collected from the GeFusn-24 trial using the type 304L stainless steel tube reactor is shown in Figure 16. As evidenced by the poor collection efficiency, most of the condensed gas from the reactor was $\mathrm{SiF}_{4}$ with only a small amount of $\mathrm{GeF}_{4}$. A trace amount of $\mathrm{BF}_{3}$ was also identified along with $\mathrm{HF}$ and $\mathrm{CO}_{2}$. The synthesis of $\mathrm{SiF}_{4}$ was a result of the destructive attack of the $\mathrm{GeF}_{4}$ on the tube material thereby ending any further use of the apparatus in additional experiments.

The FT-IR analyses of the gases produced in the nickel tube are grouped in a manner similar to how the XRD results were presented. Spectra of the samples drawn from GeFusn-25 and -26 trials are shown in Figure 17 along with references for $\mathrm{GeF}_{4}, \mathrm{SiF}_{4}$ and $\mathrm{BF}_{3}$. The quality of the $\mathrm{GeF}_{4}$ was vastly improved compared to material collected in previous experiments. The trace amounts of both $\mathrm{SiF}_{4}$ and $\mathrm{BF}_{3}$ seen in either run may be due to desorption of these substances from the interior walls of the $1 / 8$ " tube leading to the gas cell which ran about five feet from the cylinder to the instrument. Figure 18 represents a magnified view of the region showing absorption bands for residual HF which were also present in the reference spectrum of $\mathrm{GeF}_{4}$ collected at Voltaix, Inc. Multiple bands caused by $\mathrm{CO}_{2}$ present in the ambient atmosphere inside the spectrometer were also marked.

The second group of spectra representing gases collected where helium was used exclusively as the carrier, are illustrated in Figure 19 for experiments GeFusn-27, -30, and -31. Reference spectra for $\mathrm{BF}_{3}$ and $\mathrm{GeF}_{4}$ collected at Voltaix are included below those for the three synthesized samples. Only a small amount of $\mathrm{BF}_{3}$ impurity can be identified in the GeFusn-27 and -30 materials. The reaction product from GeFusn-31, which was analyzed at Voltaix (High Springs, FL), is essentially identical to the reference spectrum for $\mathrm{GeF}_{4}$. A view of the magnified scale over the 4000-2200 cm-1 region, drawn in Figure 20, shows that HF is also a trace impurity in all spectra except for the GeFusn-31 run. It is not clear why this spectrum shows only bands due to $\mathrm{H}_{2} \mathrm{O}$ and none for HF.

Spectra from experiments where air was also included in the reaction atmosphere, i.e. GeFusn-28, -29 and -32, are displayed in Figure 21. Germanium tetrafluoride produced in all three trials was essentially pure when compared to the reference spectrum supplied by Voltaix. A small trace of $\mathrm{BF}_{3}$ was again observed in the GeFusn-29 specimen and was attributed to the desorption off the surfaces of the sections of tubing bringing gas to the gas cell. The presence of air in the reaction environment did not alter the gas phase product made when $\mathrm{UF}_{4}$ was reacted with $\mathrm{GeO}_{2}$. The introduction of air was extremely beneficial to improved collection efficiency, which was due in part to less $\mathrm{GeF}_{2}$ being created. A magnified view of the $4000-2200 \mathrm{~cm}-1$ region is shown in Figure 22. There was a small amount of $\mathrm{HF}$ in each of the $\mathrm{GeF}_{4}$ spectra including the reference spectrum. Its origin in the samples made by the reactions performed here was most likely a consequence of residual adsorbed moisture being liberated during the reaction period. Using fully dehydrated $\mathrm{UF}_{4}$ and $\mathrm{GeO}_{2}$ reactants may help to further decrease the level of HF seen here. 


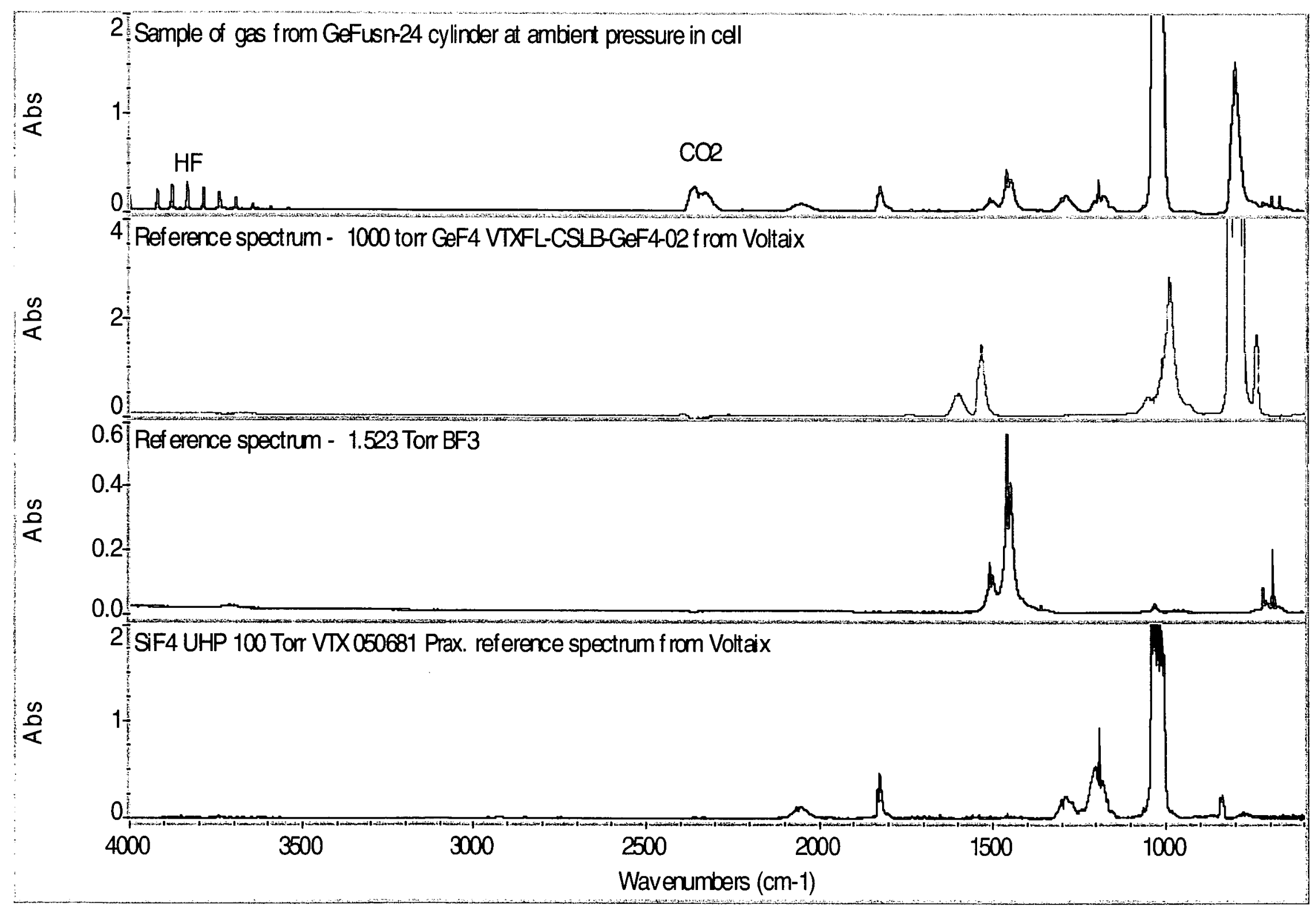

Figure 16. Infrared spectrum of gaseous product collected in GeFusn-24 and reference spectra for $\mathrm{GeF}_{4}, \mathrm{BF}_{3}$ and $\mathrm{SiF}_{4}$. 


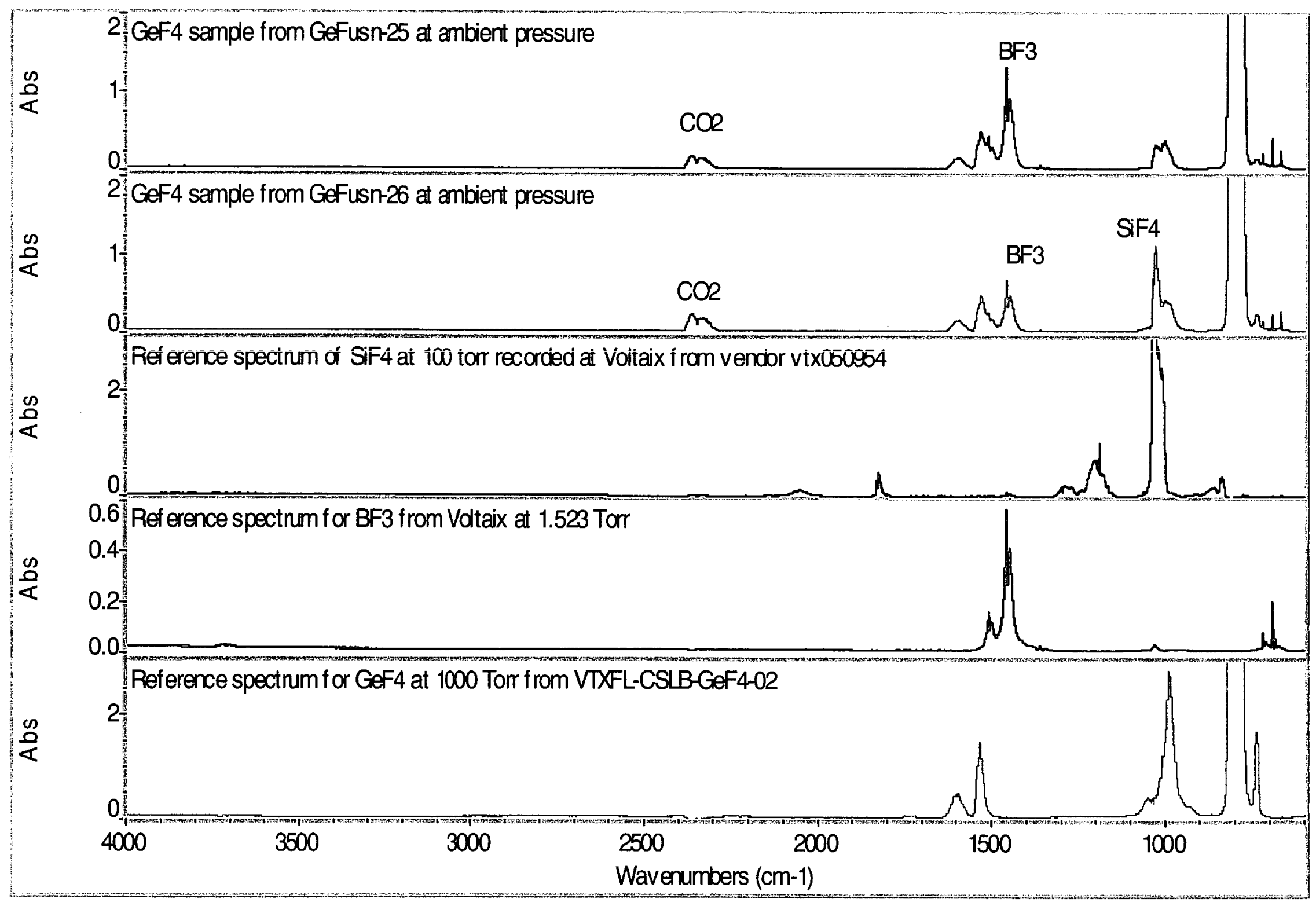

Figure 17. Infrared spectra for gases made in GeFusn-25 and -26 and reference spectra for $\mathrm{SiF}_{4}, \mathrm{BF}_{3}$ and $\mathrm{GeF}_{4}$. 


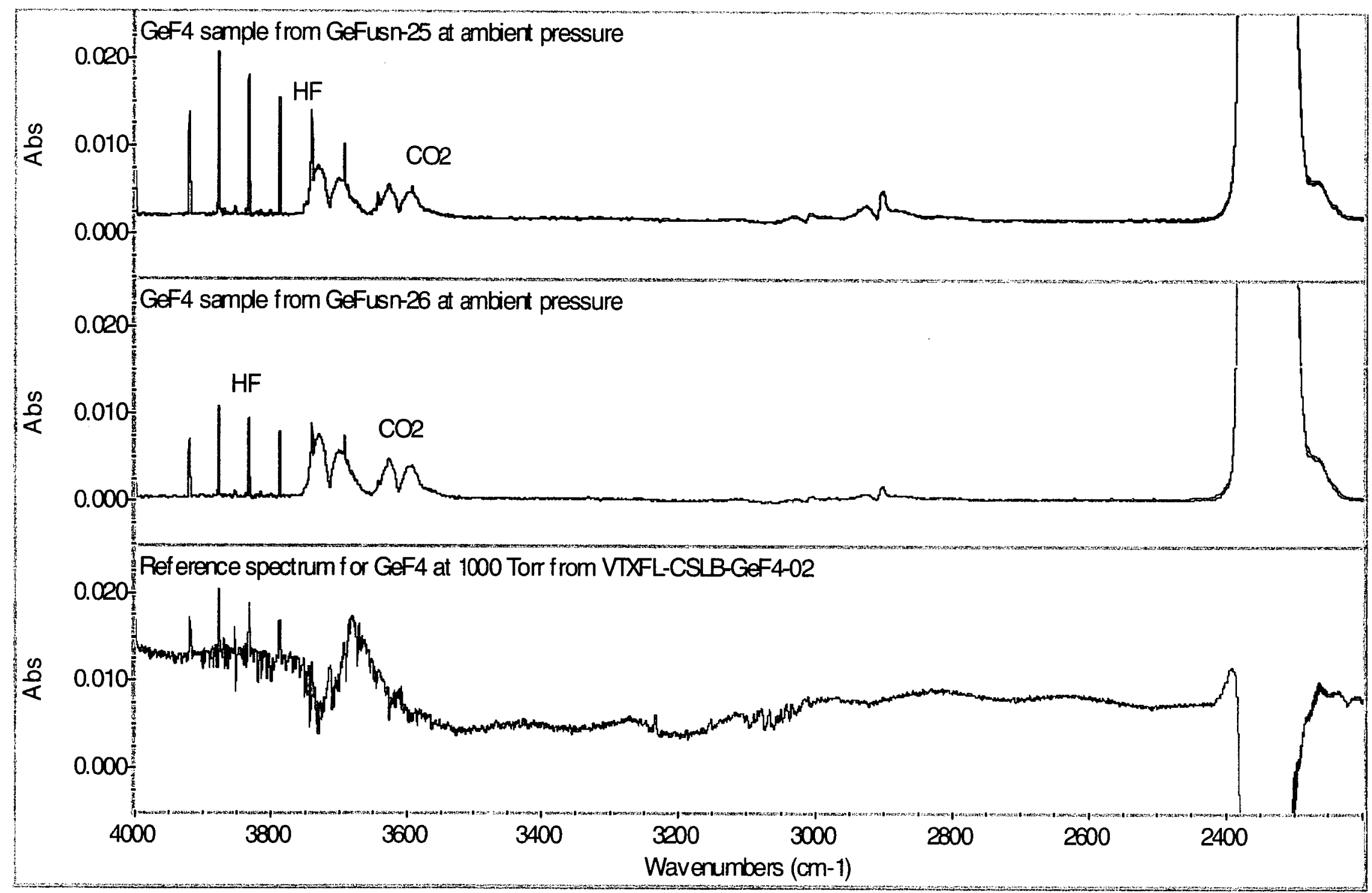

Figure 18. Enhanced view of the spectral region between $4000-2200 \mathrm{~cm}^{-1}$ for GeFusn-25 and -26 samples and reference spectrum for $\mathrm{GeF}_{4}$. 


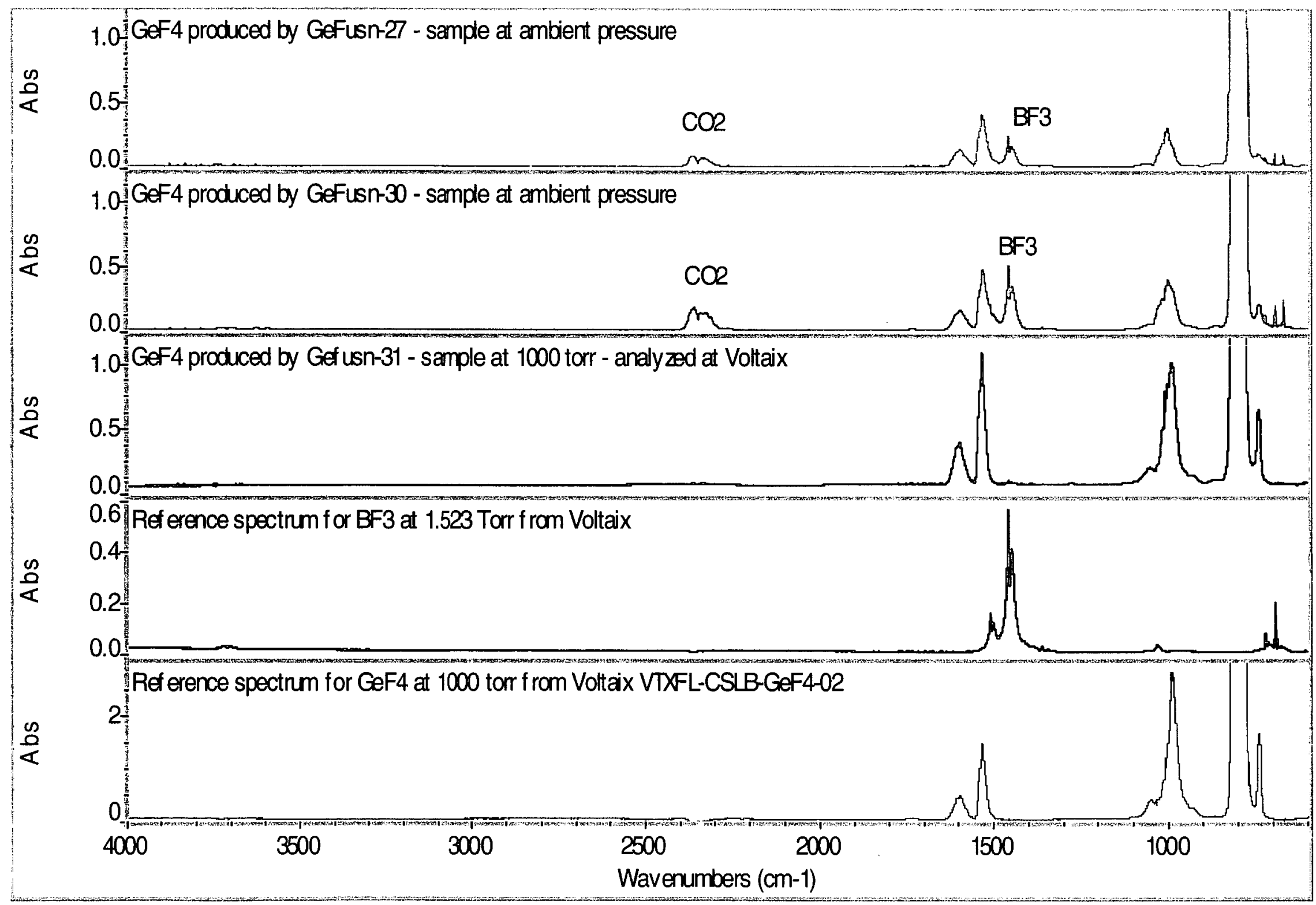

Figure 19. Infrared spectra for gas samples taken from GeFusn-27, $-\mathbf{3 0}$ and $\mathbf{- 3 1}$ and reference spectra for $\mathrm{GeF}_{\mathbf{4}}$ and $\mathrm{BF}_{3}$. 


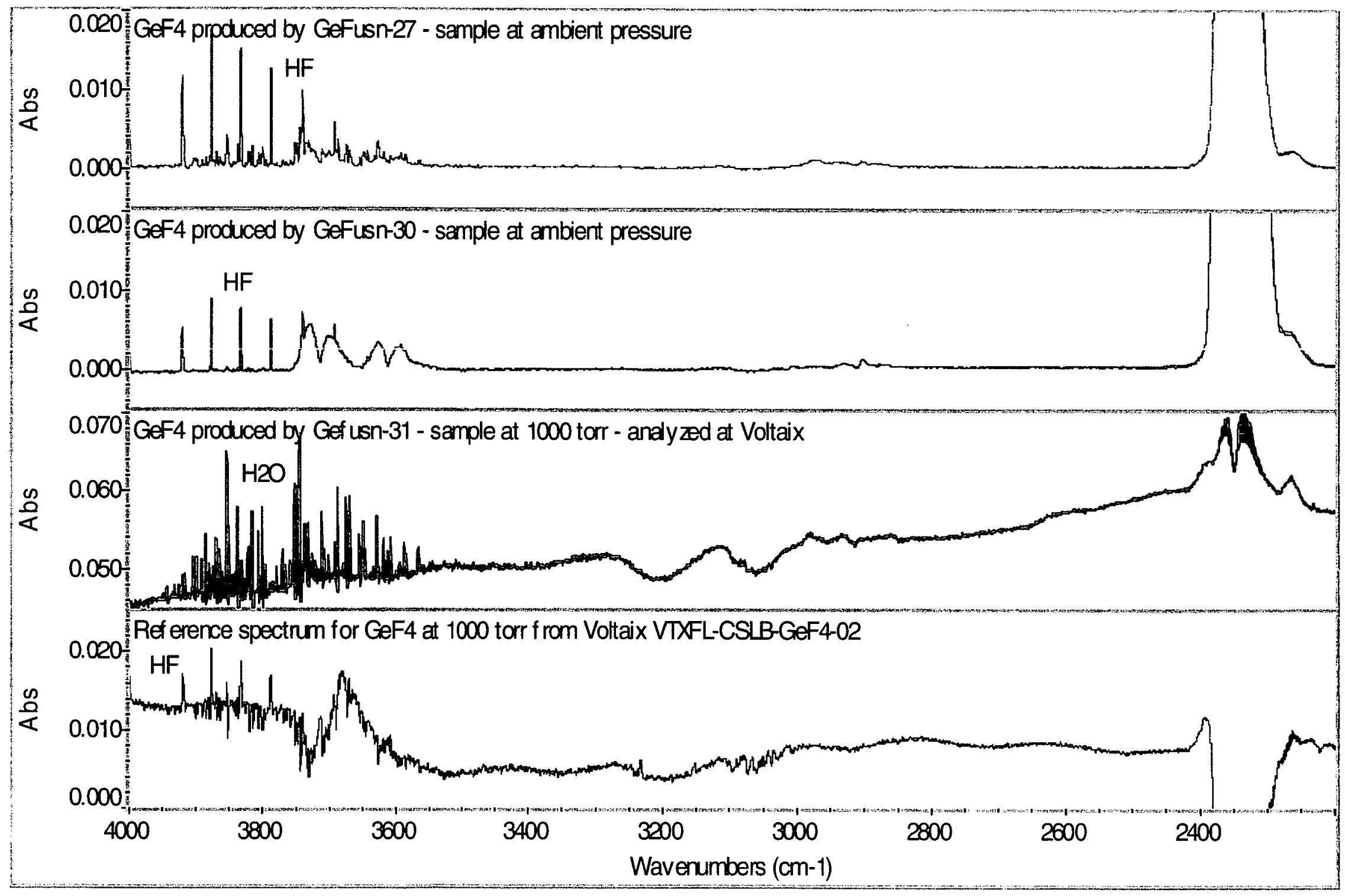

Figure 20. Enhanced view of the spectral region between $4000-2200 \mathrm{~cm}^{-1}$ for GeFusn-27, -30 and -31 and reference spectrum for $\mathrm{GeF}_{4}$. 


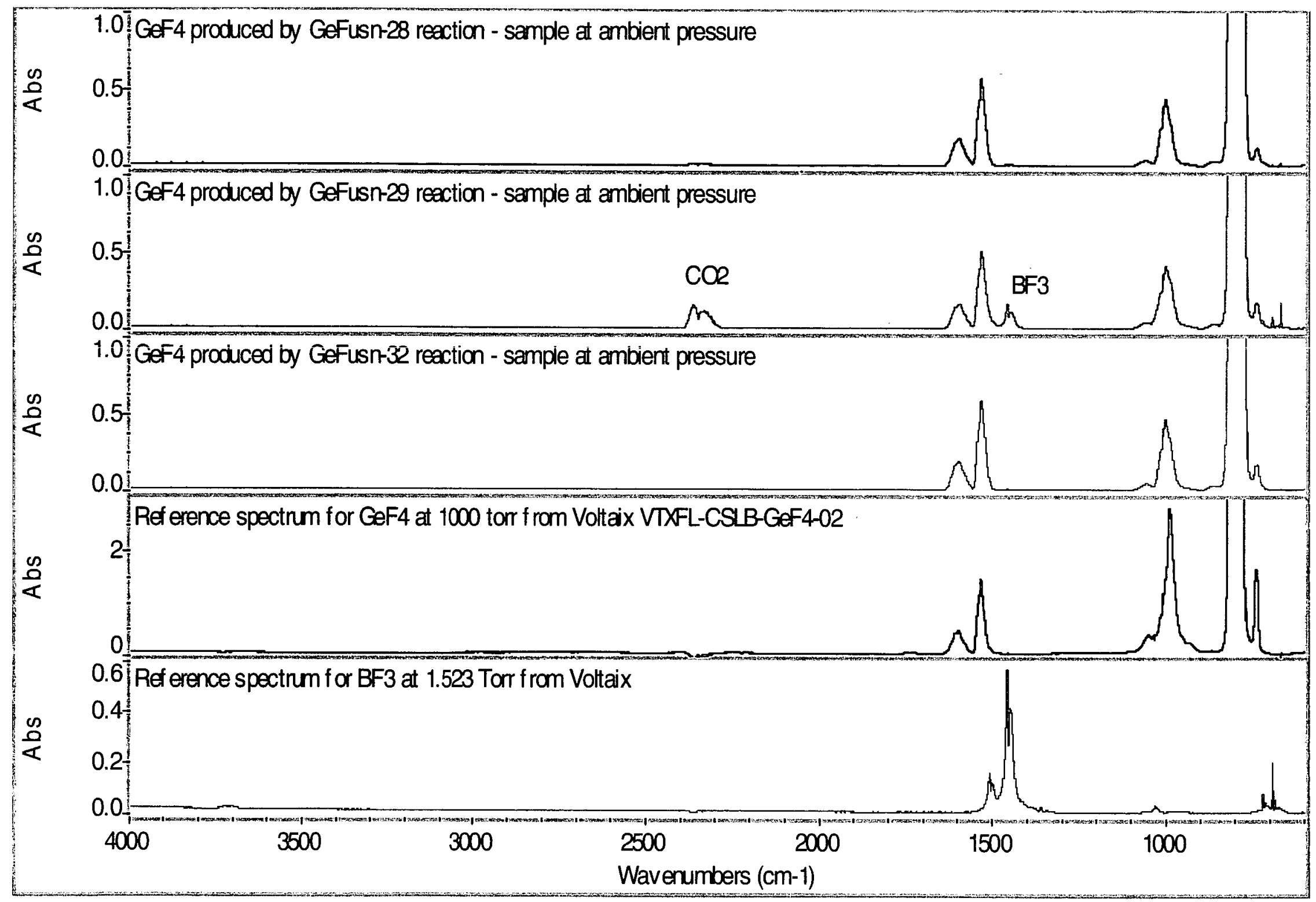

Figure 21. Infrared spectra for gas samples taken from GeFusn-28, -29 and -32 and reference spectra for $\mathrm{GeF}_{4}$ and $\mathrm{BF}_{3}$. 


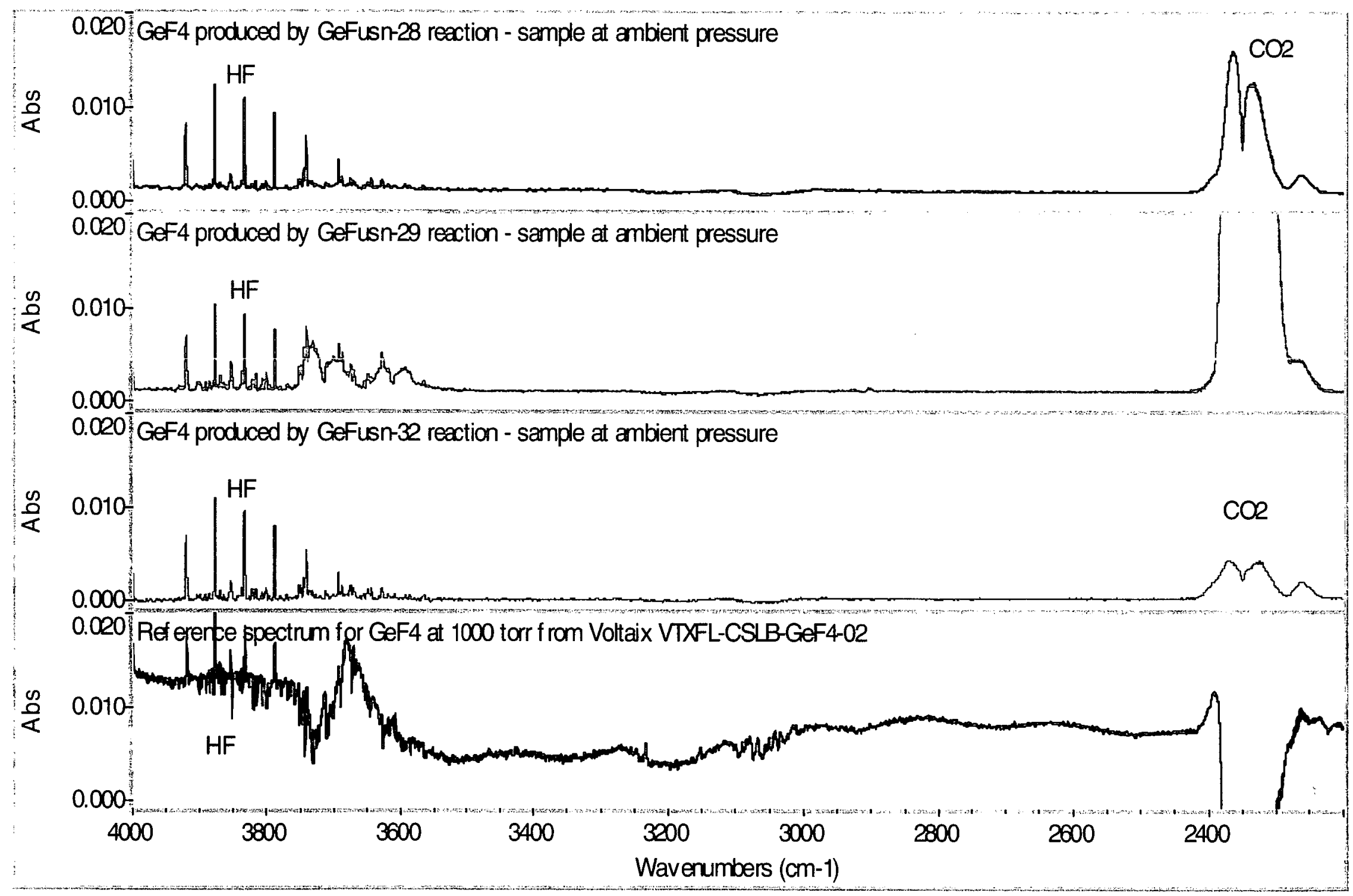

Figure 22. Enhanced view of the spectral region between $4000-2200 \mathrm{~cm}^{-1}$ for GeFusn-28, -29 and -32 and reference spectrum for $\mathbf{G e F}_{4}$. 


\subsubsection{Materials of construction for production of $\mathrm{GeF}_{4}$.}

Results for all of the corrosion studies carried out in this program are presented next. These findings are arranged by the name of the metal or alloy tested.

Nickel

The Ni coupons were tested in Corrosion Experiment 2. The sample placed in the outlet was covered with a white residue, which liquefied on contact with air. When this was rinsed off, some scale was visible. EDS analysis showed that $\mathrm{Ni}, \mathrm{Ge}$, and $\mathrm{O}$ were all present on the surface of the outlet sample. Some $\mathrm{Ca}$ was also present, due to the lime used to neutralize the white residue.

The crucible sample had scale with varying degrees of adherence. SEM/EDS analysis showed large numbers of Al-F crystals that were quite adherent. Several smooth areas proved to be high in U. Other areas, which showed up gray in the SEM photos, proved to be Ni-Ge-O with a range of grain sizes. The scale was also examined by $\mathrm{x}$-ray diffraction and matches reasonably well with both $\mathrm{Ni}_{2} \mathrm{GeO}_{4}$ and $\mathrm{NiF}_{2}$. Unreacted $\mathrm{UF}_{4}$ was also found clinging tenaciously to the $\mathrm{Ni}$, which was unexpected. It is not clear why the reaction was incomplete.

A Ni boat exposed to the product gas stream in a $\mathrm{Ni}$ reaction tube developed green residue. The SEM/EDS data shows that there are areas of $\mathrm{Ni}, \mathrm{Ge}$, and $\mathrm{O}$ as illustrated in Figure 23, and areas of $\mathrm{Ni}$ and $\mathrm{F}$ as seen in Figure $\mathbf{2 4}$ and that these areas are separate. That is, there is no $\mathrm{Ge}$ where there is $\mathrm{Ni}$ and $\mathrm{F}$, indicating the possibility of a protective $\mathrm{NiF}_{2}$ scale. This occurs on the outside of the boat as well as the inside, indicating that the reaction is also occurring in the gas phase. 


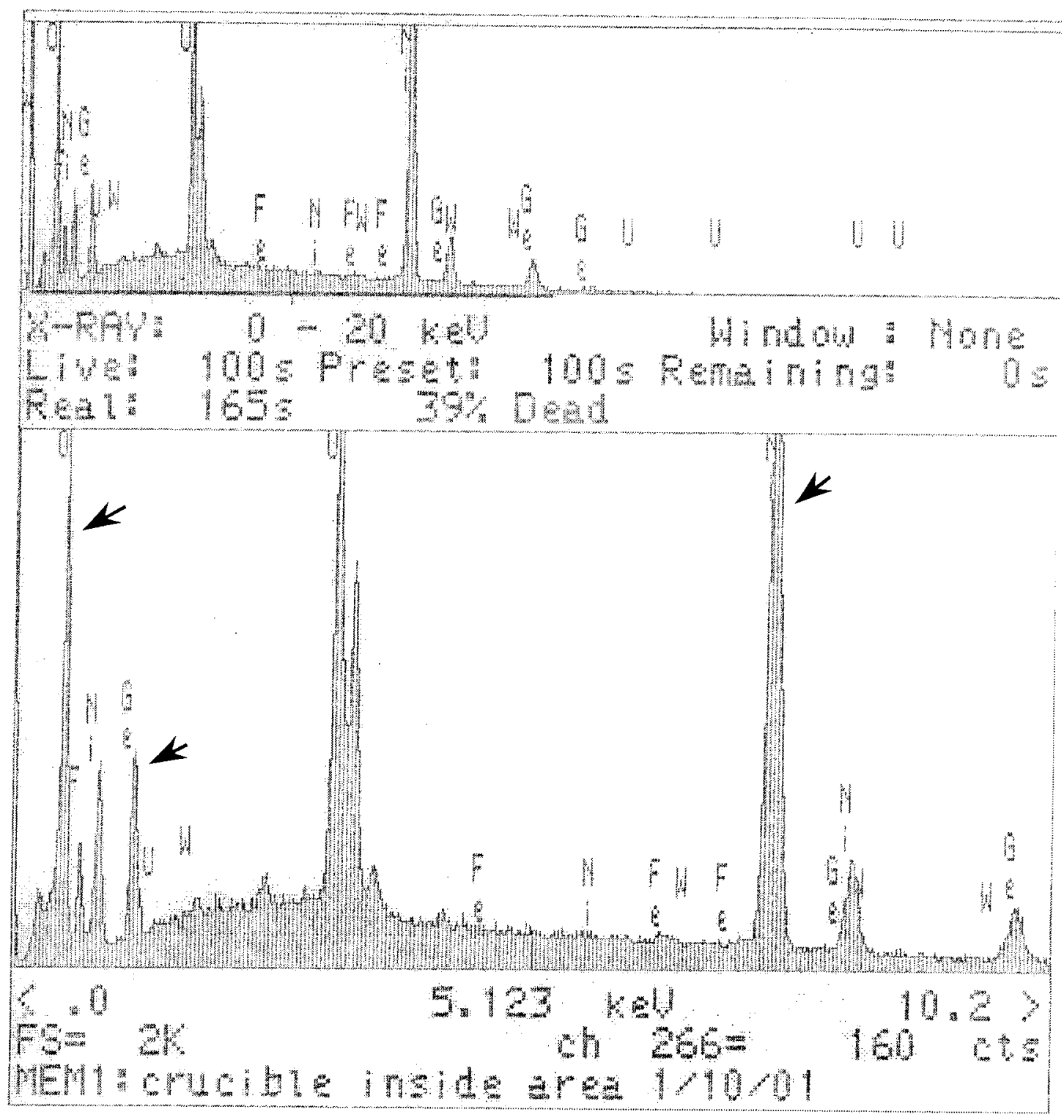

Figure 23. EDS pattern from the inside surface of the Ni boat. 


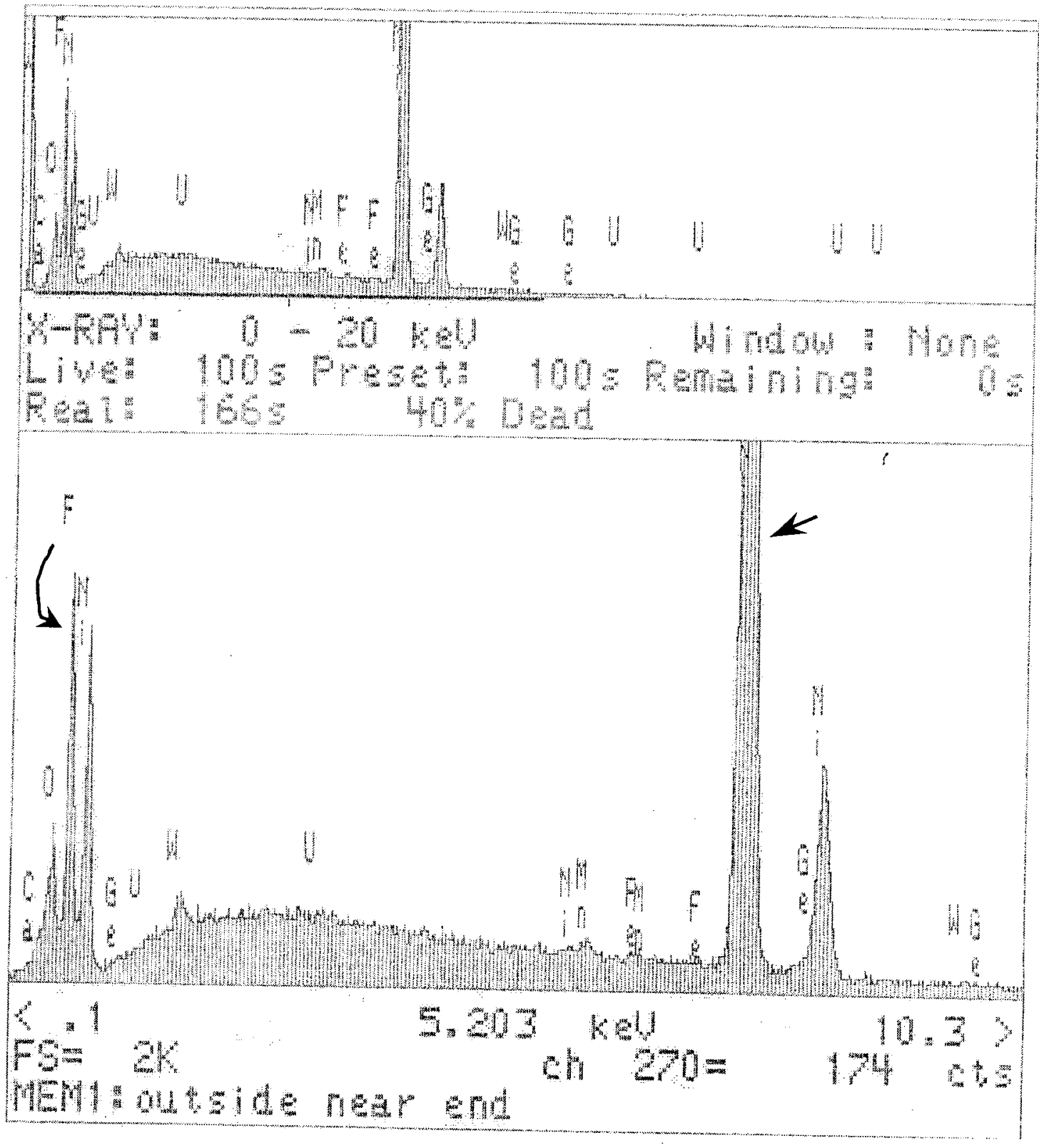

Figure 24. EDS pattern from the outside surface of the Ni boat. 
Monel

A Monel coupon was tested in the second experiment. The sample that had been embedded in the reaction mixture had a noticeable green scale. A fairly good match was made with $\mathrm{NiGeO}_{4}$ in the $\mathrm{x}$-ray diffraction pattern, but a $\mathrm{Cu}-\mathrm{Ni}-\mathrm{Ge}$ oxide was also a possible match. The scale was complex with a range of morphology, as seen in Figure 25. Small cubic crystals that appeared white in the backscattered image contained $\mathrm{Al}$ and $\mathrm{F}$. Some regions were very smooth, containing large amounts of $\mathrm{U}$, but no significant amount of any other elements. The $\mathrm{Ni}$ peak was surprisingly small in much of the area, although $\mathrm{Ge}, \mathrm{O}$, and $\mathrm{U}$ were present in large amounts. Some small crystals contained $\mathrm{Ni}, \mathrm{Ge}$, and $\mathrm{O}$. The large amount of $\mathrm{O}$ was difficult to explain, since the primary source for oxygen was the $\mathrm{GeO}_{2}$ starting material.

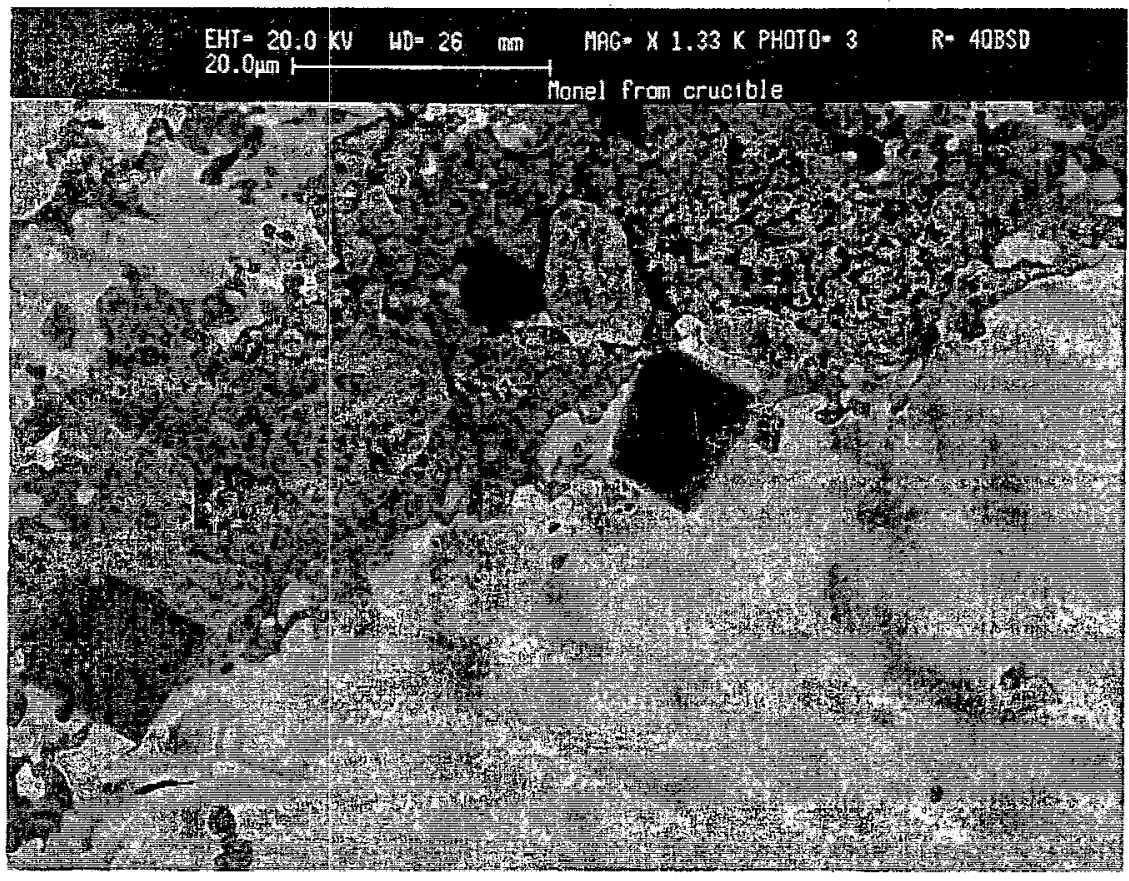

Figure 25. Backscattered image of Monel coupon after being embedded in the reaction mixture.

The sample placed in the outlet tube had obvious scale when viewed in the SEM. A scan of the entire area showed $\mathrm{Ni}, \mathrm{Cu}, \mathrm{O}$ and $\mathrm{Ge}$. The $\mathrm{Ge}$ peak was definite, but slightly smaller than the crucible sample. There were also some areas containing $\mathrm{Mn}, \mathrm{Si}$, and $\mathrm{Fe}$, most likely from the HR $160^{\circledR}$ reactor. The backscattered image had black, white, and gray areas. About $40 \%$ of the surface was black and contained $\mathrm{Ni}, \mathrm{Cu}$, a large amount of $\mathrm{O}$, and a definite Ge peak along with some $\mathrm{Si}$ and $\mathrm{Cr}$. The gray areas contained $\mathrm{Ni}, \mathrm{Cu}, \mathrm{O}$ and slightly less $\mathrm{Ge}$ than the black regions. The white regions contained $\mathrm{Ni}, \mathrm{Cu}, \mathrm{O}, \mathrm{Mn}, \mathrm{Fe}$, and just a trace of $\mathrm{Ge}$. 
Inconel 600

Coupons of Inconel 600 were tested both in Corrosion Experiment 1 and Corrosion Experiment 2. Information from the manufacturer indicated that the material should be acceptable at temperatures up to $1095^{\circ} \mathrm{C}$, but may suffer from poor resistance to $\mathrm{HF}$ vapor at $48 \%$ concentration at $75^{\circ} \mathrm{C}$. The coupon from Corrosion Experiment 1 , which had been exposed to dry $\mathrm{GeF}_{4}$ had fairly obvious scale. Dark regions in the backscattered image contained large amounts of $\mathrm{F}$ and $\mathrm{O}$, and nearly equal amounts of $\mathrm{Cr}, \mathrm{Fe}$, and $\mathrm{Ni}$. White regions in the image contained more $\mathrm{Cr}, \mathrm{O}$ and $\mathrm{F}$ than $\mathrm{Fe}$ and $\mathrm{Ni}$. No Ge was found anywhere on the coupon, and a small amount of $\mathrm{Al}$ was visible in one region. These results are consistent with the starting material and indicate some oxidation and fluoridation, but no gross corrosion.

The sample placed in the outlet of the crucible reactor did not look outwardly changed from the starting material and no obvious scale was visible. One small spot had a trace of Ge. The rest of the sample did not look different from the starting material except for some oxidation.

The sample exposed to the reaction mixture in the crucible had an obvious scale, as seen in Figure 26. Many Al-F containing crystals were present on the surface. The backscattered image contained white and gray regions. Gray areas contained $\mathrm{Ni}$ and $\mathrm{Ge}$ in large quantities along with some $\mathrm{O}$. The white regions, which were highly adherent, contained large quantities of $\mathrm{U}$ and $\mathrm{Ge}$ along with $\mathrm{Cr}, \mathrm{Ni}, \mathrm{Fe}, \mathrm{O}$ and $\mathrm{Al}$. The $\mathrm{Cr}, \mathrm{Ni}, \mathrm{Fe}$, and $\mathrm{O}$ were in similar ratios as in the outlet sample, but with $U$ and Ge present as well. In addition, there was some unreacted green salt underneath some of the coupons in the crucible, which was not the case in other similar experiments without the corrosion coupons.

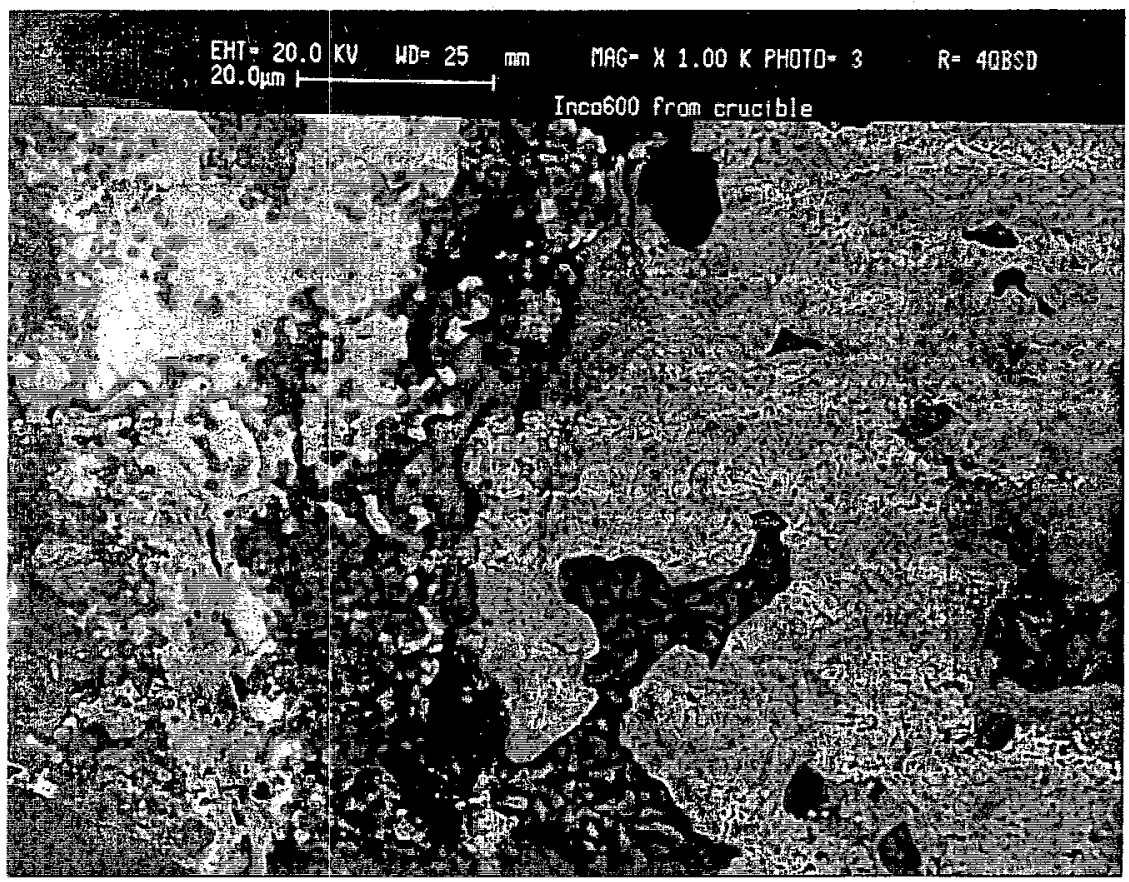

Figure 26. Backscattered image of Inconel 600 coupon after exposure to the reaction mixture. 
The sample exposed to dry $\mathrm{GeF}_{4}$ had light and dark regions in the backcattered image that appeared almost like striations in the SEM. An EDS scan of the entire surface showed Ni, F, $\mathrm{Cr}, \mathrm{O}$, and smaller amounts of $\mathrm{Fe}, \mathrm{Al}$, and Mo. Dark areas of the image seem to be high in $\mathrm{Ni}$ and $\mathrm{F}$, but have a slightly larger Mo peak. White regions had $\mathrm{Ni}, \mathrm{F}$, high $\mathrm{Cr}$ and $\mathrm{O}$ peaks, but no Mo. As the starting material is $25 \% \mathrm{Mo}$, it is significant that many surface areas contained no Mo, suggesting that volatile $\mathrm{MoF}_{6}$ may have been formed. Because of the suggestive surface results, the sample was sectioned and the cross section examined, as shown in Figure 27. The surface scale was 3-4 microns thick, and contained primarily $\mathrm{Ni}$ and $\mathrm{F}$, with some $\mathrm{Cu}$ and $\mathrm{O}$ (spots 1 and 2). Directly underneath the scale were some spots that were very high in Mo (spot 3). By 8.5 microns into the material, the composition was that of the base material (spots 4-6). Several more spots with excess Mo were found at a depth of 13 microns (spots 7 and 10). Some Ge was found slightly beneath the surface scale (spot 3), suggesting that some Ni-Ge compound may have formed before the Ni-F scale was finished forming. However, no Ge was found at the surface, indicating that the scale was protective, and did not react with the $\mathrm{GeF}_{4}$ product gas.

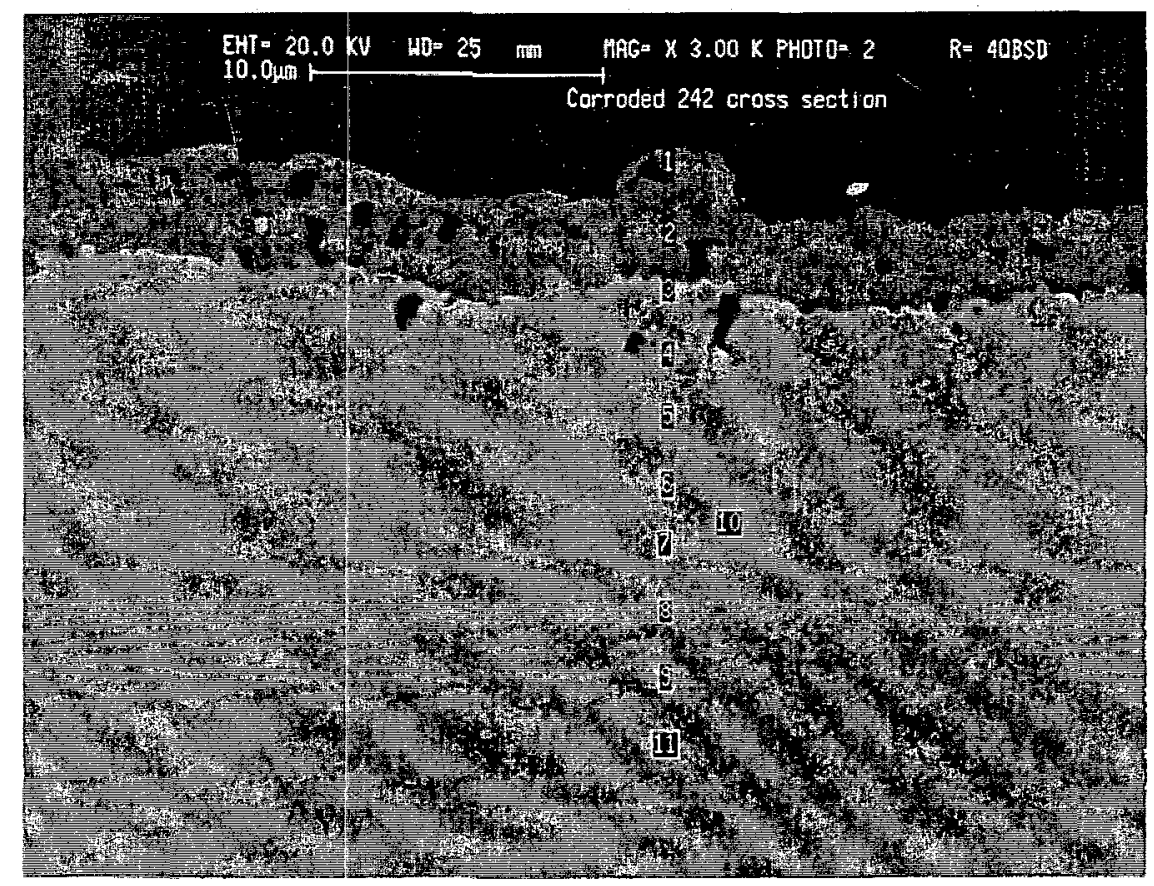

\section{Figure 27. Cross section of Haynes 242 coupon exposed to dry $\mathbf{G e F}_{4}$.}

The sample tested in the crucible furnace outlet had $\mathrm{Ni}, \mathrm{Mo}$, and $\mathrm{Cr}$ in the expected proportions. There was also a small but significant Ge peak, along with O. Some scale was present, but in reasonably small amounts.

The sample embedded in the reaction mixture appeared to have a fine scale when viewed in the SEM. Backscattered images showed white, gray, and black regions. The white region was high in $\mathrm{U}$, followed by $\mathrm{O}, \mathrm{Cr}, \mathrm{Fe}$, and a slight trace of Ge. The gray area was high in $\mathrm{Ni}$ and $\mathrm{Ge}$, 
with a small amount of $\mathrm{O}$. The black region had $\mathrm{Cr}$ as the primary constituent, accompanied by $\mathrm{Fe}, \mathrm{O}, \mathrm{Ni}$, and Ge. Again, Mo was not visible on the surface, which perhaps indicates that this alloy must be pretreated before use to form a protective scale and volatilize any $\mathrm{MoF}_{6}$ that is likely to form.

\section{Haynes $\operatorname{HR} 160^{\circledR}$}

Coupons of this alloy were tested in Corrosion Experiment 2. In addition, the crucible reactor itself was made of $H R 160^{\circledR}$, and some scale from the hot zone was also examined. The sample placed in the outlet tube showed significant scale. In addition, the grain boundaries were highly visible, and the surface was pitted. The backscattered image again showed black, gray, and white regions. The black areas contained a large amount of $\mathrm{Si}$, along with $\mathrm{Ge}$ and $\mathrm{O}$. The gray areas contained $\mathrm{Cr}, \mathrm{Ni}, \mathrm{Co}, \mathrm{Si}, \mathrm{C}, \mathrm{O}$ and a trace of $\mathrm{Ge}$. The white area contained the same elements, also with a trace of $\mathrm{Ge}$.

Scale from the hot zone of the reactor was examined by Dr. Nancy Levoy using the $\mathrm{SEM} / \mathrm{EDS}$ unit. The reactor surface was blue-green in color, and contained $\mathrm{Cr}, \mathrm{Co}, \mathrm{F}$, $\mathrm{U}$, and some $\mathrm{Ni}$ and $\mathrm{Fe}$. The side of the scale that was originally not in contact with the reaction was brown. This side contained $\mathrm{Cr}, \mathrm{Co}, \mathrm{F}, \mathrm{O}, \mathrm{Ge}, \mathrm{Ni}$, and a minor Fe peak. There was less Ni than $\mathrm{Cr}$ or Co present. Earlier results showed $\mathrm{Ge}$ on both surfaces of the scale, along with $\mathrm{Ni}$ depletion.

The sample that had been in contact with the reaction mixture was much affected. There was a large amount of scale, some of which was adherent. The scale was very porous, as seen in Figure 28. A scan of the entire scale showed $\mathrm{Co}, \mathrm{Ni}, \mathrm{O}$, a significant amount of $\mathrm{Ge}, \mathrm{U}, \mathrm{Cr}$, and a trace amount of Fe. Some regions looked very angular in the backscattered image, and those areas were high in $\mathrm{U}$, with $\mathrm{Co}, \mathrm{Ge}$, and $\mathrm{O}$ also present. The flat gray areas in the image were higher in $\mathrm{Ni}$ than other areas, with nearly equal amounts of $\mathrm{Ge}, \mathrm{Co}$, and $\mathrm{Cr}$. There was an area lacking obvious scale, and this region had high $\mathrm{Ni}$, high $\mathrm{Ge}$, and $\mathrm{O}$, with small amounts of $\mathrm{U}, \mathrm{Cr}$, and $\mathrm{Co}$. There was also a thicker looking scale on the edge of the sample that contained $\mathrm{Co}, \mathrm{Cr}$, $\mathrm{U}$, significant $\mathrm{Ge}$, and $\mathrm{O}$. 


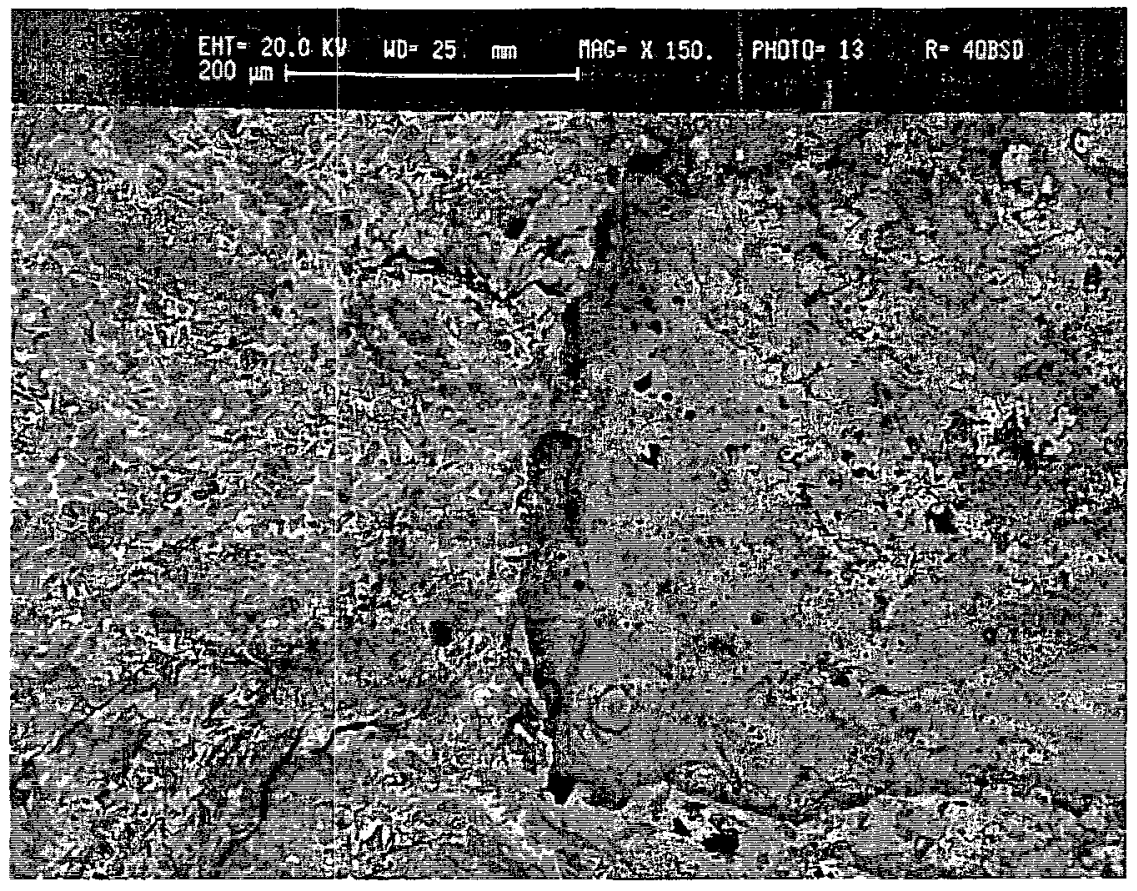

Figure 28. Haynes HR160 ${ }^{\circledR}$ coupon exposed to the reaction mixture.

\section{Type 304 Stainless Steel}

Samples of 304 stainless steel were tested in both corrosion experiments. The sample exposed to dry $\mathrm{GeF}_{4}$ had a fine scale over the whole sample, with some smaller surface crystals. A scan of the whole scale showed high amounts of $\mathrm{Fe}$ and $\mathrm{Ge}$, along with $\mathrm{Ni}, \mathrm{Cr}, \mathrm{O}, \mathrm{F}$, and a trace of $\mathrm{Si}$. One bright surface spot consisted of $\mathrm{Cr}, \mathrm{Si}, \mathrm{Cl}$, and trace $\mathrm{Ge}$. In general it seemed that even dry $\mathrm{GeF}_{4}$ reacted substantially with $304 \mathrm{SS}$.

The sample placed in the outlet of the crucible reactor did not have an enormous amount of scale, but definitely had some scale, and that scale was not particularly adherent. The most prevalent phase, which appeared gray in the backscattered image, contained $\mathrm{Fe}, \mathrm{Cr}$, a large amount of $\mathrm{Ge}, \mathrm{O}$, and $\mathrm{Ni}$. There were also black chunks that were high in $\mathrm{Ca}, \mathrm{Fe}, \mathrm{Ge}$, and $\mathrm{O}$, with some $\mathrm{Al}$. The white areas contained $\mathrm{Fe}, \mathrm{Cr}, \mathrm{Ni}, \mathrm{O}, \mathrm{Ge}$, and a small amount of $\mathrm{F}$.

The crucible samples were heavily encrusted with gray scale, including some relatively large ( 20 micron) crystals. The area scan showed $\mathrm{Fe}, \mathrm{Cr}, \mathrm{Ni}, \mathrm{F}, \mathrm{O}$ and a small but significant $\mathrm{Ge}$ peak. The white area in the backscattered image, shown in Figure 29, had high $\mathrm{Ni}$, Fe, high Ge, and a small amount of $\mathrm{F}$. The gray area (the primary phase) had $\mathrm{Fe}, \mathrm{Cr}$, high $\mathrm{F}$, some $\mathrm{O}$, nothing else. The dark area had $\mathrm{Fe}, \mathrm{Cr}$, high $\mathrm{F}$, moderate $\mathrm{O}$, trace $\mathrm{U}$, and trace $\mathrm{Ge}$. It seems that the $\mathrm{Ge}$ is in reasonably large particles on the surface. In general, this material behaved very poorly in these environments. 


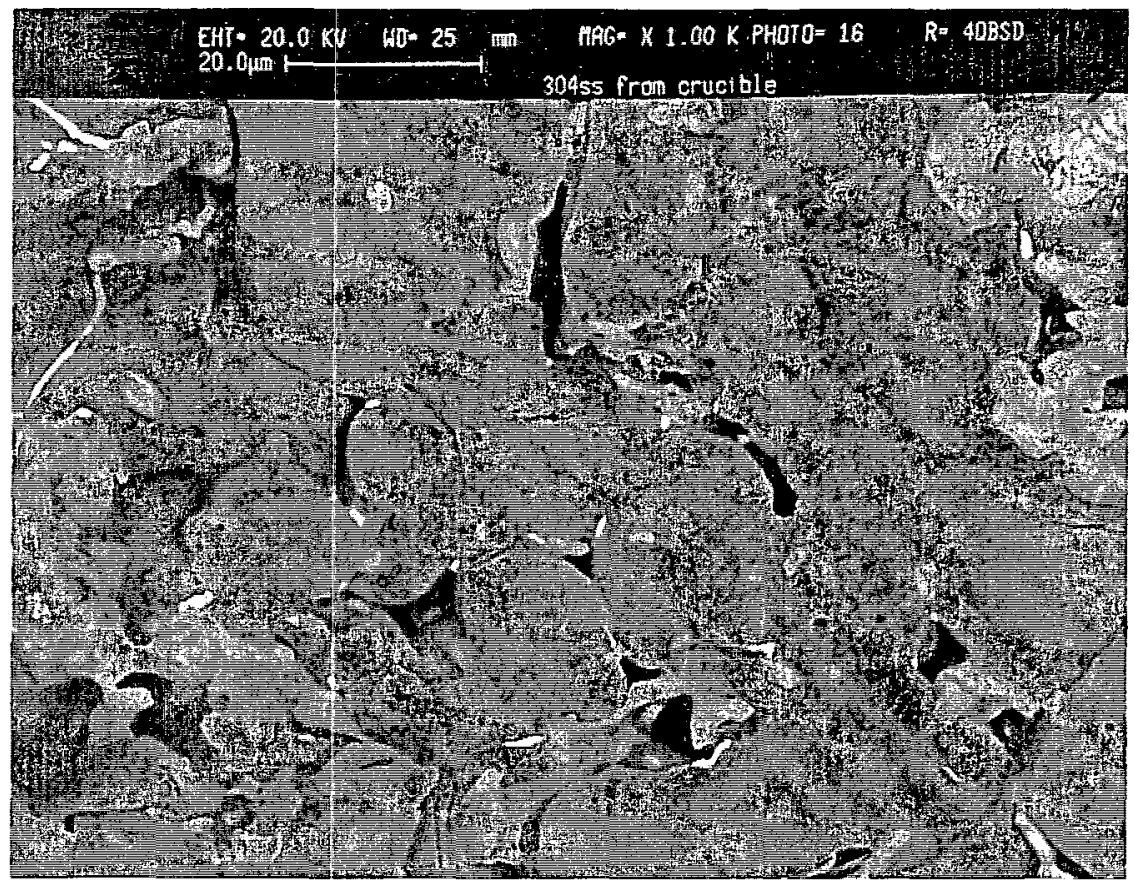

Figure 29. Type 304 Stainless Steel coupon after being embedded in the reaction mixture.

Copper

The sample exposed to dry $\mathrm{GeF}_{4}$ in the tube reactor had very clearly visible grain boundaries and surface pits. An EDS scan of the entire area showed $\mathrm{Cu}, \mathrm{Ni}, \mathrm{Ge}$, and $\mathrm{O}$ in large quantities. Some small specks on the surface contained $\mathrm{Mg}, \mathrm{F}$, and $\mathrm{Ca}$, but may be from the neutralization treatment.

A copper tube assembly had been used inside the existing crucible reactor (for GeFusn22 ) in order to create a chimney that would reduce the excessive internal volume of the reactor. At the conclusion of that reaction, the copper tube was sectioned for microscopy. Figure 30 and Figure 31 summarize the results of the EDS and visual examination of the tube sections. The inside of the tube contained large amounts of Ge everywhere but near the top, where a Ti-F-O phase was found. On the outside of the tube, $\mathrm{Cu}, \mathrm{Ge}$, and $\mathrm{O}$ were found, along with $\mathrm{U}$ in one location. Ge was always associated with $\mathrm{Cu}$ and $\mathrm{O}$, wherever it was found. 


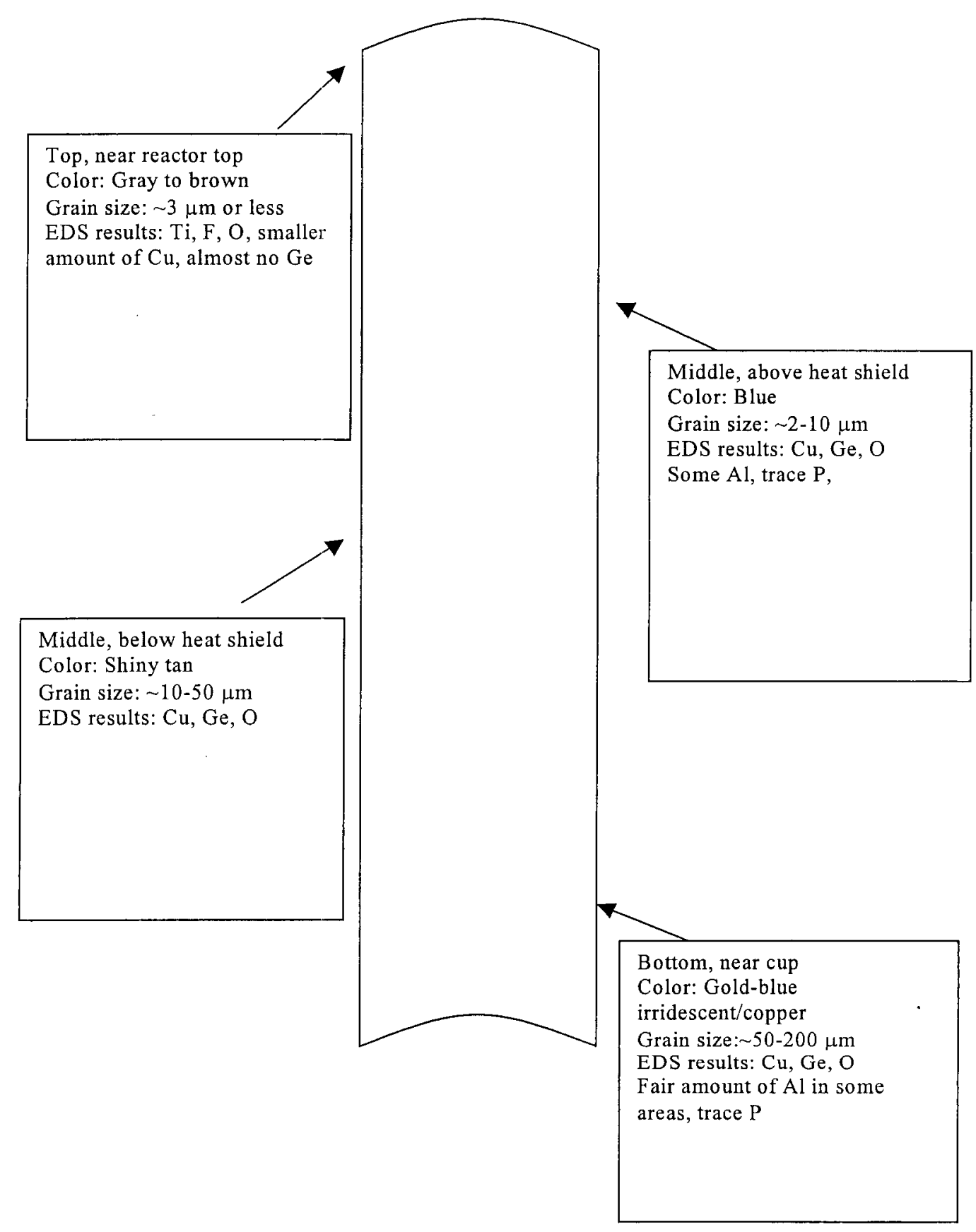

Figure 30. Summary of the examination of the internal surface of the Copper chimney tube used in GeFusn-22. 


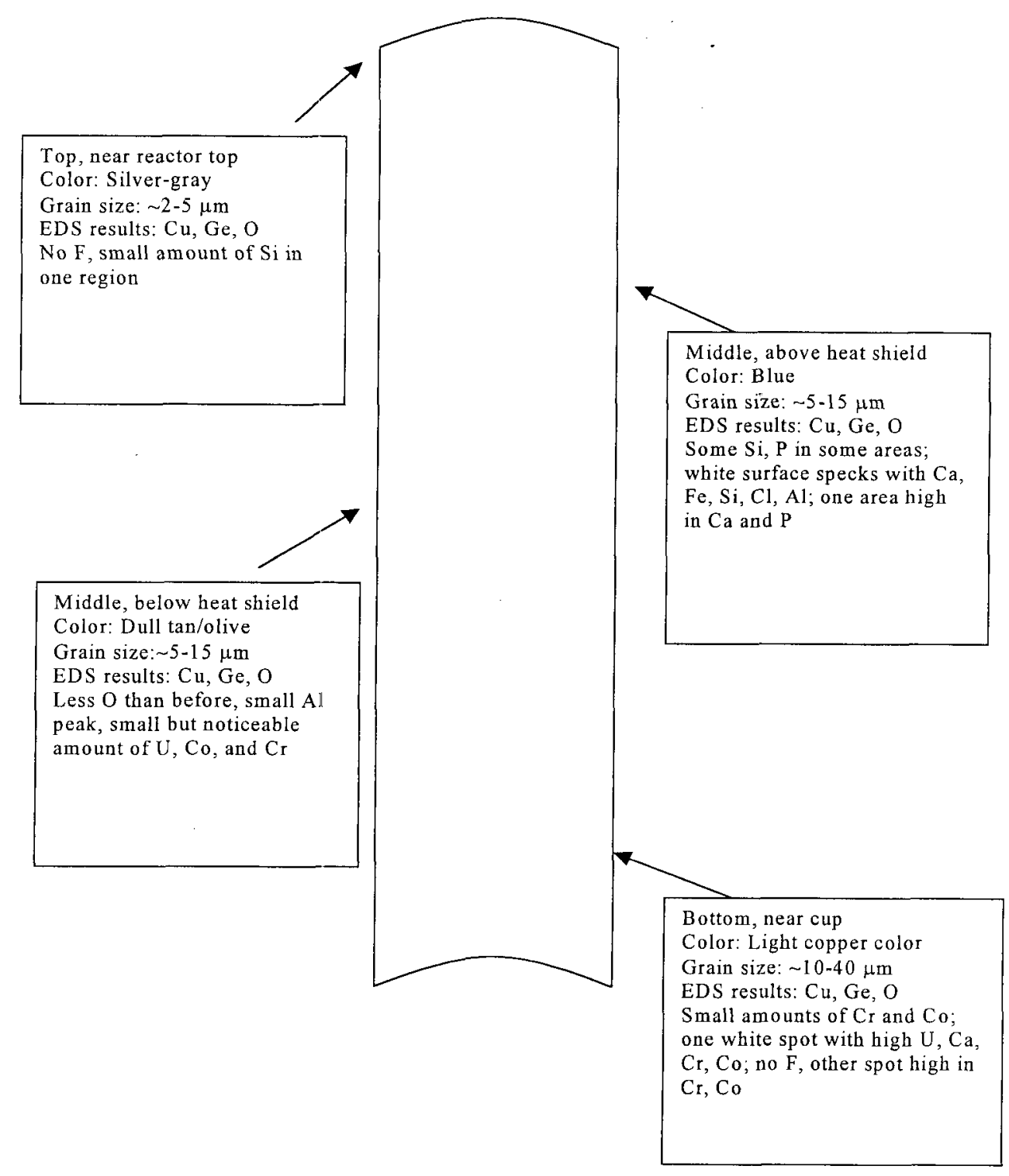

Figure 31. Summary of the examination of the external surface of the Copper chimney tube used in GeFusn-22.

The sample located in the outlet tube of the crucible reactor had a fair amount of obvious scale. As before, the EDS showed $\mathrm{Cu}, \mathrm{Ge}$, and $\mathrm{O}$, with about equal amounts of $\mathrm{O}$ and $\mathrm{Ge}$.

Multiple phases were visible in the backscattered electron image, shown in Figure 32. The gray region contained $\mathrm{Cu}$, nearly as much $\mathrm{Ge}$ as $\mathrm{Cu}$, along with $\mathrm{O}$ and some $\mathrm{Ca}$. The black BEI phase contained mostly $\mathrm{Cu}$, with smaller $\mathrm{Ge}$ and $\mathrm{O}$ peaks. The white phase in the backscattered image was almost completely $\mathrm{Cu}$, with trace amounts of $\mathrm{Ge}$ and $\mathrm{O}$. 


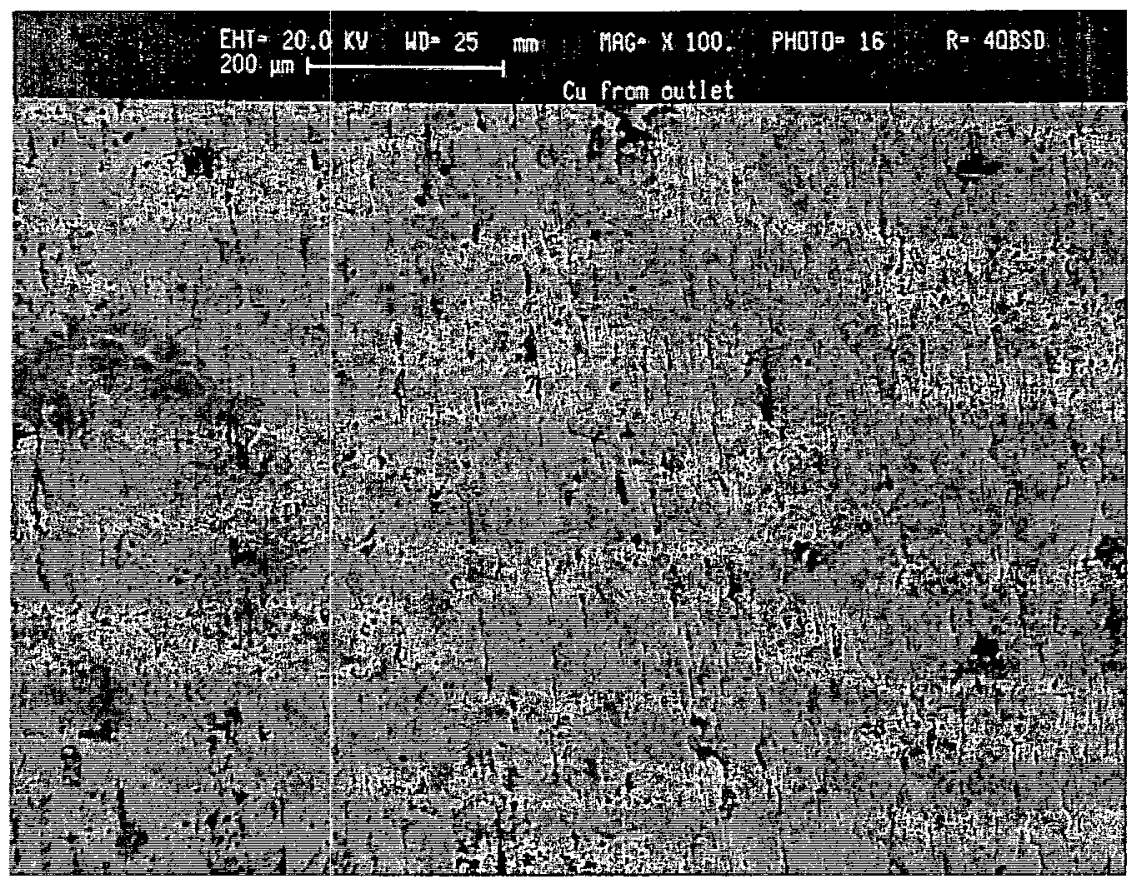

Figure 32. Copper coupon exposed to $\mathrm{GeF}_{4}$ gas in the crucible reactor outlet.

The sample that had been exposed to the reaction mixture had very large grains and some scale, along with larger adherent particles. The outside of the sample had some areas that were copper colored and some that had a silver cast, similar to the outside of some of the copper tube sections. The copper colored area contained mostly $\mathrm{Cu}$, some $\mathrm{C}$, trace $\mathrm{Ni}$, and a very small trace of $\mathrm{Ge}$. The silvery area contained a lot of $\mathrm{Ni}$, a large amount of $\mathrm{Cu}$, trace $\mathrm{U}$, and a small amount of $\mathrm{Cr}$. X-ray diffraction showed a good match with $\mathrm{CuGe}$, however, this compound was very difficult to distinguish from pure $\mathrm{Cu}$ using $\mathrm{x}$-ray diffraction.

In order to be an effective material of construction for fabricating a reactor, the alloy must be able to be structurally sound at the temperatures involved, not form extensive compounds with $\mathrm{Ge}$, and not contribute gaseous impurities to the product. Although none of the materials were completely satisfactory, nickel, Inconel 600, and Haynes 242 performed the best according to these criteria.

Copper was not acceptable for several reasons. The reaction temperatures are near the limit of the useful range for $\mathrm{Cu}$, and consequently excessive grain growth was observed. Copper and germanium formed intermetallic compounds, and although visually unchanged, the $\mathrm{Cu}$ samples picked up large quantities of $\mathrm{Ge}$. The formation of $\mathrm{Cu}-\mathrm{Ge}$ intermetallics was seen repeatedly, both in EDS and XRD analyses. In addition, literature sources indicate that $\mathrm{Cu}$ is highly undesirable in fluorine and fluorine containing gases ${ }^{15}$.

In this study, HR $160^{\circledR}$ has been shown repeatedly to suffer from scale formation when exposed to $\mathrm{GeF}_{4}$. This is supported by the literature, which shows that alloys high in $\mathrm{Cr}$ and Co perform badly in fluorine environments due to the formation of $\mathrm{Cr}$ and $\mathrm{Co}$ fluorides ${ }^{\mathbf{1 6}}$. In addition to the EDS data presented here, earlier work at Starmet showed that mixed $\mathrm{Cr}, \mathrm{Ni}$, and Co fluorides were formed after extensive exposure under reaction conditions. Monel also 
showed extensive scaling and reaction between $\mathrm{Cu}$ in the alloy and Ge. Type 304 stainless steel, even when not visibly attacked, reacted extensively to form fluorides, and picked up a large amount of Ge on its surface. Again, the literature concurs that Fe based alloys are not effective for high temperature fluorine environments ${ }^{17}$.

Evidence suggests that $\mathrm{Nj}$ or a $\mathrm{Ni}$-based alloy will be the best choice for a construction material. However, even these alloys seem to develop some $\mathrm{Ni}-\mathrm{Ge}-\mathrm{O}$ compounds in certain situations. To limit fluorine attack, it is standard practice to passivate $\mathrm{Ni}$ components by exposure to fluorine gas or $\mathrm{HF}$ in order to form $\mathrm{NiF}_{2}$ in a protective layer ${ }^{18}$. This $\mathrm{NiF}_{2}$ film has been shown to have strong resistance to both $\mathrm{F}$ containing gases and gas plasmas and is specifically recommended for semiconductor gases ${ }^{19}$. Examination of the Haynes 242 coupon indicated that a layer of $\mathrm{NiF}_{2}$ formed after exposure to the dry $\mathrm{GeF}_{4}$. Although Haynes 242 formed $\mathrm{MoF}_{6}$ on exposure to $\mathrm{GeF}_{4}$, which would introduce a gaseous contaminant, the alloy can be passivated by forming a protective $\mathrm{NiF}_{2}$ layer. In addition, Mo is thought to improve the resistance of $\mathrm{Ni}$ alloys to fluoride attack ${ }^{15}$. Inconel and pure $\mathrm{Ni}$, when properly passivated, would also form protective fluoride coatings. Evidence for this was seen when the Ni reaction boat was examined, showing no Ge present in areas high in $\mathrm{NiF}_{2}$.

In brief:

- Copper, type 304 stainless steel, Monel, and HR160 ${ }^{\circledR}$ are not acceptable materials of construction;

- Nickel, inconel 600, and Haynes 242 could be used if properly passivated;

- All materials should be passivated prior to use with $\mathrm{GeF}_{4}$. 


\subsubsection{Optimization of product yield.}

In this task, several changes to the reaction system were made to improve the yield of $\mathrm{GeF}_{4}$. A larger reagent vessel made of nickel 200 alloy was put into service and the gas collection hardware was reconfigured by using a shorter outage tube in each cylinder. The first reaction to incorporate these changes was GeFusn-33. Results for this trial are presented in Table 16. Here, the reaction conversion was only $61.3 \%$ after 7 hours in the range between $700^{\circ} \mathrm{C}-775^{\circ} \mathrm{C}$ and capture efficiency for $\mathrm{GeF}_{4}$ was $80.8 \%$.

Table 16.

Reaction Profile for GeFusn-33.

\begin{tabular}{|c|c|c|c|}
\hline Experiment ID: & \multicolumn{3}{|c|}{ 042501-GeFusn-33 } \\
\hline System: & \multicolumn{3}{|c|}{1 "OD nickel tube reactor and 8 " $\mathrm{Ni}$ boat } \\
\hline Weight of reagents $(\mathrm{gm})$ & 41.643 & \multicolumn{2}{|c|}{$\mathrm{wt} \% \mathrm{GeO}_{2}: 24.1689$} \\
\hline Sweep gas: & \multicolumn{3}{|c|}{ Helium flow at $67(\mathrm{cc} / \mathrm{min})$} \\
\hline Pre-reaction drying period: & \multicolumn{3}{|c|}{0.5 hour at $500^{\circ} \mathrm{C}$ in helium } \\
\hline Total reaction time $(\mathrm{hr})$ : & \begin{tabular}{|c|}
7 \\
\end{tabular} & & \\
\hline \multirow{5}{*}{ Reaction temperature profile } & Time (hr) & at $\mathrm{T}\left({ }^{\circ} \mathrm{C}\right)$ & \\
\hline & 2 & 700 & \\
\hline & 2 & 725 & \\
\hline & 2 & 750 & \\
\hline & 1 & 775 & \\
\hline Cylinder ID: & \multicolumn{3}{|c|}{$\# 10,150 \mathrm{cc}$ volume, 304 stainless steel, single port } \\
\hline & \multicolumn{3}{|c|}{ with shortened outage tube } \\
\hline Collection method: & liquid $\mathrm{N}_{2}$ bath & & \\
\hline Calculated weight of $\mathrm{GeF}_{4}$ expected (gm) & 14.2983 & & \\
\hline Observed weight loss of reagents (gm) & 8.769 & & \\
\hline Observed weight gain in the cylinder (gm) & 7.09 & & \\
\hline Reaction conversion $(\%)$ & 61.3 & & \\
\hline $\mathrm{GeF}_{4}$ capture efficiency $(\%)$ & 80.8 & & \\
\hline
\end{tabular}

In GeFusn-33 a stepwise increase in temperature was followed in order to start the reaction off slowly without much disturbance to the near-capacity reagent bed. Ending the reaction period at the $775^{\circ} \mathrm{C}$ plateau was believed to be sufficient to react the $\mathrm{UF}_{4}$ and $\mathrm{GeO}_{2}$ completely but it was not the case. A significant fraction of the residue remaining in the boat was green in color indicative of unreacted green salt. X-ray diffraction analysis of the residue showed it to be a mixture of $\mathrm{UO}_{2}$, unreacted $\mathrm{UF}_{4}$ and $\mathrm{UGeO}_{4}$, as shown in Figure 33. Reference patterns for the three matching phases are also included. 


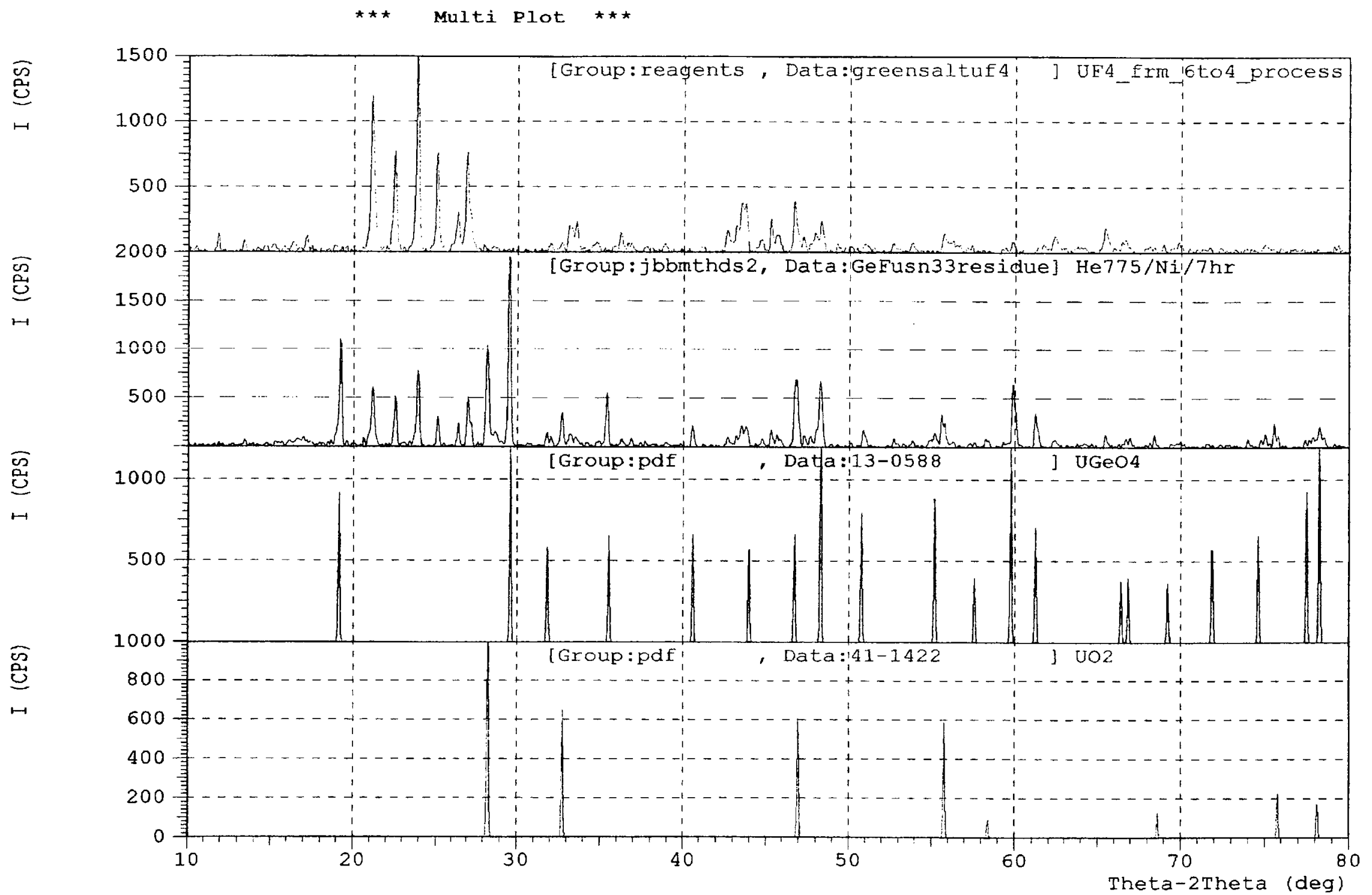

Figure 33. X-ray diffraction pattern for the residue recovered from GeFusn-33 and reference patterns for $\mathrm{UF}_{4}$, $\mathrm{UO}_{2}$ (pdf\# 41-1422) and $\mathrm{UGeO}_{4}$ (pdf\# 13-0588). 
Analysis of the $\mathrm{GeF}_{4}$ collected in cylinder \#10 was accomplished using FT-IR spectroscopy. A spectrum of the gas produced in the reaction is shown in Figure 34 along with a reference spectrum of $\mathrm{GeF}_{4}$ supplied by Voltaix, Inc. Comparing the Starmet material to the reference, the amount of HF impurity is greater in the synthesized product made by the solid state reaction. Additional in-depth analytical characterization is required to determine if the larger amount of $\mathrm{HF}$ is indeed a result of the reaction or an artifact of in-situ hydrolysis caused by moisture adsorbed on the walls of the line carrying the gas from the cylinder to the infrared spectrometer. As part of the routine reaction profile at the beginning of each trial, the reagent mixture is heated at a temperature just below the onset of reaction, typically $500^{\circ} \mathrm{C}$, for about an hour to liberate any moisture adsorbed on the $\mathrm{UF}_{4}$ or $\mathrm{GeO}_{2}$ reactants. Typically, a heat gun is used to heat trace the line leaving the reactor up to the vent valve to expel any vapor from the system.

After observing the poor results obtained in the GeFusn-33 trial, where the conversion was only $61.3 \%$ after 7 hours, a probe into the temperature profile of the tube furnace was started since leftover residue at one end of the 8" boat was black while the other end contained green, essentially unreacted powder. Using an empty tube outfitted a thermocouple (see Figure 6), temperature data were recorded at four points along the length of the tube. Those measurements are compiled in Table 17, showing the spread in temperatures at five different furnace set points.

Table 17.

Internal temperature profile in the nickel tube reactor.

\begin{tabular}{|c|c|c|c|c|}
\hline \multirow{2}{*}{$\begin{array}{c}\text { Furnace } \\
\text { Set-point Temp }{ }^{\circ} \mathbf{C}\end{array}$} & \multicolumn{4}{|c|}{ Temperature at Indicated Points $\left({ }^{\circ} \mathbf{C}\right)$} \\
\hline 23 & & B & C & D \\
\hline 250 & & & & 22 \\
\hline & & 295 & 298 & 281 \\
\hline 500 & 527 & & 297 & 280 \\
\hline & & 535 & 538 & 520 \\
\hline 700 & 715 & 535 & 537 & 518 \\
\hline & & 724 & 727 & 711 \\
\hline 775 & 787 & 723 & 726 & 710 \\
\hline & & 795 & 798 & 782 \\
\hline 850 & 862 & 795 & 798 & 782 \\
\hline & & 870 & 874 & 858 \\
\hline & 858 & 870 & 872 & 857 \\
\hline & & 869 & 871 & 856 \\
\hline & & 867 & 869 & \\
\hline
\end{tabular}

In general, within 4 inches of the midpoint of the hot zone (between points $B$ and $D$ ) the measured temperatures were always above the furnace set-point temperatures by notable margins of $15^{\circ}-25^{\circ} \mathrm{C}$. Measurements were made without the $8^{\prime \prime}$ boat or reagents in the reactor. At all the furnace set-points investigated, there was a measurable difference between temperatures at points $\mathrm{B}$ and $\mathrm{D}$ which did correlate to the approximate length of the larger nickel boat. At the $700^{\circ} \mathrm{C}$ 


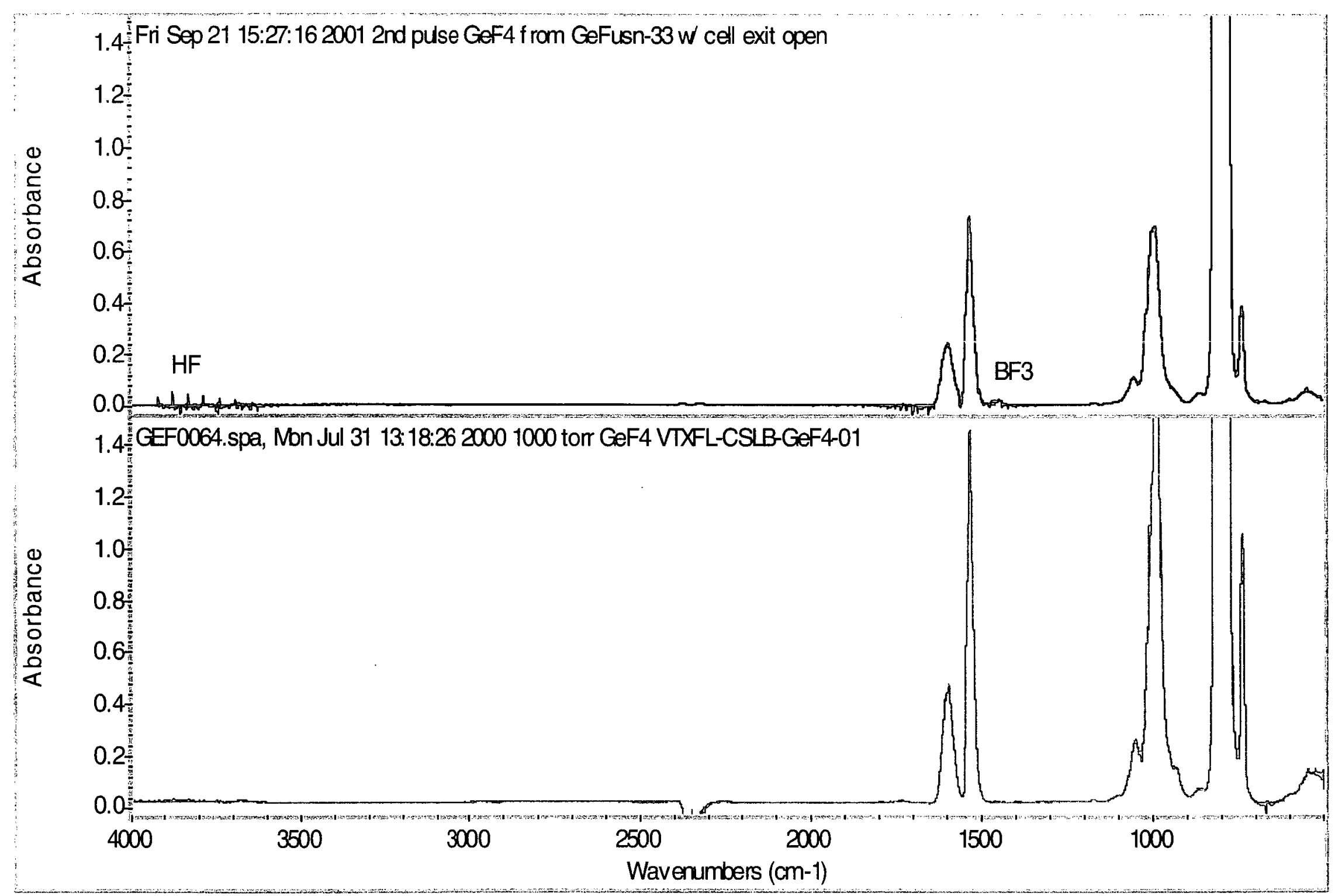

Figure 34. Infrared spectrum of $\mathrm{GeF}_{4}$ collected from GeFusn-33 and a reference spectrum of GeF 4 supplied by Voltaix, Inc. 
plateau and above, the margin was $13^{\circ} \mathrm{C}$. This could help to explain why the left side of the boat (position $\mathrm{B}$ ) contained fully reacted residue while the right side (position $\mathrm{D}$ ) only partially reacted materials.

Following the probe into the temperature profile of the tube furnace, another experiment was performed in order to document two important aspects about the fusion reaction. In GeFusn-35, the gas produced by the solid-state reaction was not collected but analyzed directly by FT-IR spectroscopy at various stages during the reaction. The specific conditions for the trial are summarized in Table 18.

\section{Table 18.}

Reaction profile for GeFusn-35.

\begin{tabular}{|l|c|c|c|}
\hline Experiment ID: & \multicolumn{2}{|l|}{ 072601-GeFusn-35 } \\
\hline System: & \multicolumn{1}{|c|}{ " OD nickel tube reactor with 8 " Ni boat } \\
\hline Weight of reagents $(\mathrm{gm}):$ & $\sim 22$ & $\quad$ wt $\% \mathrm{GeO}_{2}: 24.9847$ (stoichiometric mixture) \\
\hline Sweep gas: & Helium Flow at $68(\mathrm{cc} / \mathrm{min})$ \\
\hline Pre-reaction drying period: & 1 hour at $350^{\circ} \mathrm{C}$ in helium \\
\hline Total reaction time (hr): & 5.5 & \\
\hline Reaction temperature profile & Time $(\mathrm{hr})$ & at T $\left({ }^{\circ} \mathrm{C}\right)$ & \\
\hline & 0.75 & 650 & \\
\hline & 2 & 700 & \\
\hline & 2.75 & 725 & \\
\hline Cylinder ID: & none & \\
\hline Collection method: & none & \\
\hline Analytical method: & In-line FT-IR spectroscopy using $10 \mathrm{~cm}$ gas cell at $130^{\circ} \mathrm{C}$. \\
\hline & Multiple samples of gas were analyzed by FT-IR spectroscopy \\
\hline Calculated weight of $\mathrm{GeF}_{4}$ expected (gm) & $\sim 7.5$ & \\
\hline
\end{tabular}

Throughout the 5.5 hours of reaction the temperature was raised from $650^{\circ} \mathrm{C}$ to $700^{\circ} \mathrm{C}$ and finally to $725^{\circ} \mathrm{C}$ where it was maintained for 2.75 hours. First, the release of water vapor by the reagents during the pre-reaction drying period was cataloged. Representative spectra at temperatures between ambient and $350^{\circ} \mathrm{C}$ were recorded and presented in Figure 35. Compared to the baseline spectrum for helium, the liberation of moisture into the sweep gas passing over the reagent mixture can be seen beginning with the first analysis taken at room temperature. The broad bands characteristic of moisture grow steadily as the $350^{\circ} \mathrm{C}$ plateau is reached. After maintaining that temperature for 55 minutes, the uppermost spectrum in Figure 35 shows the sweep stream to be free of moisture vapor. It is clear that the pre-reaction period is important in clearing out adsorbed moisture from the reaction system and reactants prior to $\mathrm{GeF}_{4}$ being generated. 


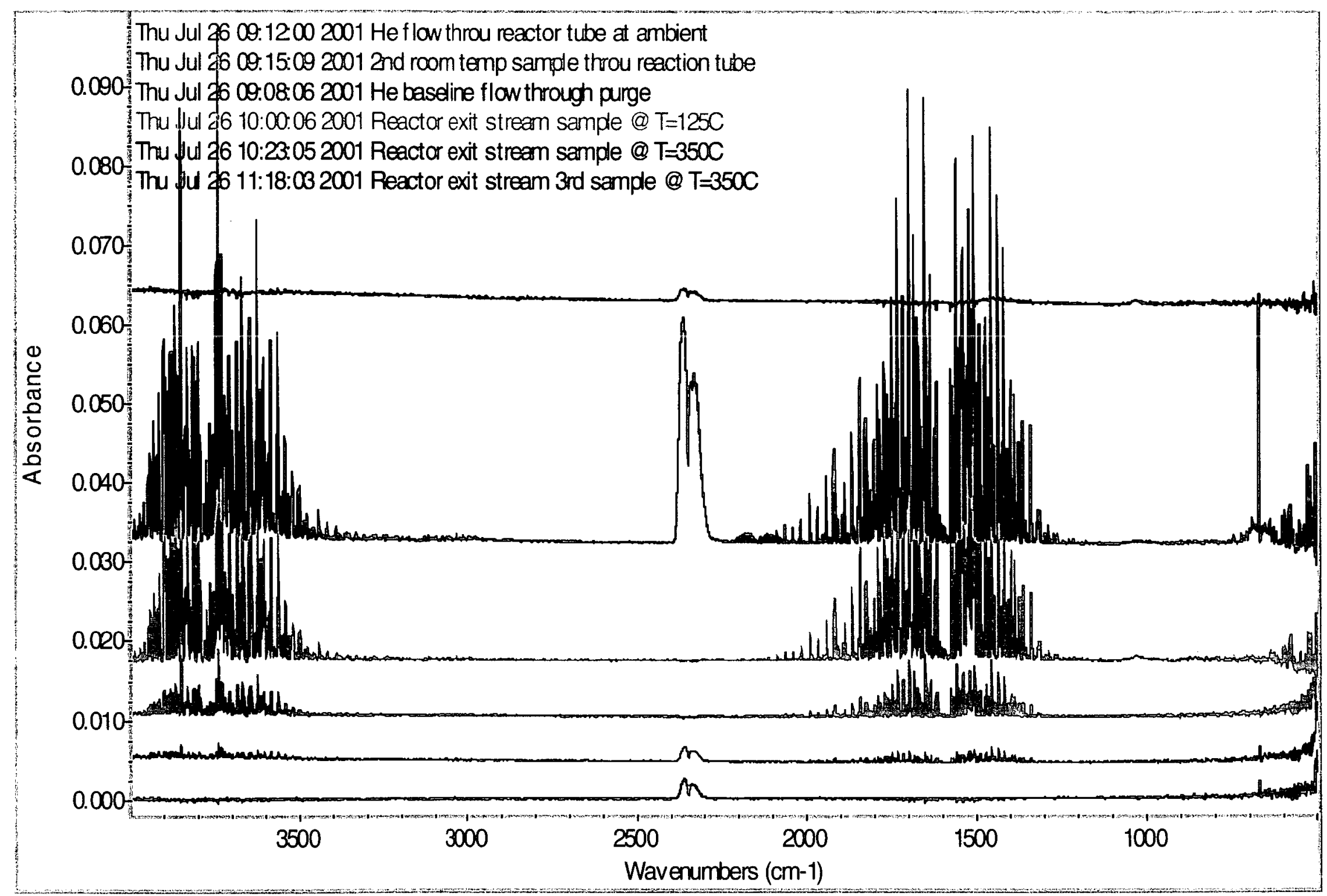

Figure 35. Infrared spectra of gas samples taken during GeFusn-35 at various temperatures between ambient and $350^{\circ} \mathrm{C}$. 
The second observation to come out of the infrared data concerned the onset of reaction between $\mathrm{UF}_{4}$ and $\mathrm{GeO}_{2}$. The liberation of $\mathrm{GeF}_{4}$ was clearly evident at temperatures well below $700^{\circ} \mathrm{C}$ as seen by the group of spectra compiled in Figure 36. At a furnace temperature of $650^{\circ} \mathrm{C}$ (the actual internal temperature based on the thermal profile measurements shown in Table 17 would be closer to $675^{\circ} \mathrm{C}$ ), the concentration of $\mathrm{GeF}_{4}$ in the gas stream is significant. At the $700^{\circ} \mathrm{C}$ and $725^{\circ} \mathrm{C}$ plateaus the amount of $\mathrm{GeF}_{4}$ in the helium sweep stream was estimated to be 30 torr and 40 torr, respectively, as determined by peak area integration of numerous reference samples compiled at Voltaix, Inc. As seen in earlier experiments, lower reaction temperature resulted in less $\mathrm{GeF}_{2}$ by-product formation, which is very desirable.

Upon removal of the boat from the reactor only a small portion of the residue was again blackened and a majority of the solid was varying shades of green. The 5.5-hour duration at the temperatures attained resulted in a small amount of conversion to $\mathrm{GeF}_{4}$. The reaction residue was analyzed by $\mathrm{x}$-ray powder diffraction and the recorded diffraction pattern is shown in Figure 37 along with reference patterns for $\mathrm{UF}_{4}, \mathrm{UO}_{2}$ and $\mathrm{UGeO}_{4}$. It is most interesting to note that diffraction peaks for $\mathrm{GeO}_{2}$ were not found and the most intense peaks matched those for the uranium germanium oxide compound. It appears at this point in the reaction scheme, the reaction dynamic is between $\mathrm{UF}_{4}$ and $\mathrm{UGeO}_{4}$ as shown in equation (8.5),

$$
\mathrm{UF}_{4}+\mathrm{UGeO}_{4} \longrightarrow 2 \mathrm{UO}_{2}+\mathrm{GeF}_{4}(\mathrm{~g})
$$

Formation of the $\mathrm{UGeO}_{4}$ compound can be expressed by the reaction given in equation (8.6),

$$
\mathrm{GeO}_{2}+\mathrm{UO}_{2} \longrightarrow \mathrm{UGeO}_{4}
$$




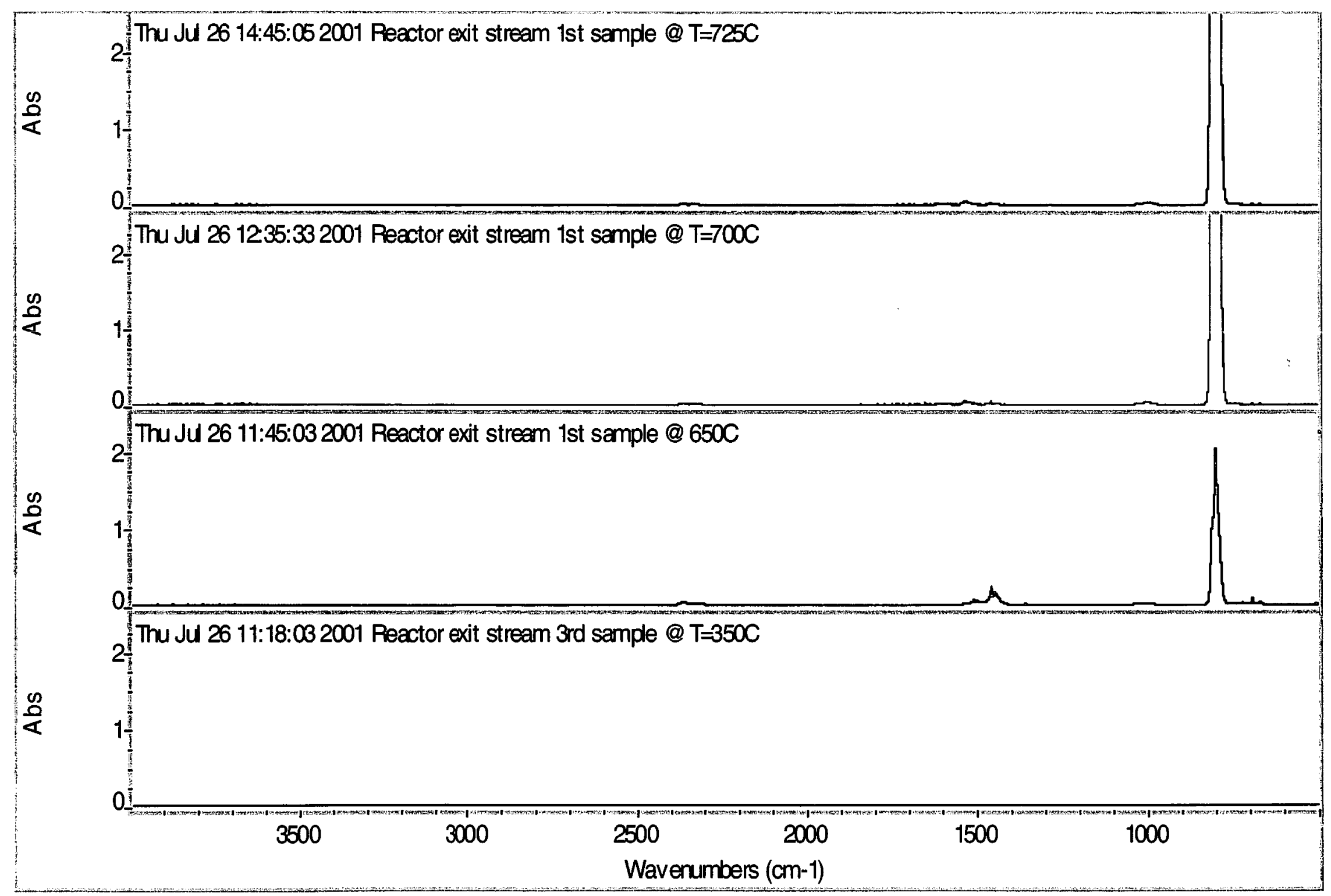

Figure 36. Infrared spectra of gas samples from GeFusn-35 at $350^{\circ} \mathrm{C}, 650^{\circ} \mathrm{C}, 700^{\circ} \mathrm{C}$ and $725^{\circ} \mathrm{C}$. 


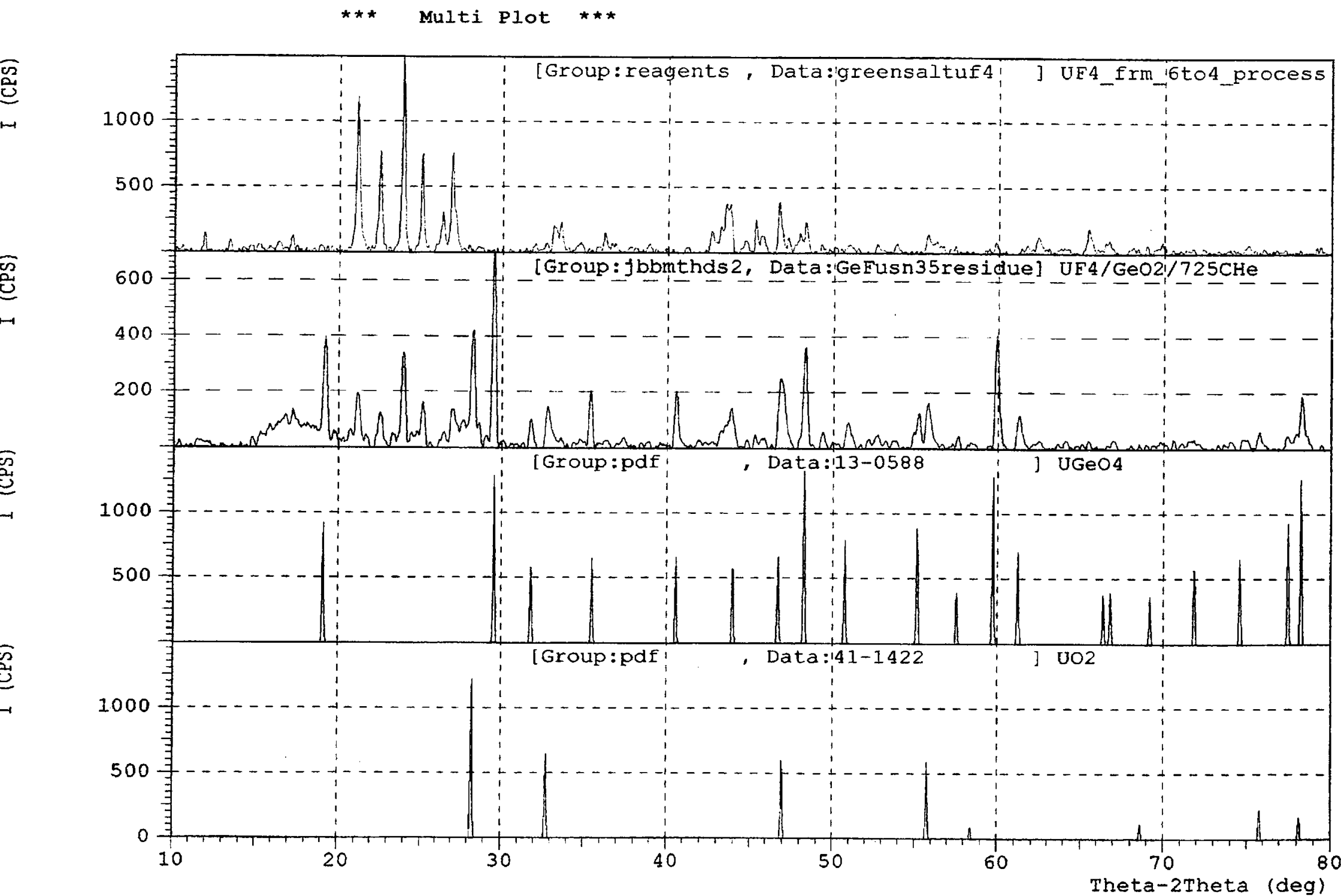

Figure 37. X-ray diffraction pattern for reaction residue from GeFusn-35 and reference patterns for $\mathrm{UF}_{4}, \mathrm{UO}_{2}$ (pdf\# 41-1422) and $\mathrm{UGeO}_{4}$ (pdf\# 13-0588). 
After performing many experiments to produce $\mathrm{GeF}_{4}$ using $\mathrm{GeO}_{2}(99.999 \%)$ as the coreagent with $\mathrm{UF}_{4}$, an alternative pathway was explored using $\mathrm{Ge}^{\circ}$ metal. The new reaction scheme is shown in equation (8.7),

$$
3 \mathrm{UF}_{4}+3 \mathrm{Ge}^{\circ}+4 \mathrm{O}_{2}(\mathrm{~g}) \longrightarrow 3 \mathrm{GeF}_{4}(\mathrm{~g})+\mathrm{U}_{3} \mathrm{O}_{8}
$$

The new chemistry is based on the in-situ oxidation of $\mathrm{Ge}^{\circ}$ to $\mathrm{GeO}_{2}$ on route to forming $\mathrm{GeF}_{4}$. There was also a potential for this pathway to deliver a higher purity of fluoride since the metallic reagent does not contain the level of adsorbed moisture that is liberated when $\mathrm{GeO}_{2}$ is reacted with green salt, as seen in GeFusn-35. Less moisture should result in a product containing less HF impurity.

For testing the pathway given in equation (8.7), two experiments were performed using the thermogravimentric analyzer (TGA) where milligram quantities of material were treated. First, the oxidation of $\mathrm{Ge}^{\circ}$ metal was investigated by heating a small sample of powder to $1000^{\circ} \mathrm{C}$ in a stream of dry air. As illustrated in Figure 38, the sample weight increased more than 11 milligrams over the course of the heating period, providing strong indication that the metal was converted to oxide.

In a second experiment, a mixture of $\mathrm{UF}_{4}$ and powdered $\mathrm{Ge}^{\circ}$ metal was heated to $850^{\circ} \mathrm{C}$ at $10^{\circ} \mathrm{C} / \mathrm{min}$ in a stream of air. Results displayed in Figure 39 showed the significant weight loss incurred as the temperature exceeded the $600^{\circ} \mathrm{C}$ range. The loss in weight is attributed to the volatilization of germanium and fluorine from the reaction mixture. Upon completion of the TGA run, the residue remaining in the TGA cup was analyzed by $x$-ray diffraction. Those results are given in Figure 40, showing that the post-reaction solid consisted of uranium oxide $\left(\mathrm{U}_{3} \mathrm{O}_{8}\right)$ and a small amount of $\mathrm{Ge}^{\circ}$ metal. These findings bolster the support for the pathway given in equation (8.7). 
Sample: Germanium

Size: $38.6212 \mathrm{mg}$

Method: Ramp to 1000

Comment: metal oxidation in dry air
File: A:1082401.002

Operator: Bulko

Run Date: 24-Aug-01 14:16

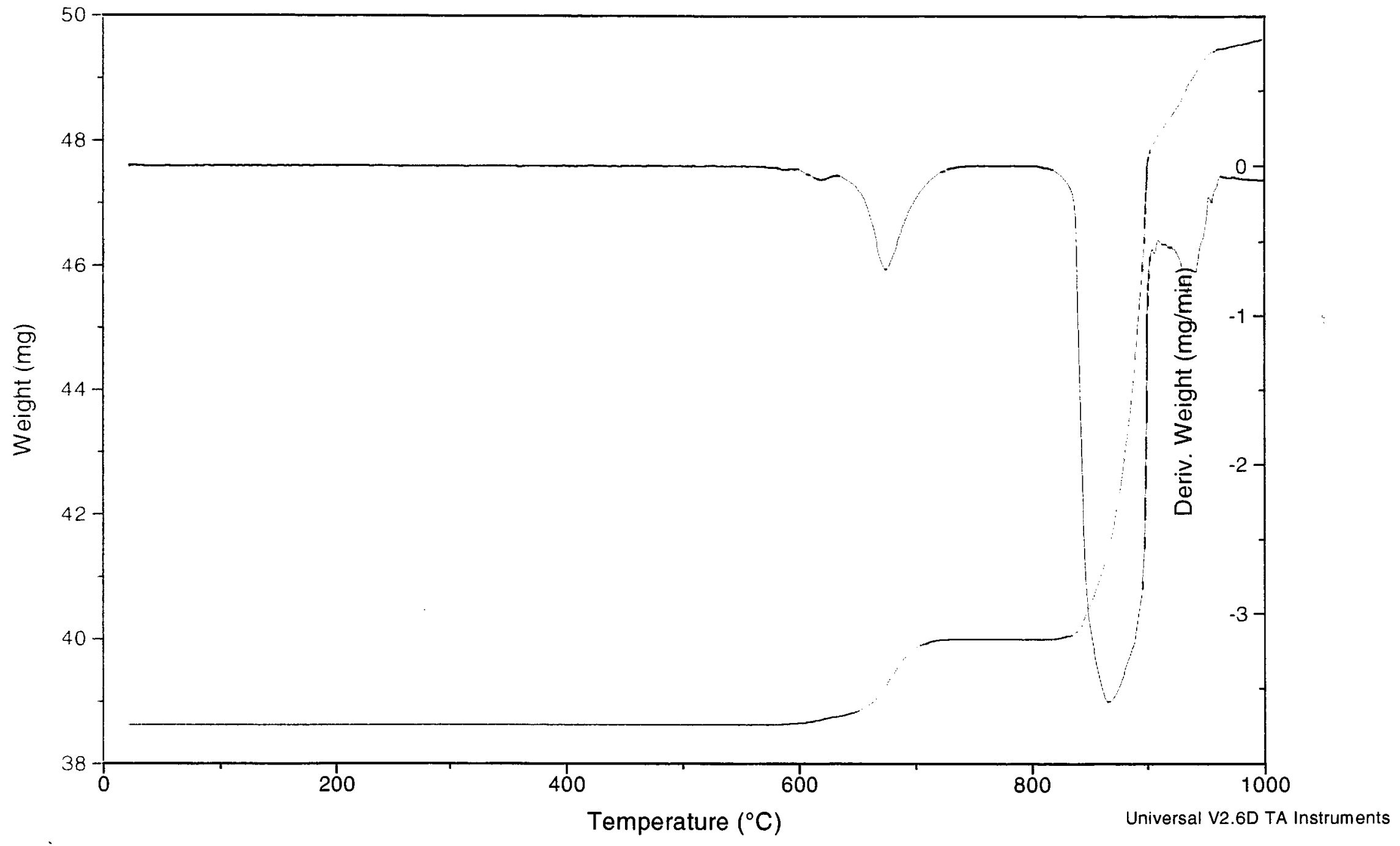

Figure 38. TGA result showing the weight gain when $\mathrm{Ge}^{\circ}$ metal was heated to $1000^{\circ} \mathrm{C}$ in dry air. 
Sample: Germanium

Size: $27.8128 \mathrm{mg}$

Method: Ramp to 1000

Comment: fusion reaction in dry air
TGA-DTA File: A:1082701.002

Operator: Bulko

Run Date: 27-Aug-01 13:50

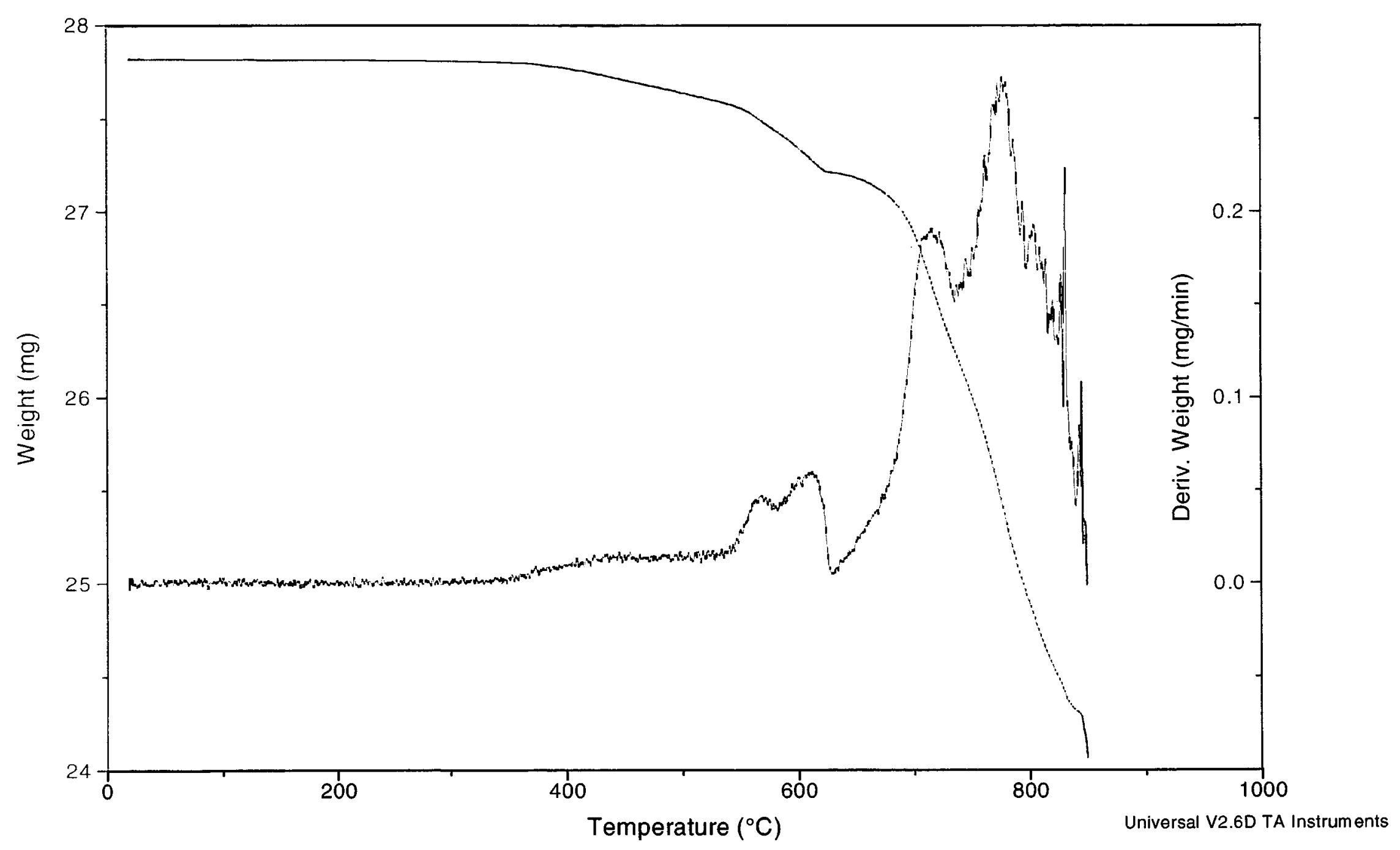

Figure 39. TGA result showing the weight loss when a mixture of $\mathrm{UF}_{4}$ and $\mathrm{Ge}^{\circ}$ metal was heated to $850^{\circ} \mathrm{C}$ in dry air. 


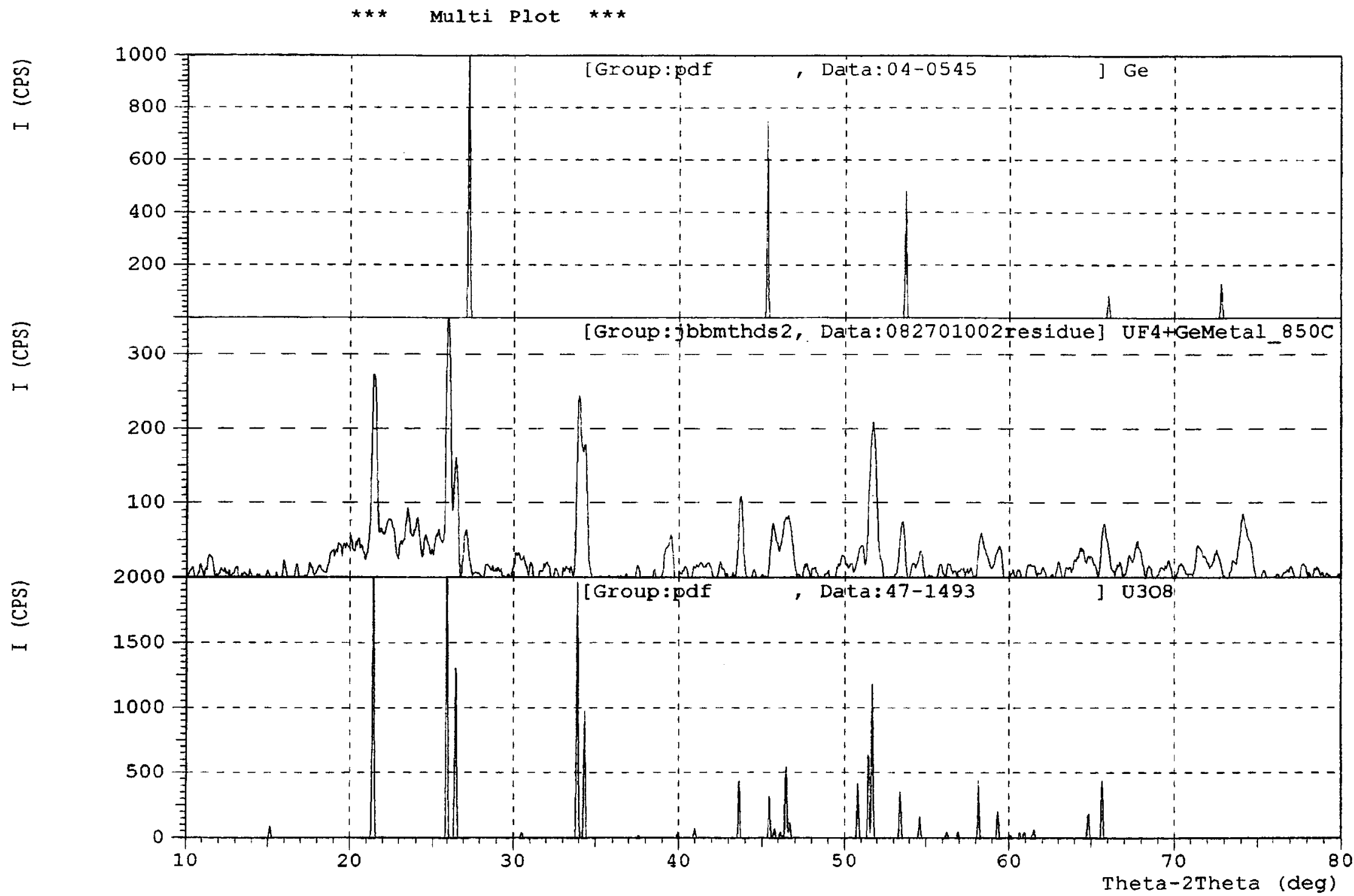

Figure 40. X-ray diffraction pattern for residue recovered from the TGA reaction performed at $850^{\circ} \mathrm{C}$ and reference patterns for $\mathrm{U}_{3} \mathrm{O}_{8}$ (pdf\# 47-1493) and $\mathrm{Ge}^{\circ}$ metal (pdf\# 04-0545). 
After establishing that the combination of $\mathrm{UF}_{4}$ with germanium metal successfully liberated $\mathrm{GeF}_{4}$, the reaction was carried out on a larger scale using the 1"OD nickel tube reactor setup. The experiment was identified as GeFusn-39 and the details are given in Table 19. The source of metal was taken from a stock of $99.9 \%$ pure Ge lump which was broken up and ground to a fine powder using a mortar and pestle. The gas flow from the reactor was connected to the input of the gas-sampling cell within the FT-IR spectrometer and multiple spectra were recorded as the reaction progressed. Representative spectra recorded at $600^{\circ} \mathrm{C}$ and $700^{\circ} \mathrm{C}$ are shown in Figure 41. The first spectrum to show peaks for $\mathrm{GeF}_{4}$ was taken as the reactor temperature reached $601^{\circ} \mathrm{C}$. Peaks due to $\mathrm{HF}$ and $\mathrm{SiF}_{4}$ impurities were also apparent. The reactor temperature was raised to $700^{\circ} \mathrm{C}$ and after 20 minutes, the gas flow to the gas cell ceased so the reaction was terminated. Upon disassembly of the reaction system, the $1 / 8$ "OD tube to the infrared cell was completely blocked with a white solid which over a short period of time became a tacky, wet slurry when exposed to air. The substance causing the blockage was believed to be $\mathrm{GeF}_{2}$, displaying similar characteristics to the white, hydroscopic solid produced in previous fusion reactions. After 30 minutes of reaction, conversion was estimated to be about $60.8 \%$ based on the weight loss of the reactants in the boat. Although the distribution of volatile fluoride between $\mathrm{GeF}_{4}$ and $\mathrm{GeF}_{2}$ was not measured, a significant fraction of the product appeared to be $\mathrm{GeF}_{2}$. Review of the literature has indicated that the difluoride compound is synthesized by passing $\mathrm{GeF}_{4}$ over germanium metal ${ }^{20,21,22}$, which in this case, is the most likely scenario occurring in this experiment. As such, further experimentation using $\mathrm{Ge}^{\circ}$ metal as the reagent was curtailed.

Table 19.

\section{Reaction profile for GeFusn-39.}

\begin{tabular}{|c|c|c|c|}
\hline Experiment ID: & \multicolumn{3}{|c|}{$083001-G e F u s n-39$} \\
\hline Reaction: & \multicolumn{3}{|c|}{$3 \mathrm{UF}_{4}+3 \mathrm{Ge}^{0}$ powder $+4 \mathrm{O}_{2}(\mathrm{~g})=3 \mathrm{GeF}_{4}(\mathrm{~g})+\mathrm{U}_{3} \mathrm{O}_{8}$} \\
\hline System: & \multicolumn{3}{|c|}{ 1" OD nickel tube reactor with 4" nickel boat } \\
\hline Weight of reagents $(\mathrm{gm})$ : & 10.9761 & & $\mathrm{wt} \% \mathrm{Ge}^{0}: 18.73$ \\
\hline Sweep gas: & \multicolumn{3}{|c|}{ aije flow at $86(\mathrm{cc} / \mathrm{min})$} \\
\hline Total reaction time $(\mathrm{hr})$ : & 0.5 & & \\
\hline \multirow[t]{3}{*}{ Reaction temperature profile } & Time $(\mathrm{hr})$ & at $\mathrm{T}\left({ }^{\circ} \mathrm{C}\right)$ & \\
\hline & 0.17 & 600 & \\
\hline & 0.33 & 700 & \\
\hline Cylinder ID: & none & & \\
\hline Collection method: & none & & \\
\hline Analytical method: & \multicolumn{3}{|c|}{ In-line FT-IR spectroscopy using $10 \mathrm{~cm}$ gas cell at $130^{\circ} \mathrm{C}$. } \\
\hline & \multicolumn{3}{|c|}{ Multiple samples of gas were analyzed by FT-IR spectroscopy } \\
\hline \multicolumn{2}{|c|}{ Calculated weight of $\mathrm{GeF}_{4}$ expected (gm) } & 1.4028 & \\
\hline \multicolumn{2}{|c|}{ Calculated weight loss of reagents (gm) } & 3.0028 & \\
\hline \multicolumn{2}{|c|}{ Observed weight loss of reagents (gm) } & 1.8264 & \\
\hline \multicolumn{2}{|c|}{\begin{tabular}{|l|l} 
Reaction Conversion $(\%)$ & \\
\end{tabular}} & 60.8 & defined as observ'd wt lost/calc'd wt lost \\
\hline
\end{tabular}




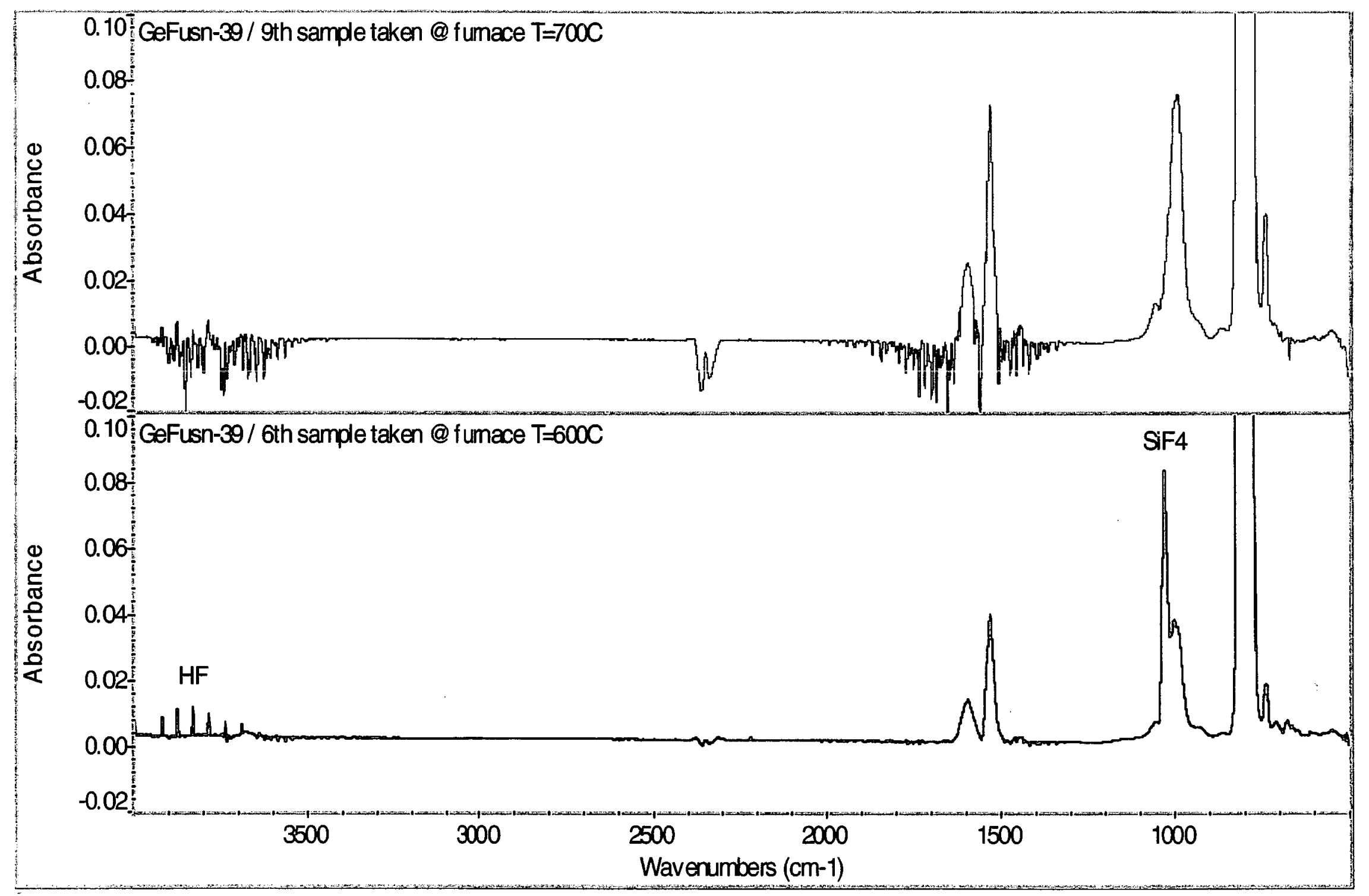

Figure 41. Infrared spectra of gas samples generated in GeFusn-39 taken at a temperature of $600^{\circ} \mathrm{C}$ and $700^{\circ} \mathrm{C}$. 
The last experiment conducted for optimizing the $\mathrm{GeF}_{4}$ reaction concerned the determination of the reaction onset temperature (ROT). Earlier results showed that heating the reactants to $350^{\circ} \mathrm{C}$ was essential for sweeping away adsorbed moisture from the reaction environment before the fluoride gas was made. At $650^{\circ} \mathrm{C}$ the reaction was well underway. It became necessary to identify the temperature at which point the reaction commenced in earnest, yielding high quality product. To accomplish this, the TGA instrument was used in performing one experiment where a mixture of $\mathrm{UF}_{4}$ and $\mathrm{GeO}_{2}$ was heated to $500^{\circ} \mathrm{C}\left(\right.$ at $\left.15^{\circ} \mathrm{C} / \mathrm{min}\right)$ in streams of air and argon. The weight loss curves for three successive heating cycles are displayed in Figure 42. The first two cycles where air was used as the sweep gas showed significant weight loss commencing about $400^{\circ} \mathrm{C}$. Likewise, the third cycle, where argon was the sweep gas, the same trend was seen. As the temperature reached the $500^{\circ} \mathrm{C}$ plateau, the loss of weight became steady at rates in the range of $0.7 \%-1.0 \%$ per hour.

In previous experiments where $\mathrm{GeF}_{4}$ was collected in sample cylinders, the temperatures employed during the pre-reaction drying period have varied from $300^{\circ} \mathrm{C}$ to $500^{\circ} \mathrm{C}$. From the TGA results in Figure 42, the production of fluoride gas was well underway at $500^{\circ} \mathrm{C}$. In order to prevent significant amounts of reactants from being converted to product during the drying period, the dehydration temperature was set at $450^{\circ} \mathrm{C}$ when $\mathrm{GeF}_{4}$ was collected for purity evaluation. 


\section{$\mathrm{UF}_{4}+\mathrm{GeO}_{2}$ Heated to $500^{\circ} \mathrm{C}$ in Air and Argon}

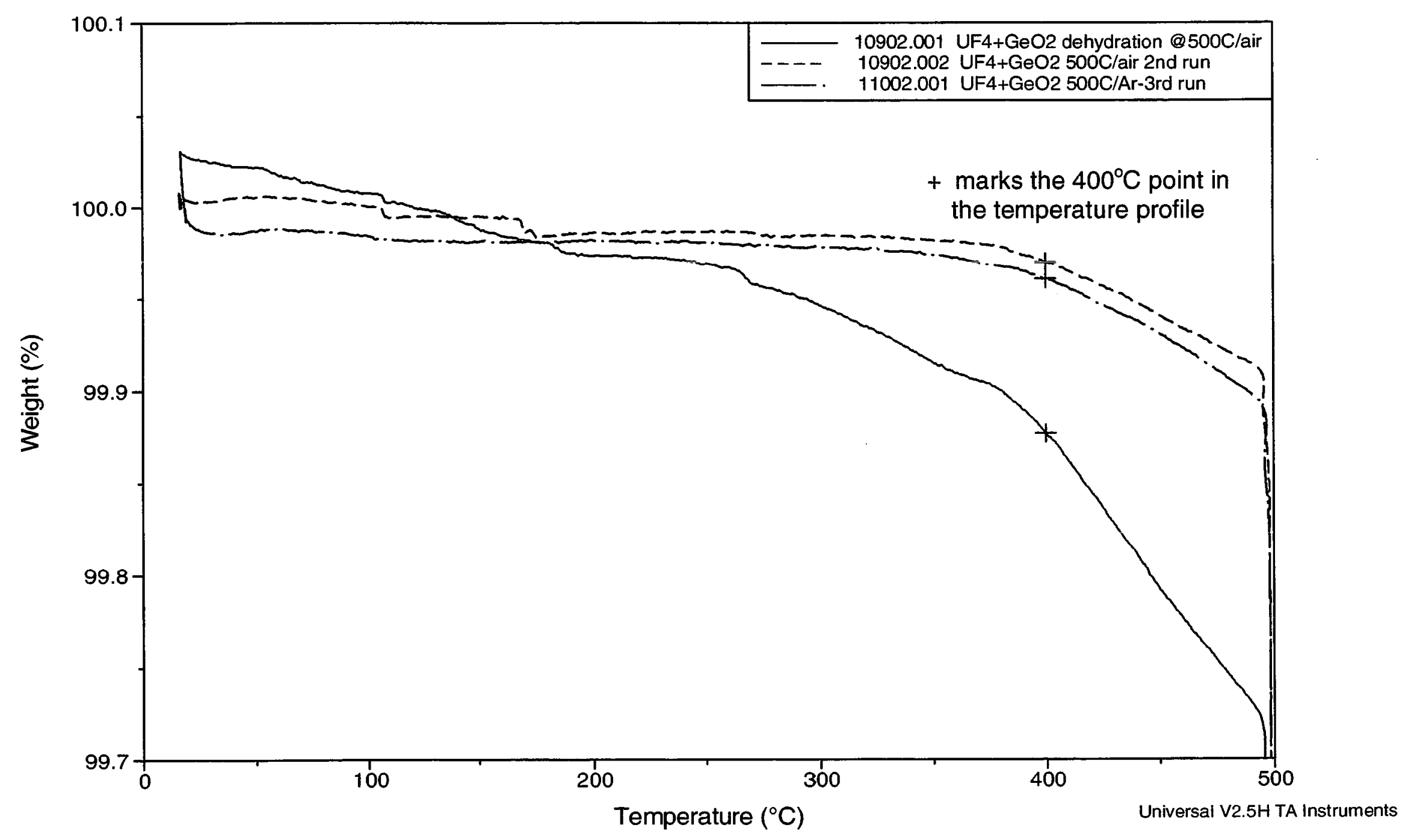

Figure 42. TGA results showing the temperature at which the reaction between $\mathrm{UF}_{4}$ and $\mathrm{GeO}_{2}$ starts producing $\mathrm{GeF}_{4}$. 


\subsubsection{Development of analytical technology for identifying trace $U$ in $\mathrm{GeF}_{4}$.}

Two samples of $\mathrm{GeF}_{4}$, synthesized in laboratory trials, were sent to Argonne National Laboratory $(A N L)$ for analysis using the two new techniques undergoing development by Dr. Beitz. The first multi-gram sample of fluoride material was made in the 1 " Ni tube reactor and was packaged in a $300 \mathrm{cc}$ Monel gas cylinder equipped with a shortened outage tube made from $1 / 4^{\prime \prime}$ nickel tube. Details of the reaction are given in Table 20 for GeFusn-36.

Table 20.

Reaction profile for GeFusn-36.

\begin{tabular}{|c|c|c|c|}
\hline Experiment ID: & \multicolumn{3}{|c|}{$080201-G e F u s n-36$} \\
\hline System: & \multicolumn{3}{|c|}{ 1" OD nickel tube reactor with 8 " Ni boat } \\
\hline Weight of reagents (gm) & \multicolumn{2}{|c|}{34.1057} & $\mathrm{wt} \% \mathrm{GeO}_{2}: 24.9847$ \\
\hline Sweep gas: & \multicolumn{3}{|c|}{ Helium $(62)+\operatorname{air}(10)=$ total flow at $72(\mathrm{cc} / \mathrm{min})$} \\
\hline Pre-reaction drying period: & \multicolumn{3}{|c|}{ 2. hours at $500^{\circ} \mathrm{C}$ in helium } \\
\hline Total reaction time $(\mathrm{hr}):$ & \multicolumn{2}{|c|}{5} & \\
\hline Reaction Temperature $\left({ }^{\circ} \mathrm{C}\right)$ & \multicolumn{2}{|c|}{750} & \\
\hline Cylinder ID: & \multicolumn{3}{|c|}{$\begin{array}{l}\text { \#A1, 300cc Monel, double port, shortened Ni outage tube and } \\
\text { Monel plug. }\end{array}$} \\
\hline Collection method: & \multicolumn{3}{|c|}{ n-propyl alcohol/liquid $\mathrm{N}_{2}$ bath at $-62^{\circ} \mathrm{C}$ to $-72^{\circ} \mathrm{C}$} \\
\hline Filter: & \multicolumn{2}{|c|}{ none } & \\
\hline \multicolumn{2}{|c|}{ Calculated weight of $\mathrm{GeF}_{4}$ expected (gm) } & 12.1056 & \\
\hline \multicolumn{2}{|c|}{ Calculated weight loss of reagents (gm) } & 11.2066 & \\
\hline \multicolumn{2}{|c|}{ Observed weight loss of reagents (gm) } & 9.1413 & \\
\hline \multicolumn{2}{|c|}{ Observed weight gain in the cylinder (gm) } & 6.46 & \\
\hline Reaction conversion $(\%)$ & 2.20 & 81.6 & defined as observid wt lost/cale'd wt lost \\
\hline $\mathrm{GeF}_{4}$ capture efficiency $(\%)$ & 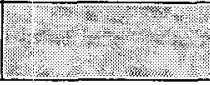 & -65.4 & $\begin{array}{l}\text { defined as observid wt gain in cylinder } / \\
\text { (rxn conversion) x xwt GeF4 expected }\end{array}$ \\
\hline
\end{tabular}

For this reaction, the sweep gas through the reactor contained a mixture of helium and air, the pre-reaction drying period was extended to 2 hours at $500^{\circ} \mathrm{C}$ and the reaction temperature was maintained at $750^{\circ} \mathrm{C}$ for 5 hours. Under these conditions the reaction reached $81.6 \%$ conversion and 6.46 grams of $\mathrm{GeF}_{4}$ was recovered in the sample cylinder. After completing the experiment, the residual helium/air atmosphere in the cylinder was removed using a mechanical vacuum pump while the cylinder was chilled at $-70^{\circ} \mathrm{C}$ in an n-propyl alcohol/liquid $\mathrm{N}_{2}$ bath. After the vacuum treatment, the cylinder contained 5.3 grams of $\mathrm{GeF}_{4}$. The gas produced in GeFusn-36 was collected without passing it through a filter and was considered as the most 'crude' form (worst case scenario) with regard to possible $U$ contamination.

The residue produced in GeFusn-36 was again characterized by $\mathrm{x}$-ray powder diffraction. The contents of the boat were predominantly black across the length of the boat except for a small portion at one end, which was green. Samples of the black and green materials were analyzed and their diffraction patterns are shown in Figure 43. The black solid was clearly a match with the $\mathrm{U}_{3} \mathrm{O}_{8}$ reference pattern while the green sample contained unreacted $U_{4}$ and 

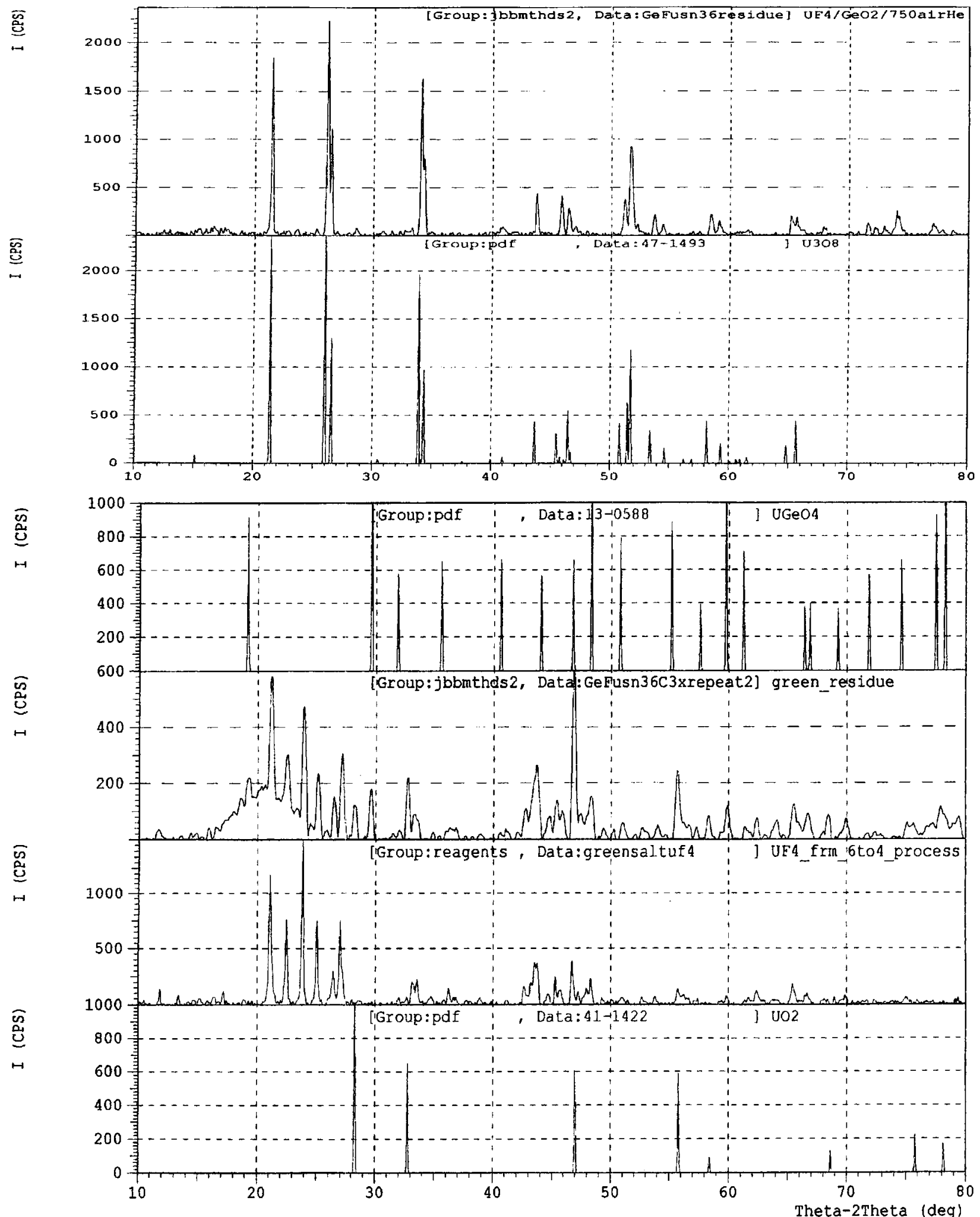

Figure 43. X-ray diffraction patterns for the black and green residues from GeFusn-36 and reference patterns for $\mathrm{UO}_{2}$, (pdf\# 41-1422), $\mathrm{U}_{3} \mathrm{O}_{8}$ (pdf\# 47-1493), $\mathrm{UGeO}_{4}$ (pdf\# 13-0588) and $\mathrm{UF}_{4}$. 
peaks matching well with both $\mathrm{UGeO}_{4}$ and $\mathrm{UO}_{2}$ patterns. The composition of the partially reacted green solid has been consistent with diffraction results from previous experiments in that both $\mathrm{UO}_{2}$ and $\mathrm{UGeO}_{4}$ have been detected. Since air was added to the sweep gas in this reaction, the presence of $\mathrm{UO}_{2}$ in the product was not expected but rather $\mathrm{U}_{3} \mathrm{O}_{8}$. This would indicate that the gas passing over the reactant bed was deficient in oxygen when the reaction was stopped after 5 hours.

The second batch-production of $\mathrm{GeF}_{4}$ was made as part of GeFusn-40. The same reaction system and gas collection hardware were used in preparing the second sample. The reaction profile for this operation is given in Table 21. Reaction conditions for this trial were slightly different than those for GeFusn-36.

Table 21.

Reaction profile for GeFusn-40.

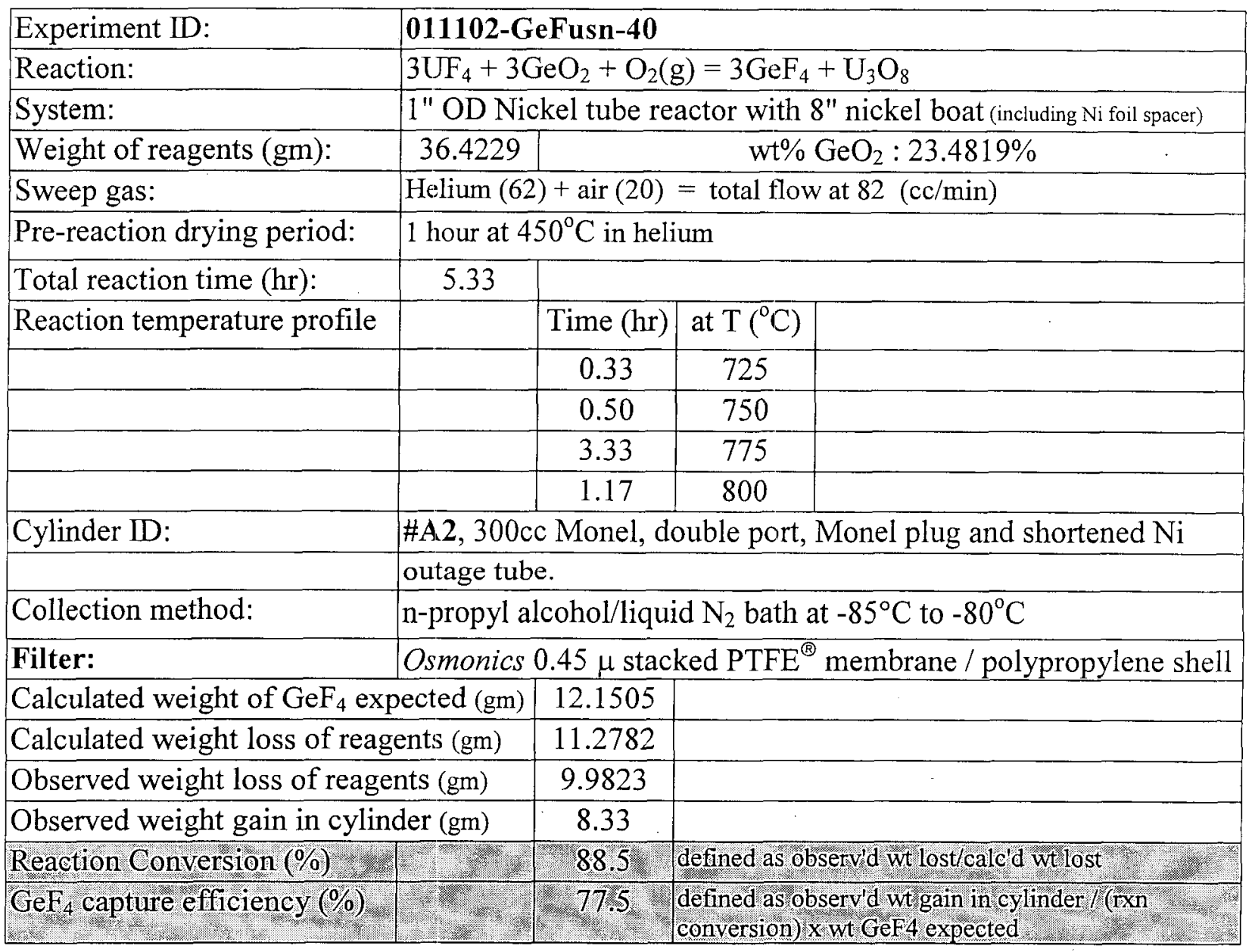

Notably, the pre-reaction drying period was changed to 1 hour at $450^{\circ} \mathrm{C}$ while the reaction temperature was ramped in steps over the range between $725^{\circ} \mathrm{C}-800^{\circ} \mathrm{C}$ during the 5.33 hour reaction period. Using this profile, reaction conversion was $88.5 \%$ and 8.3 grams of $\mathrm{GeF}_{4}$ was captured in the sample cylinder after removing the residual helium/air carrier gas with vacuum 
pump. In contrast to the first sample of gas sent to $A N L$, during the preparation of this sample, the gas was passed through a $0.45 \mu$ stacked PTFE ${ }^{\circledR}$ membrane filter (Osmonics, Inc., Westborough, MA) before collection in the $300 \mathrm{cc}$ Monel cylinder. The post-reaction residue from GeFusn- 40 was not analyzed by x-ray diffraction but visual inspection showed a small portion of the material had the characteristic green color of unreacted green salt at one end of the reagent boat.

Detailed results from the program to develop analytical methodology to measure trace uranium in $\mathrm{GeF}_{4}$ produced by the new fluoride extraction technology are contained in four interim progress reports provided by Dr. Beitz at $A N L$. Those reports describe the methods, equipment, procedures and results learned during that investigation and are included at the end of this report in APPENDIX A. Included below are the abstracts and/or summary for the interim reports highlighting the accomplishments of the program in chronological order.

\section{March 12, 2001 Progress Report (J.V. Beitz and C.W. Williams)}

We are developing two methods for ultratrace determination of uranium in germanium tetrafluoride $\left(\mathrm{GeF}_{4}\right)$ gas. Both methods are designed primarily for determination of uranium based on its most probable volatile chemical compound, namely uranium hexafluoride $\left(\mathrm{UF}_{6}\right)$. The first method relies on detection and measurement of $\mathrm{UF}_{6}$ via its characteristic and very strong ultraviolet optical absorption spectrum. The scientific basis for this method is well established, although it is technically challenging to implement. Most of our work to date has been carried out to establish the scientific basis for our second method, which relies on laserinduced fluorescence of uranyl ions in glassy germanium dioxide $\left(\mathrm{GeO}_{2}\right)$. Hydrolysis of $\mathrm{GeF}_{4}$ that contains $\mathrm{UF}_{6}$ and subsequent treatment with ammonium hydroxide is expected to generate hydrated germanium dioxide $\left(\mathrm{GeO}_{2}\right)$ that contains uranyl hydroxo complexes. Thermal fusion of this material and rapid cooling should produce glassy $\mathrm{GeO}_{2}$ that contains uranyl ions. Although this is a plausible scheme for ultratrace determination of uranium in $\mathrm{GeF}_{4}$, it rests on the presumption that uranyl ions are chemically stable in molten $\mathrm{GeO}_{2}$. We now have carried out studies on uranyl-doped glassy $\mathrm{GeO}_{2}$ that have shown that 1) uranyl ions are stable for hours in molten $\mathrm{GeO}_{2}, 2$ ) uranyl ions in glassy $\mathrm{GeO}_{2}$ at ambient temperature are strongly luminescent, and 3) the likely limit of detection for uranium in $\mathrm{GeF}_{4}$ using this method is 50 ppt (parts per trillion), or better, on a weight basis. Using our present non-optimized apparatus, we have achieved signal-to-noise ratios for uranyl ion luminescence in glassy $\mathrm{GeO}_{2}$ that are equivalent to a limit of detection of $500 \mathrm{ppt}$.

\section{October 23, 2001 Progress Report (J.V. Beitz and C.W. Williams)}

One approach that we are investigating to improve analytical methods for quantifying uranium hexafluoride $\left(\mathrm{UF}_{6}\right)$ in germanium tetrafluoride $\left(\mathrm{GeF}_{4}\right)$ is hydrolysis of impure $\mathrm{GeF}_{4}$. gas to generate $\mathrm{GeO}_{2}$ and uranyl fluoride. Subsequent heating produces uranyl ions embedded in glassy $\mathrm{GeO}_{2}$. In our earlier work, we showed that laser-induced fluorescence analysis for uranyl ion had the potential to detect less than 0.5 parts per billion of uranium in glassy $\mathrm{GeO}_{2}$. We also noted difficulty in reproducibly creating visually clear, bubble-free glassy $\mathrm{GeO}_{2}$ on the one gram scale. Bubble-free $\mathrm{GeO}_{2}$ is required to achieve reproducible measurement of luminescence intensity. Such reproducibility is essential for quantitative measurement of uranium impurity content in analyzed samples via the standard addition method.

Based on a parametric study, we now have identified a simple means of producing visually clear, bubble-free glassy $\mathrm{GeO}_{2}$ on the gram scale. However, this method creates an 
impurity that, following excitation at $355 \mathrm{~nm}$, luminesces such that its emission spectrum and luminescence decay overlap those of uranyl ion in glassy $\mathrm{GeO}_{2}$. The impurity species likely is the result of thermal reduction of some tetravalent $\mathrm{Ge}$ in $\mathrm{GeO}_{2}$ to divalent $\mathrm{Ge}$. The impurity species grows in with increased sample residence time in the high temperature zone of the furnace. This impurity interference is present to varying degrees in all other methods that we investigated to minimize the presence of small bubbles in $\mathrm{GeO}_{2}$ glass produced by melt processing in air. Given difficulties in producing glassy $\mathrm{GeO}_{2}$ of acceptable quality for quantitative uranyl luminescence analysis, we began a search for alternate, but related methods of achieving our goal of improved ultratrace analysis for $\mathrm{UF}_{6}$ in $\mathrm{GeF}_{4}$ gas. We have identified a promising method that does not require high temperature processing and so is likely to be more easily and economically implemented in a quality assurance laboratory.

Our new approach retains the same initial step, namely, hydrolysis of $\mathrm{GeF}_{4}$ gas in water to generate $\mathrm{GeO}_{2}, \mathrm{H}_{2} \mathrm{GeF}_{6}$, and $\mathrm{HF}$, and the same second processing step, namely sub-boiling point distillation of volatile species. Our new approach then dissolves the resulting non-volatile residue $\left(\mathrm{GeO}_{2}\right.$ and uranyl fluoride, if any $\mathrm{UF}_{6}$ was present in the $\left.\mathrm{GeF}_{4}\right)$ in concentrated hydrochloric acid. This converts $\mathrm{GeO}_{2}$ to volatile $\mathrm{GeCl}_{4}$ that is removed, along with excess hydrochloric acid, by a second sub-boiling point distillation. The residue (uranyl chloride and trace amounts of $\mathrm{GeO}_{2}$ ) is taken up in dilute phosphoric acid solution. The uranium content of the resulting solution is quantified by laser-induced fluorescence and the standard addition method. This new approach will permit use of $266 \mathrm{~nm}$ excitation which has the advantage of being more strongly absorbed by uranyl in dilute phosphoric acid than is light at $337 \mathrm{~nm}$ (nitrogen laser) or $355 \mathrm{~nm}$ (tripled Nd:YAG laser). In consequence, limits of detection for uranyl comparable to the best reported in the literature ( 1 to $40 \mathrm{ppt}$ ) are expected. The primary interference that we anticipate in our germanium chloride volatilization process is luminescence from trace level organic contaminants leached from the perfluoropolymer distillation vessel. We expect to eliminate such interference by $185 \mathrm{~nm}$ photolysis that should photochemically destroy such contaminants. In our initial studies of this new approach, we have hydrolyzed $\mathrm{GeF}_{4}$ gas and verified volatilization of the resulting $\mathrm{GeO}_{2}$ from concentrated hydrochloric acid.

Using a $9.3 \mathrm{~cm}$ path length nickel-bodied, elastomer-free cell equipped with single crystal aluminum oxide windows, we have recorded the ultraviolet absorption spectrum of Starmetproduced $\mathrm{GeF}_{4}$ gas. Based on those spectra and literature values for the molar absorptivity of uranium hexafluoride gas, Starmet-produced $\mathrm{GeF}_{4}$ contains less than 0.75 parts per million (by volume) of $\mathrm{UF}_{6}$. Based on an observed small decreases in pressure upon contact of Starmetproduced $\mathrm{GeF}_{4}$ gas with a clean, passivated vacuum system and subsequent FT-IR analysis of that $\mathrm{GeF}_{4}$ gas using our nickel-bodied cell, we have concluded that the sample of Starmetproduced $\mathrm{GeF}_{4}$ that we analyzed contains approximately $0.8 \%$ hydrogen fluoride (HF) gas by volume.

\section{May 11, 2002 Progress Report (J.V. Beitz and C.W. Williams)}

In lieu of a formal abstract for this report, a brief summary of the results is outlined below.

Work began on the alternative approach to determine $\mathrm{U}$ (as $\mathrm{UF}_{6}$ ) in $\mathrm{GeF}_{4}$, termed 'chloride volatility'. In testing the new approach, a sample of fluoride was hydrolyzed in a small volume of water, contacted with concentrated $\mathrm{HCl}$ and subjected to a sub-boiling point distillation treatment. Solid residue recovered from the distillation treatment was analyzed by FT-IR spectroscopy using CsI powder to make a transparent pellet. The infrared spectrum of the 
solid showed bands consistent with $\mathrm{GeO}_{2}$ and bands correlating to $\mathrm{CsGeF}_{6}$ produced by interaction of $\mathrm{H}_{2} \mathrm{GeF}_{6}$ and $\mathrm{CsI}$. Further steam hydrolysis treatments were successful in converting the $\mathrm{H}_{2} \mathrm{GeF}_{6}$ fraction to $\mathrm{GeO}_{2}$. However, in subsequent steam hydrolysis trials, it took a total of $400 \mathrm{ml}$ of water and approximately 80 hours of contact with steam at slightly above $100^{\circ} \mathrm{C}$ to completely hydrolyze the combined $\mathrm{GeO}_{2} / \mathrm{H}_{2} \mathrm{GeF}_{6}$ solids to $\mathrm{GeO}_{2}$. The steam hydrolysis apparatus was modified to enable vapor phase hydrochlorination of $\mathrm{GeO}_{2}$ produced by the steam hydrolysis procedure. After three hours of reflux at $115^{\circ} \mathrm{C}$ the hydrochloric acid vapor treatment was not effective in converting $\mathrm{GeO}_{2}$ to volatile $\mathrm{GeCl}_{4}$.

\section{March 17, 2003 Progress Report (J.V. Beitz)}

Our primary focus was evaluation of our proposed "chloride volatility" process for analysis of the uranium content of hydrolyzed $\mathrm{GeF}_{4}$ gas. The basis of this process is detailed in our May 11, 2002 progress report. The process requires conversion of "particulate $\mathrm{GeO}_{2}$ " into volatile germanium tetrachloride $\left(\mathrm{GeCl}_{4}\right)$. The "particulate $\mathrm{GeO}_{2}$ " of interest is that which arises from repeated steam hydrolysis of the solids that result from reaction (hydrolysis) of $\mathrm{GeF}_{4}$ with water. As noted in our May 11, 2002 report, the $\mathrm{GeO}_{2}$ of interest is of the hexagonal structure type based on its infrared absorption spectrum. Standard reviews of germanium chemistry state that hexagonal $\mathrm{GeO}_{2}$ reacts with concentrated hydrochloric acid to form $\mathrm{GeCl}_{4}$. We carried out extensive tests of the reactivity of our particulate $\mathrm{GeO}_{2}$ with hydrochloric acid solutions. Our particulate $\mathrm{GeO}_{2}$ failed to react with concentrated (analytical reagent grade) hydrochloric acid $(\mathrm{HCl})$ solution at ambient temperature over a period of several months contact. It did not react at temperatures up to and including the boiling point of concentrated $\mathrm{HCl}$. Particulate $\mathrm{GeO}_{2}$ was held in the refluxing vapor above constant boiling point hydrochloric acid and in the refluxing vapor above concentrated hydrochloric acid. Portions of the refluxing vapor were collected for analysis and no evidence of $\mathrm{GeCl}_{4}$ was found. To maximize the solution acidity, dry hydrogen chloride gas was passed through a stirred slurry of particulate $\mathrm{GeO}_{2}$ and concentrated $\mathrm{HCl}$ at ambient temperature. No formation of liquid $\mathrm{GeCl}_{4}$ was observed in the slurry container. The vapor exiting the reaction vessel was passed through a trap held at $273^{\circ} \mathrm{K}$. Analysis of the trap contents did not reveal any $\mathrm{GeCl}_{4}$. We conclude that our particulate $\mathrm{GeO}_{2}$, although of the hexagonal structure type, exhibits a negligible reaction rate with hydrochloric acid under our experimental test conditions. For this reason, our proposed "chloride volatility" process is not suitable for high sensitivity analysis for the presence of uranium in hydrolyzed $\mathrm{GeF}_{4}$ gas.

Reaction of particulate $\mathrm{GeO}_{2}$ with dry $\mathrm{HCl}$ gas at moderately high temperature (e.g., $400^{\circ} \mathrm{C}$ ) was not attempted due to concern about chemical reduction (due to the presence of small amounts of hydrogen gas in $\mathrm{HCl}$ ). Such reduction of trace levels of uranyl would result in lower valent uranium chlorides whose volatility likely would compromise analytical accuracy.

In a final effort to quantify uranium in hydrolyzed $\mathrm{GeF}_{4}$ gas, we contacted an aliquot of particulate $\mathrm{GeO}_{2}$ with $22 \%$ hydrofluoric acid solution and found that the particulate $\mathrm{GeO}_{2}$ readily dissolved to give a clear, colorless solution. This solution was transferred to a single crystal aluminum oxide cell that consisted of a single crystal aluminum oxide rod into which a hole that had been drilled coaxial with the cylinder axis of the rod to create a flat-bottomed "test tube" shape. A polished disk of single crystal aluminum oxide capped the cavity in the rod and prevented escape of significant amounts of HF vapor from the contained solution. Laser-induced fluorescence analysis of the solution in this cell was carried out using $355 \mathrm{~nm}$ excitation with the apparatus described in our March 12, 2001 progress report. Luminescence from the solution was observed throughout the visible spectral range and exhibited complex, non-exponential decay. 
The luminescence initially peaked in the blue. With increasing time following an excitation pulse, the peak luminescence intensity wavelength shifted to longer wavelength. An aliquot of a solution of uranyl ion in dilute nitric acid was added to the solution in the cell in an amount sufficient to give approximately 6 parts per million of uranyl on a weight basis. The characteristic luminescence emission bands of uranyl ion could not be discerned in the recorded emission spectra due to the much more intense broadband, complex luminescence of the solution. This interfering luminescence likely arises from low molecular weight polymers that had leached from the Kel-F and perfluoroalkoxy (PFA) Teflon ${ }^{\circledR}$ containers that we used to generate the particulate $\mathrm{GeO}_{2}$. Such luminescence was not observed from our HF stock solution nor was it present in solutions of commercial $\mathrm{GeO}_{2}$ dissolved in our HF stock solution. We conclude that the sensitivity of luminescence analysis for uranyl in hydrofluoric acid solutions of particulate $\mathrm{GeO}_{2}$ is significantly hindered by the presence of interfering luminescing species that likely are low molecular weight polymers that leached from the walls of $\mathrm{Kel}-\mathrm{F}^{\circledR}$ and Teflon ${ }^{\circledR}$ containers.

Absorbance Analyses of $\mathrm{GeF}_{4}$ Gas using ultraviolet absorption spectroscopy

An aliquot of germanium tetrafluoride $\left(\mathrm{GeF}_{4}\right)$ gas from Starmet Sample Reference Number "GeFusn-40" (Starmet preparation date 1/11/02) underwent analysis by ultraviolet absorption spectroscopy for the presence of uranium hexafluoride gas $\left(\mathrm{UF}_{6}\right)$. This analysis and an infrared analysis were carried out using the methods, equipment, and procedures noted in our October 23, 2001 progress report to Starmet with one exception. That exception was the averaging together of ten spectral scans, which resulted in slightly improved sensitivity. No absorbance attributable to $\mathrm{UF}_{6}$ gas was observed. If one uses three times the observed standard deviation of the measurement as the "limit of detection" criterion, then the sample of Starmetproduced $\mathrm{GeF}_{4}$ gas contained less than 0.64 parts per million of $\mathrm{UF}_{6}$ gas on a volume basis relative to $\mathrm{GeF}_{4}$. The sample also underwent infrared absorbance analysis in the 2000 to 5000 wavenumber $\left(\mathrm{cm}^{-1}\right)$ spectral region in the same sample cell used for ultraviolet absorption analysis. The characteristic fundamental vibration-rotation bands of hydrogen fluoride gas (HF) were observed in the 3700 to $4200 \mathrm{~cm}^{-1}$ spectral range with nearly the same optical density as was the case for our previous analysis of an aliquot of $\mathrm{GeF}_{4}$ from Starmet Sample Reference Number "GeFusn-36" (Starmet preparation date 8/06/0). In addition, weak absorption bands (peak absorbance: 0.002 absorbance units) of the $v_{3}$ fundamental absorption bands of carbon dioxide gas $\left(\mathrm{CO}_{2}\right)$ were observed in the 2310 to $2375 \mathrm{~cm}^{-1}$ spectral range.

\subsubsection{Particulate filtration.}

Information concerning effective gas filtration technology for semiconductor grade materials was supplied by Voltaix, Inc. It was recommended that a Wafergard II F-6 Inline Gas Filter (Millipore Corporation, Bedford, MA) or equivalent be used when processing and packaging the final fluoride product. The Wafergard product featured a teflon ${ }^{\circledR}$ membrane module rated for particulate removal of $\geq 0.003 \mu$. An equivalent filter, model \# TEM-811-P manufactured by T.E.M. Filter Company (Santa Clara, CA), was purchased from Air Products (Allentown, PA) and was to be integrated into the production-scale reaction system when built. A description of the TEM-800 Series Gas Filter is included in Figure 44 along with a picture and schematic diagram of the flow rating. 


\section{TEM-800 Series Gas Filters}

- $\quad 99.9999999 \%$ Efficient @ 0.003 Microns

- $\quad$ PTFE $^{\oplus}$ Membrane

- 0.5 square foot Effective Filtration Area

- $\quad 316 \mathrm{~L}, 10 \mathrm{Ra}$ finish, electro-polished stainless steel housing

- 750 psig operation pressure at $250^{\circ} \mathrm{F}$

- Helium leak tested to 1 X $10-9 \mathrm{cc} / \mathrm{sec}$

- $\quad$ Available with Compression, Face Seal, and N.P.T. fittings

- Interchangeable with all Pall and Millipore Filters

- Compatible with all Semiconductor Grade Gases

TEM-800 Series filters are specifically designed for filtration of critical semiconductor gases where flow rates of more than 20 liters per minute are required. The filters use a PTFE ${ }^{\circledR}$ membrane in a small pleated cartridge form to provide .003 micron absolute filtration. The teflon ${ }^{\circledR}$ membrane cartridge is encapsulated in a $316 \mathrm{~L}$ stainless steel housing that is electropolished and totally welded. The final assembly is purged at a high flow rate with filtered nitrogen for initial cleanliness.
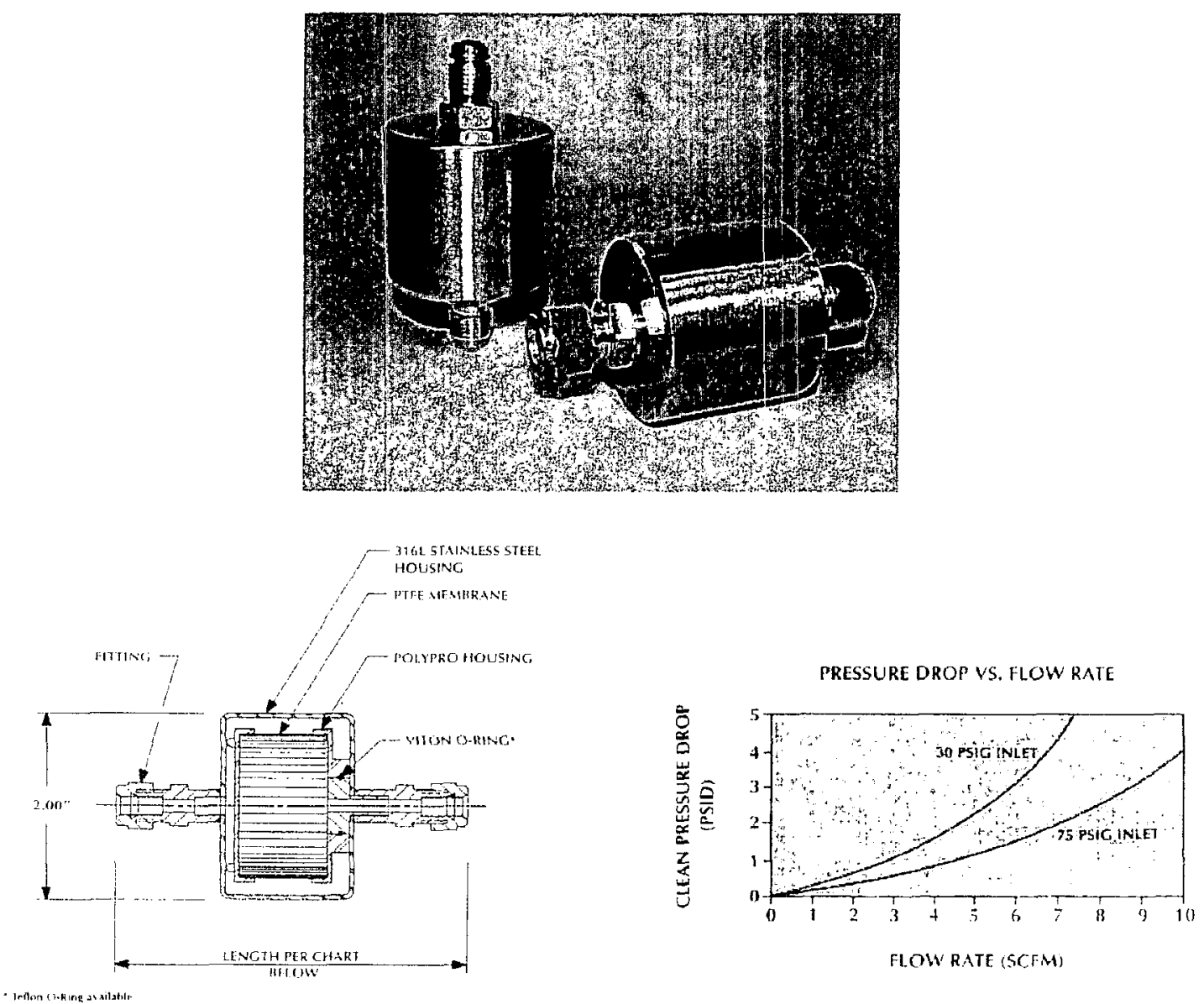

Figure 44. Description and illustration of the TEM- 800 Series Gas Filter. 
From the results gathered in section 8.2.4, uranium carryover into the laboratorysynthesized samples of gas was not detected above the minimum detection limits of the analytical instrumentation even for the unfiltered batch from GeFusn-36. None the less, filtering of the gas is essential for producing a clean, high purity product for use in the semiconductor industry.

\subsubsection{Process scale-up.}

Preliminary drawings of a six-station reaction system and gas collection station were made to begin the process of scaling-up production of $\mathrm{GeF}_{4}$ to $\sim 2 \mathrm{~kg}$ of gas per day. In order to prove-out the design concept, a small prototype of a closed-end tube reactor was fabricated from a 9" section of 1" Ni tube. The basic setup was shown in Figure 7 (section 8.1.6) where the sweep gas was piped close to the surface of the reaction mixture to convey the emerging fluoride gas out of the reaction zone and toward the collection vessel. Leaving the reaction tube, the gas was passed into a $300 \mathrm{cc}$ double-ported, Monel cylinder setup as a 'flow-through' condenser. Results for this trial, identified as GeFusn-34, are given in Table 22. After 5 hours of reaction with the temperature in the range between $735^{\circ} \mathrm{C}-800^{\circ} \mathrm{C}$, the reagent mixture lost only 3.07 grams, representing only $10.2 \%$ of the expected weight loss. Of greater significance was the fact that none of the synthesized $\mathrm{GeF}_{4}$ was captured in the collection vessel maintained at dry-ice temperature.

Table 22.

\section{Results for GeFusn-34.}

\begin{tabular}{|c|c|c|c|c|}
\hline Experiment ID: & \multicolumn{4}{|c|}{ 051501-GeFusn-34 } \\
\hline System: & \multicolumn{4}{|c|}{ Closed-end 1" OD nickel tube reactor } \\
\hline & \multicolumn{4}{|c|}{ 6" OD x 6" long ceramic heater (with manual control) } \\
\hline Weight of reagents $(\mathrm{gm})$ : & 87.84 & \multicolumn{3}{|c|}{$\mathrm{wt} \% \mathrm{GeO}_{2}: 24.1689$} \\
\hline Sweep gas: & \multicolumn{4}{|c|}{ Helium flow at $70(\mathrm{cc} / \mathrm{min})$} \\
\hline Total reaction time $(\mathrm{hr})$ & 5 & & & \\
\hline \multirow[t]{4}{*}{ Temperature profile } & & Time (hr) & at $\mathrm{T}\left({ }^{\circ} \mathrm{C}\right)$ & \\
\hline & & 2 & $735-755$ & \\
\hline & & 1 & 775 & \\
\hline & & 2 & 800 & \\
\hline Cylinder ID: & \multicolumn{4}{|c|}{$\# 11,300 \mathrm{cc}$ volume, Monel, double port, no outage tube } \\
\hline \begin{tabular}{l|l} 
Collection method: & d \\
\end{tabular} & \multicolumn{4}{|c|}{ dry ice bath, neat } \\
\hline \multicolumn{5}{|c|}{\begin{tabular}{l|l} 
Calculated weight of $\mathrm{GeF}_{4}$ expected $(\mathrm{gm}):$ & 30.1603 \\
\end{tabular}} \\
\hline \multicolumn{5}{|c|}{\begin{tabular}{|l|l|} 
Observed weight loss of reagents (gm) & 3.07 \\
\end{tabular}} \\
\hline \multicolumn{5}{|c|}{\begin{tabular}{|l|l|l|l|} 
Observed weight gain in cylinder $(\mathrm{gm})$ & none \\
\end{tabular}} \\
\hline \multicolumn{5}{|c|}{ Reaction conversion $(\%)$} \\
\hline $\mathrm{GeF}_{4}$ capture efficiency $(\%)$ & & $=0$ & & \\
\hline
\end{tabular}


The low conversion witnessed in GeFusn-34 was most likely a result of poor heat transfer through the wall of the vertically mounted tube from the ceramic heater. The reaction temperature of $800^{\circ} \mathrm{C}$ was measured outside the nickel tube and must have been substantially below that within the reaction mixture. The fact that no $\mathrm{GeF}_{4}$ was collected in the cylinder was, in part, a result of foregoing the pre-reaction drying step that allowed adsorbed moisture to migrate and condense in cooler sections of the tubing and hydrolyze some fluoride before reaching the intended collection area. Some $\mathrm{GeF}_{4}$ was also lost to passivating the nickel surfaces of the new reaction tube, forming a $\mathrm{Ni}_{2} \mathrm{GeO}_{4}$ film as seen in previous experiments. Collection was also hampered by the low concentration of fluoride gas in the stream passing through the chilled cylinder. At dry ice temperature $\left(-78^{\circ} \mathrm{C}\right)$ the equilibrium vapor pressure of $\mathrm{GeF}_{4}$ is $\sim 26$ torr or $\sim 3.4 \%$ by volume. The short condensation zone ( 6 " length of the chilled cylinder wall) was obviously not sufficient to capture measurable amounts of $\mathrm{GeF}_{4}$.

In light of the poor results observed in GeFusn-34 using the vertical tube configuration, design plans for a production scale apparatus were reviewed by the staff at Voltaix, Inc. Based on their recommendations and expertise with semiconductor grade materials, a new set of drawings for a multi-station reaction system and gas collection apparatus were drafted. The revised designs are shown in Figures $\mathbf{4 5}$ and 46. In brief:

- The closed-end reaction tube was switched to a 'pass-through' reaction tube similar to the tube reactor used in the design trials.

- The use of sintered metal disc filters was to be avoided since they clog easily and are not easily cleaned. Multi-membrane canister filters are recommended and they can be placed anywhere in the system as long as the gas has cooled to ambient.

- Capture of $\mathrm{GeF}_{4}$ using a 'flow-through' condenser approach is more efficient as the concentration (partial pressure) increases to atmospheric pressure or above. For low concentration environments the use of a closed-end vessel equipped with a short outage tube is preferred.

- For low level production, automating the transfer of gas into the product cylinder is a costly add-on to equipment. Manual transfer using alternating vacuum/pressurization cycles to move $\mathrm{GeF}_{4}$ into transportable carbon steel cylinder is recommended.

In conjunction with plans to increase the scale of $\mathrm{GeF}_{4}$ production, a Process Hazards Review (PHR) was conducted involving both the reaction and collection systems illustrated in Figures 45 and 46. The first draft of the PHR is presented in Table 23 and includes sections concerning the reactor, the gas collection cylinder, final transport cylinder and support system. In the review, various ' $w$ hat If . . ' scenarios are presented along with the effect they would have on operations, the consequences stemming from the effect and what remedial actions/resources are available to manage the situation to a satisfactory outcome. 


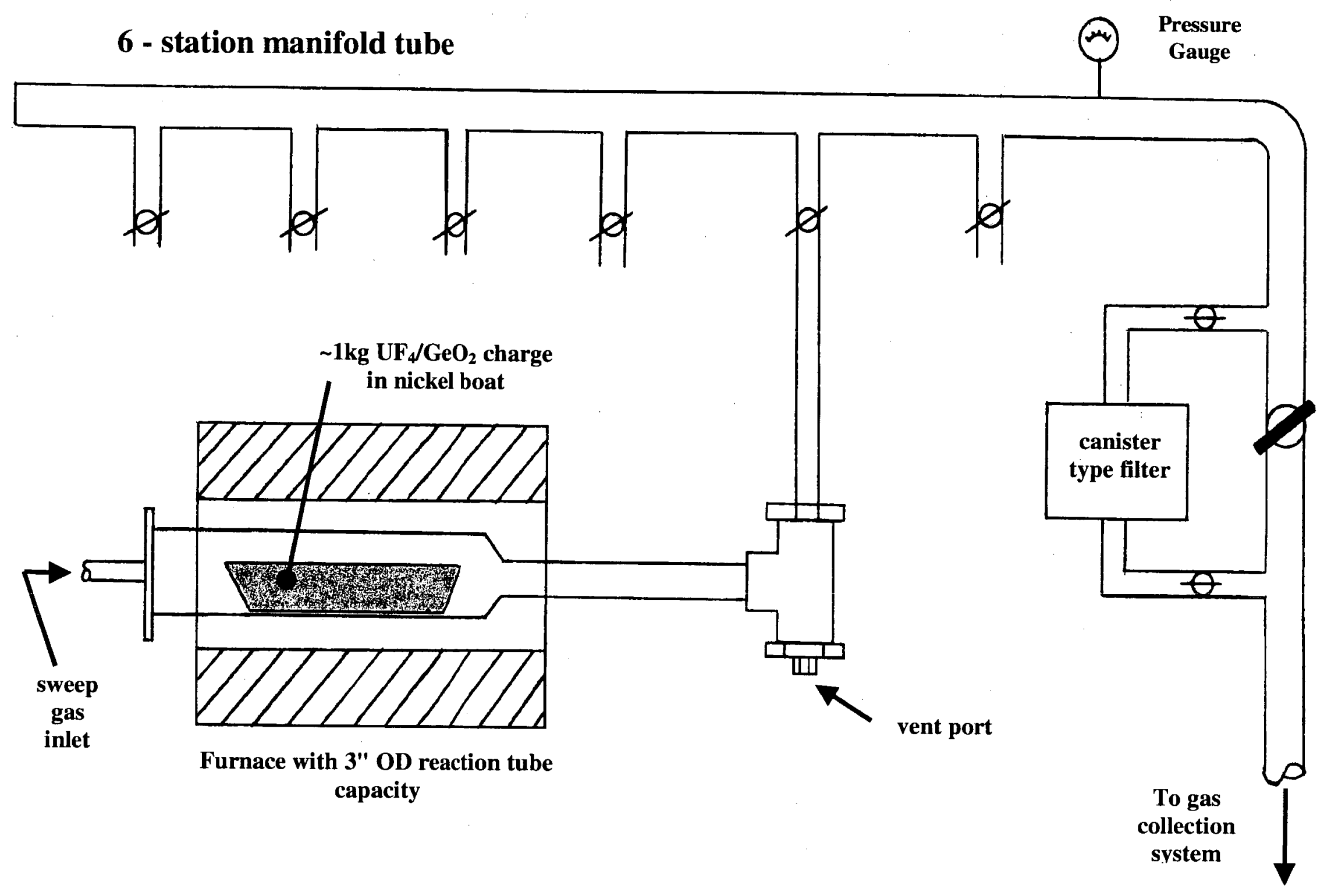

Figure 45. Revised design of the multi-station reaction system. 


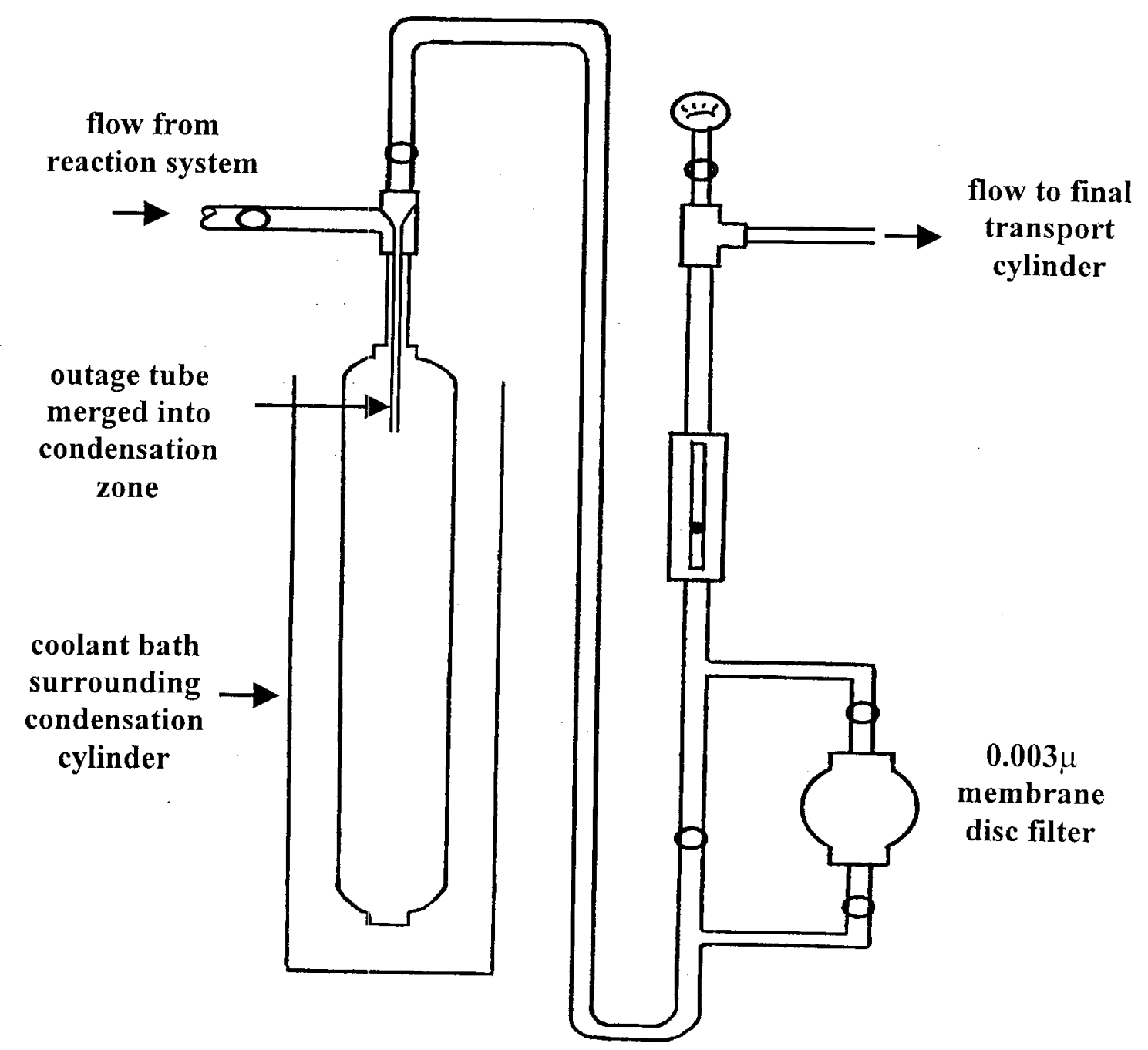

Figure 46. Revised design of the condensation zone in the collection system. 
Table 23.

Process Hazards Review for $\mathrm{GeF}_{4}$ Production.

\begin{tabular}{|c|c|c|c|c|c|}
\hline System/Question & Instrument(s) & Effect & Consequence & Remediation & Issues \\
\hline \multicolumn{6}{|l|}{ 1. Reactor system } \\
\hline a. What if reactor temperature too high? & $\begin{array}{l}\text { Reactor temperature } \\
\text { sensor }\end{array}$ & $\begin{array}{l}\text { GeF4 produced faster than } \\
\text { expected }\end{array}$ & $\begin{array}{l}\text { GeF4 may not condense } \\
\text { completely, overpressure } \\
\text { situation may exist }\end{array}$ & $\begin{array}{l}\text { Vent to scrubber system, pressure } \\
\text { relief device engaged. }\end{array}$ & none \\
\hline b. What if reactor temperature too low? & $\begin{array}{l}\text { Reactor temperature } \\
\text { sensor }\end{array}$ & $\begin{array}{l}\text { Reagents may not react at all or } \\
\text { very slowly }\end{array}$ & $\begin{array}{l}\text { No safety consequence. Fluoride } \\
\text { is not made. }\end{array}$ & & \\
\hline c. What if reactor outlet plugs? & -- & No outlet for gas & Overpressure in reaction tube. & $\begin{array}{l}\text { Shutdown reactor furnace on high } \\
\text { pressure. Vent excess pressure to } \\
\text { scrubber system }\end{array}$ & $\begin{array}{l}\text { Venting excess pressure } \\
\text { may cause exposure. }\end{array}$ \\
\hline d. What if reactor inlet plugs & $\cdots$ & No sweep gas flow & $\begin{array}{l}\text { Difficult to purge reactor of } \mathrm{GeF} 4- \\
\text { laden atmosphere after reaction } \\
\text { is completed }\end{array}$ & $\begin{array}{l}\text { Residual GeF } 4 \text { vented into hood } \\
\text { system }\end{array}$ & $\begin{array}{l}\text { Disassembly may cause } \\
\text { exposure. }\end{array}$ \\
\hline $\begin{array}{l}\text { e. What if sweep gas stops flowing (supply } \\
\text { tank is depleted)? }\end{array}$ & - & No helium/air sweep gas flow & \begin{tabular}{|l|} 
Difficult to purge GeF4 from \\
reactor after completing reaction. \\
May not get full reaction
\end{tabular} & Replace the sweep gas cylinder. & $\begin{array}{l}\text { Replacing sweep gas } \\
\text { supply could cause } \\
\text { exposure if done improperly }\end{array}$ \\
\hline f. What if reactor leaks? & -- & $\begin{array}{l}\text { GeF4 escapes into ventilation } \\
\text { hood. }\end{array}$ & Potential exposure & $\begin{array}{l}\text { Shutdown process and repair leak. } \\
\text { Gas vented into hood is scrubbed. }\end{array}$ & $\begin{array}{l}\text { Potential exposure to } \\
\text { operator. }\end{array}$ \\
\hline g. What if manifold plugs? & $\cdots$ & $\begin{array}{l}\text { Over pressure in all active } \\
\text { reactors. }\end{array}$ & Reactor overpressure & $\begin{array}{l}\text { Shutdown reactor furnace on high } \\
\text { pressure. Vent excess pressure to } \\
\text { scrubber system }\end{array}$ & none \\
\hline h. What if manifold filter plugs & & $\begin{array}{l}\text { Over pressure in all active } \\
\text { reactors. }\end{array}$ & Reactor overpressure & $\begin{array}{l}\text { Shutdown reactor furnace on high } \\
\text { pressure. Vent excess pressure to } \\
\text { scrubber system }\end{array}$ & none \\
\hline \multicolumn{6}{|l|}{ 2. Gas Collection System } \\
\hline $\begin{array}{l}\text { a. What if primary cooling bath is too } \\
\text { warm? }\end{array}$ & $\begin{array}{l}\text { Bath temperature } \\
\text { sensor }\end{array}$ & Gas will not be captured. & Gas goes to scrubber system. & $\begin{array}{l}\text { Adjust coolant bath temperature - not } \\
\text { a safety issue except potential for } \\
\text { small release to scrubber. }\end{array}$ & none \\
\hline b. What if the cooling bath is too cool? & $\begin{array}{l}\text { Bath temperature } \\
\text { sensor }\end{array}$ & $\begin{array}{l}\text { Components and impurities in the } \\
\text { sweep gas may be captured. }\end{array}$ & $\begin{array}{l}\text { Captured GeF4 contains } \\
\text { impurities. }\end{array}$ & $\begin{array}{l}\text { Raise the coolant bath temperature to } \\
\text { stop carryover of unwanted impurities. }\end{array}$ & $\begin{array}{l}\text { Condensation cylinder may } \\
\text { fill with liquefied air. }\end{array}$ \\
\hline $\begin{array}{l}\text { c. What if collection cylinder plugs during } \\
\text { filling? }\end{array}$ & $-\infty$ & $\begin{array}{l}\text { Could cause overpressure in } \\
\text { system or stop gas flow, } \\
\text { depending on where plug occurs. }\end{array}$ & Reactor overpressure & $\begin{array}{l}\text { Shutdown reactor furnace on high } \\
\text { pressure. Vent excess pressure to } \\
\text { scrubber system }\end{array}$ & none \\
\hline
\end{tabular}




\begin{tabular}{|c|c|c|c|c|c|}
\hline \multicolumn{6}{|l|}{ Table 23 (cont.) } \\
\hline System/Question & Instrument(s) & Effect & Consequence & Remediation & Issues \\
\hline $\begin{array}{l}\text { d. What if the collection cylinder plugs } \\
\text { during transfer? }\end{array}$ & & $\begin{array}{l}\text { Over pressure in all active } \\
\text { reactors. }\end{array}$ & Reactor overpressure & $\begin{array}{l}\text { Shutdown reactor furnace on high } \\
\text { pressure. Vent excess, pressure to } \\
\text { scrubber system. }\end{array}$ & none \\
\hline \multicolumn{6}{|l|}{ 3. Final Transport Cylinder } \\
\hline a. What if filter plugs? & & $\begin{array}{l}\text { No flow of GeF4 from } \\
\text { condensation cylinder to final } \\
\text { packaging cylinder. }\end{array}$ & $\begin{array}{l}\text { Pressure in condensation cylinder } \\
\text { and filter increases }\end{array}$ & $\begin{array}{l}\text { Pressure relief device engaged or } \\
\text { GeF4 recondensed by applying coolant } \\
\text { bath around collection cylinder. }\end{array}$ & $\begin{array}{l}\text { Filter can be bypassed and } \\
\text { transfer completed to lower } \\
\text { system pressure. }\end{array}$ \\
\hline b. What if bath is too cold? & & No effect & & & \\
\hline c. What if bath is too warm? & & $\begin{array}{l}\text { Transfer cylinder may not } \\
\text { condense fluoride gas }\end{array}$ & $\begin{array}{l}\text { Condensation cylinder and filter } \\
\text { overpressurize. }\end{array}$ & $\begin{array}{l}\text { Pressure relief device engaged or } \\
\text { GeF4 recondensed by applying coolant } \\
\text { bath around collection cylinder. }\end{array}$ & none \\
\hline d. What if vacuum not sufficient? & Pressure gauge & High pressure in transfer cylinder & $\begin{array}{l}\text { GeF4 is comingled with } \\
\text { impurities. }\end{array}$ & no safety effects & \\
\hline $\begin{array}{l}\text { e. What if vacuum is still on when transfer } \\
\text { is initiated? }\end{array}$ & & $\begin{array}{l}\text { Vacuum pump still pumping on } \\
\text { transfer cylinder when } \\
\text { condensation vessel is opened. }\end{array}$ & $\begin{array}{l}\text { Some GeF4 may be pumped out } \\
\text { through the vacuum pump. }\end{array}$ & $\begin{array}{l}\text { Vacuum pump outlet vented through } \\
\text { the scrubber. }\end{array}$ & \\
\hline f. What if the flowmeter fails low? & Flowmeter & $\begin{array}{l}\text { Flowmeter fails to indicate flow of } \\
\text { gas. }\end{array}$ & $\begin{array}{l}\text { No indication of gas flow may } \\
\text { make operator think that transfer } \\
\text { to packaging vessel is complete. }\end{array}$ & $\begin{array}{l}\text { Transport cylinder is weighed to check } \\
\text { transferred amount of gas. }\end{array}$ & $\begin{array}{l}\text { Condensation cylinder may } \\
\text { contain more GeF4 than } \\
\text { expected on startup of next } \\
\text { condensation cycle. }\end{array}$ \\
\hline g. What if the flowmeter fails high? & Flowmeter & Flowmeter reads high & $\begin{array}{l}\text { Operator may think gas flow is } \\
\text { proceeding when there is no or } \\
\text { little flow. }\end{array}$ & $\begin{array}{l}\text { Operator may continue gas transfer } \\
\text { longer than needed. No safety } \\
\text { implications. }\end{array}$ & none \\
\hline $\begin{array}{r}\text { h. What if pressure gauge fails high? } \\
\ldots \ldots \text { fails low? }\end{array}$ & Pressure gauges & $\begin{array}{l}\text { Operator stops transfer of gas } \\
\text { prematurely. } \\
\text { Operator continues transfer of } \\
\text { gas longer than necessary. }\end{array}$ & $\begin{array}{l}\text { Transfer of GeF4 less than } \\
\text { expected. } \\
\text { Transfer of more GeF4 than } \\
\text { expected. }\end{array}$ & $\begin{array}{l}\text { System evacuated using vacuum } \\
\text { pump. } \\
\text { System evacuated using vacuum } \\
\text { pump. }\end{array}$ & $\begin{array}{l}\text { Transport cylinder contains } \\
\text { less than desired amount. } \\
\text { Transfer cylinder contains } \\
\text { more than desired amount. }\end{array}$ \\
\hline \multicolumn{6}{|l|}{ 4. Support Systems } \\
\hline $\begin{array}{l}\text { a. What if ventilation hood fails during } \\
\text { operation? }\end{array}$ & Hood velocity sensor & $\begin{array}{l}\text { Ventilation surrounding reactor(s) } \\
\text { ceases. }\end{array}$ & $\begin{array}{l}\text { Potential for exposure to process } \\
\text { gases and GeF } 4 \text { increases } \\
\text { dramatically. }\end{array}$ & $\begin{array}{l}\text { Immediate shutdown of operations, } \\
\text { evacuate. }\end{array}$ & $\begin{array}{l}\text { Evacuation may include } \\
\text { personnel in surrounding } \\
\text { areas. }\end{array}$ \\
\hline b. What if scrubber fails during operation? & & Scrubber stops working & $\begin{array}{l}\text { Environmental discharge of gas } \\
\text { less than } 2 \mathrm{~kg} \text { maximum }\end{array}$ & $\begin{array}{l}\text { Significant residual trapping in } \\
\text { scrubber packing, HF sensor in } \\
\text { discharge. }\end{array}$ & \\
\hline
\end{tabular}




\subsubsection{Gas ultrapurification.}

Voltaix, Inc. was subcontracted to characterize the purity of $\mathrm{GeF}_{4}$ made by the new Starmet process. Material synthesized in two lab trials, GeFusn 37 and 38, was shipped to them in order that the purity of the "as-produced" gas be established and to determine if further purification steps were needed to upgrade the quality to meet current specifications. Results of the two lab runs are included in Table 24, which yielded a 15.61 gram sample of fluoride.

\section{Table 24.}

\section{Profile and results for GeFusn-37 and 38 .}

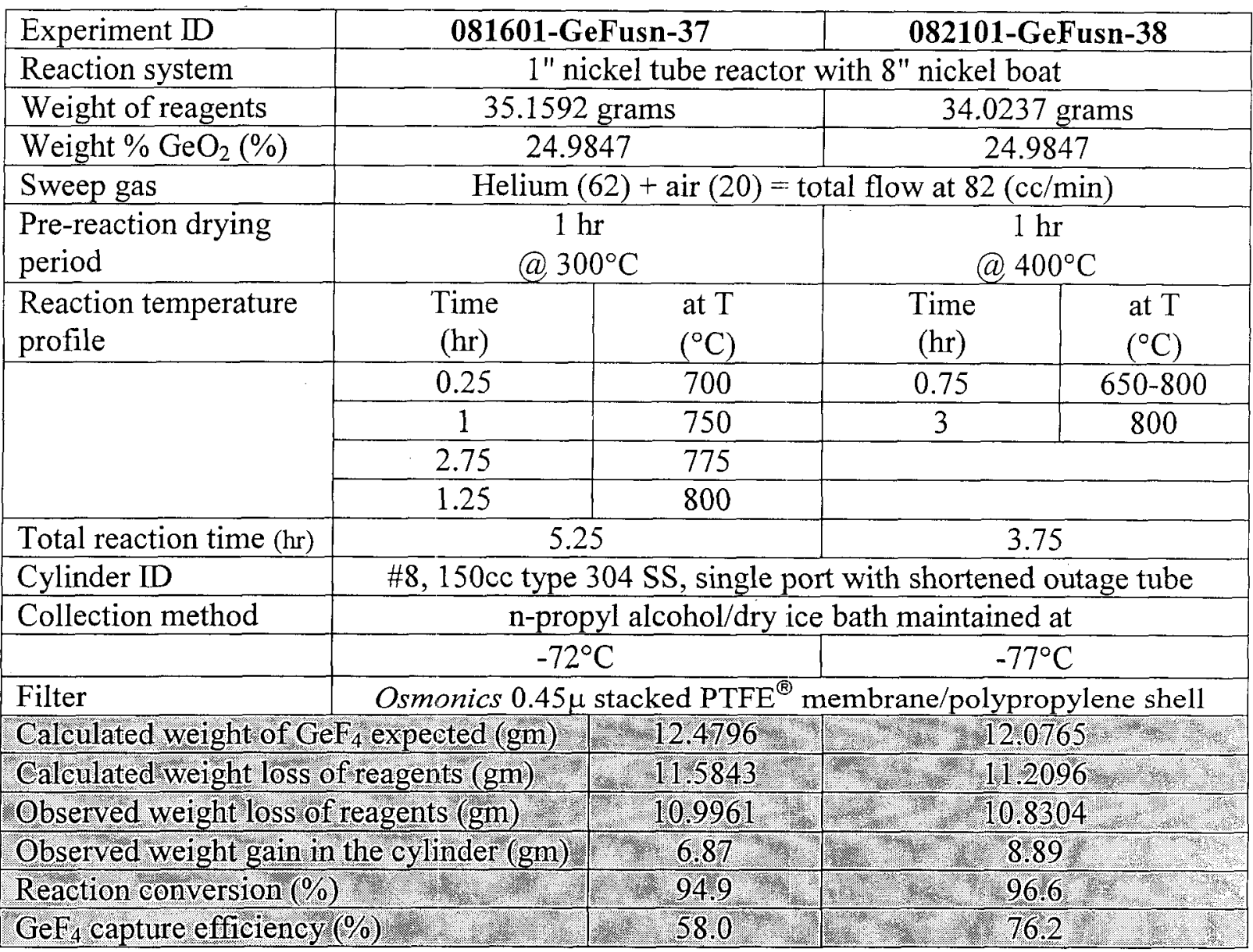

In brief, both reactions were carried out using a helium/air mixture as the sweep gas. A high degree of conversion was observed in both cases $(94.9 \%$ and $96.6 \%$ for GeFusn-37 and 38 , respectively), with the latter run yielding the larger amount of captured product ( 8.89 grams). The material produced in both reactions was filtered using a membrane filter placed immediately before the condensation cylinder. After concluding GeFusn-38, the helium/air residual was removed by vacuum processing before capping the gas container. 
Follow-up analyses of the reaction solids by $\mathrm{x}$-ray powder diffraction and gas analysis by FT-IR spectroscopy of the stream leaving the stainless steel cylinder in GeFusn-38 were also done. Those results are shown in Figures 47 and 48, respectively. X-ray diffraction results in Figure 47 indicate the black, post-reaction residue was solely $\mathrm{U}_{3} \mathrm{O}_{8}$. It can be seen in Figure 48 that the gas stream exiting the condensation cylinder, while submerged in coolant at $-77^{\circ} \mathrm{C}$, contained measurable $\mathrm{GeF}_{4}$ on the order of $3.4 \%$ (by volume). Peaks due to several impurities seen throughout the experimental program were also marked in the sample spectrum. Evidence of the $\mathrm{BF}_{3}$ and $\mathrm{SiF}_{4}$ species has been difficult to flush out of the gas sample cell and lines to the FT-IR instrument from prior sample analyses.

After being received at Voltaix, Inc., the "as-produced" fluoride was also analyzed using FT-IR spectroscopy in their laboratory. Spectra were collected for the Starmet material along with two $\mathrm{GeF}_{4}$ samples from other vendors. The spectra were collected at a cell pressure of 200 torr and arranged on a common set of axes to facilitate comparison between scans. Those results are shown in Figure 49. Locations of increased absorbance due to the presence of impurities have been marked in the spectra. It is clear the Starmet $\mathrm{GeF}_{4}$ had the least number and lowest intensity peaks due to impurities compared to the two other samples. The $\mathrm{GeF}_{4}$ material from Advance Research Chemical possessed a purity of $99.99 \%$. 


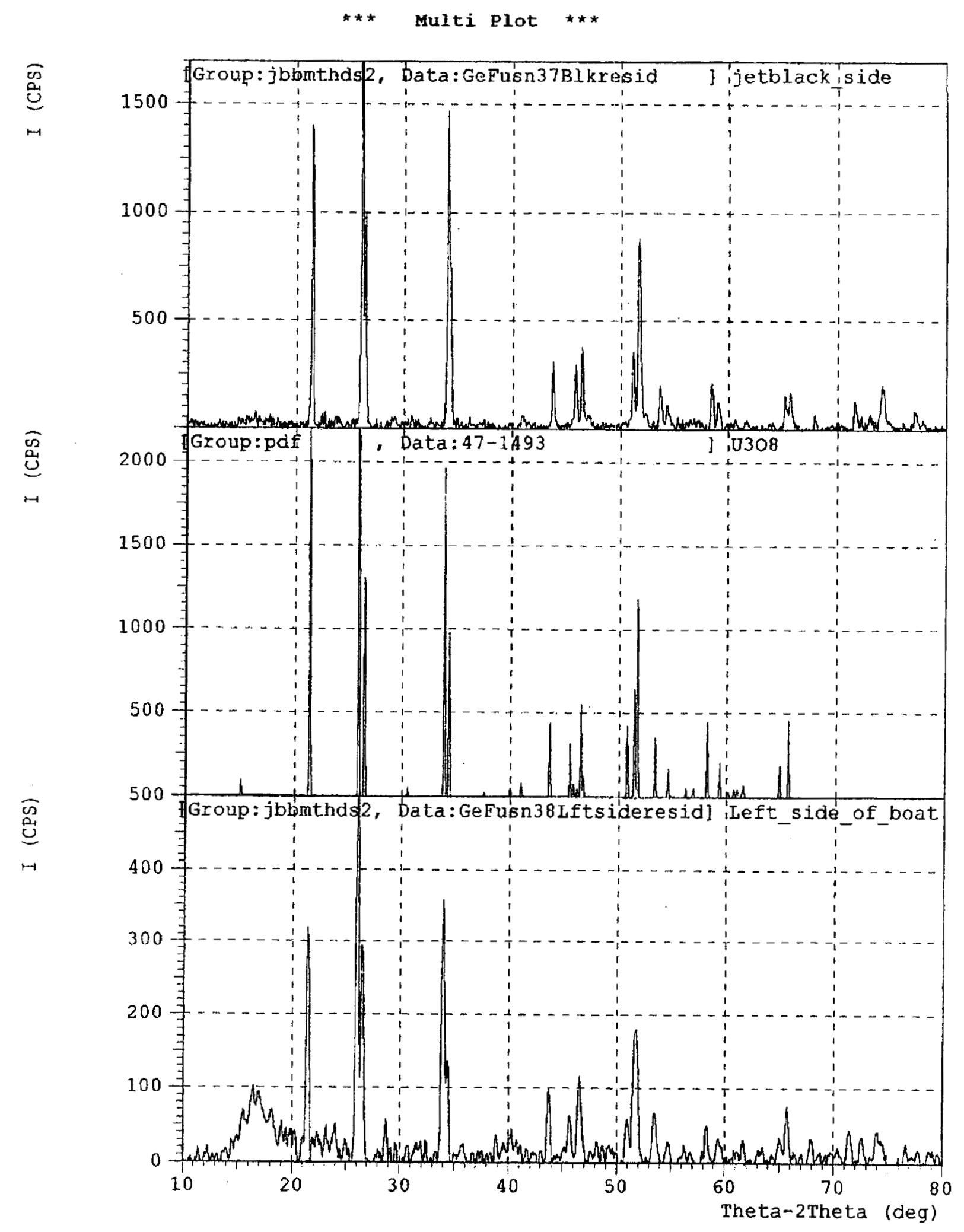

Figure 47. X-ray diffraction patterns for the solids recovered from GeFusn-37 and - 38 and reference pattern for $\mathrm{U}_{3} \mathrm{O}_{8}$ (pdf\# 47-1493). 


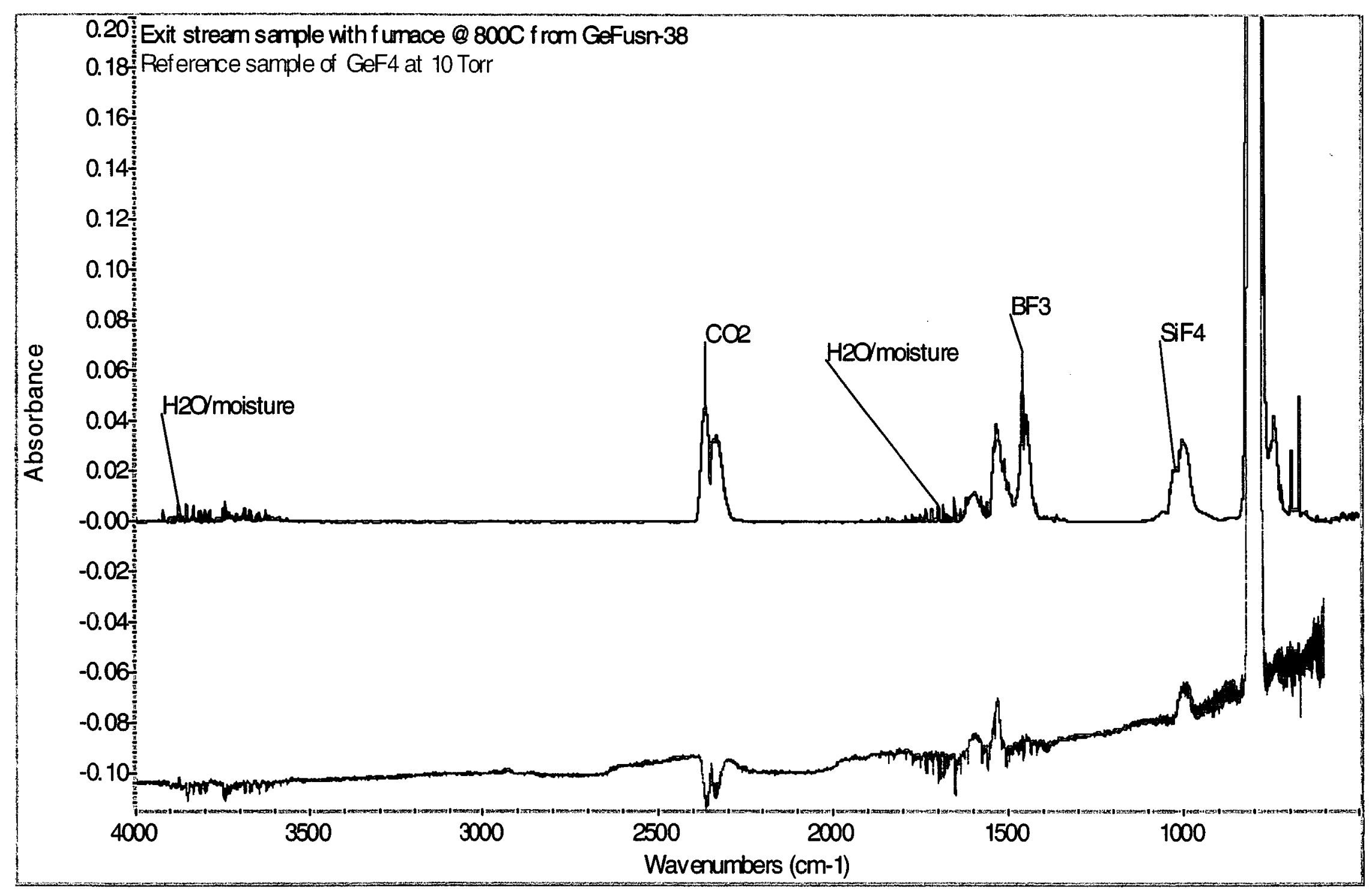

Figure 48. Infrared spectrum of the gas stream leaving the collection cylinder in GeFusn-38 with the furnace at $800^{\circ} \mathrm{C}$ and a reference sample of $\mathrm{GeF}_{4}$ at 10 torr. Peaks due to known impurities such as $\mathrm{CO}_{2}, \mathrm{BF}_{3}, \mathrm{SiF}_{4}$ and $\mathrm{H}_{2} \mathrm{O}$ have been marked. 


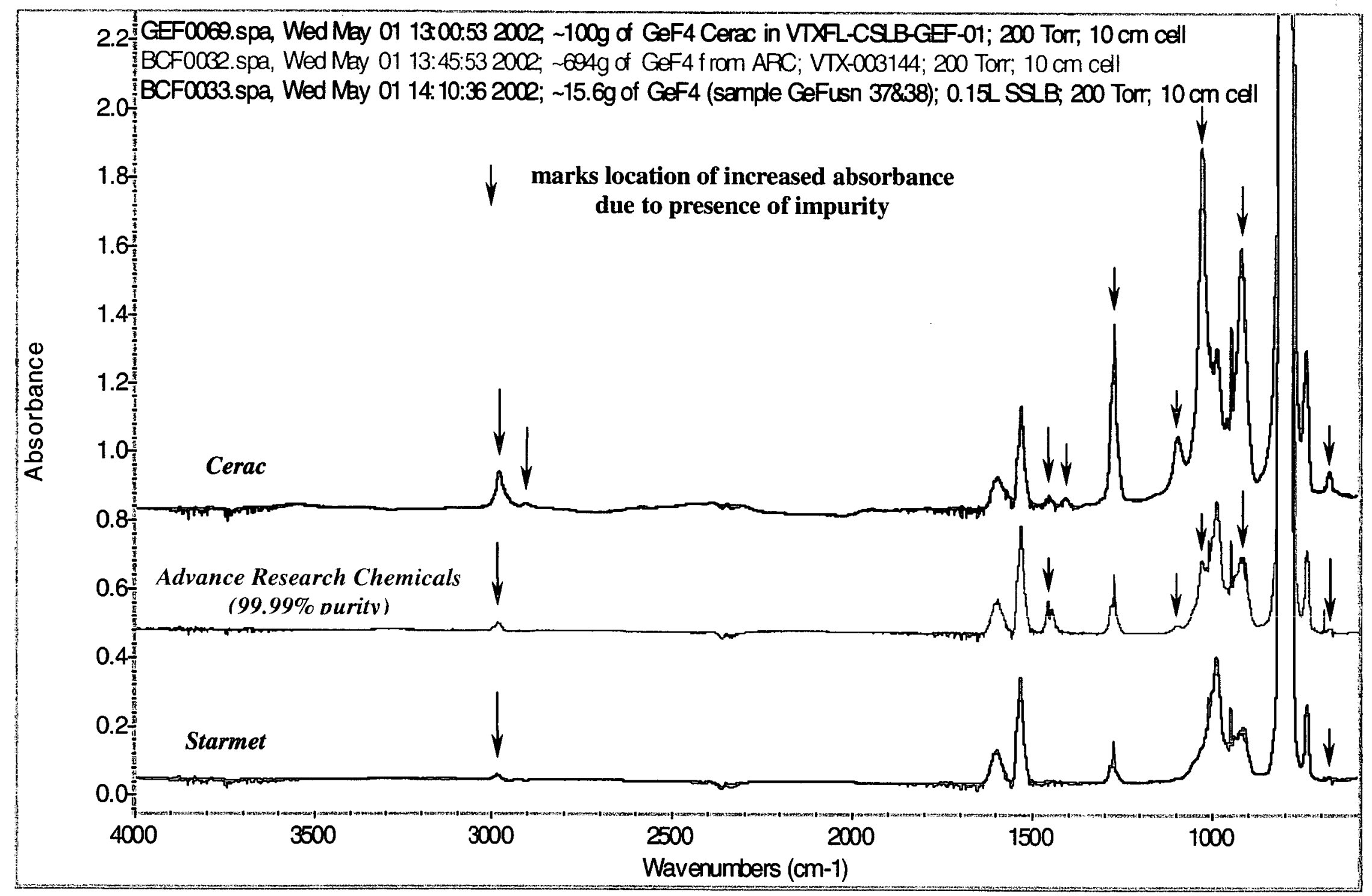

Figure 49. Infrared spectra for $\mathrm{GeF}_{4}$ produced at Starmet in GeFusn-37\&38 and two samples obtained from other vendors. 
Finally, the purity of the lab-synthesized sample of $\mathrm{GeF}_{4}$ was characterized using ICP-MS (inductively coupled plasma-mass spectroscopy) analysis. Three test specimens were prepared at Voltaix, Inc. and sent to Applied Analytical, Inc. (Austin, TX) for quantitative assessment for 37 elemental impurities including uranium. The test solutions were prepared by hydrolyzing the gas in deionized water with assistance of a nitrogen ballast. Solutions for the Starmet gas, a reference material ("Voltaix") claimed to have a purity of $99.99 \%$ and a "blank" consisting of deionized water treated with ballast gas were analyzed under similar conditions.

Results of the ICP-MS analysis for the three test solutions are arranged in Table 25. For the 'as-produced' Starmet material, only boron and niobium could be detected above their detection limits while uranium could not be detected at a detection limit of $0.019 \mathrm{ppm}-\mathrm{wt}$. In comparison, the Voltaix, Inc. material also showed detectable levels of boron and niobium and also a third impurity, namely titanium. It is clear the Starmet $\mathrm{GeF}_{4}$ had fewer detectable impurities than the reference supplied by Voltaix, Inc.

Based on the series of FT-IR and ICP-MS analyses that the $\mathrm{GeF}_{4}$ material was subjected to, both at Voltaix, Inc. and at the outside analytical laboratory, the Starmet material has been shown to be of superior quality. Additional analyses by gas chromatography to quantitatively assess the impurity levels of $\mathrm{HF}, \mathrm{CO}_{2}, \mathrm{CO}, \mathrm{SO}_{2}, \mathrm{Ar}, \mathrm{O}_{2}$ and $\mathrm{N}_{2}$ are required before stating, with certainty, that the "as produced" fluoride gas meets the most demanding specifications put forth by Voltaix, Inc. for their UHP grade - $99.99 \%$ material. The current specifications for UHP grade $\mathrm{GeF}_{4}$, as put forth by Voltaix, Inc., are compiled in Table 26.

From the investigations conducted thus far concerning the production of $\mathrm{GeF}_{4}$ using Starmet's new fluoride extraction process (FEP'М $)$, the quality of gas produced in laboratory trials is of sufficient purity for use in the semiconductor industry. 
Table 25.

Results for ICP-MS analysis of 'as-produced' $\mathrm{GeF}_{4}$ received fróm Voltaix, Inc.

\begin{tabular}{|c|c|c|c|c|c|}
\hline \multicolumn{4}{|c|}{ The following germanium fluoride solutions } & \multicolumn{2}{|c|}{ The following "Blank" Sample of germanium } \\
\hline \multicolumn{4}{|c|}{ were analyzed by ICP-MS. Results are } & \multicolumn{2}{|c|}{ fluoride solution was analyzed by } \\
\hline \multicolumn{4}{|c|}{ expressed in terms of the original gas } & \multicolumn{2}{|c|}{ ICP-MS. Results are based on the solution } \\
\hline \multicolumn{4}{|c|}{ sampled using the sample weight provided. } & \multicolumn{2}{|c|}{ as it was received. Units are ppm weight. } \\
\hline \multicolumn{4}{|c|}{ Units are ppm weight. } & \multicolumn{2}{|c|}{ nd = not detected } \\
\hline \multirow[t]{2}{*}{ Sample from: } & Starmet & "Voltaix" & & "Blank" & \\
\hline & & & Detn. & & Detn. \\
\hline Element & $253-35$ & $253-36$ & Limit & $253-34$ & Limit \\
\hline Aluminium & nd & nd & 0.240 & $\mathrm{nd}$ & 0.005 \\
\hline Antimony & nd & nd & 0.029 & nd & 0.001 \\
\hline Barium & nd & nd & 0.054 & nd & 0.001 \\
\hline Beryllium & nd & nd & 0.018 & nd & 0.001 \\
\hline Bismuth & nd & nd & 0.019 & nd & 0.001 \\
\hline Boron & 0.475 & 0.370 & 0.087 & nd & 0.002 \\
\hline Cadmium & $\mathrm{nd}$ & nd & 0.058 & $\mathrm{nd}$ & 0.001 \\
\hline Chromium & nd & nd & 0.136 & nd & 0.003 \\
\hline Cobalt & nd & nd & 0.008 & nd & 0.001 \\
\hline Copper & nd & nd & 0.040 & $\mathrm{nd}$ & 0.001 \\
\hline Gallium & nd & nd & 0.067 & nd & 0.001 \\
\hline Gold & nd & nd & 0.015 & nd & 0.001 \\
\hline Hafnium & nd & nd & 0.009 & nd & 0.001 \\
\hline Iron & nd & nd & 9.6 & nd & 0.21 \\
\hline Lanthanum & nd & nd & 0.005 & nd & 0.001 \\
\hline Lead & nd & nd & 0.019 & nd & 0.001 \\
\hline Lithium & nd & nd & 0.019 & nd & 0.001 \\
\hline Magnesium & nd & nd & 0.067 & nd & 0.001 \\
\hline Manganese & nd & nd & 0.006 & nd & 0.001 \\
\hline Mercury & nd & nd & 0.037 & nd & 0.001 \\
\hline Molybdenum & nd & nd & 0.048 & nd & 0.001 \\
\hline Nickel & $\mathrm{nd}$ & nd & 0.219 & nd & 0.005 \\
\hline Niobium & $<2.69$ & $<2.02$ & 0.019 & nd & 0.001 \\
\hline Platinum & $\mathrm{nd}$ & $\mathrm{nd}$ & 0.019 & nd & 0.001 \\
\hline Silver & nd & nd & 0.029 & nd & 0.001 \\
\hline Sodium & nd & nd & 0.173 & nd & 0.004 \\
\hline Strontium & nd & nd & 0.048 & nd & 0.001 \\
\hline Tantalum & $\mathrm{nd}$ & nd & 0.081 & nd & 0.002 \\
\hline Thallium & nd & nd & 0.013 & nd & 0.001 \\
\hline Thorium & nd & nd & 0.010 & nd & 0.001 \\
\hline Tin & nd & nd & 0.019 & $\mathrm{nd}$ & 0.001 \\
\hline Titanium & nd & 0.719 & 0.104 & 0.095 & 0.002 \\
\hline Tungsten & nd & nd & 0.039 & $\mathrm{nd}$ & 0.001 \\
\hline Uranium & nd & nd & 0.019 & nd & 0.001 \\
\hline Vanadium & nd & nd & 0.019 & nd & 0.001 \\
\hline Zinc & nd & nd & 0.106 & nd & 0.002 \\
\hline Zirconium & nd & nd & 0.024 & nd & 0.001 \\
\hline
\end{tabular}


Table 26.

Specifications for UHP grade - $99.99 \% \mathrm{GeF}_{4}$ established by Voltaix, Inc.

\begin{tabular}{|c|c|c|c|}
\hline Impurity & $\begin{array}{c}\text { Maximum } \\
\text { Concentration }\end{array}$ & Impurity & $\begin{array}{c}\text { Maximum } \\
\text { Concentration }\end{array}$ \\
\hline $\mathrm{HF}$ & $35 \mathrm{ppm}$ & $\frac{\mathrm{N}_{2}}{\mathrm{CF}_{4}}$ & $10 \mathrm{ppm}$ \\
\hline $\mathrm{CO}_{2}$ & $5 \mathrm{ppm}$ & $\mathrm{Fe}$ & $10 \mathrm{ppm}$ \\
\hline $\mathrm{CO}$ & $10 \mathrm{ppm}$ & $\mathrm{Cr}$ & $0.08 \mathrm{ppm}-\mathrm{wt}$ \\
\hline $\mathrm{SO}_{2}$ & $10 \mathrm{ppm}$ & $\mathrm{Mn}$ & $0.05 \mathrm{ppm}-\mathrm{wt}$ \\
\hline $\mathrm{Ar}+\mathrm{O}_{2}$ & $20 \mathrm{ppm}$ & $0.01 \mathrm{ppm}-\mathrm{wt}$ \\
\hline
\end{tabular}




\subsection{Discussion - $\mathrm{GeF}_{4}$.}

\subsubsection{Producing the Gas}

In the batch-type operation, the tube reactor setup was shown to be the better design for harvesting $\mathrm{GeF}_{4}$. The highest Capture Efficiency (CE) amongst the crucible reactor trials was $38.3 \%$ as determined in the GeFusn- 21 run while a $\mathrm{CE}$ of $97.7 \%$ was recorded during the GeFusn-28 trial conducted in the tube reactor system. The better efficiency was realized as a result of manipulating reaction parameters and using materials of construction that held up well under the preferred reaction conditions. The most significant factor compromising the collection of $\mathrm{GeF}_{4}$ was the formation of crystalline $\mathrm{GeF}_{2}$ residue. It was found that the unwanted byproduct could be controlled and minimized by maintaining the reaction temperature in the range between $700^{\circ} \mathrm{C}-800^{\circ} \mathrm{C}$ and using a reactor sweep stream containing a small fraction (10-12 vol.\%) of dry air. The selection of nickel 200 alloy as a construction material also helped to improve collection of product by lessening the extent of destructive side-reactions at the surface of the metal. Some interaction between $\mathrm{GeF}_{4}$ and the nickel material was noted by the formation of a $\mathrm{Ni}_{2} \mathrm{GeO}_{4}$ residue. It is anticipated that this side-reaction can be eliminated by properly passivating all nickel surfaces in and around the heated reaction zone with a protective layer of $\mathrm{NiF}_{2}$ before beginning the production of $\mathrm{GeF}_{4}$.

Reaction conversion during the tube reactor trials was determined to be at least $88 \%$ or greater except for two experiments (GeFusn-27 and -30). Those experiments performed using a $100 \%$ helium sweep gas (GeFusn-25, -26 and 31) showed higher conversion levels than the trials where air was added to the sweep stream (GeFusn-28, -29 and 32). However, the higher conversions were achieved in those runs where the reactor temperature was the highest $\left(775^{\circ} \mathrm{C}\right.$ $800^{\circ} \mathrm{C}$ ). In two trial-to-trial comparisons where the same reactor temperature was reached, the greater conversion was attained when the reaction environment contained a small amount of air in the sweep gas as shown in Figure $\mathbf{5 0 .}$

Likewise, when the reaction conversion was plotted against reaction temperature for the eight trial series (see Table 14), experiments carried out using a pure helium sweep stream showed a significant increase in conversion with rise in temperature. In contrast, those runs where the helium/air sweep gas was employed showed almost no change in conversion as the temperature was stepped up between $700^{\circ} \mathrm{C}-750^{\circ} \mathrm{C}$. These trends are demonstrated in Figure 51 below. In subsequent runs where $\mathrm{GeF}_{4}$ was produced for purity characterization (GeFusn-37 and -38), conversion levels of $94.9 \%$ and $96.6 \%$ were attained when a reaction temperature of $800^{\circ} \mathrm{C}$ was employed while using the helium/air sweep stream. Additional discussion concerning reaction mechanism and kinetic issues will be included after discussing the quality of the gas produced by the solid-state reaction. 


\section{Effect of Sweep gas on the Reaction Conversion}

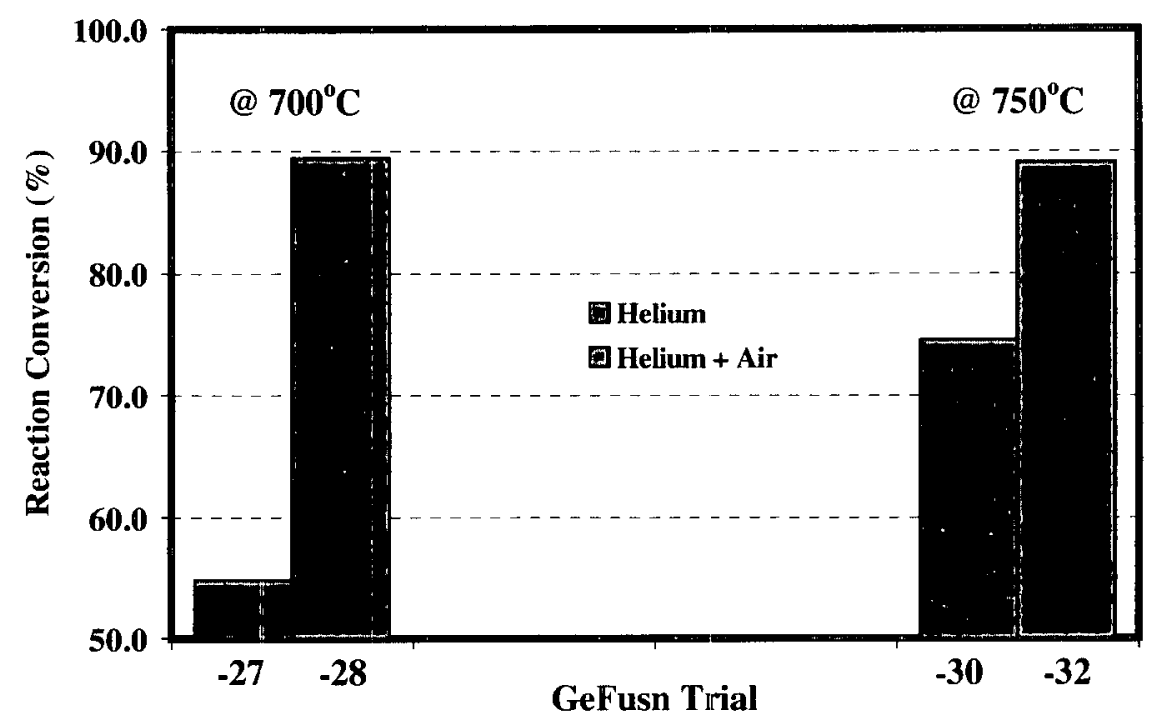

Figure 50. Comparison of reaction conversions using either $100 \%$ helium or a mixture of helium + air as the sweep gas at $700^{\circ} \mathrm{C}$ and $750^{\circ} \mathrm{C}$.

\section{Conversion vs Temperature}

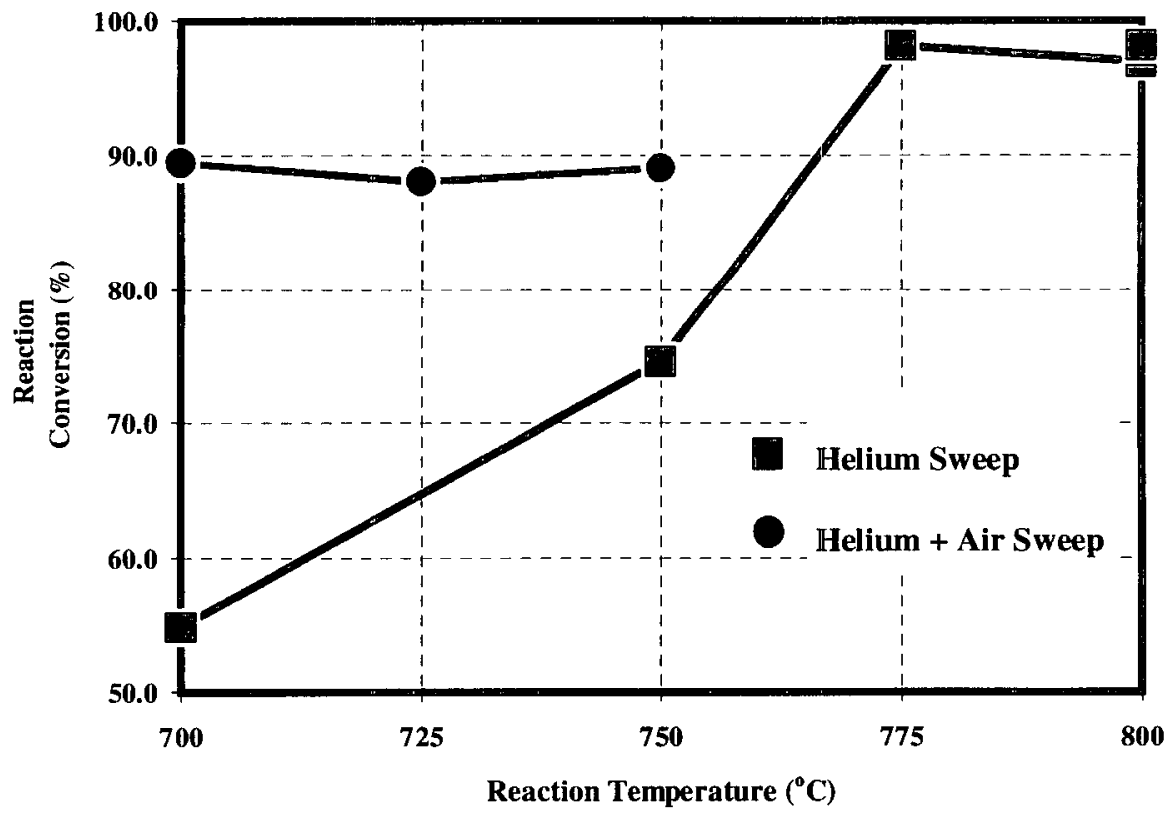

Figure 51. Reaction conversion charted as a function of temperature for the series of tube reactor experiments where pure helium and helium/air sweep streams were employed. 


\subsubsection{Quality of the Gas}

The quality of the $\mathrm{GeF}_{4}$ produced throughout the development program was constantly monitored by FT-IR spectroscopy and routinely compared to several commercial $\mathrm{GeF}_{4}$ sources both at Starmet and Voltaix, Inc. Laboratory synthesized samples made during the reactor design and parameter optimization trials routinely contained low levels of impurities such as $\mathrm{SiF}_{4}, \mathrm{BF}_{3}$, $\mathrm{CO}_{2}$, $\mathrm{HF}$ and moisture that were formed by side reaction between $\mathrm{GeF}_{4}$ and the system hardware components (i.e., HR $160^{\circledR}$ alloy reactor, silicone-based valve lubricant, etc.). Traces of boron trifluoride in the gas produced in the crucible reactor experiments could be tracked back to prior use of the reactor hardware for making $\mathrm{BF}_{3}$ by similar technology reacting $\mathrm{UF}_{4}$ with $\mathrm{B}_{2} \mathrm{O}_{3}$. Likewise, $\mathrm{GeF}_{4}$ produced in the nickel tube reactor showed a similar pattern of impurities which, in the case for $\mathrm{BF}_{3}$, probably diffused off the interior walls of the $10 \mathrm{~cm}$ gas cell, which was used repeatedly to analyze several other fluoride gases made by Starmet's fluoride extraction process. Varying traces of $\mathrm{CO}_{2}$ were observed in many infrared scans and was caused by changing atmospheric conditions in the infrared spectrometer's sample compartment since the cell compartment could not be totally enclosed and purged due to input and exhaust lines connecting the cell to the reaction system.

However, the levels of $\mathrm{HF}$ and moisture could be managed through implementation of the pre-reaction drying period where the $\mathrm{UF}_{4} / \mathrm{GeO}_{2}$ reaction mixture was first heated to $\sim 450^{\circ} \mathrm{C}$ under a helium purge. Removal of moisture from the system prior to generating $\mathrm{GeF}_{4}$ was successful in lowering the level of $\mathrm{HF}$ impurity by minimizing the amount of $\mathrm{GeF}_{4}$ consumed by hydrolysis with $\mathrm{H}_{2} \mathrm{O}$.

After completing the tube reactor trials and optimization runs, $\mathrm{GeF}_{4}$ produced for analytical characterization at Argonne National Laboratory and Voltaix, Inc. proved to be superior in quality when compared to other $\mathrm{GeF}_{4}$ sources. Lab synthesized $\mathrm{GeF}_{4}$ from GeFusn37 and-38 analyzed at Voltaix, Inc. showed it to contain the least amount of infrared-detectable impurities as illustrated in Figure 49. The benchmark reference material supplied by Advanced Research Chemicals, Inc. was claimed to have a purity of $99.99 \%$. In addition to the analysis by FT-IR spectroscopy, the Starmet material was found to contain only two of the 37 elements analyzed for by ICP-MS. The benchmark reference gas had three detectable impurities. More importantly, uranium could not be detected in the fusion-derived gas at the detection limit of $0.019 \mathrm{ppm}-\mathrm{wt}$.

Trace level detection of uranium in $\mathrm{GeF}_{4}$ samples sent to $A N L$ also proved to be a challenge. The two techniques being developed to detect $U$ at low levels, i.e., laser-induced photoluminescence spectrometry and UV optical absorption spectroscopy, could not detect uranium in the Starmet product. The luminescence method for detecting uranyl species $\left(\mathrm{UO}_{2}{ }^{-2}\right.$ ions) in glassy $\mathrm{GeO}_{2}$ met with unexpected interferences preventing further analyses. Alternative procedures to convert hydrolyzed $\mathrm{GeO}_{2}$ to $\mathrm{GeCl}_{4}$ met with resistance in chlorinating precipitated $\mathrm{GeO}_{2}$ thereby hindering the analysis for uranyl species. Analysis for $\mathrm{U}$ (as $\mathrm{UF}_{6}$ ) using optical absorption spectroscopy was accomplished on both samples of lab synthesized material produced in GeFusn-36 and GeFusn-40. Using a $9.3 \mathrm{~cm}$ gas cell, no uranium could be detected in either the unfiltered or filtered batch of $\mathrm{GeF}_{4}$, although the detection limits $(0.75$ and $0.64 \mathrm{ppm}$-vol., respectively) were slightly higher than what was achieved in the ICP-MS analysis. To enhance the detection limit for $U$ as $\mathrm{UF}_{6}$, a longer pathlength cell on the order of 1 meter in length was considered as an option but not pursued due to both excessive fabrication costs and limited time concerns. The goal of attaining a uranium detection sensitivity in the parts-per-trillion range was 
not achieved. However, it is believed that additional development of the laser photoluminescence technique to measure uranyl species in glassy $\mathrm{GeO}_{2}$ may prove successful with continued research to overcome the noted interferences.

\subsubsection{Mechanistic Considerations}

It was previously shown (in section 8.2.3) that the onset of reaction between $\mathrm{UF}_{4}$ and $\mathrm{GeO}_{2}$ begins to take place around $400^{\circ} \mathrm{C}$ when air is included in the sweep stream (refer to Figure 42). By $500^{\circ} \mathrm{C}$ the conversion to $\mathrm{GeF}_{4}$ is well underway and at temperatures between $700^{\circ} \mathrm{C}-750^{\circ} \mathrm{C}$ conversions near $90 \%$ have been documented. In contrast, when the reaction was run without air in the sweep stream, conversion was very much dependent on reaction temperature. Review of TGA data collected during the Phase I SBIR program showed that the onset of reaction, when conducted in an argon atmosphere, was delayed until $\sim 600^{\circ} \mathrm{C}$. From this data and the x-ray diffraction results of the residues left behind at various stages of completion, it is clear that the reaction mechanism to liberate $\mathrm{GeF}_{4}$ is different for the air-laden sweep gas environment versus a pure inert stream. One pathway to make $\mathrm{GeF}_{4}$ in an inert sweep stream, which is supported by the $x$-ray diffraction data from many trials including GeFusn-27, $-30,-31$, -33 and -35 , is given below:

Helium sweep stream -

$$
\begin{aligned}
& \mathrm{UF}_{4}+\mathrm{GeO}_{2} \longrightarrow \mathrm{GeF}_{4}(\mathrm{~g})+\mathrm{UO}_{2} \\
& \mathrm{UO}_{2}+\mathrm{GeO}_{2} \longrightarrow \mathrm{UGeO}_{4} \\
& \mathrm{UGeO}_{4}+\mathrm{UF}_{4} \longrightarrow \mathrm{GeF}_{4}(\mathrm{~g})+\mathrm{UO}_{2}
\end{aligned}
$$

Net reaction: $2 \mathrm{UF}_{4}+2 \mathrm{GeO}_{2} \longrightarrow 2 \mathrm{GeF}_{4}(\mathrm{~g})+2 \mathrm{UO}_{2}$

In this scenario, $\mathrm{UO}_{2}$ being formed in equation $(\mathrm{A})$ is subsequently combined with available $\mathrm{GeO}_{2}$ to form a stable compound with the formula $\mathrm{UGeO}_{4}$. This compound was identified in residues collected from GeFusn-33 and GeFusn-35 in which there was only partial conversion. No traces of $\mathrm{GeO}_{2}$ could be detected in the diffraction patterns of either residue. Once all $\mathrm{GeO}_{2}$ is consumed, the reaction cross-section is between $\mathrm{UF}_{4}$ and $\mathrm{UGeO}_{4}$, which leaves behind $\mathrm{UO}_{2}$ as the only solid remaining after complete conversion.

In studying the kinetic behavior of the $\mathrm{GeF}_{4}$ reaction as part of the Phase I SBIR program $^{23}$, a mathematical expression was developed to model the rate of gas production for engineering a larger reaction system. Data for the $\mathrm{GeF}_{4}$ reaction carried out in argon was fitted to a version of the Avrami equation for a solid-solid transformation process ${ }^{24,25}$. This was one of several known kinetic models for a solid-solid reaction to be applied for approximating the rate of gas evolution and the only one that fit the experimental data well.

When air is added into the reactor sweep stream the above scenario changes. Diffraction data for post-reaction residues made in environments containing air (such as GeFusn-28, -29 and-32) showed $\mathrm{UO}_{2} \mathrm{~F}_{2}$ and $\mathrm{U}_{3} \mathrm{O}_{8}$ were the only identifiable constituents (see Figure 13). A reaction sequence can be written which involves these species: 
Helium + Air sweep stream -

$$
\begin{aligned}
& 2 \mathrm{UF}_{4}+\mathrm{GeO}_{2}+\mathrm{O}_{2}(\mathrm{~g}) \longrightarrow \mathrm{GeF}_{4}(\mathrm{~g})+2 \mathrm{UO}_{2} \mathrm{~F}_{2} \\
& \mathrm{UF}_{4}+\mathrm{GeO}_{2} \longrightarrow \mathrm{GeF}_{4}(\mathrm{~g})+\mathrm{UO}_{2} \\
& 2 \mathrm{UO}_{2} \mathrm{~F}_{2}+\mathrm{GeO}_{2} \longrightarrow \mathrm{GeF}_{4}(\mathrm{~g})+2 \mathrm{UO}_{2}+\mathrm{O}_{2}(\mathrm{~g}) \\
& 3 \mathrm{UO}_{2}+\mathrm{O}_{2}(\mathrm{~g}) \longrightarrow \mathrm{U}_{3} \mathrm{O}_{8}
\end{aligned}
$$

Net reaction: $3 \mathrm{UF}_{4}+3 \mathrm{GeO}_{2} \longrightarrow 3 \mathrm{GeF}_{4}(\mathrm{~g})+\mathrm{U}_{3} \mathrm{O}_{8}$

The sum of the four simultaneous equations results in the net reaction (I) for producing $\mathrm{GeF}_{4}$. Early attempts to apply the Avrami equation for modeling the data derived in Phase I trials was unsuccessful. Correlation to other standard kinetic models was found to be poor as well. Additional work will be necessary in order to model the kinetics of process when air is included in the reaction atmosphere.

Kinetic issues notwithstanding, it is clear that inclusion of air in the sweep stream is advantageous during production since the reaction is initiated at a lower temperature and conversion is greater at intermediate temperatures $\left(700^{\circ} \mathrm{C}-750^{\circ} \mathrm{C}\right)$ where the amount of $\mathrm{GeF}_{2}$ byproduct can be controlled. Although the rate-determining step amongst the 4-step mechanism may not be certain, this description offers three parallel pathways in which $\mathrm{GeF}_{4}$ can be formed. At this time it is the preferred scenario over that for the inert gas synthesis scheme. 


\section{$9 \quad \mathrm{WF}_{6}$ PRODUCTION}

\subsection{Experimental Procedures - $\mathrm{WF}_{6}$.}

\subsubsection{Bench-scale process development for $\mathrm{WF}_{6}$ from $\mathrm{WOF}_{4}$.}

The goal of this task was to establish a pathway for making $\mathrm{WF}_{6}$ using the intermediate compound, $\mathrm{WOF}_{4}$, formed in the reaction between $\mathrm{UF}_{4}$ and tungsten oxide. The first series of experiments carried out to investigate the chemistry involved milligram quantities of material and the TA Instruments TGA/DTA setup as the reaction apparatus. The use of the TGA facilitated the study of several reaction parameters including selection of tungsten oxide reactant, i.e. $\mathrm{WO}_{2}$ or $\mathrm{WO}_{3}$, reaction stoichiometry and reaction temperature. The list of 14 micro-scale experiments is given in Table 27 below.

Table 27.

Micro-scale experiments performed using the thermogravimetric analyzer.

\begin{tabular}{|c|c|c|c|c|}
\hline Mixture & $\begin{array}{c}\text { Stoichiometric } \\
\text { Ratio UF } \mathbf{U}: \mathbf{W O x}\end{array}$ & $\begin{array}{c}\text { Reaction } \\
\text { cup }\end{array}$ & $\begin{array}{c}\text { Heat rate } \\
\left({ }^{\circ} \mathbf{C} / \mathbf{m i n}\right)\end{array}$ & $\begin{array}{c}\text { Reaction } \\
\text { Temperature }\left({ }^{\circ} \mathbf{C}\right)\end{array}$ \\
\hline $\mathrm{UF}_{4}+\mathrm{WO}_{2}$ & $1.014: 1$ & alumina & 15 & 600 \\
\hline $\mathrm{UF}_{4}+\mathrm{WO}_{2}$ & $1.014: 1$ & $\mathrm{Pt}$ & 15 & 600 \\
\hline $\mathrm{UF}_{4}+\mathrm{WO}_{2}$ & $1.014: 1$ & $\mathrm{Pt}$ & 20 & 600 \\
\hline $\mathrm{UF}_{4}+\mathrm{WO}_{2}$ & $1.014: 1$ & $\mathrm{Pt}$ & 20 & 700 \\
\hline $\mathrm{UF}_{4}+\mathrm{WO}_{2}$ & $1.844: 1$ & $\mathrm{Pt}$ & 20 & 700 \\
\hline $\mathrm{UF}_{4}+\mathrm{WO}_{2}$ & $1.844: 1$ & $\mathrm{Pt}$ & 20 & 800 \\
\hline $\mathrm{UF}_{4}+\mathrm{WO}_{2}$ & $2.013: 1$ & $\mathrm{Pt}$ & 20 & 700 \\
\hline $\mathrm{UF}_{4}+\mathrm{WO}_{3}$ & $1: 1.025$ & $\mathrm{Pt}$ & 20 & 700 \\
\hline $\mathrm{UF}_{4}+\mathrm{WO}_{3}$ & $1.908: 1$ & $\mathrm{Pt}$ & 20 & 800 \\
\hline $\mathrm{UF}_{4}+\mathrm{WO}_{3}$ & $1.908: 1$ & $\mathrm{Pt}$ & 20 & 700 \\
\hline $\mathrm{UF}_{4}+\mathrm{WO}_{3}$ & $1.908: 1$ & $\mathrm{Pt}$ & 20 & 750 \\
\hline $\mathrm{WO}_{2}$ & & $\mathrm{Pt}$ & 15 & 600 \\
\hline $\mathrm{WO}_{2}$ & & alumina & 15 & 600 \\
\hline $\mathrm{WO}_{2}$ & & $\mathrm{Pt}$ & 20 & 800 \\
\hline
\end{tabular}

For these trials, mixtures of $\mathrm{UF}_{4}$ with $\mathrm{WO}_{2}$ and $\mathrm{UF}_{4}$ with $\mathrm{WO}_{3}$ were made up in varying proportions to explore various stoichiometric ratios between the reactants. Three different combinations of $\mathrm{UF}_{4}$ and $\mathrm{WO}_{2}$, ranging between 1.014:1 to 2.013:1 ( $\left.\mathrm{UF}_{4}: \mathrm{WO}_{2}\right)$, were examined. Likewise, two compositions between $\mathrm{UF}_{4}$ and $\mathrm{WO}_{3}$ were investigated. Three trials were performed to follow the conversion of $\mathrm{WO}_{2}$ to $\mathrm{WO}_{3}$ under oxidizing conditions. Reaction temperatures in the range between $600^{\circ} \mathrm{C}$ to $800^{\circ} \mathrm{C}$ were employed with all experiments being run in a flow of dry air. With the exception of several trials, the reactions were conducted in platinum cups following a procedure where the reagents were first held under isothermal conditions at room temperature for up to 15 minutes. The temperature was then ramped to the desired maximum at the specified rate and held there for a period of either 45 or 90 minutes. For 
each experiment, the change in weight of the reagents was recorded as a function of temperature and/or time. At the conclusion of each run, the residue remaining in the cup was subjected to analysis by $x$-ray diffraction to identify the material composition.

After concluding the study involving milligram quantities of reagents and the thermogravimetric analyzer, experimentation using gram-scale quantities of material commenced using several variations of the tube reactor design. A total of 11 trials were performed, 10 using a 24" long, horizontal, 1"OD nickel tube and one using a 10" long, vertically oriented 1"OD tube (closed at one end) described earlier in section 8.1.6 (refer to Figure 7) for producing $\mathrm{GeF}_{4}$. This group of experiments is shown in Table 28 listing experiment $\mathrm{ID}$, tungsten reagent used, reactor configuration, stoichiometry and ultimate reaction temperature.

Table 28.

Experiments performed in the bench-scale reaction system.

\begin{tabular}{|c|c|c|c|c|c|}
\hline $\begin{array}{c}\text { Experiment } \\
\text { ID }\end{array}$ & $\begin{array}{c}\text { Primary } \\
\text { Tungsten } \\
\text { Reagent }\end{array}$ & $\begin{array}{c}\text { Second } \\
\text { Stage } \\
\text { Reactants }\end{array}$ & Configuration & $\begin{array}{c}\text { UF } \\
\text { ( }: \mathbf{W O}_{\mathbf{x}} \\
\text { (mol) }\end{array}$ & $\begin{array}{c}\text { Reaction } \\
\text { Temperature } \\
\left({ }^{\circ} \mathbf{C}\right)\end{array}$ \\
\hline WFusn-7 & $\mathrm{WO}_{2}$ & & Vertical & $2.013: 1$ & 800 \\
\hline WFusn-8 & $\mathrm{WO}_{2}$ & & Horizontal & $2.013: 1$ & 775 \\
\hline WFusn-9 & $\mathrm{WO}_{2}$ & & Horizontal & $2.013: 1$ & 780 \\
\hline WFusn-10 & $\mathrm{WO}_{2}$ & & Horizontal & $2.013: 1$ & 790 \\
\hline WFusn-11 & $\mathrm{WO}_{3}$ & & Horizontal & $2.001: 1$ & 790 \\
\hline WFusn-12 & $\mathrm{WO}_{3}$ & & Horizontal & $2.001: 1$ & 750 \\
\hline WFusn-13 & $\mathrm{WO}_{2}$ & $\mathrm{WOF}_{4}, \mathrm{UF}_{4}$ & Horizontal & $2.013: 1$ & 750 \\
\hline WFusn-14 & $\mathrm{WO}_{2}$ & & Horizontal & $2.013: 1$ & 800 \\
\hline WFusn-15 & $\mathrm{WO}_{2}$ & WOF $_{4}, \mathrm{SiO}_{2}$ & Horizontal & $2.013: 1$ & 800 \\
\hline WFusn-16 & $\mathrm{WO}_{2}$ & & Horizontal & $2.013: 1$ & 780 \\
\hline WFusn-17 & $\mathrm{WO}_{2}$ & $\mathrm{WOF}_{4}, \mathrm{TiF}_{4}$ & Horizontal & $2.013: 1$ & 800 \\
\hline
\end{tabular}

A brief summary of pertinent data, reaction parameters and experimental details is included below for each of the eleven experiments along with the respective reaction profile chart. 
The first bench-scale experiment, WFusn-7, was conducted using a 10" long section of 1" OD nickel tube, closed at one end, oriented vertically and heated with a Minimite ${ }^{\circledast}$ tube furnace (Lindberg/Blue M). The furnace was supported so that the $\sim 4$ " hot zone overlapped the reagent mixture at the bottom of the tube. A stream of dry air was introduced to the tube via a $1 / 4$ " feed tube passed through the wall of the vessel's top closure fitting and brought to a level about 1 " above the reactant bed. The reaction conditions are shown in Table 29. A $250 \mathrm{ml} 2$-neck round bottom flask was used as the collection vessel, which was maintained at ambient temperature for trapping the $\mathrm{WOF}_{4}$ product.

Table 29.

\section{Reaction Profile for WFusn-7.}

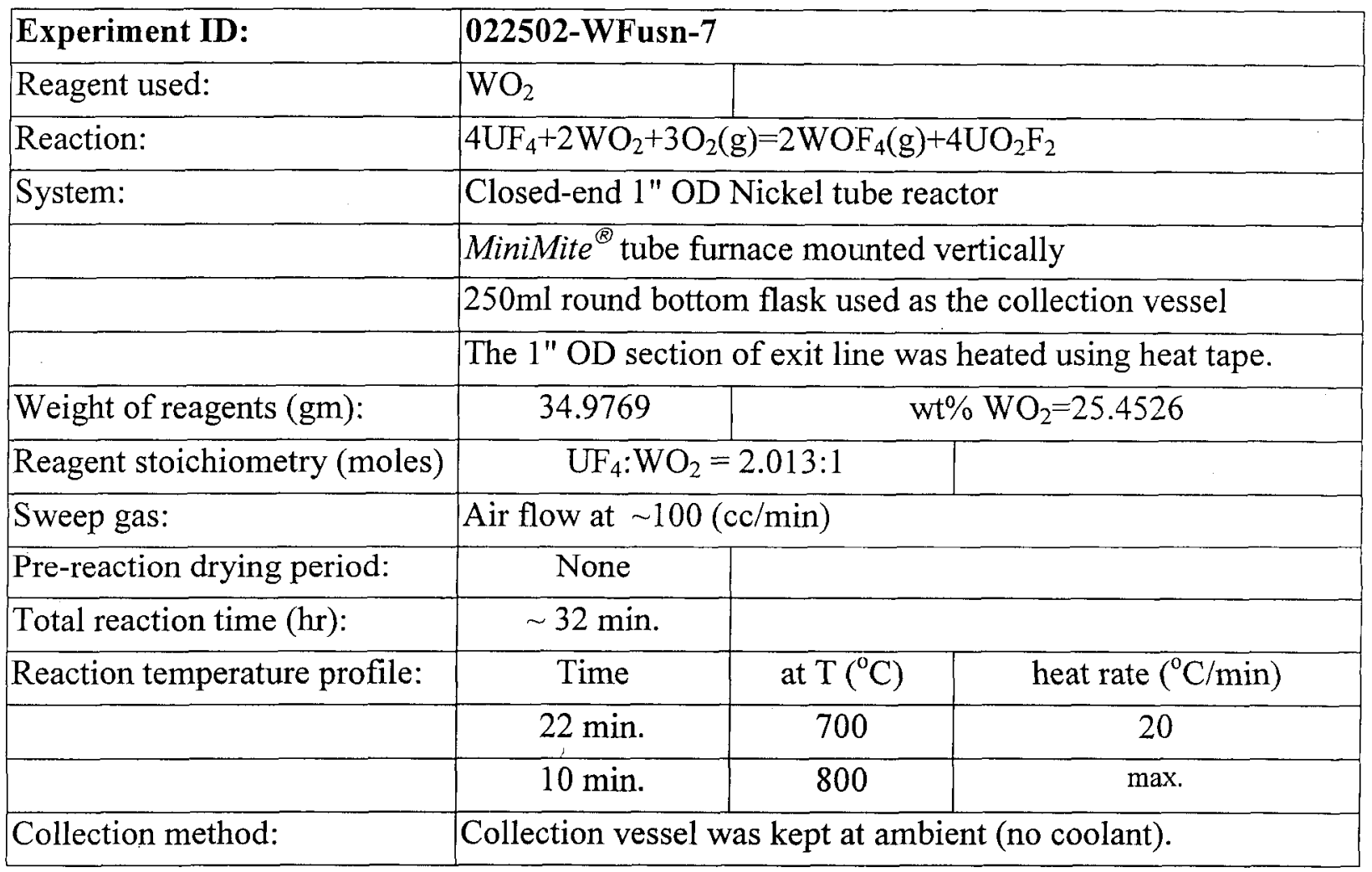


The vertical tube configuration was used for just one experiment. It was replaced with a 24 " long, horizontally mounted 1" OD nickel tube using the same Minimite ${ }^{\circledR}$ furnace. A 4" long nickel boat was used to hold reactants and the same pyrex ${ }^{\circledR}$ collection flask as before was connected to the exit stream through a series of Swagelok ${ }^{\circledR}$ reducing unions (1" to $1 / 2^{\prime \prime}$ and 1/2" to $\left.1 / 4^{\prime \prime}\right)$. For the WFusn-8 trial the flask was submerged in an ice-water bath to aid in condensing the product vapor cloud. Details of WFusn-8 are compiled in Table 30.

Table 30.

Reaction Profile for WFusn-8.

\begin{tabular}{|c|c|c|c|}
\hline Experiment ID: & \multicolumn{3}{|c|}{ 022802-WFusn-8 } \\
\hline Reagent used: & \multicolumn{3}{|c|}{$\mathrm{WO}_{2}$} \\
\hline Reaction: & \multicolumn{3}{|c|}{$4 \mathrm{UF}_{4}+2 \mathrm{WO}_{2}+3 \mathrm{O}_{2}(\mathrm{~g})=2 \mathrm{WOF}_{4}(\mathrm{~g})+4 \mathrm{UO}_{2} \mathrm{~F}_{2}$} \\
\hline System: & \multicolumn{3}{|c|}{ Horizontal 1" OD Ni tube reactor with 4" nickel boat } \\
\hline & \multicolumn{3}{|c|}{ MiniMite tube furnace with $\sim 4$ " hot zone; integral } \\
\hline & \multicolumn{3}{|c|}{ temperature programmable controller. } \\
\hline & \multicolumn{3}{|c|}{$250 \mathrm{ml}$ round bottom flask used as the collection vessel } \\
\hline Weight of reagents $(\mathrm{gm})$ : & 13.3549 & \multicolumn{2}{|c|}{$\mathrm{wt} \% \mathrm{WO}_{2}=25.4526$} \\
\hline Reagent stoichiometry (moles) & \multicolumn{2}{|c|}{$\mathrm{UF}_{4}: \mathrm{WO}_{2}=2.013: 1$} & \\
\hline Sweep gas: & \multicolumn{3}{|c|}{ Air flow at $\sim 100(\mathrm{cc} / \mathrm{min})$} \\
\hline Pre-reaction drying period: & None & & \\
\hline Total reaction time $(\mathrm{hr}):$ & $46 \mathrm{~min}$. & & \\
\hline \multirow[t]{3}{*}{ Reaction temperature profile: } & Time & at $\mathrm{T}\left({ }^{\circ} \mathrm{C}\right)$ & heat rate $\left({ }^{\circ} \mathrm{C} / \mathrm{min}\right)$ \\
\hline & $10 \mathrm{~min}$. & 725 & 20 \\
\hline & $36 \mathrm{~min}$. & 775 & 50 \\
\hline \multirow[t]{2}{*}{ Collection method: } & \multicolumn{3}{|c|}{ short $1 / 4$ " OD ss tube carried flow into glass flask. } \\
\hline & \multicolumn{3}{|c|}{ Flask was chilled with ice/water bath } \\
\hline
\end{tabular}

The post-reaction solids were analyzed by x-ray powder diffraction. 
For the third experiment, the reaction system was assembled as in the previous setup (WFusn-8) with the addition of wrapping the sections of tubing, from where the tube left the furnace to the point where the collection flask was joined at the $1 / 4$ " reducing union, with heat tape and insulation. This was done to prevent condensation of $\mathrm{WOF}_{4}$ and blockage of flow to the flask. During the heating of the $\mathrm{UF}_{4} / \mathrm{WO}_{2}$ mixture to $780^{\circ} \mathrm{C}$, the exit line from the furnace was heated to $209^{\circ} \mathrm{C}$. The individual details for the WFusn-9 reaction are given in Table 31 .

Table 31.

\section{Reaction Profile for WFusn-9.}

\begin{tabular}{|c|c|c|c|}
\hline Experiment ID: & \multicolumn{3}{|c|}{ 030702-WFusn-9 } \\
\hline Reagent used: & \multicolumn{3}{|l|}{$\mathrm{WO}_{2}$} \\
\hline Reaction: & \multicolumn{3}{|c|}{$4 \mathrm{UF}_{4}+2 \mathrm{WO}_{2}+3 \mathrm{O}_{2}(\mathrm{~g})=2 \mathrm{WOF}_{4}(\mathrm{~g})+4 \mathrm{UO}_{2} \mathrm{~F}_{2}$} \\
\hline System: & \multicolumn{3}{|c|}{ Horizontal 1" OD Ni tube reactor with 4" nickel boat } \\
\hline & \multicolumn{3}{|c|}{ MiniMite ${ }^{(8)}$ tube furnace with $\sim 4$ " hot zone; integral temperature } \\
\hline & \multicolumn{3}{|c|}{ programmable controller. } \\
\hline & \multicolumn{3}{|c|}{$250 \mathrm{ml}$ round bottom flask collection vessel with ss tube } \\
\hline & \multicolumn{3}{|c|}{ carrying flow into glass flask. } \\
\hline & \multicolumn{3}{|c|}{ Exit line was wrapped w/ heat tape from elbow to $1 / 4$ " ss tube. } \\
\hline Weight of reagents $(\mathrm{gm})$ : & 14.0759 & \multicolumn{2}{|c|}{$\mathrm{wt} \% \mathrm{WO}_{2}=25.4526$} \\
\hline Reagent stoichiometry (moles) & \multicolumn{2}{|c|}{$\mathrm{UF}_{4}: \mathrm{WO}_{2}=2.013: 1$} & \\
\hline Sweep gas: & \multicolumn{3}{|c|}{ Air flow at $\sim 100(\mathrm{cc} / \mathrm{min})$} \\
\hline Pre-reaction drying period: & \multicolumn{3}{|c|}{$\begin{array}{l}2 \mathrm{hr} \text { at } 150^{\circ} \mathrm{C} \text { in } \\
\text { air }\end{array}$} \\
\hline Total reaction time $(\mathrm{hr})$ : & \multicolumn{3}{|l|}{$30 \mathrm{~min}}$. \\
\hline \multirow[t]{3}{*}{ Reaction temperature profile: } & Time & at $\mathrm{T}\left({ }^{\circ} \mathrm{C}\right)$ & heat $\mathrm{rate}\left({ }^{\circ} \mathrm{C} / \mathrm{min}\right)$ \\
\hline & $10 \mathrm{~min}$. & 750 & 20 \\
\hline & $20 \mathrm{~min}$. & 780 & 50 \\
\hline Collection method: & \multicolumn{3}{|c|}{ Flask was chilled with ice/water bath } \\
\hline
\end{tabular}

Collection of post-reaction data included weight measurements of the solid residue in the boat and $\mathrm{x}$-ray diffraction analysis to determine material composition. Solids generated when the condensed vapor in the flask and clogged exit lines were hydrolyzed with water were also examined using $x$-ray diffraction. 
In light of the trouble experienced during trials WFusn-8 and 9, where the lines to the collection flask became blocked with condensed product, the pathway to the condensation vessel was redesigned. For WFusn-10, the $250 \mathrm{ml}$ round bottom flask was replaced with a $10^{\prime \prime}$ long section of 1 " OD tube connected at a $90^{\circ}$ angel to the reactor out flow via a union elbow fitting modified with a $1 / 4$ " outage tube welded through the wall to direct flow from the tube. In this configuration, the diameter of the line from the reaction zone to the condensation zone was preserved at 1" diameter. Details of this trial are compiled in Table 32 for WFusn-10.

Table 32.

Reaction Profile for WFusn-10.

\begin{tabular}{|c|c|c|c|}
\hline Experiment ID: & \multicolumn{3}{|c|}{ 031302-WFusn-10 } \\
\hline Reagent used: & \multicolumn{3}{|l|}{$\mathrm{WO}_{2}$} \\
\hline Reaction: & \multicolumn{3}{|c|}{$4 \mathrm{UF}_{4}+2 \mathrm{WO}_{2}+3 \mathrm{O}_{2}(\mathrm{~g})=2 \mathrm{WOF}_{4}(\mathrm{~g})+4 \mathrm{UO}_{2} \mathrm{~F}_{2}$} \\
\hline System: & \multicolumn{3}{|c|}{ Horizontal 1" OD Ni tube reactor with 4" nickel boat } \\
\hline & \multicolumn{3}{|c|}{ MiniMite $\left.{ }^{(}\right)$tube furnace with $\sim 4 "$ hot zone; integral temperature } \\
\hline & \multicolumn{3}{|c|}{ programmable controller. } \\
\hline & \multicolumn{3}{|c|}{ Collection vessel was 1 "OD Monel tube w/1/4" outage tube exit. } \\
\hline Weight of reagents $(\mathrm{gm})$ : & 14.5138 & \multicolumn{2}{|c|}{$\mathrm{wt} \% \mathrm{WO}_{2}=25.4526$} \\
\hline Reagent stoichiometry (moles) & \multicolumn{2}{|c|}{$\mathrm{UF}_{4}: \mathrm{WO}_{2}=2.013: 1$} & \\
\hline Sweep gas: & \multicolumn{3}{|c|}{ Air flow at $\sim 100(\mathrm{cc} / \mathrm{min})$} \\
\hline Pre-reaction drying period: & \multicolumn{3}{|l|}{ None } \\
\hline Total reaction time $(\mathrm{hr})$ : & \multicolumn{3}{|l|}{$2 \mathrm{hr}-5 \min }$. \\
\hline \multirow[t]{3}{*}{ Reaction temperature profile: } & Time & at $\mathrm{T}\left({ }^{\circ} \mathrm{C}\right)$ & heat rate $\left({ }^{\circ} \mathrm{C} / \mathrm{min}\right)$ \\
\hline & 5 min. & 750 & 20 \\
\hline & $2 \mathrm{hr}$ & 790 & 50 \\
\hline Collection method: & \multicolumn{3}{|c|}{ 1"OD Monel tube was chilled in ice/water bath } \\
\hline
\end{tabular}

Samples of the residue remaining after reaction and also after hydrolyzing the condensed product in the collection tube were isolated for characterization by $\mathrm{x}$-ray diffraction. 
After completing three trials using $\mathrm{WO}_{2}$ as the tungsten oxide source, a bench-scale reaction between $\mathrm{UF}_{4}$ and $\mathrm{WO}_{3}\left[\mathrm{UF}_{4}: \mathrm{WO}_{3}=2.001: 1\right]$ was investigated. The profile for WFusn-11 is shown in Table 33. Here, the reagent mixture was heated to $790^{\circ} \mathrm{C}$ for 3 hours and the volatile reaction product captured in the 1" OD collection tube described in the previous trial.

Table 33.

Reaction Profile for WFusn-11.

\begin{tabular}{|c|c|c|c|}
\hline Experiment ID: & \multicolumn{3}{|c|}{ 041702-WFusn-11 } \\
\hline Reagent used: & $\mathrm{WO}_{3}$ & & \\
\hline Reaction: & \multicolumn{3}{|c|}{$2 \mathrm{UF}_{4}+\mathrm{WO}_{3}+\mathrm{O}_{2}(\mathrm{~g})=\mathrm{WOF}_{4}(\mathrm{~g})+2 \mathrm{UO}_{2} \mathrm{~F}_{2}$} \\
\hline System: & \multicolumn{3}{|c|}{ Horizontal 1" OD Ni tube reactor with 4" nickel boat } \\
\hline & \multicolumn{3}{|c|}{ MiniMite $^{\circledR}$ tube furnace with $\sim 4$ " hot zone; integral temperature } \\
\hline & \multicolumn{3}{|c|}{ programmable controller. } \\
\hline & \multicolumn{3}{|c|}{ Collection vessel was 1"OD Monel tube w/1/4" outage tube } \\
\hline & \multicolumn{3}{|c|}{ elongated to bottom of Monel tube. } \\
\hline Weight of reagents $(\mathrm{gm})$ : & 11.8572 & \multicolumn{2}{|c|}{$\mathrm{wt} \% \mathrm{WO}_{3}=26.9519$} \\
\hline Reagent stoichiometry (moles) & \multicolumn{2}{|c|}{$\mathrm{UF}_{4}: \mathrm{WO}_{3}=2.001: 1$} & \\
\hline Sweep gas: & \multicolumn{3}{|c|}{ Air flow at $\sim 100(\mathrm{cc} / \mathrm{min})$} \\
\hline Pre-reaction drying period: & \multicolumn{3}{|l|}{ None } \\
\hline Total reaction time $(\mathrm{hr})$ : & \multicolumn{3}{|l|}{$3 \mathrm{hr}-10 \mathrm{~min}}$. \\
\hline \multirow[t]{4}{*}{ Reaction temperature profile: } & Time & at $\mathrm{T}\left({ }^{\circ} \mathrm{C}\right)$ & heat rate $\left({ }^{\circ} \mathrm{C} / \mathrm{min}\right)$ \\
\hline & $5 \mathrm{~min}$. & 725 & 20 \\
\hline & $5 \mathrm{~min}$. & 750 & 50 \\
\hline & $3 \mathrm{hr}$ & 790 & 50 \\
\hline Collection method: & \multicolumn{3}{|c|}{ 1"OD Monel tube was chilled in ice/water bath } \\
\hline
\end{tabular}

Data collection included measurement of the weight of captured product and post-reaction residue. Specimens of the residue created after hydrolyzing the solid captured in the condenser as well as the reaction product remaining in the nickel boat were analyzed by $\mathrm{x}$-ray diffraction. 
After reviewing the information collected from WFusn-11, a second reaction, similar to the previous run, was performed using the same parent $\mathrm{UF}_{4} / \mathrm{WO}_{3}$ stock mixture with the 2.001:1 molar stoichiometry. For this experiment, identified as WFusn-12, the $250 \mathrm{ml}$ round bottom flask was joined to the exit stream via a 1/4" 316 stainless steel tube and the line wrapped with heat tape back to where the reaction tube emerged from the furnace. The flask was again submerged in an ice-water bath. In this reaction, volatile product was collected for about 100 minutes while the reactor was at $750^{\circ} \mathrm{C}$. The exit stream was maintained at $204^{\circ} \mathrm{C}$ during the reaction. Full details of this experiment are given in Table 34 below.

Table 34.

Reaction Profile for WFusn-12.

\begin{tabular}{|c|c|c|c|}
\hline Experiment ID: & \multicolumn{3}{|c|}{ 042402-WFusn-12 } \\
\hline Reagent used: & \multicolumn{3}{|l|}{$\mathrm{WO}_{3}$} \\
\hline Reaction: & \multicolumn{3}{|c|}{$2 \mathrm{UF}_{4}+\mathrm{WO}_{3}+\mathrm{O}_{2}(\mathrm{~g})=\mathrm{WOF}_{4}(\mathrm{~g})+2 \mathrm{UO}_{2} \mathrm{~F}_{2}$} \\
\hline System: & \multicolumn{3}{|c|}{ Horizontal 1" OD Ni tube reactor with 4" nickel boat } \\
\hline & \multicolumn{3}{|c|}{ MiniMite $^{\Theta}$ tube furnace with $\sim 4$ " hot zone; integral temperature } \\
\hline & \multicolumn{3}{|c|}{ programmable controller. } \\
\hline & \multicolumn{3}{|c|}{$250 \mathrm{ml}$ round bottom flask $\mathrm{w} / 1 / 4$ " ss tube connection } \\
\hline & \multicolumn{3}{|c|}{ Exit line wrapped $\mathrm{w} /$ heat tape from elbow to joint at $1 / 4$ " tube. } \\
\hline Weight of reagents $(\mathrm{gm}):$ & 10.3506 & \multicolumn{2}{|c|}{$\mathrm{wt} \% \mathrm{WO}_{3}=26.9519$} \\
\hline Reagent stoichiometry (moles) & \multicolumn{2}{|c|}{$\mathrm{UF}_{4}: \mathrm{WO}_{3}=2.001: 1$} & \\
\hline Sweep gas: & \multicolumn{3}{|c|}{ Air flow at $120(\mathrm{cc} / \mathrm{min})$} \\
\hline Pre-reaction drying period: & \multicolumn{3}{|c|}{\begin{tabular}{|c|c|} 
None & \\
\end{tabular}} \\
\hline Total reaction time $(\mathrm{hr})$ : & \multicolumn{3}{|l|}{$2 \mathrm{hr}$} \\
\hline \multirow[t]{4}{*}{ Reaction temperature profile: } & Time & at $\mathrm{T}\left({ }^{\circ} \mathrm{C}\right)$ & heat rate $\left({ }^{\circ} \mathrm{C} / \mathrm{min}\right)$ \\
\hline & $10 \mathrm{~min}$. & 700 & 20 \\
\hline & 10 min. & 725 & 50 \\
\hline & $1 \mathrm{hr}-40 \mathrm{~min}$. & 750 & 50 \\
\hline Collection method: & \multicolumn{3}{|c|}{ Flask was chilled in ice/water bath } \\
\hline
\end{tabular}

As done before, gravimetric measurements and x-ray diffraction analysis were collected for the condensed product and bulk residue, respectively. 
After completing the two trials using $\mathrm{WO}_{3}$, further experimentation with $\mathrm{WO}_{2}$ as the tungsten source was resumed. In this trial, the experimental plan was to first react $\mathrm{UF}_{4}$ and $\mathrm{WO}_{2}$ to produce $\mathrm{WOF}_{4}$, then react the condensed product with more $\mathrm{UF}_{4}$. The profile for the 2-step reaction is given in Table 35. Thermodynamic considerations ${ }^{14}$ for the step (2) reaction shown in Table 35 indicate favorable reaction energetics for converting $\mathrm{WOF}_{4}$ to $\mathrm{WF}_{6}(\mathrm{~g})$, as illustrated in Table 36.

\section{Table 35.}

\section{Reaction Profile for WFusn-13.}

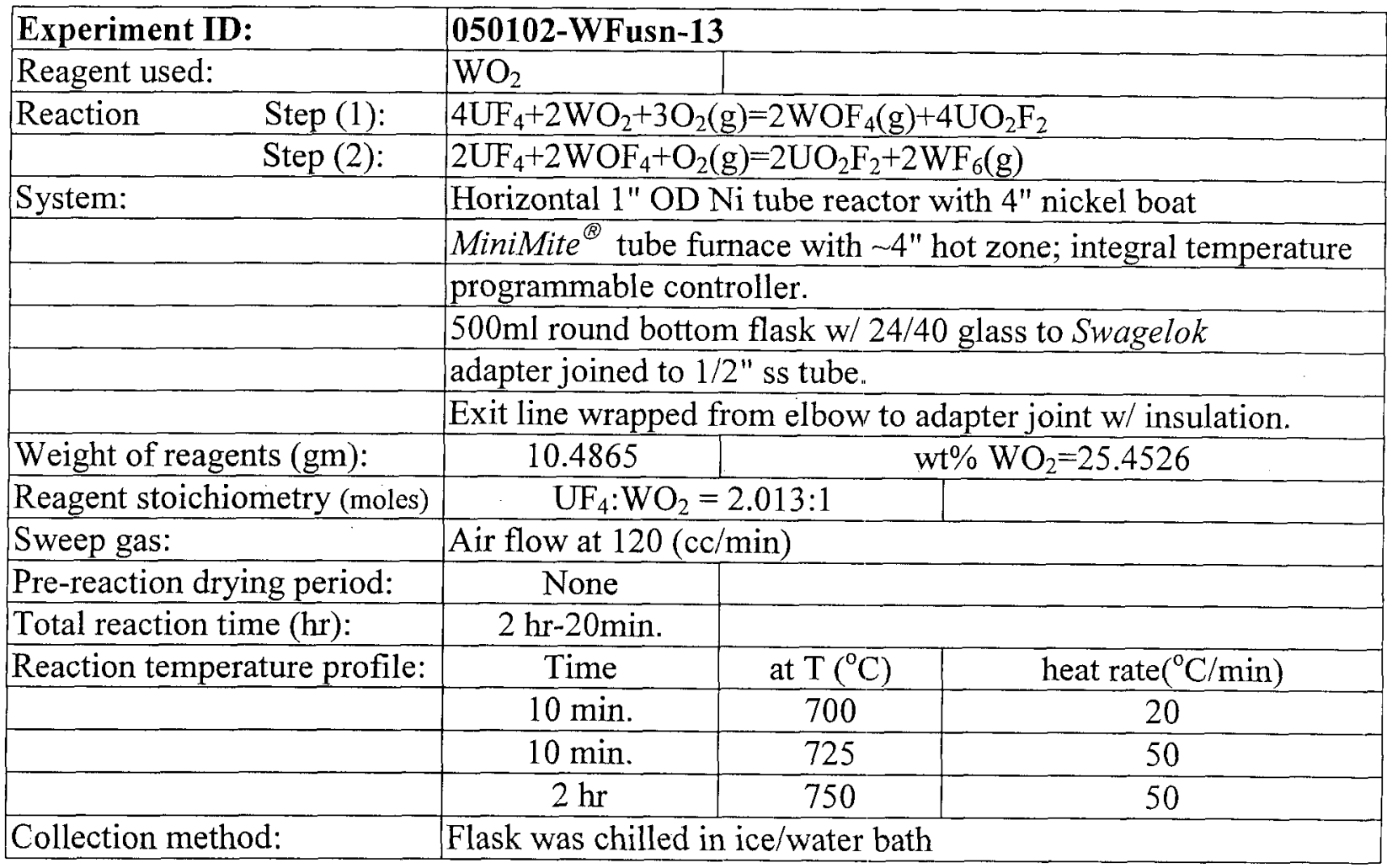

Table 36.

Thermodynamic calculations for reacting $\mathrm{UF}_{4}$ with $\mathrm{WOF}_{4}$.

\begin{tabular}{|c|c|c|c|c|}
\hline \multicolumn{5}{|c|}{$\mathbf{2 U F}_{\mathbf{4}}+\mathbf{2} \mathbf{W O F}_{\mathbf{4}}+\mathbf{O}_{\mathbf{2}} \mathbf{( g )} \longrightarrow \mathbf{2} \mathbf{U}_{\mathbf{2}} \mathbf{F}_{\mathbf{2}}+\mathbf{2 W} \mathbf{W F}_{\mathbf{6}}(\mathbf{g})$} \\
\hline Temperature ${ }^{\circ} \mathbf{C}$ & delta H (kcal) & delta S (cal) & delta G (kcal) & $\mathbf{K}$ \\
\hline 0.00 & -25.540 & 24.223 & -32.157 & $5.381 \mathrm{E}+025$ \\
\hline 100.0 & -27.508 & 18.049 & -34.243 & $1.142 \mathrm{E}+020$ \\
\hline 200.0 & -33.092 & 4.160 & -35.061 & $1.570 \mathrm{E}+016$ \\
\hline 300.0 & -35.993 & -1.410 & -35.185 & $2.616 \mathrm{E}+013$ \\
\hline 400.0 & -38.682 & -5.738 & -34.820 & $2.022 \mathrm{E}+011$ \\
\hline 500.0 & -41.241 & -9.283 & -34.063 & $4.262 \mathrm{E}+009$ \\
\hline 600.0 & -43.714 & -12.292 & -32.981 & $1.802 \mathrm{E}+008$ \\
\hline 700.0 & -46.128 & -14.910 & -31.618 & $1.263 \mathrm{E}+007$ \\
\hline 800.0 & -48.498 & -17.229 & -30.009 & $1.294 \mathrm{E}+006$ \\
\hline 900.0 & -50.836 & -19.312 & -28.180 & $1.779 \mathrm{E}+005$ \\
\hline 1000.0 & -53.149 & -21.205 & -26.153 & $3.089 \mathrm{E}+004$ \\
\hline
\end{tabular}


The experimental setup was similar to previous trials. Here, a $500 \mathrm{ml} 2$-neck round bottom flask was used as the condensation vessel. To the flask was added $\sim 2.17$ grams of $U_{4}$ while the mixture of $\mathrm{UF}_{4}+\mathrm{WO}_{2}\left(2.013: 1 \mathrm{UF}_{4}: \mathrm{WO}_{2}\right)$ was added to the nickel boat. The first stage of the reaction was carried out for two hours and attained a temperature of $750^{\circ} \mathrm{C}$. During this time volatile product was captured on top of the $U_{4}$ layer in the flask maintained at $0^{\circ} \mathrm{C}$ in the ice-water bath. After concluding the high temperature stage of the reaction, the reactor was allowed to cool to ambient. The flask containing the $\mathrm{WOF}_{4} / \mathrm{UF}_{4}$ powder was then swirled to mix the solids thoroughly and then connected to a flow of dry air and heated to carry out the second step to produce $\mathrm{WF}_{6}$.

Upon concluding both steps of the scenario, routine gravimetric and $\mathrm{x}$-ray diffraction data were collected. 
In the eighth trial, WFusn-14, a group of reaction parameters was selected with the intent to optimize and deliver the maximum yield of oxyfluoride intermediate. The specific details for Wfusn-14 are compiled in Table 37. As in previous runs, the exit line downstream from the furnace to the condenser was wrapped with heat tape and insulation and maintained at $\sim 205^{\circ} \mathrm{C}$ to keep the $\mathrm{WOF}_{4}$ vapor trail flowing to the collection vessel. For this reaction, an accelerated heating profile was implemented where the furnace temperature was first raised to $750^{\circ} \mathrm{C}$ at $20^{\circ} \mathrm{C} / \mathrm{min}$ during the initial heating step and maintained there for only 5 minutes. This was followed by a rapid temperature jump (at $50^{\circ} \mathrm{C} / \mathrm{min}$ ) to $775^{\circ} \mathrm{C}$ and similar dwell time of 5 minutes. In the final step, the furnace temperature was raised to $800^{\circ} \mathrm{C}$ (at $50^{\circ} \mathrm{C} / \mathrm{min}$ ) where it was held for 3 hours.

Table 37.

Reaction Profile for WJFusn-14.

\begin{tabular}{|c|c|c|c|}
\hline Experiment ID: & \multicolumn{3}{|c|}{ 061902-WFusn-14 } \\
\hline Reagent used: & \multicolumn{3}{|l|}{$\mathrm{WO}_{2}$} \\
\hline Reaction & \multicolumn{3}{|c|}{$4 \mathrm{UF}_{4}+2 \mathrm{WO}_{2}+3 \mathrm{O}_{2}(\mathrm{~g})=2 \mathrm{WOF}_{4}(\mathrm{~g})+4 \mathrm{UO}_{2} \mathrm{~F}_{2}$} \\
\hline System: & \multicolumn{3}{|c|}{ Horizontal 1" OD Ni tube reactor with 4" nickel boat } \\
\hline & \multicolumn{3}{|c|}{ MiniMite tube furnace with $\sim 4$ " hot zone; integral temperature } \\
\hline & \multicolumn{3}{|c|}{ programmable controller. } \\
\hline & \multicolumn{3}{|c|}{$500 \mathrm{ml}$ round bottom flask w/24/40 glass to Swagelok ${ }^{\circledast}$} \\
\hline & \multicolumn{3}{|c|}{ adapter joined to $1 / 2$ " stainless steel tube. } \\
\hline & \multicolumn{3}{|c|}{ Exit line from elbow to $24 / 40$ adapter joint was wrapped with } \\
\hline & \multicolumn{3}{|c|}{ heat tape under the insulation. } \\
\hline Weight of reagents $(\mathrm{gm}):$ & 11.4094 & \multicolumn{2}{|c|}{$\mathrm{wt} \% \mathrm{WO}_{2}=25.4526$} \\
\hline Reagent stoichiometry (moles) & \multicolumn{2}{|c|}{$\mathrm{UF}_{4}: \mathrm{WO}_{2}=2.013: 1$} & \\
\hline Sweep gas: & \multicolumn{3}{|c|}{ Air flow at $120(\mathrm{cc} / \mathrm{min})$} \\
\hline Pre-reaction drying period: & \multirow{2}{*}{\multicolumn{3}{|c|}{$\frac{\text { None }}{3 \mathrm{hr}-10 \mathrm{~min} .}$}} \\
\hline Total reaction time $(\mathrm{hr}):$ & & & \\
\hline \multirow[t]{4}{*}{ Reaction temperature profile: } & Dwell Time & at $\mathrm{T}\left({ }^{\circ} \mathrm{C}\right)$ & heat rate to $\mathrm{T}\left({ }^{\circ} \mathrm{C} / \mathrm{min}\right)$ \\
\hline & $5 \mathrm{~min}$. & 750 & 20 \\
\hline & 5 min. & 775 & 50 \\
\hline & $180 \mathrm{~min}$. & 800 & 50 \\
\hline Collection method: & \multicolumn{3}{|c|}{ Flask was chilled in ice/water bath } \\
\hline Exit line temperature $\left({ }^{\circ} \mathrm{C}\right)$ & 205 & & \\
\hline
\end{tabular}

Upon concluding the trial, $x$-ray diffraction analysis of the product residue from the boat and material coating the reactor walls was performed. A gravimetric measurement of the resultant end product was also gathered. 
Experiment WFusn-15 consisted of a two-step reaction scheme in order to probe the reactivity of $\mathrm{WOF}_{4}$. Tungsten oxyfluoride generated in the first step was reacted with $\mathrm{SiO}_{2}$ in the second step. Details of this scenario are included in Table 38 while the thermodynamic calculations $^{\mathbf{1 4}}$, showing a favorable and spontaneous reaction (negative Gibbs free energy change, $-\Delta \mathrm{G}$ ) between $\mathrm{WOF}_{4}$ and $\mathrm{SiO}_{2}$, are tabulated in Table 39.

Table 38.

\section{Reaction Profile for WFusn-15.}

\begin{tabular}{|c|c|c|c|}
\hline Experiment ID: & \multicolumn{3}{|c|}{ 071102-WFusn-15 } \\
\hline Reagent used: & \multicolumn{3}{|l|}{$\mathrm{WO}_{2}$} \\
\hline Reaction & \multicolumn{3}{|c|}{$4 \mathrm{UF}_{4}+2 \mathrm{WO}_{2}+3 \mathrm{O}_{2}(\mathrm{~g})=2 \mathrm{WOF}_{4}(\mathrm{~g})+4 \mathrm{UO}_{2} \mathrm{~F}_{2}$} \\
\hline Step (2): & \multicolumn{3}{|c|}{$\mathrm{WOF}_{4}+\mathrm{SiO}_{2}=\mathrm{WO}_{3}+\mathrm{SiF}_{4}(\mathrm{~g})$} \\
\hline System: & \multicolumn{3}{|c|}{ Horizontal 1" OD Ni tube reactor with 4" nickel boat } \\
\hline & \multicolumn{3}{|c|}{ MiniMite tube furnace with $\sim 4$ " hot zone; integral temperature } \\
\hline & \multicolumn{3}{|c|}{ programmable controller. } \\
\hline & \multicolumn{3}{|c|}{$500 \mathrm{ml}$ round bottom flask w/ 24/40 glass to Swagelok } \\
\hline & \multicolumn{3}{|c|}{ adapter joined to $1 / 2$ " stainless steel tube. } \\
\hline & \multicolumn{3}{|c|}{ Exit line from elbow to $24 / 40$ adapter joint was wrapped with } \\
\hline & \multicolumn{3}{|c|}{ heat tape under the insulation. } \\
\hline Weight of reagents $(\mathrm{gm})$ : & 13.4509 & \multicolumn{2}{|c|}{$\mathrm{wt} \% \mathrm{WO}_{2}=25.4526$} \\
\hline Reagent stoichiometry (moles) & \multicolumn{2}{|c|}{$\mathrm{UF}_{4}: \mathrm{WO}_{2}=2.013: 1$} & \\
\hline Sweep gas: & \multicolumn{3}{|c|}{ Air flow at $120(\mathrm{cc} / \mathrm{min})$} \\
\hline Pre-reaction drying period: & \multicolumn{3}{|c|}{ None } \\
\hline Total reaction time $(\mathrm{hr}):$ & $3 \mathrm{hr}$. & \multicolumn{2}{|l|}{$\cdot$} \\
\hline \multirow[t]{5}{*}{ Reaction temperature profile: } & Dwell Time & at $\mathrm{T}\left({ }^{\circ} \mathrm{C}\right)$ & heat rate to $\mathrm{T}\left({ }^{\circ} \mathrm{C} / \mathrm{min}\right)$ \\
\hline & $5 \mathrm{~min}$ & 725 & 20 \\
\hline & $10 \mathrm{~min}$. & 750 & 50 \\
\hline & $65 \mathrm{~min}$. & 780 & 50 \\
\hline & $100 \mathrm{~min}$. & 800 & 50 \\
\hline Collection method: & \multicolumn{3}{|c|}{ Flask was chilled in ice/water bath } \\
\hline Exit line temperature $\left({ }^{\circ} \mathrm{C}\right)$ & 202 & & \\
\hline
\end{tabular}


Table 39.

Thermodynamic calculations for reacting $\mathrm{WOF}_{4}$ with $\mathrm{SiO}_{2}$.

\begin{tabular}{|c|c|c|c|c|}
\hline \multicolumn{5}{|c|}{$\mathrm{WOF}_{4}+\mathrm{SiO}_{2} \longrightarrow \mathrm{WO}_{3}+\mathrm{SiF}_{4}(\mathrm{~g})$} \\
\hline Temperature ${ }^{\circ} \mathrm{C}$ & delta H (kcal) & delta $S$ (cal) & delta G (kcal) & $\mathbf{K}$ \\
\hline 0.00 & -36.289 & 34.475 & -45.706 & $3.739 \mathrm{E}+036$ \\
\hline 100.0 & -37.072 & 32.037 & -49.027 & $5.212 \mathrm{E}+028$ \\
\hline 200.0 & -39.838 & 25.161 & -51.743 & $7.982 E+023$ \\
\hline 300.0 & -41.327 & 22.303 & -54.110 & $4.310 \mathrm{E}+020$ \\
\hline 400.0 & -42.748 & 20.017 & -56.222 & $1.799 \mathrm{E}+018$ \\
\hline 500.0 & -44.142 & 18.085 & -58.125 & $2.702 \mathrm{E}+016$ \\
\hline 600.0 & -45.661 & 16.240 & -59.842 & $9.543 \mathrm{E}+014$ \\
\hline 700.0 & -46.814 & 14.990 & -61.402 & $6.176 \mathrm{E}+013$ \\
\hline 800.0 & -47.590 & 14.222 & -62.853 & $6.328 \mathrm{E}+012$ \\
\hline 900.0 & -49.265 & 12.713 & -64.179 & $9.060 \mathrm{E}+011$ \\
\hline 1000.0 & -50.424 & 11.764 & -65.402 & $1.690 \mathrm{E}+011$ \\
\hline
\end{tabular}

For the first step of WFusn-15, a mixture of $\mathrm{UF}_{4}$ and $\mathrm{WO}_{2}$ (2.013:1 mole ratio) was heated, again to a reaction temperature of $800^{\circ} \mathrm{C}$ using a less aggressive heating program compared to the previous experiment. After two short dwell periods at $725^{\circ} \mathrm{C}$ and $750^{\circ} \mathrm{C}$ (totaling 15 minutes), the heating program raised the reaction temperature to $780^{\circ} \mathrm{C}$ where it was held for 65 minutes before climbing to the plateau temperature of $800^{\circ} \mathrm{C}$ for the final 100 minutes. In similar fashion, the exit line from the furnace to the collection vessel was maintained at $\sim 202^{\circ} \mathrm{C}$ to maximize the collection of $\mathrm{WOF}_{4}$. In preparation for the reaction in step (2), approximately 0.5 gram of $\mathrm{SiO}_{2}$ (99.5\% purity, -325 mesh powder from Alfa Aesar, Ward Hill, MA) was added to the $500 \mathrm{ml}$ condensation flask before the start of the experiment. During the collection of $\mathrm{WOF}_{4}$, the condensation flask was maintained at $0^{\circ} \mathrm{C}$ in an ice/water bath. Upon conclusion of the reaction, the ice/water bath was removed and the flask warmed to ambient temperature while maintaining a flow of air through the vessel. A heating mantle was placed around the flask with a thermocouple situated near the bottom where the bulk of the residue had deposited. The mixture of condensed residue and $\mathrm{SiO}_{2}$ was then slowly heated to explore the step (2) reaction in Table 38.

Following the completion of the second reaction step, the post-reaction solids in the $\mathrm{Ni}$ tube were recovered and analyzed by x-ray diffraction. The final weight of the reacted solids was also measured. 
For the next experiment, WFusn-16, several changes were made to the experimental plan. First, a clean nickel boat was used to contain the $\mathrm{UF}_{4} / \mathrm{WO}_{2}$ mixture. Again, the furnace-heating program was adjusted by starting the reaction at a lower temperature, $700^{\circ} \mathrm{C}$, and lengthening the dwell periods to reach the plateau temperature of $780^{\circ} \mathrm{C}$. A new condenser vessel, consisting of a $10.5^{\prime \prime} \times 2.5^{\prime \prime}$ OD pyrex ${ }^{\circledR}$ cylinder with $0.5^{\prime \prime}$ entry and exit ports, was attached to the exit line from the reactor. The new collection vessel provided a larger surface area for condensing product vapors and allowed direct connection to the 0.5 " stainless steel tube section immediately adjacent to the reaction tube. The complete list of experimental parameters for WFusn-16 is given in the profile listed in Table 40. During the three-hour reaction period the exit line to the condenser was maintained at $210^{\circ} \mathrm{C}$ while the collector was submerged in an ice-water bath.

Table 40.

\section{Reaction Profile for WFusn-16.}

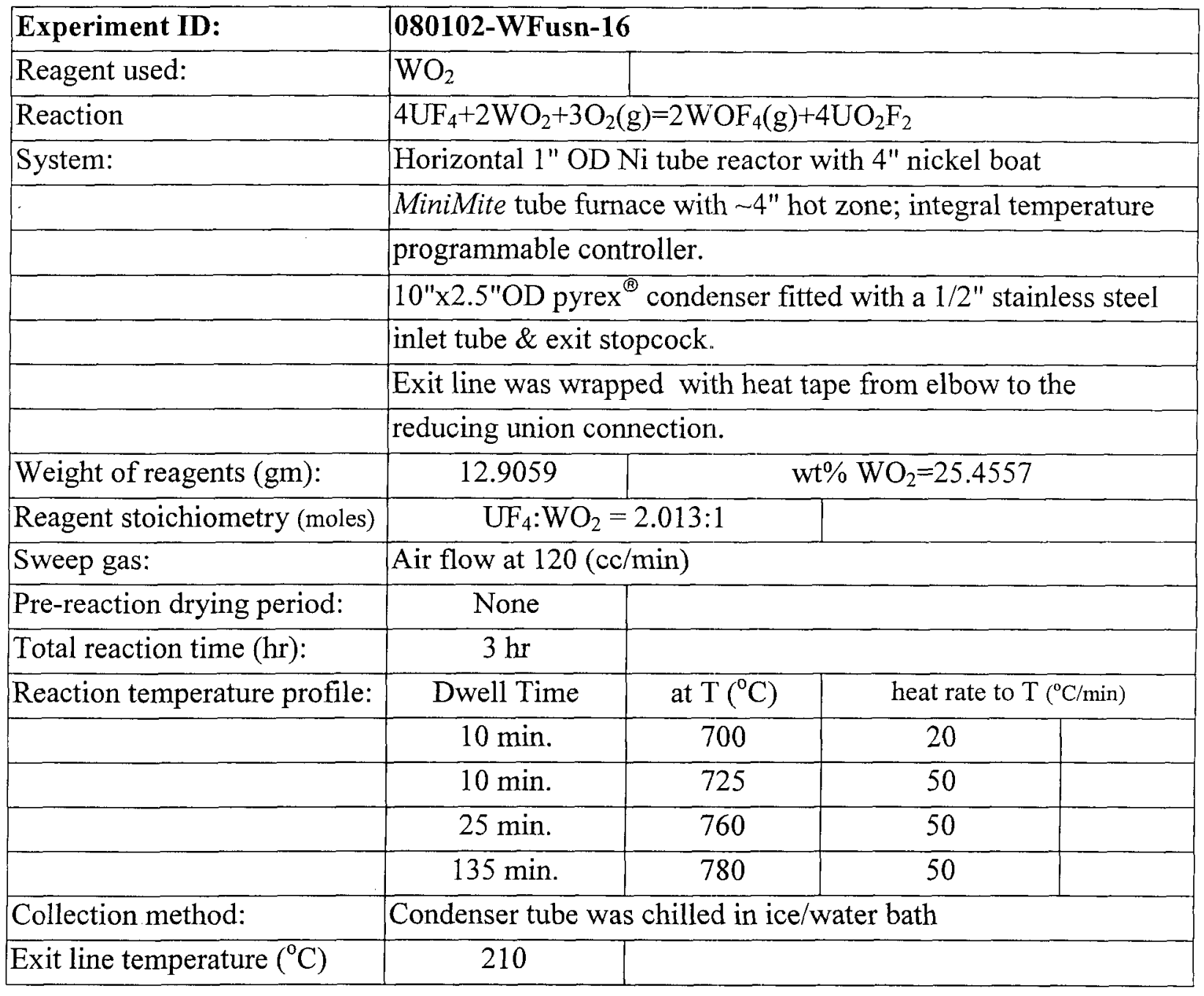

Routine x-ray diffraction analysis was conducted on the recovered residue from the reactor. 
The last experiment in the series listed in Table 28 was WFusn-17. This trial was performed in order to add to the amount of $\mathrm{WOF}_{4}$ contained in the pyrex ${ }^{\circledR}$ condenser synthesized in the WFusn-16 run. The reaction system setup was similar to that used previously with the exception that the exit line to the collection vessel was only wrapped with insulation (from the elbow to the reducing union connection) and not heated by heat tape. The reaction between $\mathrm{WO}_{2}$ and $\mathrm{UF}_{4}$ was the first step in another two-step scenario where the oxyfluoride material was reacted further with $\mathrm{TiF}_{4}$. This two-step reaction scenario is shown in the reaction profile for WFusn-17 given in Table 41 below.

Table 41.

\section{Reaction Profile for WFusn-17.}

\begin{tabular}{|c|c|c|c|}
\hline Experiment ID: & \multicolumn{3}{|c|}{ 082002-WFusn-17 } \\
\hline Reagent used: & \multicolumn{3}{|c|}{\begin{tabular}{|l|l|}
$\mathrm{WO}_{2}$ & \\
\end{tabular}} \\
\hline Reaction (Step 1) & \multicolumn{3}{|c|}{$4 \mathrm{UF}_{4}+2 \mathrm{WO}_{2}+3 \mathrm{O}_{2}(\mathrm{~g})=2 \mathrm{WOF}_{4}(\mathrm{~g})+4 \mathrm{UO}_{2} \mathrm{~F}_{2}$} \\
\hline (Step 2) & \multicolumn{3}{|c|}{$\mathrm{TiF}_{4}+2 \mathrm{WOF}_{4}=2 \mathrm{WF}_{6}(\mathrm{~g})+\mathrm{TiO}_{2}$} \\
\hline System: & \multicolumn{3}{|c|}{ Horizontal 1" OD Ni tube reactor with 4" nickel boat } \\
\hline & \multicolumn{3}{|c|}{ MiniMite tube furnace with $\sim 4$ " hot zone; integral temperature } \\
\hline & \multicolumn{3}{|c|}{ programmable controller. } \\
\hline & \multicolumn{3}{|c|}{$10^{\prime \prime} \times 2.5^{\prime \prime O D}$ pyrex ${ }^{\circledR}$ condenser fitted with a $1 / 2$ " stainless steel } \\
\hline & \multicolumn{3}{|c|}{ inlet tube \& exit stopcock. Condenser contained the residue } \\
\hline & \multicolumn{3}{|c|}{ from WFusn-16. Exit line was wrapped with insulation from } \\
\hline & \multicolumn{3}{|c|}{ elbow to the 1 "to $1 / 2$ " reducing union connection. } \\
\hline Weight of reagents (gm): & 14.1475 & \multicolumn{2}{|c|}{$\mathrm{wt} \% \mathrm{WO}_{2}=25.4557$} \\
\hline Reagent stoichiometry (moles) & \multicolumn{2}{|c|}{$\mathrm{UF}_{4}: \mathrm{WO}_{2}=2.013: 1$} & \\
\hline Sweep gas: & \multicolumn{3}{|c|}{ Air flow at $120(\mathrm{cc} / \mathrm{min})$} \\
\hline Pre-reaction drying period: & None & & \\
\hline Total reaction time $(\mathrm{hr})$ : & $3 \mathrm{hr}$. & & \\
\hline \multirow[t]{5}{*}{ Reaction temperature profile: } & Dwell Time & at $\mathrm{T}\left({ }^{\circ} \mathrm{C}\right)$ & heat rate to $\mathrm{T}\left({ }^{\circ} \mathrm{C} / \mathrm{min}\right)$ \\
\hline & $10 \mathrm{~min}$. & 700 & 20 \\
\hline & $10 \mathrm{~min}$. & $\overline{725}$ & 50 \\
\hline & $25 \mathrm{~min}$. & 760 & 50 \\
\hline & $135 \mathrm{~min}$. & 800 & 50 \\
\hline Collection method: & \multicolumn{3}{|c|}{ Condenser tube was chilled in ice/water bath. } \\
\hline Exit line temperature $\left({ }^{\circ} \mathrm{C}\right)$ & $\mathrm{N} / \mathrm{M}$ & & \\
\hline
\end{tabular}


The reaction between $\mathrm{WOF}_{4}$ and $\mathrm{TiF}_{4}$ displayed favorable thermodynamic parameters ${ }^{14}$ (negative Gibbs free energy change, $-\Delta \mathrm{G}$ ) for producing $\mathrm{WF}_{6}$, as indicated by the tabulated values in Table 42. The selection of $\mathrm{TiF}_{4}$ as the fluorinating agent has the noted distinction that it too can be produced when ilmenite or other titanium-bearing ores are reacted with $U_{4}$. This chemistry has been demonstrated at Starmet as part of a DCE Phase I SBIR grant (grant no. DEFG02-99ER82893) conducted by M.D. Stephens ${ }^{26}$.

Table 42.

Thermodynamic calculations for reacting $\mathrm{WOF}_{4}$ with $\mathrm{TiF}_{4}$.

\begin{tabular}{|c|c|c|c|c|}
\hline \multicolumn{5}{|c|}{$\mathrm{TiF}_{4}+2 \mathrm{WOF}_{4} \longrightarrow \mathrm{TiO}_{2}+2 \mathrm{WF}_{6}(\mathrm{~g})$} \\
\hline Temperature ${ }^{\circ} \mathrm{C}$ & delta H (kcal) & delta S (cal) & delta G (kcal) & $\mathbf{K}$ \\
\hline 0.00 & 12.472 & 60.994 & -4.189 & $2.247 \mathrm{E}+003$ \\
\hline 100.0 & 10.314 & 54.258 & -9.932 & $6.571 \mathrm{E}+005$ \\
\hline 200.0 & 4.282 & 39.315 & -14.320 & $4.119 \mathrm{E}+006$ \\
\hline 300.0 & 0.765 & 32.567 & -17.901 & $6 . \overline{706 \mathrm{E}+006}$ \\
\hline 400.0 & -2.699 & 26.996 & -20.872 & $5.982 \mathrm{E}+006$ \\
\hline 500.0 & -6.210 & 22.135 & -23.323 & $3.922 \mathrm{E}+006$ \\
\hline 600.0 & -9.840 & 17.722 & -25.313 & $2.170 \mathrm{E}+006$ \\
\hline 700.0 & -13.650 & 13.592 & -26.877 & $1.088 \mathrm{E}+006$ \\
\hline 800.0 & -17.696 & 9.636 & -28.038 & $5.133 \mathrm{E}+005$ \\
\hline 900.0 & -22.028 & 5.779 & -28.808 & $2.329 \mathrm{E}+005$ \\
\hline 1000.0 & -26.694 & 1.965 & -29.195 & $1.028 \mathrm{E}+005$ \\
\hline
\end{tabular}

To qualitatively explore the reaction between $\mathrm{WOF}_{4}$ and $\mathrm{TiF}_{4}$, the pyrex ${ }^{\circledR}$ condenser containing the oxyfluoride intermediate was placed in an argon-filled glovebag along with the source of $\mathrm{TiF}_{4}$ purchased from Advanced Research Chemicals, Inc., (Catoosa, OK). About 1.0636 grams of $\mathrm{TiF}_{4}$ was weighed out in a separate container and then added to the condenser while being kept in the inert atmosphere. The sealed condenser was then taken out of the glovebag and connected to two traps placed in series at the sidearm port of the cylinder. The first trap contained a solution of $\mathrm{NaOH}$ to neutralize and capture any $\mathrm{WF}_{6}$ gas while the second trap consisted of distilled water and used as an in-line scrubber. The $\mathrm{WOF}_{4} / \mathrm{TiF}_{4}$ mixture was heated slowly using a heat gun to bring about reaction. After heating the condenser vessel once, it was allowed to cool to ambient temperature and was put back into the argon-filled glovebag where the material deposited in the upper sections was dislodged and recombined with the bulk solids. The pyrex ${ }^{\circledR}$ condenser was then heated a second time using the heat gun.

After completing the reaction, the residue was transferred to a storage container while being handled in the glovebag. However, $x$-ray diffraction analysis of the residue was not done due to the potential for release of hazardous hydrogen fluoride vapors should there be any unreacted materials leftover that would interact with moisture in the air to produce HF. 
Based on the results of the qualitative reaction performed in step (2) of WFusn-17, the chemistry to use $\mathrm{TiF}_{4}$ as a fluorinating agent was targeted for further investigation. Another reaction to form $\mathrm{WF}_{6}$ directly from $\mathrm{WO}_{2}$, using $\mathrm{TiF}_{4}$ as the fluorine source, was put forth after considering the results from the previous trial. The new pathway for producing $\mathrm{WF}_{6}$ is given in equation (9.1),

$$
3 \mathrm{TiF}_{4}+2 \mathrm{WO}_{2}+\mathrm{O}_{2}(\mathrm{~g}) \longrightarrow 2 \mathrm{WF}_{6}(\mathrm{~g})+3 \mathrm{TiO}_{2}
$$

Thermodynamic calculations ${ }^{14}$ for this reaction are compiled in Table 43 and show favorable Gibbs free energy changes ( $-\Delta \mathrm{G}$ values) over a wide temperature range. To explore the feasibility of this pathway, the first reaction between these two materials was performed using a small amount of each substance in the thermogravimetric analyzer (TGA).

Table 43.

Thermodynamic calculations for reaction $\mathrm{WO}_{2}$ with $\mathrm{TiF}_{4}$.

\begin{tabular}{|c|c|c|c|c|}
\hline \multicolumn{5}{|c|}{$3 \mathrm{TiF}_{4}+2 \mathrm{WO}_{2}+\mathrm{O}_{2}(\mathrm{~g}) \longrightarrow 2 \mathrm{WF}_{6}(\mathrm{~g})+3 \mathrm{TiO}_{2}$} \\
\hline Temperature ${ }^{\circ} \mathrm{C}$ & delta H (kcal) & delta S (cal) & delta G (kcal) & $\mathbf{K}$ \\
\hline 0.00 & -35.434 & 31.572 & -44.058 & $1.794 \mathrm{E}+035$ \\
\hline 100.0 & -37.370 & 25.529 & -46.897 & $2.945 \mathrm{E}+027$ \\
\hline 200.0 & -39.358 & 20.814 & -49.207 & $5.378 \mathrm{E}+022$ \\
\hline 300.0 & -41.529 & 16.660 & -51.078 & $3.008 \mathrm{E}+019$ \\
\hline 400.0 & -44.019 & 12.665 & -52.544 & $1.150 \mathrm{E}+017$ \\
\hline 500.0 & -46.965 & 8.593 & -53.608 & $1.429 \mathrm{E}+015$ \\
\hline 600.0 & -50.505 & 4.295 & -54.255 & $3.812 \mathrm{E}+013$ \\
\hline 700.0 & -54.779 & -0.332 & -54.456 & $1.701 \mathrm{E}+012$ \\
\hline 800.0 & -59.925 & -5.358 & -54.175 & $1.081 \mathrm{E}+011$ \\
\hline 900.0 & -66.081 & -10.835 & -53.369 & $8.774 \mathrm{E}+009$ \\
\hline 1000.0 & -73.387 & -16.805 & -51.992 & $8.427 \mathrm{E}+008$ \\
\hline
\end{tabular}

For this micro-scale experiment, the reactants were premixed in a glass vial under an argon atmosphere using 0.1850 gram of $\mathrm{WO}_{2}$ and 0.1501 gram of $\mathrm{TiF}_{4}$. After thoroughly mixing the materials, a small amount $(\sim 8.549 \mathrm{mg})$ was transferred to a tared platinum cup and quickly mounted onto the TGA balance pan and isolated under a flow of dry air. The TGA was programmed to maintain the reaction mixture at room temperature for 15 minutes followed by ramping the temperature at $15^{\circ} \mathrm{C} / \mathrm{min}$. to $500^{\circ} \mathrm{C}$ where it was held for 15 minutes. The weight change of the reactants was recorded over the course of the thermal treatment.

After completing the micro-scale experiment, two additional trials were conducted using gram-scale quantities of reactants and a different reaction system than used in previous runs. For these last two trials, WFusn-18 and 19, the reaction vessel consisted of a Series 4566 Bench-top Mini-Reactor from Parr Instruments, Co. (Moline, IL) featuring 316 stainless steel construction and $\sim 100 \mathrm{cc}$ internal volume. The two-piece vessel, when assembled with a teflon ${ }^{\circledR}$ gasket, was capable of staging a reaction up to a $350^{\circ} \mathrm{C}$ temperature maximum and pressure maximum of $3000 \mathrm{psi}$. The temperature of the reactor was controlled by a Model 4842 PID controller, which 
was also capable of stirring the contents of the vessel. However, for the two experiments between $\mathrm{TiF}_{4}$ and $\mathrm{WO}_{2}$, the stirring capability was not included in the reactor setup. A schematic diagram of the new reaction system is shown in Figure 52. Here, the exit port on the reactor was connected to a 3-way valve to direct flow of gas either through an aqueous scrubber or through a $10 \mathrm{~cm}$ gas cell equipped with $\mathrm{ZnSe}$ windows for analysis of the product stream by FT-IR spectroscopy. The attached pressure gauge was used to monitor the internal pressure while the thermocouple was inserted to sense and regulate the reaction chamber temperature.

Experiments WFusn-18 and WFusn-19 are presented together as a result of a technical glitch during the execution of WFusn-18. During that trial a computer malfunction caused the loss of accumulated FT-IR data and was terminated prematurely so a second experiment, WFusn-19, was performed. The reaction profiles for both experiments are included in Table 44. 


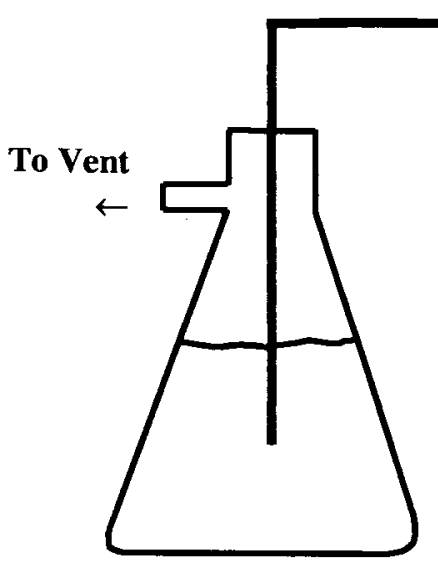

Temperature Programmable Controller

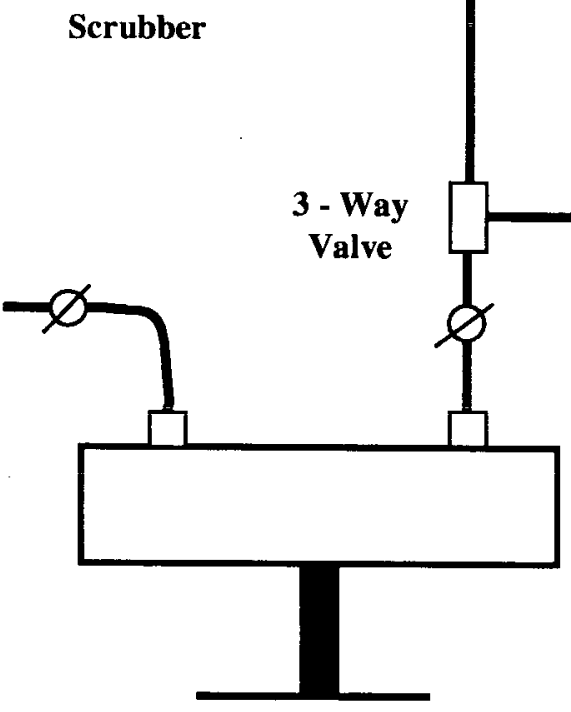

$10 \mathrm{~cm}$ Gas Cell for FT-IR analysis

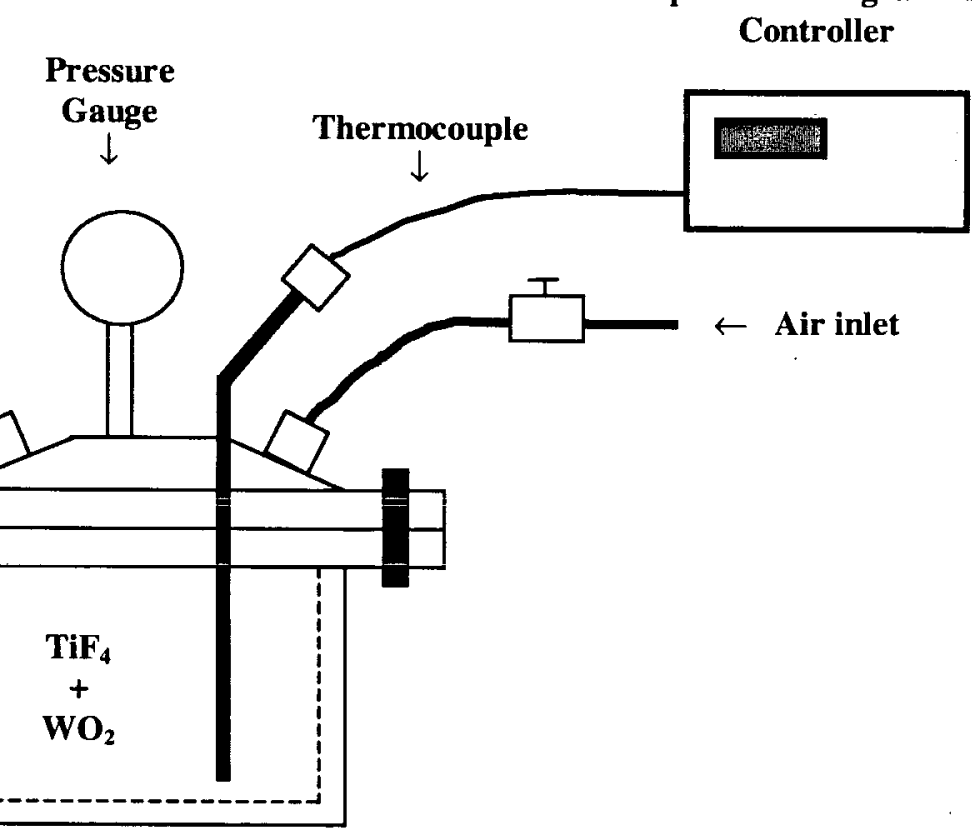

Parr Instruments

Reaction Vessel

Figure 52. Schematic diagram of the reaction system used for conducting WFusn-18 and 19. 
Table 44.

Reaction Profiles for WFusn-18 and WFusn-19.

\begin{tabular}{|c|c|}
\hline Experiment ID: & 091802-WFusn-18 \\
\hline Reagent used: & $\mathrm{TiF}_{4}, \mathrm{WO}_{2}$ \\
\hline Reaction & $3 \mathrm{TiF}_{4}+2 \mathrm{WO}_{2}+\mathrm{O}_{2}(\mathrm{~g})=2 \mathrm{WF}_{6}(\mathrm{~g})+3 \mathrm{TiO}_{2}$ \\
\hline System: & Parr Instrument Co. Model 4566C T316 stainless steel reactor \\
\hline & with teflon ${ }^{\circledast}$ gasket, $100 \mathrm{ml}$ internal vol. and integrated PID \\
\hline & temperature controller. Exit stream from reactor connected to \\
\hline & $10 \mathrm{~cm}$ gas cell for analysis by FT-IR spectroscopy. \\
\hline Weight of reagents $(\mathrm{gm}):$ & \begin{tabular}{|l|l|}
7.6389 & $\mathrm{wt} \% \mathrm{WO}_{2}=52.7157$ \\
\end{tabular} \\
\hline Reagent stoichiometry (moles) & $\mathrm{TiF}_{4}: \mathrm{WO}_{2}=1.563: 1$ \\
\hline Sweep gas: & Air flow at $120(\mathrm{cc} / \mathrm{min})$ \\
\hline Pre-reaction drying period: & \begin{tabular}{|l|l|} 
None & \\
\end{tabular} \\
\hline Total reaction time (hr): & $1 \mathrm{hr}$. \\
\hline Reaction temperature profile: & Reaction vessel heated slowly, stopping periodically to capture \\
\hline & an aliquot of gas for analysis by FT-IR. \\
\hline & Maximum temperature reached $-155^{\circ} \mathrm{C}$ \\
\hline Collection method: & $10 \mathrm{~cm}$ gas cell equipped with $\mathrm{ZnSe}$ windows \\
\hline Exit line temperature $\left({ }^{\circ} \mathrm{C}\right)$ & \begin{tabular}{l|l}
$\mathrm{N} / \mathrm{M}$ & \\
\end{tabular} \\
\hline Experiment ID: & 110502-WFusn-19 \\
\hline Reagent used: & \begin{tabular}{|l|l|}
$\mathrm{TiF}_{4}, \mathrm{WO}_{2}$ & \\
\end{tabular} \\
\hline Reaction & $3 \mathrm{TiF}_{4}+2 \mathrm{WO}_{2}+\mathrm{O}_{2}(\mathrm{~g})=2 \mathrm{WF}_{6}(\mathrm{~g})+3 \mathrm{TiO}_{2}$ \\
\hline System: & Parr Instrument Co. Model 4566C T316 stainless steel reactor \\
\hline & with teflon ${ }^{\circledR}$ gasket, $100 \mathrm{ml}$ internal vol. and integrated PID \\
\hline & temperature controller. Exit stream from reactor connected to \\
\hline & $10 \mathrm{~cm}$ gas cell for analysis by FT-IR spectroscopy. \\
\hline Weight of reagents $(\mathrm{gm})$ : & \begin{tabular}{|l|l|}
7.6916 & $\mathrm{wt} \% \mathrm{WO}_{2}=52.9539$ \\
\end{tabular} \\
\hline Reagent stoichiometry (moles) & $\mathrm{TiF}_{4}: \mathrm{WO}_{2}=1.548: 1$ \\
\hline Sweep gas: & Air flow at $100(\mathrm{cc} / \mathrm{min})$ \\
\hline Pre-reaction drying period: & \begin{tabular}{|l|l|} 
None & \\
\end{tabular} \\
\hline Total reaction time $(\mathrm{hr})$ : & \begin{tabular}{|c|l|}
$2.5 \mathrm{hr}$. & \\
\end{tabular} \\
\hline Reaction temperature profile: & Reaction vessel heated slowly from ambient to $265^{\circ} \mathrm{C}$ over a 2.5 \\
\hline & hour period, stopping periodically to capture an aliquot of reactor \\
\hline & off-gas for analysis by FT-IR spectroscopy. \\
\hline & Maximum temperature reached $-265^{\circ} \mathrm{C}$ \\
\hline Collection method: & $10 \mathrm{~cm}$ gas cell equipped with $\mathrm{ZnSe}$ windows \\
\hline Exit line temperature $\left({ }^{\circ} \mathrm{C}\right)$ & N/M \\
\hline
\end{tabular}


To begin WFusn-18, the given amounts of $\mathrm{WO}_{2}$ and $\mathrm{TiF}_{4}$ reagents were weighed out in such a manner where the fluoride compound was added to the oxide material (1.563:1 mole ratio $\mathrm{TiF}_{4}: \mathrm{WO}_{2}$ ) contained in a small plastic bottle kept in the argon-filled glovebag. The combined solids were mixed thoroughly before being transferred to the Parr mini-reactor also maintained under the inert atmosphere. Before heating the reaction vessel, a set of background infrared scans was collected with the gas cell containing dry air for use as a reference. The first sample scans were collected after beginning the flow of air through the reactor at $25^{\circ} \mathrm{C}$ and diverting gas through the cell for a five minute period. The reactor was then heated, raising the temperature in stages. Samples of the reactor effluent were isolated in the gas cell after sweeping through the cell for 2 minutes each at various temperatures along the heat-up. It was prior to the analysis of the sample captured at $96^{\circ} \mathrm{C}$ that the computer controlling the FT-IR spectrometer faulted, making it impossible to analyze more samples or retrieve previously recorded data files. The temperature of the reactor climbed to $155^{\circ} \mathrm{C}$ before the experiment was terminated.

The reaction vessel was cleaned and reassembled to conduct the same reaction over again in WFusn-19. In this trial, the exit line leaving the top of the Parr vessel was changed to a 1/4" line from the previous $1 / 8$ " OD tubing. The closure valve on the exit line from the reactor was switched to a Swagelok ${ }^{\circledR} 1 / 4$ " ball valve compared to the $1 / 8$ " stem valve used in WFusn-18. The larger diameter lines downstream from the reactor were inserted to address the near stoppage of flow observed during the last reaction. The setup downstream from the 3-way valve was the same as that shown in Figure 52 with the option to direct flow through the $10 \mathrm{~cm}$ gas cell or through the aqueous scrubber.

For WFusn-19, 7.6916 grams of combined reagents were heated slowly from room temperature to $265^{\circ} \mathrm{C}$ over a 2.5 hour period, stopping periodically to capture an aliquot of reactor off-gas for analysis by FT-IR spectroscopy. As before, the sweep period for the off-gas through the cell was 2 minutes before closing the cell to flow. A set of background scans was collected with air passing through the reactor at room ternperature. Sample scans were collected for aliquots of gas when the temperature reached $85^{\circ} \mathrm{C}, 185^{\circ} \mathrm{C}, 187^{\circ} \mathrm{C}, 190^{\circ} \mathrm{C}$ and $245^{\circ} \mathrm{C}$.

After completing the trial, the post-reaction solid from WFusn-19 was not analyzed by $\mathrm{x}$ ray diffraction due to the potential for release of $\mathrm{HF}$ vapors during the analysis. However, residue formed from the hydrolysis of material found coating the internal surfaces of the reactor was examined further by $\mathrm{x}$-ray diffraction after drying the aqueous solution to recover the solid. 


\subsubsection{Selection of suitable materials of construction for producing $\mathrm{WF}_{6}$.}

The experimental program to investigate the chemistry to produce $\mathrm{WF}_{6}$ was conducted using a reaction system made of nickel 200 alloy. The material performed well during the trials for producing $\mathrm{GeF}_{4}$ so it was put to the test in carrying out the $\mathrm{WF}_{6}$ program. Along with the 1" OD tube reactor, the boat used to hold the reactant mixture was also made of nickel. After performing the many experiments to produce $\mathrm{WOF}_{4}$, the nickel boat showed significant signs of corrosion and deterioration. An investigation into the corrosion was begun in order to learn what effects the high temperature fusion chemistry would have on a reaction system constructed of nickel.

The corrosion on the nickel boat was documented through a series of images. Much of the boat's exterior and interior walls were covered with a green-brown layer of flaky solid. A large piece of this corrosion layer was removed and divided into two specimens for characterization by $x$-ray diffraction. One piece of the corrosion solid was mounted exposing the outward-facing surface to the x-ray beam while the other sample was prepared with the interfacial side (side oriented against the wall of the boat) facing the analysis beam. X-ray diffraction patterns were collected for each specimen in order to identify the composition of the corrosion layer.

Rigorous testing of other materials besides nickel was not pursued in light of the information gathered during the materials compatibility studies performed for $\mathrm{GeF}_{4}$ production (refer to section 8.1.2).

\subsubsection{Reactor design.}

Two reactor configurations were used in conducting the experimental program to derive $\mathrm{WF}_{6}$. Both of these lab-scale systems were batch-type operations suitable for exploring the chemistry in small bench-top equipment. Since a pathway to the final product was not deduced, no effort was put into designing a production scale apparatus until the process was worked out where $\mathrm{WOF}_{4}$ was fluorinated to $\mathrm{WF}_{6}$.

\subsection{4 $\mathrm{WF}_{6}$ product characterization.}

In preparation for characterizing the purity of $\mathrm{WF}_{6}$ generated by the high temperature fusion process, a small quantity (250 grams) of $\mathrm{WF}_{6}$ was purchased from Advanced Research Chemicals, Inc. (Catoosa, OK). This material was certified at $99.99 \%$ purity. Using the Nicolet Instruments Magna-IR 560 infrared spectrometer and $10 \mathrm{~cm}$ gas cell with $\mathrm{ZnSe}$ windows, several aliquots of fluoride gas were analyzed to record a reference spectrum for this material.

Since the pathway to tungsten hexafluoride from $\mathrm{WOF}_{4}$ remained unresolved, no further work could be performed on this task. 


\subsection{Experimental Results for $\mathrm{WF}_{6}$.}

\subsubsection{Bench-scale process development for $\mathrm{WF}_{6}$ from $\mathrm{WOF}_{4}$.}

The first experimental efforts to develop the chemistry to make $\mathrm{WF}_{6}$ began by investigating a group of reaction parameters including the selection of a tungsten oxide reagent $\left(\mathrm{WO}_{2}\right.$ or $\mathrm{WO}_{3}$ ), the reaction temperature and the reagent stoichiometry (between $\mathrm{UF}_{4}$ and tungsten species). A series of 14 experiments was performed using milligram quantities of material and the thermogravimetric analyzer (TGA). A description of the reaction mixture and specific test conditions for each trial was compiled in Table 27 in section 9.1.1. Results for the 14 TGA runs have been clustered into groups sharing the same parent reaction mixture.

Examination of each of the post-reaction residues by x-ray diffraction was done in order to identify the leftover material. After presenting the findings for the five combinations of $U_{4}$ with tungsten oxide, trending between the various groups will be addressed.

The first group of reactions involved a mixture of $\mathrm{UF}_{4}$ and $\mathrm{WO}_{2}$ in a 1.014:1

stoichiometric ratio. The maximum reaction temperature was either $600^{\circ} \mathrm{C}$ or $700^{\circ} \mathrm{C}$. One of the reactions in this group was carried out in an alumina cup. Although no abnormalities were observed during the reaction at $600^{\circ} \mathrm{C}$, this data set was not evaluated due to possible interference caused by material incompatibilities. As illustrated in Figure 53, when the reactants were heated to $600^{\circ} \mathrm{C}$ in air, there appeared to be two events occurring. At about $400^{\circ} \mathrm{C}$, the sample weight started to decrease, suggesting the start of the fusion reaction. However, at about $500^{\circ} \mathrm{C}$ the weight of the sample started to increase at an accelerated rate as the maximum temperature was reached. The dominant weight increase observed here was similar to that seen in the oxidation of $\mathrm{WO}_{2}$ to $\mathrm{WO}_{3}$, which is also plotted in Figure 53.

In contrast, when this combination of reagents was heated to $700^{\circ} \mathrm{C}$ in air, the results were dramatically different as illustrated in Figure 54. Beginning at a temperature around $660^{\circ} \mathrm{C}$ the sample weight dropped on the order of 30 weight percent as a result of the fusion between $\mathrm{UF}_{4}$ and $\mathrm{WO}_{2}$ and release of $\mathrm{WOF}_{4}$ as a gas. The reaction happening at $700^{\circ} \mathrm{C}$ is given in equation (9.2)

$$
4 \mathrm{UF}_{4}+2 \mathrm{WO}_{2}+3 \mathrm{O}_{2}(\mathrm{~g}) \longrightarrow 4 \mathrm{UO}_{2} \mathrm{~F}_{2}+2 \mathrm{WOF}_{4}(\mathrm{~g})
$$

As further evidence to support equation (9.2), the residue from the platinum cup was analyzed by $\mathrm{x}$-ray powder diffraction. The diffraction pattern for that material is shown in Figure 55 along with a reference pattern for $\mathrm{UO}_{2} \mathrm{~F}_{2}$ (pdf \# 27-0933). With the exception of several unassigned small peaks, the sample and reference patterns were an excellent match. 


\section{$\mathrm{UF}_{4}+\mathrm{WO}_{2}$ and $\mathrm{WO}_{2}$ Heated to $600^{\circ} \mathrm{C}$ in Air}

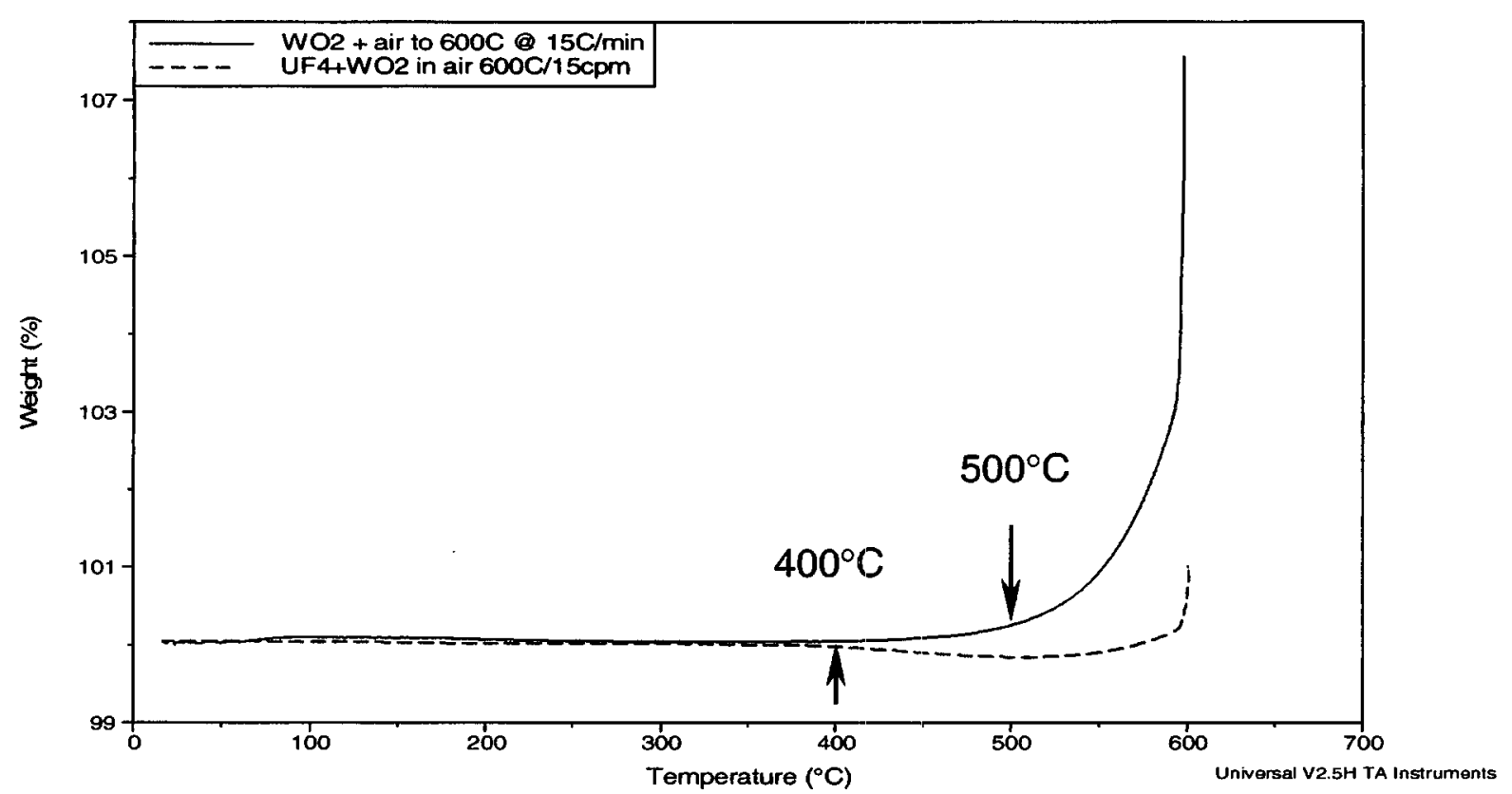

Figure 53. TGA results showing the weight change during the reaction between $\mathrm{UF}_{4}$ and $\mathrm{WO}_{2}\left[\mathrm{UF}_{4}: \mathrm{WO}_{2}=1.014: 1\right]$ in air at $600^{\circ} \mathrm{C}$ and the oxidation of $W O_{2}$ in air at $600^{\circ} \mathrm{C}$.

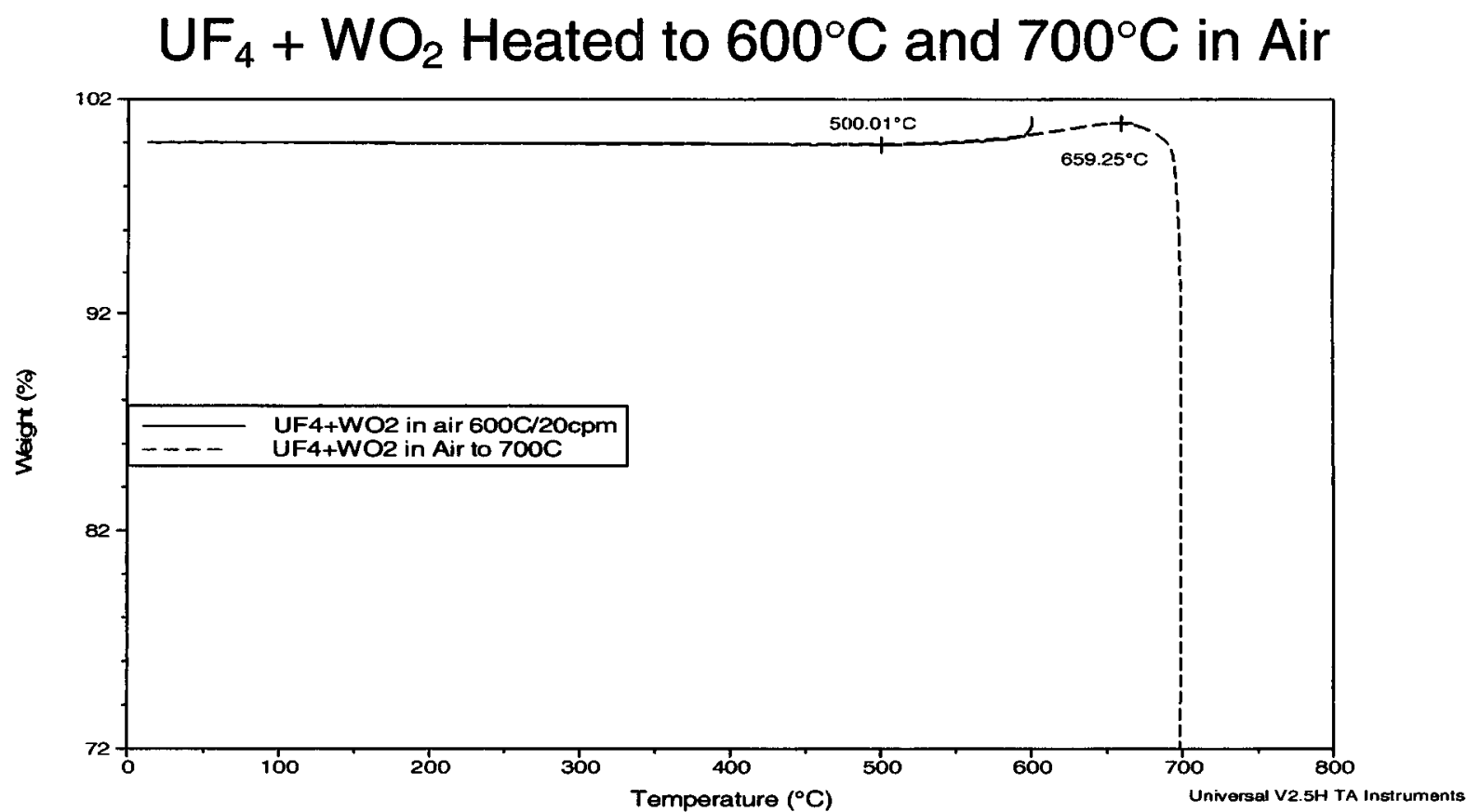

Figure 54. TGA result comparing the weight change during the reaction between $\mathrm{UF}_{4}$ and $\mathrm{WO}_{2}\left[\mathrm{UF}_{4}: \mathrm{WO}_{2}=1.014: 1\right]$ at $600^{\circ} \mathrm{C}$ and $700^{\circ} \mathrm{C}$ in air. 


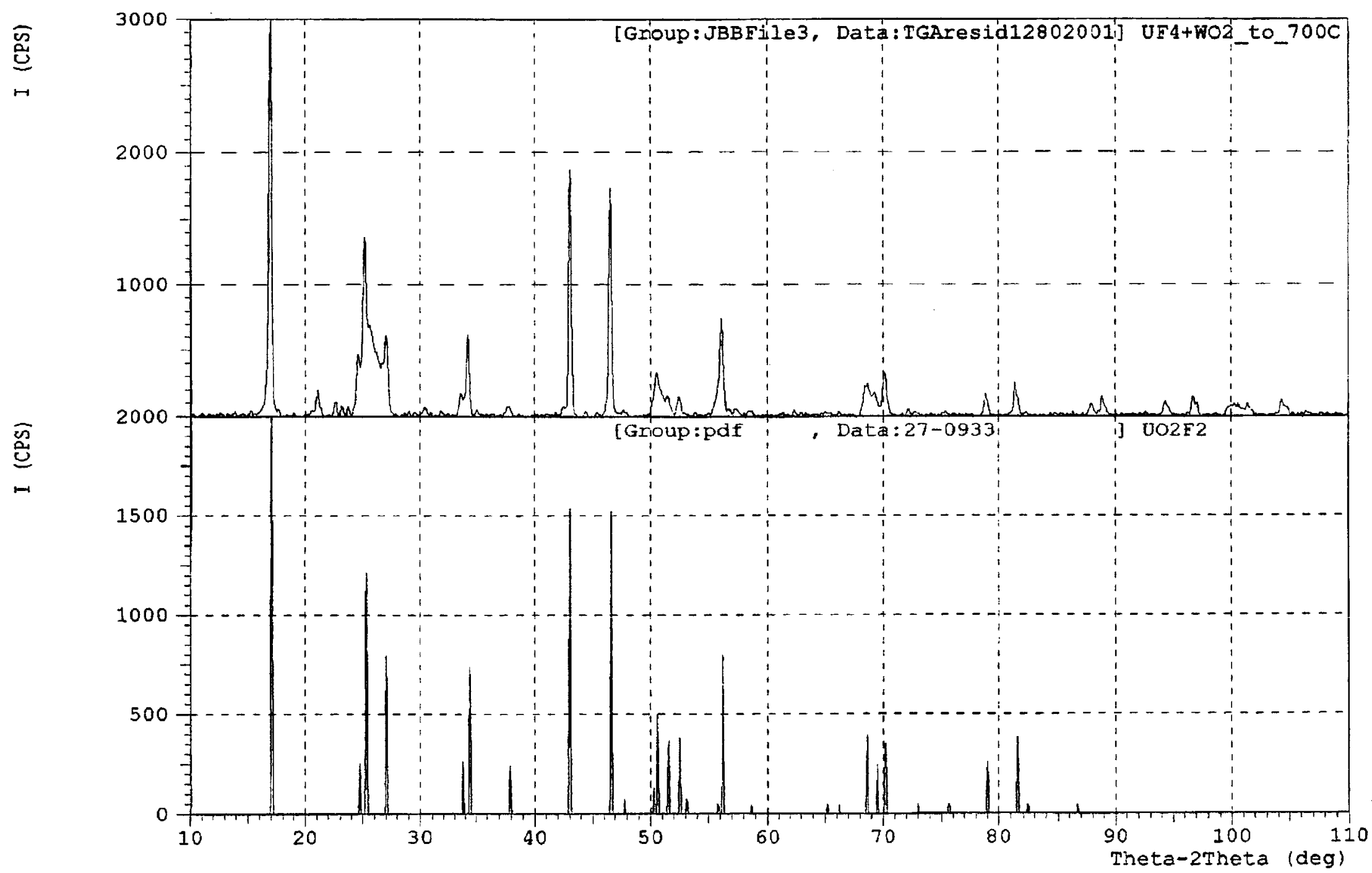

Figure 55. $\mathrm{X}$-ray diffraction pattern of the residue from $\mathrm{UF}_{4}+\mathrm{WO}_{2}\left[\mathrm{UF}_{4}: \mathrm{WO}_{2}=1.014: 1\right]$ reacted at $700^{\circ} \mathrm{C}$ in air and the reference pattern for $\mathrm{UO}_{2} \mathrm{~F}_{2}$ (pdf\# 27-0933). 
In contrast, the diffraction pattern for the residue from the reaction carried out at $600^{\circ} \mathrm{C}$ supported the conclusion that reaction between components had not proceeded very far. In Figure 56, the reaction product matched well to the reference pattern for $\mathrm{UF}_{4}$ (pdf \# 32-1401) and to a fluoride exchanged tungsten oxide compound with the formula $\mathrm{WO}_{2.96} \mathrm{~F}_{0.04}$ (pdf \# 22-0960). The presence of a fluorine-doped oxide is one indication the interaction between $\mathrm{UF}_{4}$ and $\mathrm{WO}_{2}$ had started.

From a quantitative perspective, results for the four micro-scale experiments are presented in Table $\mathbf{4 5}$ below.

\section{Table 45.}

TGA results for the reactions using $\mathrm{UF}_{4}+\mathrm{WO}_{2}\left[\mathrm{UF}_{4}: \mathrm{WO}_{2}=1.014: 1\right]$.

\begin{tabular}{|c|c|c|c|c|c|}
\hline Reaction & Temperature & $\begin{array}{l}\text { Sample } \\
\text { Weight }\end{array}$ & $\begin{array}{c}\text { Observed } \\
\text { Weight } \\
\text { Change }\end{array}$ & $\begin{array}{c}\text { Calc'd Wt. } \\
\text { Change for } \\
\mathrm{WO}_{2} \rightarrow \mathrm{WO}_{3} \\
\text { Only }\end{array}$ & $\begin{array}{l}\text { Calc'd Weight } \\
\text { Change for } \\
\mathrm{UO}_{2} \mathrm{~F}_{2}+\mathrm{WOF}_{4}\end{array}$ \\
\hline & $\left({ }^{\circ} \mathrm{C}\right)$ & (mg) & (mg) & (mg) & (mg) \\
\hline $\mathrm{UF}_{4}+\mathrm{WO}_{2}$ & 600 & 25.0164 & 0.252 & 0.7489 & -5.0409 \\
\hline $\mathrm{UF}_{4}+\mathrm{WO}_{2}$ & 600 & 34.7404 & 0.4097 & 1.0400 & -7.0003 \\
\hline $\mathrm{UF}_{4}+\mathrm{WO}_{2}$ & 700 & 46.2571 & -13.14 & & $-9 . \overline{3210}$ \\
\hline $\mathrm{WO}_{2}+\mathrm{O}_{2}$ & 600 & 19.3901 & 1.463 & 1.4370 & --- \\
\hline
\end{tabular}

Included in the table are "calculated" weight changes based on either complete reaction of the $\mathrm{UF}_{4}$ with $\mathrm{WO}_{2}$ to $\mathrm{UO}_{2} \mathrm{~F}_{2}$ and $\mathrm{WOF}_{4}(\mathrm{~g})$ or the oxidation of $\mathrm{WO}_{2}$ to $\mathrm{WO}_{3}$ only. For the trial where $\mathrm{WO}_{2}$ was heated to $600^{\circ} \mathrm{C}$ by itself, the observed weight gain was on par with the predicted increase. For those runs using the combined reactants, at $600^{\circ} \mathrm{C}$, the observed weight changes fell in-between the two calculated values. As one would expect, the smaller than predicted weight gains signaled the fusion process and release of gaseous product was beginning to offset the effects of the oxidation process. The weight loss observed for the reaction carried out at $700^{\circ} \mathrm{C}$ was larger than that predicted by equation (9.2) (page 133). Explanation of the excessive weight loss will be discussed after presenting the results for the other TGA experiments. 


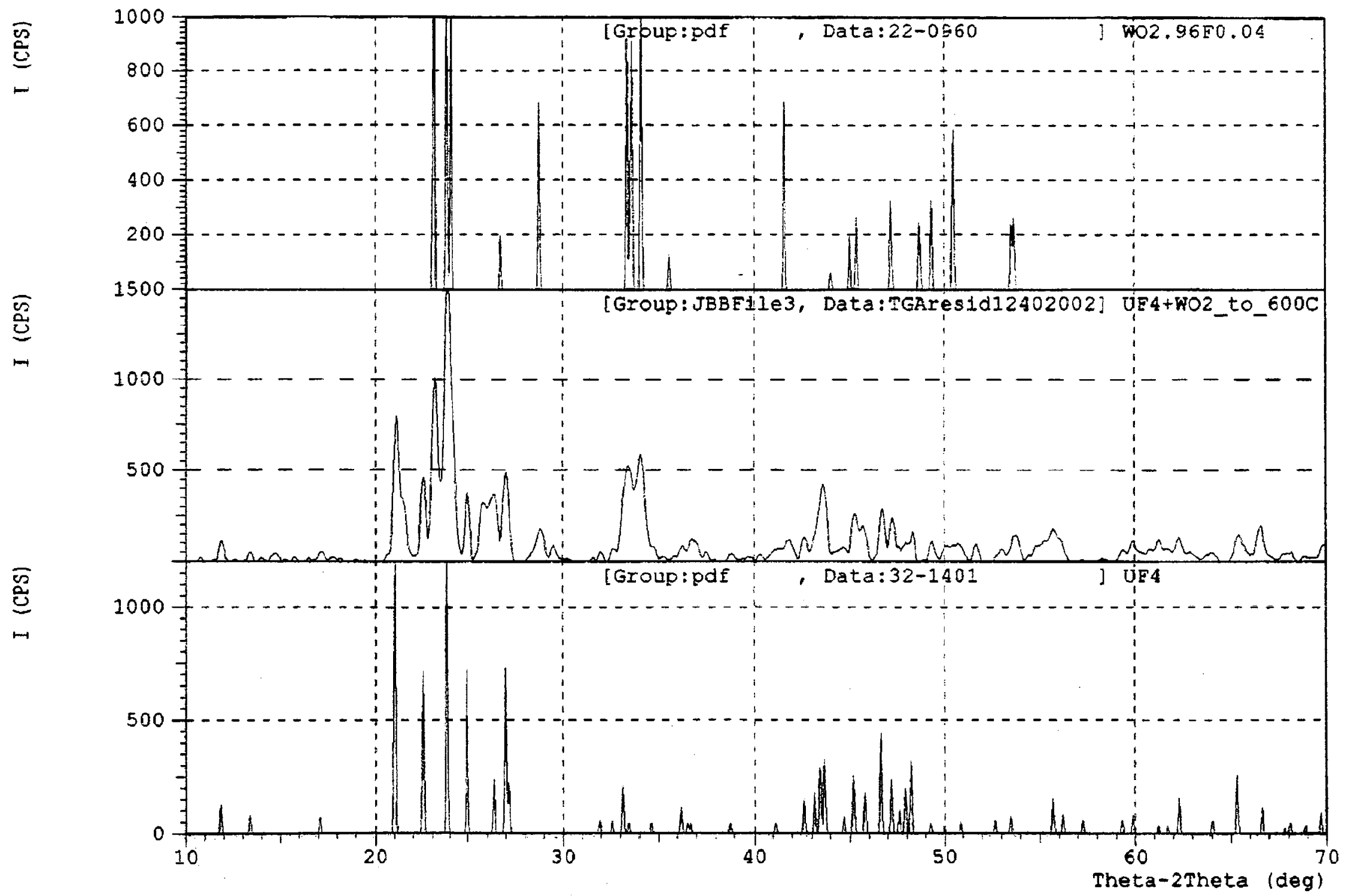

Figure 56. X-ray diffraction pattern of the residue from $\mathrm{UF}_{4}+\mathrm{WO}_{2}\left[\mathrm{UF}_{4}: \mathrm{WO}_{2}=1.014: 1\right]$ reacted at $600^{\circ} \mathrm{C}$ in air and reference patterns for $\mathrm{WO}_{2.96} \mathrm{O}_{0.04}$ (pdf\# 22-0960) and $\mathrm{UF}_{4}$ (pdf\# 32-1401). 
The second set of experiment using $\mathrm{WO}_{2}$ as the oxide source consisted of two trials encompassing a stoichiometric ratio of $1.844: 1 \mathrm{UF}_{4}: \mathrm{WO}_{2}$. Here, one reaction was done at $700^{\circ} \mathrm{C}$ while the other at $800^{\circ} \mathrm{C}$, both using a $20^{\circ} \mathrm{C} /$ min heating profile and a 45 minute dwell period at their respective temperatures. The TGA results are shown in Figure $\mathbf{5 7}$ for both trials. The dominant feature again was the weight loss caused by the release of $\mathrm{WOF}_{4}$ starting around $660^{\circ} \mathrm{C}-680^{\circ} \mathrm{C}$. For the mixture reacted at $700^{\circ} \mathrm{C}$, the observed weight loss was $10.58 \mathrm{mg}$, which was the exact loss predicted by the scheme in equation (9.2) (page 133). For the trial at $800^{\circ} \mathrm{C}$, the mixture lost weight at a faster rate initially but took longer to achieve a steady weight. As seen in other reactions, the actual weight loss of $28.34 \mathrm{mg}$ was considerably greater than the calculated loss of $17.04 \mathrm{mg}$.

$\mathrm{X}$-ray diffraction analyses of both residues were collected. Patterns are shown in Figure 58 along with the reference for $\mathrm{UO}_{2} \mathrm{~F}_{2}$ (pdf \# 27-0933). Both products were similar to each other and matched well with the reference. Within each of the experimental patterns, there were small peaks in the range between $21^{\circ}-28^{\circ} 2$-theta indicating the presence of other phases in very low concentration. In the material made at $700^{\circ} \mathrm{C}$, there was evidence of $\mathrm{UF}_{4}$ left over along with $\mathrm{U}_{3} \mathrm{O}_{8}$. The $800^{\circ} \mathrm{C}$ residue had several peaks matching well with the $\mathrm{U}_{3} \mathrm{O}_{8}$ reference pattern (pdf \# 47-1493). Visual inspection of the solids in the platinum cups revealed the surface of each powder had discolored from the typical pale yellow color found in the bulk. The top layer of the $800^{\circ} \mathrm{C}$ material was charcoal gray-black while the $700^{\circ} \mathrm{C}$ residue had a less intense gray-brown surface. The specimens collected and mounted for $\mathrm{X}$-ray analysis were representative of the bulk reaction product in each case. Examination of the undisturbed discolored surface layers could not be done easily using the $\mathrm{x}$-ray equipment in-house. 


\section{$\mathrm{UF}_{4}+\mathrm{WO}_{2}$ Heated in Air}

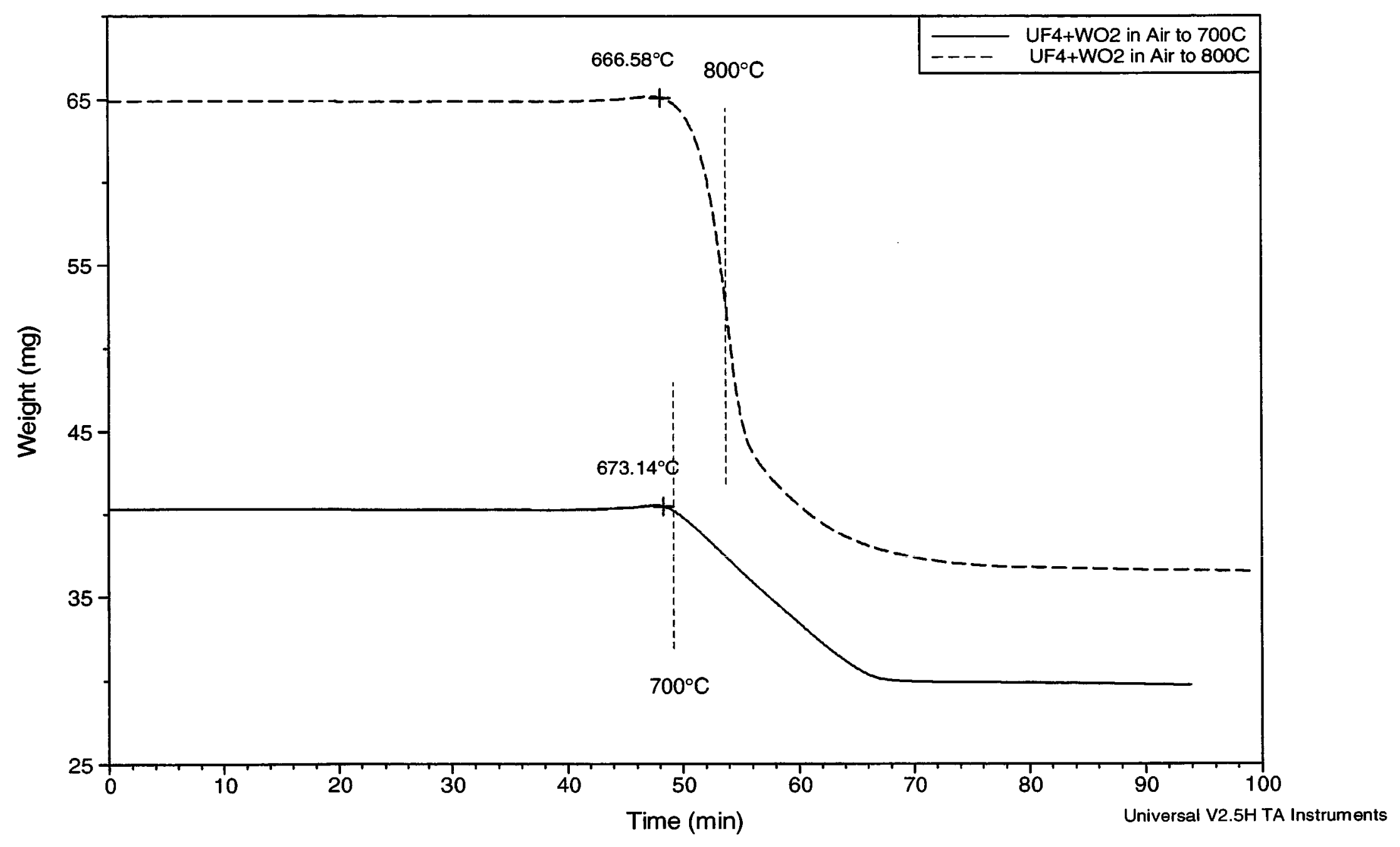

Figure 57. TGA results showing the weight change during the reaction between $\mathrm{UF}_{4}$ and $\mathrm{WO}_{2}\left[\mathrm{UF}_{4}: \mathrm{WO}_{2}=1.844: 1\right]$ at $700^{\circ} \mathrm{C}$ and $800^{\circ} \mathrm{C}$ in air. 


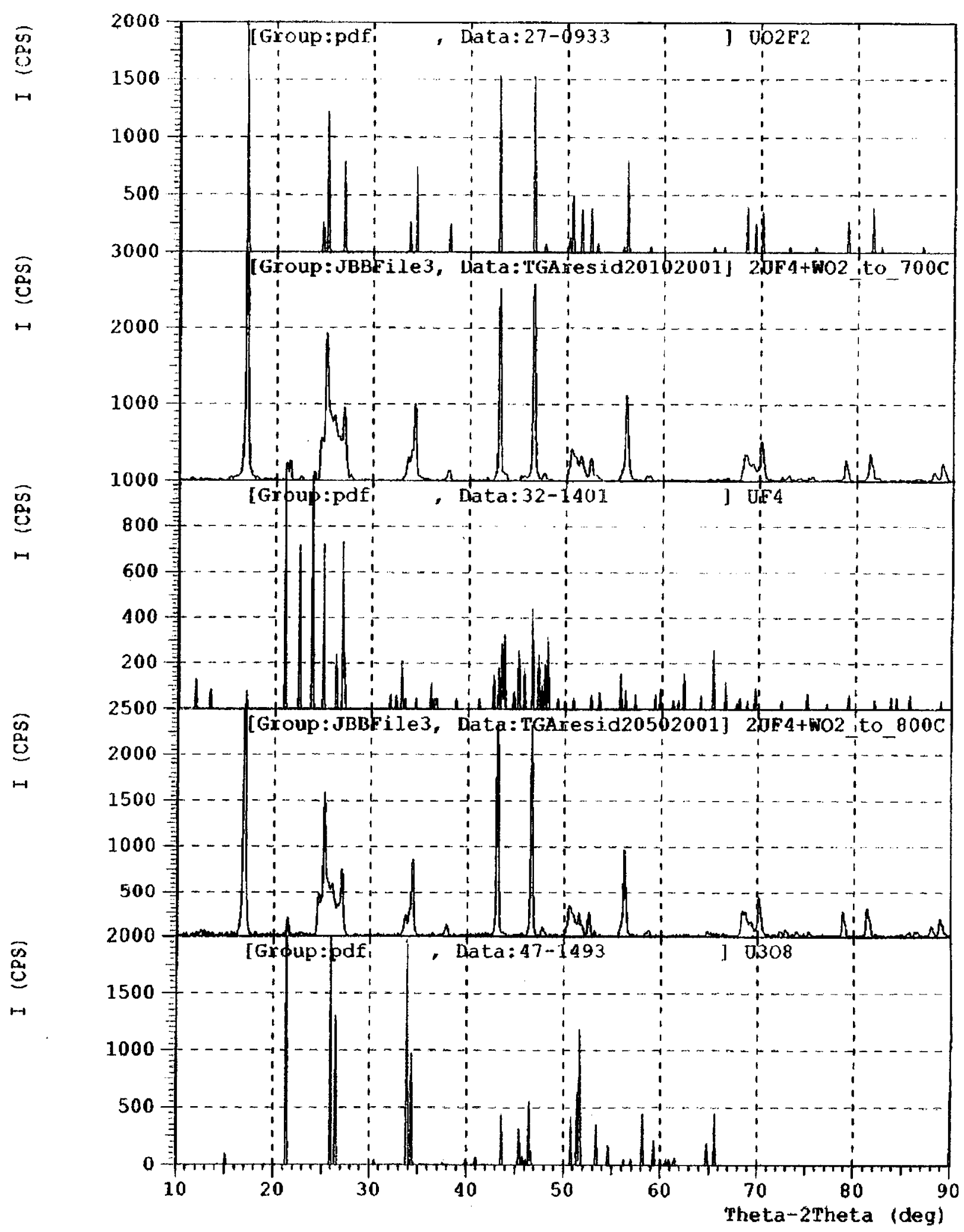

Figure 58. X-ray diffraction patterns for the residues from $U_{4}+W_{2}\left[\mathrm{UF}_{4}: W_{2}=1.844: 1\right]$ reacted at $700^{\circ} \mathrm{C}$ and $800^{\circ} \mathrm{C}$ in air and reference patterns for $\mathrm{UO}_{2} \mathrm{~F}_{2}$ (pdf\# 27-0933), $\mathrm{UF}_{4}$ (pdf\# 32-1401) and $\mathrm{U}_{3} \mathrm{O}_{8}$ (pdf\# 47-1493). 
The third mixture between $\mathrm{UF}_{4}$ and $\mathrm{WO}_{2}$ to be investigated had the stoichiometric ratio of 2.013:1 UF $: \mathrm{WO}_{2}$. Only one experiment was performed with this combination of reagents. The material was heated at $20^{\circ} \mathrm{C} / \mathrm{min}$ to $700^{\circ} \mathrm{C}$ and held there for 90 minutes. The dwell time was lengthened to evaluate the stability of the reaction product under thermal stress. The TGA result is shown in Figure 59. As before, there was a significant weight loss as the temperature crested at $700^{\circ} \mathrm{C}$ and continued at a steady rate for about 15 minutes before subsiding at the 80 minute point into the run. From that point on until the end ( $\sim 59$ minutes) there was a very gradual loss amounting to $0.77 \mathrm{mg}$. The weight loss during the first 80 minutes totaled $16.41 \mathrm{mg}$. The residue in the $\mathrm{Pt}$ cup again had a brown-black top layer covering a fine, pale yellow powder. $\mathrm{X}$-ray diffraction analysis of the material, pictured in Figure 60, showed it to be $\mathrm{UO}_{2} \mathrm{~F}_{2}$ along with a second phase matching that of $\mathrm{U}_{3} \mathrm{O}_{8}$ (pdf \# 47-1493). The gradual weight loss over the last 60 minutes coupled with the presence of an increased amount of $\mathrm{U}_{3} \mathrm{O}_{8}$ are attributed to the decomposition of $\mathrm{UO}_{2} \mathrm{~F}_{2}$ said to begin around $300^{\circ} \mathrm{C}^{27}$.

In addition to the reactions carried out using $\mathrm{WO}_{2}$, a parallel investigation into reacting $\mathrm{WO}_{3}$ with $\mathrm{UF}_{4}$ was undertaken because it became evident that some of the $\mathrm{WO}_{2}$ reactant in the previous trials was converted to $\mathrm{WO}_{3}$ beginning at temperatures as low as $400^{\circ} \mathrm{C}$ (see Figure 53). The oxidation of $\mathrm{WO}_{2}$ to $\mathrm{WO}_{3}$ could impede the desired reaction to liberate $\mathrm{WOF}_{4}(\mathrm{~g})$ should the trioxide compound be non-reactive or produce an unwanted by-product. From a thermodynamic viewpoint, the reaction between $\mathrm{UF}_{4}$ and $\mathrm{WO}_{3}$ to produce $\mathrm{WOF}_{4}(\mathrm{~g})$ and $\mathrm{UO}_{2} \mathrm{~F}_{2}$ as written in equation (9.3)

$$
2 \mathrm{UF}_{4}+\mathrm{WO}_{3}+\mathrm{O}_{2}(\mathrm{~g}) \longrightarrow 2 \mathrm{UO}_{2} \mathrm{~F}_{2}+\mathrm{WOF}_{4}(\mathrm{~g})
$$

is not spontaneous at temperatures below $1000^{\circ} \mathrm{C}$ according to the calculations ${ }^{14}$ shown in Table 46.

Table 46.

Thermodynamic calculations for the reaction between $\mathrm{UF}_{4}$ and $\mathrm{WO}_{3}$.

\begin{tabular}{|c|c|c|c|c|}
\hline \multicolumn{5}{|c|}{$\mathbf{2 U F}_{\mathbf{4}}+\mathrm{WO}_{\mathbf{3}}+\mathbf{O}_{\mathbf{2}}(\mathbf{g}) \longrightarrow 2 \mathbf{U O}_{\mathbf{2}} \mathbf{F}_{\mathbf{2}}+\mathrm{WOF}_{\mathbf{4}}(\mathbf{g})$} \\
\hline Temperature ${ }^{\circ} \mathbf{C}$ & delta $\mathbf{H}(\mathrm{kcal})$ & delta $\mathbf{S}(\mathbf{c a l})$ & delta $\mathbf{~}$ (kcal) & $\mathbf{K}$ \\
\hline 0 & 12.607 & 5.851 & 11.008 & $1.553 \mathrm{E}-009$ \\
\hline 100 & 11.918 & 3.674 & 10.547 & $6.641 \mathrm{E}-007$ \\
\hline 200 & 11.454 & 2.566 & 10.240 & $1.861 \mathrm{E}-005$ \\
\hline 300 & 11.084 & 1.856 & 10.021 & $1.509 \mathrm{E}-004$ \\
\hline 400 & 10.754 & 1.324 & 9.863 & $6.276 \mathrm{E}-004$ \\
\hline 500 & 10.436 & 0.884 & 9.753 & $1.749 \mathrm{E}-003$ \\
\hline 600 & 10.115 & 0.493 & 9.684 & $3.765 \mathrm{E}-003$ \\
\hline 700 & 9.779 & 0.129 & 9.654 & $6.790 \mathrm{E}-003$ \\
\hline 800 & 9.095 & -0.532 & 9.666 & $1.075 \mathrm{E}-002$ \\
\hline 900 & 8.833 & -0.765 & 9.730 & $1.539 \mathrm{E}-002$ \\
\hline 1000 & 8.544 & -1.001 & 9.818 & $2.063 \mathrm{E}-002$ \\
\hline
\end{tabular}




\section{$\mathrm{UF}_{4}+\mathrm{WO}_{2}$ Heated to $700^{\circ} \mathrm{C}$ in Air}

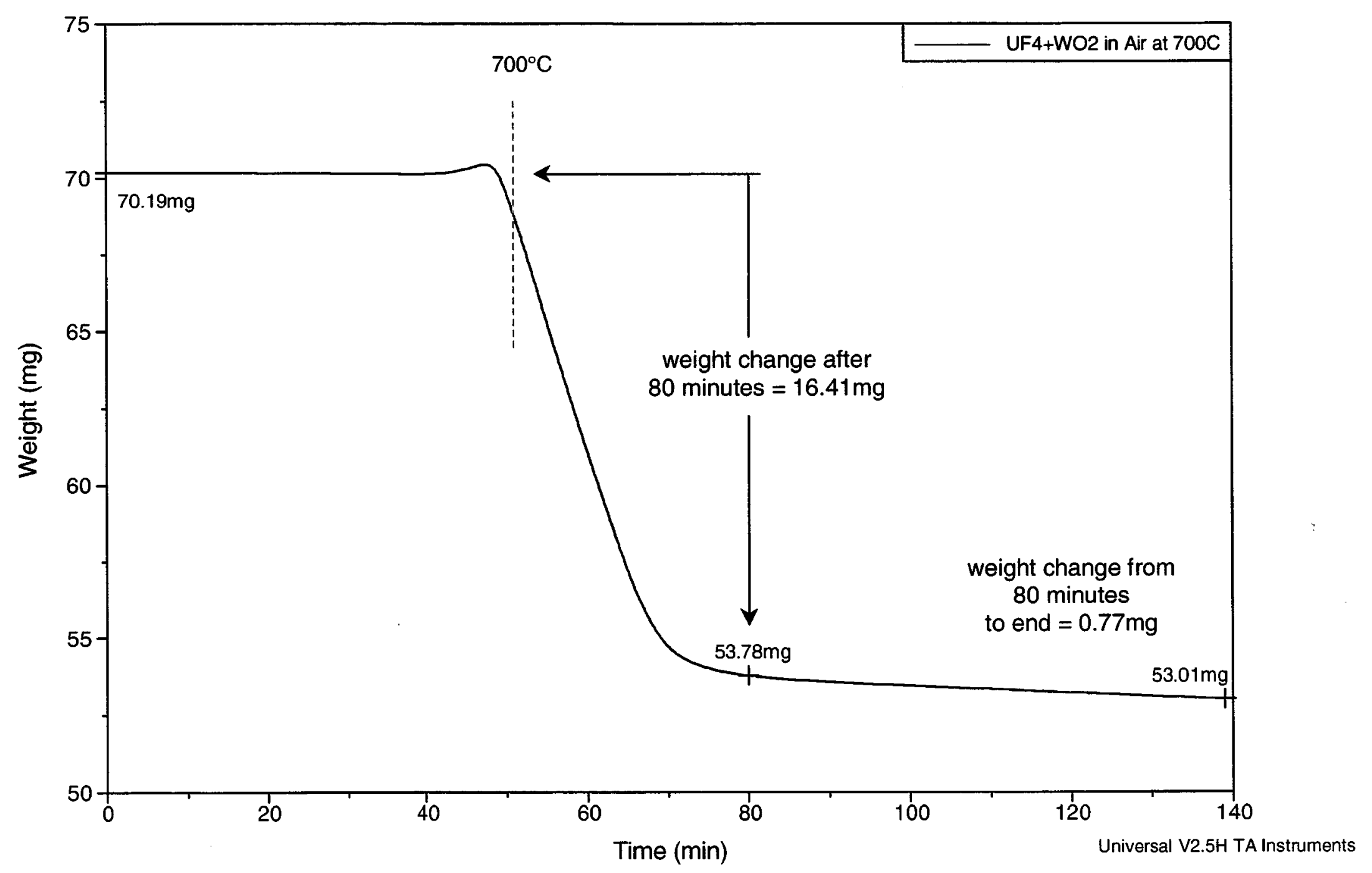

Figure 59. TGA result showing weight change during reaction between $\mathrm{UF}_{4}$ and $\mathrm{WO}_{2}\left[\mathrm{UF}_{4}: \mathrm{WO}_{2}=2.013: 1\right]$ at $700^{\circ} \mathrm{C}$ in air. 


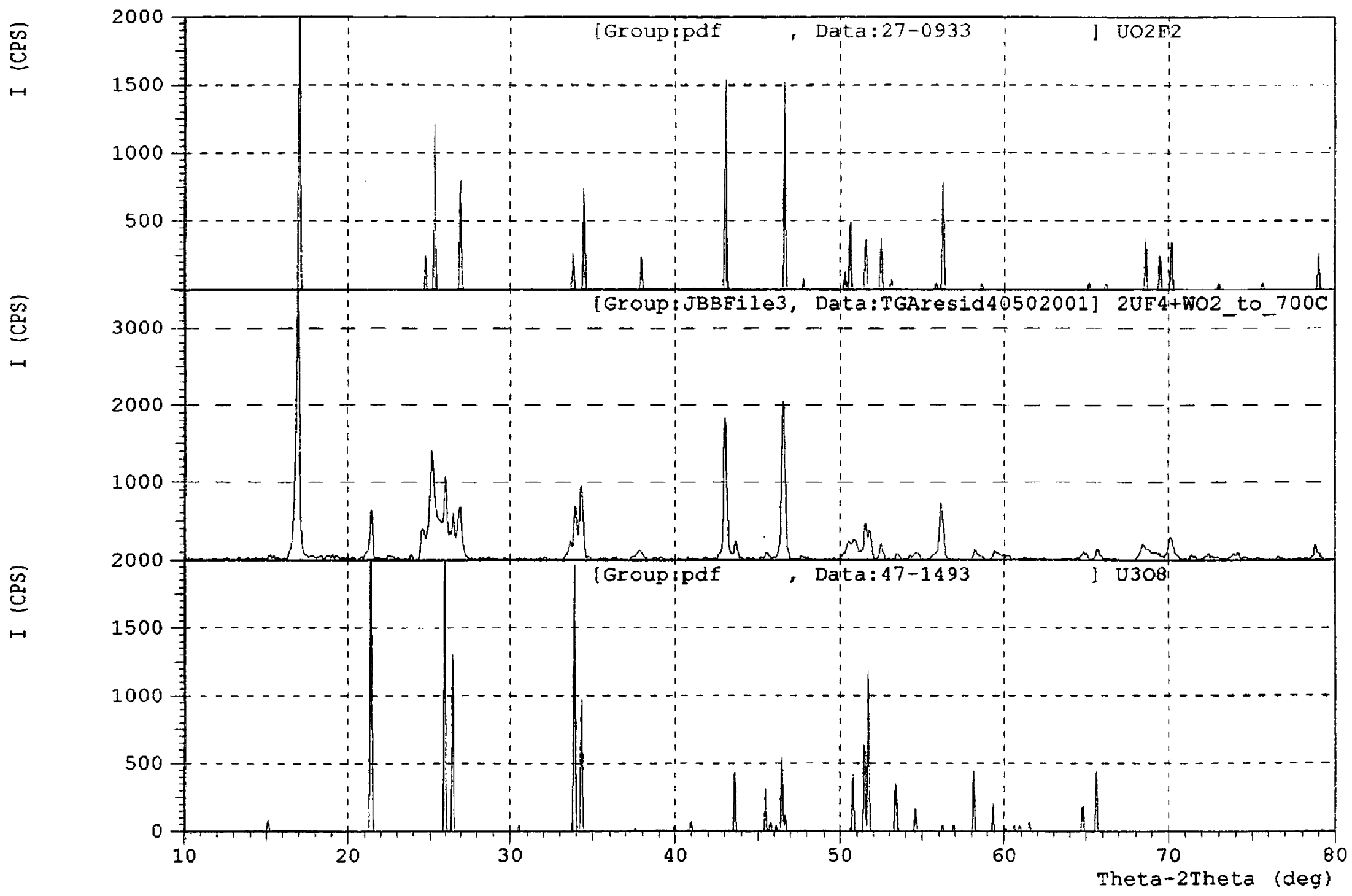

Figure 60. X-ray diffraction pattern for the residue from $\mathrm{UF}_{4}+\mathrm{WO}_{2}\left[\mathrm{UF}_{4}: \mathrm{WO}_{2}=2.013: 1\right]$ and reference patterns for $\mathrm{UO}_{2} \mathrm{~F}_{2}$ (pdf\# 27-0933) and $\mathrm{U}_{3} \mathrm{O}_{8}$ (pdf\# 47-1493). 
With that knowledge in hand, a mixture of $\mathrm{UF}_{4}$ and $\mathrm{WO}_{3}$ was prepared where the stoichiometric proportions were 1:1.025 $\mathrm{UF}_{4}: \mathrm{WO}_{3}$. This mixture was heated at $20^{\circ} \mathrm{C} / \mathrm{min}$ to $700^{\circ} \mathrm{C}$ and held there for 30 minutes. The result is shown in Figure 61. The mixture began loosing weight beginning around $655^{\circ} \mathrm{C}$. After the 30 minute period there was a weight loss of $3.57 \mathrm{mg}$. Using the scenario in equation (9.3) (page 141), the calculated weight loss, assuming complete reaction, was $5.80 \mathrm{mg}$. The residue remaining in the platinum cup was yellow with just a trace of gold and brown discoloration on the surface of the powder. The reaction product was characterized by x-ray diffraction and that result is included in Figure 62. It was clear that the reacted solid did contain a sizeable amount of $\mathrm{UO}_{2} \mathrm{~F}_{2}$ as indicated from the match with the corresponding reference pattern (pdf \# 27-0933). However, additional diffraction peaks associated with one or more phases were present but could not be matched with much certainty to any materials containing any combination of $\mathrm{U}, \mathrm{W}, \mathrm{O}$ and $\mathrm{F}$ in the ICDD database ${ }^{\mathbf{1 3}}$. A diffraction pattern recorded for $\mathrm{WO}_{3}$ is also included in Figure 62 since the final residue should contain $\sim 27.5 \%$ (by weight) $\mathrm{WO}_{3}$ left behind due to stoichiometric excess. The pattern for the reaction product does not correlate well with that for the starting tungsten oxide material.

The last group of TGA experiments to be completed were done using a mixture possessing a $1.908: 1$ mole ratio of $\mathrm{UF}_{4}: \mathrm{WO}_{3}$. Reactions at temperatures of $700^{\circ} \mathrm{C}, 750^{\circ} \mathrm{C}$ and $800^{\circ} \mathrm{C}$ were performed, all using a similar heating rate of $20^{\circ} \mathrm{C} / \mathrm{min}$ and 45 minute dwell at the indicated maximum. The weight loss curves for the three runs are pictured in Figure 63. In all three cases, weight loss began about $650^{\circ} \mathrm{C}$. The mixture heated to $700^{\circ} \mathrm{C}$ lost $6.40 \mathrm{mg}$ over the course of the reaction. A total of $21.03 \mathrm{mg}$ was lost in the $750^{\circ} \mathrm{C}$ reaction while a decrease of $13.52 \mathrm{mg}$ was observed during the first 68 minutes of the run carried out at $800^{\circ} \mathrm{C}$. During the last 30 minutes of the $800^{\circ} \mathrm{C}$ fusion, an additional loss of $0.44 \mathrm{mg}$ was recorded. These weight loss results are compiled in Table 47 below

Table 47.

Weight loss results for the reactions between $\mathrm{UF}_{4}+\mathrm{WO}_{3}\left[\mathrm{UF}_{4}: \mathrm{WO}_{3}=1.908: 1\right]$.

\begin{tabular}{|c|c|c|c|c|}
\hline $\begin{array}{c}\text { Reaction } \\
\text { Temperature }\end{array}$ & $\begin{array}{c}\text { Sample } \\
\text { Weight }\end{array}$ & $\begin{array}{c}\text { Observed } \\
\text { Weight Loss }\end{array}$ & $\begin{array}{c}\text { Calculated } \\
\text { Weight Loss }\end{array}$ & $\begin{array}{c}\text { Ratio } \\
\text { Obsv'd/Calc'd }\end{array}$ \\
\hline$\left({ }^{\circ} \mathbf{C}\right)$ & $\mathbf{( m g )}$ & $\mathbf{( m g )}$ & $\mathbf{( m g )}$ & $\mathbf{( \% )}$ \\
\hline 700 & 32.61 & 6.40 & 9.13 & 70.1 \\
\hline 750 & 54.27 & 21.03 & 15.19 & 138 \\
\hline 800 & 32.31 & 13.96 & 9.05 & 154 \\
\hline
\end{tabular}




\section{$\mathrm{UF}_{4}+\mathrm{WO}_{3}$ Heated to $700^{\circ} \mathrm{C}$ in Air}

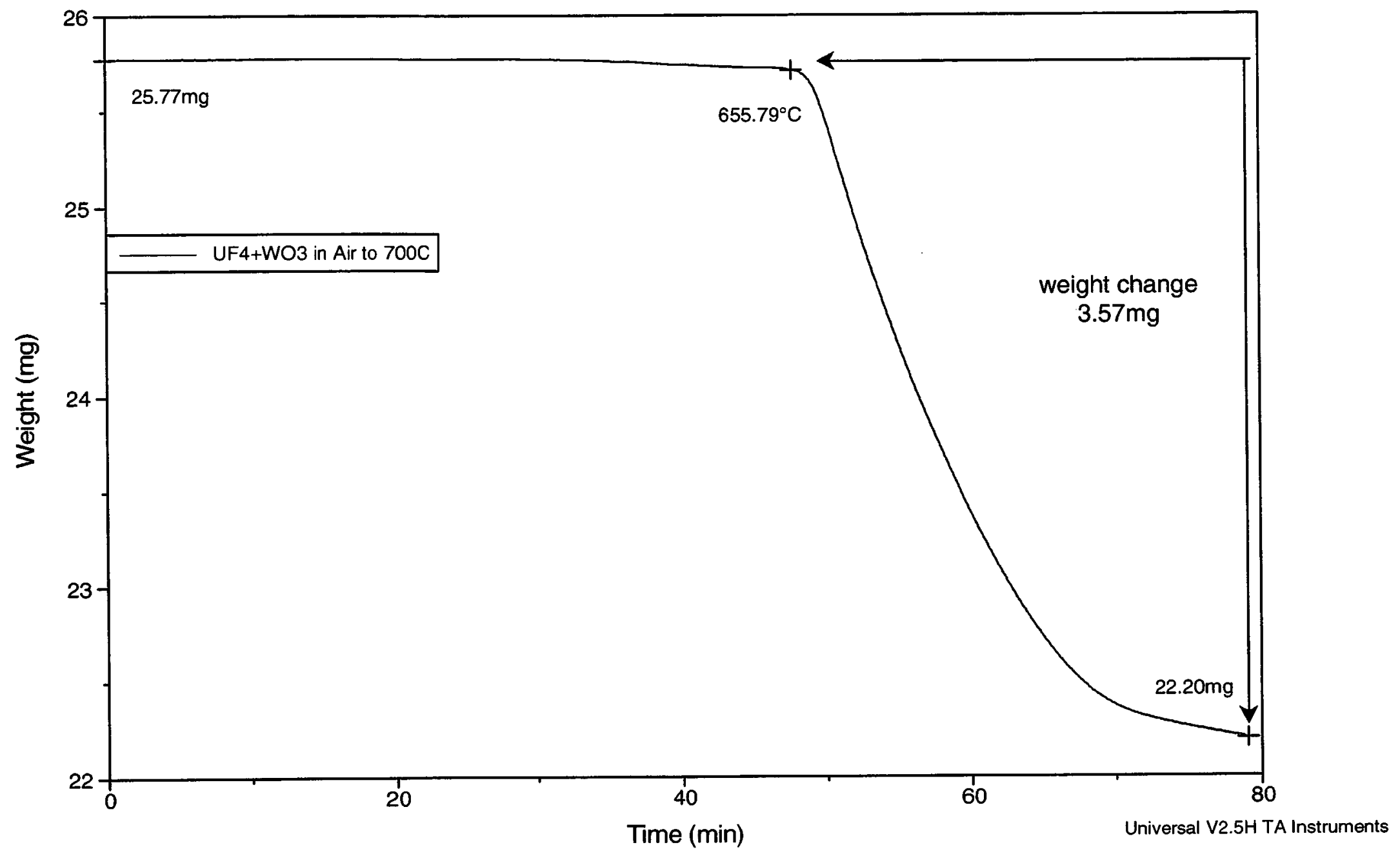

Figure 61. TGA result showing the weight change during the reaction between $\mathrm{UF}_{4}$ and $\mathrm{WO}_{3}\left[\mathrm{UF}_{4}: \mathrm{WO}_{3}=1: 1.025\right]$ at $700^{\circ} \mathrm{C}$ in air. 


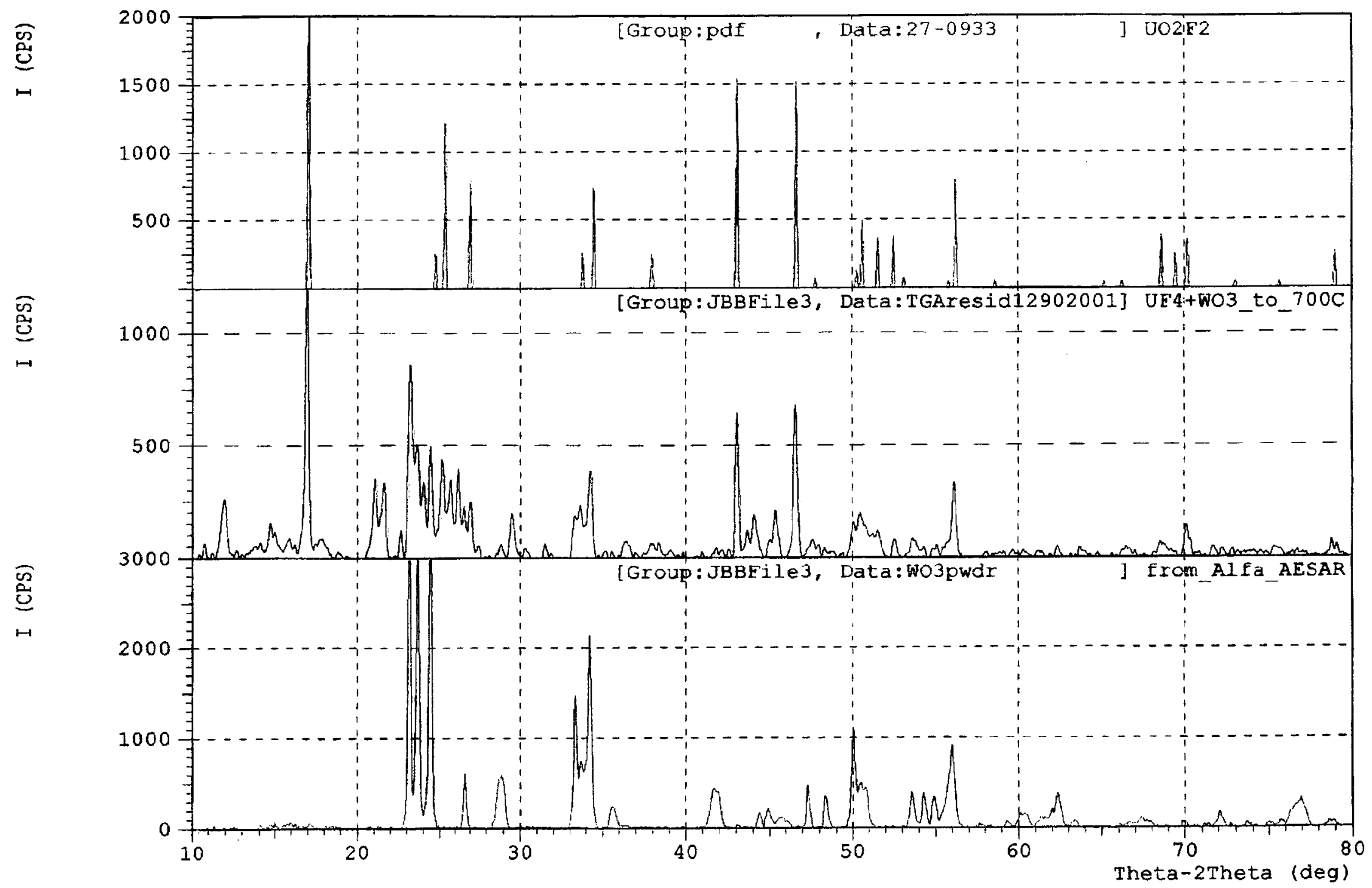

Figure 62. X-ray diffraction patterns for the residue from $\mathrm{UF}_{4}+\mathrm{WO}_{3}\left[\mathrm{UF}_{4}: \mathrm{WO}_{3}=1: 1.025\right]$ reacted in air at $700^{\circ} \mathrm{C}$, $\mathrm{WO}_{3}$ reagent from $A l f a$ Aesar and the reference pattern for $\mathrm{UO}_{2} \mathrm{~F}_{2}$ (pdf\# 27-0933). 


\section{$\mathrm{UF}_{4}+\mathrm{WO}_{3}$ Heated to $700^{\circ} \mathrm{C}, 750^{\circ} \mathrm{C}$ and $800^{\circ} \mathrm{C}$ in Air}

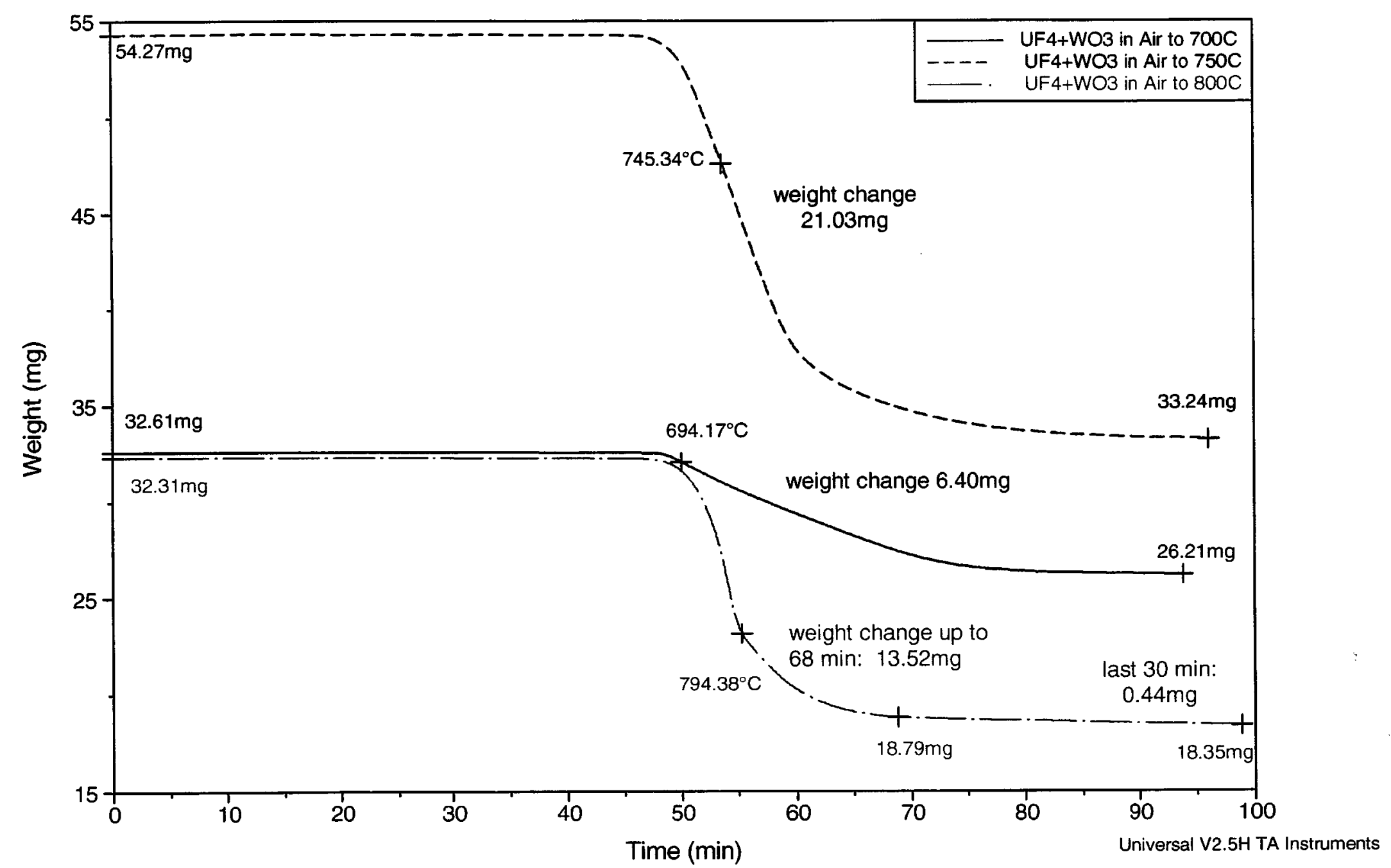

Figure 63. TGA results showing weight change during the reaction between $\mathrm{UF}_{4}$ and $\mathrm{WO}_{3}\left[\mathrm{UF}_{4}: \mathrm{WO}_{3}=1.908: 1\right]$ at $700^{\circ} \mathrm{C}, 750^{\circ} \mathrm{C}$ and $800^{\circ} \mathrm{C}$ in air. 
When compared to the calculated weight change using equation (9.3) (page 141), the reaction at $700^{\circ} \mathrm{C}$ was only partially complete while the other two fusions produced a greater than expected loss. Visual inspection of each residue showed a progressively darker surface layer beginning with a tan coloring over the $700^{\circ} \mathrm{C}$ material and transitioning to a gray-black overlayer covering the $800^{\circ} \mathrm{C}$ powder. Material at the core of each platinum cup was pale yellow. Characterization of two residues by $\mathrm{x}$-ray diffraction is shown in Figure 64 along with the matching references for $\mathrm{UO}_{2} \mathrm{~F}_{2}$ (pdf \# 27-0933), $\mathrm{U}_{3} \mathrm{O}_{8}$ (pdf \# 47-1493) and $\mathrm{UF}_{4}$ (pdf \# 321401). The detection of $\mathrm{UF}_{4}$ peaks in the pattern of the $700^{\circ} \mathrm{C}$ residue was consistent with the TGA result showing incomplete reaction. The correlation of peaks in the $800^{\circ} \mathrm{C}$ product matching those for $\mathrm{U}_{3} \mathrm{O}_{8}$ confirmed the decomposition of $\mathrm{UO}_{2} \mathrm{~F}_{2}$ was contributing to and was most likely responsible for the $0.44 \mathrm{mg}$ loss observed during the last 30 minutes of that experiment. The dominant phase in both sample patterns was that of $\mathrm{UO}_{2} \mathrm{~F}_{2}$.

Now that all TGA results have been summarized, comparisons and trending across the groups can be highlighted with respect to the three parameters of interest. First off, with regard to selection of a tungsten oxide reagent, it is apparent that both $\mathrm{WO}_{2}$ and $\mathrm{WO}_{3}$ reacted with $\mathrm{UF}_{4}$ to liberate a volatile tungsten oxyfluoride compound and in the process leave behind $\mathrm{UO}_{2} \mathrm{~F}_{2}$. Based on the thermodynamic calculations in Table 46, the reaction between $\mathrm{WO}_{3}$ and $\mathrm{UF}_{4}$ was not predicted to be spontaneous with a Gibbs free energy $(\Delta \mathrm{G})$ of $+9.654 \mathrm{kcal}$ at $700^{\circ} \mathrm{C}$. Yet, a reaction between substances did take place suggesting that: 1) the pathway to $\mathrm{WOF}_{4}$ may be more complex than the one-step reaction shown in equation (9.3) and 2) the data calculated by the software program be considered an estimate containing some degree of uncertainty.

In the presence of air, it has been shown that $\mathrm{WO}_{2}$ was oxidized to $\mathrm{WO}_{3}$ beginning below $500^{\circ} \mathrm{C}$ so some $\mathrm{WO}_{3}$ was already present when the fusion reaction with $\mathrm{UF}_{4}$ kicked off around $660^{\circ} \mathrm{C}$. It is not certain what influence the exotherm from the $\mathrm{WO}_{2} \rightarrow \mathrm{WO}_{3}$ may exert on the reaction dynamic. From an economic viewpoint, using $\mathrm{WO}_{3}$ as the starting reagent would lower production costs in making the $\mathrm{WOF}_{4}$ intermediate. There is about a factor of ten price difference between $\mathrm{WO}_{2}$ and $\mathrm{WO}_{3}$ for kilogram quantities of reagent (source: Alfa Aesar catalog).

The second parameter studied using the TGA apparatus was that of stoichiometry between reagents. Weight loss and temperature difference curves for the three combinations of $\mathrm{UF}_{4}+\mathrm{WO}_{2}$ are depicted in Figure 65. The 1.014:1 $\mathrm{UF}_{4}: \mathrm{WO}_{2}$ mixture showed the largest weight increase before dropping at the fastest rate amongst the three data sets. This trend is mimicked in the temperature difference curves where the greatest change was observed in the reaction with equi-molar amounts of reactants. At this stoichiometric ratio, there is almost a $100 \%$ excess of $\mathrm{WO}_{2}$ above what is required for reaction with $\mathrm{UF}_{4}$. It is probable that the exotherm generated in converting excess $\mathrm{WO}_{2}$ to $\mathrm{WO}_{3}$ supplied additional thermal energy beyond the external heat input thereby increasing the rate of reaction and evolution of $\mathrm{WOF}_{4}$ vapor. The 2.013:1 composition, possessing the ratio closest to theoretical stoichiometry, tracked along at a somewhat slower rate of weight loss where the exotherm was marginally perceptible in the temperature difference curve.

The weight loss and temperature difference curves for the two compositions of $\mathrm{UF}_{4}+\mathrm{WO}_{3}$ are shown in Figure 66. Here, the difference in reagent stoichiometry appeared to have little impact on liberation of the gaseous intermediate as viewed from the weight loss curves. Beyond the 60 minute point into the reaction profile, the curves showed some divergence with respect to weight loss which was most likely due to the presence of excess $\mathrm{WO}_{3}$ in the 1:1.025 $\mathrm{UF}_{4}: \mathrm{WO}_{3}$ 


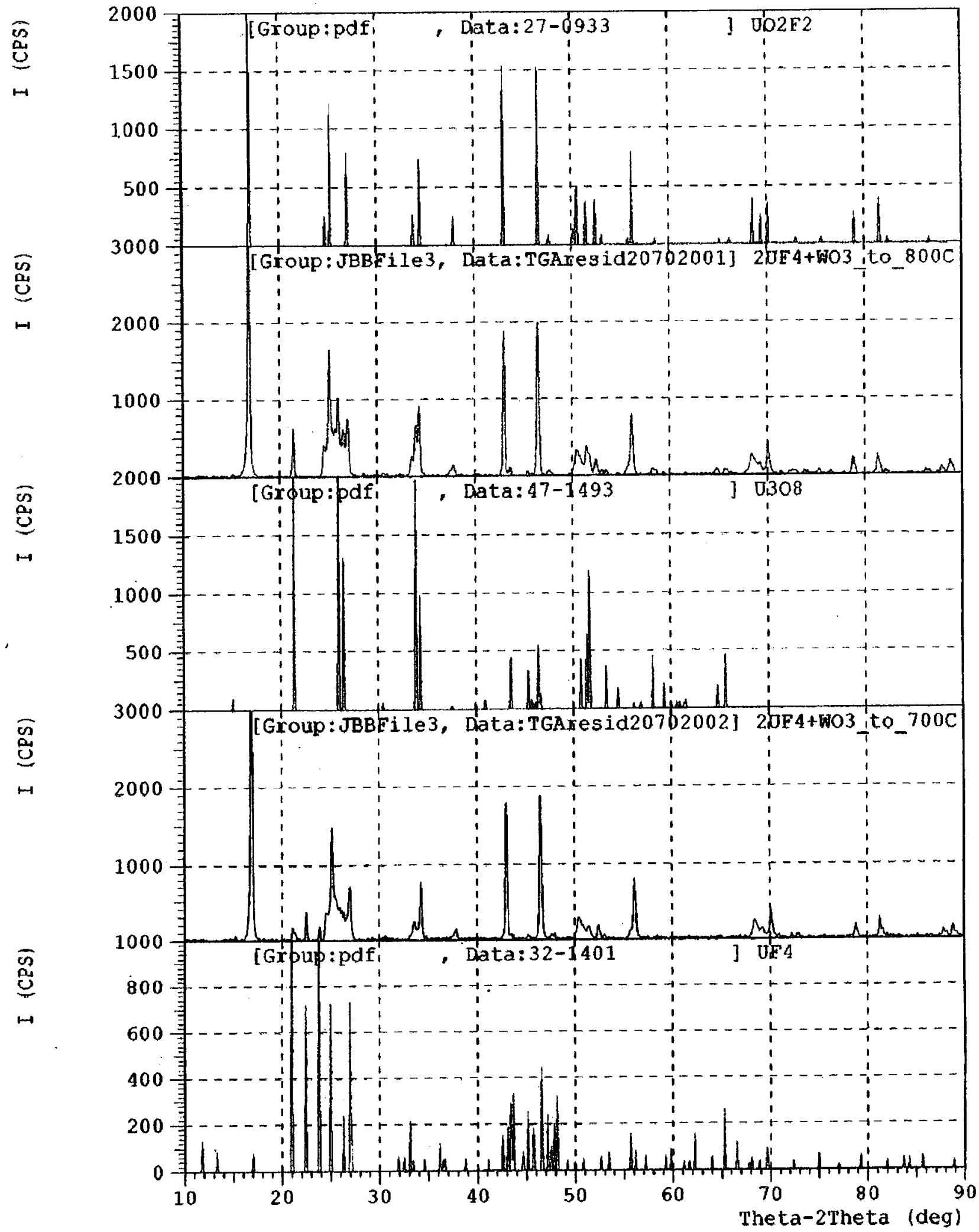

Figure 64. X-ray diffraction patterns for the residues from the reactions between $\mathrm{UF}_{4}+\mathrm{WO}_{3}\left[\mathrm{UF}_{4}: \mathrm{WO}_{3}=1.908: 1\right]$ and reference patterns for $\mathrm{UO}_{2} \mathrm{~F}_{2}(p d f \# 27-0933), \mathrm{U}_{3} \mathrm{O}_{8}$ (pdf\# 47-1493) and $\mathrm{UF}_{4}(p d f \# 32-1401$ ). 


\section{$\mathrm{UF}_{4}+\mathrm{WO}_{2}$ Heated to $700^{\circ} \mathrm{C}$ in Air}

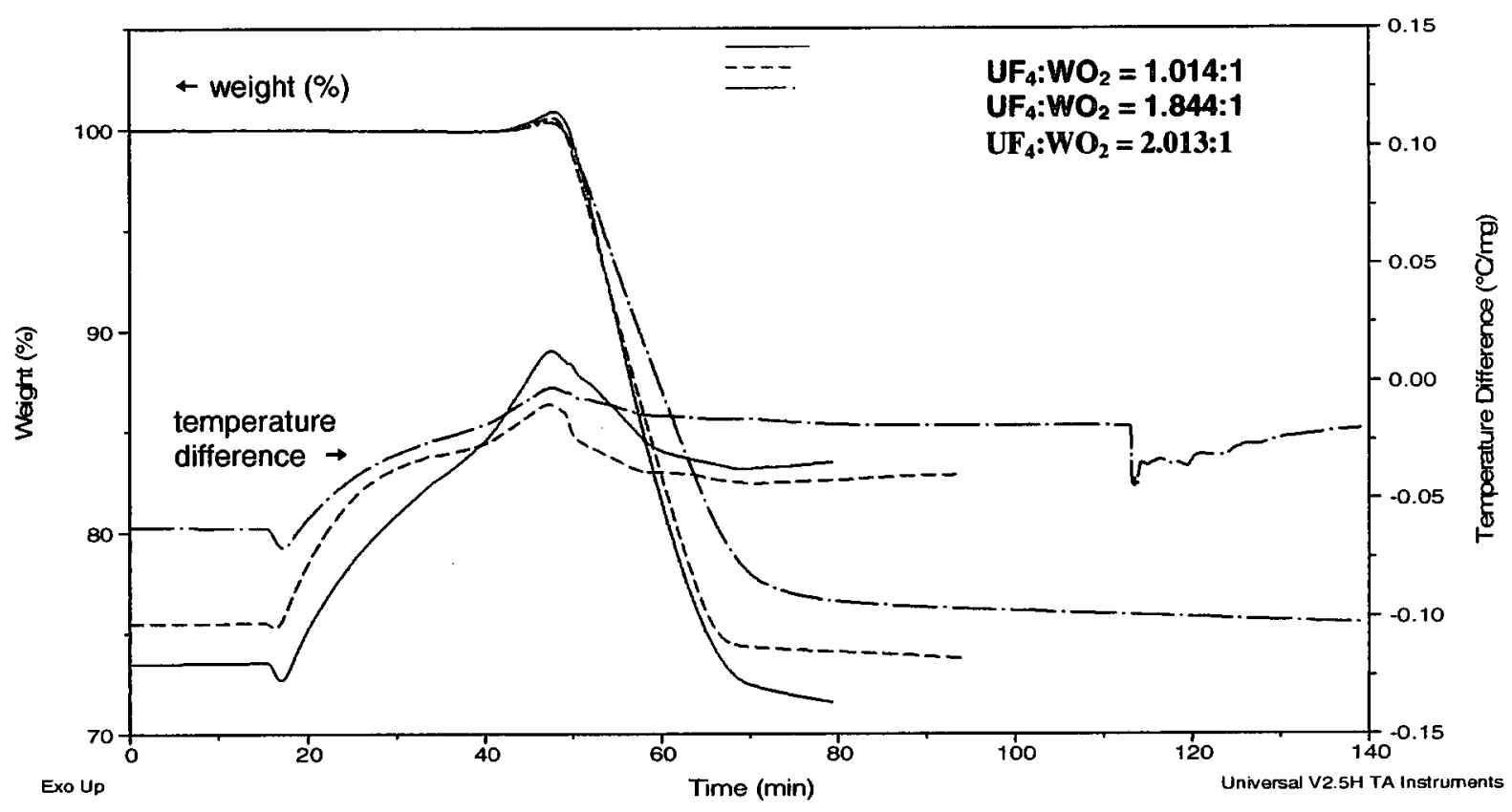

Figure 65. TGA results showing weight loss and temperature difference for three stoichiometric mixtures of $\mathrm{UF}_{4}$ with $\mathrm{WO}_{2}$ heated to $700^{\circ} \mathrm{C}$ in air.

\section{$\mathrm{UF}_{4}+\mathrm{WO}_{3}$ Heated to $700^{\circ} \mathrm{C}$ in Air}

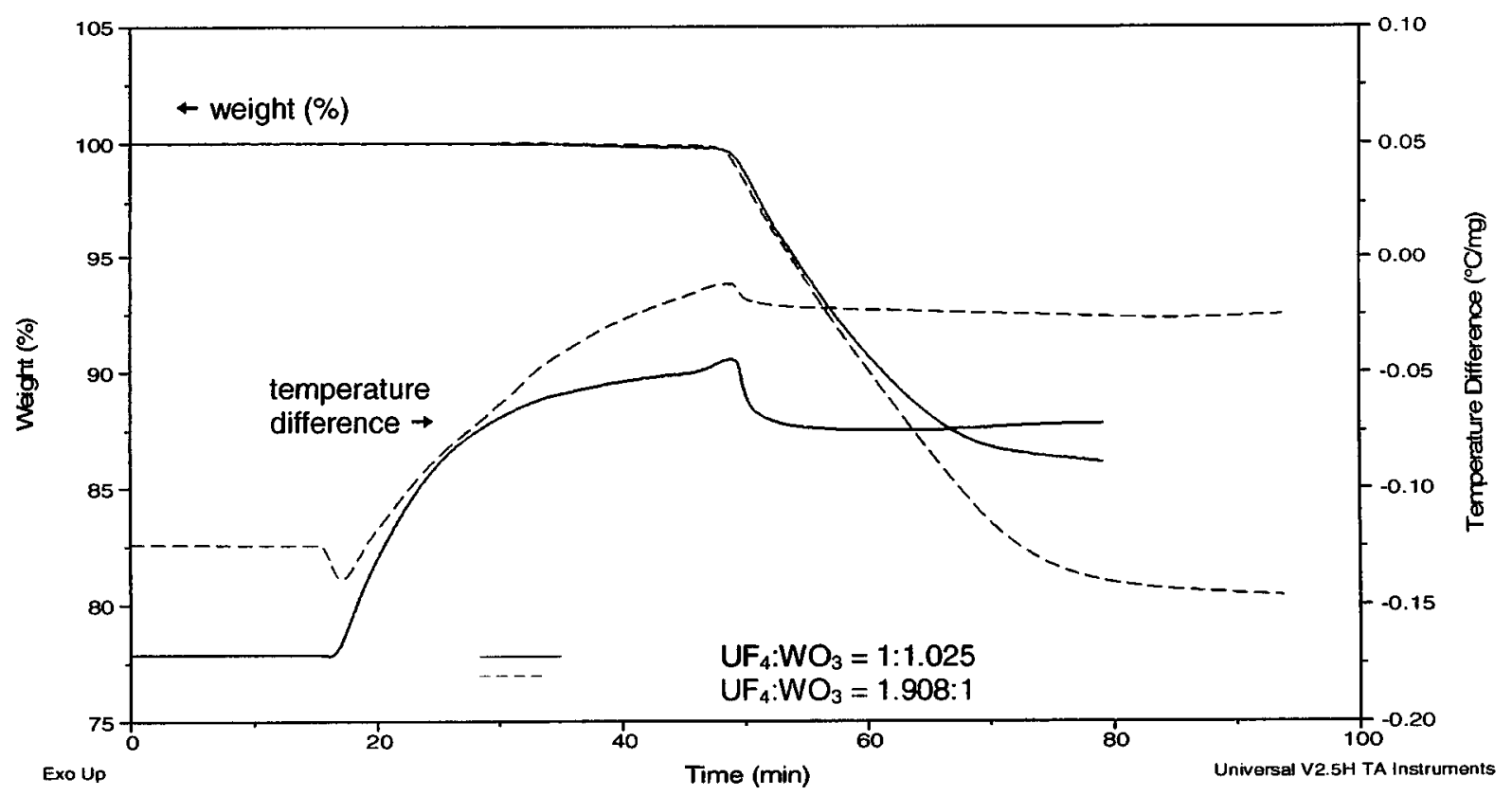

Figure 66. TGA results showing weight loss and temperature difference for two stoichiometric mixtures of $\mathrm{UF}_{4}$ with $\mathrm{WO}_{3}$ heated to $700^{\circ} \mathrm{C}$ in air. 
experiment. From the temperature difference curves, the reaction exotherm is minimal compared to that seen in the $\mathrm{UF}_{4} / \mathrm{WO}_{2}$ trials.

The third variable to be examined involved the reaction temperature. The two experiments utilizing the $1.844: 1 \mathrm{UF}_{4}: \mathrm{WO}_{2}$ reagent combination and the three trials involving the 1.908:1 UF $4: \mathrm{WO}_{3}$ mixtures are plotted in Figure 67 displaying the weight change during the $20^{\circ} \mathrm{C} / \mathrm{min}$ heating cycle and 45 minute dwell period at temperature. Within either parent mixture, the higher the reaction temperature the faster the weight loss. At $800^{\circ} \mathrm{C}$, there was little difference in the rate of weight loss observed whether the co-reagent was $\mathrm{WO}_{2}$ or $\mathrm{WO}_{3}$. In both experiments, the loss trailed off to a slow but steady decline attributed to the decomposition of $\mathrm{UO}_{2} \mathrm{~F}_{2}$. A more significant difference emerged when the reaction temperature was lowered to $700^{\circ} \mathrm{C}$. At that temperature, the weight loss for the $\mathrm{UF}_{4} / \mathrm{WO}_{2}$ mixture was notably faster than that for the $\mathrm{UF}_{4} / \mathrm{WO}_{3}$ combination and went essentially to $100 \%$ completion while the latter reaction yielded only $70 \%$ of the expected loss.

The last point of discussion addressing the micro-scale experiments concerns the composition of the post-reaction residue. For all reactions performed at $700^{\circ} \mathrm{C}$ and above, the solid, end-product was similar, being predominantly $\mathrm{UO}_{2} \mathrm{~F}_{2}$. Several diffraction patterns of materials synthesized under different conditions are pictured in Figure 68. The presence of small peaks caused by small amounts of $\mathrm{UF}_{4}$ and $\mathrm{U}_{3} \mathrm{O}_{8}$ has been pointed out in previous discussion of $x$-ray data. What is of interest to note is the absence of diffraction peaks for any tungsten oxide species where stoichiometric conditions are not satisfied. As an example, the reaction between $\mathrm{UF}_{4}$ and $\mathrm{WO}_{2}$ at $700^{\circ} \mathrm{C}$ for the 1.014:1 UF $/ \mathrm{WO}_{2}$ mixture should have left behind approximately half the supplied tungsten oxide as $\mathrm{WO}_{3}$ if the proposed reaction pathway in equation (9.2) (page 133) was followed. Based on calculation, the residue composition would contain $\sim 27 \mathrm{wt} \% \mathrm{WO}_{3}$, yet none was detected. One plausible explanation would be that the excess $\mathrm{WO}_{3}$ reacted with $\mathrm{UF}_{4}$ and/or the $\mathrm{UO}_{2} \mathrm{~F}_{2}$ product. The diffraction pattern of the residue from the $700^{\circ} \mathrm{C}$ fusion between $\mathrm{UF}_{4}$ and $\mathrm{WO}_{3}\left(1: 1.025 \mathrm{UF}_{4}: \mathrm{WO}_{3}\right)$ did show a second phase in addition to $\mathrm{UO}_{2} \mathrm{~F}_{2}$ as a result of the excess $\mathrm{WO}_{3}$ in the final material. However, the identity of this second phase could not be matched to anything in the $\mathrm{x}$-ray database. 


\section{$\left[\mathrm{UF}_{4}+\mathrm{WO}_{2}\right]$ and $\left[\mathrm{UF}_{4}+\mathrm{WO}_{3}\right]$ Mixtures Heated to $700^{\circ} \mathrm{C}, 750^{\circ} \mathrm{C}$ and $800^{\circ} \mathrm{C}$ in Air}

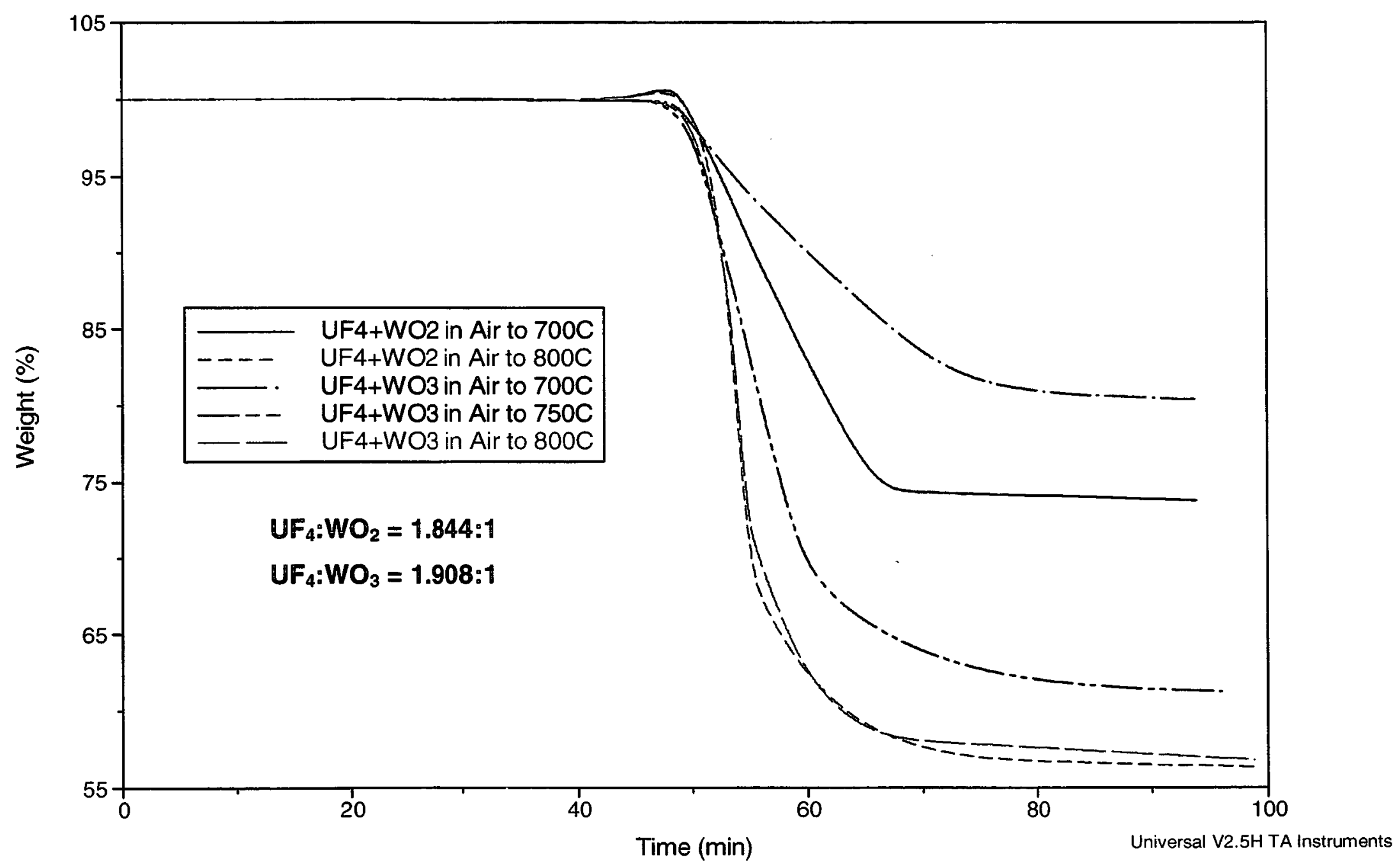

Figure 67. TGA results showing the weight change during reactions between mixtures of $\mathrm{UF}_{4}$ with $\mathrm{WO}_{2}$ and $\mathrm{WO}_{3}$ at $700^{\circ} \mathrm{C}, 750^{\circ} \mathrm{C}$ and $800^{\circ} \mathrm{C}$ in air. 


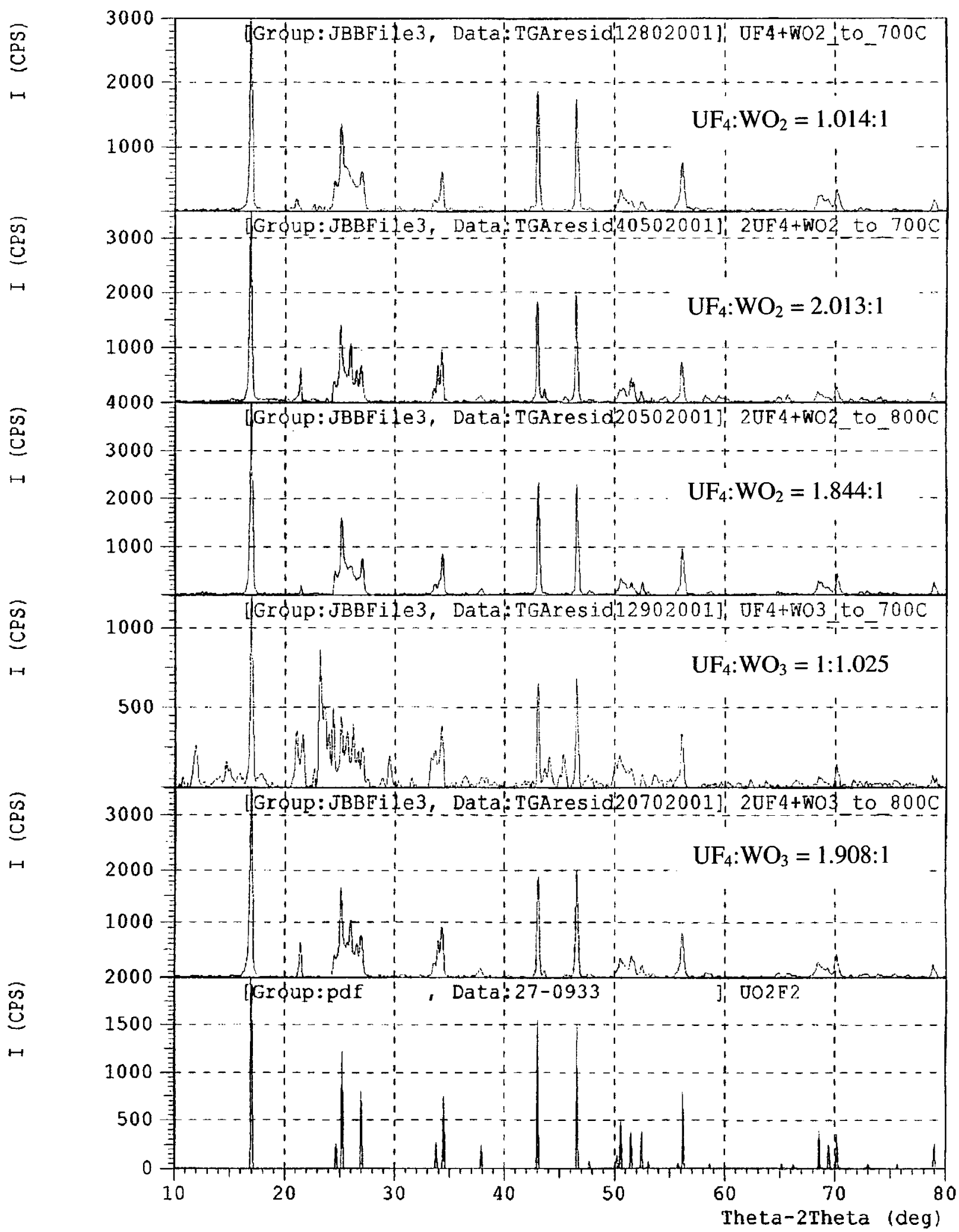

Figure 68. X-ray diffraction patterns for several residues from reactions between $\mathrm{UF}_{4}$ with $\mathrm{WO}_{2}$ and $\mathrm{WO}_{3}$ at $700^{\circ} \mathrm{C}$ and $800^{\circ} \mathrm{C}$ and the reference patterm for $\mathrm{UO}_{2} \mathrm{~F}_{2}$ (pdf\# 27-0933). 
Following the parameter study using the TGA apparatus, bench-scale trials began. The reactor configuration was explored briefly by performing one experiment in a vertically oriented, closedend tube setup (WFusn-7) similar to the GeFusn-34 run. For the other ten experiments listed in

Table 28 (p.112), a horizontally mounted, flow-through tube reactor was used as the reaction apparatus. Experimental details for each run were provided in section 9.1.1. Results for the first

six reactions, WFusn-7 to WFusn-12, are compiled in Table $\mathbf{4 8}$ and provide feedback on the effect of reaction temperature and choice of tungsten oxide reagent for producing $\mathrm{WOF}_{4}$. A brief review of each of these trials is presented below including the analysis of the post-reaction solids by $\mathrm{x}$-ray diffraction.

Table 48.

Summary of results for trials WFusn-7 to WFusn-12.

\begin{tabular}{|c|c|c|c|c|c|c|}
\hline $\begin{array}{l}\text { Experiment ID } \\
\text { WFusn- }\end{array}$ & 7 & 8 & 9 & 10 & 11 & 12 \\
\hline $\begin{array}{l}\text { Reactor } \\
\text { Configuration }\end{array}$ & $\begin{array}{l}\text { Vertical } \\
\text { closed-end } \\
\text { tube }\end{array}$ & $\begin{array}{l}\text { Horizontal } \\
\text { flow-throu } \\
\text { tube }\end{array}$ & $\begin{array}{c}\text { Horizontal } \\
\text { flow-throu } \\
\text { tube }\end{array}$ & $\begin{array}{l}\text { Horizontal } \\
\text { flow-throu } \\
\text { tube } \\
\end{array}$ & $\begin{array}{c}\text { Horizontal } \\
\text { flow-throu } \\
\text { tube }\end{array}$ & $\begin{array}{l}\text { Horizontal } \\
\text { flow-throu } \\
\text { tube }\end{array}$ \\
\hline $\begin{array}{l}\text { Tungsten } \\
\text { Reactant }\end{array}$ & $\mathrm{WO}_{2}$ & $\mathrm{WO}_{2}$ & $\mathrm{WO}_{2}$ & $\mathrm{WO}_{2}$ & $\mathrm{WO}_{3}$ & $\mathrm{WO}_{3}$ \\
\hline $\begin{array}{l}\text { Reaction } \\
\text { Temperature }\left({ }^{\circ} \mathrm{C}\right)\end{array}$ & 800 & 775 & 780 & 790 & 790 & 750 \\
\hline $\begin{array}{l}\text { Calculated weight } \\
\text { WOF }_{4} \text { expected (gm) }\end{array}$ & 11.3769 & 4.3439 & 4.5785 & 4.7209 & 3.8022 & 3.3190 \\
\hline $\begin{array}{l}\text { Calculated weight } \\
\text { loss by reagents (gm) }\end{array}$ & 9.3974 & 3.5881 & 3.7820 & 3.8994 & 3.3612 & 2.9339 \\
\hline $\begin{array}{l}\text { Observed weight } \\
\text { loss by reagents (gm) }\end{array}$ & $\mathrm{N} / \mathrm{M}$ & 1.5897 & 1.9596 & 5.1143 & 4.2912 & 2.8975 \\
\hline $\begin{array}{l}\text { Observed weight } \\
\text { gain in condenser } \\
\text { flask ( } \mathrm{gm} \text { ) }\end{array}$ & Trace & $\mathrm{N} / \mathrm{M}$ & $\mathrm{N} / \mathrm{M}$ & 3.17 & 2.44 & 1.61 \\
\hline $\begin{array}{l}\text { Reaction } \\
\text { Conversion }^{\mathrm{a}}(\%)\end{array}$ & Trace & 44.3 & 51.8 & 131.2 & 127.7 & 98.8 \\
\hline $\begin{array}{l}\text { Capture } \\
\text { Efficiency }^{\text {b }}(\%)\end{array}$ & $\mathrm{N} / \mathrm{M}$ & $\mathrm{N} / \mathrm{M}$ & $\mathrm{N} / \mathrm{M}$ & 67.1 & 64.2 & 48.5 \\
\hline
\end{tabular}

${ }^{a}$ [Observed weight loss by reagents/Calculated weight loss by reagents] x $100 \%$

${ }^{b}$ [Observed weight gain in flask/Calculated weight of $\mathrm{WOF}_{4}$ expected] $\mathrm{x} 100 \%$

$\mathrm{N} / \mathrm{M}=$ Not Measured

The first bench trial, WFusn-7, was performed in the 1"OD closed-end, nickel tube reactor which was oriented in a vertical position and heated by the MiniMite ${ }^{\circledast}$ tube furnace. After raising the furnace temperature to $800^{\circ} \mathrm{C}$ and holding for 30 minutes, only a very faint stream of vapor was observed entering the flask. A short time later it ceased so the experiment was terminated. It was obvious that heat transfer into the tube was poor using the vertical orientation since prior TGA experiments showed considerable reaction between reagents occurred even at $700^{\circ} \mathrm{C}$. Visual inspection of the material in the reaction tube showed it was still green like the starting mixture. 
The vertically oriented tube configuration was again abandoned and replaced with a horizontally mounted 1"OD flow-through tube reactor heated by the same MiniMite ${ }^{\circledast}$ tube furnace. In WFusn-8, the $250 \mathrm{ml}$ collection flask was submerged in an ice-water bath to enhance the condensation of product vapor. After 36 minutes at a reaction temperature of $775^{\circ} \mathrm{C}$, the flow of white vapor into the flask came to a halt, suggesting either the reaction was complete or a blockage was restricting flow to the receiver. Again, the reaction was terminated after trapping only a very small amount of white solid. Upon disassembling the flow path from the flask back to the 1 " tube, a white solid had deposited along the interior section of the $1 / 2$ " to $1 / 4$ " reducing union, causing the interruption in flow. The white solid was removed to a ceramic dish where it slowly changed to a wet, green yellow mass. This residue was analyzed by $\mathrm{x}$-ray diffraction but no discernable diffraction pattern was found after scanning several times, suggesting it was amorphous.

The post-reaction solid remaining in the nickel boat was recovered and analyzed. During the short reaction period, the $\mathrm{UF}_{4} / \mathrm{WO}_{2}$ mixture lost 1.5897 grams, presumably $\mathrm{WOF}_{4}$. The resulting powder was pale yellow toward one side of the container where the volume of material had more than doubled. The powder closer to the bottom of the boat was a lighter shade of green. An x-ray diffraction pattern of this yellow powder is displayed in Figure 69 along with the reference pattern for $\mathrm{UO}_{2} \mathrm{~F}_{2}$ (pdf \# 27-0933). As seen in the TGA experiments, the pale yellow residue was essentially $\mathrm{UO}_{2} \mathrm{~F}_{2}$ and only very small peak intensities associated with $\mathrm{UF}_{4}$ were present.

For WFusn-9, the reaction system was assembled as in the previous set-up. In order to prevent the condensation of white solid in the line to the flask, the sections of tubing from where the 1 " tube left the furnace to the point where the collection flask was joined at the $1 / 4$ " reducing union were wrapped with heat tape and insulation. During the run, this section of tubing was kept at $209^{\circ} \mathrm{C}$. As the furnace temperature passed through the $700^{\circ} \mathrm{C}$ point, a white fume was seen passing into the flask being chilled in the ice-water bath. After 30 minutes into the reaction, the vapor stream stopped so the operation was terminated. Once again a blockage in the line formed in the 3" section of $1 / 4$ " stainless steel tubing carrying product into the flask. This section of tube was the only section not heated because the connection to the flask was made using a viton o-ring and could not withstand the heat stress. As before, only a small amount of white fume was captured.

Assessment of post-reaction data included weight lost by the reactants (1.9596 grams) and $\mathrm{x}$-ray analyses of the hydrolyzed solid causing the blockage, the residue remaining in the boat and the hydrolyzed solid trapped in the flask. The x-ray diffraction patterns for the three samples are included in Figure $\mathbf{7 0}$ along with reference patterns identifying their compositions. When the solid causing the blockage in the tube was contacted with $\mathrm{H}_{2} \mathrm{O}$, it turned bright yellow. The same occurred when $\mathrm{H}_{2} \mathrm{O}$ was added to the flask containing the white condensate. After removing the water in each sample, the yellow precipitate was analyzed and matched to a combination of hydrated $\mathrm{WO}_{3}$ compounds, namely $\mathrm{WO}_{3} \bullet 2 \mathrm{H}_{2} \mathrm{O}$ (pdf \# 18-1419) and $\mathrm{WO}_{3} \bullet \mathrm{H}_{2} \mathrm{O}$ (pdf \# 43-0679). The partially reacted residue in the boat was matched to $\mathrm{UO}_{2} \mathrm{~F}_{2}$ (pdf \# 27-0933) and unreacted $\mathrm{UF}_{4}$ (pdf \# 32-1401). 


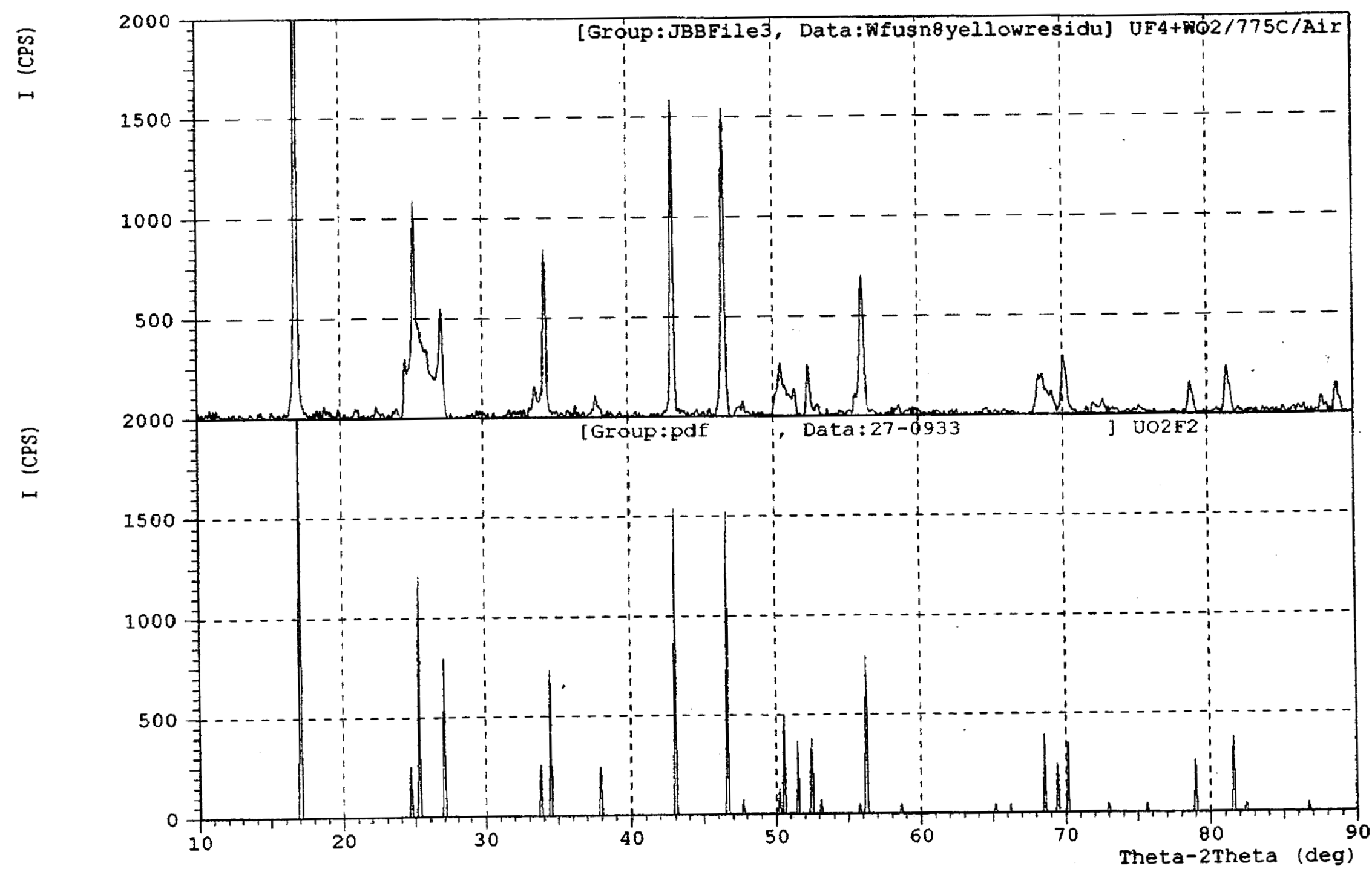

Figure 69. X-ray diffraction pattern for residue from Wfusn-8 and the reference pattern for $\mathrm{UO}_{2} \mathrm{~F}_{2}$ (pdf\# 27-0933). 


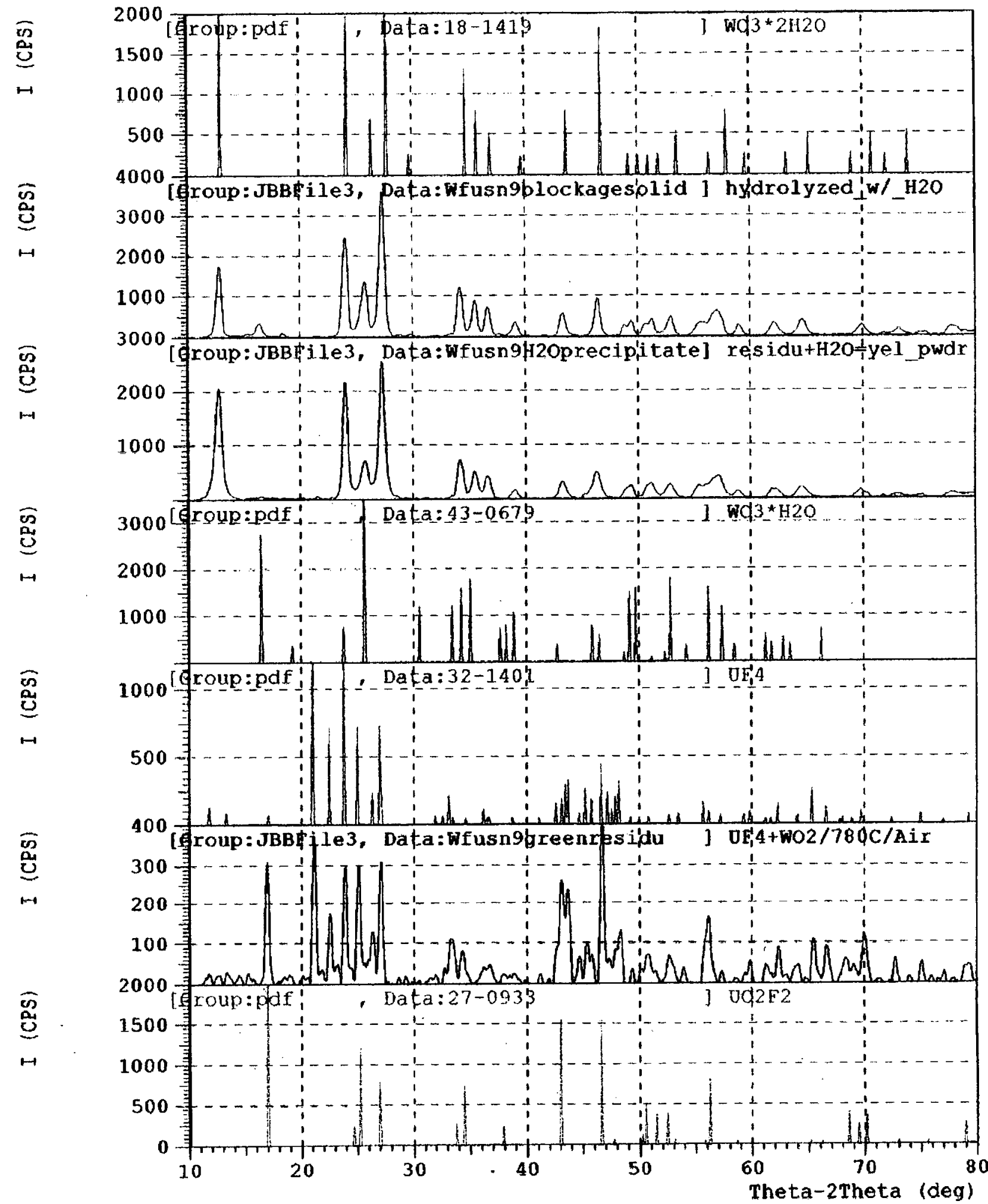

Figure 70. X-ray diffraction patterns for the hydrolyzed residue causing the blockage in the tube, the hydrolyzed solid captured in the flask and residue in the boat from

WFusn-9 and reference patterns for $\mathrm{WO}_{3} \bullet 2 \mathrm{H}_{2} \mathrm{O}$ (pdf\# 18-1419), $\mathrm{WO}_{3} \bullet \mathrm{H}_{2} \mathrm{O}$ (pdf\# 43-0679), $\mathrm{UF}_{4}$ (pdf\# 32-1401) and $\mathrm{UO}_{2} \mathrm{~F}_{2}$ (pdf\# 270933). 
Using the weight loss data, the conversion of $\mathrm{WO}_{2}$ to $\mathrm{WOF}_{4}$ was estimated by ratioing the "Observed weight lost by the reagents" to the "Calculated weight loss by the reagents" predicted according to equation (9.2) (page 133) given earlier. In WFusn-9 the estimated reaction conversion was $51.8 \%$.

Since the previous two experiments were terminated prematurely because of blocked lines, the pathway to the condensation zone was redesigned in the next trial, WFusn-10. The flask used for capturing the white fume was replaced with a 1"OD tube approximately 10 " long. The tube was connected at a $90^{\circ}$ angle to the reactor outflow via a union elbow modified with a $1 / 4$ " outage tube welded through the wall to direct flow from the tube. In this configuration, the diameter of the line from the reaction zone to the condensation zone was maintained at 1"OD.

The reaction in WFusn- 10 was carried out for two hours at $790^{\circ} \mathrm{C}$ with the condensation tube submerged in ice-water. Approximately 3.17 grams of condensed product was trapped while a loss of 5.1143 grams was recorded for the contents of the boat. Upon retrieving the boat from the reaction zone, it was observed that the volume of residue had expanded so much so that it overflowed the confines of the vessel. A sample of the bulk residue was taken for x-ray analysis. The condensed solid in the tube was contacted with $\mathrm{H}_{2} \mathrm{O}$, forming the familiar yellow precipitate, which was also isolated for characterization by $\mathrm{x}$-ray diffraction. The experimental patterns are shown in Figure $\mathbf{7 1}$ along with matching reference patterns. When dried, the yellow precipitate matched the reference for hydrated $\mathrm{WO}_{3}$. For this reaction, a capture efficiency of $67.1 \%$ was reported. It was defined as the ratio between "Observed weight gain in condensation flask" compared to the "Calculated weight of $\mathrm{WOF}_{4}$ expected" for the complete reaction. 


\section{5 [Group:JBPFile3, Data! Wfusnlobulkyellwresidu] OEA+W02/79dC/Air}

垔

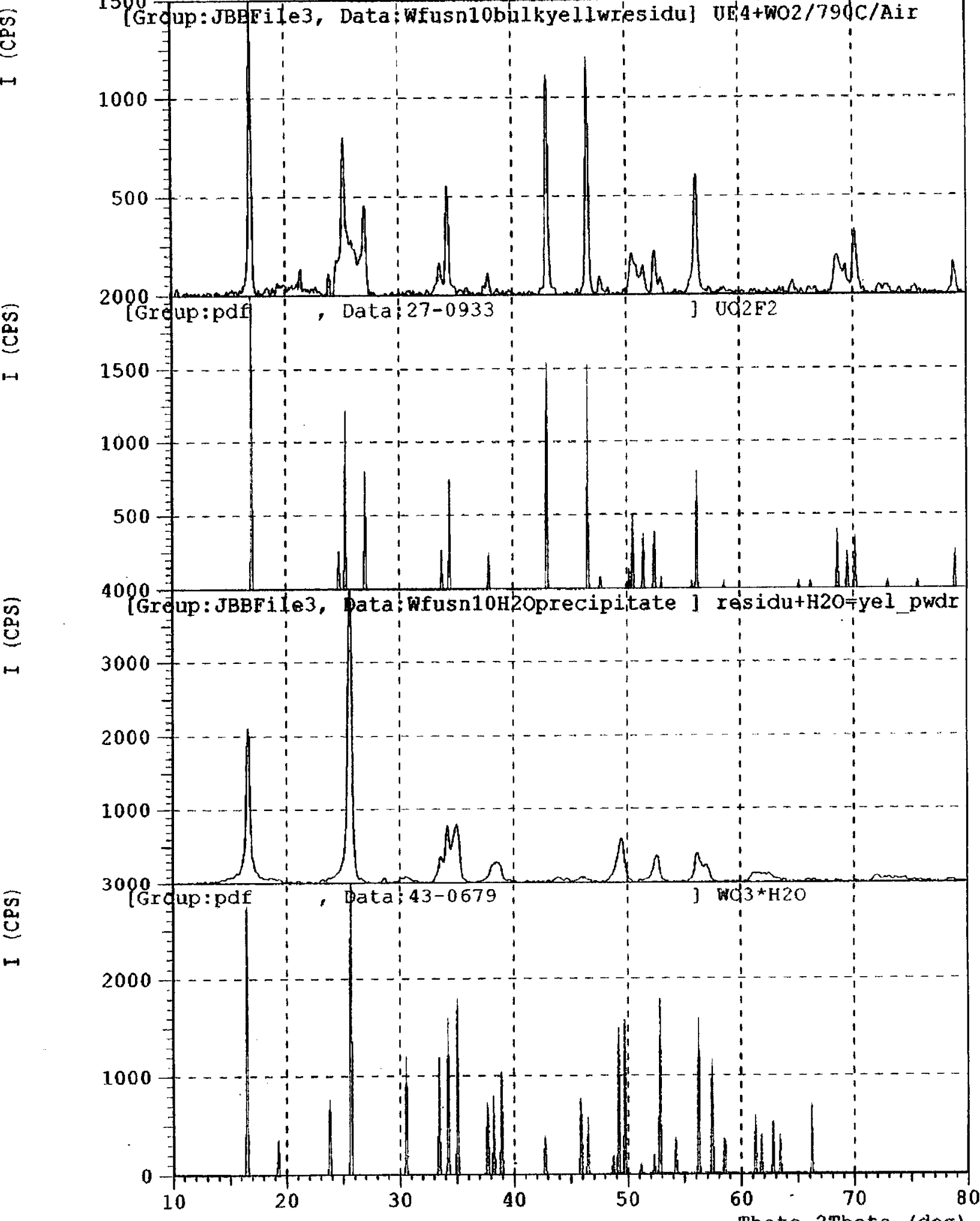

Figure 71. X-ray diffraction patterns for the residue recovered after WFusn-10, the hydrolyzed residue from the condensation tube and reference patterns for $\mathrm{UO}_{2} \mathrm{~F}_{2}$ (pdf\# 27-0933) and $\mathrm{WO}_{3} \bullet \mathrm{H}_{2} \mathrm{O}$ (pdf\# 43-0679). 
After completing three trials using $\mathrm{WO}_{2}$ as the oxide source, a bench-scale reaction between $\mathrm{UF}_{4}$ and $\mathrm{WO}_{3}\left[\mathrm{UF}_{4}: \mathrm{WO}_{3}=2.001: 1\right]$ was investigated. The combination of reagents was heated at $790^{\circ} \mathrm{C}$ for 3 hours and a volatile reaction product was captured in the 1"OD collection tube as in the previous trial. During the reaction, 4.2912 grams was lost from the starting mixture while 2.44 grams was captured in the chilled tube. Capture efficiency was determined to be $64.2 \%$. The residue recovered from the reactor was pale yellow and had swelled in volume but remained within the boat. There was evidence of a light coating of residue along the interior surfaces of the elbow union and upper section of the collection tube where it was not chilled by the ice-water bath.

The solid from WFusn-11 was analyzed by $\mathrm{x}$-ray diffraction along with a hydrolyzed sample of material captured in the tube. Patterns for those specimens are displayed in Figure 72 and Figure 73. The residue from the boat shown in Figure 72, did contain the familiar $\mathrm{UO}_{2} \mathrm{~F}_{2}$ but another phase(s) was present which did not match well to any reference compound in the $\mathrm{x}$ ray database. The solid residue made between $\mathrm{UF}_{4}$ and $\mathrm{WO}_{3}$ when reacted at $800^{\circ} \mathrm{C}$ in the TGA apparatus is also included for comparison. Patterns for the white fume after being hydrolyzed by $\mathrm{H}_{2} \mathrm{O}$ and dried are presented in Figure 73. The bright yellow precipitate was matched to a combination of hydrated $\mathrm{WO}_{3}$ species similar to what was seen after hydrolyzing the condensed material from WFusn-10 where $\mathrm{WO}_{2}$ was the co-reagent.

Since the residue left behind in WFusn-11 contained a phase not seen before, a second reaction was performed using the same parent $\mathrm{UF}_{4} / \mathrm{WO}_{3}$ stock mixture with the 2.001:1 molar stoichiometry. In WFusn-12, the receiver vessel was changed to the $250 \mathrm{ml}$ round bottom flask and the line wrapped with heat tape back to where the reaction tube emerged from the furnace. During the trial, white fume was collected for about 100 minutes at $750^{\circ} \mathrm{C}$. At that point the reaction was stopped since no fume was seen entering the flask. That observation was a strong indication the line might be blocked again. The heated section of the line to the flask did reach $204^{\circ} \mathrm{C}$ during the run. Upon cooling and disassembly, no blockages or restrictions were found in the pathway to the round bottom flask. The powder in the boat had swelled in volume and was pale yellow over the surface but took on a greenish tint as the bulk was probed. An x-ray diffraction pattern of this residue is shown in Figure 74 along with matching reference patterns for $\mathrm{UO}_{2} \mathrm{~F}_{2}$ (pdf \# 27-0933) and $\mathrm{UF}_{4}$ (pdf \# 32-1401). The unidentified phase produced in WFusn-11 was not observed in the WFusn-12 product but rather the same two phases seen in many of the trials.

The overall reaction conversion for WFusn-12 was $98.8 \%$ based on the observed weight loss by the reagents while the capture efficiency was only $48.5 \%$ of the expected amount of $\mathrm{WOF}_{4}$. From inspection of the interior walls of the line from the reactor exit to the flask, there was a coating of a deep blue colored residue evenly deposited over the surface. The intense blue color is consistent with a tungsten oxide phase with the formula $\mathrm{W}_{2} \mathrm{O}_{5}{ }^{28}$, which obviously developed through deposition and decomposition of $\mathrm{WOF}_{4}$ as it passed through the heated line to the flask. 


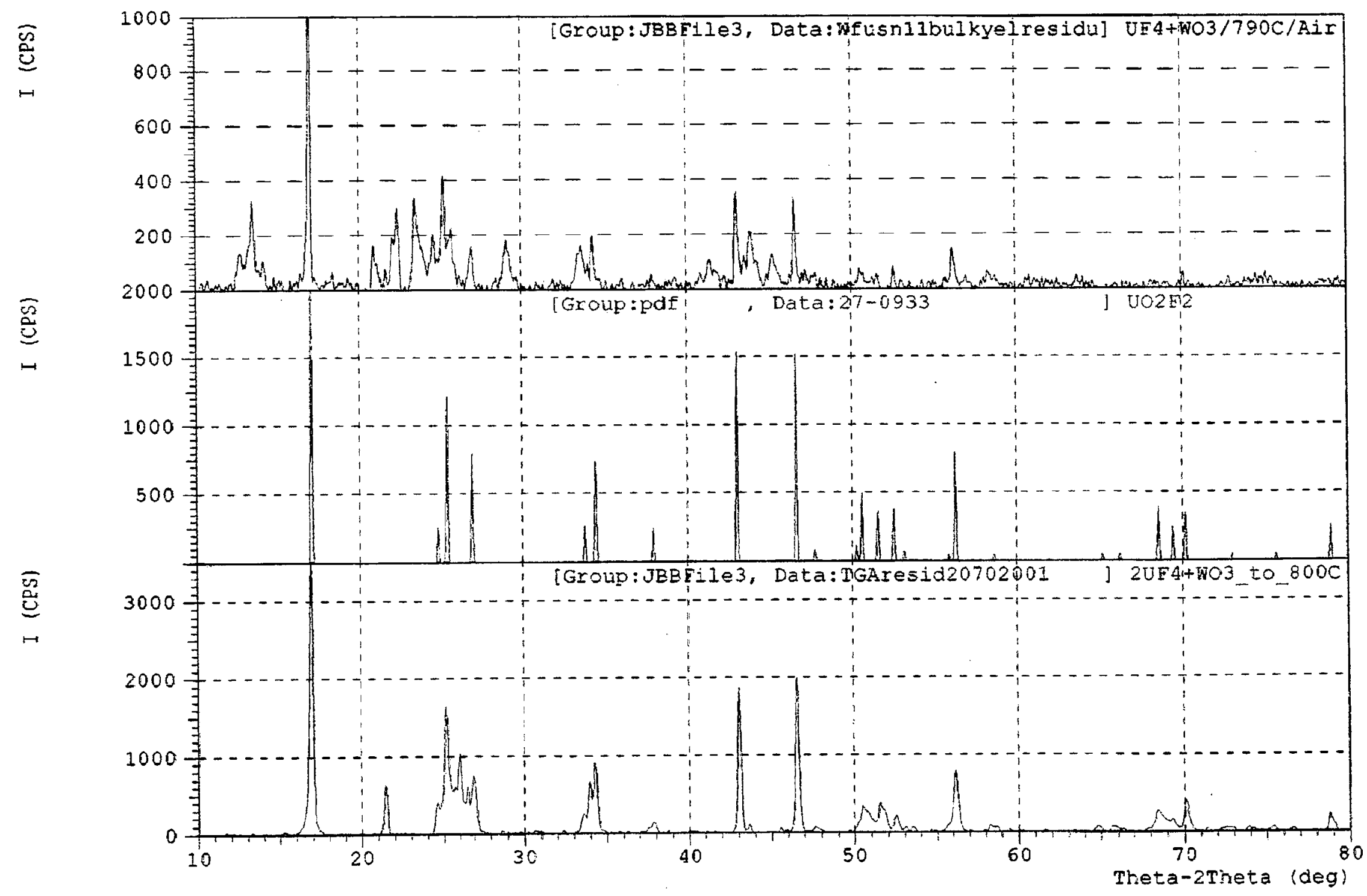

Figure 72. X-ray diffraction patterns for the residue recovered after WFusn-11, the residue produced by the reaction between $\mathrm{UF}_{4}$ and $\mathrm{WO}_{3}$ at $800^{\circ} \mathrm{C}$ in the TGA apparatus and the reference pattern for $\mathrm{UO}_{2} \mathrm{~F}_{2}$ (pdf\# 27-0933). 


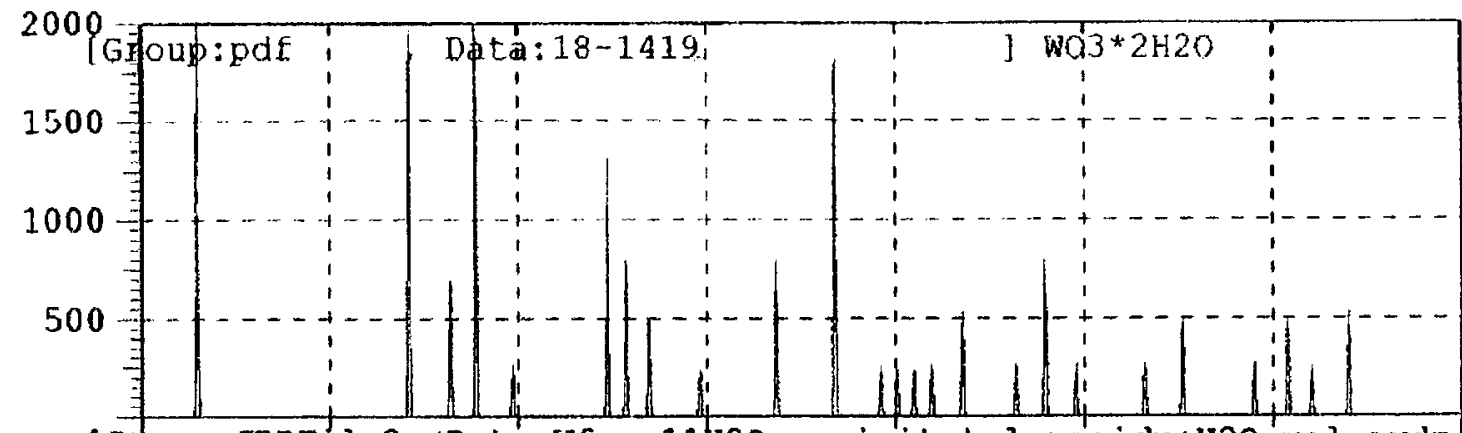

$\stackrel{n}{3}$

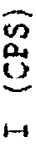

कิ

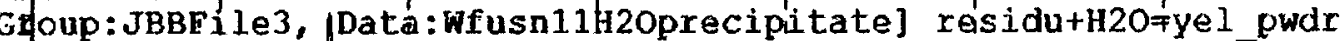

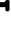

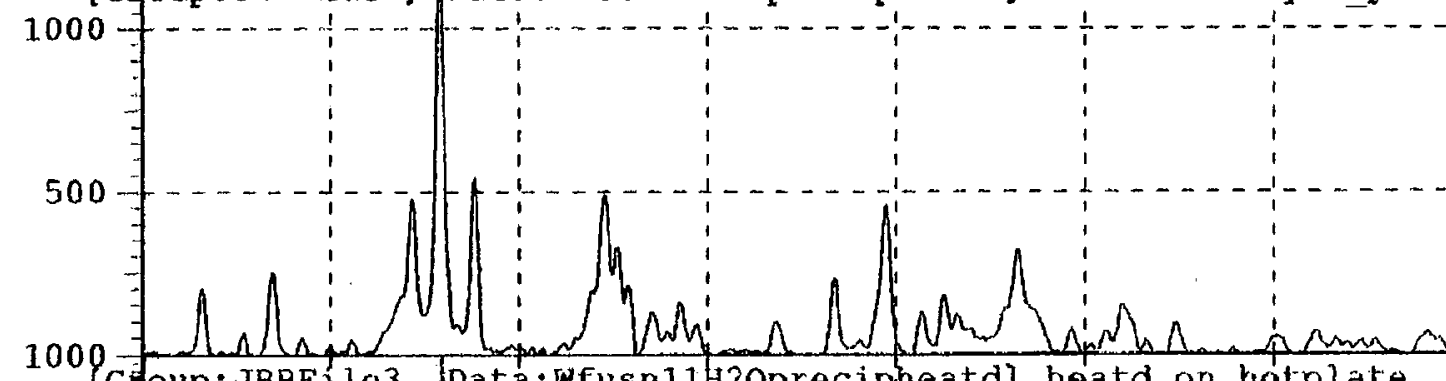

옹

$\underset{n}{\widehat{a}}$
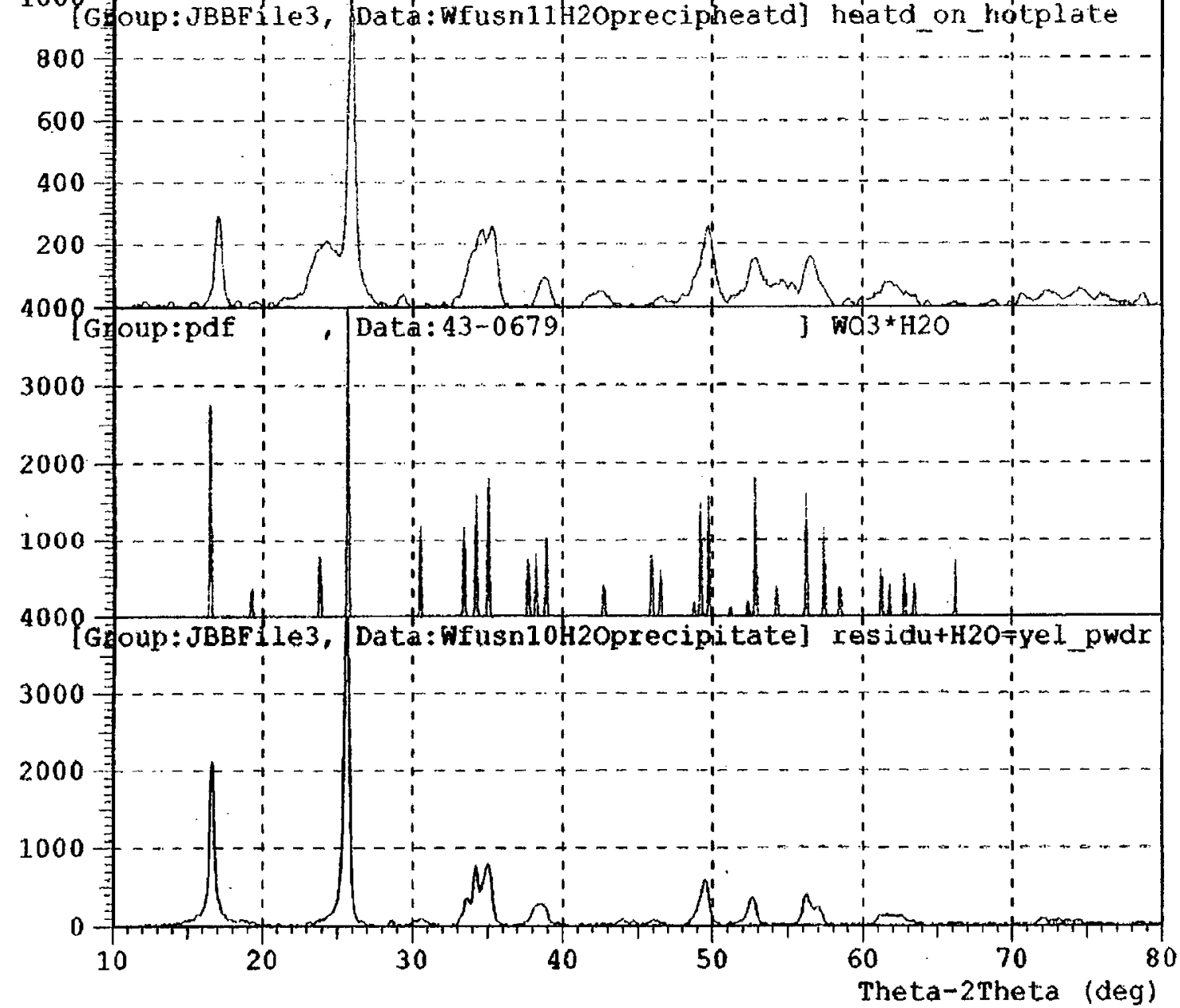

Figure 73. X-ray diffraction patterns for hydrolyzed samples of condensed solid produced in WFusn-10 and WFusn-11 and reference patterns for $\mathrm{WO}_{3} \bullet 2 \mathrm{H}_{2} \mathrm{O}$ (pdf\# 18-1419) and $\mathrm{WO}_{3} \bullet \mathrm{H}_{2} \mathrm{O}$ (pdf\# 43-0679). 


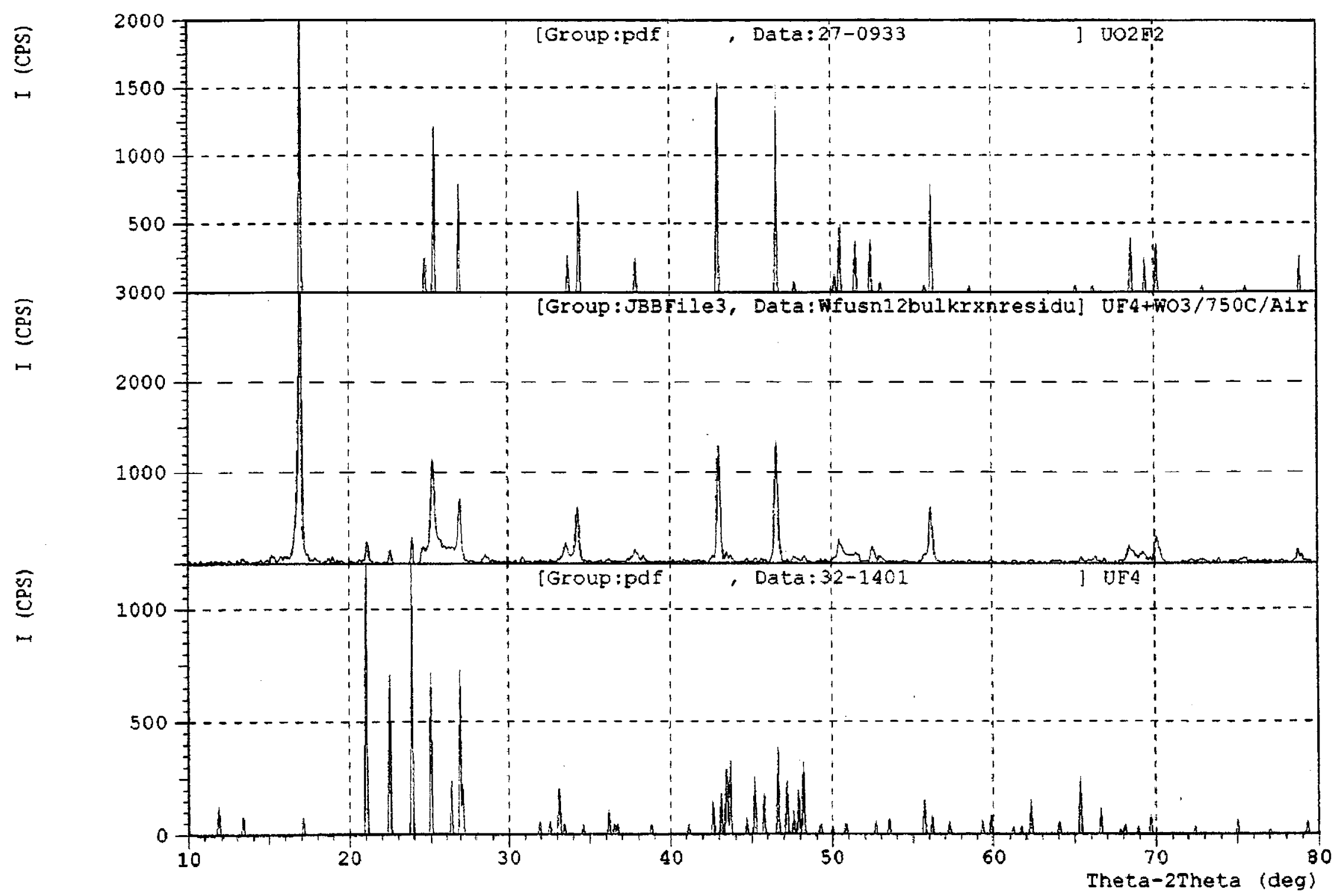

Figure 74. X-ray diffraction patterns for the bulk reaction residue recovered from WFusn-12 and reference patterns for $\mathrm{UO}_{2} \mathrm{~F}_{2}$ (pdf\# 27-0933) and $\mathrm{UF}_{4}$ (pdf\# 32-1401). 
After completing WFusn-12, five additional bench trials were performed, all using $\mathrm{WO}_{2}$ as the primary tungsten source. Of the five, three runs consisted of two reaction steps in order to probe the reactivity of the $\mathrm{WOF}_{4}$ compound and explore pathways to produce $\mathrm{WF}_{6}$. As before, the experimental details for each of the trials were given in section 9.1.1. Results for WFusn-13, $-14,-15,-16$ and -17 are arranged below in Table 49. A brief review of each run, including material characterization of the post-reaction residues is presented here.

Table 49.

Summary of results for WFusn-13 to WFusn-17.

\begin{tabular}{|l|c|c|c|c|c|}
\hline $\begin{array}{l}\text { Experiment ID } \\
\text { WFusn- }\end{array}$ & $\mathbf{1 3}$ & $\mathbf{1 4}$ & $\mathbf{1 5}$ & $\mathbf{1 6}$ & $\mathbf{1 7}$ \\
\hline Reaction step (1) & $\mathrm{UF}_{4}+\mathrm{WO}_{2}$ & $\mathrm{UF}_{4}+\mathrm{WO}_{2}$ & $\mathrm{UF}_{4}+\mathrm{WO}_{2}$ & $\mathrm{UF}_{4}+\mathrm{WO}_{2}$ & $\mathrm{UF}_{4}+\mathrm{WO}_{2}$ \\
\cline { 2 - 6 } & $\mathrm{WOF}_{4}+\mathrm{UF}_{4}$ & - & $\mathrm{WOF}_{4}+\mathrm{SiO}_{2}$ & - & $\mathrm{WOF}_{4}+\mathrm{TiF}_{4}$ \\
\hline $\begin{array}{l}\text { Reaction } \\
\left.\text { Temperature ( }{ }^{\circ} \mathbf{C}\right)\end{array}$ & 750 & 800 & 800 & 780 & 800 \\
\hline $\begin{array}{l}\text { Calculated } \\
\text { weight WOF } \\
\text { expected (gm) }\end{array}$ & 3.4109 & 3.7112 & 4.3751 & 4.1984 & 4.6023 \\
\hline $\begin{array}{l}\text { Calculated weight } \\
\text { loss by reagents (gm) }\end{array}$ & 2.8172 & 3.0655 & 3.6138 & 3.4677 & 3.8015 \\
\hline $\begin{array}{l}\text { Observed weight } \\
\text { loss by reagents (gm) }\end{array}$ & 3.3090 & 4.2125 & 4.1800 & 4.1181 & 4.5586 \\
\hline $\begin{array}{l}\text { Observed weight } \\
\text { gain in condenser } \\
\text { flask (gm) }\end{array}$ & $\mathrm{N} / \mathrm{M}$ & 1.80 & $\mathrm{~N} / \mathrm{M}$ & 2.19 & 2.44 \\
\hline $\begin{array}{l}\text { Reaction } \\
\text { Conversion }\end{array}$ & $11 \%)$ & 13.5 & 115.7 & 118.8 & 119.9 \\
\hline $\begin{array}{l}\text { Capture } \\
\text { Efficiency }\end{array}$ & (\%)
\end{tabular}

a [Observed weight loss by reagents/Calculated weight loss by reagents] $\times 100 \%$

${ }^{b}$ [Observed weight gain in flask/Calculated weight of $\mathrm{WOF}_{4}$ expected] $\mathrm{x} 100 \%$

$\mathrm{N} / \mathrm{M}=$ Not Measured

The first of the 2-step experiments to be performed was WFusn-13. Here, the plan was to first react $\mathrm{UF}_{4}$ with $\mathrm{WO}_{2}$ to make $\mathrm{WOF}_{4}$, then react that material with more $\mathrm{UF}_{4}$, as shown in the step (2) reaction given in Table 35 (p.119). The reaction was setup as in previous trials using a 2 -neck $500 \mathrm{ml}$ round bottom flask as the condensation vessel. About 2.17 grams of $\mathrm{UF}_{4}$ was added to the flask before the $\mathrm{UF}_{4}+\mathrm{WO}_{2}$ reaction was started: During the two-hour reaction period at $750^{\circ} \mathrm{C}$, white fume was deposited over the bed of green salt maintained at $0^{\circ} \mathrm{C}$ in the flask submerged in the ice-water bath. There were no signs of spontaneous reaction between the condensed fume and $\mathrm{UF}_{4}$. After concluding the reaction, the flask was removed from the line and sealed. The white fume was thoroughly mixed with the green salt by gently swirling the 
flask and the combination allowed to stand overnight at ambient temperature. After finding no change in appearance of the mixed materials, the flask was then connected to a flow of dry air and heated to $196^{\circ} \mathrm{C}$ where very little change was observed after one hour.

Upon conducting the post-reaction assessment, contents of the nickel boat lost 3.3090 grams compared to the 2.8172 grams expected by calculation using the reaction in step (1) shown in Table 35 (page 119). As seen earlier, the powdery residue was pale yellow and had swelled in volume across the right half of the boat. The left side surface and subsurface materials contained a notably greener tint. All was recovered for analysis by x-ray diffraction. Those results are shown in Figure 75. The solid product was consistent with previous experiments where $\mathrm{UO}_{2} \mathrm{~F}_{2}$ and a small amount of unreacted green salt were the only constituents present.

The amount of condensed white fume was not determined although it was sufficient to investigate if the equation given in Table 36 is a viable pathway to $\mathrm{WF}_{6}$. X-ray analysis of the green material recovered after heating the condensed fume/UF 4 mixture is shown in Figure 76. Here the sample pattern matched well with the pattern collected for untreated $\mathrm{UF}_{4}$. The reference pattern for $\mathrm{UO}_{2} \mathrm{~F}_{2}$ is also included since detection of any amount in the residue would be a signal that the conversion to $\mathrm{WF}_{6}(\mathrm{~g})$ listed in Table 36 had gotten underway. The small diffraction peak observed at $\sim 17^{\circ} 2-\theta$ in the middle pattern of Figure 76 may be the first indication that $\mathrm{UO}_{2} \mathrm{~F}_{2}$ was indeed produced by the reaction of $\mathrm{UF}_{4}$ with $\mathrm{WOF}_{4}$. However, from the observations and data collected, evidence for that reaction was not clearly established. 


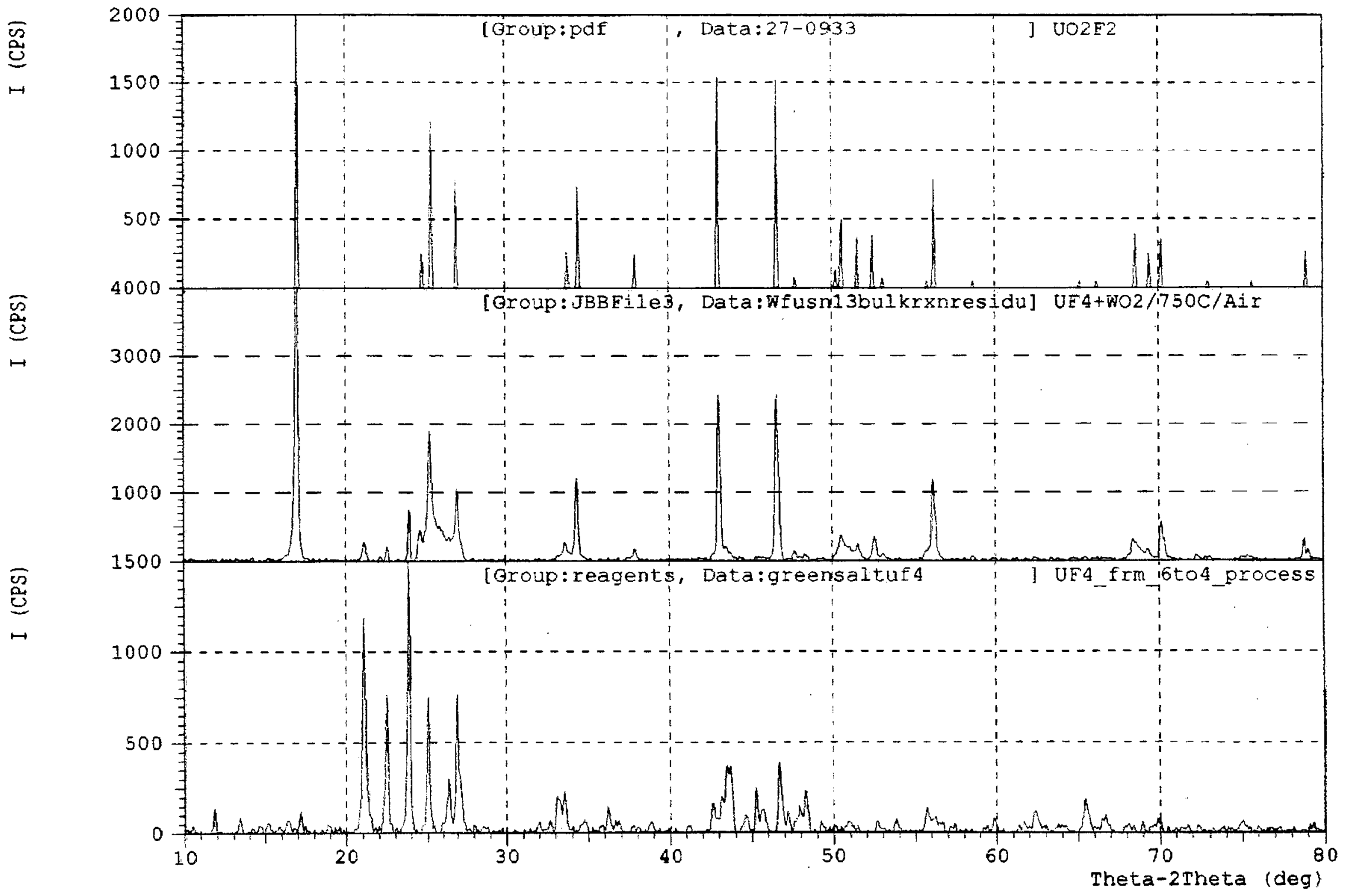

Figure 75. X-ray diffraction patterns for the residue recovered from WFusn-13 and untreated UF 4 and the reference pattern for $\mathrm{UO}_{2} \mathrm{~F}_{2}$ (pdf\# 27-0933). 


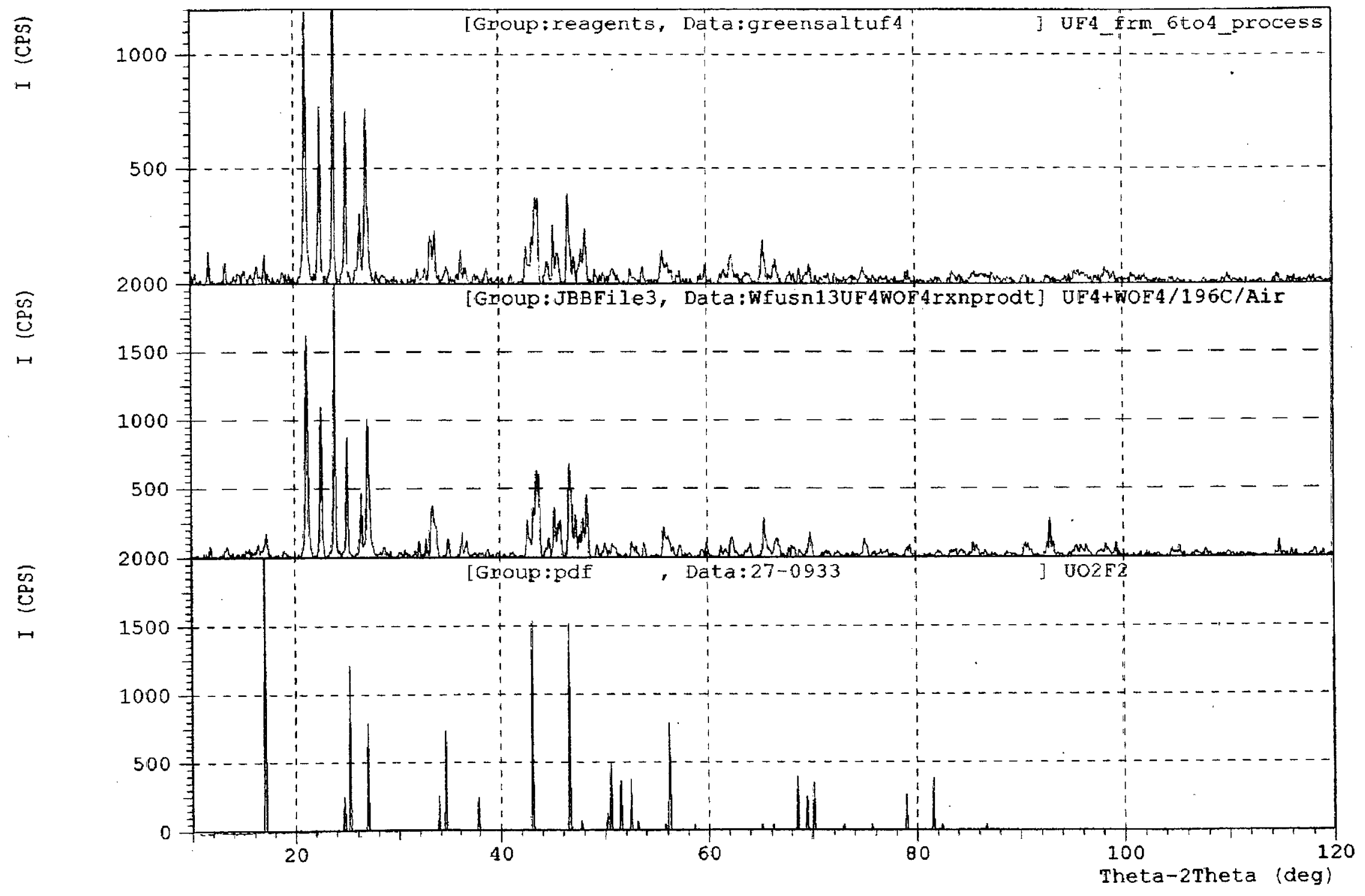

Figure 76. X-ray diffraction patterns for the residue recovered after heating the $\mathrm{UF}_{4} / \mathrm{WOF}_{4}$ mixture to $196^{\circ} \mathrm{C}$ in air, untreated $\mathrm{UF}_{4}$ and the reference pattern for $\mathrm{UO}_{2} \mathrm{~F}_{2}$ (pdf\# 27-0933). 
After completing the first two-step reaction using $\mathrm{UF}_{4}$, another single-step reaction, WFusn-14, was performed with the intent to optimize the yield of oxyfluoride intermediate. During this trial, the line from the reaction tube to the collection flask was heated and an accelerated heating profile (shown in Table 37 (p.121)) was tested. Upon concluding the run, approximately 1.80 grams of residue was collected in the condenser which represented $\sim 48.5 \%$ of the calculated yield. Along with the white residue, there was also evidence of a fine green residue in the collection vessel. During disassembly of the reactor to recover the reacted solids, the interior walls of the exit line leading back to the Ni tube were dusted with a green powdery film. The contents of the Ni boat were completely yellow on the surface and throughout the bulk and had expanded in volume filling the boat to capacity without spillover.

Both the pale yellow solid from the boat and the fine green powder found on the interior walls downstream from the reactor were analyzed by $x$-ray powder diffraction. Those results are shown in Figures 77, 78 and 79. As in previous trials, the pattern for the pale yellow solid matched the reference pattern for $\mathrm{UO}_{2} \mathrm{~F}_{2}$ (pdf\# 27-0933), depicted in Figure 77. However, there were additional peaks of low intensity in the pattern that proved a challenge to index. As seen in Figure 78, the residual peaks in the pattern for the post-reaction solid indexed well with several hydrated species of $\mathrm{UO}_{2} \mathrm{~F}_{2}$, namely $\mathrm{UO}_{2} \mathrm{~F}_{2} \bullet 1.5 \mathrm{H}_{2} \mathrm{O}$ (pdf\# 24-1154) and $\mathrm{UO}_{2} \mathrm{~F}_{2} \bullet 2 \mathrm{H}_{2} \mathrm{O}$ (pdf\# 241153). The diffraction pattern for the green powder coating the interior walls of the exit line is shown in Figure 79. It is clearly evident the green solid is $\mathrm{UF}_{4}$ when compared to the pattern recorded for the virgin reagent. The conveyance of $\mathrm{UF}_{4}$ throughout the exit line down to the condenser must be a direct result of the accelerated heating profile to $800^{\circ} \mathrm{C}$ which lead to the rapid and disruptive evolution of $\mathrm{WOF}_{4}$ vapor entrained with green salt. The loss of $\mathrm{UF}_{4}$ from the reaction vessel would also help to explain the larger weight loss by the reagents $(4.2125 \mathrm{gm})$ when compared to the calculated weight loss expected (3.0655gm).

Following the completion of WFusn-14, all components of the reaction system from the $\mathrm{Ni}$ tube to the condenser vessel were thoroughly cleaned to remove any $\mathrm{UF}_{4}$ deposited downstream during the reaction. The 1 " $\mathrm{Ni}$ tube was heated to $150^{\circ} \mathrm{C}$ for 4 hours to thoroughly dry the reaction chamber. The cleaned components were re-assembled for use in the next experiment, WFusn-15. 


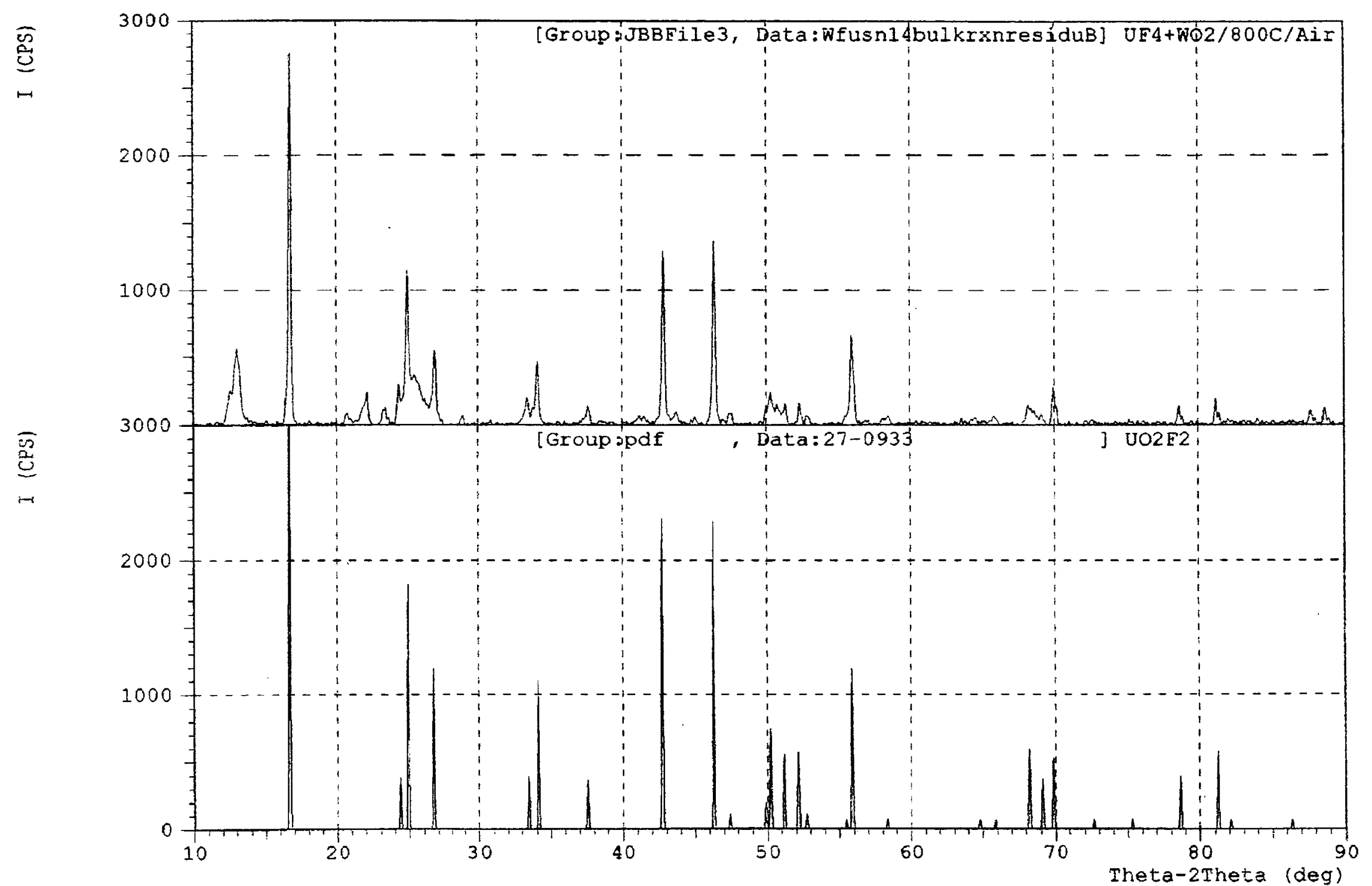

Figure 77. X-ray diffraction pattern for the residue from WFusn-14 and the reference pattern for $\mathrm{UO}_{2} \mathrm{~F}_{2}(\mathrm{pdf} \# 27-0933)$. 


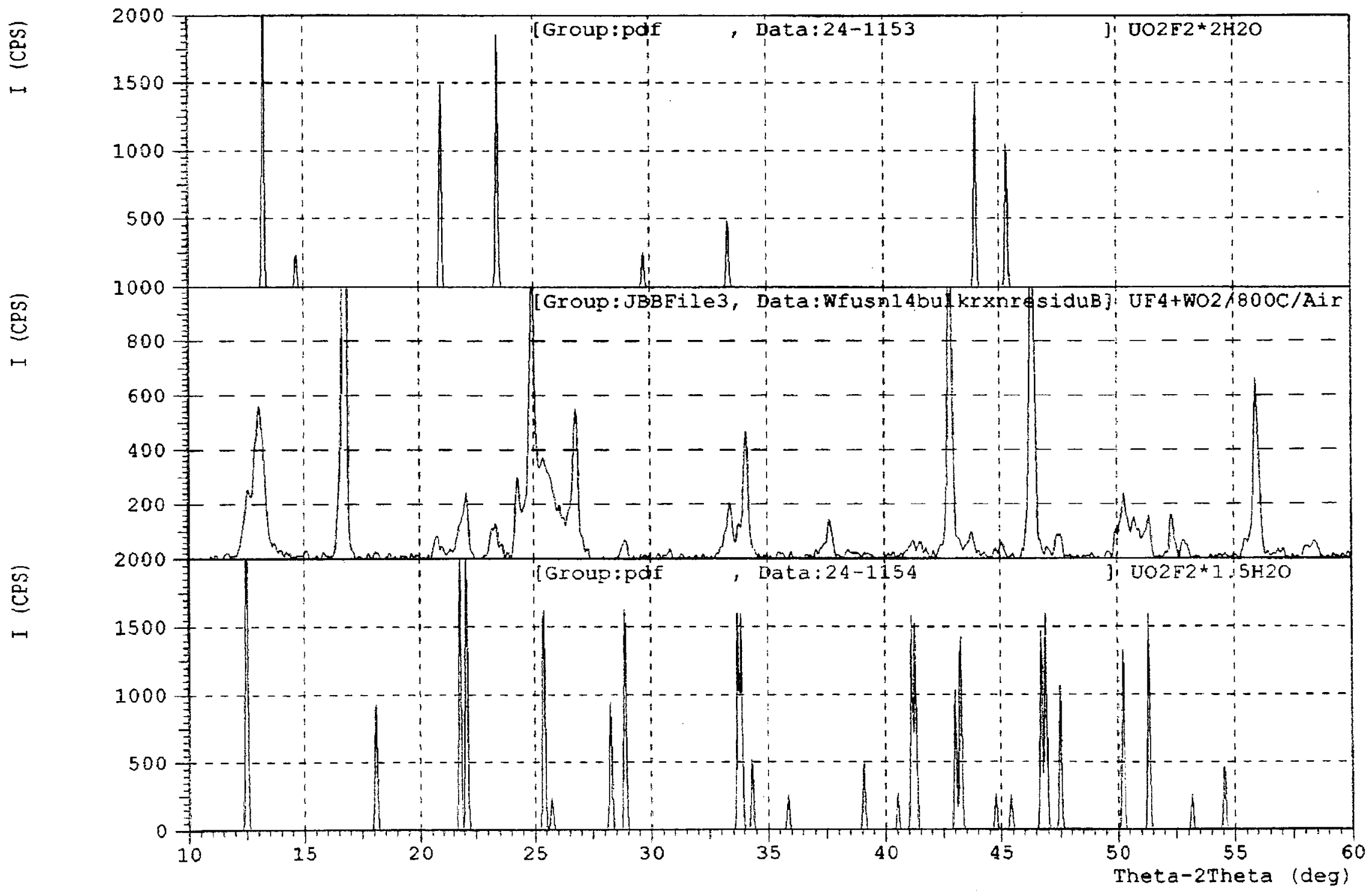

Figure 78. X-ray diffraction pattern for the WFusn-14 residue and reference patterns for two hydrated analogs of $\mathrm{UO}_{2} \mathrm{~F}_{2}$ formed by adsorption of moisture from the air, $\mathrm{UO}_{2} \mathrm{~F}_{2} \bullet 1.5 \mathrm{H}_{2} \mathrm{O}$ (pdf\# 24-1154) and $\mathrm{UO}_{2} \mathrm{~F}_{2} \bullet 2 \mathrm{H}_{2} \mathrm{O}$ (pdf\# 24-1153). 


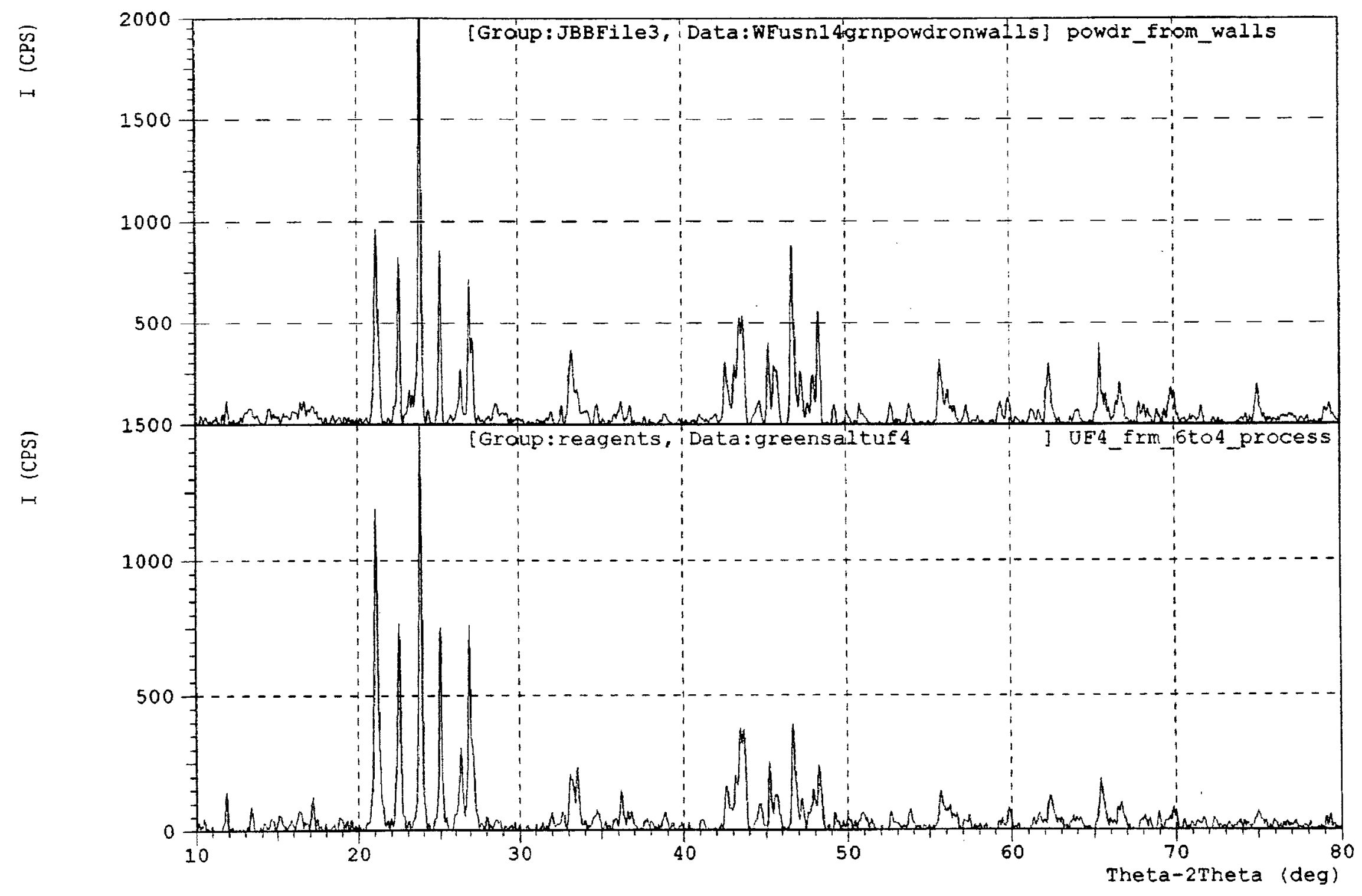

Figure 79. X-ray diffraction pattern for the green powder coating the interior walls of the reaction tube and reference pattern for untreated $\mathrm{UF}_{4}$. 
For the WFusn-15 trial, a two-step reaction scenario was undertaken. Details of this scheme were given in Table 38 (p.122). A less aggressive heating program was implemented in an attempt to prevent the expulsion of green salt from the reagent boat while the line to the condenser was heated and maintained at $\sim 202^{\circ} \mathrm{C}$. In preparation for the reaction in step (2), approximately 0.5 gram of $\mathrm{SiO}_{2}$ was added to the $\mathrm{WOF}_{4}$ condenser. Initially and throughout the reaction period, as $\mathrm{WOF}_{4}$ accumulated in the flask, there was no visible sign of reaction between $\mathrm{WOF}_{4}$ and $\mathrm{SiO}_{2}$ at the $0^{\circ} \mathrm{C}$ temperature of the surrounding ice/water bath.

Upon conclusion of the step (1) reaction, the ice/water bath surrounding the collection flask was removed and the flask warmed to ambient temperature while maintaining a flow of air through the vessel. A heating mantle was placed around the flask with a thermocouple situated near the bottom where the bulk of the residue had deposited. The mixture of condensed residue and $\mathrm{SiO}_{2}$ was slowly heated to explore the reaction in step (2). After reaching $\sim 100^{\circ} \mathrm{C}$, the $\mathrm{WOF}_{4}$ component began to melt, showing no signs of reaction. At $\sim 187^{\circ} \mathrm{C}$, the tungsten oxyfluoride began to vaporize and re-crystallize on the upper sections of the flask which were not heated, again without displaying any signs of color change or evolution of $\mathrm{SiF}_{4}$ gas. The anticipated product, $\mathrm{WO}_{3}$, is bright yellow but no hint of color change was observed. It might well be that the reaction requires a higher temperature than what was attained here for significant conversion to occur.

Following the completion of the second reaction step, the post-reaction solids in the $\mathrm{Ni}$ tube were recovered and analyzed. The $\mathrm{UF}_{4} / \mathrm{WO}_{2}$ reagent mixture lost 4.18 grams, which was slightly more than the calculated loss of 3.6138 grams. Again, the contents of the boat were completely pale yellow and the volume of solids expanded to maximum capacity. During the weight measurement, a slow but steady weight gain was observed as the boat sat on the balance, most probably as a result of the adsorption of moisture from the air. An x-ray diffraction pattern of the pale yellow residue is shown in Figure $\mathbf{8 0}$ along with the reference patterns for $\mathrm{UO}_{2} \mathrm{~F}_{2}$ (pdf\# 27-0933) and a hydrated analog, $\mathrm{UO}_{2} \mathrm{~F}_{2} \bullet 1.5 \mathrm{H}_{2} \mathrm{O}$ (pdf\# 24-1154). Similar to WFusn-14, a coating of green powder was detected on the walls of the $\mathrm{Ni}$ tube downstream from the reaction zone but to a lesser extent. It appears the rapid rise in temperature from $725^{\circ} \mathrm{C}$ to $780^{\circ} \mathrm{C}$ over a 15 minute span was too severe for keeping the reagent bed from loosing $\mathrm{UF}_{4}$.

After completing WFusn-15, it was observed that the nickel boat used in the majority of reactions conducted in the tube reactor between $\mathrm{UF}_{4}$ and $\mathrm{WO}_{2} / \mathrm{WO}_{3}$ showed evidence of significant corrosion. The used boat was set aside for more detailed examination and analysis. A discussion of those results is included in section 9.2.2 as part of the investigation into suitable materials of construction for the $\mathrm{WF}_{6}$ production system. Another clean nickel boat was used for the remainder of the program.

As done previously, the nickel reaction tube was cleaned again due to the expulsion of green salt from the reagent mixture. The reaction apparatus was re-assembled and heated to insure it was free from moisture. 


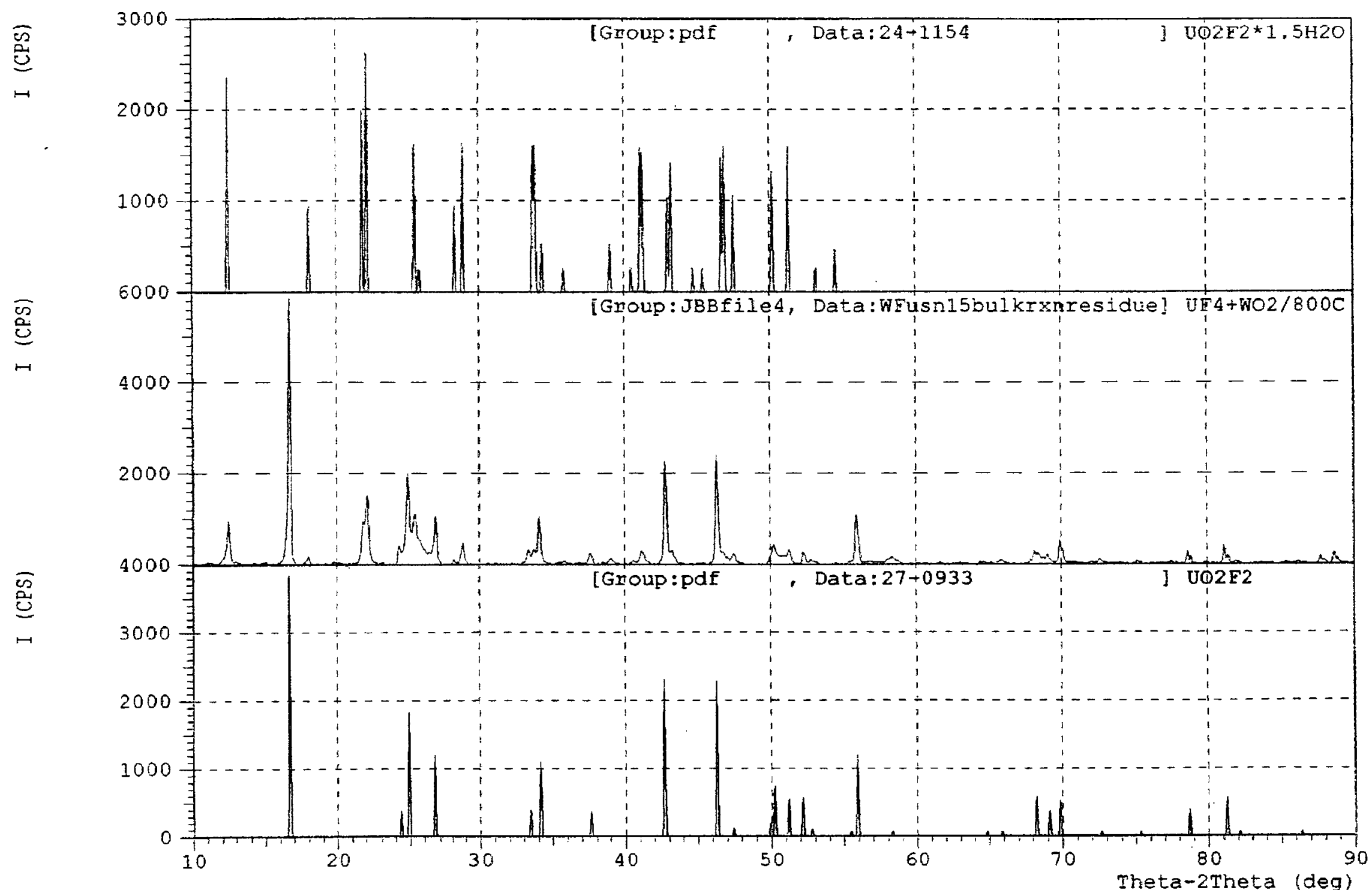

Figure 80. X-ray diffraction pattern for the pale yellow solid recovered from WFusn-15 and reference patterns for $\mathrm{UO}_{2} \mathrm{~F}_{2}\left(\mathrm{pdf} \#\right.$ 27-0933) and $\mathrm{UO}_{2} \mathrm{~F}_{2} \bullet 1.5 \mathrm{H}_{2} \mathrm{O}$ (pdf\# 24-1154). 
Before starting WFusn-16, a single-step reaction, several changes to the experimental procedure and apparatus were instituted. The furnace heating cycle was adjusted in order to control the displacement of $\mathrm{UF}_{4}$ from the reagent mixture and a larger collection vessel was inserted into the exit stream to enhance product capture. During the three-hour reaction period the exit line to the condenser was maintained at $210^{\circ} \mathrm{C}$ while the condenser was submerged in an ice/water bath. The $780^{\circ} \mathrm{C}$ maximum temperature was held for 135 minutes before concluding the run. Under these conditions, 2.19 grams of $\mathrm{WOF}_{4}$ was collected which was about $52.2 \%$ of the theoretical yield. The condensed solid was completely white with no sign of contamination by displaced $\mathrm{UF}_{4}$.

Upon recovery of the post-reaction solids, the material in the boat had a green tint on the surface off to one end. Approximately $80 \%$ of the reagent mixture expanded to maximum capacity while leaving the green-tinted area undisturbed. As the solid was transferred to a storage container, the powder adjacent to the bottom of the boat had the familiar green tint of partially reacted material. It did not appear that any material was expelled from the boat. It was also evident that the exterior surfaces of the boat changed from metallic gray to green, similar to the exterior color of the previous boat.

As in previous trials, the solid produced in WFusn-16 was analyzed by x-ray diffraction. The pattern for the recovered residue is shown in Figure 81 along with matching reference patterns for $\mathrm{UO}_{2} \mathrm{~F}_{2}$ (pdf\# 27-0933) and $\mathrm{UO}_{2} \mathrm{~F}_{2} \bullet 1.5 \mathrm{H}_{2} \mathrm{O}$ (pdf\# 24-1154). There were also low intensity peaks indexed to the pattern collected for unreacted green salt. Similarly, during the transfer of the pale yellow solid to the storage container, the residue appeared to adsorb moisture and form a sticky, wet mass.

In regard to the changes implemented for WFusn-16, use of the larger collection vessel did not appear to greatly improve the efficiency of capturing $\mathrm{WOF}_{4}$. However, the attenuated heating program did appear to curtail the liberation of $\mathrm{UF}_{4}$ from the reagent bed but may have contributed to the presence of unreacted material left behind. 


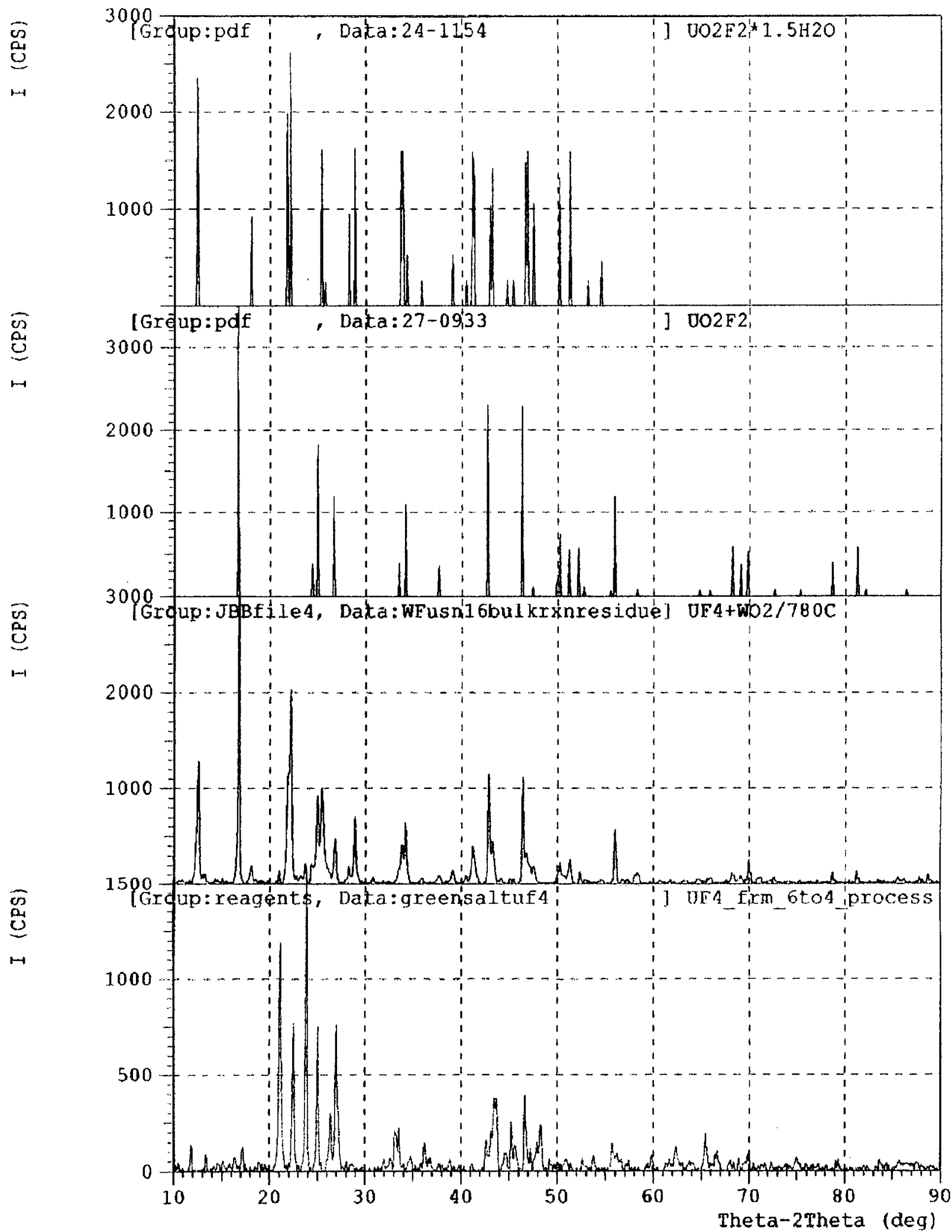

Figure 81. X-ray diffraction pattern for the residue reclaimed from WFusn-16 and reference patterns for $\mathrm{UO}_{2} \mathrm{~F}_{2}$ (pdf\# 27-0933), $\mathrm{UO}_{2} \mathrm{~F}_{2} \bullet 1.5 \mathrm{H}_{2} \mathrm{O}$ (pdf\# 24-1154) and unreacted $\mathrm{UF}_{4}$. 
The last trial conducted in the horizontal tube reactor setup was WFusn-17, which was planned as a two-step scenario. The reaction system was setup similar to that for the WFusn-16 run with the exception that the exit line to the condenser was not heated but wrapped only with insulation. The same condenser containing the 2.19 grams of $\mathrm{WOF}_{4}$ collected in WFusn-16 was put in place to receive the output from step (1) of this trial. Details of the WFusn-17 experiment were given in Table 41 (p.125) in section 9.1.1. Using a duplicate set of heating parameters and reaction times, the reaction between $\mathrm{UF}_{4}$ and $\mathrm{WO}_{2}$ produced an additional 2.44 grams of $\mathrm{WOF}_{4}$, which was about $53.0 \%$ of the expected amount. As before, the post-reaction solids in the boat were green-tinted at one end while completely yellow at the other. Weight lost by the reagents during

the reaction amounted to 4.5586 grams compared to the theoretical loss of 3.8015 grams calculated. The residue was split into two samples, separating the pale yellow solid from the green-tinted material. It is interesting to note that before removing the powder from the boat, there were many fragments of dark-colored scale scattered across the surface of the powder as seen below in Figure 82.

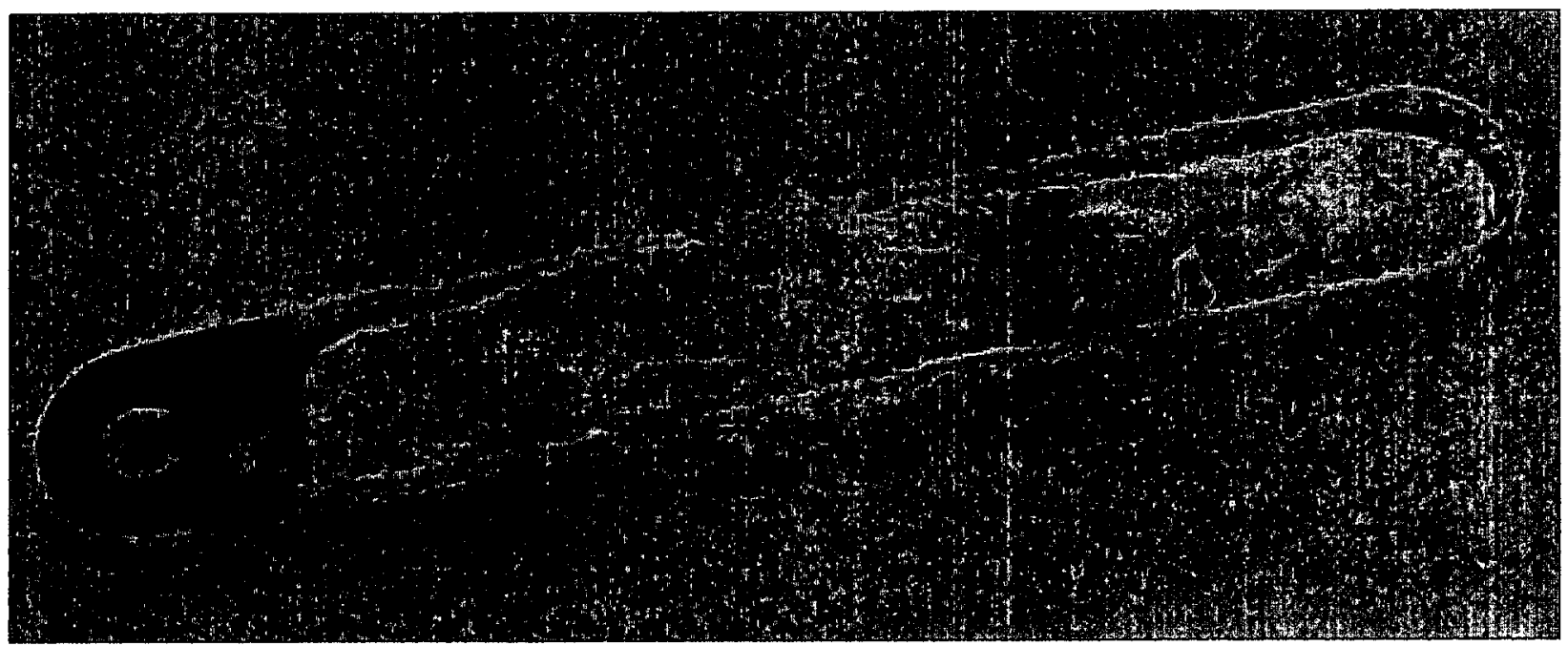

Figure 82. Post-reaction residue in the nickel boat after WFusn-17 showing many pieces of scale scattered across the surface of the $\mathrm{UO}_{2} \mathrm{~F}_{2}$ powder.

A detailed discussion of the origin of the scale is included in the next section concerning the selection of appropriate materials of construction for the reaction system.

The two samples of residue collected from the boat were analyzed by x-ray diffraction. Those results are shown in Figure 83 and Figure 84 for the green-tinted and pale yellow powders, respectively. The green-tinted material was indexed to three phases including $\mathrm{UO}_{2} \mathrm{~F}_{2}$ (pdf\# 27-0933), $\mathrm{UO}_{2} \mathrm{~F}_{2} \bullet 2 \mathrm{H}_{2} \mathrm{O}$ (pdf\# 24-1153) and a small amount of unreacted $\mathrm{UF}_{4}$ (see Figure 83). The pale yellow fraction, representing a majority of the bulk, was indexed to $\mathrm{UO}_{2} \mathrm{~F}_{2}$ and a small amount of the hydrated analog, $\mathrm{UO}_{2} \mathrm{~F}_{2} \bullet 2 \mathrm{H}_{2} \mathrm{O}$ (Figure 84). 


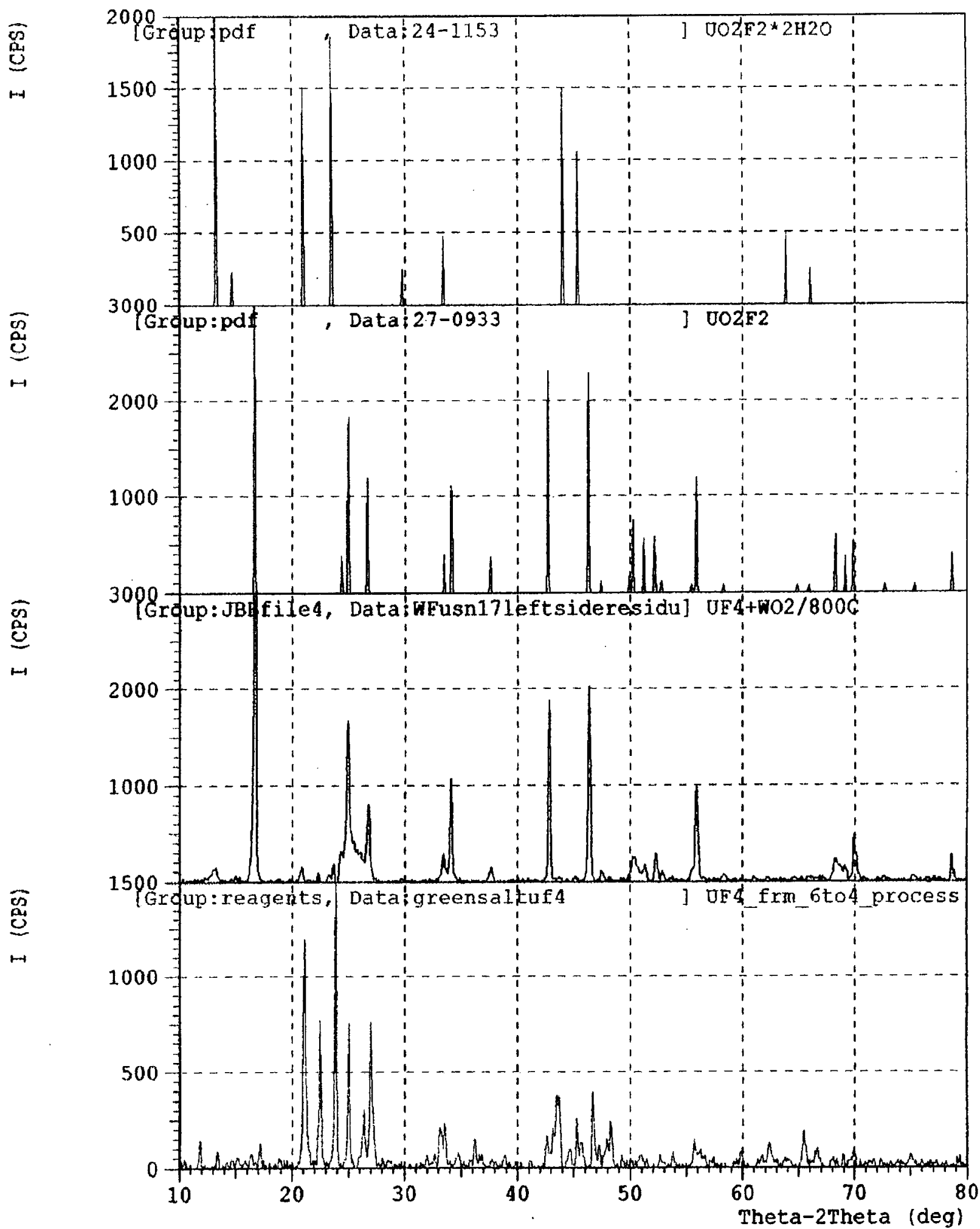

Figure 83. X-ray diffraction pattern for the green-tinted portion of residue from WFusn-17 and reference patterns for $\mathrm{UO}_{2} \mathrm{~F}_{2}$ (pdf\# 27-0933), $\mathrm{UO}_{2} \mathrm{~F}_{2} \bullet 2 \mathrm{H}_{2} \mathrm{O}$ (pdf\# 24-1153) and unreacted $\mathrm{UF}_{4}$. 


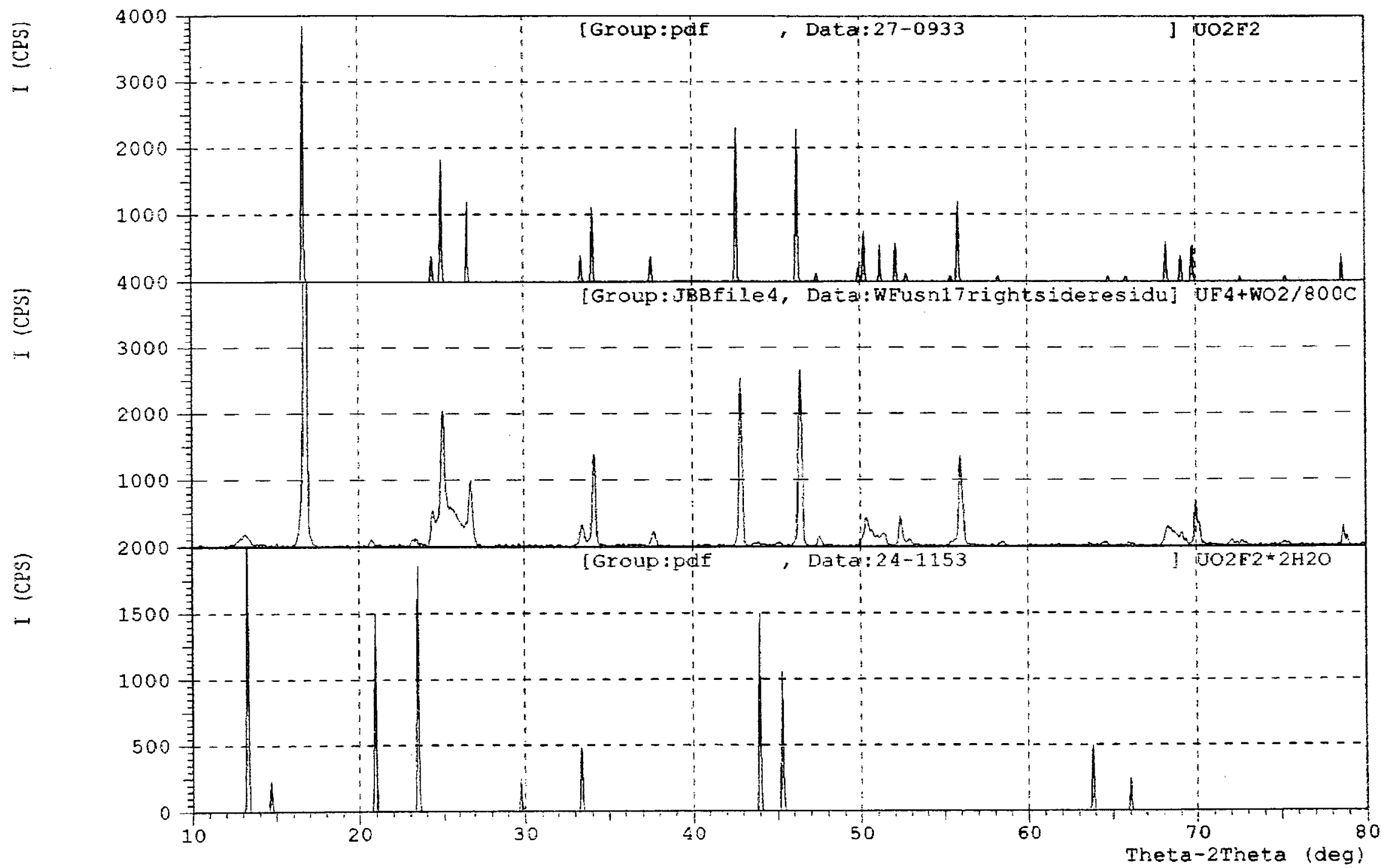

Figure 84. X-ray diffraction pattern for the pale yellow residue from WFusn-17 and reference patterns for $\mathrm{UO}_{2} \mathrm{~F}_{2}$ (pdf\# 27-0933) and $\mathrm{UO}_{2} \mathrm{~F}_{2} \bullet 2 \mathrm{H}_{2} \mathrm{O}$ (pdf\# 24-1153). 
After completing the first stage of WFusn-17, the total amount of WOF 4 contained in the pyrex ${ }^{\circledR}$ cylinder climbed to 4.63 grams. This material was then used as a reactant for the reaction shown in Table 42 (page 126), that being the reaction with $\mathrm{TiF}_{4}$. When $\mathrm{TiF}_{4}$ was added to the $\mathrm{WOF}_{4}$ powder, there were no visible changes observed as the two compounds were mixed. The combined powder mixture was then heated slowly using a heat gun. Gas bubbles began to pass through the in-line traps and at one point a vapor cloud appeared above the liquid $\mathrm{NaOH}$ trap. After 5-7 minutes of heating, it appeared the temperature reached the vaporization point for $\mathrm{WOF}_{4}\left(\sim 187^{\circ} \mathrm{C}\right)$ which lead to a buildup of condensed film on the upper sections of the cylinder. Throughout the heating period, the white color of the mixture did not appear to change.

However, no color change was expected since the $\mathrm{TiO}_{2}$ product is also white.

After cooling the cylinder to ambient temperature, it was put back into the argon-filled glovebag where the material deposited in the upper sections was dislodged and recombined with the bulk solids. The pyrex ${ }^{\circledR}$ condenser was then heated a second time using the heat gun. After 10 minutes of applied heat, there was no sign of further reaction or sublimation of components so the experiment was terminated. The post-reaction solid was transferred to a storage container while being handled in the glovebag. X-ray diffraction analysis of the residue was not done due to the potential release of hazardous hydrogen fluoride vapors from any leftover unreacted materials.

Based on the observation of bubble formation and a vapor cloud in the $\mathrm{NaOH}$ trap, it was concluded that there was at least partial reaction between $\mathrm{TiF}_{4}$ and $\mathrm{WOF}_{4}$ and that further experimentation using $\mathrm{TiF}_{4}$ as the fluorinating agent was warranted. The new chemistry proposed for making $\mathrm{WF}_{6}$ is based on the reaction of $\mathrm{TiF}_{4}$ with $\mathrm{WO}_{2}$, as presented in Table 43 (p.127). To explore this scenario, milligram quantities of reactants were combined and reacted in the thermogravimetric analyzer (TGA).

For this micro-scale experiment, 8.549 milligrams of combined reactants were heated to $500^{\circ} \mathrm{C}$ in a stream of dry air. The results of the prescribed treatment are shown in Figure 85, displaying the weight change of the reactants over the course of the thermal treatment. During the first 15 minutes at ambient temperature, the contents of the cup gained weight $(\sim 0.1 \mathrm{mg})$, most likely as a result of moisture adsorption. Then, as the temperature rose to the $500^{\circ} \mathrm{C}$ plateau, there were three weight loss events clearly delineated before the sample weight stabilized at the peak temperature. Overall, the starting materials lost a total of $1.61 \mathrm{mg}$ during the experiment. The first significant weight loss event began around $44^{\circ} \mathrm{C}$ and carried out to a temperature of $\sim 321{ }^{\circ} \mathrm{C}$, accounting for a loss of $\sim 0.8 \mathrm{mg}$. A second, smaller weight loss of $\sim 0.3 \mathrm{mg}$ occurred between $321^{\circ} \mathrm{C}$ and $441^{\circ} \mathrm{C}$ followed by a third decline of $\sim 0.5 \mathrm{mg}$ as the $500^{\circ} \mathrm{C}$ plateau was reached. A complete explanation of each event is not possible without performing additional trials and supplemental analytical data gathering. However, the first weight loss (representing $\sim 50 \%$ of the total loss) strongly suggests that a reaction did occur between $\mathrm{TiF}_{4}$ and $\mathrm{WO}_{2}$ to produce a gaseous product. The second and third losses occurred at temperatures well above the sublimation temperature for $\mathrm{TiF}_{4}\left(285.5^{\circ} \mathrm{C}\right)^{29}$ which may help to explain, at least in part, the remaining $0.8 \mathrm{mg}$ loss. 


\section{$\mathrm{TiF}_{4}+\mathrm{WO}_{2}$ Heated in Air to $500^{\circ} \mathrm{C}$}

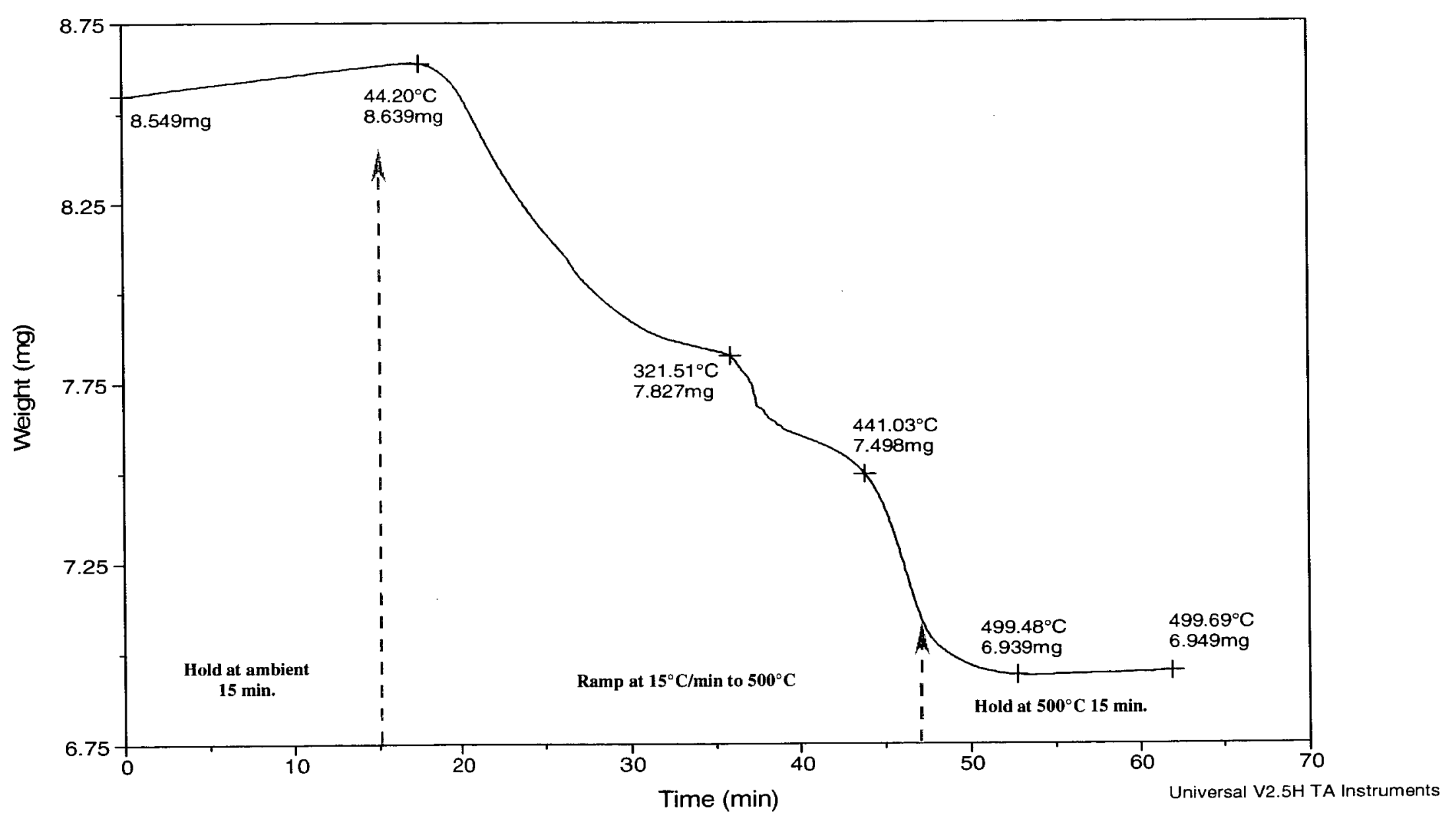

Figure 85. TGA Plot showing the weight change during reaction between $\mathrm{TiF}_{4}$ and $\mathrm{WO}_{2}$ at $500^{\circ} \mathrm{C}$ in air. 
After completing the micro-scale experiment in the TGA apparatus, gram quantities of $\mathrm{TiF}_{4}$ and $\mathrm{WO}_{2}$ were combined in a larger $\mathrm{Parr}^{\circledR}$ reaction apparatus illustrated in Figure 52 in section 9.1.1. Results for the WFusn-19 trial were archived since the WFusn-18 experiment was terminated without preserving any FT-IR data for the gaseous reaction products made in that run.

During the WFusn-19 trial, 7.6916 grams of $\mathrm{TiF}_{4} / \mathrm{WO}_{2}$ mixture were heated slowly to $265^{\circ} \mathrm{C}$ over a 2.5 -hour period. FT-IR spectra were collected for aliquots of gas captured in the gas cell when the reactor temperature reached $85^{\circ} \mathrm{C}, 185^{\circ} \mathrm{C}, 187^{\circ} \mathrm{C}, 190^{\circ} \mathrm{C}$ and $245^{\circ} \mathrm{C}$. At $85^{\circ} \mathrm{C}$, a stream of white vapor was again seen exiting the scrubber line. This was the point at which the first aliquot of gas was isolated in the gas cell. Approximately 32 minutes into the reaction period, the flow of air through the vessel to the scrubber stopped. Pressure in the reactor rose to $\sim 30 \mathrm{psi}$ with the temperature at $\sim 180^{\circ} \mathrm{C}$. The contents of the vessel were vented through the gas cell and several aliquots were analyzed at this juncture. The last sample of reactor off-gas was taken when the reactor was at $245^{\circ} \mathrm{C}$. Following that sample, the reactor was closed to flow and the experiment allowed to continue for an additional 30 minutes at a pressure of $\sim 10 \mathrm{psi}$ with the temperature between $245^{\circ} \mathrm{C}-265^{\circ} \mathrm{C}$. During this period, the pressure in the vessel did not change which was taken as a sign that the reaction did not produce additional gaseous products so the trial was terminated.

The FT-IR spectra collected at the aforementioned temperatures are shown in Figure 86 along with the times during the reaction the aliquots were taken. It was clear that the samples captured at temperatures of $185^{\circ} \mathrm{C}$ and $187^{\circ} \mathrm{C}$ contained strong absorption peaks in the range between $4000-3000 \mathrm{~cm}^{-1}, 1350-1100 \mathrm{~cm}^{-1}$ and $950-700 \mathrm{~cm}^{-1}$. At the $190^{\circ} \mathrm{C}$ plateau 89 minutes into the reaction, the intensity of the absorption peaks dropped off dramatically and at $245^{\circ} \mathrm{C}$ the absorption intensity of the sample was diminished to near-background levels.

Interpretation of the FT-IR data shown in Figure 86 was started by comparing the spectrum for the $185^{\circ} \mathrm{C}$ aliquot with reference spectra for $\mathrm{HF}$ and $\mathrm{WF}_{6}$, as shown in Figure 87. The highly absorbing specimen collected at $185^{\circ} \mathrm{C}$ was subsequently pulsed several times with aliquots of ultra-high purity (UHP) grade helium gas to dilute the material and bring the strong absorption peaks within the range of the spectrometer's detector. The five narrow peaks between $4000-37000 \mathrm{~cm}^{-1}$ indicated the presence of $\mathrm{HF}$, which was essentially present in all the aliquots of reactor off-gas examined. The strong absorption band between $3700-3100 \mathrm{~cm}^{-1}$ became better defined in the spectrum for the diluted sample, revealing the presence of two peaks with maxima at $\sim 3500 \mathrm{~cm}^{-1}$ and $3380 \mathrm{~cm}^{-1}$ and a shoulder band at $\sim 3200 \mathrm{~cm}^{-1}$. As yet, these bands remain unidentified but their presence suggest the specimen contained more species than the two reference compounds shown. The broad bands in the $1350-1100 \mathrm{~cm}^{-1}$ region diminished in the diluted sample and also did not correspond with the reference materials. The small narrow peak located at $\sim 1025 \mathrm{~cm}^{-1}$ indicated the presence of $\mathrm{SiF}_{4}$, which could be traced back to the fluorination of silicon-based lubricant used in the Swagelok ${ }^{\circledR}$ valves used to close the entrance and exit ports on the gas cell and exit lines from the Parr reaction vessel. The remaining three broad bands across the $950-700 \mathrm{~cm}^{-1}$ region corresponded with peak locations found in the $\mathrm{WF}_{6}$ reference spectrum and could be the first indications that $\mathrm{WF}_{6}$ was produced during the reaction.

After completing the trial, the reaction system was disassembled in stages to learn more about where blockages in the exit line formed which stopped flow of gas to the scrubber. The $1 / 8$ " OD tube connecting the 3-way valve to the scrubber (refer to Figure 52) was packed with a white solid at the connection to the 3 -way valve. The sections of $1 / 4$ " OD line from the 3-way valve to the ball valve and ball valve to reactor top also contained a heavy deposit of white residue. Upon opening the Parr vessel, the underside of the reactor lid was totally covered 


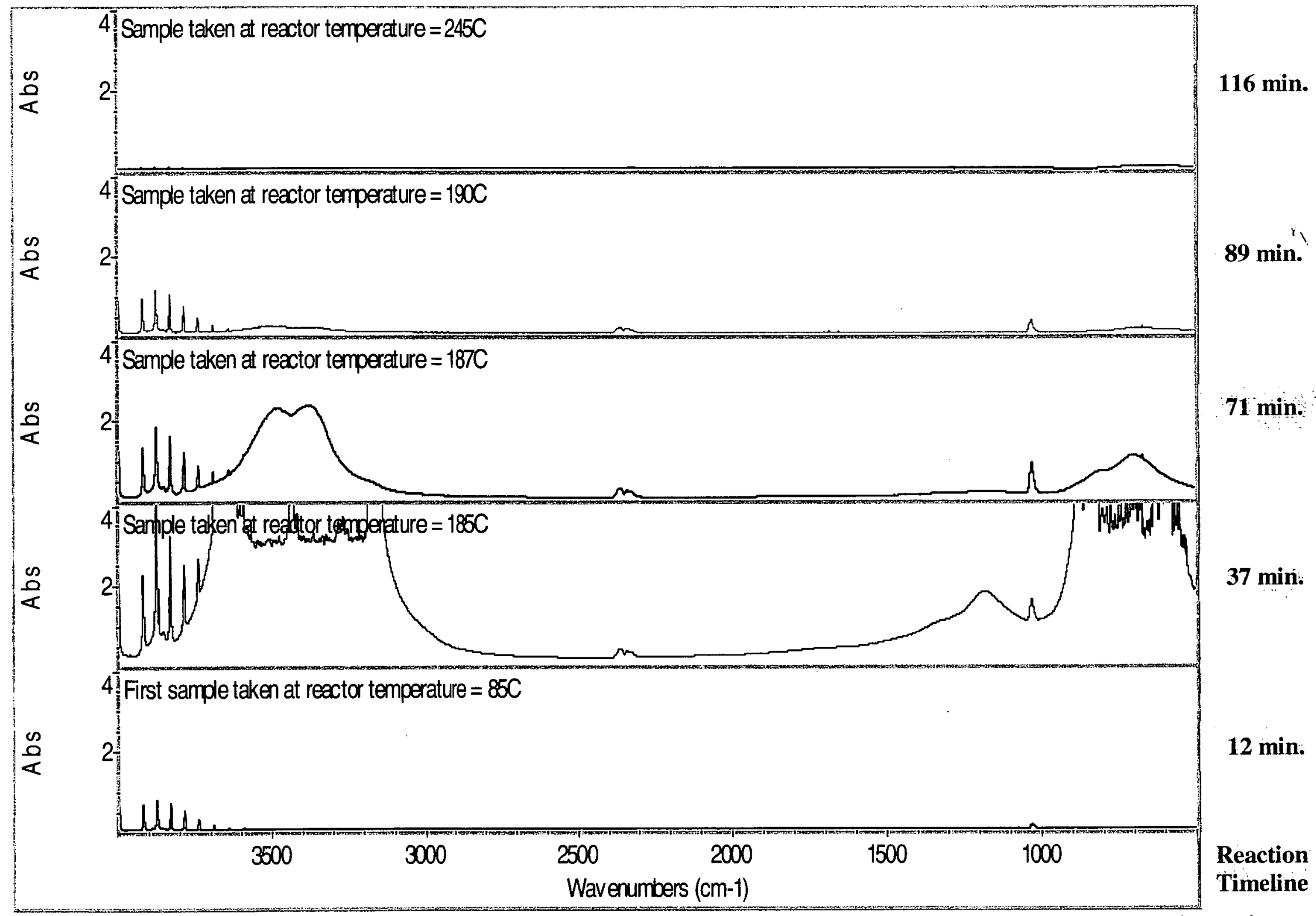

Figure 86. FT-IR spectra of gaseous samples collected at various reactor temperatures during the WFusn-19 reaction. 


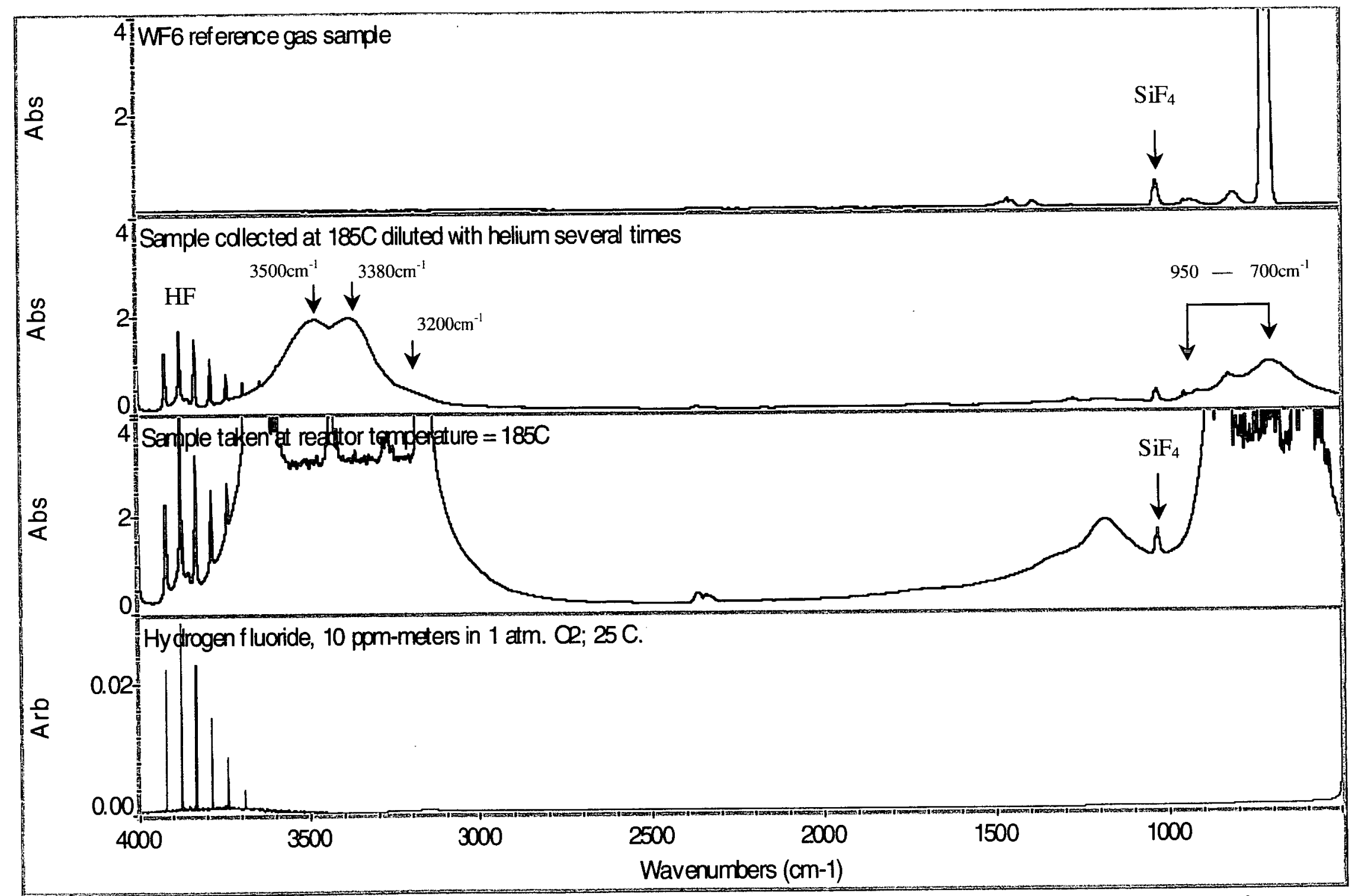

Figure 87. FT-IR spectra of the gas aliquot collected at $185^{\circ} \mathrm{C}$, the same sample after diluting with helium and reference spectra for $\mathrm{WF}_{6}$ and $\mathrm{HF}$. 
with a layer of white solid. After sitting exposed to the air for an hour the solid appeared to hydrolyze, leaving a wet surface in areas where the residue was not very thick. At this point, the reactor lid was submerged in distilled water to remove the residue. The resulting solution had a blue tint and the material sticking to the underside turned dark blue in color. The solid remaining in the lower section of the reactor was a mix of gray and white particles of loose powder that did not appear to change or adsorb moisture after standing in air for several hours. The post-reaction solid was not analyzed by $\mathrm{x}$-ray diffraction due to the potential for release of HF vapors during the analysis. However, the residue collected from the underside of the reactor lid in the aqueous solution was examined further by $\mathrm{x}$-ray diffraction after drying the solution to recover the solid. The $\mathrm{x}$-ray diffraction pattern for the dried material is shown in Figure 88 along with the matching reference pattern for $\mathrm{TiOF}_{2}$ (pdf\# 08-0060). Based on the presence of oxyfluoride after contact with water, the white solid deposited on the lid and accumulated downstream causing the blockages in the lines was most likely $\mathrm{TiF}_{4}$ which separated from the reaction mixture via sublimation. The hydrolysis reaction to produce the $\mathrm{TiOF}_{2}$ is given in equation (9.4) below,

$$
\mathrm{TiF}_{4}+\mathrm{H}_{2} \mathrm{O}(\mathrm{aq}) \longrightarrow \mathrm{TiOF}_{2}+2 \mathrm{HF}(\mathrm{aq})
$$

Although the $\mathrm{TiF}_{4}$ sublimation temperature of $285^{\circ} \mathrm{C}$ was not reached, the temperature of the reaction vessel was high enough to cause a significant amount of $\mathrm{TiF}_{4}$ to volatilize and collect downstream on cooler surfaces. 


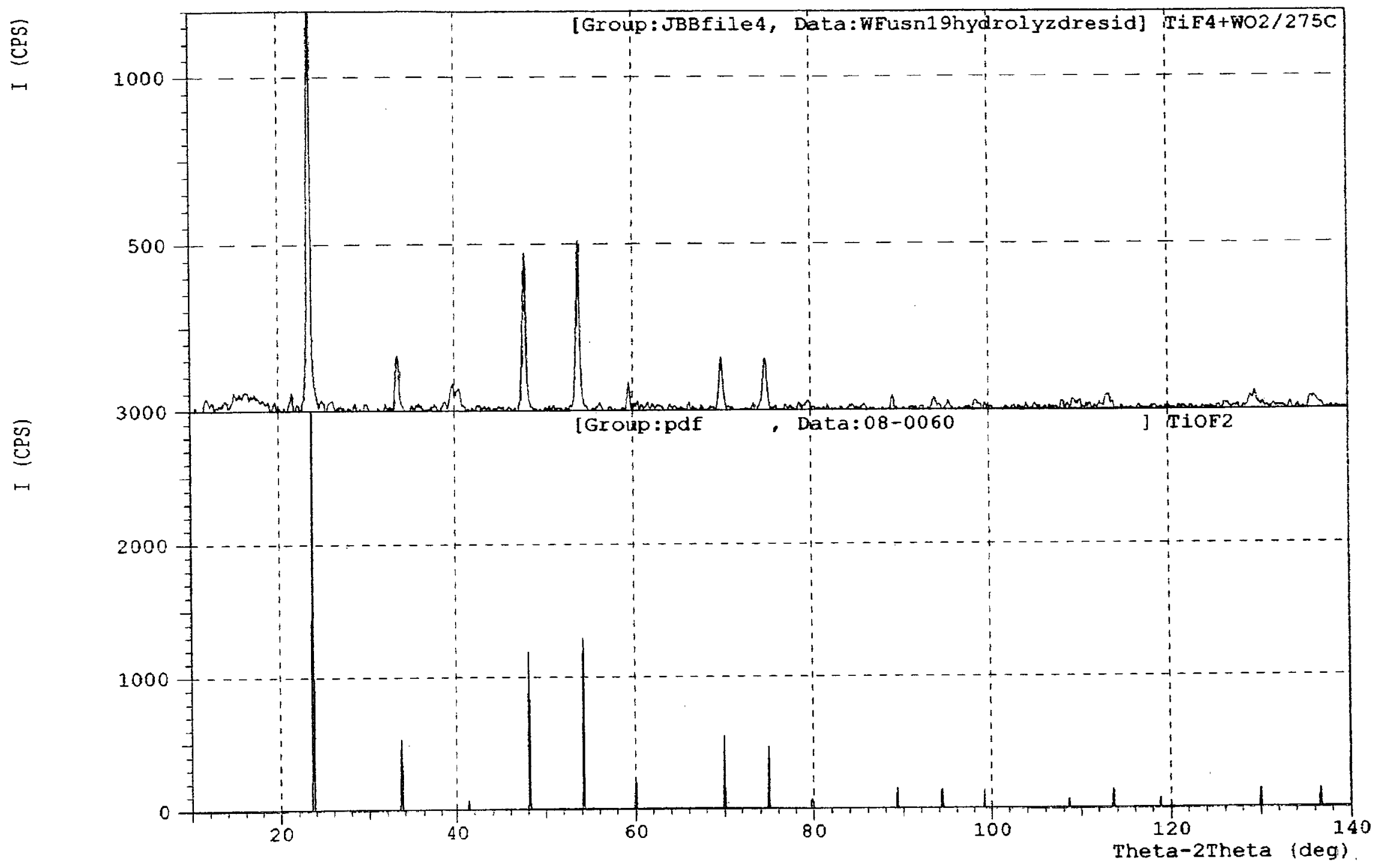

Figure 88. X-ray diffraction pattern for the hydrolyzed residue recovered from the underside of the reactor lid and the reference pattern for $\mathrm{TiOF}_{2}$ (pdf\# 08-0060). 


\subsubsection{Selection of suitable materials of construction for producing $\mathrm{WF}_{6}$.}

The nickel boat used to hold the uranium tetrafluoride/tungsten oxide mixtures during the many experiments to produce $\mathrm{WOF}_{4}$ showed significant corrosion and deterioration. An investigation into the corrosion was begun in order to learn what effects the high temperature fusion chemistry would have on a reaction system constructed of nickel. To document the corrosion, several images of the boat were collected and are presented below in Figure 89, Figure 90 and Figure 91.

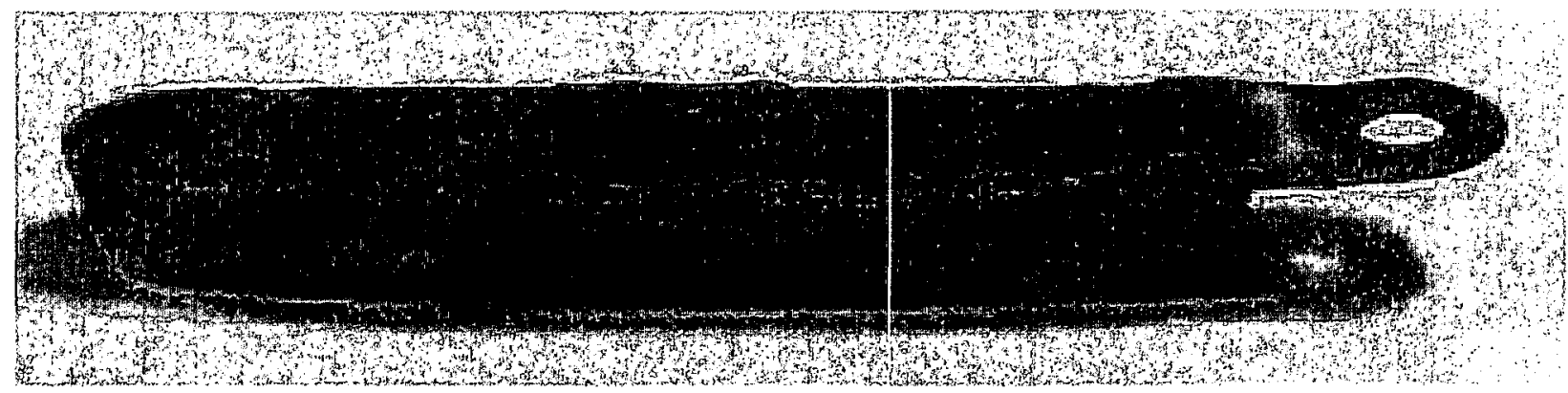

Figure 89. Image of nickel boat used in the high temperature fusion reactions between $\mathrm{UF}_{4}$ and $\mathrm{WO}_{2} / \mathrm{WO}_{3}$ mixtures.

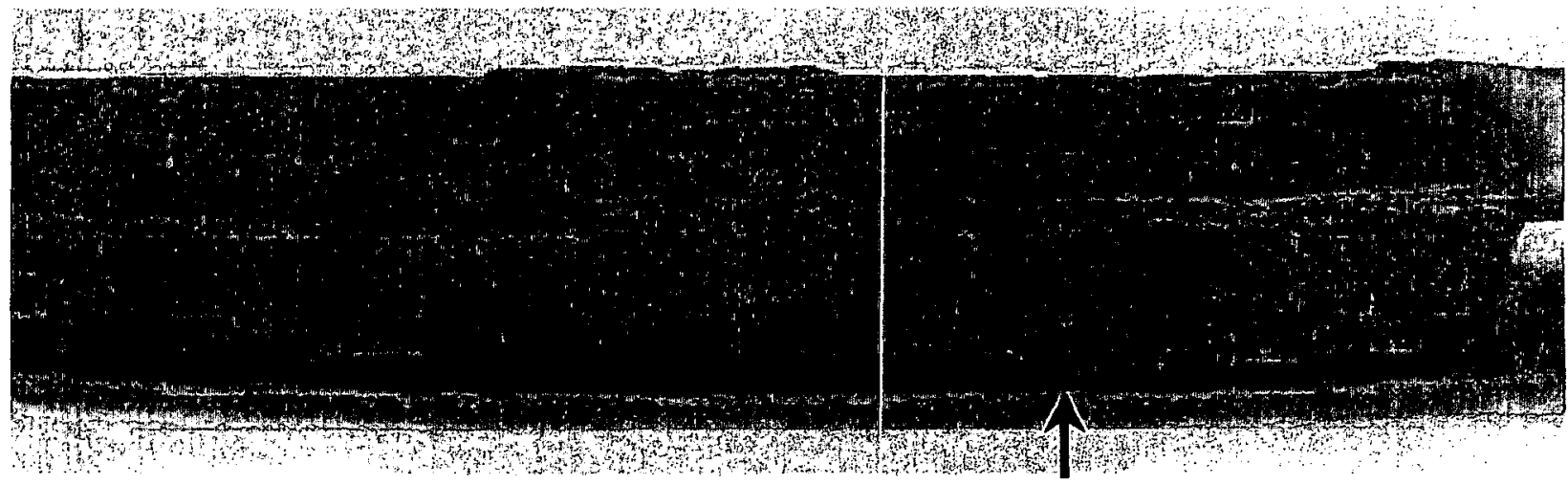

Figure 90. Side view image of the nickel boat showing the green-brown corrosion layer covering the exterior and interior walls. The arrow shows where a piece of scale was removed from the exterior wall. 


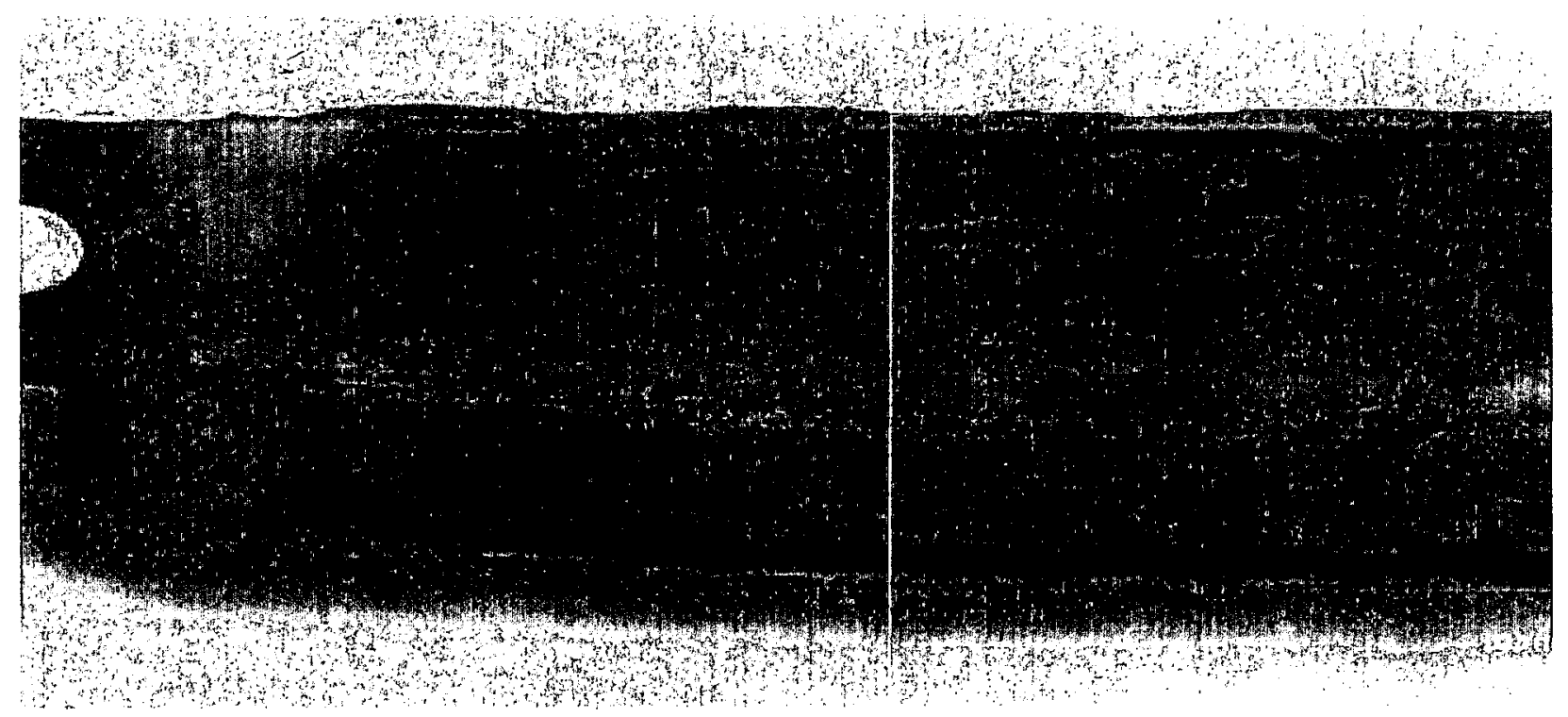

Figure 91. A close-up image of the nickel boat showing the corrosion of the interior walls.

It was clear much of the boat's exterior and interior walls were covered with a greenbrown layer of flaky solid. A large piece of the corrosion layer was removed (refer to Figure 90) and divided into two specimens for characterization by x-ray diffraction. One piece of scale was mounted exposing the outward-facing surface of the flake to the x-ray beam while the other sample was prepared with the interfacial side (side oriented against the wall of the boat) facing the analysis beam. The x-ray diffraction patterns for the two specimens are given in Figure 92, showing dissimilar patterns at first glance. Both patterns were then analyzed in detail and indexed to constituent phases. As shown in Figure 93, the outward facing surface of the flake was matched to three phases including $\mathrm{NiO}$ (pdf\# 47-1049), $\mathrm{NiWO}_{4}$ (pdf\# 15-0755) and $\mathrm{NiF}_{2}$ (pdf\# 24-0791). Here, the peak intensities indexed to each compound were about equal. As depicted in Figure 94, the interfacial side of the flake was also indexed to the same three compounds with the exception that the intensity of the $\mathrm{NiO}$ component was the dominant phase by a wide margin.

Using the x-ray results of the scale material, the corrosion of nickel can be described by the following sequence of reactions:

First

$$
2 \mathrm{Ni}+\mathrm{O}_{2}(\mathrm{~g}) \longrightarrow 2 \mathrm{NiO}
$$

Second

$$
3 \mathrm{NiO}+\mathrm{WOF}_{4}(\mathrm{~g}) \longrightarrow \mathrm{NiWO}_{4}+\mathrm{NiF}_{2}
$$




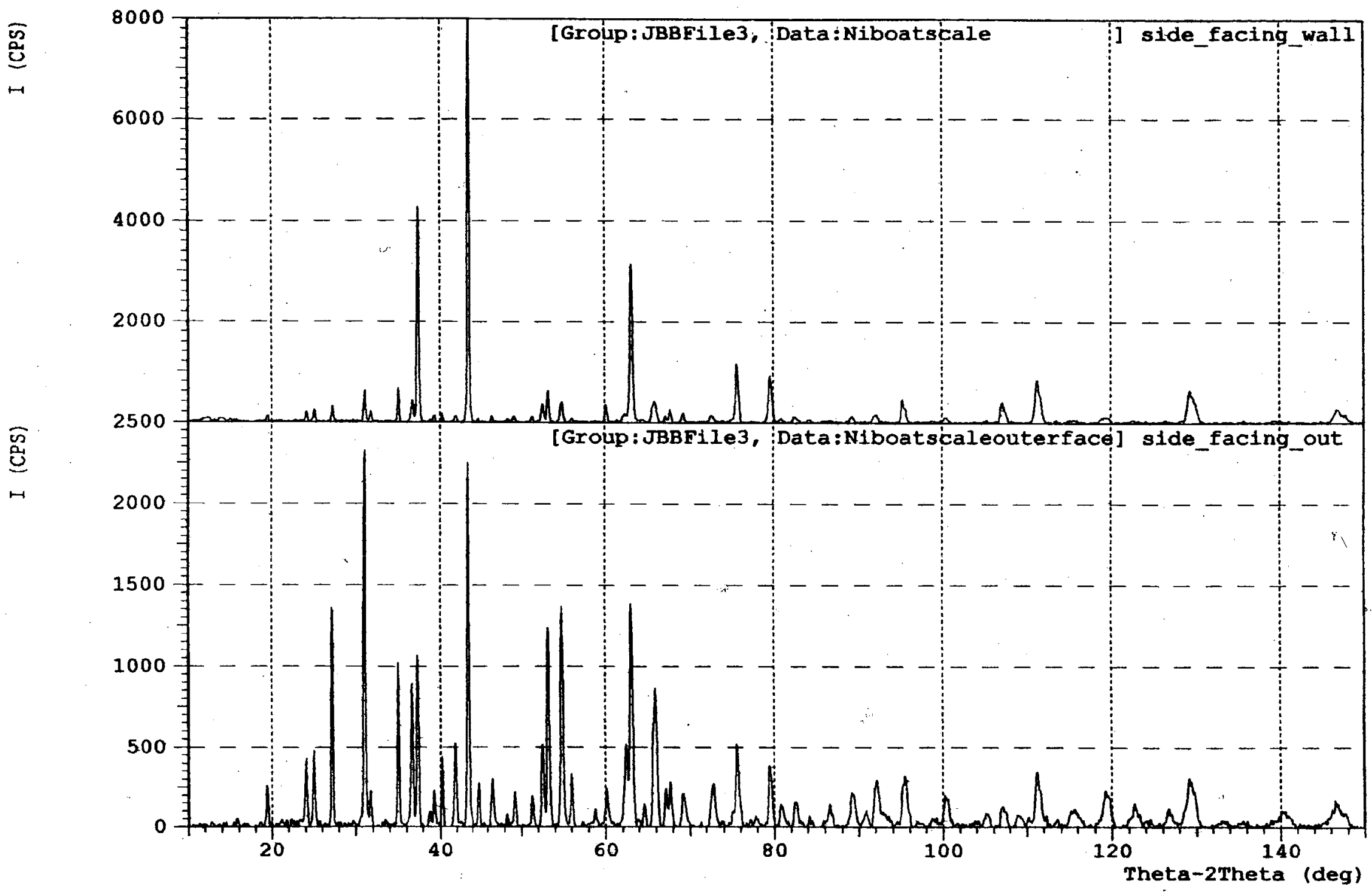

Figure 92. X-ray diffraction patterns for the outward and inward facing sides of the scale removed from the side of the nickel boat shown in Figure 90. 


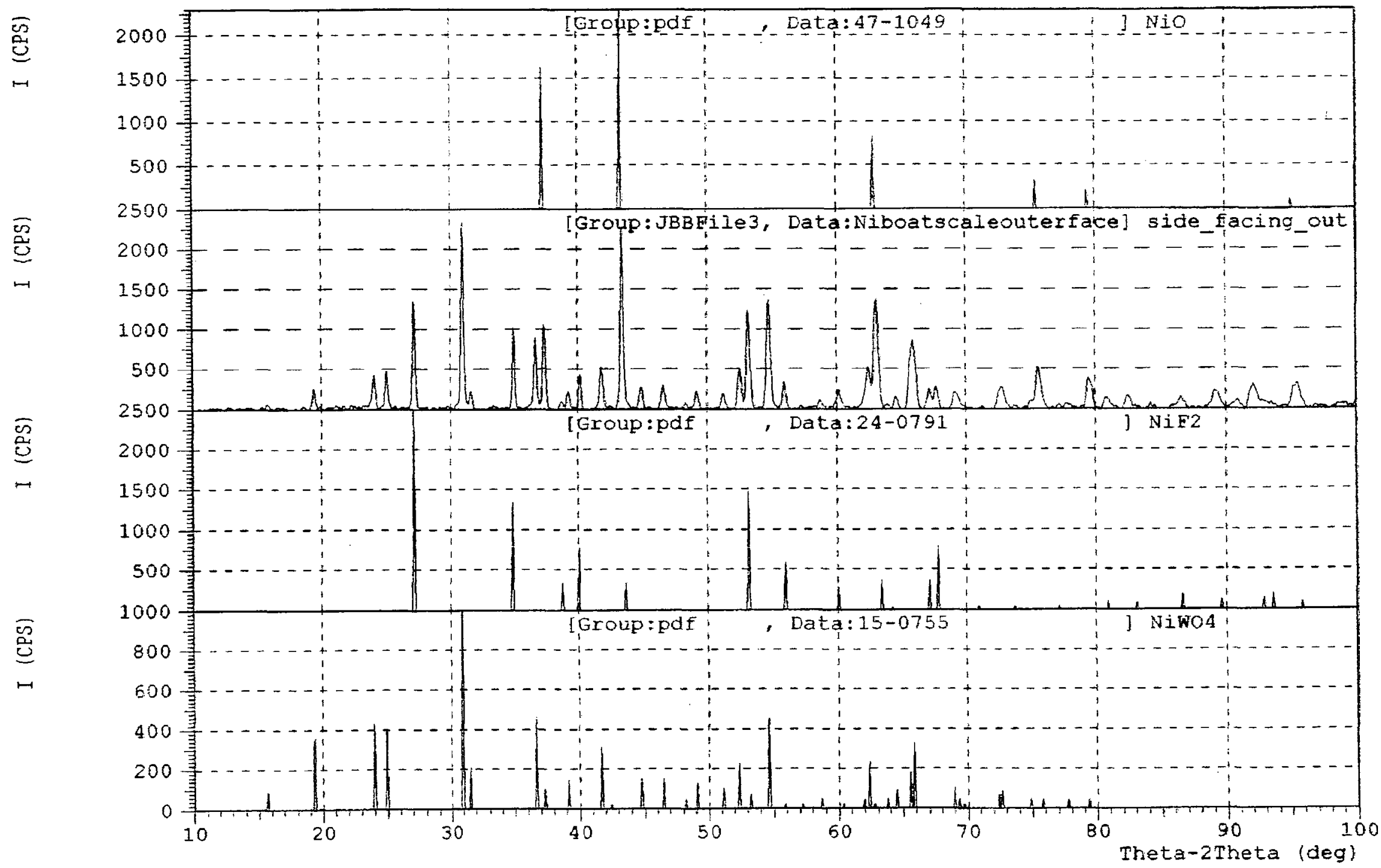

Figure 93. X-ray diffraction pattern for the outward facing side of the scale and reference patterns for NiO (pdf\# 47-1049), $\mathrm{NiF}_{2}$ (pdf\# 24-0791) and $\mathrm{NiWO}_{4}$ (pdf\# 15-0755). 


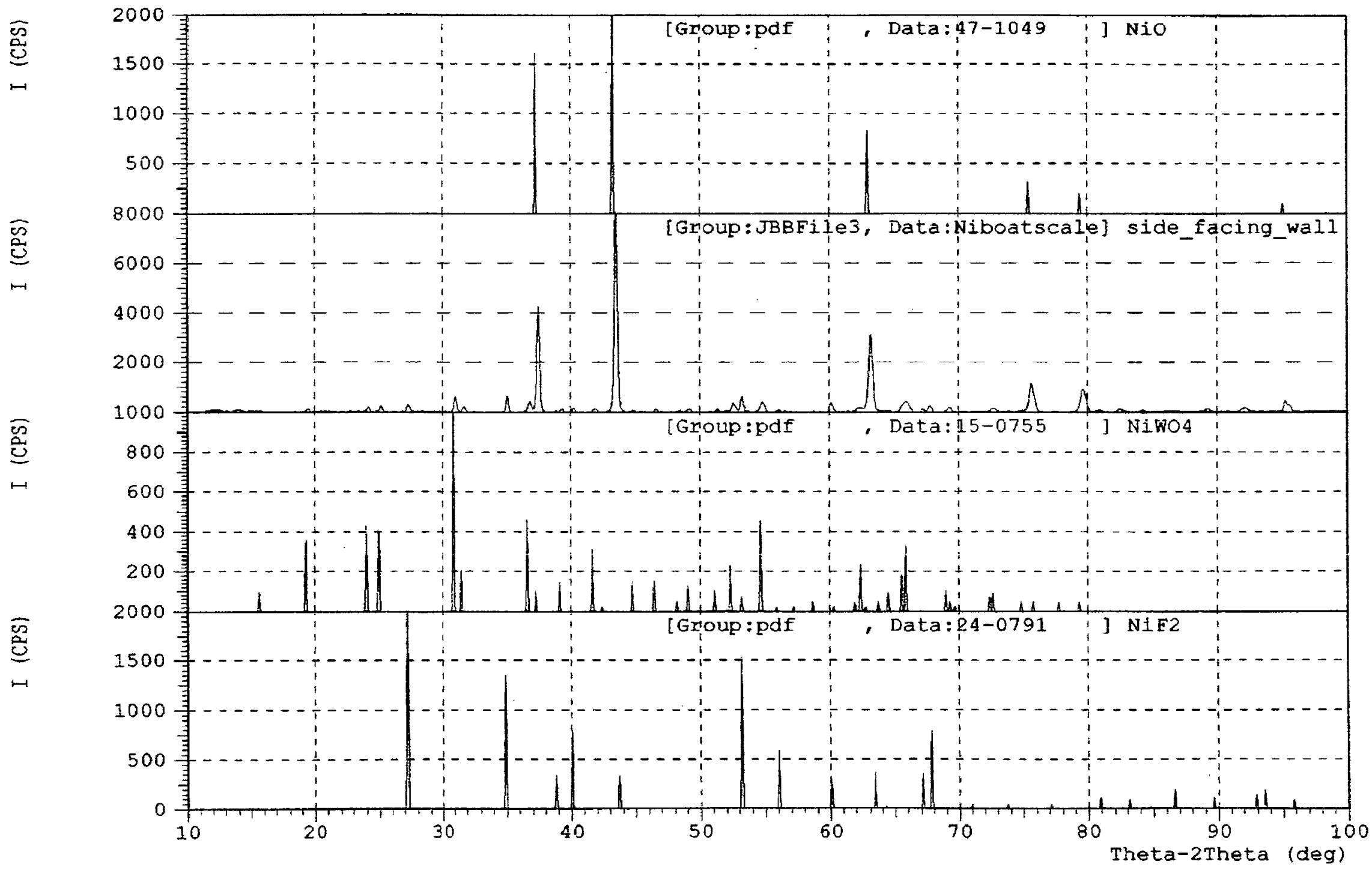

Figure 94. X-ray diffraction pattern for the inward facing side of the scale and reference patterns for $\mathrm{NiO}$ (pdf\# 47-1049), $\mathrm{NiWO}_{4}$ (pdf\# 15-0755) and $\mathrm{NiF}_{2}$ (pdf\# 24-0791). 
As shown in Table 50 below, both reactions displayed favorable thermodynamic parameters $^{14}$ (negative Gibbs free energy change, $-\Delta \mathrm{G}$ ) over the temperature ranges used in the fusion experiments. The interfacial side of the scale was essentially nickel oxide (NiO) since that surface had little or no direct contact with $\mathrm{WOF}_{4}$ vapor. The reaction in equation (9.6) (page 187) will likely occur on all the oxidized nickel surfaces around and downstream from the heated reaction zone, including the boat and the walls of the Ni reaction tube.

Table 50.

Thermodynamic calculations describing the two-step corrosion process occurring on the surface of nickel.

\begin{tabular}{|c|c|c|c|c|}
\hline Step (1): & $2 \mathrm{P}$ & $\mathrm{O}_{2}(\mathrm{~g})$ & $2 \mathrm{NiO}$ & $\ln ^{2}=\sqrt{2}$ \\
\hline $\mathrm{T}\left({ }^{\circ} \mathrm{C}\right)$ & delta $\mathrm{H}($ kcal) & delta S(cal) & delta G(kcal) & $\mathbf{K}$ \\
\hline 0.00 & -114.608 & -45.249 & -102.248 & $6.555 \mathrm{E}+081$ \\
\hline 100.00 & -114.383 & -44.567 & -97.753 & $1.809 \mathrm{E}+057$ \\
\hline 200.00 & -113.936 & -43.522 & -93.344 & $1.316 \mathrm{E}+043$ \\
\hline 300.00 & -113.234 & -42.162 & -89.069 & $9.249 \mathrm{E}+033$ \\
\hline 400.00 & -113.100 & -41.946 & -84.864 & $3.587 \mathrm{E}+027$ \\
\hline 500.00 & -112.859 & -41.611 & -80.687 & $6.456 \mathrm{E}+022$ \\
\hline 600.00 & -112.639 & -41.345 & -76.539 & $1 . \overline{443 \mathrm{E}+019}$ \\
\hline 700.00 & -112.436 & -41.124 & -72.416 & $1.839 \mathrm{E}+016$ \\
\hline 800.00 & -112.242 & -40.934 & -68.313 & $8.192 E+013$ \\
\hline 900.00 & -112.051 & -40.764 & -64.229 & $9.254 \mathrm{E}+011$ \\
\hline 1000.00 & -111.856 & -40.605 & -60.160 & $2.128 \mathrm{E}+010$ \\
\hline
\end{tabular}

\begin{tabular}{|c|c|c|c|c|}
\hline Step (2): & \multicolumn{5}{|c|}{$3 \mathrm{NiO}^{+}+\mathrm{WOF}_{4}(\mathbf{g})$} & $\mathbf{N}$ \\
\hline $\mathbf{T}\left({ }^{\circ} \mathbf{C}\right)$ & delta H(kcal) & delta S(cal) & delta G(kcal) & $\mathbf{K}$ \\
\hline 0.00 & -92.628 & -42.610 & -80.989 & $6.389 \mathrm{E}+064$ \\
\hline 100.00 & -92.260 & -41.410 & -76.807 & $9.749 \mathrm{E}+044$ \\
\hline 200.00 & -92.437 & -41.799 & -72.660 & $3.670 \mathrm{E}+033$ \\
\hline 300.00 & -93.116 & -43.122 & -68.401 & $1.215 \mathrm{E}+026$ \\
\hline 400.00 & -93.172 & -43.215 & -64.082 & $6.412 \mathrm{E}+020$ \\
\hline 500.00 & -93.113 & -43.134 & -59.764 & $7.853 \mathrm{E}+016$ \\
\hline 600.00 & -92.989 & -42.984 & -55.457 & $7.623 \mathrm{E}+013$ \\
\hline 700.00 & -92.820 & -42.801 & -51.168 & $3.106 \mathrm{E}+011$ \\
\hline 800.00 & -92.606 & -42.592 & -46.898 & $3.562 \mathrm{E}+009$ \\
\hline 900.00 & -92.336 & -42.352 & -42.650 & $8.834 \mathrm{E}+007$ \\
\hline 1000.00 & -91.995 & -42.074 & -38.429 & $3.956 \mathrm{E}+006$ \\
\hline
\end{tabular}


The choice of nickel as a suitable material from which to construct a reaction system appears to have significant corrosion issues that must be resolved before a production system can be built. One approach requiring further investigation and verification would be to passivate the boat and internal surfaces of the nickel reaction tube with a tightly bound layer of $\mathrm{NiF}_{2}$ as suggested by Dr. Beitz at Argonne National Laboratory. His description of such a procedure is included below,

"... it struck me that you might not be aware of a property of nickel that influences its passivation with respect to good fluorinating agents.

That property is its tendency to have some oxidation (nickel oxide) on its surface. Nickel oxide does not readily convert to nickel fluoride and has the tendency to flake off when the nickel part is heated to high temperature. In consequence, bare nickel can suddenly be exposed to the fluorinating agent at high temperature which, in the case of fluorine gas, might lead to burn through.

For these reasons, it is useful to heat nickel in hydrogen gas to reduce any surface oxide to elemental nickel. Ideally, the next step is to heat in fluorine gas at sub-atmospheric pressure (without having exposed the hydrogen-reduced surface to air or oxygen) to produce an adherent nickel fluoride passivation layer. For our vacuum systems, this process is straightforward, because we can add hydrogen gas, heat the metal parts (aside from the valve bodies) with a hand torch, pump out the hydrogen gas, and then add fluorine gas and heat again."

The boundary layer of $\mathrm{NiF}_{2}$ would nullify the first step in the sequence of corrosion reactions (equation 9.5, p.187), thereby blocking the formation of $\mathrm{NiO}$ and prevent subsequent interactions with $\mathrm{WOF}_{4}$. 


\subsection{Discussion - $\mathbf{W F}_{6}$.}

\subsubsection{Producing the $\mathrm{WOF}_{4}$ Intermediate.}

Tungsten tetrafluoride oxide, $\mathrm{WOF}_{4}$, was successfully produced by reacting either $\mathrm{WO}_{2}$ or $\mathrm{WO}_{3}$ with $\mathrm{UF}_{4}$. At $800^{\circ} \mathrm{C}$, there is little difference in the weight loss curves recorded during the TGA experiments using these constituents (refer to Figure 67). However, at lower temperatures around $700^{\circ} \mathrm{C}$, it appears that the preferred tungsten source is $\mathrm{WO}_{2}$. In the presence of air, the reaction scheme describing the process is given below along with the calculated (ref) Gibbs free energy change $(\Delta \mathrm{G})$.

$\mathrm{WO}_{2}$ Reaction Scheme
(A) $4 \mathrm{UF}_{4}+2 \mathrm{WO}_{2}+3 \mathrm{O}_{2}(\mathrm{~g}) \longrightarrow 2 \mathrm{WOF}_{4}(\mathrm{~g})+4 \mathrm{UO}_{2} \mathrm{~F}_{2}$
(B) $12 \mathrm{UO}_{2} \mathrm{~F}_{2}+6 \mathrm{WO}_{2}+\mathrm{O}_{2}(\mathrm{~g}) \longrightarrow \mathrm{WOF}_{4}(\mathrm{~g})+4 \mathrm{U}_{3} \mathrm{O}_{8}$
(C) $2 \mathrm{WO}_{2}+\mathrm{O}_{2}(\mathrm{~g}) \longrightarrow 2 \mathrm{WO}_{3}$

\begin{tabular}{c|c}
$\mathbf{T}\left({ }^{\circ} \mathbf{C}\right)$ & $\Delta \mathbf{G}(\mathbf{k c a l})$ \\
\hline 700 & -33.344 \\
800 & -31.631 \\
\hline 700 & +11.683 \\
800 & -10.721 \\
\hline 700 & -85.994 \\
800 & -82.594 \\
\hline
\end{tabular}

It is important to note that equation (C) plays a role in how far equations (A) and (B) proceed before the reaction dynamic switches to that for a scheme involving $\mathrm{WO}_{3}$.

$\mathrm{WO}_{3}$ Reaction Scheme

$$
\begin{aligned}
& \text { (D) } 2 \mathrm{UF}_{4}+\mathrm{WO}_{3}+\mathrm{O}_{2}(\mathrm{~g}) \longrightarrow \mathrm{WOF}_{4}(\mathrm{~g})+2 \mathrm{UO}_{2} \mathrm{~F}_{2} \\
& \text { (E) } 6 \mathrm{UO}_{2} \mathrm{~F}_{2}+3 \mathrm{WO}_{3} \longrightarrow 3 \mathrm{WOF}_{4}(\mathrm{~g})+2 \mathrm{U}_{3} \mathrm{O}_{8}+\mathrm{O}_{2}(\mathrm{~g}) \\
& \text { (F) } 2 \mathrm{UO}_{2} \mathrm{~F}_{2}+\mathrm{WO}_{3} \longrightarrow \mathrm{WOF}_{4}(\mathrm{~g})+2 \mathrm{UO}_{2}+\mathrm{O}_{2}(\mathrm{~g}) \\
& \text { (G) } 3 \mathrm{UO}_{2}+\mathrm{O}_{2}(\mathrm{~g}) \longrightarrow \mathrm{U}_{3} \mathrm{O}_{8}
\end{aligned}
$$

\begin{tabular}{c|c}
$\mathbf{T}\left({ }^{\circ} \mathbf{C}\right)$ & $\Delta \mathbf{G}(\mathbf{k c a l})$ \\
\hline 700 & +9.654 \\
800 & +9.666 \\
\hline 700 & +134.833 \\
800 & +118.530 \\
\hline 700 & +73.106 \\
800 & +65.557 \\
\hline 700 & -42.242 \\
800 & -39.070 \\
\hline
\end{tabular}

In comparing schemes for both tungsten oxides, all equations written with $\mathrm{WO}_{2}$ show spontaneous behavior (negative $\Delta \mathrm{G}$ values) except for equation (B) at $700^{\circ} \mathrm{C}$ while all equations using $\mathrm{WO}_{3}$ have positive free energies at all temperatures. This trend bolsters the observation that $\mathrm{UF}_{4} / \mathrm{WO}_{2}$ mixtures showed greater reactivity at lower reaction temperatures. At the $800^{\circ} \mathrm{C}$ 
temperature, conversion using either $\mathrm{WO}_{2}$ or $\mathrm{WO}_{3}$ appeared similar since the oxidation of $\mathrm{WO}_{2}$ to $\mathrm{WO}_{3}$ in an air-laden stream was rapid (see Figure 53) and redirects the reaction pathway to equation (D). Further consumption of $\mathrm{UO}_{2} \mathrm{~F}_{2}$ to make $\mathrm{WOF}_{4}$ and $\mathrm{U}_{3} \mathrm{O}_{8}$ or $\mathrm{UO}_{2}$ is thermodynamically hindered (equations $(\mathrm{E})$ and $(\mathrm{F})$ ). X-ray diffraction results of the postreaction solids reclaimed from the TGA trials showed only minimal amounts of the $\mathrm{U}_{3} \mathrm{O}_{8}$ phase, which was more likely due to the thermal decomposition of $\mathrm{UO}_{2} \mathrm{~F}_{2}$ than equation $(\mathrm{E})$ above.

Bench-scale trials were successful in making $\mathrm{WOF}_{4}$ in larger quantities. Condensation of the intermediate within the reaction system caused blockages during several early experiments, bringing them to an end prematurely. The first significant amount of $\mathrm{WOF}_{4}$ was made in WFusn-10 where 3.17 grams was collected in a redesigned capture vessel. In the following run, WFusn-11, 2.44 grams of crystalline product was collected when $\mathrm{WO}_{3}$ was fused with $\mathrm{UF}_{4}$ at a reaction temperature of $790^{\circ} \mathrm{C}$. From these two experiments it is apparent that significant amounts of the same material can be made using either oxide source.

Of the ten experiments performed in the tube reactor, seven trials showed larger than predicted weight loss by the reagents ranging from $15.7 \%$ to $37.4 \%$. This excessive weight loss is reflected in the calculated 'Reaction Conversion' values given in Tables 48 and 49 reporting conversions greater than $100 \%$. The only reasonable explanation for the extraordinary weight loss suggests that some of the $\mathrm{UO}_{2} \mathrm{~F}_{2}$ by-product is being lost from the reagent boat, possibly as fine particulate. This may be occurring as the volume of reactants undergoes a large expansion on the order of $200-300 \%$. In particular, after the WFusn-10 trial, the contents of the reagent boat had expanded so much that some of the $\mathrm{UO}_{2} \mathrm{~F}_{2}$ yellow powder spilled out of the boat before removing it from the reaction zone in the tube reactor. In several experiments (WFusn-14 and -15), the furnace temperature was ramped too aggressively, causing $\mathrm{UF}_{4}$ to carry downstream into the condensation flask and contaminate the $\mathrm{WOF}_{4}$ powder. Here the release of gaseous intermediate was so rapid that particles of solid became entrained in the gas stream. The fluidization of $\mathrm{UF}_{4}$ was ultimately controlled by slowing down the furnace-heating schedule to a level where the reagent bed was left undisturbed.

\subsubsection{Fluorinating $\mathrm{WOF}_{4}$ to form $\mathrm{WF}_{6}$.}

After studying the chemistry to form the $\mathrm{WOF}_{4}$ compound, emphasis shifted to finding a suitable fluorinating agent for converting the oxyfluoride to tungsten hexafluoride. Candidate reactions using $\mathrm{UF}_{4}$ and $\mathrm{TiF}_{4}$ as fluoride sources showed that $\mathrm{WOF}_{4}$ was resistant to conversion up to the vaporization temperature of the oxyfluoride $\left(\sim 187^{\circ} \mathrm{C}\right)$. Likewise, a probe reaction using $\mathrm{SiO}_{2}$ to extract fluorine away from the tungsten compound was unsuccessful at bringing about a transformation where the thermodynamic variables were shown to be very favorable $\left(-\Delta \mathrm{G}\right.$ value). When the reaction between $\mathrm{WO}_{2}$ and $\mathrm{TiF}_{4}$ was performed in the TGA apparatus to evaluate the single-step synthesis route, a significant weight loss was observed and taken to be the start of the fluorination process. Potential reaction schemes describing the process are shown below including their thermodynamic assessment. 
$\mathrm{WF}_{6}$ Reaction Schemes

$$
\begin{aligned}
& 3 \mathrm{TiF}_{4}+2 \mathrm{WO}_{2}+\mathrm{O}_{2}(\mathrm{~g}) \longrightarrow 2 \mathrm{WF}_{6}(\mathrm{~g})+3 \mathrm{TiO}_{2} \\
& 2 \mathrm{TiF}_{4}+2 \mathrm{WO}_{2}+\mathrm{O}_{2}(\mathrm{~g}) \longrightarrow 2 \mathrm{WOF}_{4}(\mathrm{~g})+2 \mathrm{TiO}_{2} \\
& 2 \mathrm{WOF}_{4}(\mathrm{~g})+\mathrm{TiF}_{4}(\mathrm{~g}) \longrightarrow 2 \mathrm{WF}_{6}(\mathrm{~g})+\mathrm{TiO}_{2}
\end{aligned}
$$

$$
4 \mathrm{TiF}_{4}+2 \mathrm{WO}_{2}+\mathrm{O}_{2}(\mathrm{~g}) \longrightarrow 2 \mathrm{WOF}_{4}(\mathrm{~g})+4 \mathrm{TiOF}_{2}(\mathrm{~g})
$$

\begin{tabular}{c|c}
$\mathbf{T}\left({ }^{\circ} \mathbf{C}\right)$ & $\Delta \mathbf{G}(\mathbf{k c a l})$ \\
\hline 200 & -49.207 \\
500 & -53.608 \\
\hline 200 & -41.676 \\
500 & -51.951 \\
\hline 100 & -16.660 \\
200 & -5.038 \\
500 & +6.223 \\
\hline 200 & +228.204 \\
500 & +168.124 \\
\hline
\end{tabular}

The feasibility of equations $(\mathrm{H})$ and $(\mathrm{I})$ are supported by spontaneous free energy changes up to the $500^{\circ} \mathrm{C}$ plateau temperature attained during the trial. However, there is a steady weight loss starting about $44^{\circ} \mathrm{C}$ shown in Figure 85 that should not occur if equation (I) were the controlling pathway. $\mathrm{WOF}_{4}(\mathrm{~g})$ generated by equation $(\mathrm{I})$ could not vaporize until the temperature reached at least $187^{\circ} \mathrm{C}$. Only then would a significant weight loss be observed. Beyond the $300^{\circ} \mathrm{C}$ mark, weight loss shown in the TGA result is most likely due to vaporization of unreacted $\mathrm{TiF}_{4}$ out of the TGA cup. The $\mathrm{TiF}_{4} / \mathrm{WO}_{2}$ reaction was heated to a maximum of $500^{\circ} \mathrm{C}$ to prevent oxidation of $\mathrm{WO}_{2}$ to $\mathrm{WO}_{3}$. All reaction schemes between $\mathrm{TiF}_{4}$ and $\mathrm{WO}_{3}$ possessed positive Gibbs free energy values, thereby reducing the feasibility of making $\mathrm{WF}_{6}$ by that alternative pathway.

The reaction between $\mathrm{TiF}_{4}$ and $\mathrm{WO}_{2}$ was then repeated in a flow-through bench-top reactor (WFusn-19) where the gas stream was analyzed by FT-IR spectroscopy to identify volatile reaction products. An aliquot of gas collected when the reactor temperature reached $85^{\circ} \mathrm{C}$ showed absorption bands assigned to $\mathrm{HF}$, which was most likely formed by the interaction of adsorbed moisture (bound to $\mathrm{WO}_{2}$ ) with $\mathrm{TiF}_{4}$. Weight loss observed during the micro-scale experiment in this temperature region may have been due to the same $\mathrm{TiF}_{4}$ hydrolysis sidereaction. However, the gas samples collected at $185^{\circ} \mathrm{C}$ and $187^{\circ} \mathrm{C}$ showed new bands that presented a challenge in matching their vibrational frequencies to known reference compounds. What is more interesting is the temperature at which the new bands show up in the gas stream. The intense absorption bands appeared at the same temperature that $\mathrm{WOF}_{4}$ converts to a gas. If this is the case, then the reaction given in equation (I) may be the preferred pathway. As the temperature climbed above $200^{\circ} \mathrm{C}$ the absorption intensities of the new bands disappeared. This could be caused by the loss of intimate contact between the reagents as the evolving gas pushed the reactants further apart, thereby limiting the conversion to only nearest-neighbor proximity. Above $285^{\circ} \mathrm{C} \mathrm{TiF}_{4}$ goes into the gaseous state and could react with $\mathrm{WOF}_{4}(\mathrm{~g})$, as in equation $(\mathrm{J})$. However, the thermodynamic feasibility shifts to a non-spontaneous situation where the gas/gas scenario is not favored.

Since the reaction between $\mathrm{TiF}_{4}$ and $\mathrm{WO}_{2}$ may require a temperature above $300^{\circ} \mathrm{C}$ to bring about conversion, a static-bed flow-through reactor configuration like the one used here is not the most efficient design to facilitate a reaction between a gas and solid. At $285^{\circ} \mathrm{C}$ and above, titanium tetrafluoride would separate from the reaction mixture before significant 
conversion could take place. This was indeed the case in WFun-19 where a layer of white solid $\left(\mathrm{TiF}_{4}\right)$ collected on the underside of the Parr reactor lid during the course of the experiment.

As a result of the limited interaction observed in WFusn-19, the $\mathrm{TiF}_{4} / \mathrm{WO}_{2}$ reaction scenario may be evaluated more effectively using a fluid bed reactor. This would require setting up an apparatus to create a continuous vapor stream of $\mathrm{TiF}_{4}$ for passing through a bed of $\mathrm{WO}_{2}$ maintained at a temperature up to $500^{\circ} \mathrm{C}$. This reaction scheme is given in equation $(\mathrm{L})$ along with relevant thermodynamic calculations.

$$
3 \mathrm{TiF}_{4}(\mathrm{~g})+2 \mathrm{WO}_{2}+\mathrm{O}_{2}(\mathrm{~g}) \longrightarrow 2 \mathrm{WF}_{6}(\mathrm{~g})+3 \mathrm{TiO}_{2}
$$

\begin{tabular}{c|c}
$\mathbf{T}\left({ }^{\circ} \mathbf{C}\right)$ & $\Delta \mathbf{G}(\mathbf{k c a l})$ \\
\hline 100 & -68.876 \\
200 & -59.001 \\
500 & -29.969 \\
\hline
\end{tabular}

Before concluding the discussion concerning fluorinating agents, several other candidate reactions can be proposed for converting the $\mathrm{WOF}_{4}$ intermediate to $\mathrm{WF}_{6}$. The chemistries are tabulated as above, showing the calculated Gibbs free energy change at the indicated temperature.

Potential Fluorination Routes

$$
2 \mathrm{WOF}_{4}+\mathrm{GeF}_{4}(\mathrm{~g}) \longrightarrow 2 \mathrm{WF}_{6}(\mathrm{~g})+\mathrm{GeO}_{2}
$$

$$
5 \mathrm{WOF}_{4}+2 \mathrm{As}_{2} \mathrm{~F}_{5} \longrightarrow 5 \mathrm{WF}_{6}(\mathrm{~g})+\mathrm{As}_{2} \mathrm{O}_{5}
$$

\begin{tabular}{c|c}
$\mathbf{T}\left({ }^{\circ} \mathbf{C}\right)$ & $\Delta \mathbf{G}(\mathbf{k c a l})$ \\
\hline 100 & -16.622 \\
200 & -16.999 \\
500 & -15.027 \\
& \\
100 & -47.291 \\
200 & -51.189 \\
500 & -54.881 \\
& \\
100 & -72.958 \\
200 & -72.471 \\
500 & -69.382 \\
100 & -45.089 \\
200 & -48.695 \\
500 & -54.649 \\
\hline
\end{tabular}

(O)

$$
\mathrm{WOF}_{4}+2 \mathrm{~F}_{2}(\mathrm{~g}) \longrightarrow \mathrm{WF}_{6}(\mathrm{~g})+\mathrm{OF}_{2}(\mathrm{~g})
$$

$$
3 \mathrm{WOF}_{4} \longrightarrow 2 \mathrm{WF}_{6}(\mathrm{~g})+\mathrm{WO}_{3}
$$

Equation (M) presents an interesting pathway where germanium can be used to shuttle fluorine from $\mathrm{UF}_{4}$ to $\mathrm{WF}_{6}$ via $\mathrm{GeF}_{4}$. More traditional fluorinating agents such as arsenic pentafluoride 
and elemental fluorine also have the necessary thermodynamic favorability to transform $\mathrm{WOF}_{4}$ to $\mathrm{WF}_{6}$, as shown in equations $(\mathrm{N})$ and $(\mathrm{O})$, respectively. Lastly, $\mathrm{WF}_{6}$ has been generated electrochemically ${ }^{30}$ from acetonitrile solutions containing $\mathrm{WOF}_{4}$. All of these alternatives would require further study in order to establish their commercial viability and economic feasibility. 


\section{Conclusions}

\subsection{Conclusions $-\mathrm{GeF}_{4}$.}

A process to produce $\mathrm{GeF}_{4}$ of exceptional purity has been developed based on Starmet's new fluoride extraction technology. In this process, fluorine contained in $\mathrm{UF}_{4}$ is recovered as a highvalue fluoride gas when green salt is reacted with germanium dioxide. Of the nine tasks outlined in the Phase II work plan, seven have been completed, leaving two items concerning product qualification and fabrication of a production-scale apparatus to be addressed in the future as the demand for high purity material in the electronics and semiconductor sectors rebounds from an 18 month slump in the global marketplace.

From investigations performed here, it was determined that a horizontally oriented, tubestyle reaction apparatus fabricated from nickel 200 alloy outperformed a larger crucible reactor setup constructed from Haynes HR $160^{\circledR}$ alloy. The best overall performance observed during the reactor design trials occurred in GeFusn-28 where a conversion of $89.4 \%$ was posted in combination with a $97.7 \%$ capture efficiency. Here the reaction temperature reached a high of $700^{\circ} \mathrm{C}$. Conversions as high as $98.1 \%$ were observed when $\mathrm{UF}_{4}$ was reacted with $\mathrm{GeO}_{2}$ at $775^{\circ} \mathrm{C}-800^{\circ} \mathrm{C}$ in a helium sweep stream. However, the highest capture efficiency in the heliumonly carrier was $75.8 \%$ in contrast to $97.7 \%$ when the reactor sweep stream contained $10-12$ vol.\% of dry air. The presence of air in the sweep stream was beneficial in reducing the formation of $\mathrm{GeF}_{2}$ residue by maintaining an oxidizing atmosphere above the reactant bed and initiating the reaction at a lower temperature.

Reaction sequences describing the synthesis of $\mathrm{GeF}_{4}$ in inert and air-laden streams were proposed based on the experimental results collected. Those reactions where a pure helium stream was used revealed the formation of $\mathrm{UGeO}_{4}$ intermediate, which appeared to be the dominant germanium containing species left in the latter stages of the reaction. In contrast, only $\mathrm{UO}_{2} \mathrm{~F}_{2}$ and $\mathrm{UF}_{4}$ could be detected in residues collected where conversion was incomplete using a helium/air sweep stream. Kinetics of the $\mathrm{UF}_{4} / \mathrm{GeO}_{2}$ reaction could not modeled using the Avrami equation when air was present in the sweep stream as was the case for runs made in pure helium.

Corrosion studies revealed that materials such as copper, Monel, type 304 stainless steel and Haynes $\mathrm{HR} 160^{\circledR}$ alloy were significantly compromised from attack by $\mathrm{GeF}_{4}$, forming germanium-rich scale and intermetallic compounds. Inconel 600, Haynes 242 and nickel 200 alloy were considered acceptable materials of construction if first passivated in a fluorine environment.

It was shown that the $\mathrm{UF}_{4} / \mathrm{GeO}_{2}$ reaction began just above $400^{\circ} \mathrm{C}$ with the release of a significant amount of moisture. A 1-2 hour pre-reaction drying period at $\sim 450^{\circ} \mathrm{C}$ was inserted into the reactor- heating schedule to off-load the moisture from the reactants and the system before collecting $\mathrm{GeF}_{4}$ of high quality. When compared with a reference material possessing 99.99\% purity, the Starmet product was shown to contain the least number of elemental impurities and fewest infrared-active species. ICP-MS analysis of a lab-synthesized sample could not detect uranium above a detection limit of $0.019 \mathrm{ppm}-\mathrm{wt}$.

The fluoride gas was also examined using two new methods under development at Argonne National Laboratory for determining trace levels of $\mathrm{U}$. Analyses by ultraviolet optical absorption spectroscopy to detect $U$ as $U_{F}$ found both the unfiltered and filtered batches of gas void of uranium at detection limits of 0.75 and $0.64 \mathrm{ppm}$-vol., respectively. The second method 
being investigated involving laser-induced photoluminescence spectroscopy encountered several problems, which impacted the ability to measure the luminescence of uranyl ions first in a glassy $\mathrm{GeO}_{2}$ matrix and later in treated solutions of hydrolyzed $\mathrm{GeO}_{2}$ particulate at a sensitivity in the range of 1-40 parts-per-trillion (ppt). The "chloride volatility" approach was unsuccessful due to the inability to convert hydrolyzed $\mathrm{GeO}_{2}$ particulate to uranyl chloride using concentrated hydrochloric acid and acid vapor reflux conditions. Fluorescence measurements performed on hydrofluoric acid solutions of dissolved $\mathrm{GeO}_{2}$ particulate revealed intense broad band interference arising from low molecular weight polymer leached from the wall of the perfluoroalkoxy (PFA) Teflon ${ }^{\circledR}$ containers used in preparing the hydrolyzed $\mathrm{GeF}_{4}$ material.

Based on information learned throughout the program, conceptual drawings of a 6-station manifold reaction system involving tube-style reactors and a gas collection station were made. The production-scale system was configured to generate and package up to $2 \mathrm{~kg}$ of product per day when operated to capacity. Production of the gas can be started with operation of just one station and additional capacity phased-in over time as demand for $\mathrm{GeF}_{4}$ grows.

\subsection{Conclusions - $\mathrm{WF}_{6}$.}

Development of a process to make $\mathrm{WF}_{6}$ using the same fluoride extraction technology perfected for $\mathrm{GeF}_{4}$ proved to be more challenging. Before carrying out trials using a bench-scale apparatus, milligram quantities of $\mathrm{UF}_{4}$ and two different tungsten oxide compounds were reacted in the thermogravimetric analyzer (TGA). It was determined that both forms of tungsten oxide could be converted to the oxyfluoride intermediate at temperatures in the range between $700^{\circ} \mathrm{C}$ $800^{\circ} \mathrm{C}$ when reacted in air. It was also shown that $\mathrm{WO}_{2}$ was oxidized to $\mathrm{WO}_{3}$ beginning about $500^{\circ} \mathrm{C}$, adding a degree of complexity to the reaction scheme in deriving $\mathrm{WOF}_{4}$. At $700^{\circ} \mathrm{C}$, the $\mathrm{UF}_{4} / \mathrm{WO}_{2}$ combination appeared to react at a faster rate and went essentially to $100 \%$ completion while the $\mathrm{UF}_{4} / \mathrm{WO}_{3}$ mixture yielded only $70 \%$ of the expected weight loss and the formation of a new solid phase that could not be matched to any substance in the $\mathrm{x}$-ray database. At $800^{\circ} \mathrm{C}$, there was little difference in the weight loss curves using either combination of reagents.

Reactions to produce the white crystalline oxyfluoride compound were moved to a horizontally oriented, tube-style reactor constructed of nickel 200 alloy. Best results were achieved in WFusn-10 where 3.17 grams of material were collected when $U_{4}$ was reacted with $\mathrm{WO}_{2}$ at $790 \mathrm{C}$ for 2 hours. In contrast, 2.44 grams of $\mathrm{WOF}_{4}$ were recovered when $\mathrm{WO}_{3}$ was reacted with green salt under similar conditions in WFusn-11. When contacted with $\mathrm{H}_{2} \mathrm{O}$, both residues from WFusn-10 and -11 formed similar hydrolysis products as shown by $\mathrm{x}$-ray diffraction, notably $\mathrm{WO}_{3} \bullet \mathrm{H}_{2} \mathrm{O}$ and $\mathrm{WO}_{3} \bullet 2 \mathrm{H}_{2} \mathrm{O}$.

After defining the chemistry to make $\mathrm{WOF}_{4}$, several candidate reactions were selected for completing the process to make $\mathrm{WF}_{6}$. Based on favorable thermodynamic assessments, $\mathrm{UF}_{4}$, $\mathrm{SiO}_{2}$ and $\mathrm{TiF}_{4}$ were employed as probes to explore the reactivity of the oxyfluoride. Uranium tetrafluoride was not able to convert $\mathrm{WOF}_{4}$ to $\mathrm{WF}_{6}$ below $196^{\circ} \mathrm{C}$ since the oxyfluoride began to separate from the reaction mixture above $187^{\circ} \mathrm{C}$, the boiling point for the intermediate. Silicon dioxide was reacted with $\mathrm{WOF}_{4}$ in a similar manner to test the stability of the W-F bond in the presence of a strong fluoride scavenger. It, too, did not react up to a temperature of $185^{\circ} \mathrm{C}$. In contrast, when $\mathrm{TiF}_{4}$ was heated in the presence of the oxyfluoride, there were indications that a gaseous product was released, signaling the need for a more detailed investigation. 
Based on this result, a new pathway to $\mathrm{WF}_{6}$ was proposed whereby $\mathrm{WO}_{2}$ is directly fluorinated using $\mathrm{TiF}_{4}$. A milligram-scale experiment where a $\mathrm{WO}_{2} / \mathrm{TiF}_{4}$ mixture was heated to $500^{\circ} \mathrm{C}$ in air, showed significant weight loss at temperatures below $285^{\circ} \mathrm{C}$ ( $\mathrm{TiF}_{4}{ }^{\prime} \mathrm{s}$ sublimation temperature). The same reaction was repeated in a bench-scale apparatus where the volatile reaction products were analyzed by FT-IR spectroscopy as the temperature was raised to $265^{\circ} \mathrm{C}$. Intense absorption bands appeared in the infrared spectrum of the sample collected at $185^{\circ} \mathrm{C}$, which dissipated as the reactor temperature increased. Bands with maxima located at $3500 \mathrm{~cm}^{-1}$ and $3380 \mathrm{~cm}^{-1}$ could not be easily identified while those in the $950-700 \mathrm{~cm}^{-1}$ region corresponded with absorption band frequencies observed for a reference sample of $\mathrm{WF}_{6}$. Further experimentation is required in order to confirm if $\mathrm{TiF}_{4}$ is a feasible and effective fluorinating agent in converting $\mathrm{WO}_{2}$ to $\mathrm{WF}_{6}$.

Finally, the corrosion layer occurring on the nickel boat and in the tube reactor during the $\mathrm{WF}_{6}$ development program was investigated. The formation of surface scale was described by a two-step process whereby the nickel surface is first oxidized to $\mathrm{NiO}$ in an oxygen containing environment followed by reaction of the oxidized surface with tungsten oxyfluoride. It is anticipated that nickel will be a suitable material for constructing a production-scale reaction system once it is properly passivated with fluorine to form a tightly bound protective layer of $\mathrm{NiF}_{2}$. 


\section{LITERATURE CITED}

1 U.S. Department of Energy, DUF 6 Materials Use Roadmap, M.J. Haire and A.G. Croff Editors, ORNL-6968, Oak Ridge National Laboratory (August 27, 2001).

2 U.S. Department of Energy, Final Programmatic Impact Statement for Alternative Strategies for Long-Term Management and Use of Depleted Uranium Hexafluoride, DOE/EIS-0269 (April, 1999).

3 "Record of Decision for Long-Term Management and Use of Depleted Uranium Hexafluoride", Fed. Reg. 43358, 64(153), August 10, 1999.

4 Quapp, W. J., "DUCRETE Shielding Applications in the Yucca Mountain Repository", Waste Management 99, Feb. 28 to March 4, 1999, Tucson, AZ.

5 Cogema, Allied Signal, and Siemans

6 D.S. Schlier and B.M. Smyser, "Production of High-Value Fluoride Gas From Uranium Tetrafluoride Using a Rotary Calciner", Waste Management '01, Feb. 25 to March 1, 2001, Tucson, AZ.

7. Justification of this estimated cost savings is based upon market studies and the combined production of gases such as those discussed in this proposal as well as $\mathrm{SiF}_{4}, \mathrm{TiF}_{4}$, and $\mathrm{BF}_{3}$. The $\mathrm{SiF}_{4}$ and $\mathrm{BF}_{4}$ are also used in the semiconductor industry as process gases as well as evolving uses for producing special isotopic variants for advanced semiconductor applications. $\mathrm{TiF}_{4}$, the subject of another $\mathrm{SBIR}$ research program, will be used to produce ultra pure $\mathrm{TiO}_{2}$ and possibly Ti metal.

8 C.J. Hoffman and J.S. Gutowsky, Inorg. Syn., Vol. 4, 1953, 147.

9 N. Barlett and K.C. Yu, Can. J. Chem., Vol. 39, 1961, 80.

10 I. Harada, Y. Yoda, N. Iwanaga, T. Nishitsuti and A. Kikkawa, European Patent EP 89-104364, March 11, 1989.

11 S.P. Mallela, O.D. Gupta and J.M. Shreeve, Inorg. Chem., 27(1), 1988, pp. 208-209.

12 R. Doetzer, German Patent DE 3841212, June 13, 1990.

13 International Centre for Diffraction Data, Newtown Square, PA, Powder Diffraction File Release 1997, Data Sets 1-47.

14 HSC Chemistry for Windows, Chemical Reaction and Equilibrium software, Version 2.03, Outokumpu Research Oy, 1994.

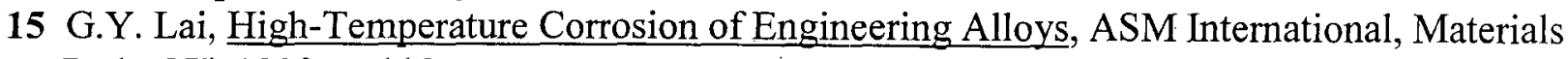
Park, OH, 1990, p. 110.

16 ibid. p. 109.

17 ibid. p. 109-110.

18 D.F. Shriver and M.A. Drezdzon, The Manipulation of Air-Sensitive Compounds, $2^{\text {nd }}$ Edition, John Wiley \& Sons, New York, 1986, p. 228.

19 M. Maeno et al, "Fluorine Passivation of Metal Alloy Surface with Volatile Reaction Enhanced Mechanism", Journal of the Electrochemical Society, Vol. 139, (7), 1992, pp. 1865-1869.

20 Bartlett, N. et al, Can J. Chem., 1961, Vol. 39, p. 80.

21 Mutterties, E.L., Inorg. Chem., 1962, Vol. 1, p. 342.

22 Kirk-Othmer Encyclopedia of Chemical Technology., $3^{\text {rd }}$ Edition, Wiley, New York, 19781984, Vol. 10, p. 720.

23 "Production of High Value Fluorine Gases for the Semiconductor Industry", Phase I Final Report, DOE SBIR Grant \# DE-FG02-99ER82894, 1999, p.14-16. 
24 Avrami, Journal of Chemical Physics, Vol. 7, 1939, p.1103.

25 William D. Callister, Jr., Materials Science and Engineering: An Introduction, Third Ed., John Wiley \& Sons, Inc., 1994.

26 "Extraction of Fluorine from Uranium Hexafluoride for the Production of Titanium Metal", DOE SBIR Grant No. DE-FG02-99ER82893 Phase I-FY1999, awarded to Starmet Corporation, M.D. Stephens, Principal Investigator.

27 "The Chemistry of Uranium, Part I, The Element, Its Binary and Related Compounds: Joseph J. Katz and Eugene Rabinowitch, McGraw-Hill Book Co., New York, 1951, p570.

28 Handbook of Chemistry and Physics, $66^{\text {th }}$ ed., Robert C. Weast editor, CRC Press Inc., Boca Raton, FL, 1985-1986.

29 "Fluorine Compounds, Inorganic", Kirk-Othmer Encyclopedia of Chemical Technology, $4^{\text {th }}$ Ed., John Wiley \& Sons Inc., New York, 1994, Vol. 11, pp. 456.

30 Thomas W. Boyle, C. David Desjardins and David W. A. Sharp, J. Fluor. Chem., Vol. 11, (3-4), 1978, pp. 399-406.

\section{General References}

"Germanium Tetrafluoride", A. Misra, J.D. Hogan and R. Chorush, Handbook of Chemicals and Gases for the Semiconductor Industry, John Wiley \& Sons, Inc. 2002.

"Tungsten Hexafluoride", A. Misra, J.D. Hogan and R. Chorush, Handbook of Chemicals and Gases for the Semiconductor Industry, John Wiley \& Sons, Inc. 2002.

\section{Acknowledgements}

Teflon is a registered trademark of the E.I. du Pont de Nemours and Company, Wilmington, DE. Kel-F is a registered trademark of the $3 M$ Corporation, St. Paul, Minnesota.

Swagelok is a registered trademark of the Crawford Fitting Company, Cleveland, OH.

Pyrex is a registered trademark of the Corning Glass Works, Corning, NY.

Contributions to the Phase II SBIR Program by William Nachtrab, Nancy Levoy, David Schlier, Matt Stephens, Bridget Smyser (Starmet Corporation) and James Beitz (Argonne National Laboratory) are gratefully acknowledged. 


\section{APPENDIX A}

Interim progress reports from Argonne National Laboratory

"Ultratrace Determination Of Uranium In Germanium Tetrafluoride"

March 12, 2001 Progress Report (J.V. Beitz and C.W. Williams)

October 23, 2001 Progress Report (J.V. Beitz and C.W. Williams)

May 11, 2002 Progress Report (J.V. Beitz and C.W. Williams)

March 17, 2003 Progress Report (J.V. Beitz) 


\section{ULTRATRACE \\ DETERMINATION OF URANIUM \\ IN GERMANIUM TETRAFLUORIDE}

\section{March 12, 2001 Progress Report}

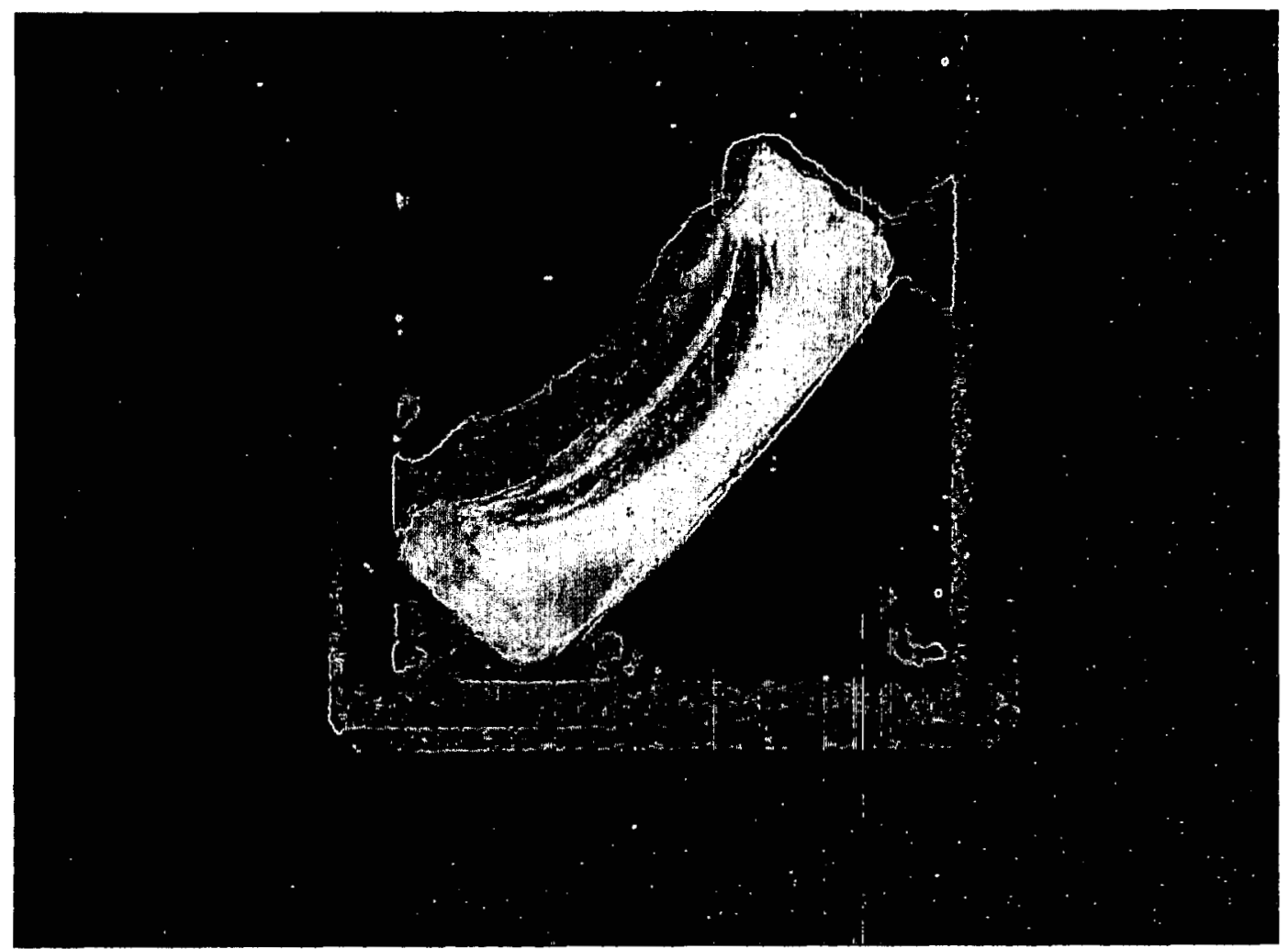

J. V. Beitz and C. W. Williams

Chemistry Division Argonne National Laboratory Argonne, IL 60439-4831 


\section{Table of Contents}

Abstract __ 3

Introduction __ 4

Objectives__ 4

Materials and Methods__ 6

Vitrification of $\mathrm{GeO}_{2}$

Photomicrography ___ 8

Laser-induced fluorescence studies ___ 9

Experimental Observations __ 10

Visual observations ___ 10

Luminescence spectrum of uranyl ion in glassy $\mathrm{GeO}_{2} \ldots 11$

Estimated limit of detection ___ 12

Photophysics of uranyl ion in glass $\mathrm{GeO}_{2}$

Crystallization of $\mathrm{GeO}_{2}$ can occur with our present apparatus __ 14

Discussion 17

Issues for future work 18

Ensuring bubble-free glassy $\mathrm{GeO}_{2}$

Suppressing crystallization___ 19

Analytical limits__ 19

Ultraviolet Absorption Analysis for $\mathrm{UF}_{6}$ in $\mathrm{GeF}_{4}$

Conclusions __ 20

Acknowledgements __ 21

Literature Cited ___ 21

The cover photograph of this report shows the characteristic yellow-green luminescence of uranyl ion in an ultraviolet-illuminated sample of uraniumdoped glassy germanium dioxide. 


\begin{abstract}
We are developing two methods for ultratrace determination of uranium in germanium tetrafluoride $\left(\mathrm{GeF}_{4}\right)$ gas. Both methods are designed primarily for determination of uranium based on its most probable volatile chemical compound, namely uranium hexafluoride $\left(\mathrm{UF}_{6}\right)$. The first method relies on detection and measurement of $\mathrm{UF}_{6}$ via its characteristic and very strong ultraviolet optical absorption spectrum. The scientific basis for this method is well established, although it is technically challenging to implement. Most of our work to date has been carried out to establish the scientific basis for our second method which relies on laserinduced fluorescence of uranyl ions in glassy germanium dioxide $\left(\mathrm{GeO}_{2}\right)$. Hydrolysis of $\mathrm{GeF}_{4}$ that contains $\mathrm{UF}_{6}$ and subsequent treatment with ammonium hydroxide is expected to generate hydrated germanium dioxide $\left(\mathrm{GeO}_{2}\right)$ that contains uranyl hydroxo complexes. Thermal fusion of this material and rapid cooling should produce glassy $\mathrm{GeO}_{2}$ that contains uranyl ions. Although this is a plausible scheme for ultratrace determination of uranium in $\mathrm{GeF}_{4}$, it rests on the presumption that uranyl ions are chemically stable in molten $\mathrm{GeO}_{2}$. We now have carried out studies on uranyl-doped glassy $\mathrm{GeO}_{2}$ that have shown that 1) uranyl ions are stable for hours in molten $\mathrm{GeO}_{2}$, 2) uranyl ions in glassy $\mathrm{GeO}_{2}$ at ambient temperature are strongly luminescent, and 3) the likely limit of detection for uranium in $\mathrm{GeF}_{4}$ using this method is 50 ppt (parts per trillion), or better, on a weight basis. Using our present non-optimized apparatus, we have achieved signal-to-noise ratios for uranyl ion luminescence in glassy $\mathrm{GeO}_{2}$ that are equivalent to a limit of detection of $500 \mathrm{ppt}$.
\end{abstract}




\section{Introduction}

Determination of uranium in germanium tetrafluoride $\left(\mathrm{GeF}_{4}\right)$ is challenging due to the chemically aggressive nature of $\mathrm{GeF}_{4}$ and the strong fluorinating ability of the most probable volatile uranium impurity in $\mathrm{GeF}_{4}$, namely uranium hexafluoride $\left(\mathrm{UF}_{6}\right)$ gas. Conventional high sensitivity methods, such as ICP-based mass spectrometry or atomic emission spectroscopy, lose sensitivity because $\mathrm{GeF}_{4}$ must be hydrolyzed in water (diluted) prior to analysis of the hydrolysis solution.

\section{Objectives}

We are developing two methods for ultratrace determination of uranium in $\mathrm{GeF}_{4}$ gas. Both of these methods are primarily sensitive to uranium as uranium hexafluoride $\left(\mathrm{UF}_{6}\right)$. Our first method relies on the very strong optical absorbance of $U_{6}$ gas in the ultraviolet [1] at wavelengths where $\mathrm{GeF}_{4}$ should be essentially transparent [2]. This method is non-destructive (does not involve chemical alteration of $\mathrm{GeF}_{4}$ ), and may be suitable for on-line monitoring of $\mathrm{UF}_{6}$ impurity levels during $\mathrm{GeF}_{4}$ production.

Our second method relies on laser-induced fluorescence measurement of uranium, as uranyl ion $\left(\mathrm{UO}_{2}{ }^{2+}\right.$ ), in glassy $\mathrm{GeO}_{2}$ and requires destructive analysis of $\mathrm{GeF}_{4}$. This method, in our present plan, starts with hydrolysis of a sample of $\mathrm{GeF}_{4}$ gas. Any $\mathrm{UF}_{6}$ impurity in the $\mathrm{GeF}_{4}$ will hydrolyze to uranyl ions $\left(\mathrm{UO}_{2}{ }^{2+}\right)$. Hydrolysis of $\mathrm{GeF}_{4}$ is reported [3] to follow the chemical reaction

$$
3 \mathrm{GeF}_{4}+2 \mathrm{H}_{2} \mathrm{O} \rightarrow \mathrm{GeO}_{2}+2 \mathrm{H}_{2} \mathrm{GeF}_{6}
$$

although no detailed study of this reaction has been reported nor are the properties of $\mathrm{H}_{2} \mathrm{GeF}_{6}$ well established. It is known [4] that $\mathrm{UF}_{6}$ hydrolyzes according to the reaction

$$
\mathrm{UF}_{6}+2 \mathrm{H}_{2} \mathrm{O} \rightarrow \mathrm{UO}_{2} \mathrm{~F}_{2}+4 \mathrm{HF}
$$

In addition, uranyl fluoride $\left(\mathrm{UO}_{2} \mathrm{~F}_{2}\right)$ is one of the most water-soluble uranyl salts known. With excess water, the above reactions should give an aqueous solution that contains $\mathrm{GeO}_{2}, \mathrm{H}_{2} \mathrm{GeF}_{6}$, 
and $\mathrm{UO}_{2}{ }^{2+}$ and its fluoride ion complexes as well as hydrofluoric acid (HF) and fluoride ion (F-) in amounts that depend on the $\mathrm{pH}$ of the solution. We expect that addition of excess ammonium hydroxide to the solution, followed by heating to volatilize excess water, ammonium hydroxide, and ammonium fluoride, will give a hydrated $\mathrm{GeO}_{2}$ gel that contains trapped within it uranyl ions, likely as hydroxo complexes. Fusion of this $\mathrm{GeO}_{2}$ gel will produce glassy $\mathrm{GeO}_{2}$ for subsequent analysis for uranyl content by laser-induced fluorescence. Glassy $\mathrm{GeO}_{2}$ is preferred over crystalline $\mathrm{GeO}_{2}$ for two reasons. The first is that $\mathrm{GeO}_{2}$ can exist in either of two crystalline modifications and preparation of it in a single crystalline phase is difficult [3]. The second is that crystallization tends to concentrate impurities, such uranyl ions, along defects or grain boundaries. This is undesirable because uranyl species frequently undergo luminescence selfquenching (some times referred to as concentration quenching). Such quenching would reduce the sensitivity for detecting uranyl via laser-induced fluorescence.

Our experimental work to date has largely centered on development of laser-induced fluorescence analysis for detection of uranyl in $\mathrm{GeO}_{2}$. This is to ensure that the fundamental basis of this method is sound and due to ordering and delivery delays in our procurement of high purity $(99.99 \%) \mathrm{GeF}_{4}$ from a commercial source (Advance Research Chemicals).

Nothing has been reported in the literature concerning the photophysics of uranyl-doped glassy $\mathrm{GeO}_{2}$ so we began our work in this area by preparing glassy $\mathrm{GeO}_{2}$ that contains added uranium. Our objectives were to

1. Determine the chemical stability of uranyl ion in molten $\mathrm{GeO}_{2}$ and glassy $\mathrm{GeO}_{2}$

2. Optimize the heating cycle requirements for producing glassy $\mathrm{GeO}_{2}$ of acceptable optical quality.

3. Generate benchmark data for the photophysics and spectroscopy of uranyl ions in glassy $\mathrm{GeO}_{2}$.

We prepared uranium-doped glassy $\mathrm{GeO}_{2}$ material by adding uranyl nitrate in nitric acid to $\mathrm{GeO}_{2}$ powder and then heating this material as detailed below. 
Although uranyl luminescence has been studied in many phases, no utilization of such luminescence for uranium analysis in vitreous $\mathrm{GeO}_{2}$ has been reported. Based on literature reports, however, vitreous $\mathrm{GeO}_{2}$ is a very favorable matrix for such analyses. The reported optical absorption bands of vitreous $\mathrm{GeO}_{2}[5]$ occur further into the ultraviolet than do those of the lowest lying excited electronic states of uranyl ion. Excitation of the low lying uranyl states generally provides the highest quantum yield, and therefore best sensitivity, for luminescence detection of uranyl. In addition, the reported emission bands of $\mathrm{GeO}_{2}[6]$ occur at wavelengths that should provide little interference with quantification of uranyl luminescence.

\section{Materials and Methods}

\section{Vitrification of $\mathrm{GeO}_{2}$}

The $\mathrm{GeO}_{2}$ that we used was specified by its manufacturer (Alfa) to be $99.999 \%$ pure on a metals basis. Physically, this material is a white, finely divided powder. We confirmed that it is largely the hexagonal form of $\mathrm{GeO}_{2}$ by the heat evolved as it underwent dissolution in hydrofluoric acid [3]. We detected the presence of tetragonal phase $\mathrm{GeO}_{2}$ in that a small fraction of this material did not dissolved in $25 \%$ hydrofluoric acid solution.

A Linderg/BlueM horizontal tube furnace capable of attaining $1700^{\circ} \mathrm{C}$ was fitted with a 3 inch diameter Coors high purity alumina tube that was capped at each end with a Fiberfrax insulating plug. Platinum foil ( 0.002 inch thick) was shaped into a $0.94 \mathrm{~cm}$ wide by $0.94 \mathrm{~cm}$ long square boat and used as the primary container for melting $\mathrm{GeO}_{2}$ samples. Uranium-doped $\mathrm{GeO}_{2}$ was prepared by placing a weighed amount of $\mathrm{GeO}_{2}$ (typically $0.7 \mathrm{~g}$ ) into a Pt boat on a hot plate. An aliquot of uranyl nitrate stock solution ( $5.24 \mu \mathrm{g}$ uranium per milliliter) in $0.3 \mathrm{~mol} /$ liter nitric acid was added to the $\mathrm{GeO}_{2}$. Visible liquid was evaporated under a stream of dry nitrogen gas. The Pt boat then was placed within an open top, high purity alumina boat. In some cases, the Pt boat was covered with Pt foil; in other cases, the Pt boat was left uncovered. The boat assembly was placed within the 3 inch alumina tube in the furnace and centered on its hot zone. The furnace controller was programmed to carry out the desired heating profile. When the furnace temperature returned to ambient, the boat assembly was removed from it. The Pt foil was mechanically stripped from the glassy $\mathrm{GeO}_{2}$ sample that had been molded by the Pt foil boat into 
the form of a square plate which was thinner in the middle due to a meniscus that formed as the molten $\mathrm{GeO}_{2}$ contracted during solidification.

The heating profile most commonly used for vitrification of $\mathrm{GeO}_{2}$ is shown in Fig 1 . It consists of a constant rate ramp to $1400^{\circ} \mathrm{C}$, a four hour soak at $1400{ }^{\circ} \mathrm{C}$, natural cool down of the furnace (no power to the heating elements) to $500{ }^{\circ} \mathrm{C}$ (which is the glass transition temperature of $\mathrm{GeO}_{2}$ [7]), and then cooling at $2{ }^{\circ} \mathrm{C}$ per minute to ambient temperature. The heating cycle shown in Fig 1 produces strain-free glassy $\mathrm{GeO}_{2}$ at the level of $0.7 \mathrm{~g} \mathrm{GeO}_{2}$ in a $0.94 \mathrm{~cm}$ long $x 0.94 \mathrm{~cm}$ wide platinum foil boat as judged by viewing the produced glass between crossed polarizing filters.

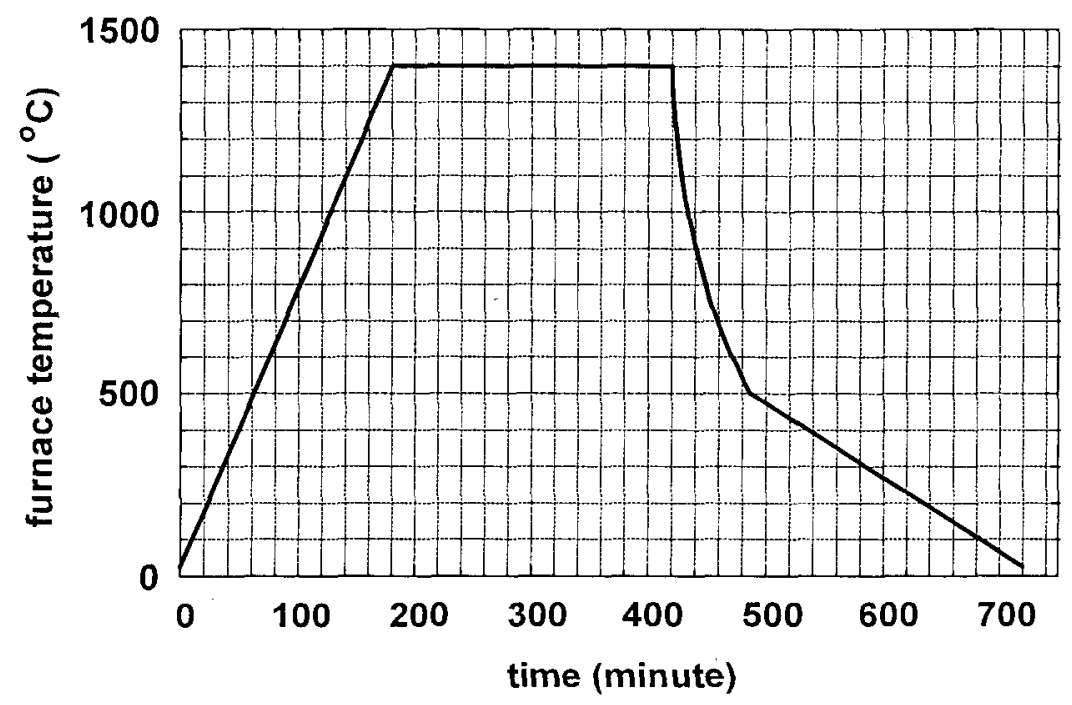

Fig 1. Heating profile typically used to produce glassy $\mathrm{GeO}_{2}$.

Fig 2 shows in more detail the portion of the observed furnace temperature during the cool down period. Cooling from $1000{ }^{\circ} \mathrm{C}$ to $800^{\circ} \mathrm{C}$ requires approximately 15 minutes. 


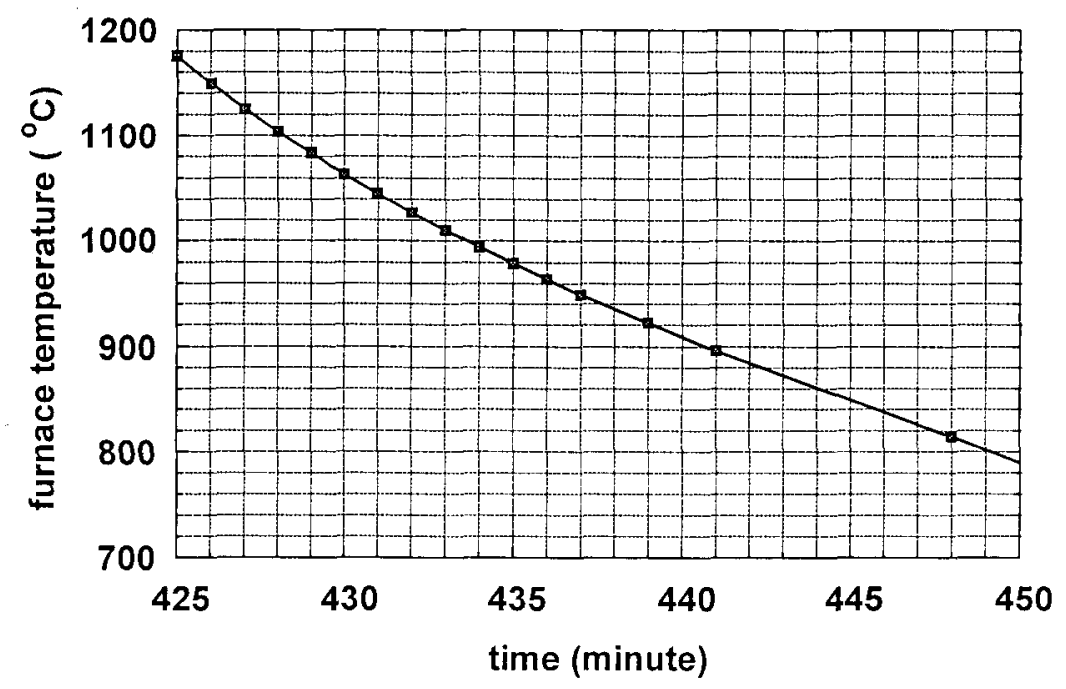

Fig 2. Enlarged detail of the rapid cool down portion of the heating profile typically used to produce glassy $\mathrm{GeO}_{2}$. The measured furnace temperatures are shown as symbols $(\bullet$ ) and are connected by a straight line segment to aid the eye in following trends.

The heating cycle selected (Fig 1) is based in part on consideration of literature studies on the viscosity of $\mathrm{GeO}_{2}$ [7] in which $\mathrm{GeO}_{2}$ commonly was reported to have been heated to $1400{ }^{\circ} \mathrm{C}$ for at least several hours to as much as 24 hours prior to the melt being cooled and viscosity measurements made. It also is based on our observation that application of the heating cycle shown in Fig 1 results in approximately $10 \%$ loss of $\mathrm{GeO}_{2}$ from the Pt boat in which it is heated if that boat is open (has no cover).

\section{Photomicrography}

A Nikon CoolPix 990 digital camera was used to record digital images of some of the produced glassy $\mathrm{GeO}_{2}$ samples. This camera has a 3.3 megapixel, uncooled CCD photosensor and is equipped with a zoom lens that in macro mode focuses down to object-to-lens distances of just under one inch. This produces a slightly larger than life size image of the object on the photosensor. The ultraviolet lamp used as the illumination source for some images was a UVP Products model Pen-Ray ${ }^{\circledR}$ type $11 \mathrm{SC}-1$ which is a low pressure mercury arc lamp. The lamp was fitted with a UVP Products model "G-275, LW" long wavelength pass filter that restricted the 
emitted wavelengths primarily to the $330 \mathrm{~nm}$ to $390 \mathrm{~nm}$ wavelength range. A Schott Glass low fluorescence long pass filter, model KV500, was used to eliminate yellow and shorter wavelengths from images recorded using ultraviolet illumination.

\section{Laser-induced fluorescence studies}

A Continuum model Surelite I-10 Q-switched Nd:YAG laser system provided 5 ns (nominal) duration $355 \mathrm{~nm}$ excitation pulses at a repetition rate of 10 pulses per second and a pulse energy typically of 0.1 millijoule. Emission spectra were record on an Acton 275 spectrograph $(27.5 \mathrm{~cm}$ focal length) that was equipped with a 150 groove/millimeter ruled grating and a Princeton Instrument model RE/IRY-700 optical multichannel spectral analyzer (OSMA) that was fitted with a CFC-100 photocathode cooler run with $-15{ }^{\circ} \mathrm{C}$ coolant and a model PG-10 pulse generator. The OSMA provides an on:off gating ratio of $10^{7}: 1$ with gate width and gate delay each of which is variable from $\sim 50 \mathrm{~ns}$ to $10 \mathrm{~ms}$. This spectrograph system was used to record time- and wavelength-resolved emission spectra of glassy $\mathrm{GeO}_{2}$ samples from $400 \mathrm{~nm}$ to $800 \mathrm{~nm}$ without changing the spectrograph wavelength setting. OSMA data typically were recorded for 300 laser pulses ( 30 seconds) and were averaged together to obtain an emission spectrum. The $355 \mathrm{~nm}$ laser beam was focused at a point in space a few centimeters in front of the sample so that the beam was diverging as it passed through the sample.

Light emitted from the sample was collected perpendicular to the laser beam path using a $\mathrm{f} / 1.5$ UV-grade fused silica lens. The collimated luminescence light then was focused onto the slits of the spectrograph using a f/4.0 UV-grade fused silica lens. A Schott Glass low fluorescence, long pass optical filter (model KV418) passed wavelengths longer than $418 \mathrm{~nm}$ to the spectrograph. The luminescence decay of a sample following $355 \mathrm{~nm}$ excitation was recorded using a cooled RCA model 31034A photomultiplier (GaAs photocathode) as the photodetector. Luminescence from the sample passed through a series of Schott Glass low fluorescence filters before it entered the photomultiplier housing. This and the properties of the photomultiplier restricted the detected luminescence to wavelengths from approximately $500 \mathrm{~nm}$ to $900 \mathrm{~nm}$. The current from the anode of the $31034 \mathrm{~A}$ passed through a coaxial cable to a variable value load resistor that was located at the input of Tektronix TDS 640A digital oscilloscope. Oscilloscope sweeps were triggered by a synchronization pulse from the laser power supply. Typically, the data from 128 
sweeps were averaged together by the TDS 640A. The averaged luminescence decay data were transferred to a personal computer and analyzed using nonlinear least squares fitting to model equations. This fitting was carried out using PSI-PLOT software (Poly Software International, Pearl River, NY).

\section{Experimental Observations}

\section{Visual observations}

The photomicrograph at the left in Fig 3 was recorded using visible light. It shows an edge on view of a uranyl-doped glassy $\mathrm{GeO}_{2}$ sample tipped at an angle of approximately 45 degrees within a $1 \mathrm{~cm} \times 1 \mathrm{~cm}$ square cross section spectrometer cuvette. The meniscus resulting from contraction during cooling of the molten $\mathrm{GeO}_{2}$ is clearly visible. The glassy $\mathrm{GeO}_{2}$ sample contained $11 \mathrm{ppm}$ uranium by weight. The photomicrograph at the right in Fig 3 shows the characteristic yellow-green luminescence of uranyl ion from the same sample when the illumination was switched from visible light to ultraviolet light.
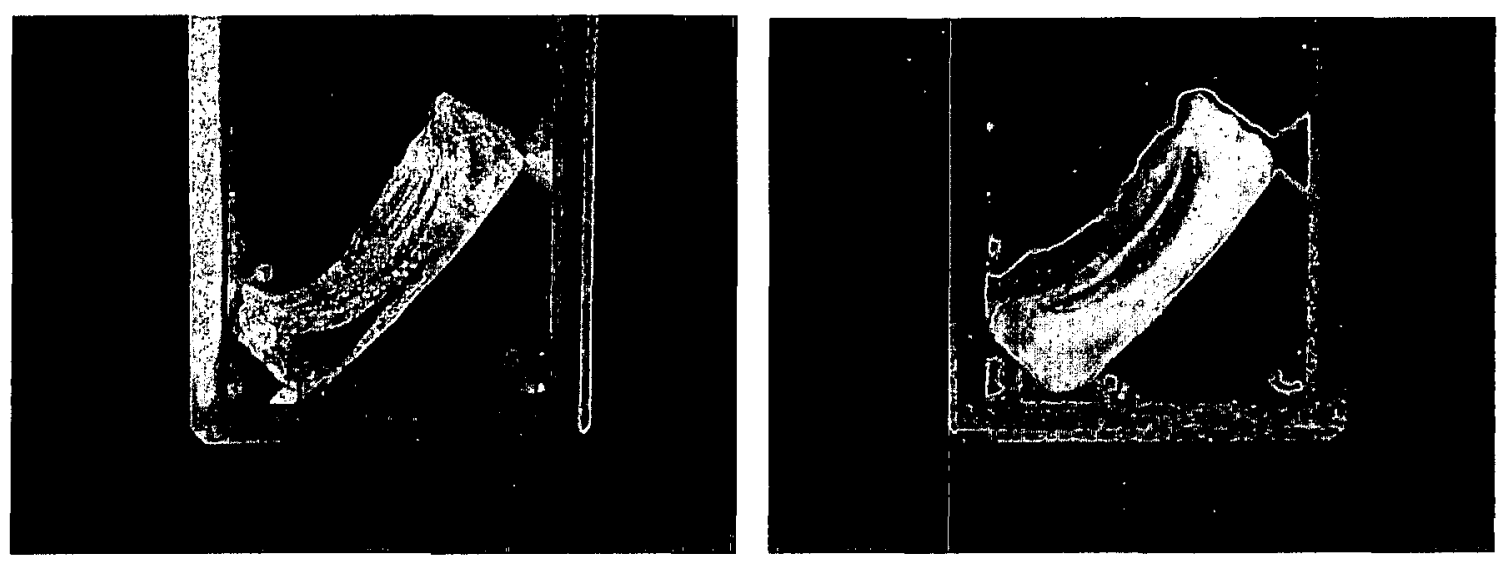

Fig 3. Photomicrographs of a uranium-doped glassy $\mathrm{GeO}_{2}$ sample that contained $11 \mathrm{ppm}$ uranium. The 1 $\mathrm{cm} \times 1 \mathrm{~cm}$ sample cell was illuminated by visible light (left photo above) and ultraviolet light (right photo above). The characteristic yellow-green luminescence of uranyl ion is easily seen under ultraviolet illumination. 


\section{Luminescence spectrum of uranyl ion in glassy $\mathrm{GeO}_{2}$}

The observed emission spectrum of uranyl-doped glassy $\mathrm{GeO}_{2}$ is shown in Fig 4. These data also are shown plotted with a logarithmic intensity axis in Fig 5. The observed emission spectrum peaks at $536 \mathrm{~nm}$, has a full width at half maximum of $65 \mathrm{~nm}$, and is typical of uranyl ions that are distributed over several types of sites. The sample contained $11 \mathrm{ppm}$ uranium on a weight basis. This characteristic uranyl emission spectrum was not observed in the absence of uranyl doping of glassy $\mathrm{GeO}_{2}$.

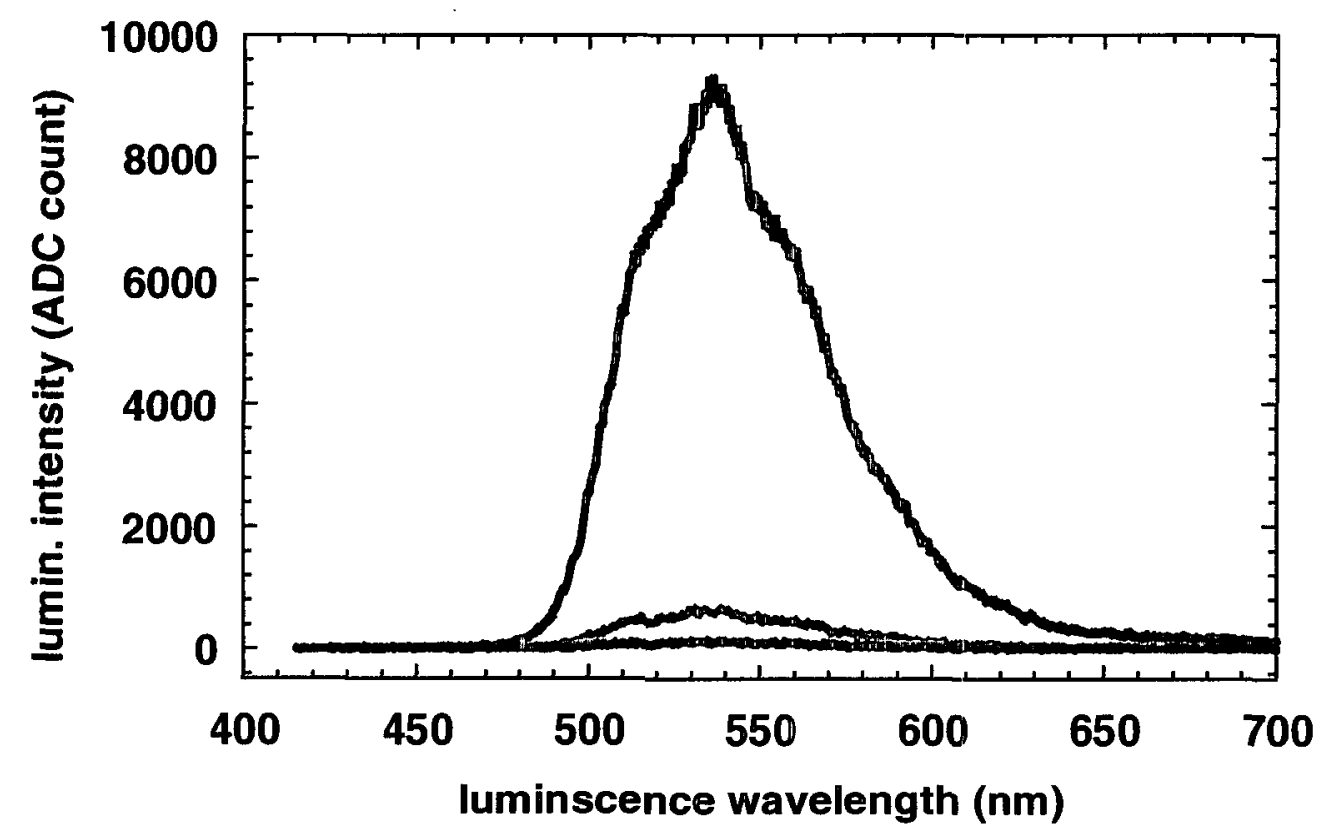

Fig 4. Luminescence emission spectrum of uranyl-doped glassy $\mathrm{GeO}_{2}$ recorded at $22{ }^{\circ} \mathrm{C}$ after pulsed excitation at $355 \mathrm{~nm}$ following a $1.2 \mu$ s gate start delay (red curve), a $320 \mu$ s gate start delay (green curve), and a $750 \mu$ s gate start delay (blue curve). A constant gate width $(320 \mu \mathrm{s})$ was used. 


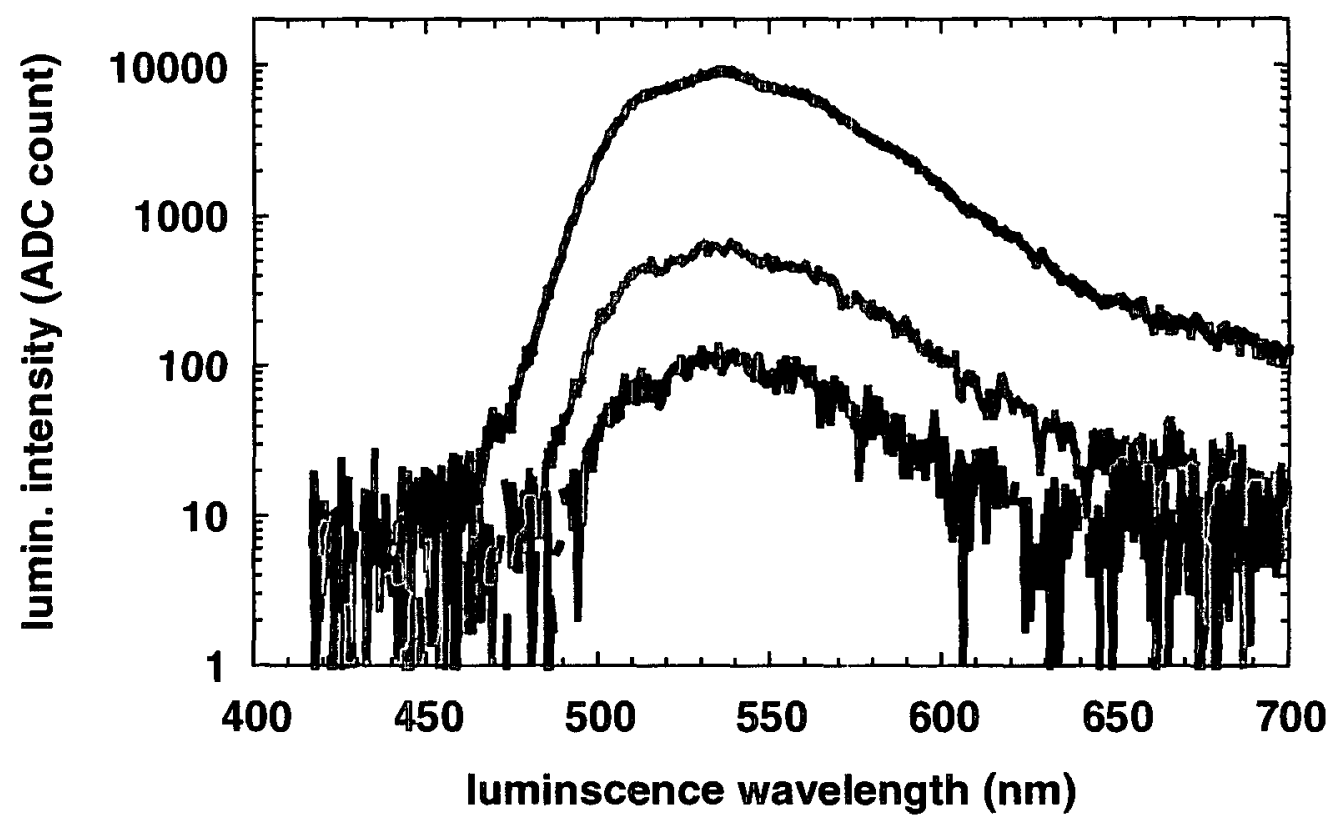

Fig. 5 The data of Fig 4 are re-plotted here using a logarithmic intensity axis. The observed spectrum changes little with time following pulsed excitation.

\section{Estimated limit of detection}

Luminescence emission data such as that shown in Fig 4 can be used to estimate the limit of detection for uranyl ions in glassy $\mathrm{GeO}_{2}$ using our apparatus as configured for these studies. The uncertainty in the zero luminescence light intensity level in the recorded data can be assessed by statistical analysis of the observed data from $420 \mathrm{~nm}$ to $460 \mathrm{~nm}$ where there is little if any sample luminescence. The resulting standard deviation $(\sigma)$ is $7.6 \mathrm{ADC}$ counts per photosensitive element of the OSMA system. Summing together the observed ADC counts for photosensors that recorded a light intensity level of 5\% or larger of the peak intensity level (i.e., integrating the spectrum from $489 \mathrm{~nm}$ to $630 \mathrm{~nm}$ ) gives the signal + dark level with little contribution from dark level uncertainty. Subtracting the dark level over these same photosensors gives the net signal intensity. Dividing this value by the expected uncertainty in the dark level for these photosensors gives a signal-to-dark noise level ratio of 69206. Assuming that the term "limit of detection" (LOD) is defined as an observed signal level whose value is $3 \sigma$ where $\sigma$ is the standard deviation in the measured value in the absence of the analyte, then we have achieved a 
sensitivity for detecting uranyl ion in glassy $\mathrm{GeO}_{2}$ that is equivalent to an LOD of 0.5 parts per billion (ppb) of uranium in $\mathrm{GeO}_{2}$ if the only luminescence recorded is that from uranyl.

\section{Photophysics of uranyl ion in glass $\mathrm{GeO}_{2}$}

Luminescence decay rate data were recorded, following pulsed $355 \mathrm{~nm}$ excitation, using a cooled photomultiplier, long pass optical filters, and a signal averaging digital oscilloscope. These data are shown in Fig 6. The observed decay is complex and not single exponential. Such complex decays typically arise for one of two reasons. The first is energy transfer from an initially electronically excited $\mathrm{UO}_{2}{ }^{2+}$ ion to a neighboring ground state $\mathrm{UO}_{2}{ }^{2+}$ species having a different local environment and therefore a somewhat different emission spectrum. When such energy transfer occurs, the observed emission spectrum changes as a function of time following pulsed excitation because the fraction of the total emission due to each type of $\mathrm{UO}_{2}{ }^{2+}$ ion changes with time. The other physical situation that gives rise to complex decays is initial excitation of a

distribution of $\mathrm{UO}_{2}{ }^{2+}$ species each of which then undergoes radiative and nonradiative decay processes that are first order in time. The net result is that the observed decay is the sum of multiple independent first order decays, each arising from $\mathrm{UO}_{2}{ }^{2+}$ ions of differing local environments. Given the low uranium concentration (11 ppm uranium by weight, which is equivalent to $1.49 \times 10^{-4} \mathrm{~mol} /$ liter $\mathrm{UO}_{2}{ }^{2+}$ in glassy $\mathrm{GeO}_{2}$ ), energy transfer among uranyl ions is unlikely to cause the observed complex decays. In addition, the observed emission spectra are not significantly time-dependent. For these reasons, the observed luminescence decay was fit to a phenomenological model consisting of a sum exponential decays in which the number of decays included was increased until a plot of the residuals (the difference between the observed and calculated intensity at a particular time) showed no systematic deviations. In the least square error sense, the model equation

$$
I(t)=1997 \exp (-64530 t)+6158 \exp (-10625 t)+2969 \exp (-3529 t)
$$

where $I(t)$ is the calculated intensity at time $t$ in seconds, provides the best fit to the observed data. The three fit decay rates $\left(64530 \mathrm{~s}^{-1}, 10625 \mathrm{~s}^{-1}\right.$, and $\left.3529 \mathrm{~s}^{-1}\right)$ are typical of uranyl ions in local environments that induce nonradiative decay to degrees that vary from moderate to weak to none, respectively. It should be emphasized that Eqn 3 represents a phenomenological model 
and should not be taken to imply that there are only three local environments for $\mathrm{UO}_{2}^{2+}$ in glassy $\mathrm{GeO}_{2}$.

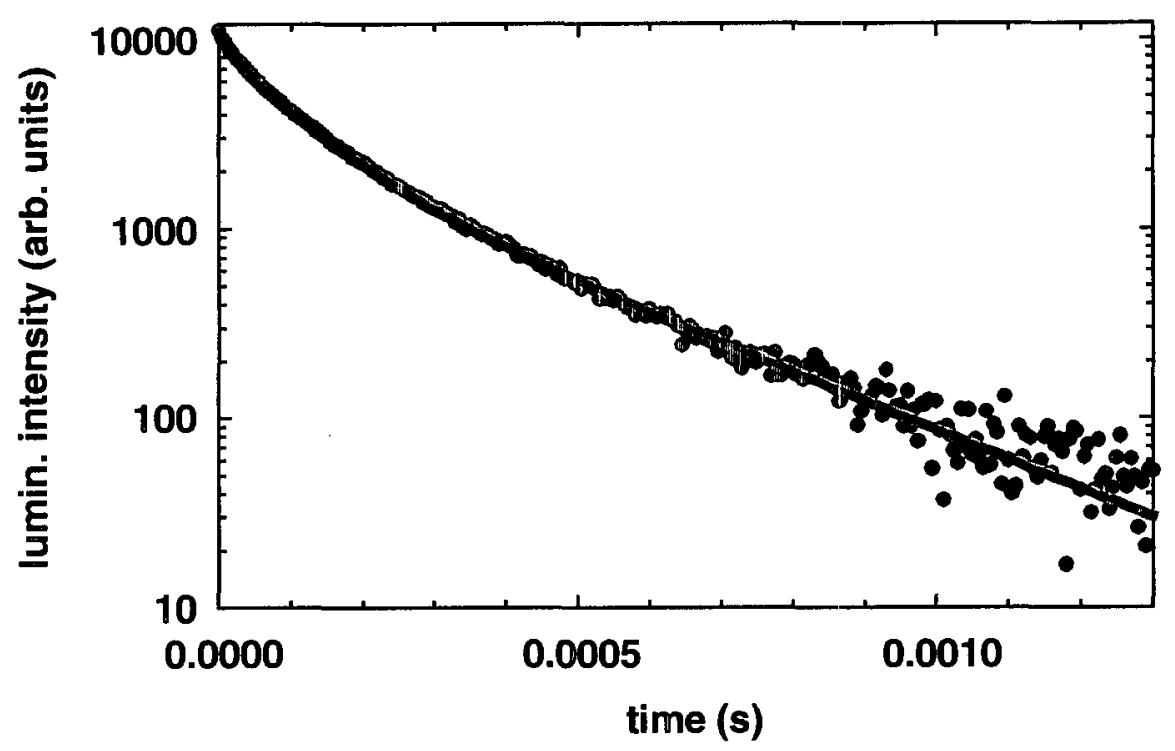

Fig 6. The observed luminescence decay of uranyl-doped $\mathrm{GeO}_{2}$ following pulsed $355 \mathrm{~nm}$ excitation is shown as symbols $(\bullet)$. The solid red line is the result of fitting a "sum of three exponential decays" model to the observed data (see text).

\section{Crystallization of $\mathrm{GeO}_{2}$ can occur with our present apparatus}

The heating profile that we have used is not optimal in terms of ensuring formation of bubblefree glassy $\mathrm{GeO}_{2}$. Fig 7 shows an example of a partially successful attempt to produce a glassy $\mathrm{GeO}_{2}$ sample for laser-induced fluorescence analysis. The photomicrograph shows a $\mathrm{GeO}_{2}$ sample, tipped on edge, within a $1 \mathrm{~cm} \times 1 \mathrm{~cm}$ square spectrometer cuvette. Small gas bubbles that nucleated at the surface of the platinum boat failed to rise to the surface of the molten $\mathrm{GeO}_{2}$ before the end of the $1400^{\circ} \mathrm{C}$ soak period. 


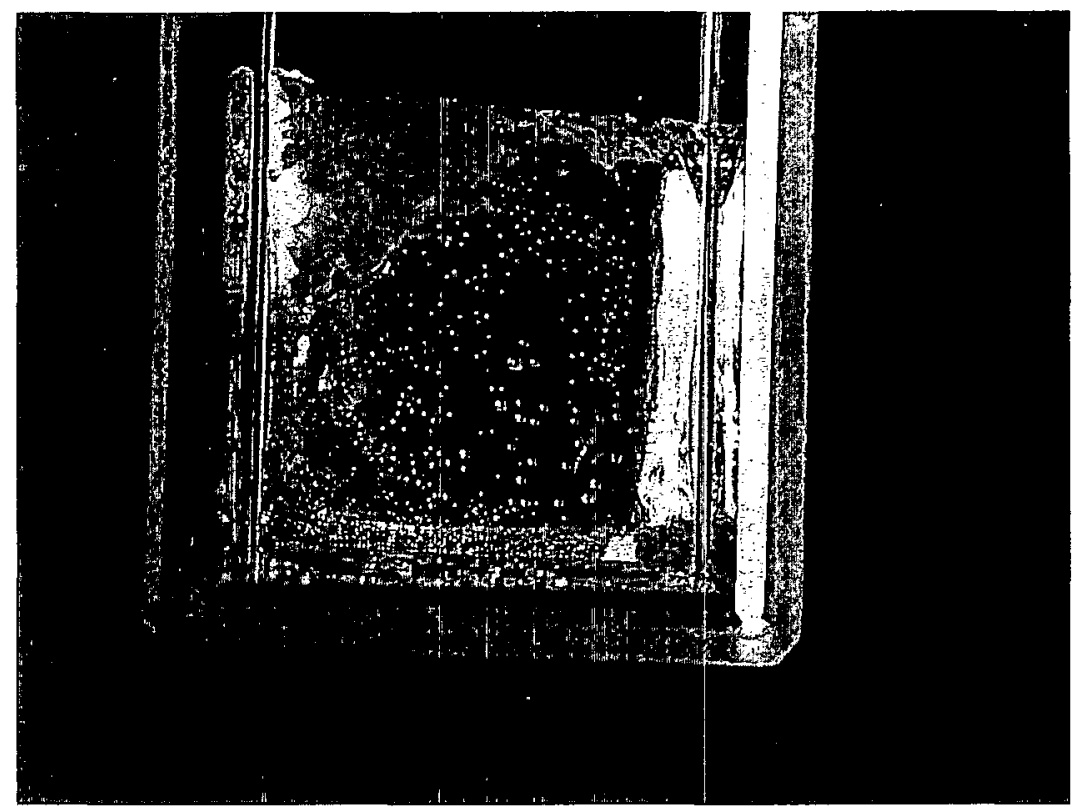

Fig. 7. Photomicrograph of a glassy $\mathrm{GeO}_{2}$ sample in the bottom of a $1 \mathrm{~cm} x$ $1 \mathrm{~cm}$ spectrometer cuvette showing incomplete removal of trapped gas bubbles and partial crystallization (white area at upper left) during vitrification of the $\mathrm{GeO}_{2}$.

The upper left portion of the above photograph is shown enlarged in Fig 8. The cool down time from $1400{ }^{\circ} \mathrm{C}$ to $500{ }^{\circ} \mathrm{C}$ evidently was insufficiently rapid to prevent some crystallization of the $\mathrm{GeO}_{2}$ because a mass of crystallites formed (see upper left corner of the enlarged photo). 


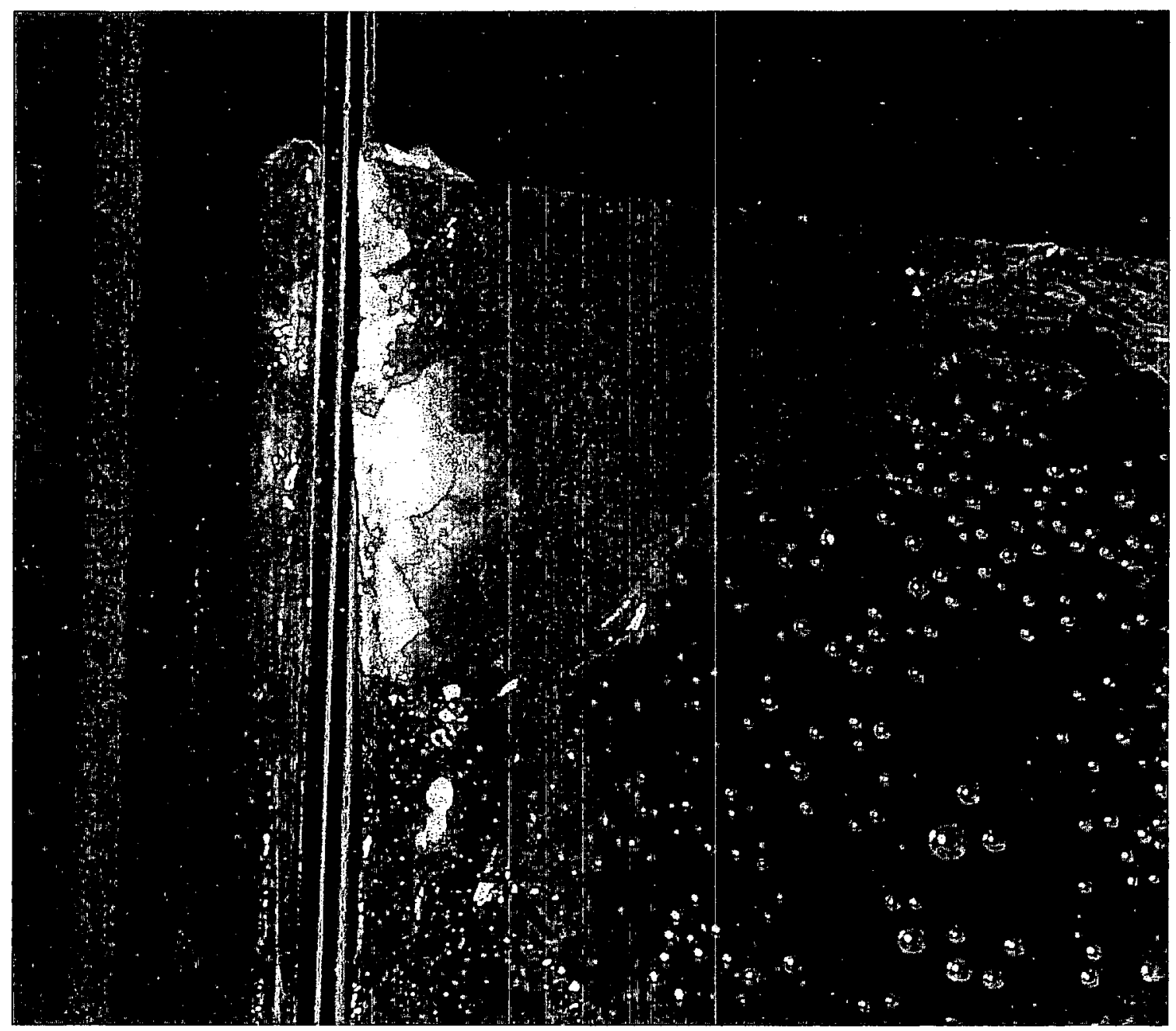

Fig 8. The upper left portion of Fig 7 is shown above enlarged to emphasize the presence of microcrystallites that evidently began forming in a coner of the Pt fusion boat and propagated toward the bulk of the $\mathrm{GeO}_{2}$ before crystallite growth was terminated by the increasing viscosity of the glassy $\mathrm{GeO}_{2}$ as it cooled.

Using the heating cycle shown in Fig 1 with $\mathrm{GeO}_{2}$ dried at $110^{\circ} \mathrm{C}$ in a laboratory oven produced glassy $\mathrm{GeO}_{2}$ that had such a high concentration of small gas bubbles that the resulting material was translucent milky white rather than being clear, colorless, and transparent. This observation is evidence that the initial water content of $\mathrm{GeO}_{2}$ is an important parameter in determining the viscosity of molten $\mathrm{GeO}_{2}$ at $1400{ }^{\circ} \mathrm{C}$. A similar phenomena occurs in the case of glassy silica (often referred to as fused quartz). The presence of water (often denoted as "OH" in the fused quartz literature) reduces the viscosity of vitreous silica. For example, a grade of fused silica that contains $1000 \mathrm{ppm} \mathrm{OH}$ is reported to have a strain point temperature that is $117^{\circ} \mathrm{C}$ lower than that of a grade of nominally "water-free" fused silica [8]. 


\section{Discussion}

We have found that platinum foil boats are acceptable for making glassy $\mathrm{GeO}_{2}$ samples. Our visual observations have shown that near ultraviolet illumination in a dark room is sufficient to detect the presence of uranyl, at the ppm level, in glassy $\mathrm{GeO}_{2}$. This provides evidence that uranyl ions are appreciably luminescent in glassy $\mathrm{GeO}_{2}$. Blaase and Grabmaier's monograph provides a good introduction to luminescing materials in general and provides some insight into uranyl luminescence [9]. A classic reference concerning uranyl luminescence is the work of Rabinowitch and Belford [10] although it contains little information about uranyl in glass phases. Denning's review article provides the most definitive information about the photophysics and spectroscopy of uranyl ions [11] although it too deals primarily with uranyl in crystalline phases. Near ultraviolet excitation of uranyl populates a charge transfer state whose emission to the ground state is a formally "forbidden" transition. Emission becomes partially allowed due to coupling of that excited electronic state to a vibrational motion of the linear dioxo (O-U-O) uranyl cation. This results in highly structured luminescence spectra that exhibit a long progression of "vibronic" transitions. The purely radiative lifetime of uranyl ion typically is on the order of $1 \mathrm{~ms}$. Nonradiative decay processes frequently result in shorter observed uranyl luminescence lifetimes.

Because our heating cycle involves holding molten $\mathrm{GeO}_{2}$ at $1400{ }^{\circ} \mathrm{C}$ for four hours and the only uranium species that we have detected in the glassy $\mathrm{GeO}_{2}$ that we have made is uranyl ion, it is clear that uranyl ions are chemically stable for hours in molten $\mathrm{GeO}_{2}$. Our laser-induced fluorescence studies have shown that luminescence from uranyl ion in glassy $\mathrm{GeO}_{2}$ peaks at 536 $\mathrm{nm}$ in a board band that contains a number of shoulders. The near-invariance of the observed emission spectrum with time following pulsed $355 \mathrm{~nm}$ excitation and the complex observed luminescence decays are consistent with the presence of uranyl ions having differing local environments. This likely arises because uranyl ions are positively charged species for which negatively charged compensating species, such as $\mathrm{OH}^{-}$, necessarily must be present although the framework of a $\mathrm{GeO}_{2}$ glass contains no charged species. Uranyl ions, in consequence, likely reside on a variety of sites that differ in terms of the position and nature of neighboring atoms 
and the location of charge compensating species. The vibronic progressions usually clearly evident in uranyl ion emission spectra are less obvious in the present case (Fig 4). This is attributed to the observed emission being the sum of the slightly differing vibronic progressions from uranyl ions whose local environments differ.

\section{Issues for future work}

The precision and accuracy that we ultimately will achieve using our laser-induced fluorescence method are likely to depend on the degree to which we achieve dimensionally uniform glassy $\mathrm{GeO}_{2}$ samples that are free of bubbles, strain, and embedded microcrystallites of $\mathrm{GeO}_{2}$. Our present heating cycle produces strain-free glass. Finding optimal methods for eliminating bubbles and microcrystallites is challenging.

\section{Ensuring bubble-free glassy $\mathrm{GeO}_{2}$}

Three issues concerning preparation of high optical quality glassy $\mathrm{GeO}_{2}$ are interrelated. These are the volatility of liquid $\mathrm{GeO}_{2}$, the viscosity of liquid $\mathrm{GeO}_{2}$, and removal of trapped gas bubbles from molten $\mathrm{GeO}_{2}$. Normally, removal of trapped bubbles from a glass is achieved by increasing temperature or applying mechanical agitation. In our case, significant temperature increase is likely to result in unacceptable volatilization of $\mathrm{GeO}_{2}$. In addition, heating to a higher temperature in a closed or sealed metallic container is more likely to favor chemical reduction of uranyl which has not been a problem using our present heating cycle. Fortunately, our preliminary evidence suggests that increased water content lowers the viscosity of molten $\mathrm{GeO}_{2}$. Hydrolysis of $\mathrm{GeF}_{4}$ and subsequent treatment with ammonium hydroxide is likely to increase the water (more accurately, $\mathrm{OH}$ ) content of $\mathrm{GeO}_{2}$ that is produced during analysis of $\mathrm{GeF}_{4}$, relative to that in the samples that we have prepared to date. For this reason, it may be that our present heating cycle will prove adequate for all $\mathrm{GeF}_{4}$ analysis purposes although it may not guarantee bubble-free glassy $\mathrm{GeO}_{2}$ when starting from dry $\mathrm{GeO}_{2}$. The impact of $\mathrm{OH}$ content on uranyl luminescence in $\mathrm{GeO}_{2}$ is unknown at present. 


\section{Suppressing crystallization}

The key to suppressing crystallization of $\mathrm{GeO}_{2}$ is the rapidity with which molten $\mathrm{GeO}_{2}$ is cooled to below its glass transition temperature $\left(\sim 500^{\circ} \mathrm{C}\right.$ [7]) and, based on literature reports [7], more particularly, the rate at which it is cooled from $1000{ }^{\circ} \mathrm{C}$ to $800{ }^{\circ} \mathrm{C}$. Using our present heating cycle, we can not guarantee achieving samples that are $100 \%$ free of microcrystallites. We are exploring relatively simple modifications to our furnace system that may enable removal of a molten $\mathrm{GeO}_{2}$ sample to a relatively cold zone in a matter of a few seconds. We expect that this would suppress crystallization in all samples of interest.

\section{Analytical limits}

The upper (highest concentration) limit for determination of uranyl in $\mathrm{GeO}_{2}$ is likely to be set by the solubility limit of uranyl in glassy $\mathrm{GeO}_{2}$ which has not been reported in the literature. Due to the necessity of charge compensation, it seems unlikely the solubility of uranium as uranyl in glassy $\mathrm{GeO}_{2}$ will be high. Precipitation of uranate or germanate phases is likely to set the practical upper limit. The limit of detection (lowest concentration detectable) for this method is likely to be set by impurities other than $\mathrm{UF}_{6}$ in the $\mathrm{GeF}_{4}$, if such impurities result in interfering luminescence.

The temperature dependence of the observed complex uranyl luminescence decays should be determined to establish the degree of temperature control that must be maintained to obtain reproducible measurements of the uranium content of glassy $\mathrm{GeO}_{2}$.

\section{Ultraviolet Absorption Analysis for $\mathbf{U F}_{6}$ in $\mathbf{G e F}_{4}$}

We expect delivery of 100 grams of $99.99 \%$ pure $\mathrm{GeF}_{4}$ before the end of this week. When this material arrives, we will begin hydrolysis studies as well as record the ultraviolet absorption spectrum of $\mathrm{GeF}_{4}$ with and without added $\mathrm{UF}_{6}$. These latter studies will establish the basis for ultraviolet absorption analysis of $\mathrm{UF}_{6}$ in $\mathrm{GeF}_{4}$ gas and will provide a measure of the $\mathrm{UF}_{6}$ detection sensitivity that we can achieve with our conventional dual beam optical spectrometer in conjunction with our present nickel-bodied gas cell that is equipped with single crystal aluminum oxide windows. The basis of this method is the very strong and characteristic ultraviolet 
absorption spectrum of $\mathrm{UF}_{6}[1]$ and an expected lack of interfering absorbance in the ultraviolet from $\mathrm{GeF}_{4}$ [2].

\section{Conclusions}

The conclusions that we have reached to date in our research on the luminescence of uranyl ions in glassy $\mathrm{GeO}_{2}$ are:

1. Uranyl ion is chemically stable at least for several hours at $1400{ }^{\circ} \mathrm{C}$ in molten $\mathrm{GeO}_{2}$ in contact with air.

2. Platinum crucibles are acceptable containers for preparation of glassy $\mathrm{GeO}_{2}$ as to ease of removal of the produced glassy $\mathrm{GeO}_{2}$ and lack of significant addition of luminescing impurities to the produced glassy $\mathrm{GeO}_{2}$.

3. $\mathrm{GeO}_{2}$ heated to $1400{ }^{\circ} \mathrm{C}$ and then cooled to below its glass transition temperature over a span of 60 minutes can form water clear, colorless, glassy $\mathrm{GeO}_{2}$ although more rapid cooling is to be preferred.

4. Uranyl ions in glassy $\mathrm{GeO}_{2}$ are highly luminescent at ambient temperature when excited in the near ultraviolet spectral range, emit a characteristic luminescence spectrum, and exhibit long-lived, but complex luminescence decay as is typically found for luminescing metal ions dispersed in glassy phases.

5. Based on the observed signal-to-dark noise level ratio for luminescence from uranyldoped $\mathrm{GeO}_{2}$, a limit of detection (LOD) of $0.5 \mathrm{ppb}$ (or 500 parts per trillion) uranium (on a weight basis) in $\mathrm{GeF}_{4}$ is expected using our present apparatus configuration which was optimized to determine the spectroscopy and photophysics of uranyl ions in glassy $\mathrm{GeO}_{2}$. Re-configuring our apparatus to maximize detection sensitivity is likely to result in a further LOD improvement of at least a factor of ten, i.e. 50 parts per trillion or better sensitivity for detection of uranium in $\mathrm{GeF}_{4}$ when the chemical form of the uranium is $U_{6}$. This presumes the absence of significant interference from other luminescing impurities in glassy $\mathrm{GeO}_{2}$. 


\section{Acknowledgements}

Helpful discussions with J. B. Bulko (Starmet Corporation) concerning the properties of $\mathrm{GeF}_{4}$ are gratefully acknowledged. This research was carried out as a subcontract to a DOE Phase II SBIR grant to Starmet Corporation (Concord, MA).

\section{Literature Cited}

1) "The absorption spectrum of $\mathrm{UF}_{6}$ from $2000 \AA$ to $4000 \AA$ ", G. L. DePoorter and C. K. RoferDePoorter, Spectroscopy Letters, 8 (1975) 521 - 524.

2) "Absorption spectra of $\mathrm{Si}_{2} \mathrm{Cl}_{6}, \mathrm{SiF}_{3} \mathrm{CH}_{3}$, and $\mathrm{GeF}_{4}$ in the VUV region", T. Ibuki, N. Washida, U. Itoh, Y. Toyoshima, and H. Onuki, Chem. Phys. Let. 136 (1987) 447 - 450.

3) "The Chemistry of Germanium", F. Glocking, Academic Press, London, 1969.

4) "Uranium Hexafluoride: A Manual of Good Handling Practices", U. S. DOE Field Office, Oak Ridge, TN, Report Number ORO-651 (Rev. 6), dated October, 1991.

5) "Localized states in germanate glasses. Ultraviolet absorption tail of crystalline and glassy germanium dioxide and alkali germanate", A. N. Trukhin and P. Kulis, J. Non-crystalline Solids, 188 (1995) 125-129.

6) "Optical transitions in germanium dioxide", X.-L. Xu, L.-X. Zhu, T. P. Chen, S. Fung. and S.M. Li, Thin Solid Films, 283 (1996) $230-234$.

7) "Handbook of Glass Data, Part B - Single Component and Binary Non-silicate Oxide Glasses", O. V. Mazurin, M. V. Streltsina, and T. P. Shvaiko-Shvaikovskaya, Elsevier, Amsterdam, 1985, pgs. 353-384. This is volume 15 of Elseveir's Physical Sciences Data Series.

8) "Silica (Vitreous)" in "Kirk-Othmer Encyclopedia of Chemical Technology", $3^{\text {rd }}$ Edition, Vol. 20 (John Wiley and Sons, New York, 1982), pgs 787-788.

9) "Luminescent Materials", G. Blasse and B. C. Grabmaier, Springer-Verlag, Berlin, 1994.

10) "Spectroscopy and Photochemistry of Uranyl Compounds", E. Rabinowitch and R. L. Belford, Pergamon Press, New York, 1964.

11) "Electronic Structure and Bonding in Actinyl Ions", R. G. Denning, Structure and Bonding, 79 (1992) 215-276. 


\section{ULTRATRACE \\ DETERMINATION OF URANIUM \\ IN GERMANIUM TETRAFLUORIDE}

October 23, 2001 Progress Report

J. V. Beitz and C. W. Williams

Chemistry Division

Argonne National Laboratory

Argonne, IL 60439-4831 


\section{Table of Contents}

Abstract ___ 3

Introduction

Objectives _ 5

Ultraviolet Absorption Analysis for $\mathrm{UF}_{6}$ in $\mathrm{GeF}_{4}$

Nickel Gas Cell Assembly ____________ 9

Ultraviolet Absorption Spectrum of Starmet-Produced $\mathrm{GeF}_{4}$

Investigation of Initial Pressure Loss___ 14

Observation of a Small Initial Pressure Loss _______________ 14

Near-Infrared Absorption Spectrum of Starmet-Produced $\mathrm{GeF}_{4} \_16$

Preparation and Characterization of Glassy $\mathrm{GeO}_{2} \quad 19$

Laser-induced Fluorescence Characterization _______ 21

Ultratrace Uranium Analysis Using a Chloride Volatility Approach ___ 23

Hydrolysis Procedure for $\mathrm{GeF}_{4} \_25$

Sub-boiling Point Distillation Apparatus____ 26

Issues for Future Work __ 28

Conclusions _ـ 29

Acknowledgements___ 30

Literature Cited ___ 30 


\begin{abstract}
One approach that we are investigating to improve analytical methods for quantifying uranium hexafluoride $\left(\mathrm{UF}_{6}\right)$ in germanium tetrafluoride $\left(\mathrm{GeF}_{4}\right)$ is hydrolysis of impure $\mathrm{GeF}_{4}$ gas to generate $\mathrm{GeO}_{2}$ and uranyl fluoride. Subsequent heating produces uranyl ions embedded in glassy $\mathrm{GeO}_{2}$. In our earlier work, we showed that laser-induced fluorescence analysis for uranyl ion had the potential to detect less than 0.5 parts per billion of uranium in glassy $\mathrm{GeO}_{2}$. We also noted difficulty in reproducibly creating visually clear, bubble-free glassy $\mathrm{GeO}_{2}$ on the one gram scale. Bubble-free $\mathrm{GeO}_{2}$ is required to achieve reproducible measurement of luminescence intensity. Such reproducibility is essential for quantitative measurement of uranium impurity content in analyzed samples via the standard addition method.
\end{abstract}

Based on a parametric study, we now have identified a simple means of producing visually clear, bubble-free glassy $\mathrm{GeO}_{2}$ on the gram scale. However, this method creates an impurity that, following excitation at $355 \mathrm{~nm}$, luminesces such that its emission spectrum and luminescence decay overlap those of uranyl ion in glassy $\mathrm{GeO}_{2}$. The impurity species likely is the result of thermal reduction of some tetravalent $\mathrm{Ge}$ in $\mathrm{GeO}_{2}$ to divalent $\mathrm{Ge}$. The impurity species grows in with increased sample residence time in the high temperature zone of the furnace. This impurity interference is present to varying degrees in all other methods that we investigated to minimize the presence of small bubbles in $\mathrm{GeO}_{2}$ glass produced by melt processing in air. Given difficulties in producing glassy $\mathrm{GeO}_{2}$ of acceptable quality for quantitative uranyl luminescence analysis, we began a search for alternate, but related methods of achieving our goal of improved ultratrace analysis for $\mathrm{UF}_{6}$ in $\mathrm{GeF}_{4}$ gas. We have identified a promising method that does not require high temperature processing and so is likely to be more easily and economically implemented in a quality assurance laboratory.

Our new approach retains the same initial step, namely, hydrolysis of $\mathrm{GeF}_{4}$ gas in water to generate $\mathrm{GeO}_{2}, \mathrm{H}_{2} \mathrm{GeF}_{6}$, and $\mathrm{HF}$, and the same second processing step, namely sub-boiling point distillation of volatile species. Our new approach then dissolves the resulting non-volatile 
residue $\left(\mathrm{GeO}_{2}\right.$ and uranyl fluoride, if any $U_{6}$ was present in the $\left.\mathrm{GeF}_{4}\right)$ in concentrated hydrochloric acid. This converts $\mathrm{GeO}_{2}$ to volatile $\mathrm{GeCl}_{4}$ that is removed, along with excess hydrochloric acid, by a second sub-boiling point distillation. The residue (uranyl chloride and trace amounts of $\mathrm{GeO}_{2}$ ) is taken up in dilute phosphoric acid solution. The uranium content of the resulting solution is quantified by laser-induced fluorescence and the standard addition method. This new approach will permit use of $266 \mathrm{~nm}$ excitation which has the advantage of being more strongly absorbed by uranyl in dilute phosphoric acid than is light at $337 \mathrm{~nm}$ (nitrogen laser) or $355 \mathrm{~nm}$ (tripled Nd:YAG laser). In consequence, limits of detection for uranyl comparable to the best reported in the literature (1 to $40 \mathrm{ppt}$ ) are expected. The primary interference that we anticipate in our germanium chloride volatilization process is luminescence from trace level organic contaminants leached from the perfluoropolymer distillation vessel. We expect to eliminate such interference by $185 \mathrm{~nm}$ photolysis that should photochemically destroy such contaminants. In our initial studies of this new approach, we have hydrolyzed $\mathrm{GeF}_{4}$ gas and verified volatilization of the resulting $\mathrm{GeO}_{2}$ from concentrated hydrochloric acid.

Using a $9.3 \mathrm{~cm}$ path length nickel-bodied, elastomer-free cell equipped with single crystal aluminum oxide windows, we have recorded the ultraviolet absorption spectrum of Starmetproduced $\mathrm{GeF}_{4}$ gas. Based on those spectra and literature values for the molar absorptivity of uranium hexafluoride gas, Starmet-produced $\mathrm{GeF}_{4}$ contains less than 0.75 parts per million (by volume) of $\mathrm{UF}_{6}$. Based on an observed small decreases in pressure upon contact of Starmetproduced $\mathrm{GeF}_{4}$ gas with a clean, passivated vacuum system and subsequent FT-IR analysis of that $\mathrm{GeF}_{4}$ gas using our nickel-bodied cell, we have concluded that the sample of Starmetproduced $\mathrm{GeF}_{4}$ that we analyzed contains approximately $0.8 \%$ hydrogen fluoride $(\mathrm{HF})$ gas by volume. 


\section{Introduction}

Determination of uranium in germanium tetrafluoride $\left(\mathrm{GeF}_{4}\right)$ is challenging due to the chemically aggressive nature of $\mathrm{GeF}_{4}$ and the strong fluorinating ability of the most probable volatile uranium impurity in $\mathrm{GeF}_{4}$, namely uranium hexafluoride $\left(\mathrm{UF}_{6}\right)$ gas. Conventional high sensitivity methods, such as inductively coupled plasma mass spectrometry (ICP-MS) or atomic emission spectroscopy, lose sensitivity because $\mathrm{GeF}_{4}$ must be hydrolyzed in water (diluted) prior to analysis of the hydrolysis solution and due to interference from hydrolysis products of $\mathrm{GeF}_{4}$ Such interference often is termed a "matrix" effect.

We are developing methods for ultratrace determination of uranium in germanium tetrafluoride $\left(\mathrm{GeF}_{4}\right)$ gas as part of a Small Business Innovative Research Phase II project of Starmet Corporation. This progress report covers work carried out since March 19, 2001. Our methods are designed primarily for determination of uranium based on its most probable volatile chemical compound, namely uranium hexafluoride $\left(\mathrm{UF}_{6}\right)$. Our first method relies on detection and measurement of $\mathrm{UF}_{6}$ via its characteristic and very strong ultraviolet optical absorption spectrum. The scientific basis for this method is well established, although it is technically challenging to implement. The second method that we are developing seeks to establish the scientific basis for ultratrace determination of $\mathrm{UF}_{6}$ via one of its hydrolysis products, namely the uranyl ion, as detected by laser-induced fluorescence. Most of our studies to date have focussed on use glassy germanium dioxide $\left(\mathrm{GeO}_{2}\right)$ as the matrix in which such uranyl ions are embedded by heating $\mathrm{GeO}_{2}$ that is produced when $\mathrm{a} \mathrm{GeF}_{4}$ sample is hydrolyzed in water. In effect, the sample to be analyzed generates the matrix in which uranyl is analyzed. Our past work showed uranyl ions are stable for hours in molten $\mathrm{GeO}_{2}$ that is in contact with air and that uranyl ions in glassy $\mathrm{GeO}_{2}$ at ambient temperature are strongly luminescent. It also showed that

\section{Objectives}

We are developing two methods for ultratrace determination of uranium in $\mathrm{GeF}_{4}$ gas. Both of these methods are primarily sensitive to uranium as uranium hexafluoride $\left(\mathrm{UF}_{6}\right)$. Our first method relies on the very strong optical absorbance of $\mathrm{UF}_{6}$ gas in the ultraviolet [1] at wavelengths where $\mathrm{GeF}_{4}$ should be essentially transparent [2]. This method is non-destructive 
(does not involve chemical alteration of $\mathrm{GeF}_{4}$ ), and may be suitable for on-line monitoring of $\mathrm{UF}_{6}$ impurity levels during $\mathrm{GeF}_{4}$ production.

Our second method relies on destructive analysis of $\mathrm{GeF}_{4}$ and is based on laser-induced fluorescence (LIF) measurement of uranyl ion $\left(\mathrm{UO}_{2}{ }^{2+}\right)$ that is formed when $\mathrm{UF}_{6}$ reacts with water. Most of our effort has been directed towards use of a $\mathrm{GeF}_{4}$ hydrolysis product, $\mathrm{GeO}_{2}$, as the matrix in which uranyl ions are embedded prior to LIF analysis. This method starts with hydrolysis of a sample of $\mathrm{GeF}_{4}$ gas. Any $\mathrm{UF}_{6}$ impurity in the $\mathrm{GeF}_{4}$ will hydrolyze to uranyl ions $\left(\mathrm{UO}_{2}{ }^{2+}\right)$. Hydrolysis of $\mathrm{GeF}_{4}$ is reported [3] to follow the chemical reaction

$$
3 \mathrm{GeF}_{4}+2 \mathrm{H}_{2} \mathrm{O} \rightarrow \mathrm{GeO}_{2}+2 \mathrm{H}_{2} \mathrm{GeF}_{6}
$$

although no detailed study of this reaction has been reported nor are the properties of $\mathrm{H}_{2} \mathrm{GeF}_{6}$ well established. It is known [4] that $\mathrm{UF}_{6}$ hydrolyzes according to the reaction

$$
\mathrm{UF}_{6}+2 \mathrm{H}_{2} \mathrm{O} \rightarrow \mathrm{UO}_{2} \mathrm{~F}_{2}+4 \mathrm{HF}
$$

In addition, uranyl fluoride $\left(\mathrm{UO}_{2} \mathrm{~F}_{2}\right)$ is one of the most water-soluble uranyl salts known. With excess water, the above reactions should give an aqueous solution that contains $\mathrm{GeO}_{2}, \mathrm{H}_{2} \mathrm{GeF}_{6}$, $\mathrm{UO}_{2}{ }^{2+}$ and its fluoride ion complexes, and hydrofluoric acid (HF) and fluoride ion (F) in amounts that depend on the $\mathrm{pH}$ of the solution. Sub-boiling point distillation of the hydrolysis solution results in hydrated $\mathrm{GeO}_{2}$ and uranyl fluoride. Fusion of this $\mathrm{GeO}_{2}$ will produce glassy $\mathrm{GeO}_{2}$ for subsequent analysis for uranyl content by laser-induced fluorescence. Glassy $\mathrm{GeO}_{2}$ is preferred over crystalline $\mathrm{GeO}_{2}$ for two reasons. The first is that $\mathrm{GeO}_{2}$ can exist in either of two crystalline modifications and preparation of it in a single crystalline phase is difficult [3]. The second is that crystallization tends to concentrate impurities, such uranyl ions, along defects or grain boundaries. This is undesirable because uranyl species frequently undergo luminescence self-quenching (some times referred to as concentration quenching). Such quenching would reduce the sensitivity for detecting uranyl via laser-induced fluorescence.

\section{Ultraviolet Absorption Analysis for $\mathrm{UF}_{6}$ in $\mathrm{GeF}_{4}$}

The basis of this method is the very strong and characteristic ultraviolet absorption spectrum of $\mathrm{UF}_{6}[1]$ and an expected lack of interfering absorbance in the ultraviolet from $\mathrm{GeF}_{4}$ [2]. The vacuum system that we have used for handling $\mathrm{GeF}_{4}$ is shown schematically in Fig 1. 


\section{Schematic Diagram of $\mathrm{GeF}_{4}$ Gas Handling System}

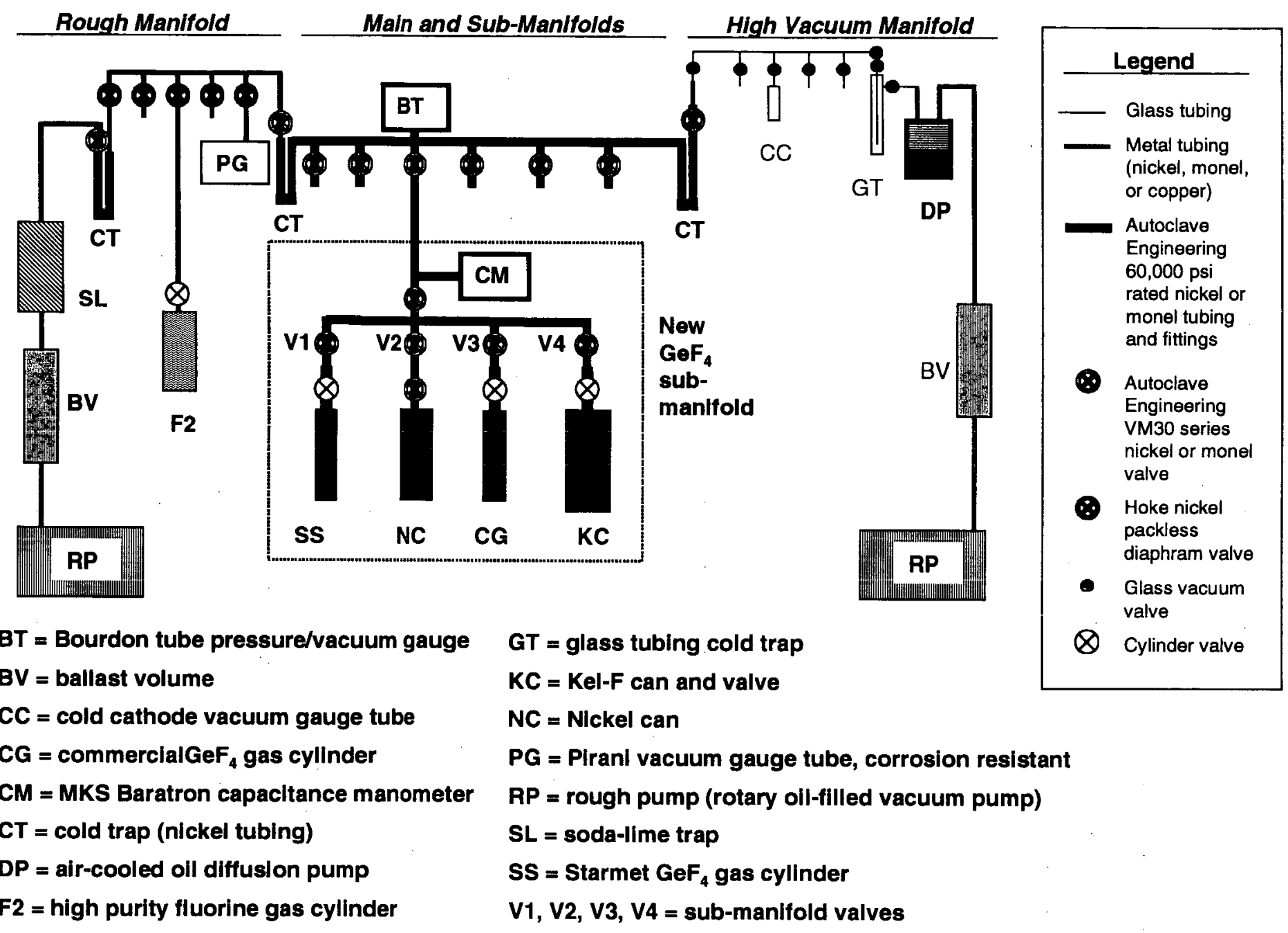

Figure 1. Schematic diagram of $\mathrm{GeF}_{4}$ gas handling system. 
As noted in Fig. 1, our $\mathrm{GeF}_{4}$ gas handling system consists of

- A rough vacuum $\left(\sim 10^{-3}\right.$ torr $)$ manifold constructed from nickel, monel, and copper fittings and tubing

- A main manifold constructed out of Autoclave Engineers high pressure fittings

- A high vacuum $\left(\sim 10^{-6}\right.$ torr $)$ glass and metal vacuum manifold

- A sub-manifold constructed from Autoclave Engineers high pressure tubing and fittings and that contains a high accuracy capacitance manometer

The rough, main, and high vacuum manifolds were originally constructed for studies involving $\mathrm{WF}_{6}$ and $\mathrm{WF}_{6}$ that contained trace level $\mathrm{UF}_{6}$. It subsequently has been heated with both hydrogen and fluorine gases to remove tungsten and uranium fluorides from its surfaces and repassivate its nickel and monel surfaces. The sub-manifold was constructed specifically for use with $\mathrm{GeF}_{4}$. Its 1000 torr full scale $\mathrm{MKS}$ Baratron capacitance manometer is a model $629 \mathrm{~B} 13 \mathrm{TACJ} 2 \mathrm{~B}$. It is an absolute pressure sensor and has a dynamic range of $\sim 10^{5}$ and accuracy of $0.12 \%$. Gases contact only Inconel, its internal volume is 6.3 cubic centimeters, and its sensor is thermostated at $45 \mathrm{C}$. The voltage output of the manometer was displayed on a Keitheley model 197 5-1/2 digit digital voltmeter. The Autoclave Engineers (AE) tubing ("nipples") used in constructing the main and sub-manifolds was $3 / 8$ inch od and $1 / 8$ inch id nickel or monel. The AE fittings use metal-metal contact seals that employee a cone and taper principle. The nickel or monel AE valves are 30VM series and are all metal-construction aside from PTFE packing on their non-rotating stems. The relatively small diameter of the fittings minimizes the internal volume of manifold sections. The fluorine gas used for passivation of the main and sub-manifolds had been purified by fractional distillation at cryogenic temperature. The commercial $\mathrm{GeF}_{4}$ that we used was purchased from Advance Research Chemicals, Inc, (Catoosa, OK) and was specified to be $99.99 \%$ pure by its manufacturer.

During commissioning of a new nickel or monel-based manifold section, it is first He leaked tested, then filled with hydrogen gas and heated to reduce any surface metal oxides. It is pumped out and filled with a few torr of fluorine gas. It is then heated to fluorine-passivate the metal surfaces and pumped out. This fluorine-passivation procedure is repeated with increasing fluorine pressures to ensure formation an adherent passivation layer. Metal surfaces in the sub- 
manifold that contact $\mathrm{GeF}_{4}$ were passivated by exposure to commercial high purity $\mathrm{GeF}_{4}$. Submanifold sections exposed to the atmosphere (such as those between manifold and cylinders valves, when a cylinder is removed), after being thoroughly evacuated following such exposure, are then re-passivated by exposure to commercial $\mathrm{GeF}_{4}$ gas and then thoroughly evacuated.

\section{Nickel Gas Cell Assembly}

The nickel gas cell assembly that we have used for our ultraviolet and near-infrared spectral studies is shown in Figs 2, 3, and 4. These are several views of the cell assembly from different angles. The numbered divisions of the ruler in Figs 3 and 4 are spaced by $1 \mathrm{~cm}$. The cell assembly is constructed of nickel and monel tubing and fittings and is equipped with single crystal aluminum oxide (sapphire) windows. The rim of each window was metalized and then brazed onto a thin metal transition flange that in turn was welded to the main cell body. The cell assembly originally was used in a flow loop so it was equipped with an inlet tube near one end window and an outlet tube near the other end window. For use as a static gas cell, a plug was welded onto the end of one of these tubes and the other was machined down to $3 / 8$ inch outer diameter (od). A 3/8 inch Swagelok "tee" connector was added to which was attached a Hoke 413A all-metal packless diaphragm valve and a $3 / 8$ inch od tube bent into an " $L$ " shape and into whose opposite end was welded a plug. An Autoclave Engineers 3/8 inch od "nipple" fitting was welded to the Hoke valve to facilitate connection of the gas cell assembly to the vacuum systems

such as our $\mathrm{GeF}_{4}$ vacuum system. The "L"-shaped tube is used as a side arm that can be immersed in a cryogenic fluid, such as liquid nitrogen, to freeze out the gas in the cell and so remove it from the optical path length of the cell. The oblique view in Fig 2 shows the cell resting on a right angle aluminum support. The "L" -shaped tube is to the left and the Hoke valve is above the cell body. The Autoclave Engineers fitting is above the Hoke valve and is capped with a PTFE cap to prevent dust from entering the interior of the fitting The only materials that gas contacts in the nickel gas cell assembly are nickel, monel, and single crystal aluminum oxide. 


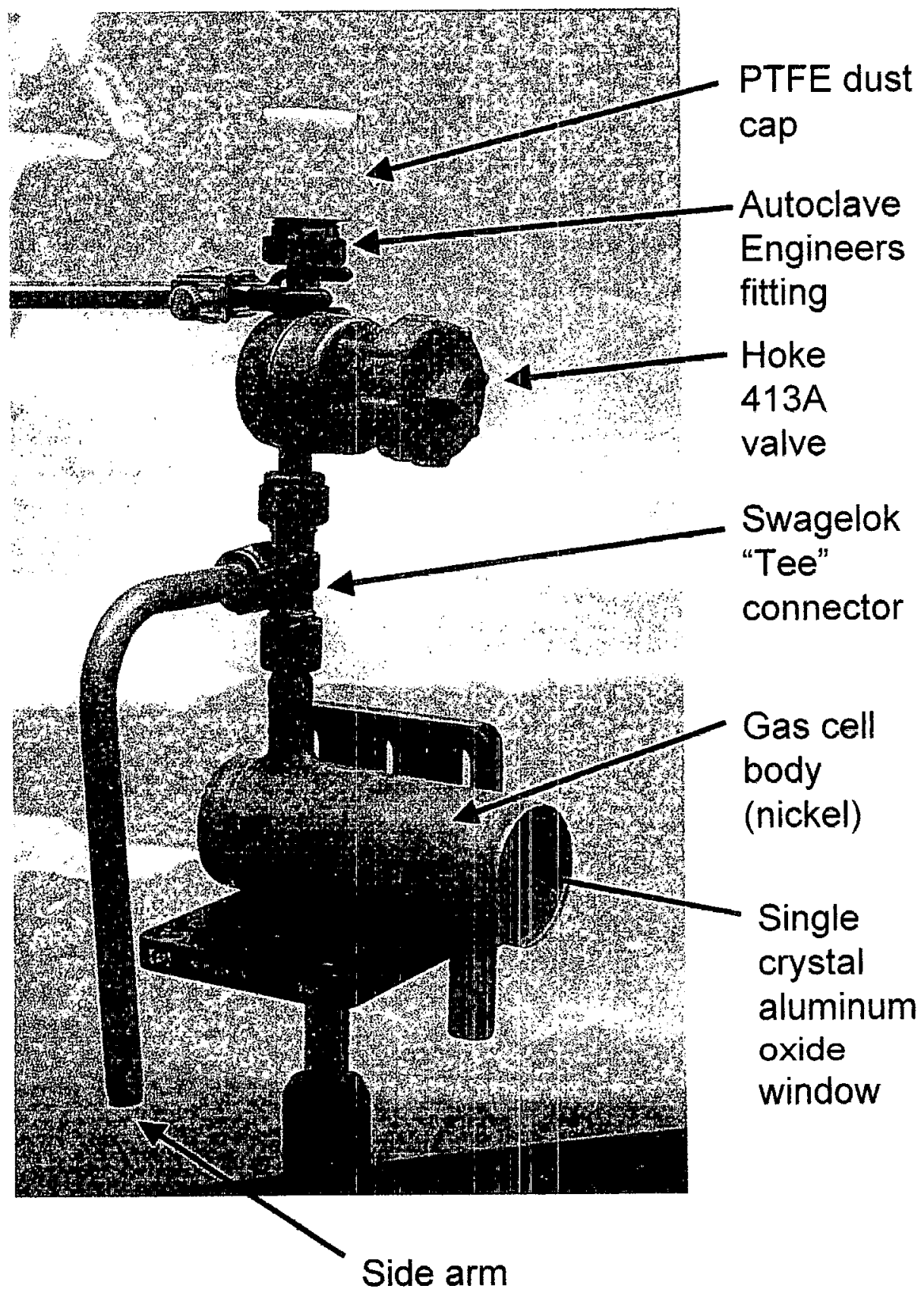

Fig. 2. Oblique view of nickel gas cell assembly. 


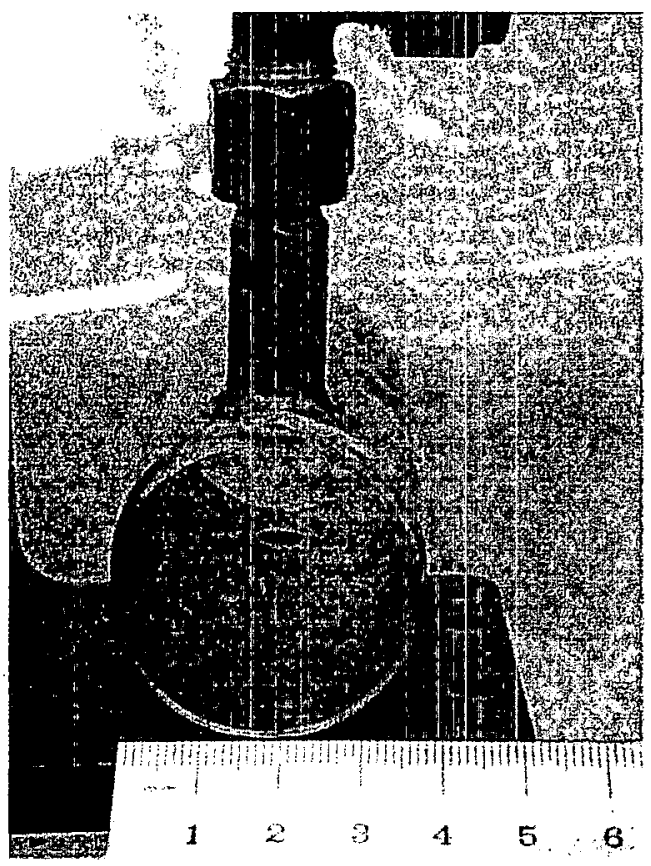

Fig. 3. End on view through single crystal aluminum oxide window on nickel gas cell.

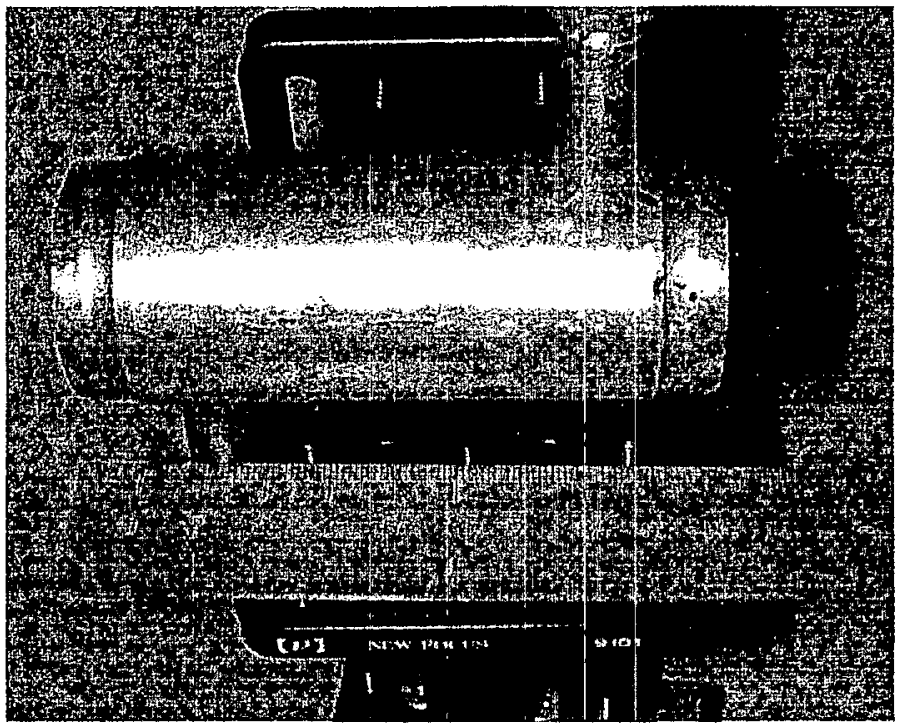

Fig. 4. Side view of nickel gas cell assembly. 


\section{Ultraviolet Absorption Spectrum of Starmet-Produced $\mathrm{GeF}_{4}$}

The $200 \mathrm{~nm}$ to $400 \mathrm{~nm}$ absorption spectrum of the nickel gas cell that contained 713 torr (at 298 $\mathrm{K}$ ) of Starmet-produced $\mathrm{GeF}_{4}$ was recorded digitally three times on a Olis-converted Cary 17 dual beam optical spectrometer with the side arm of the cell at ambient temperature. Without moving the cell, the side arm of the cell was immersed in liquid nitrogen and the absorption spectrum of the cell was recorded three times again. Immersing the side arm of the cell in liquid nitrogen freezes out $\mathrm{GeF}_{4}$ and removes it from the optical path length of the cell. The arithmetic mean of each of these two sets of spectra was calculated. The resulting mean spectrum of the cell with liquid nitrogen on its side arm was subtracted from the mean spectrum of the cell with Starmet-produced $\mathrm{GeF}_{4}$ in its optical path. The resulting "differential" absorption spectrum shown is Fig. 5. This is the absorption spectrum of the Starmet-produced $\mathrm{GeF}_{4}$ plus residual noise and any systematic baseline deviations. Based on the literature [lb] one expects $\mathrm{UF}_{6}$ to absorb most strongly at $214 \mathrm{~nm}$ in a band whose width is approximately $30 \mathrm{~nm}$ (see Fig 6 and note that the wavelength scales for Figs 5 and 6 differ). There is no evidence of such a peak in Fig 5 and in consequence we conclude that observable amounts of $\mathrm{UF}_{6}$ were not present in the Starmet-produced $\mathrm{GeF}_{4}$ sample that we investigated. We can provide an upper bound for the amount of $\mathrm{UF}_{6}$ based on the reported molar absorptivity of $\mathrm{UF}_{6}$ gas at $273 \mathrm{~K}$ [1b], which is 3200 (mole/liter) ${ }^{-1} \mathrm{~cm}^{-1}$, the noise level in the differential absorption spectrum, and the concentration of $\mathrm{GeF}_{4}$ in the gas cell. The overall pattern of the differential absorption spectrum (decrease from a positive deviation at $200 \mathrm{~nm}$ to a negative deviation maximum near $230 \mathrm{~nm}$ followed by a positive deviation and then a gradually decreasing deviation into negative values at $400 \mathrm{~nm}$ was present when any of the three as-recorded spectra of the cell with its side arm in liquid nitrogen was subtracted from any of the as-recorded spectra with the cell side arm at ambient temperature. 


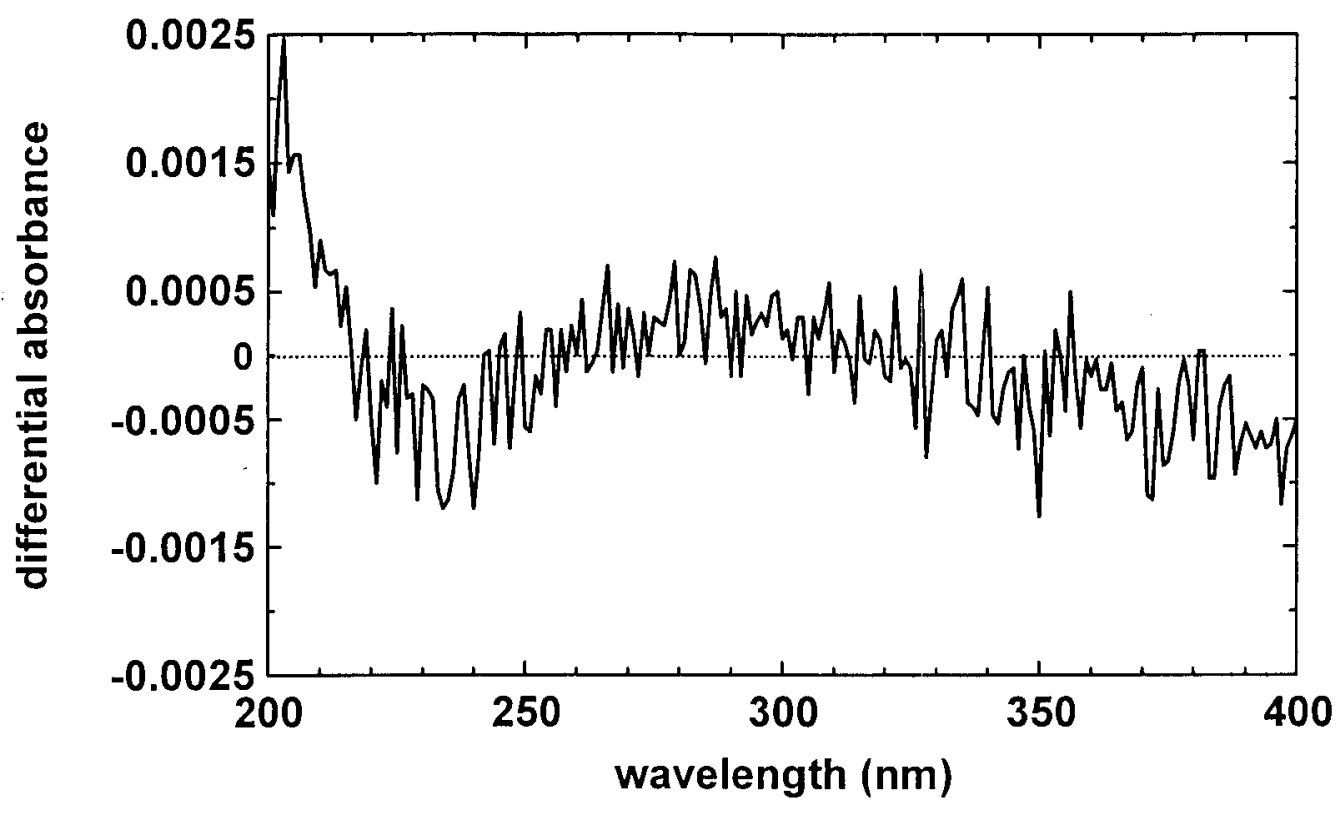

Fig. 5. Absorption spectrum of 713 torr of Starmet-produced $\mathrm{GeF}_{4}$ shows no evidence of $\mathrm{UF}_{6}$ or other gases that absorb significantly in the ultraviolet.

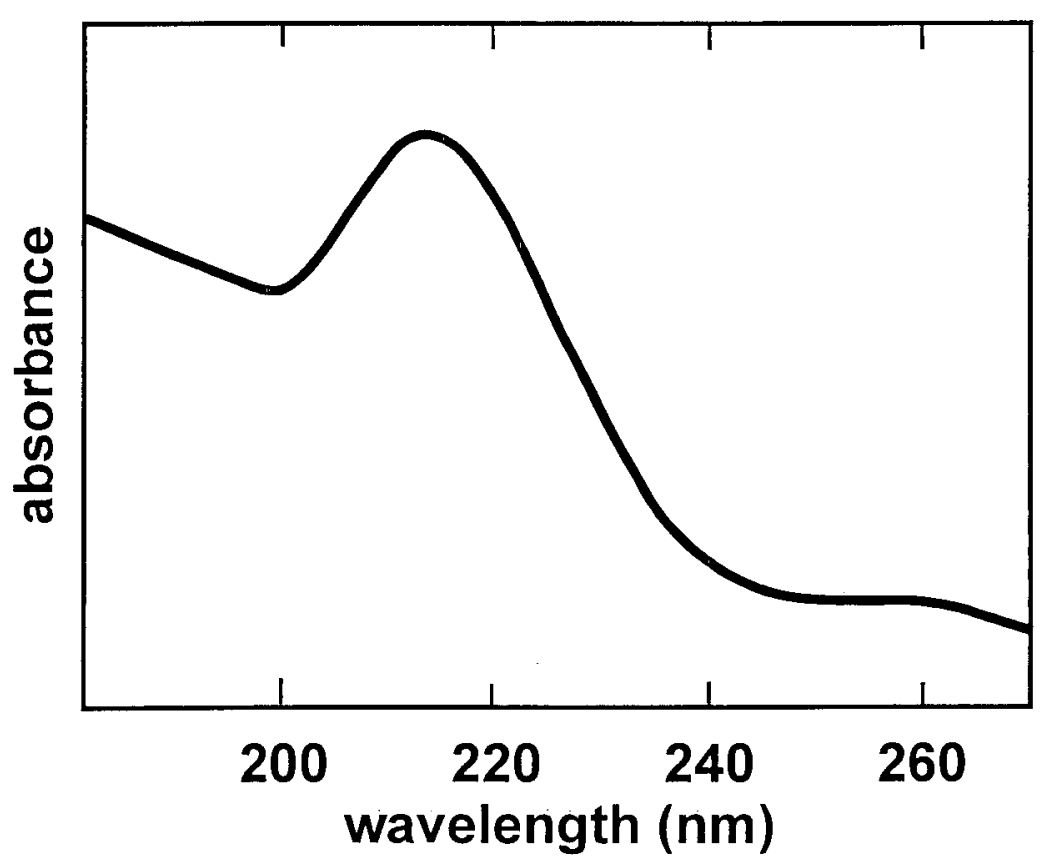

Fig. 6. Strongest ultraviolet absorbing band of $\mathrm{UF}_{6}$ gas at $273 \mathrm{~K}$ as reported by R. McDiarmid [1b]. 
This suggests that the slight change in index of refraction due to the presence or absence of $\mathrm{GeF}_{4}$ gas at approximately one atmosphere pressure in the cell is the cause of such systematic baseline deviations. For this reason, the standard deviation for our absorption measurement was calculated using the data from $250 \mathrm{~nm}$ to $350 \mathrm{~nm}$ in Fig 5 and is $2.84 \times 10^{-4}$ absorbance units. The concentration of $\mathrm{GeF}_{4}$ in the cell was $0.0383 \mathrm{M}$. If one uses three times the observed standard deviation of the measurement as the "limit of detection" criterion, then the largest concentration of $\mathrm{UF}_{6}$ that might have been present without our detecting it would have been

$$
\left(2.84 \times 10^{-4} \times 3\right) /\left(3200 \mathrm{M}^{-1} \mathrm{~cm}^{-1} \times 9.3 \mathrm{~cm}\right)=2.86 \times 10^{-8} \mathrm{M} \mathrm{UF}_{6}
$$

where $9.3 \mathrm{~cm}$ is that gas path length of our nickel gas cell. The concentration of $\mathrm{GeF}_{4}$ in the gas cell was $3.83 \times 10^{-2} \mathrm{M}$. This means that the Starmet-produced $\mathrm{GeF}_{4}$ gas contained less than

$$
\left(2.86 \times 10^{-8} \mathrm{M} / 3.83 \times 10^{-2} \mathrm{M}\right)\left(1 \times 10^{6}\right)=0.75 \mathrm{ppm} \mathrm{UF}_{6}
$$

on a volume basis relative to $\mathrm{GeF}_{4}$.

\section{Investigation of Initial Pressure Loss}

\section{Observation of a Small Initial Pressure Loss}

We observed a small loss of gas pressure when Starmet-produced $\mathrm{GeF}_{4}$ gas was introduced into the sub-manifold + capacitance manometer section of our gas line. That gas was pumped out briefly and additional Starmet-produced $\mathrm{GeF}_{4}$ was introduced into the sub-manifold. Very little pressure loss was observed (less than 0.1 torr in 3 minutes) so the sub-manifold was again briefly pumped on, the valve to the evacuated nickel gas cell was opened, and a nearly atmospheric pressure amount of Starmet-produced $\mathrm{GeF}_{4}$ was introduced into the sub-manifold + capacitance manometer + nickel gas cell. The pressure values reported by the capacitance manometer were recorded periodically and are shown in Fig 7. It is evident that there was a small but very rapid initial pressure drop followed by a period during which a smaller pressure drop occurred and the loss of pressure decreased at a nearly exponential rate that was 0.137 minute $^{-1}$. After 

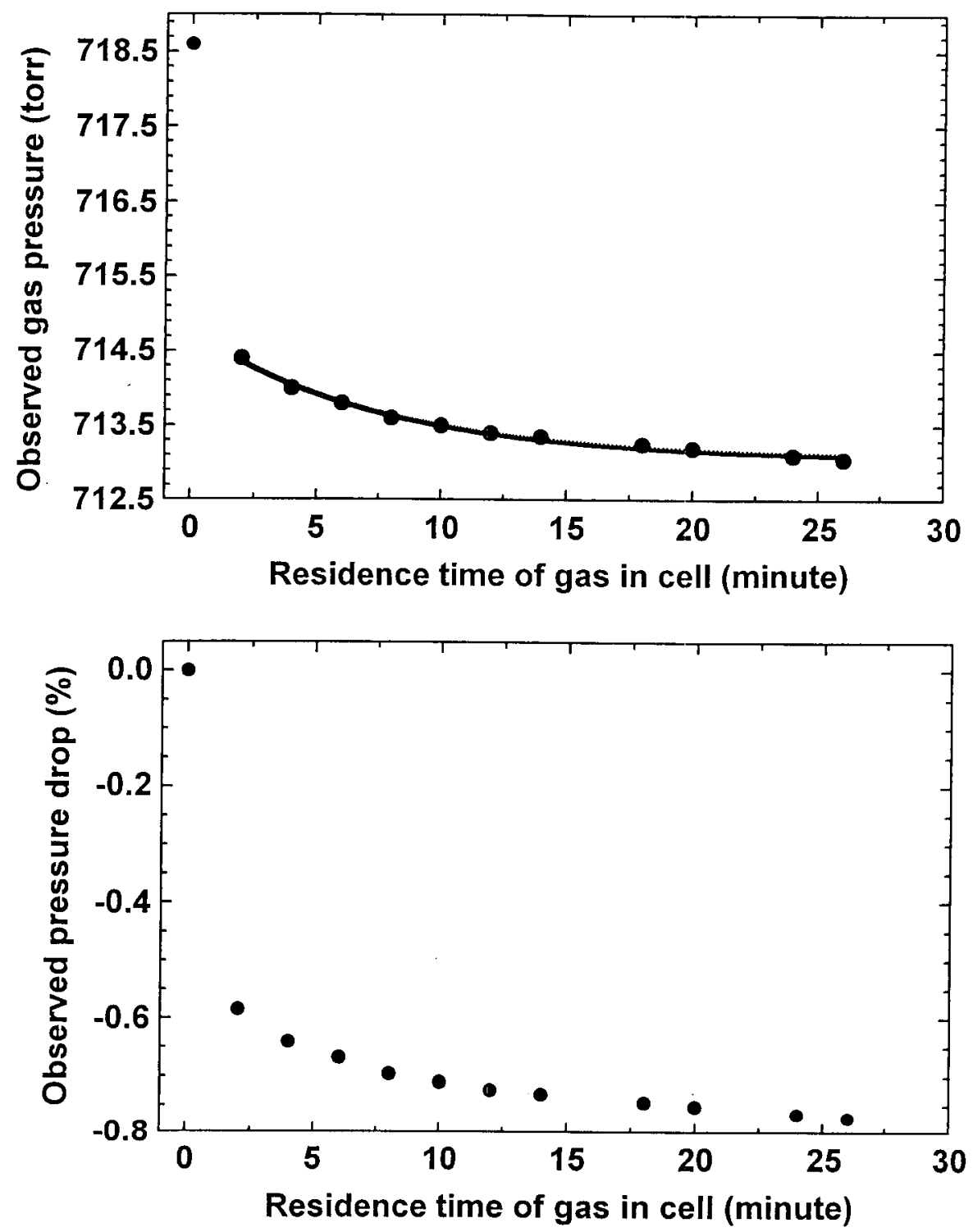

Fig. 7. Pressure drop observed upon introduction of Starmet-produced $\mathrm{GeF}_{4}$ into the sub-manifold + capacitance manometer + nickel gas cell volumes which had been passivated by previous exposure to commercial high purity $\mathrm{GeF}_{4}$ and then evacuated. The upper panel shows the observed pressure (symbols) and a fit (solid line) to a part of that data using a single exponential decay model:

$$
P_{\text {obs }}=713.06+1.7096 \exp (-0.1366 t)
$$

where $P_{o b s}$ is the observed pressure in torr and $t$ is time in minutes. The lower panel shows the same observed data plotted as percent pressure change from the time that the gas was introduced into the cell. 
26 minutes residence time, the gas pressure was nearly independent of time and $\sim 0.8 \%$ of the initial gas pressure had been lost. The nickel gas cell was valved off and the sub-manifold pumped out. The nickel gas cell was transferred to the sample compartment of a UV-VIS dual beam optical spectrometer where the ultraviolet absorption spectra discussed above were recorded and then to an FT-IR spectrometer where near-infrared absorption spectra were recorded because it seemed likely that the observed pressure drop was due to the presence of hydrogen fluoride (HF) gas. If this is the case, then the observed behavior suggests that HF in the $\mathrm{GeF}_{4}$ was sorbed onto the metal fluoride passivation layer on interior of the nickel gas cell. The sorbed HF presumably generated a metal fluoride-HF adduct layer that retarded further sorption of HF and thereby resulted in diffusion-limited sorption of additional HF until an equilibrium between gas and surface-bound HF was reached.

\section{Near-Infrared Absorption Spectrum of Starmet-Produced $\mathrm{GeF}_{4}$}

Near-infrared absorption spectra of the nickel gas cell that contained 713 torr of $\mathrm{GeF}_{4}$ were recorded on a Nicole Magna 860 Fourier transform infrared (FT-IR) spectrometer which is a nitrogen gas purged, single beam instrument that was operated at $1 \mathrm{~cm}^{-1}$ spectral resolution $(0.5$ $\mathrm{cm}^{-1}$ data point spacing). The spectrometer was equipped with a calcium fluoride beamsplitter and a KBr-windowed DTGS pyroelectric detector. The spectral range $1700 \mathrm{~cm}^{-1}$ to $5000 \mathrm{~cm}^{-1}$ was scanned and 128 sweeps of that range were averaged. Because our nickel gas cell assembly, when mounted in the sample compartment, did not allow closing the sample compartment cover, we used a "tent" made of plastic sheeting over the open sample compartment to improve nitrogen gas purging of the sample compartment. This reduced, but did not eliminate, interference from atmospheric water vapor and carbon dioxide. The only infrared absorbing gas observed within the nickel gas cell was hydrogen fluoride (HF). The P-branch transitions from its ground vibrational state to its first excited vibrational state were overlapped by residual atmospheric water vapor lines. Its R-branch lines, however, were free of such interference. The portion of spectra recorded over the R-branch region are shown in Fig 8. Fig 8a shows the spectrum observed with 713 torr of Starmet-produced $\mathrm{GeF}_{4}$ in the nickel gas cell. The nickel gas cell then was put back on the $\mathrm{GeF}_{4}$ vacuum line and evacuated to less than 0.1 torr through the rough vacuum manifold and pumped on with the high vacuum manifold system for a few minutes. The gas cell was put back in the FT-IR spectrometer, the sample compartment was purged with nitrogen gas, and spectra were recorded. An example of those spectra is shown in Fig 8b. The 


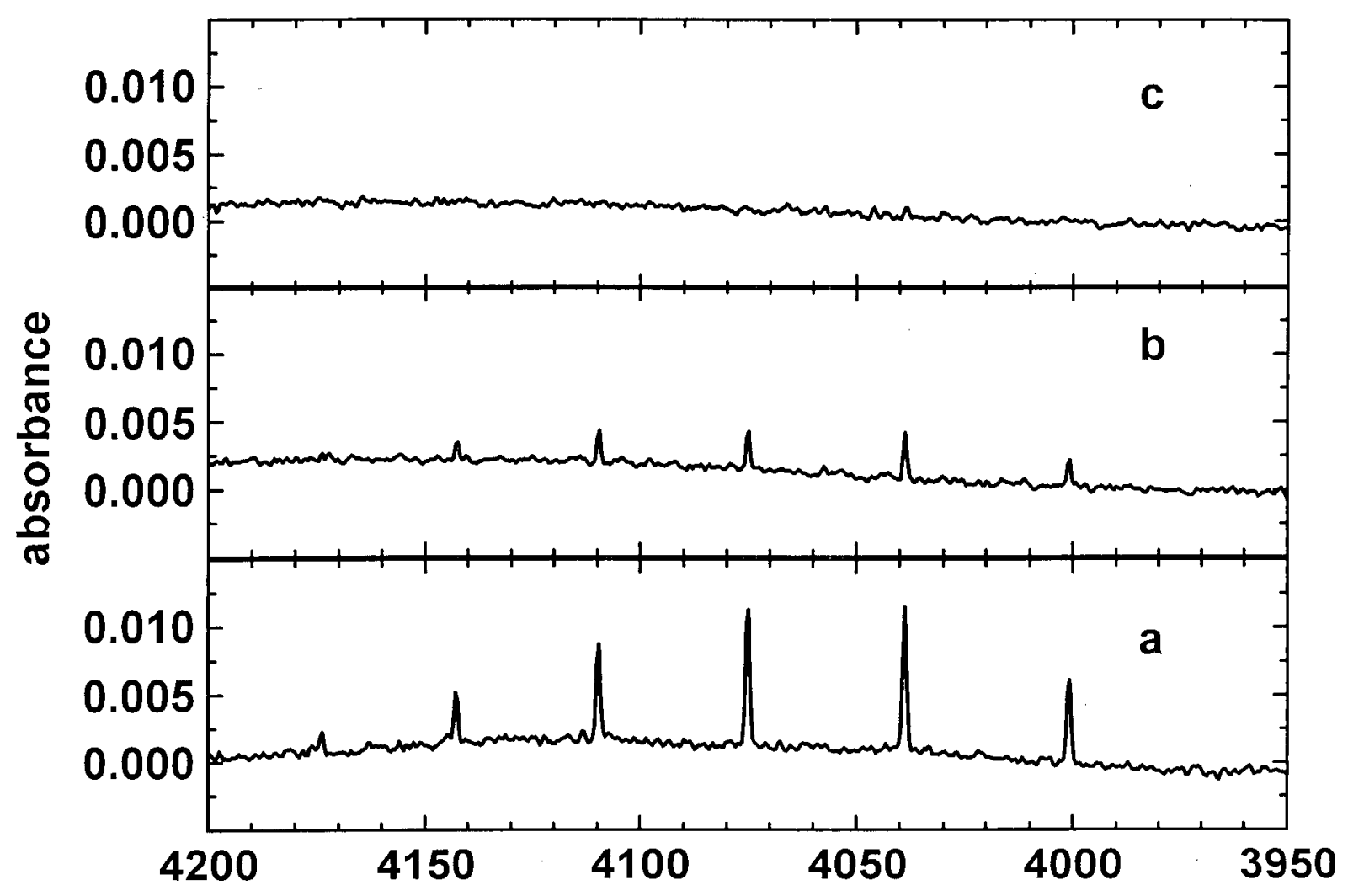

Fig 8. Portion of the observed FT-IR absorption spectrum of a) 713 torr of Starmet-produced $\mathrm{GeF}_{4}$ in the nickel gas cell shown in Figs 2, 3 and 4,b) the nickel gas cell after pumping out the Starmet-produced $\mathrm{GeF}_{4}$ for a few minutes, and c) the nickel gas cell after 15 hours of evacuation. To facilitate comparison, a constant has been subtracted from each of the above spectra to bring the trace start or end to zero absorbance. The 6 equally spaced absorbance peaks in panel a are R-branch vibration-rotation bands of hydrogen fluoride $(\mathrm{HF})$ gas as are the narrow peaks at the same wavenumber values in panel $\mathbf{b}$. 
nickel gas cell was returned to the vacuum line and pumped on with the high vacuum manifold system for 15 hours. It was then put back in the FT-IR spectrometer, the sample compartment was purged with nitrogen gas, and spectra were recorded. An example of one of those spectra is shown in Fig 8c. It is clear from the spectra shown in Fig 8 that

- Hydrogen fluoride (HF) gas was present in the nickel gas cell filled with Starmetproduced $\mathrm{GeF}_{4}$

- Prolonged pumping on that gas cell was necessary to remove observable HF from the cell.

Unfortunately, the recorded FT-IR spectra do not provide a quantitative measure of the amount of HF in the nickel gas cell. At low pressure and $298 \mathrm{~K}$, the true width of an R-branch HF vibration-rotation line is $0.011 \mathrm{~cm}^{-1}$ based on the usual expression for the Doppler width of a transition of a gas phase absorber [5]. At higher pressure (a few torr total pressure) pressure broadening increases the true width of these transitions and what was a nearly Gaussian line shape tends toward Lorentzian. At atmospheric pressure, the line width is dominated by pressure broadening effects and the line shape is nearly Lorentzian.

Because the spectral resolution of our FT-IR is poor compared to the true line width of R-branch HF lines at any of the gas pressures used in our work, the observed absorbances will not follow Beers law. For example, the observed absorbance of a given HF R-branch line in Fig $8 \mathrm{~b}$ is smaller than that for the same line in Fig 8a. However, the HF partial pressure in the gas cell may have been larger in the case of Fig $8 \mathrm{~b}$ than it was in the case of Fig 8a. At low pressure and with spectral resolution that is less than the true line width, very little of the analysis light will be absorbed near an HF R-branch line because the line shape for those lines will be Gaussian. At atmospheric pressure, the line shape becomes nearly Lorentzian. A Lorentzian line shape decreases more slowly as one moves away from line center than is the case for a Gaussian line shape, For this reason, two gas samples with equal HF partial pressures, but differing total pressures, will exhibit differing observed absorbance values for HF R-branch lines under our 
experimental conditions such that the largest absorbance will occur for the sample whose total pressure is highest.

The traditional method for making quantitative measurement of absorbing gas concentration under these experimental conditions is preparation of a series of gas samples in which the partial pressure of the absorbing gas and an inert broadening gas are systematically varied. The absorption spectra of these gas samples are recorded at a fixed spectral resolution. Plotting either the observed peak or integrated line intensities as a function of absorbing and total gas pressures generates calibration curves that can be used with samples to be analyzed. Unfortunately, HF

self-associates with increasing HF partial pressure and it adsorbs on most surfaces. For these reasons, preparation of a series of gas samples of known HF partial pressure and total gas pressure is extremely difficult and we have not attempted it.

\section{Preparation and Characterization of Glassy $\mathrm{GeO}_{2}$}

Our experimental work in this area has focussed on determining the conditions under which visually clear, colorless, bubble-free glassy $\mathrm{GeO}_{2}$ can be produced that is suitable for quantitative uranyl analysis via LIF and the standard addition method. Our past work [6] largely centered on development of laser-induced fluorescence analysis for detection of uranyl in $\mathrm{GeO}_{2}$. It identified two problems. These were difficulty in preparing glassy $\mathrm{GeO}_{2}$ at the level of 1 gram of $\mathrm{GeO}_{2}$ that was free from crystalline inclusions and that contained no trapped air bubbles. The $\mathrm{GeO}_{2}$ that we used was specified by its manufacturer (Alfa) to be $99.999 \%$ pure on a metals basis. Physically, this material is a white, finely divided powder. We confirmed that it is largely the hexagonal form of $\mathrm{GeO}_{2}$ by the heat evolved as it underwent dissolution in hydrofluoric acid [3]. We detected the presence of tetragonal phase $\mathrm{GeO}_{2}$ in that a small fraction of this material did not dissolved in $25 \%$ hydrofluoric acid solution.

We varied a number of factors in our preparations of glassy $\mathrm{GeO}_{2}$. These factors included:

- The $\mathrm{pH}$ and composition of the aqueous phase in contact with powdered $\mathrm{GeO}_{2}$ immediately prior to heating. Specifically, commercial $\mathrm{GeO}_{2}(\mathrm{Alfa}, 99.999 \%$ pure metals basis) was contacted with nitric acid, high purity water, and concentrated ammonium hydroxide. 
- The melting temperature used and the time at the melt temperature

- The crucible material (platinum, polycrystalline alumina, and single crystal aluminum oxide) and whether or not the crucible was covered during heating.

- The presence or absence of added uranyl nitrate.

Visually clear, colorless, bubble-free glassy $\mathrm{GeO}_{2}$ was produced from $\mathrm{GeO}_{2}$ that had been immersed in concentrated ammonium hydroxide solution, dried under a stream of dry nitrogen gas, and then loaded into a shallow square crucible formed from 0.002 inch thick platinum foil. This crucible was placed in an alumina boat and that assermbly was placed within a horizontal tube furnace and heated to $1400^{\circ} \mathrm{C}$. After being held at $1400^{\circ} \mathrm{C}$ for the desired time, the sample was quickly withdrawn from the hot zone of the furnace by pulling on a platinum wire attached to the alumina boat. Contacting $\mathrm{GeO}_{2}$ powder with concentrated ammonium hydroxide likely produced a gel layer on the surface of the $\mathrm{GeO}_{2}$ particles and thereby promoted reduced viscosity and increased gas permeability. As detailed below, however, it gave rise to other, luminescencerelated problems

Rapid withdrawal of the sample from the hot zone prevented the formation of crystalline inclusions that we sometimes had observed when samples were cooled within the furnace at its natural rate following cut off of electrical current to its heating elements. The key to suppressing crystallization of $\mathrm{GeO}_{2}$ is the rapidity with which molten $\mathrm{GeO}_{2}$ is cooled to below its glass transition temperature $\left(\sim 500{ }^{\circ} \mathrm{C}[7]\right)$ and, based on literature reports [7], more particularly, the rate at which it is cooled from $1000{ }^{\circ} \mathrm{C}$ to $800^{\circ} \mathrm{C}$. Using a platinum wire attached to an alumina boat, we rapidly pulled the $\mathrm{GeO}_{2}$ fusion crucibles in the alumina boat out of the hot zone of the furnace. Our horizontal tube furnace is equipped with a round Coors high purity alumina process tube. The platinum wire was threaded through a small hole bored through an insulating plug that is inserted into the alumina process tube. The small $\mathrm{GeO}_{2}$ fusion crucibles in the alumina boat could be withdrawn in a few seconds from the heated zone of the furnace into a relatively cool, unheated zone of the alumina process tube. We have found that this suppressed crystallization in all of the $\mathrm{GeO}_{2}$ samples that were prepared using this cooling method. 


\section{Laser-induced Fluorescence Characterization}

The glassy $\mathrm{GeO}_{2}$ that we produced was characterized as to its luminescence properties using the laser-induced fluorescence techniques and apparatus described in our March 19, 2001 progress report. Briefly, we used $355 \mathrm{~nm}$ pulses from a frequency tripled, Q-switched Nd:YAG laser as the excitation light source and recorded luminescence emission spectra and lifetimes at ambient temperature.

Fig 9 compares some of the observed emission spectra for $\mathrm{GeO}_{2}$ samples heated to $1400{ }^{\circ} \mathrm{C}$ for 4 hours. The red curve shows emission due to the uranyl ion that peaks at $536 \mathrm{~nm}$ in glassy $\mathrm{GeO}_{2}$. Treatment of $\mathrm{GeO}_{2}$ powder with nitric acid followed by drying in a $110^{\circ} \mathrm{C}$ oven generates nearly the same emission spectrum peaking at $620 \mathrm{~nm}$ as seen upon heating untreated $\mathrm{GeO}_{2}$ powder except that the observed intensity is much more larger. This emission band is so intense that in a similarly nitric acid-treated sample that contained $0.1 \mathrm{ppm}$ uranium, no uranyl emission was observable. As noted above, treatment of $\mathrm{GeO}_{2}$ powder with concentrated ammonium hydroxide gives a visually clear, colorless, and bubble-free glass when heated to $1400{ }^{\circ} \mathrm{C}$. Unfortunately, it also generates a broad, intense emission band peaking near $650 \mathrm{~nm}$ (Fig 9, blue curve).

The broad intense red emission bands likely arise from thermal reduction of tetravalent Ge to divalent Ge. These impurity luminescence bands spectrally overlap luminescence from uranyl in glass $\mathrm{GeO}_{2}$ as is evident in Fig 9. Fig 10 compares the luminescence decays observed from glassy $\mathrm{GeO}_{2}$ that contained $11 \mathrm{ppm}$ uranium and from a clear, colorless, bubble-free sample of glassy $\mathrm{GeO}_{2}$ made from $\mathrm{GeO}_{2}$ powder that been treated with concentrated ammonium hydroxide. As is evident in Fig 11, there is not a sufficiently large difference in lifetime between uranyl ions and the impurity species to enable effective discrimination against the strong luminescence from impurity species that form when $\mathrm{GeO}_{2}$ treated with nitric acid or concentrated ammonium hydroxide is heated to $1400^{\circ} \mathrm{C}$ for prolonged periods. 


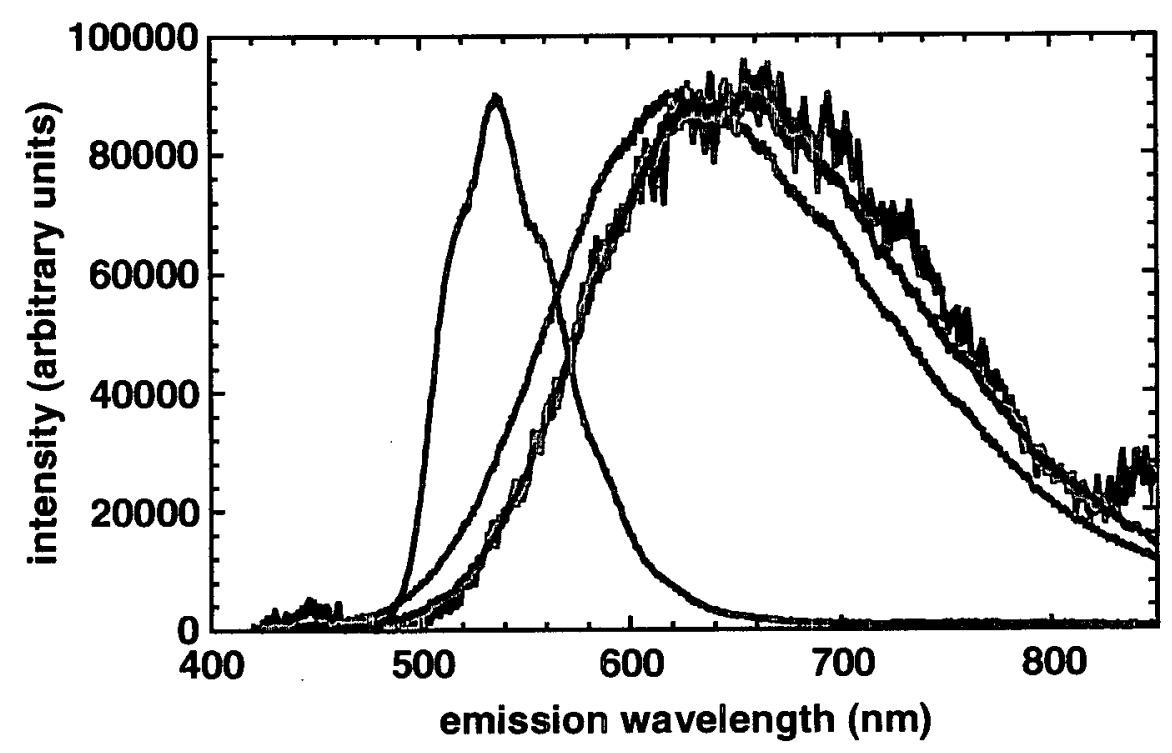

Fig. 9. Comparison of the observed emission spectra, recorded at $295 \mathrm{~K}$ following pulsed 355 $\mathrm{nm}$ excitation, from glassy $\mathrm{GeO}_{2}$ that had been heated to $1400^{\circ} \mathrm{C}$ and contained $11 \mathrm{ppm}$ uranium (red curve) or contained no uranium (green curve). The black curve is that for $\mathrm{GeO}_{2}$ treated with nitric acid and then heated to $1400^{\circ} \mathrm{C}$. The blue curve is that for $\mathrm{GeO}_{2}$ treated with concentrated ammonium hydroxide and then heated to $1400^{\circ} \mathrm{C}$. The spectra have been scaled to equal peak intensity to facilitate comparison.

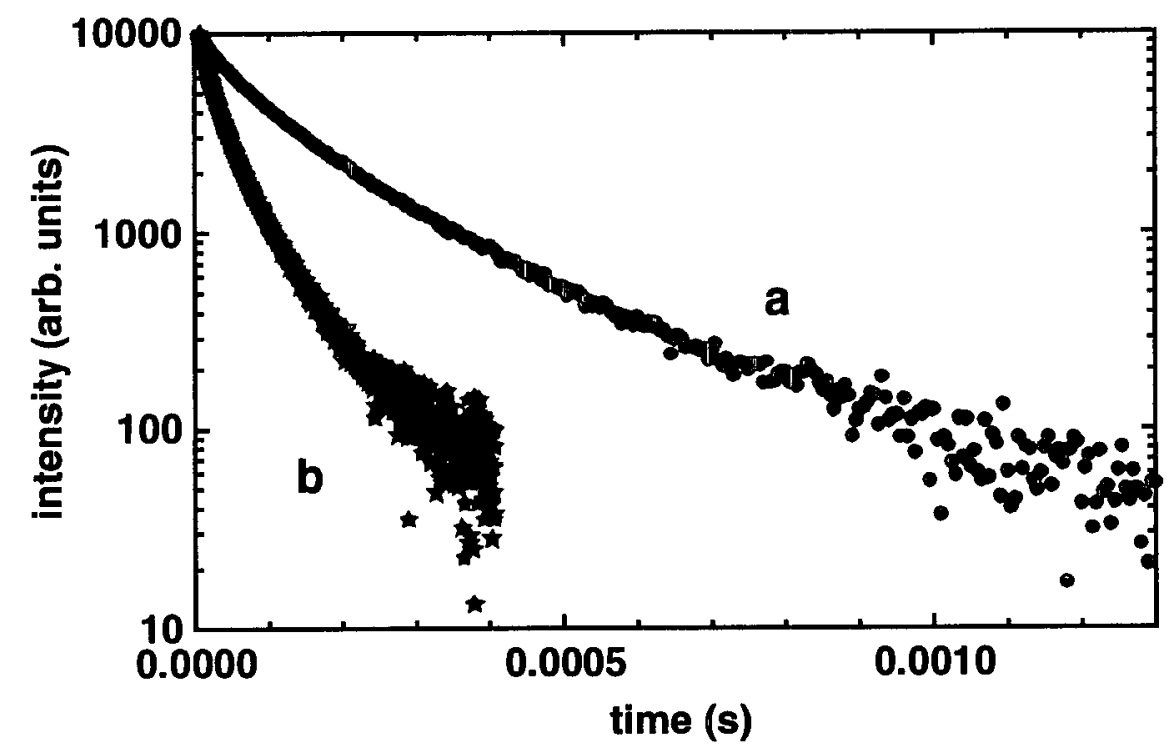

Fig. 10. Comparison of the observed luminescence decays at $295 \mathrm{~K}$ following pulsed 355 $\mathrm{nm}$ excitation of glassy $\mathrm{GeO}_{2}$ that contained $11 \mathrm{ppm}$ uranium and had been heated to $1400{ }^{\circ} \mathrm{C}$ (curve a, red symbols) and glassy $\mathrm{GeO}_{2}$ prepared by heating $\mathrm{GeO}_{2}$ that had been treated with concentrated ammonium hydroxide prior to being heated to $1400^{\circ} \mathrm{C}$ (curve b, black symbols). 
Melting $\mathrm{GeO}_{2}$ in alumina or single crystal aluminum oxide did not significantly alter the ingrowth of the impurity specie or species that gives rise to the red luminescence that strongly interferes with ultratrace determination of uranyl in glassy $\mathrm{GeO}_{2}$. Holding a given $\mathrm{GeO}_{2}$ sample at $1400{ }^{\circ} \mathrm{C}$ for increasingly longer times in any of the crucibles investigated increased the intensity of impurity species luminescence following $355 \mathrm{~nm}$ excitation.

\section{Ultratrace Uranium Analysis Using a Chloride Volatility Approach}

Given difficulties in producing glassy $\mathrm{GeO}_{2}$ of acceptable quality for quantitative uranyl luminescence analysis, we began a search for alternate, but related methods of achieving our goal of improved ultratrace analysis for $\mathrm{UF}_{6}$ in $\mathrm{GeF}_{4}$ gas. We have identified a promising method that does not require high temperature processing and so is likely to be more easily and economically implemented in a quality assurance laboratory.

Our new approach retains the same initial step, namely, hydrolysis of $\mathrm{GeF}_{4}$ gas in water to generate $\mathrm{GeO}_{2}, \mathrm{H}_{2} \mathrm{GeF}_{6}$, and $\mathrm{HF}$, and the same second processing step, namely sub-boiling point distillation of volatile species. Our new approach then dissolves the resulting non-volatile residue $\left(\mathrm{GeO}_{2}\right.$ and uranyl fluoride, if any $\mathrm{UF}_{6}$ was present in the $\left.\mathrm{GeF}_{4}\right)$ in concentrated hydrochloric acid. This converts $\mathrm{GeO}_{2}$ to volatile $\mathrm{GeCl}_{4}$ that is removed, along with excess hydrochloric acid, by a second sub-boiling point distillation step. The residue (uranyl chloride and trace amounts of $\mathrm{GeO}_{2}$ ) is taken up in dilute phosphoric acid solution. The uranium content of the resulting solution is quantified by laser-induced fluorescence and the standard addition method. This new approach will permit use of $266 \mathrm{~nm}$ excitation which has the advantage of being more strongly absorbed by uranyl in dilute phosphoric acid than is light at $337 \mathrm{~nm}$ (nitrogen laser) or $355 \mathrm{~nm}$ (tripled Nd:YAG laser) [8].

Our new approach removes most of the fluoride content of $\mathrm{GeF}_{4}$ in the first sub-boiling point distillation. To remove any remaining fluoride and all but traces of germanium, $\mathrm{GeO}_{2}$ from hydrolysis of $\mathrm{GeF}_{4}$ is reacted with excess concentrated hydrochloric acid solution. This generates $\mathrm{GeCl}_{4}$ and converts any fluoride into $\mathrm{HF}$. Pure $\mathrm{GeCl}_{4}$ is a rather volatile liquid whose boiling point is $83.1^{\circ} \mathrm{C}$ [3]. Due to its significant vapor pressure [9], volatilization of $\mathrm{GeCl}_{4}$ from concentrated hydrochloric acid has been used as a means of purifying germanium. We expect that any $\mathrm{UF}_{6}$ initially present in the $\mathrm{GeF}_{4}$ that is undergoing analysis will be converted through 
our process into uranyl chloride $\left(\mathrm{UO}_{2} \mathrm{Cl}_{2}\right)$. Uranyl chloride is not volatile nor is it significantly luminescent at ambient temperature. To enhance uranyl luminescence, the residue (containing the uranyl chloride) from the second sub-boiling point distillation step will be taken up in dilute phosphoric acid solution. This is a uranyl luminescence enhancing medium that is the basis for literature reports of detection of uranyl at concentrations as low as $1 \mathrm{ppt}$ [10 ] to $40 \mathrm{ppt}$ [11]. It is significant for our new approach that chloride ion quenching of uranyl luminescence is suppressed to a considerable degree by dilute phosphoric acid. By removing fluoride and HF, our approach enables use of high purity, ultraviolet grade fused silica fluorescence cells that exhibit very low luminescence following ultraviolet excitation. Our tests of single crystal aluminum oxide (sapphire) from several sources, following ultraviolet excitation, showed significant luminescence in the spectral region where uranyl emits. Sapphire is, however, highly resistant to HF.

The primary interference that we anticipate in our germanium chloride volatilization process is luminescence from trace level organic contaminants leached from the perfluoropolymer distillation vessel or the Kel-F hydrolysis can. We expect to eliminate such interference, it is significant, by $185 \mathrm{~nm}$ photolysis which is a sufficiently short wavelength that it should photochemically destroy such contaminants. Several alternative oxidation methods exist, if other impurities in the solution absorb $185 \mathrm{~nm}$ to an extent that renders $185 \mathrm{~nm}$ photodestruction of organics ineffective. These alternative oxidation methods include addition of hydrogen peroxide followed by $254 \mathrm{~nm}$ photolysis (this produces highly reactive hydroxyl radicals) and addition of nitric acid as well as concentrated hydrochloric acid following the first sub-boiling point distillation step (this mixture of acids is a form of aqua regia and generates chlorine atoms and reactive nitrogen oxides).

In our initial studies of key steps this new approach, we have verified volatilization of germanium from $\mathrm{GeO}_{2}$ dissolved in concentrated hydrochloric acid. We did observe a very thin film deposit on the upper portion of the PFA Teflon(B) distillation pot after volatile species were distilled away. It seems likely that the thin film is $\mathrm{GeO}_{2}$ deposited as the equilibrium

$$
\mathrm{GeO}_{2}+4 \mathrm{HCl} \leftrightarrow \mathrm{GeCl}_{4}+2 \mathrm{H}_{2} \mathrm{O}
$$


becomes displaced toward the left as the partial pressure of $\mathrm{HCl}$ decreases at the distillation end point.

It should be noted that our chloride volatility approach should generate solutions suitable for analysis by other ultratrace methods such as inductively coupled plasma mass spectrometry (ICP-MS). Attempting ICP-MS directly on hydrolyzed $\mathrm{GeF}_{4}$ results in a significant "matrix" interference due to the high concentration of germanium species in such a solution. By removing nearly all of the germanium from the hydrolysis solution, "matrix" interference should be eliminated. This should allow analysis of selected samples that have been processed using our chloride volatility approach by both laser-induced fluorescence and higher cost ICP-MS methods for quality assurance and technique development purposes.

\section{Hydrolysis Procedure for $\mathrm{GeF}_{4}$}

The volume of the nickel can on the sub-manifold of our $\mathrm{GeF}_{4}$ gas handling system is $323 \mathrm{~cm}^{3}$ and that of the Kel-F can is $596 \mathrm{~cm}^{3}$ (see Fig 1). The amount of $\mathrm{GeF}_{4}$ gas hydrolyzed is determined based on the assumption of ideal gas behavior

$$
\mathrm{PV}=\mathrm{nRT}
$$

where $\mathrm{P}$ is the gas pressure, $\mathrm{V}$ is volume of the gas, $\mathrm{T}$ is its temperature, $\mathrm{R}$ is the gas constant, and $\mathrm{n}$ is the number of moles of gas. The volume $\mathrm{V}$ is that of the nickel can, $\mathrm{P}$ is measured with a high accuracy $(0.12 \%)$ thermostated capacitance manometer, and $\mathrm{T}$ is measured adjacent to the metal fitting. The Kel-F can has a demountable cap and a polytetrafluoroethylene (PTFE) sealing gasket. Kel-F is a cholorfluoropolymer that is stiffer and more readily machined to a precise shape than is PTFE. The Kel-F can assembly is a design originally used for studies on liquid anhydrous HF. A measured amount of water from a Barnstead E-Pure water purification system is added to the Kel-F can, its cap and gasket fitted, and that seal is He leak checked with the bottom section of the can assembly in liquid nitrogen (to freeze out water and its vapor). Freeze-thaw pumping is used to vacuum degas the water. The Kel-F can assembly is put on the sub-manifold of the $\mathrm{GeF}_{4}$ vacuum system, its connection to the sub-manifold is thoroughly evacuated, and its bottom section is immersed in liquid nitrogen. The sub-manifold down to the Kel-F can valve is then exposed to commercial $\mathrm{GeF}_{4}$ to ensure passivation and then it is 
thoroughly evacuated. The nickel can valve is opened, the sub-manifold is isolated, and Starmet $\mathrm{GeF}_{4}$ is added to the desired pressure as recorded by the capacitance manometer. The nickel can valve is closed and the sub-manifold is pumped out. The sub-manifold is isolated, the nickel can valve is opened, and then the Kel-F can valve is opened. This cryopumps the $\mathrm{GeF}_{4}$ into the Kel$\mathrm{F}$ can. After a few minutes, the Kel-F can valve is closed and the capacitance manometer reading is recorded (normally, this is less 0.1 torr). The sub-manifold and nickel can are thoroughly evacuated and the bottom of the Kel-F can is allowed to warm to ambient temperature. Reaction of $\mathrm{GeF}_{4}$ with the water (ice) in the Kel-F can occurs as the $\mathrm{GeF}_{4}$ warms and begins to assert its vapor pressure.

\section{Sub-boiling Point Distillation Apparatus}

This apparatus shown schematically in Fig. 11 has been used for removal of the volatile species created during hydrolysis of $\mathrm{GeF}_{4}$. In use, a thermocouple was immersed in the oil-filled beaker and its output connected to a temperature controller that regulated the electrical power supplied to a heating tape that was wrapped around the beaker. The solids and liquid resulting from hydrolysis of $\mathrm{GeF}_{4}$ in water were removed from the Kel-F can (Fig 1) and transferred into the distillation pot (vessel "a" in Fig. 11) using a syringe constructed from Teflon tubing and fittings with suction supplied by a conventional glass syringe. The walls and bottom of the can were rinsed with aliquots of water that were added to the distillation pot. A slow stream of dry nitrogen gas swept vapors from the distillation pot through the traps. 


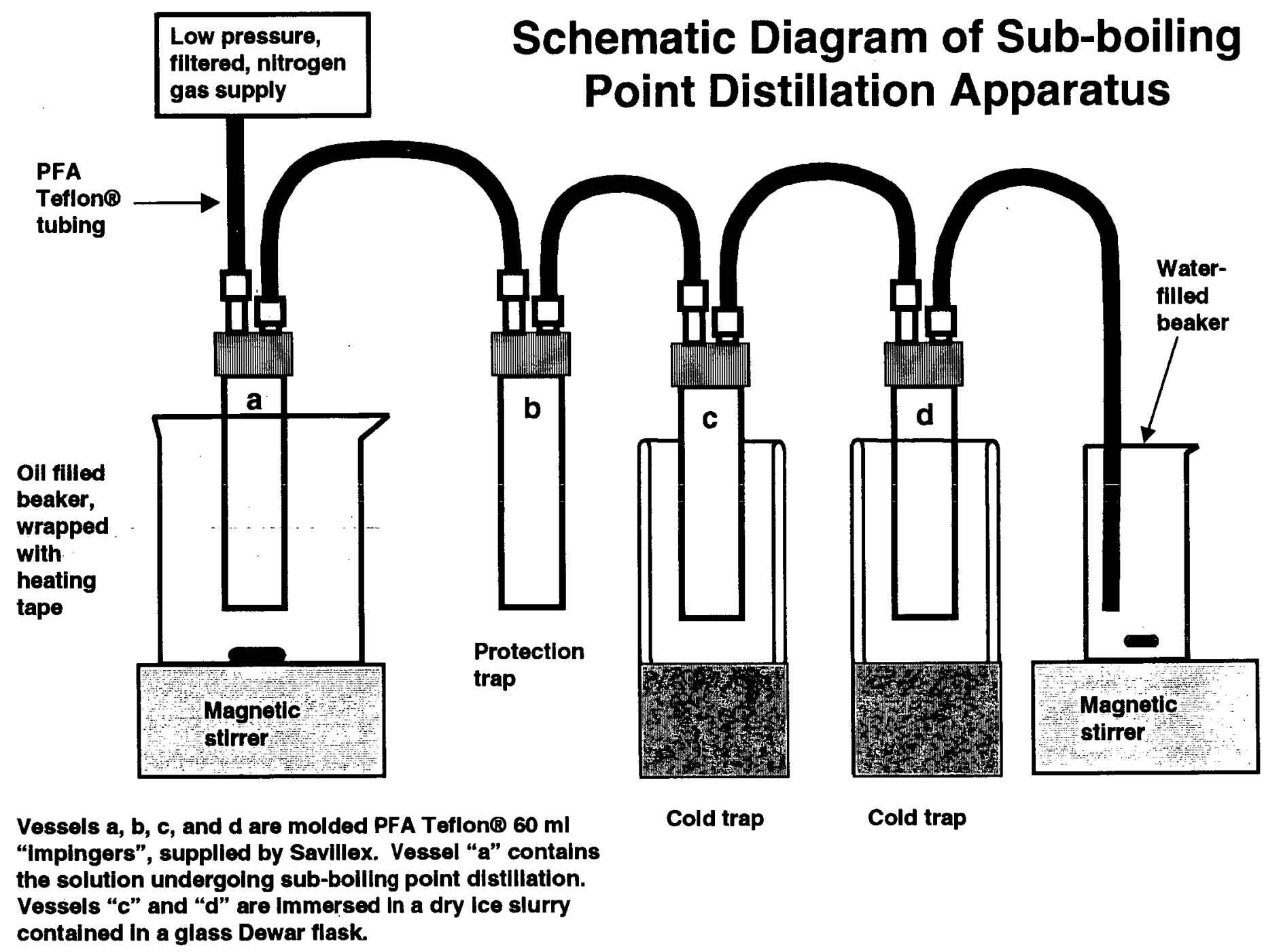

Figure 11. Schematic diagram of sub-boiling point distillation apparatus. 


\section{Issues for Future Work}

1. Given the finite time and financial resources available for development of methods for ultratrace determination of $\mathrm{UF}_{6}$ in $\mathrm{GeF}_{4}$, a decision likely will have to made as to whether those resources primarily should be directed toward development and publication in a peer-reviewed journal of our chloride volatility approach or toward development and demonstration of long path ultraviolet absorption spectroscopy to measure $\mathrm{UF}_{6}$ impurity in $\mathrm{GeF}_{4}$ gas. Our chloride volatility approach which requires hydrolysis of $\mathrm{GeF}_{4}$ and wet chemistry processes. It should achieve 40 parts per trillion or better sensitivity for uranium in $\mathrm{GeF}_{4}$. Long path length ultraviolet absorption spectroscopy is a potential online, near real time process monitor for $\mathrm{UF}_{6}$ impurity in $\mathrm{GeF}_{4}$ gas. It should achieve a sensitivity of 15 parts per billion (by volume) or better for $\mathrm{UF}_{6}$ impurity in $\mathrm{GeF}_{4}$ gas using a 1 meter path length.

2. In our new chloride volatility approach, traces of $\mathrm{GeO}_{2}$ may remain in the distillation pot. We need to determine if trace level $\mathrm{GeO}_{2}$ is soluble in dilute phosphoric acid and whether it enhances, diminishes, or otherwise interferes with ultratrace determination of uranyl via laser-induced fluorescence and the standard addition method. We also need to determine the degree to which the uranium content of a known amount of $\mathrm{UF}_{6}$ in $\mathrm{GeF}_{4}$ gas is recovered and converted into luminescing uranyl ions in phosphoric acid in our new approach.

3. The temperature dependence of the intensity of uranyl luminescence in dilute phosphoric has not been reported. We should determine the degree of sample temperature control that is required to eliminate temperature variation as a significant factor in applying the standard addition method in our chloride volatility-based approach to ultratrace determination of $\mathrm{UF}_{6}$ in $\mathrm{GeF}_{4}$. 


\section{Conclusions}

1. Formation of crystalline inclusions in glassy $\mathrm{GeO}_{2}$ was eliminated by rapid withdrawal of molten $\mathrm{GeO}_{2}$ samples from the hot zone of the alumina process tube of our horizontal tube furnace into a relatively cool end zone of that process tube.

2. Treatment of $\mathrm{GeO}_{2}$ with concentrated ammonium hydroxide followed by heating to $1400{ }^{\circ} \mathrm{C}$ for four hours resulted in visually clear, colorless, bubble-free glassy $\mathrm{GeO}_{2}$. Unfortunately, it also produced impurities whose strong luminescence following ultraviolet excitation precluded use of this method for generating glassy $\mathrm{GeO}_{2}$ that was suitable for ultratrace determination of uranyl via the standard addition method.

3. Although we varied a number factors, we found no processing conditions that produced glassy $\mathrm{GeO}_{2}$ of a quality suitable for quantitative determination of uranyl at the ultratrace level via the standard addition method.

4. Using the same initial processing steps as required for production of glassy $\mathrm{GeO}_{2}$, we have identified a promising chloride volatility-based approach for ultratrace determination of the uranyl ions that result from hydrolysis of $\mathrm{UF}_{6}$ in impure $\mathrm{GeF}_{4}$ gas. We have verified a key step in this new approach, namely the volatility of $\mathrm{GeCl}_{4}$ resulting from reaction of $\mathrm{GeO}_{2}$ with concentrated hydrochloric acid. This method promises a limit of detection of 40 parts per trillion or better for uranium (as $\mathrm{UF}_{6}$ gas) in $\mathrm{GeF}_{4}$.

5. Using ultraviolet absorption spectroscopy, we examined a sample of Starmetproduced $\mathrm{GeF}_{4}$ and determined that it contained less than 0.75 parts per million (ppm) of $\mathrm{UF}_{6}$ on a volume basis. No other ultraviolet absorbing gas species were observed.

6. Based an observed small decrease in pressure when a sample of the Starmet-produced $\mathrm{GeF}_{4}$ gas was brought into contact with clean, passivated metal surfaces and observation of vibration-rotation bands of hydrogen fluoride (HF) gas in the near- 
infrared absorption spectrum of the gas, we concluded that the sample of Starmetproduced $\mathrm{GeF}_{4}$ that we analyzed contained approximately $0.8 \% \mathrm{HF}$ gas by volume.

\section{Acknowledgements}

Helpful discussions with J. B. Bulko (Starmet Corporation) concerning the properties of $\mathrm{GeF}_{4}$ are gratefully acknowledged. This research was carried out as a subcontract to a DOE Phase II SBIR grant to Starmet Corporation (Concord, MA). Teflon is a registered trademark of E. I. DuPont.

\section{Literature Cited}

1a) "The absorption spectrum of $\mathrm{UF}_{6}$ from $2000 \AA$ to $4000 \AA$ ", G. L. DePoorter and C. K. Rofer-DePoorter, Spectroscopy Letters, 8, 521 - 524 (1975).

b) "Assignments in the electronic spectrum of $\mathrm{UF}_{6}$ ", R. McDiarmid, J. Chem. Phys., 65, 169-173 (1976).

2) "Absorption spectra of $\mathrm{Si}_{2} \mathrm{Cl}_{6}, \mathrm{SiF}_{3} \mathrm{CH}_{3}$, and $\mathrm{GeF}_{4}$ in the VUV region", T. Ibuki, N. Washida, U. Itoh, Y. Toyoshima, and H. Onuki, Chem. Phys. Let. 136 (1987) 447 450 .

3) "The Chemistry of Germanium", F. Glocking, Academic Press, London, 1969.

4) "Uranium Hexafluoride: A Manual of Good Handling Practices", U. S. DOE Field Office, Oak Ridge, TN, Report Number ORO-651 (Rev. 6), dated October, 1991.

5 "Resonance Radiation and Excited Atoms", A. C. G. Mitchell and M. W. Zemansky (Cambridge Univ. Press, London, 1971), Eqn 33, page 99.

6 "Ultratrace Determination of Uranium in Germanium Tetrafluoride, March 19, 2001 Progress Report", J. V. Beitz and C. W. Williams, Chemistry Division, Argonne National Laboratory, unpublished, 2001.

7) "Handbook of Glass Data, Part B - Single Component and Binary Non-silicate Oxide Glasses", O. V. Mazurin, M. V. Streltsina, and T. P. Shvaiko-Shvaikovskaya, Elsevier, Amsterdam, 1985, pgs. 353-384. This is volume 15 of Elseveir's Physical Sciences Data Series. 
8. "Uranyl phosphorescence at the parts-per-trillion level", R. Kaminski, F. J. Purcell, and E. Russavage, Anal. Chem. 53, 1093-1096 (1981).

9. "Vapor pressure of germanium tetrachloride over its aqueous hydrochloride solutions", M. I. Boluntsova and M. Ya. Shpirt, Zh. Fiz. Khim., 45, 2106-2107 (1971).

10. "Kinetic analysis of laser-induced phosphorescence in uranyl phosphate for improved analytical measurements", B. A. Bushaw, Anal. Chem. Symp. Ser. 19 (Anal. Spectrosc.), 57-62 (1984).

"Direct detection of trace levels of uranium by laser-induced kinetic phosphorimetry", R. Brina, and A. G. Miller, Anal. Chem. 64, 1413-1418 (1992).

11. "Fluorescence determination of trace amounts of uranium(VI) in various materials by a repetitive laser technique", G. I. Romanovskaya, V. I. Pogonin, and A. K. Chibisov, Talanta, 34, 207-210 (1987). 


\section{ULTRATRACE DETERMINATION OF URANIUM IN GERMANIUM TETRAFLUORIDE}

May 11, 2002 Progress Report

J. V. Beitz and C. W. Williams

Chemistry Division Argonne National Laboratory Argonne, IL 60439-4831 
Table of Contents

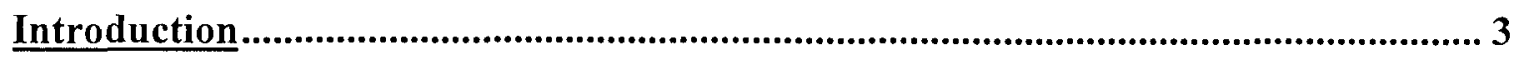

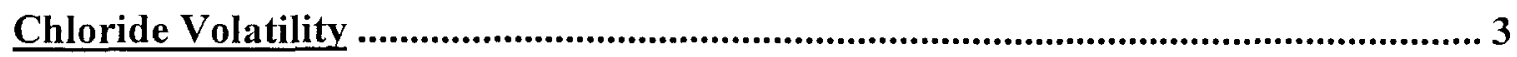

Testing Process Simplification ....................................................................................... 4

Infrared Analysis of Hydrolysis Solids ................................................................... 4

Steam Hydrolysis Apparatus ......................................................................................... 8

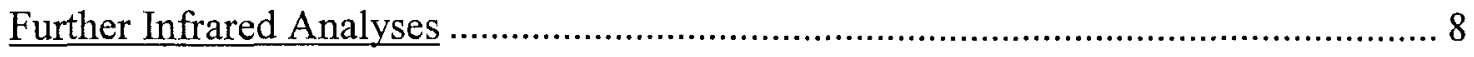

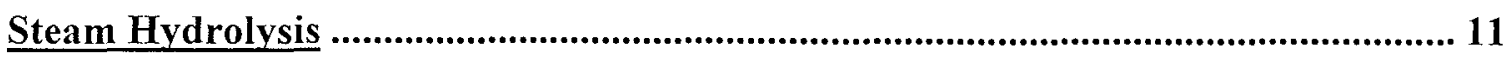

Preliminary Vapor Phase Hydrochlorination Results.................................................... 12

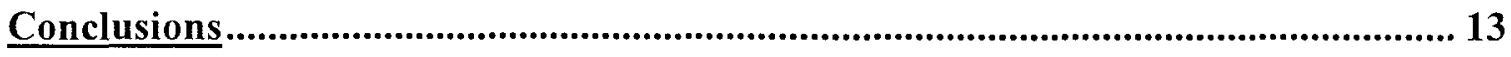

Future Work

Acknowledgements ......................................................................................................... 14

Literature References ................................................................................................ 15 


\section{Introduction}

As noted in our October 23, 2001 Progress Report, our initial approach to ultratrace determination of uranium (as uranium hexafluoride, $\mathrm{UF}_{6}$ ) in $\mathrm{GeF}_{4}$ relied on hydrolysis of $\mathrm{GeF}_{4}$ (and any $\mathrm{UF}_{6}$ present) followed by removal of fluoride and fusion of the resulting $\mathrm{GeO}_{2}$. This process would convert $\mathrm{UF}_{6}$ to uranyl ion which we showed luminesced strongly in $\mathrm{GeO}_{2}$ glass. However, we also found that fusion of $\mathrm{GeO}_{2}$ at the gram scale in air at sufficiently high temperature to minimize bubbles and crystallization also results in formation of a ultraviolet-absorbing, visible light emitting species whose presence severely interfered with ultratrace determination of uranyl ion via luminescence detection. For this reason, we have begun work on an alternate approach to determination of uranium (as uranium hexafluoride) in $\mathrm{GeF}_{4}$ that we term chloride volatility.

\section{Chloride Volatility}

As with our previous approach, the first step of our chloride volatility method is hydrolysis of $\mathrm{GeF}_{4}$ in water which is reported [1] to occur via the overall reaction:

$$
3 \mathrm{GeF}_{4}+2 \mathrm{H}_{2} \mathrm{O} \rightarrow \mathrm{GeO}_{2}+2 \mathrm{H}_{2} \mathrm{GeF}_{6} .
$$

Assuming that the $\mathrm{H}_{2} \mathrm{GeF}_{6}$ can be further hydrolyzed to produce $\mathrm{GeO}_{2}$

$$
\mathrm{H}_{2} \mathrm{GeF}_{6}+2 \mathrm{H}_{2} \mathrm{O} \rightarrow \mathrm{GeO}_{2}+6 \mathrm{HF}
$$

addition of concentrated aqueous hydrochloric acid would then dissolve $\mathrm{GeO}_{2}$ with formation of $\mathrm{GeCl}_{4}$ via

$$
4 \mathrm{HCl}+\mathrm{GeO}_{2} \rightarrow \mathrm{GeCl}_{4}+2 \mathrm{H}_{2} \mathrm{O}
$$

Simple distillation should be sufficient to remove most of the germanium as $\mathrm{GeCl}_{4}$ and leave behind nonvolatile uranyl chloride formed via hydrolysis

$$
\mathrm{UF}_{6}+2 \mathrm{H}_{2} \mathrm{O} \rightarrow \mathrm{UO}_{2} \mathrm{~F}_{2}+4 \mathrm{HF}
$$

and mass displacement:

$$
\text { excess } \mathrm{HCl}+\mathrm{UO}_{2} \mathrm{~F}_{2} \rightarrow \mathrm{UO}_{2} \mathrm{Cl}_{2}+\mathrm{HF}+\mathrm{HCl} \text {. }
$$

Because $\mathrm{GeCl}_{4}$ (boiling point: $83.1{ }^{\circ} \mathrm{C}[1]$ ) is relatively volatile in comparison with uranyl chloride which exhibits no volatility until temperatures approaching $800{ }^{\circ} \mathrm{C}$, simple distillation should suffice to remove most germanium as $\mathrm{GeCl}_{4}$ while retaining 
nonvolatile uranyl chloride for subsequent analysis via laser-induced luminescence in dilute phosphoric acid used as a uranyl luminescence enhancing medium [2-5].

\section{Testing Process Simplification}

The above sequence of reactions suggested that process simplification might be achieved by hydrolyzing the analyte $\mathrm{GeF}_{4}$ gas in water, taking the resulting solution to dryness via sub-boiling point distillation, adding concentrated $\mathrm{HCl}$, and again removing volatiles, expected to be $\mathrm{GeCl}_{4}$ and the excess $\mathrm{HCl}$ [6], via sub-boiling point distillation.

To test this hypothesis, 1 gram of $\mathrm{GeF}_{4}$ gas was hydrolyzed in $10 \mathrm{ml}$ of water using the procedure described in October 23, 2001 Progress Report. The contents of the Kel-F hydrolysis reactor were rinsed into a Savillex $60 \mathrm{ml}$ PFA Teflon "impinger" with an additional $10 \mathrm{ml}$ of water. The impinger was used as the distillation pot of the PFA Teflon apparatus shown in Figure 11 of our October 23, 2001 Progress Report. Subboiling point distillation was carried out at $95{ }^{\circ} \mathrm{C}$ under a slow flow of high purity nitrogen gas. After cooling to ambient temperature, approximately $15 \mathrm{ml}$ of 9 mole/liter hydrochloric acid was added to the distillation point and sub-boiling point distillation again carried out. Upon cooling to ambient temperature, solid residue remained in the distillation pot so approximately $15 \mathrm{ml}$ of concentrated ( $\sim 12$ mole/liter) hydrochloric acid was added and sub-boiling distillation resumed. After cooling to ambient temperature, solid residue remained in the distillation pot. The solid was recovered and placed in a capped borosilicate vial. After several days, some fogging of the interior of the vial was observed to have occurred. This suggested that the solid contained fluoride ions that were capable of undergoing hydrolysis to produce hydrofluoric acid (HF).

\section{Infrared Analysis of Hydrolysis Solids}

Infrared analysis of the white solid residue was carried out by grinding a few milligrams of it with white powdered FT-IR grade cesium iodide (CsI) in an agate mortar and pestle in a nitrogen gas-purged plastic gloved bag. During grinding the powdered mixture turned yellow. The yellow powder was pressed into a $10 \mathrm{~mm}$ diameter pellet using a press ("Econo-Press", Aldrich catalog number Z28,188-3). Infrared absorption spectra of 
pellets were recorded on a Nicole Magna 860 Fourier transform infrared (FT-IR) spectrometer which is a nitrogen gas purged, single beam instrument that was operated at $1 \mathrm{~cm}^{-1}$ spectral resolution $\left(0.5 \mathrm{~cm}^{-1}\right.$ data point spacing). The spectrometer was equipped with a silicon beamsplitter and a CsI-windowed DTGS pyroelectric detector. The spectral range $1200 \mathrm{~cm}^{-1}$ to $200 \mathrm{~cm}^{-1}$ typically was scanned and 128 sweeps of that range were averaged.

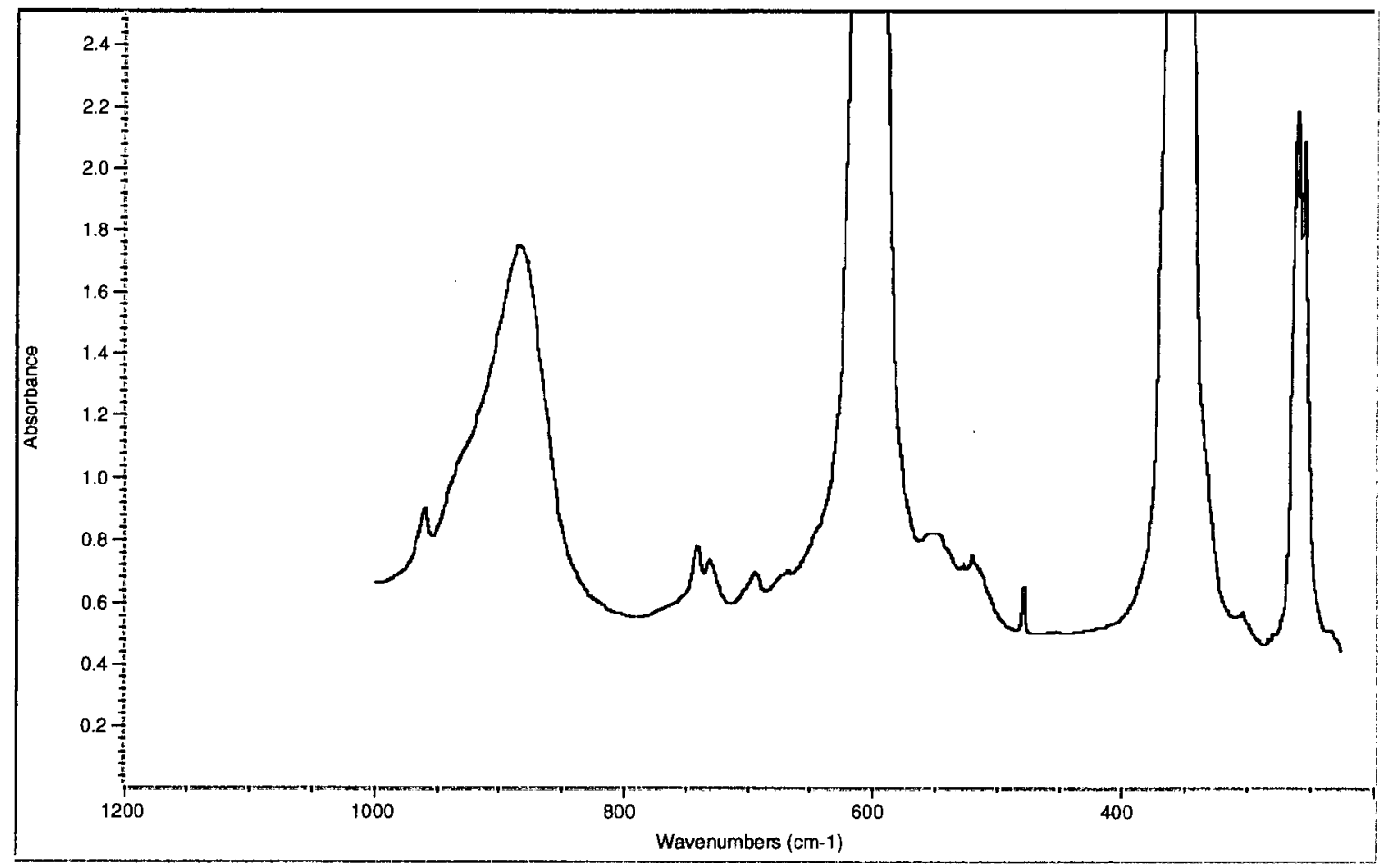

Fig 1. FT-IR absorption spectrum of a CSI pellet that contained the solid remaining after twice hydrochlorinating hydrolyzed $\mathrm{GeF}_{4}$ gas.

In Fig 1, two peaks, those centered at $600 \mathrm{~cm}^{-1}$ and $350 \mathrm{~cm}^{-1}$, were so intense that the spectrometer could not accurately recorded their peak absorbance.

For comparison purposes, a few $\mathrm{mg}$ of $99.999 \%$ pure $\mathrm{GeO}_{2}$ from Alfa were ground with CsI to a produce a white powder that was pressed into a pellet whose FT-IR spectrum was recorded (see Fig 2). Based on observed incomplete dissolution of the $\mathrm{Alfa}^{\mathrm{GeO}} \mathrm{G}_{2}$ in hydrofluoric acid, this $\mathrm{GeO}_{2}$ contains a mixture of hexagonal and tetragonal $\mathrm{GeO}_{2}$ (tetragonal $\mathrm{GeO}_{2}$ is nearly insoluble in hydrofluoric acid [1]). 


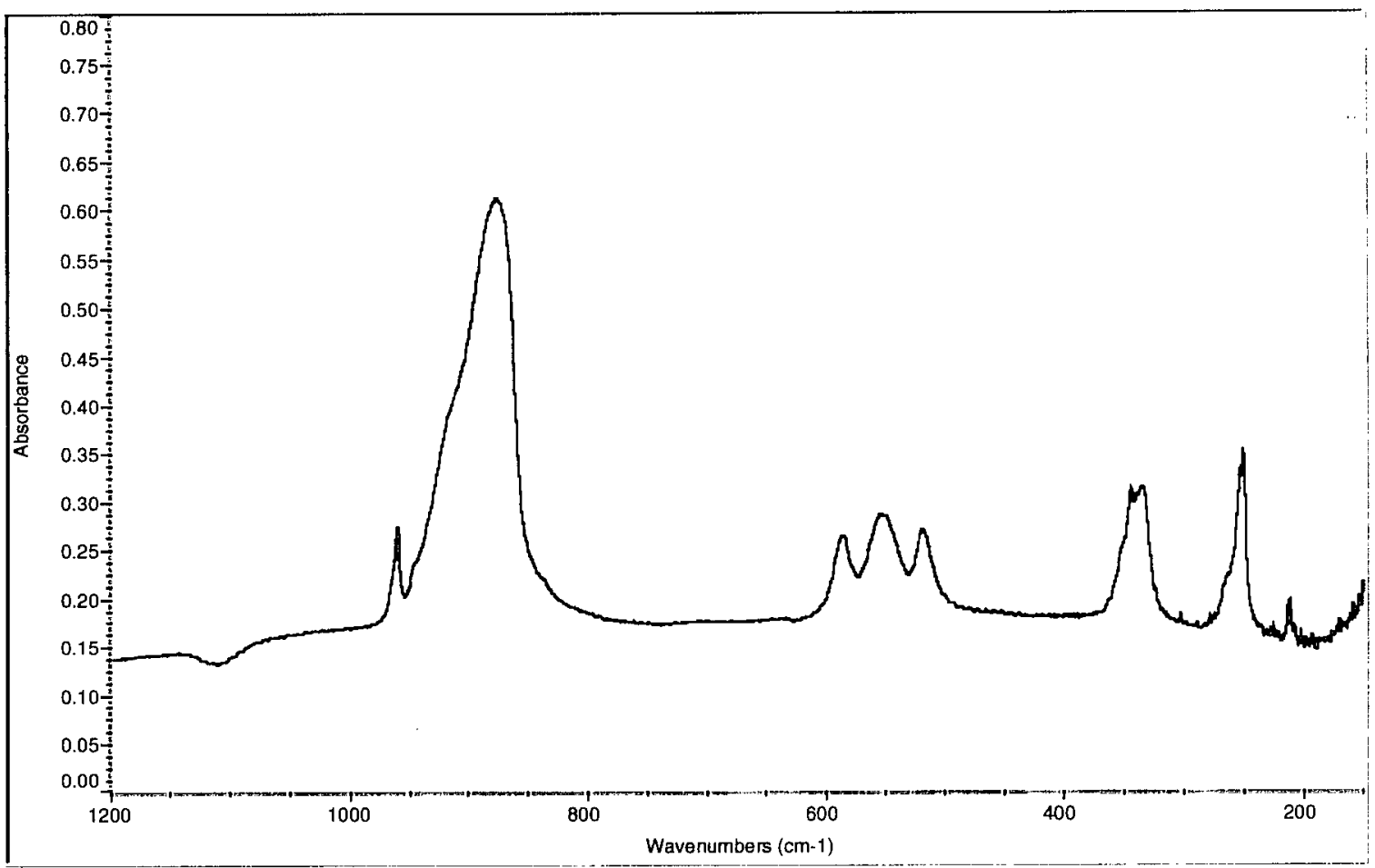

Fig 2. FT-IR absorption spectrum of a CsI pellet that contained commercial 99.999\% pure $\mathrm{GeO}_{2}$.

As is evident in comparing Figs 1 and $2, \mathrm{GeO}_{2}$ is present in the "twice hydrochlorinated hydrolyzed $\mathrm{GeF}_{4}$ " sample. A search of literature IR absorption spectra of germanium containing species was carried out to identify the species that gave rise to the two most intense bands $\left(600 \mathrm{~cm}^{-1}\right.$ and $\left.350 \mathrm{~cm}^{-1}\right)$ in Fig 1 . A literature study of vibrational spectra of the hexafluorogermanate ion, $\mathrm{GeF}_{6}{ }^{2-}$, concluded that $\mathrm{GeF}_{6}{ }^{2-}$ in cubic $\mathrm{Cs}_{2} \mathrm{GeF}_{6}$ has 6 fundamental vibrational frequencies, four of which are Raman active, two of which are infrared active, and one of which is inactive[7]. These workers report that the IR active bands of $\mathrm{Cs}_{2} \mathrm{GeF}_{6}$ are symmetric and centered at $600 \mathrm{~cm}^{-1}$ and $350 \mathrm{~cm}^{-1}$. We presume that the source of $\mathrm{Cs}_{2} \mathrm{GeF}_{6}$ in our pellet was reaction of $\mathrm{CsI}$ with $\mathrm{H}_{2} \mathrm{GeF}_{6}$ during grinding:

$$
2 \mathrm{CsI}+\mathrm{H}_{2} \mathrm{GeF}_{6} \rightarrow 2 \mathrm{Cs}_{2} \mathrm{GeF}_{6}+2 \mathrm{HI}
$$

and that the yellow color of pellet was the result of formation of triiodide ion $\left(\mathrm{I}_{3}{ }^{-}\right)$which would imply some dissociation of $\mathrm{HI}$ to $\mathrm{H}_{2}$ and $\mathrm{I}_{2}$ due to the heat generated during grinding. Taking into account the presence of $\mathrm{GeO}_{2}$ and $\mathrm{Cs}_{2} \mathrm{GeF}_{6}$ in Fig 1, there remain weak bands in the 690 to $740 \mathrm{~cm}^{-1}$ region and the sharp weak band at $479 \mathrm{~cm}^{-1}$ that are 
not attributable to either $\mathrm{GeO}_{2}$ or $\mathrm{Cs}_{2} \mathrm{GeF}_{6}$. Plausibly, they are due to an oxyfluoride of germanium, such as $\mathrm{GeOF}_{2}$.

The remaining white pot residue was transferred back into the PFA distillation apparatus along with approximately $15 \mathrm{ml}$ of water. Sub-boiling point distillation was carried out again in an effort to achieve further hydrolysis of the solid. A few milligrams of the resulting white solid were ground together with CsI which produced a lighter yellow powder that was pressed into a pellet. The IR absorption spectrum of that pellet is shown in Fig 3. Note that none of the spectra presented in this Report have been "baseline corrected" to produce an artificially flat baseline. In the case of Fig. 3, the pellet contained a significant concentration of light scattering centers (most likely due to incomplete coagulation of particles during the pressing step) that resulted in light scattering being a significant contribution to the overall change in light transmission as a function of wavenumber.

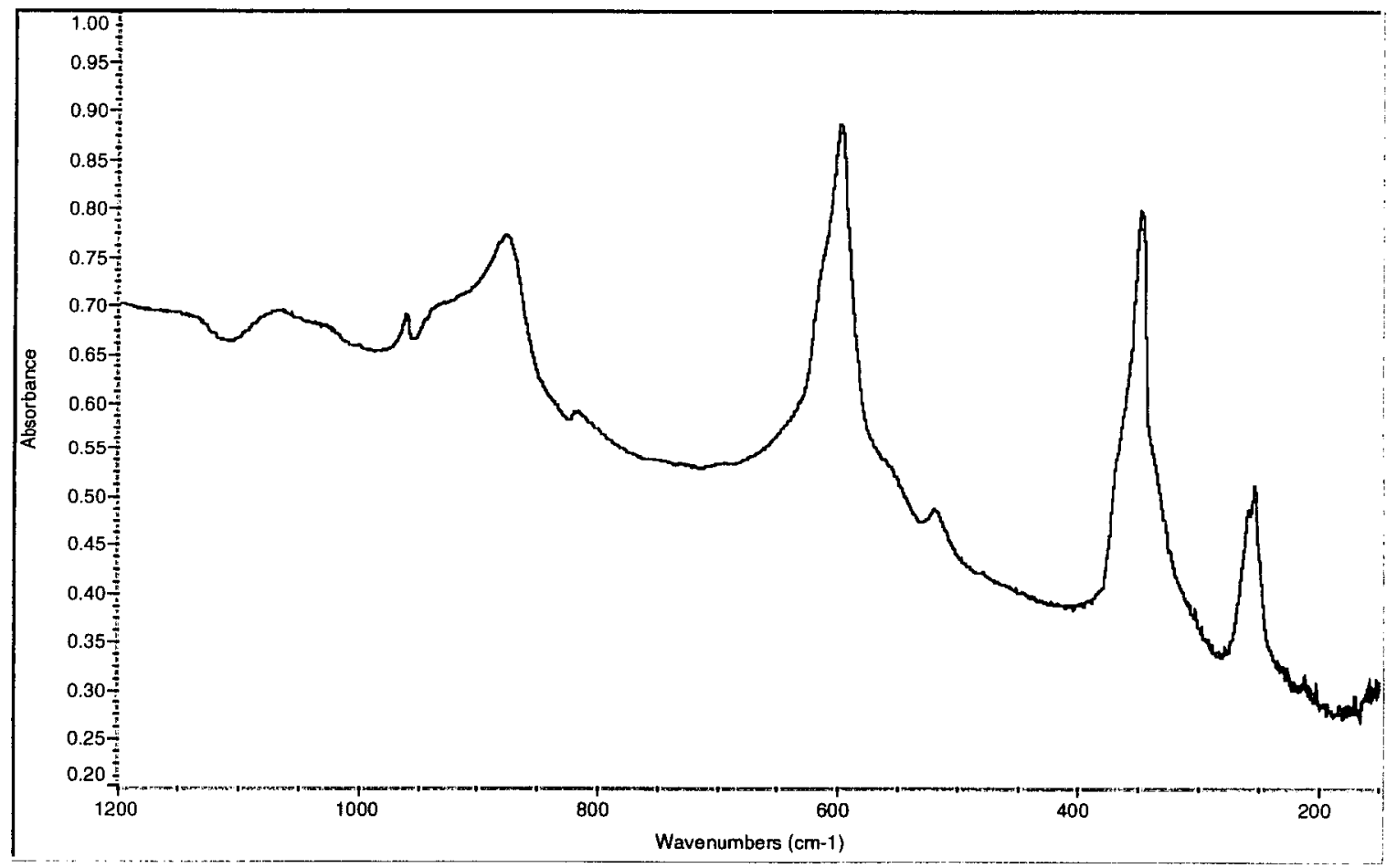

Fig 3. FT-IR absorption spectrum of a CsI pellet that contained some of the solid that remained after the first hydrolysis of the material whose absorption spectrum is shown in Fig 1. 
As is evident in comparing Figs 1 and 3, heating the sample material in water greatly reduced the intensity of the 600 and $350 \mathrm{~cm}^{-1}$ bands of $\mathrm{Cs}_{2} \mathrm{GeF}_{6}$ relative to the bands of $\mathrm{GeO}_{2}$ and almost completely removed the 690 to $740 \mathrm{~cm}^{-1}$ and $470 \mathrm{~cm}^{-1}$ bands.

A second hydrolysis in liquid water was carried out and another CsI pellet made from an aliquot of the resulting white solid. Grinding CsI and the white solid again gave a light yellow powder. The IR absorption spectrum of the resulting pellet (not shown) differed little from the spectrum shown in Fig. 3. We presume that heating in liquid water resulted in partially hydrolysis of $\mathrm{H}_{2} \mathrm{GeF}_{6}$ which generated some HF. Because dilute $\mathrm{HF}$ solutions become more concentrated in HF upon evaporation, our sub-boiling point distillation process (in which the solid undergoing hydrolysis remains in contact with the liquid is being distilled) may be less effective than would a steam hydrolysis process.

\section{Steam Hydrolysis Apparatus}

We devised a simple steam hydrolysis apparatus made primarily from Savillex PFA Teflon components (see Fig 4.). In this apparatus, the solid undergoing hydrolysis is contained in a $5 \mathrm{ml}$ vial that is suspended in steam that, upon further rising within the apparatus, condenses and returns to the liquid at the bottom of the $240 \mathrm{ml}$ PFA vessel. An air condenser (as shown in Fig. 4) was used when total reflux was desired. An "J" shaped FEP tube (inverted) was used in place of the 18 inch long straight air-condenser tubing when partial reflux was desired. Holding the oil bath at $128{ }^{\circ} \mathrm{C}$ with partial reflux typically resulted in a $1 \mathrm{ml} /$ hour condensate collection rate.

\section{Further Infrared Analyses}

A portion of the white solid residue from the sub-boiling point apparatus was transferred to the steam hydrolysis apparatus shown in Fig 4. Following steam hydrolysis, a few $\mathrm{mg}$ of the white solid in the $5 \mathrm{ml}$ PFA vial was ground with CsI to produced a light yellow powder that was pressed into a pellet. The IR absorption spectrum of that pellet is shown in Fig. 5. 


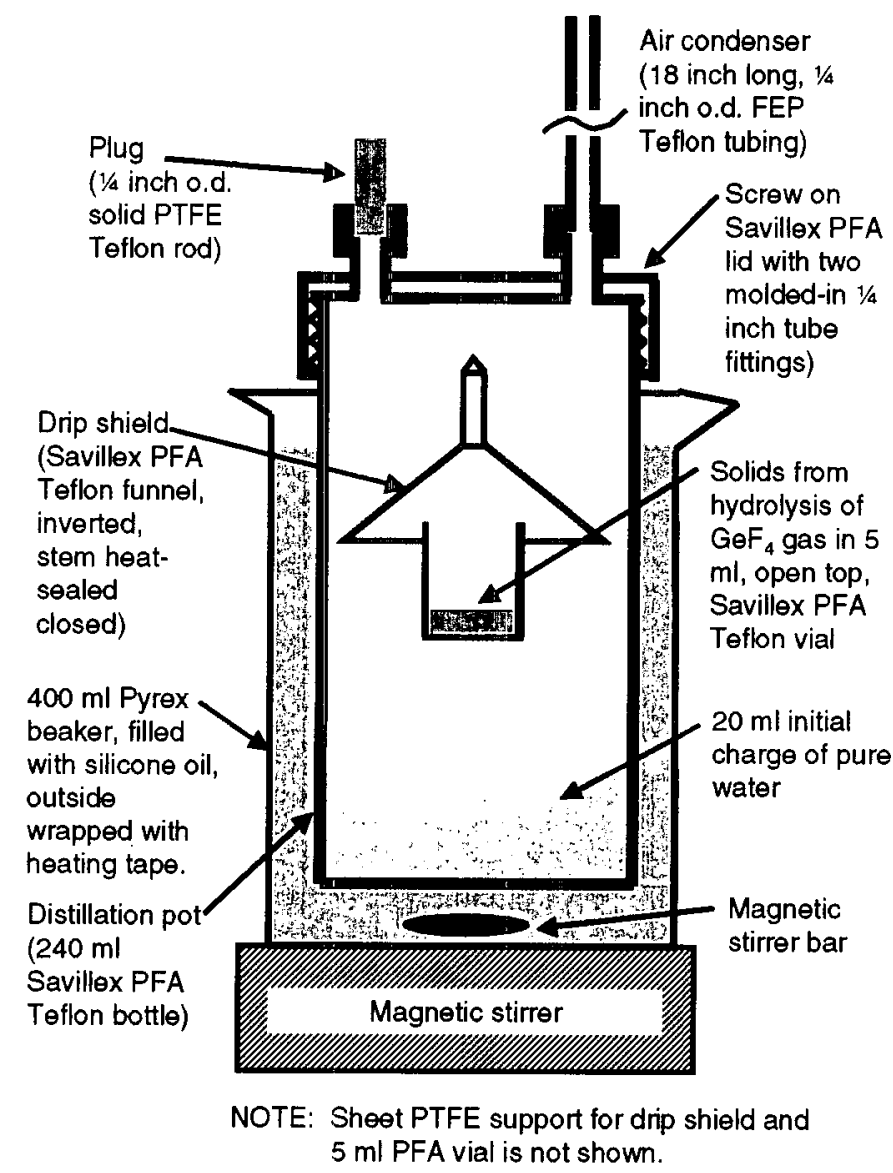

Fig. 4. Schematic cross-section view of steam hydrolysis apparatus.

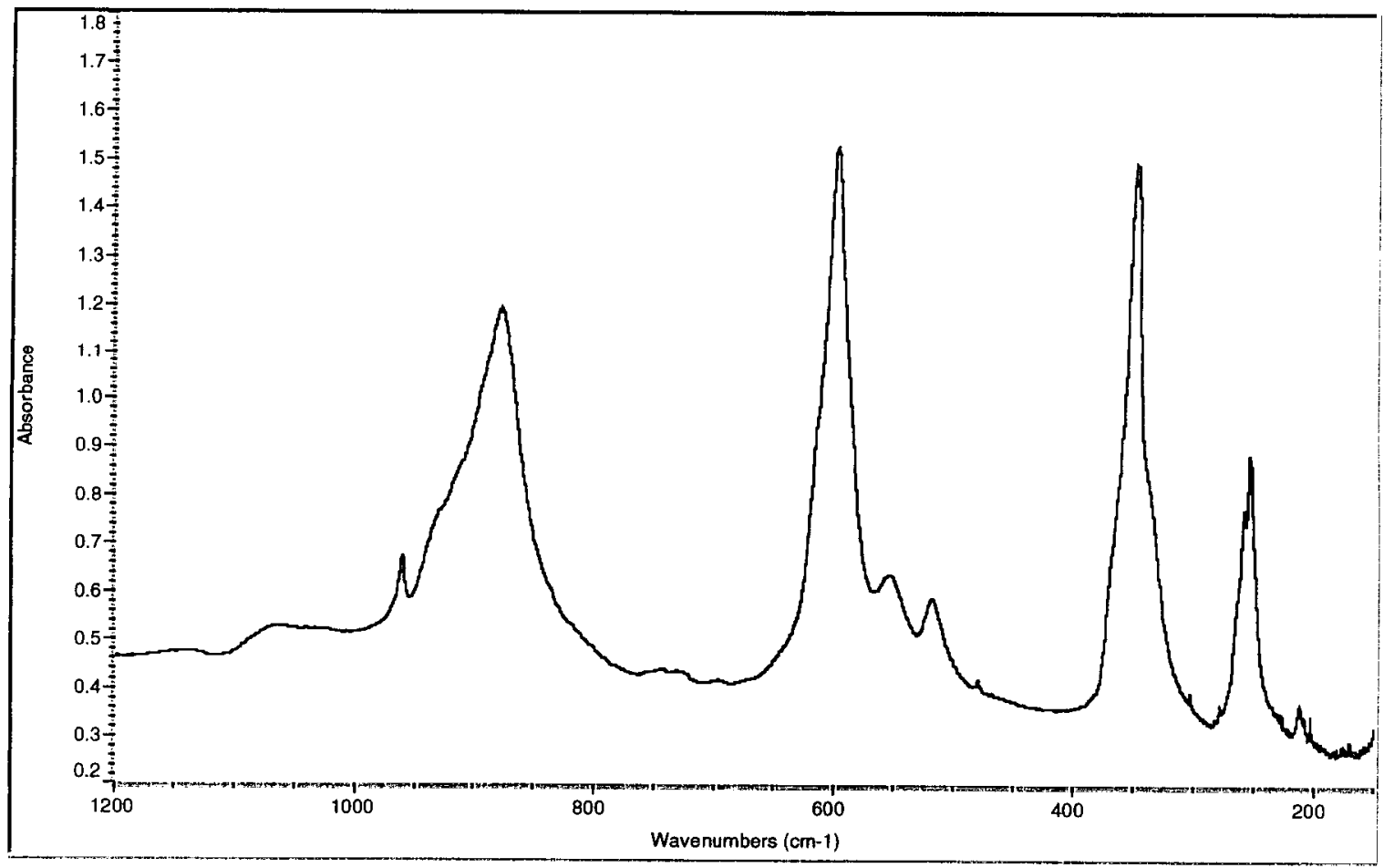

Fig 5. FT-IR absorption spectrum of a CsI pellet that contained some of the solid remaining after the steam hydrolysis of the material whose absorption spectrum is shown in Fig 3. 
Comparing Figs 1, 2, 3, and 5, it is most evident in comparing the intensity of the $600 \mathrm{~cm}^{-1}$ peak (due to $\mathrm{Cs}_{2} \mathrm{GeF}_{6}$ formed during grinding) to the intensity of the $876 \mathrm{~cm}^{-1}$ peak of $\mathrm{GeO}_{2}$, that steam hydrolysis resulted in further conversion of $\mathrm{H}_{2} \mathrm{GeF}_{6}$ to $\mathrm{GeO}_{2}$.

A second steam hydrolysis was carried. A few mg of the white solid was ground with CsI to a nearly white powder that was pressed into a pellet. The absorption spectrum of the pellet is shown in Fig 6.

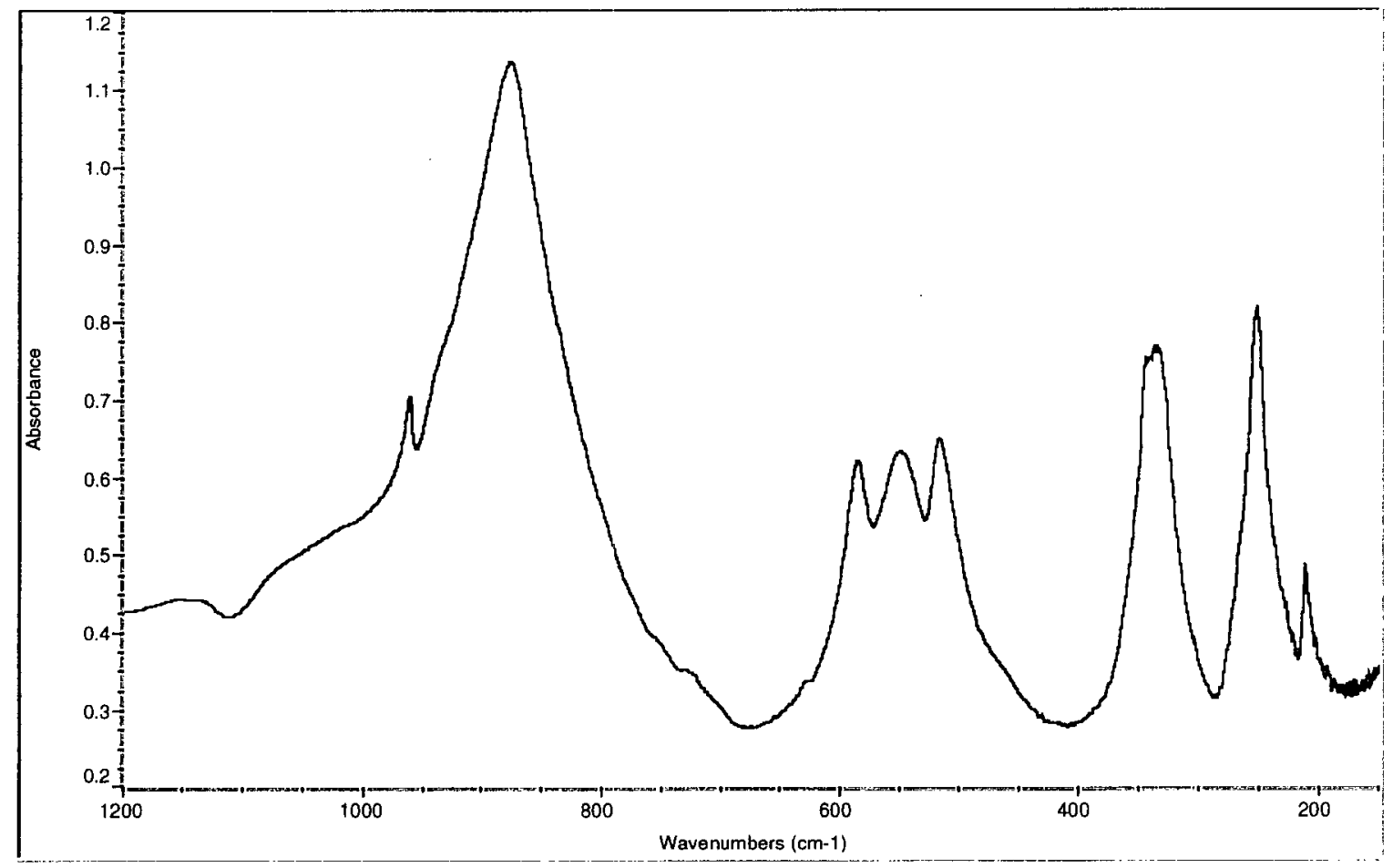

Fig 6. FT-IR absorption spectrum of a CsI pellet that contained some of the solid remaining after steam hydrolysis of the material whose absorption spectrum is shown in Fig 5.

Comparing Fig $2\left(99.999 \% \mathrm{GeO}_{2}\right)$ and Fig 6 (multiply hydrolyzed and hydrochlorinated $\mathrm{GeF}_{4}$ ), the primary visual difference is the width of the $876 \mathrm{~cm}^{-1}$ band. Table 1 compares the peaks reported by the Nicolet FT-IR peak find algorithm for these two sample pellets. We conclude that the FT-IR absorption spectrum shown is that of $\mathrm{GeO}_{2}$ with no other species observable. 
Table 1. Comparison of observed peaks in the infrared absorption spectrum of multiply hydrolyzed and hydrochlorinated $\mathrm{GeF}_{4}$ and commercial $99.999 \%$ pure $\mathrm{GeO}_{2}$.

\begin{tabular}{|c|c|}
\hline $\begin{array}{l}\text { Hydrolyzed and } \\
\text { hydro-chlorinated } \\
\mathrm{GeF}_{4}\left(\mathrm{~cm}^{-1}\right)\end{array}$ & $\begin{array}{l}\text { Commercial } \\
99.999 \% \mathrm{GeO}_{2} \\
\left(\mathrm{~cm}^{-1}\right)\end{array}$ \\
\hline 960.6 & 960.2 \\
\hline 875.4 & 876.4 \\
\hline 585.0 & 585.6 \\
\hline 549.5 & 552.6 \\
\hline 516.4 & 518.6 \\
\hline 334.8 & 334.9 \\
\hline 251.9 & 250.9 \\
\hline 211.5 & 212.3 \\
\hline
\end{tabular}

\section{Steam Hydrolysis}

From the above results, steam hydrolysis to convert $\mathrm{H}_{2} \mathrm{GeF}_{6}$ to $\mathrm{GeO}_{2}$ seemed preferable to hydrolysis in liquid water. To test this conclusion, we hydrolyzed one gram of $\mathrm{GeF}_{4}$ gas in $10 \mathrm{ml}$ of water in our Kel-F hydrolysis vessel. Using $10 \mathrm{ml}$ of rinse water, the contents of the Kel-F vessel were transferred into the sub-boiling point distillation apparatus. Volatiles were removed by sub-boiling distillation. The resulting white solid was transferred to a $5 \mathrm{ml}$ PFA vial that was inserted into the steam hydrolysis apparatus shown in Fig 4.

Steam hydrolysis was carried out typically for 3 to 5 hours at which time the $240 \mathrm{ml}$ PFA bottle was raised out of the oil bath and allowed to cool. The liquid at the bottom of the PFA bottle was suctioned out using a "tandem syringe" (see Fig 7). The liquid contact part of the syringe was made from PFA tubing and fittings. A conventional glass syringe (with a greased piston) was used to apply suction to lift the liquid from the PFA bottle.

The $\mathrm{pH}$ of the solution removed from the PFA bottle was checked with $\mathrm{pH}$ paper and typically was 1.8 to 2 . The steam hydrolysis apparatus was charged with $20 \mathrm{ml}$ of water for each run. Twenty runs were required to achieve a significant drop in $\mathrm{pH}$. The observed $\mathrm{pH}$ on the $21^{\text {st }}$ run was 6 and was taken to correspond to complete hydrolysis. This means that a total of $400 \mathrm{ml}$ of water and approximately 80 hours of contact with 
steam at slightly above $100^{\circ} \mathrm{C}$ was needed to completely hydrolyze the mixture of $\mathrm{GeO}_{2}$ and $\mathrm{H}_{2} \mathrm{GeF}_{6}$ solids that resulted from reacting $1 \mathrm{~g}$ of $\mathrm{GeF}_{4}$ with $10 \mathrm{ml}$ of water. It is possible that one reason for this slow observed reaction rate is the accumulation of HF in the liquid and vapor within the steam hydrolysis apparatus. This might result in an equilibrium forming between hydrolysis of $\mathrm{H}_{2} \mathrm{GeF}_{6}$ and re-formation of $\mathrm{H}_{2} \mathrm{GeF}_{6}$ due to reaction of $\mathrm{GeO}_{2}$ with very dilute $\mathrm{HF}$ vapor. The relative constancy of the observed $\mathrm{pH}$ values until nearly at complete hydrolysis supports this possibility.

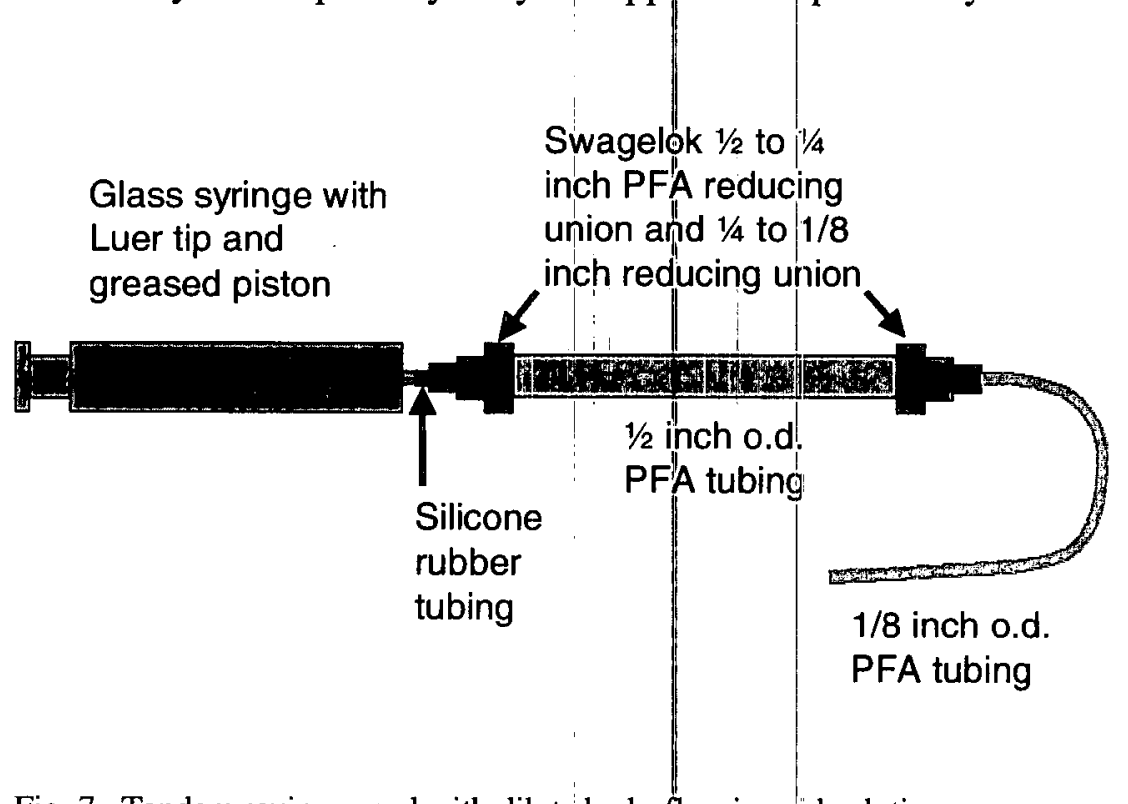

Fig. 7. Tandem syringe used with dilute hydrofluoric acid solutions

\section{Preliminary Vapor Phase Hydrochlorination Results}

We modified our steam hydrolysis apparatus (Fig. 4) to enable vapor phase hydrochlorination of $\mathrm{GeO}_{2}$ that had been produced by our steam hydrolysis method. We added three traps in series on the outlet of the air condenser of our steam hydrolysis apparatus. Each trap consisted of a Savillex $60 \mathrm{ml}$ PFA Teflon impinger. The trap nearest the condenser was left empty, the middle trap was also left empty but was immersed in a water ice bath $\left(0^{\circ} \mathrm{C}\right)$, and the last trap was filled with soda-lime pellets. Soda-line was used to ensure sorption of acidic vapors. The traps were connected with $1 / 4$ inch outer diameter FEP Teflon tubing. The outlet of the final trap was a tube that was immersed below the surface of a dilute $\mathrm{NaOH}$ solution to enable observation of the gas flow rate through the apparatus. The solid plug on the lid of the $240 \mathrm{ml}$ PFA bottle was 
replaced with an FEP Teflon tube through which was flowed a slow stream of high purity nitrogen gas. The $240 \mathrm{ml}$ PFA bottle was charged with $20 \mathrm{ml}$ of ultrapure $34 \%$ hydrochloric acid (Baker Ultrex II grade) $\mathrm{GeO}_{2}$ from steam hydrolysis was placed within the $5 \mathrm{ml}$ PFA vial and the rest of the apparatus assembled. The oil bath was heated to $115^{\circ} \mathrm{C}$ to achieve a slow condensate collection rate $(\sim 1 / 3 \mathrm{ml}$ per hour). Under these conditions, the mixture of water and $\mathrm{HCl}$ vapors rising from the liquid hydrochloric acid is enriched in $\mathrm{HCl}$ compared to the liquid. The rising vapor comes in contact with $\mathrm{GeO}_{2}$ in the $5 \mathrm{ml}$ vial and then is condensed on the upper walls and lid of the $240 \mathrm{ml}$ PFA bottle and flows back down into the liquid at the bottom of the $240 \mathrm{ml}$ PFA bottle. The expected reaction is:

$$
\mathrm{GeO}_{2}+4 \mathrm{HCl}(\mathrm{g}) \rightarrow \mathrm{GeCl}_{4}(\mathrm{~g})+2 \mathrm{H}_{2} \mathrm{O}(\mathrm{g})
$$

with the gaseous $\mathrm{GeCl}_{4}$ and $\mathrm{H}_{2} \mathrm{O}$, along with excess $\mathrm{HCl}$ vapor, expected to be swept by the slow flow of nitrogen gas out of the $240 \mathrm{ml}$ PFA bottle into the series of traps.

After 3 hours of refluxing, the clear, colorless liquid condensate in the first (initially empty) trap was removed. As expected, this liquid was strongly acidic and, after addition of an equal volume of water, the acidity of the solution was neutralized by addition of solid sodium bicarbonate to reach $\mathrm{pH} 6$ by $\mathrm{pH}$ test paper. The resulting solution was colorless and no precipitate or gel was observed to form which is evidence that little, if any, $\mathrm{GeCl}_{4}$ was present in the condensate. Hydrochlorination using a mixture of $\mathrm{HCl}$ and water vapors at $115^{\circ} \mathrm{C}$ evidently is not a rapid means of converting solid $\mathrm{GeO}_{2}$ to volatile $\mathrm{GeCl}_{4}$.

\section{Conclusions}

1. FT-IR analysis of CsI pellets that contain partially hydrolyzed $\mathrm{GeF}_{4}$ provides a rapid method for assessing the relative amounts of $\mathrm{GeO}_{2}$ and $\mathrm{H}_{2} \mathrm{GeF}_{6}$ present, based on absorption bands of $\mathrm{GeO}_{2}$ and $\mathrm{Cs}_{2} \mathrm{GeF}_{6}$ respectively. 
2. Hydrolysis of $\mathrm{GeF}_{4}$ is incomplete when $\mathrm{GeF}_{4}$ gas reacts at ambient temperature with excess water.

3. Heating the solids resulting from incompletely hydrolyzed $\mathrm{GeF}_{4}$ in liquid water or steam slowly completes the hydrolysis reaction and resulted in production of $\mathrm{GeO}_{2}$.

4. Under our process conditions, heating the solids that resulted from incompletely hydrolyze $\mathrm{GeF}_{4}$ in aqueous hydrochloric acid solution, then in liquid water, and finally in steam more rapidly completed hydrolysis and resulted in production of $\mathrm{GeO}_{2}$.

5. Heating $\mathrm{GeO}_{2}$ (produced by steam hydrolysis at slightly above $100{ }^{\circ} \mathrm{C}$ ) in a mixture of water and $\mathrm{HCl}$ vapors at $115^{\circ} \mathrm{C}$ is ineffective at rapidly generating volatile $\mathrm{GeCl}_{4}$ for removal of germanium from any uranium initially present in $\mathrm{GeF}_{4}$ as uranium hexafluoride.

\section{Future Work}

Our immediate emphasis will be on achieving more rapid hydrolysis of $\mathrm{GeF}_{4}$ to $\mathrm{GeO}_{2}$ and rapid conversion of $\mathrm{GeO}_{2}$ to volatile $\mathrm{GeCl}_{4}$ This likely will require contact of the solids generated with a significant excess of aqueous hydrochloric acid. This raises the possibility that our limit of detection for uranyl that results from hydrolysis of uranium hexafluoride in $\mathrm{GeF}_{4}$ gas will be limited by the uranium impurity level in commercial ultrapure hydrochloric acid.

\section{Acknowledgements}

Teflon is a registered trademark of the E.I. du Pont de Nemours and Company. Helpful discussions with J. B. Bulko (Starmet Corporation) concerning the properties of $\mathrm{GeF}_{4}$ are gratefully acknowledged. This research was carried out as a subcontract to a DOE Phase II SBIR grant to Starmet Corporation (Concord, MA). 


\section{Literature References}

[1] F. Glocking, The Chemistry of Germanium, Academic Press, New York, 1969.

[2] "Kinetic analysis of laser-induced phosphorescence in uranyl phosphate for improved analytical measurements", B. A. Bushaw, Anal. Chem. Symp. Ser. 19 (Anal. Spectrosc.), 57-62 (1984).

[3] "Direct detection of trace levels of uranium by laser-induced kinetic phosphorimetry", R. Brina, and A. G. Miller, Anal. Chem. 64, 1413-1418 (1992).

[4] "Fluorescence determination of trace amounts of uranium(VI) in various materials by a repetitive laser technique", G. I. Romanovskaya, V. I. Pogonin, A. K. Chibisov, Talanta, 34, 207-210 (1987).

[5] "Uranyl phosphorescence at the parts-per-trillion level", R. Kaminski, F. J. Purcell, and E. Russavage, Anal. Chem. 53, 1093-1096 (1.981).

[6] "Vapor pressure of germanium tetrachloride over its aqueous hydrochloride solutions", M. I. Boluntsova, M. Ya. Shpirt, Zh. Fiz. Khim., 45, 2106-2107 (1971).

[7] "Vibrational Spectrum of the Hexafluorogermanate Ion", J. W. Griffiths and D. E. Irish, , Inorg. Chem. 3, 1134-1137 (1964). 


\section{ULTRATRACE \\ DETERMINATION OF \\ URANIUM \\ IN GERMANIUM TETRAFLUORIDE}

March 17, 2003 Progress Report

\section{J. V. Beitz}

Chemistry Division

Argonne National Laboratory

Argonne, IL 60439-4831 


\section{Table of Contents}

Abstract.

Absorbance Analyses of Germanium Tetrafluoride Gas

2

Development of a Chloride Volatility-Based Analysis for Uranium in Hydrolyzed

Germanium Tetrafluoride. .5

Selection of Experimental Routes Based on Literature Search Results. 6

Our Experimental Tests. . .7

Laser-induced Fluorescence on $\mathrm{GeO}_{2} 2$ Dissolved in Hydrofluoric Acid Solution. 8

Recommendations for Possible Future Studies. 9

Acknowledgements 11

Literature References. 12 


\section{Abstract}

We report ultraviolet absorbance analyses of Starmet-produced germanium tetrafluoride $\left(\mathrm{GeF}_{4}\right)$ gas and near- to mid-infrared absorbance analysis of the same sample material. An upper limit for the amount of uranium hexafluoride gas is reported based on analysis of the observed ultraviolet absorption spectra. Hydrogen fluoride and carbon dioxide gases were detected based on the recorded infrared absorption spectra. Efforts to develop a germanium tetrachloride volatility-based approach for analysis of uranium in hydrolyzed $\mathrm{GeF}_{4}$ gas are reported. The starting point for this work was hexagonal germanium dioxide from steam hydrolysis of hydrolyzed $\mathrm{GeF}_{4}$ gas. No experimental conditions were found that resulted in significant conversion of steam hydrolysisproduced hexagonal germanium dioxide to germanium tetrachloride. Our steam hydrolysis-produced hexagonal germanium dioxide was found to be soluble in hydrofluoric acid although the resulting solution was not suitable for high sensitivity luminescence analysis for the presence of uranyl ion due interfering luminescing impurities that are attributed to leaching of low molecular weight polymers from the Kel$F$ and Teflon containers used for chemical manipulations. Recommendations for possible future studies are made. This is the final progress report concerning our studies on ultratrace determination of uranium in germanium tetrafluoride.

\section{Absorbance Analyses of Germanium Tetrafluoride Gas}

An aliquot of germanium tetrafluoride $\left(\mathrm{GeF}_{4}\right)$ gas from Starmet Sample Reference Number "GeFusn-40" (Starmet preparation date 1/11/02) underwent analysis by ultraviolet absorption spectroscopy for the presence of uranium hexafluoride gas (UF 6 ). This analysis and an infrared analysis were carried out using the methods, equipment, and procedures noted in our October 23, 2001 progress report to Starmet with one exception. That exception was the averaging together of ten spectral scans which resulted in slightly improved sensitivity. No absorbance attributable to $\mathrm{UF}_{6}$ gas was observed. As filled, the gas cell contained 641 torr of gas at $27^{\circ} \mathrm{C}$. If one uses three times the observed standard deviation of the measurement as the "limit of detection" criterion, then the sample of Starmet-produced $\mathrm{GeF}_{4}$ gas contained less than 0.64 parts per million of $\mathrm{UF}_{6}$ gas on a volume basis relative to $\mathrm{GeF}_{4}$. 
The sample also underwent infrared absorbance analysis in the 2000 to 5000 wave number $\left(\mathrm{cm}^{-1}\right)$ spectral region in the same sample cell used for ultraviolet absorption analysis. A Nicolet Magna 860 FT-IR equipped with a calcium fluoride beamsplitter coated for mid- to near-infrared use and a potassium bromide-windowed DTGS pyroelectric detector were used to acquire 128 scans of the $2000 \mathrm{~cm}^{-1}$ to $5000 \mathrm{~cm}^{-1}$ spectral range at $1 \mathrm{~cm}^{-1}$ spectral resolution $\left(0.5 \mathrm{~cm}^{-1}\right.$ data point spacing). The Magna 860 is a single beam instrument. Using Nicolet's OMNIC software, the observed transmission spectrum of the $\mathrm{GeF}_{4}$ gas sample cell was converted into an absorbance spectrum by dividing it, point-by-point, with a "background" transmission spectrum acquired without the $\mathrm{GeF}_{4}$ sample cell in the sample compartment. Due to the valve assembly on the $\mathrm{GeF}_{4}$ gas cell and the dimensions of the sample compartment of the Magna 860, it was not possible to use liquid nitrogen to cryopump the $\mathrm{GeF}_{4}$ into the side arm of the cell assembly to remove the gas from the optical path and thereby obtain a spectrum of the empty gas cell without physically removing the cell from the optical path. Moving the cell resulted in baseline shifts due to the high index of refraction of the single crystal aluminum oxide windows on the gas cell and difficulty in exactly reproducing its position in the optical path. Figure 1 shows the observed absorbance spectrum of the gas cell.

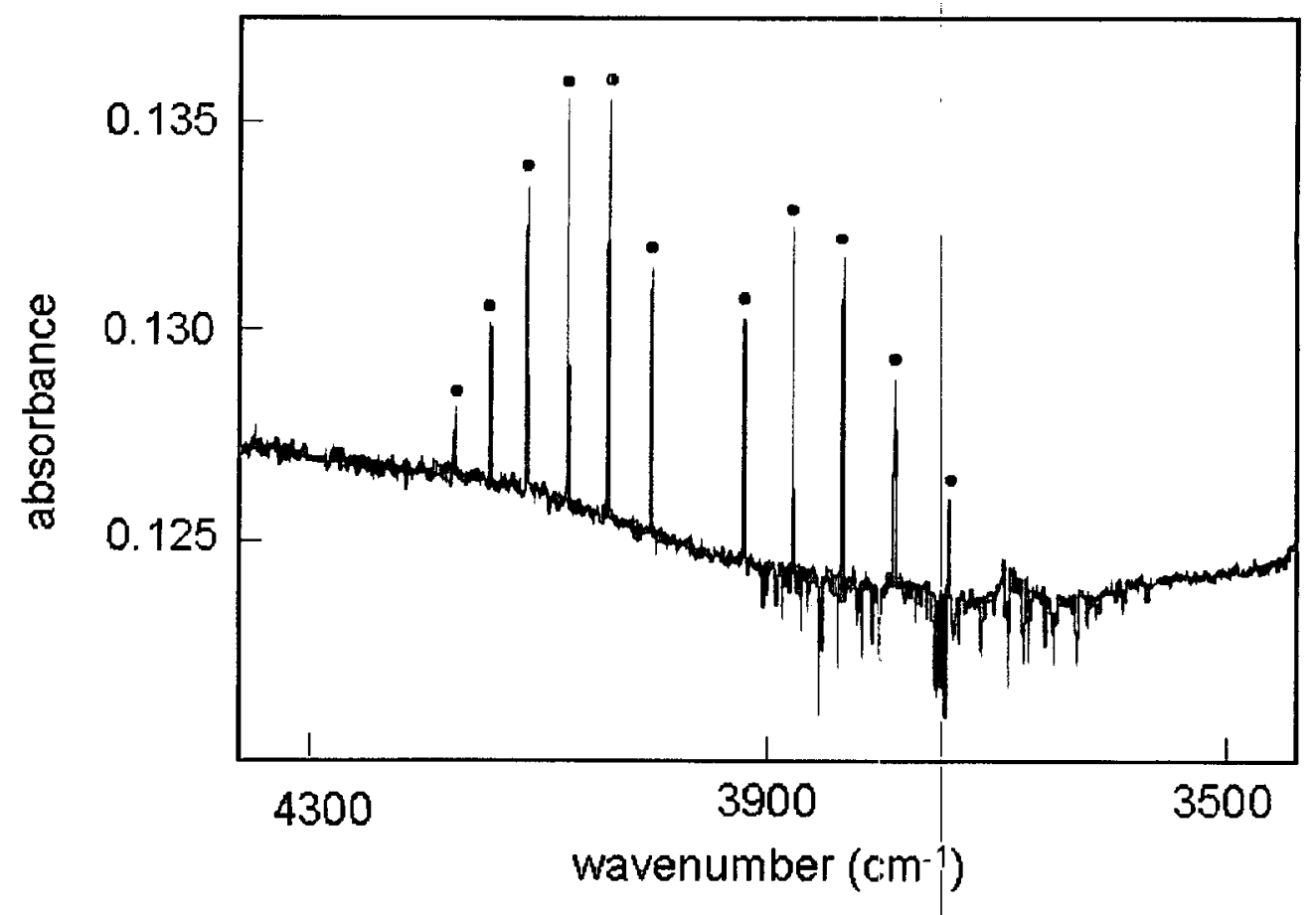

Fig. 1. Absorbance spectrum of an aluminum oxide-iwindowed gas cell that contained 641 torr of Starmet-produced $\mathrm{GeF}_{4}$ (Starmet Sample Reference Number "GeFusn-40"). Vibration-rotation bands of hydrofluoride (HF) gas are denoted by a symbol (•). 
The very narrow characteristic fundamental vibration-rotation bands of hydrogen fluoride gas (HF) were observed in the 3700 to $4200 \mathrm{~cm}^{-1}$ spectral range and are denoted by a dot $(\bullet)$ symbol. These bands had nearly the same observed absorbance (optical density) as was the case for our previous FT-IR analysis of an aliquot of $\mathrm{GeF}_{4}$ from Starmet Sample Reference Number "GeFusn-36" (Starmet preparation date 8/06/0). The sloping background is due primarily to the single crystal aluminum oxide (sapphire) windows of the gas cell. The numerous sharp bands in the 3550 to $3900 \mathrm{~cm}^{-1}$ spectral range whose peaks occur as decreased absorbance (compared to the sloping background) are due to vibration-rotation bands of water vapor. Although the Magna 860 was well purged by dry nitrogen gas, some water vapor was always present in its optical path. When the $\mathrm{GeF}_{4}$ gas cell was inserted into the optical path of the 860 , the infrared analysis light path through the nitrogen gas purged interior of the instrument was reduced by about $9.3 \mathrm{~cm}$ in comparison with the path length when the "background" transmission spectrum was recorded. The "negative" absorbance water peaks result from that change in path length when the transmission spectrum recorded with the $\mathrm{GeF}_{4}$ gas cell in the path was divided by the "background" transmission spectrum.

In addition, weak absorption bands (peak absorbance: 0.002 absorbance units) of the $v_{3}$ fundamental absorption bands of carbon dioxide gas $\left(\mathrm{CO}_{2}\right)$ were observed in the 2310 to $2375 \mathrm{~cm}^{-1}$ spectral range and are shown in Figure 2. These peaks are on a strongly sloping background that is due to the increasing absorbance of the aluminum oxide windows of the gas cell with decreasing wave number. Because the peaks occur as increased absorbance they are indicative of the presence of $\mathrm{CO}_{2}$ as an impurity in the $\mathrm{GeF}_{4}$ gas in the sample cell.

Because the spectral resolution that we achieved is much broader than the true line widths of the $\mathrm{HF}$ or $\mathrm{CO}_{2}$ absorption peaks, the spectra shown in Figures 1 and 2 are qualitative in nature as to the peak absorption of a given vibration-rotation transition. Put another way, the spectra identify the presence of impurity $\mathrm{HF}$ and $\mathrm{CO}_{2}$ gases in the Starmet-produced $\mathrm{GeF}_{4}$ gas sample but are insufficient to quantify the amount (concentration) of such impurities. 


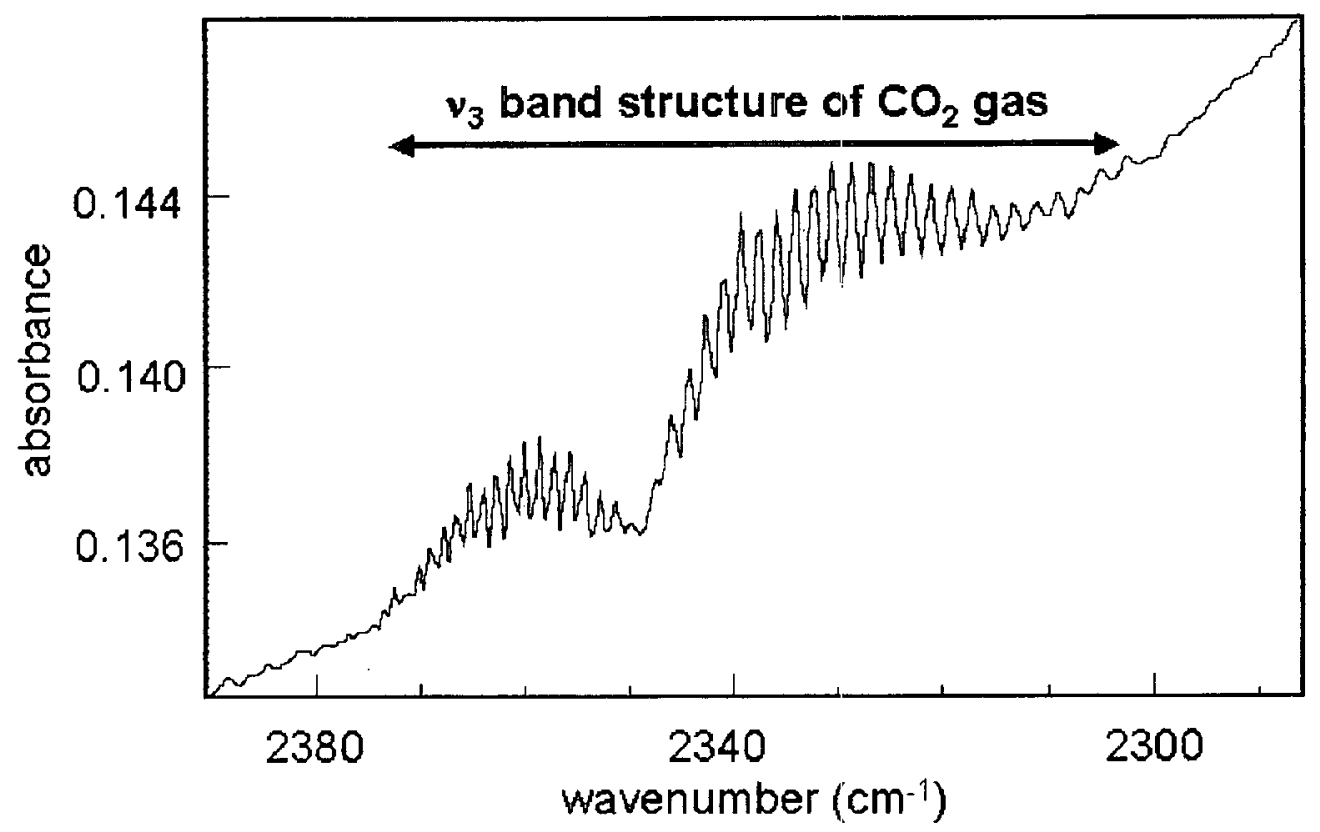

Fig. 2. Absorbance spectrum of an aluminum oxide-windowed gas cell that contained 641 torr of Starmet-produced $\mathrm{GeF}_{4}$ (Starmet Sample Reference Number "GeFusn-40"). The numerous sharp peaks in the 2310 to 2375 wave number range are due to the vibration-rotation bands of carbon dioxide gas.

\section{Development of a Chloride Volatility-Based Analysis for Uranium in Hydrolyzed Germanium Tetrafluoride}

Our primary focus was evaluation of our proposed "chloride volatility" process for analysis of the uranium content of hydrolyzed $\mathrm{GeF}_{4}$ gas. The basis of this process is detailed in our May 11, 2002 progress report. The process requires conversion of "particulate $\mathrm{GeO}_{2}$ " into volatile germanium tetrachloride $\left(\mathrm{GeCl}_{4}\right)$. The "particulate $\mathrm{GeO}_{2}$ " of interest is that which arises from repeated steam hydrolysis of the solids that result from reaction (hydrolysis) of $\mathrm{GeF}_{4}$ with water. As noted in our May 11, 2002 report, the particulate $\mathrm{GeO}_{2}$ that we produce via steam hydrolysis is of the hexagonal structure type based on its infrared absorption spectrum. Standard reviews of germanium chemistry [1] state that hexagonal $\mathrm{GeO}_{2}$ reacts with concentrated hydrochloric acid to form $\mathrm{GeCl}_{4}$. We were surprised, therefore, when our particulate $\mathrm{GeO}_{2}$ failed to react with concentrated hydrochloric acid (American Chemical Society analytical reagent grade) solution at ambient temperature over periods of time that eventually extended to several months contact. For this reason, we carried out both a literature search as to conditions 
that favor reaction of $\mathrm{GeO}_{2}$ with hydrochloric acid $(\mathrm{HCl})$ and our own extensive experimental tests of the reactivity of our particulate $\mathrm{GeO}_{2}$ with hydrochloric acid solutions.

\section{Selection of Experimental Routes Based on Literature Search Results}

The primary tool that we used was SciFinder which is a product of the American Chemical Society and provides access to the $\sim 22$ million literature and report abstracts of the Chemical Abstract Services that are on-line and typically date back as far as the 1950's and in some cases even further. Most of: the literature references related to conversion of $\mathrm{GeO}_{2}$ to $\mathrm{GeCl}_{4}$ were published more than twenty years ago in Russian language journals. Difficulty in converting hexagonal $\mathrm{GeO}_{2}$ to $\mathrm{GeCl}_{4}$ arises from at least two effects. One is the higher thermodynamic stability of hexagonal $\mathrm{GeO}_{2}$ in comparison with that of glassy $\mathrm{GeO}_{2}$. For example, a $\sim 100$-fold slower rate was reported for the dissolution in water of hexagonal $\mathrm{GeO}_{2}$, in comparison with glassy $\mathrm{GeO}_{2}$.[2] The other effect is the influence of particle size with higher reaction rates expected for smaller particles. There is general agreement that, in comparison with hexagonal $\mathrm{GeO}_{2}$, glassy $\mathrm{GeO}_{2}$ dissolves more readily in water and is, therefore, more readily converted to $\mathrm{GeCl}_{4}$ because dissolution of $\mathrm{GeO}_{2}$ is believed to be the rate-limiting step in conversion to $\mathrm{GeCl}_{4}$. In addition, high $\mathrm{HCl}$ concentration is desired. Aqueous reagent grade "concentrated" $\mathrm{HCl}$ (nominally, 37\% weight percent $\mathrm{HCl}$ ) is the lowest recommended $\mathrm{HCl}$ concentration [3], at least at the start of conversion of solid $\mathrm{GeO}_{2}$ to $\mathrm{GeCl}_{4}$ (recall that reaction of $\mathrm{GeO}_{2}$ to produce $\mathrm{GeCl}_{4}$ produces $\mathrm{H}_{2} \mathrm{O}$ which reduces the concentration of $\mathrm{HCl}$ over the course of the reaction). Recommended temperatures for reaction of $\mathrm{GeO}_{2}$ with $\mathrm{HCl}$ from ambient to above the boiling point of $\mathrm{GeCl}_{4}$ when separation of $\mathrm{GeCl}_{4}$ by distillation was the goal. Dissolution of "aged" hexagonal $\mathrm{GeO}_{2}$ has been recognized as a significant problem in the analytical chemistry of germanium. The common approach to this problem has been to heat the $\mathrm{GeO}_{2}$ to above its melting point followed by rapid thermal quenching to achieve conversion to glassy $\mathrm{GeO}_{2}$. Only one study of chemical methods to achieve the same end, namely dissolution of "aged" hexagonal $\mathrm{GeO}_{2}$ was found. It recommended use of 2.5 mole/liter sodium hydroxide at elevated temperature in preference to acidic oxidative or reductive routes.[4] 
Because heating the particulate $\mathrm{GeO}_{2}$ that we produce to convert it to a glassy state fuses the powder to a mass, grinding of the resulting fused mass of glass would be needed to produce small particles and achieve a significant rate of reaction with $\mathrm{HCl}$. All means of grinding available to us would result in significant chemical contamination of the $\mathrm{GeO}_{2}$. Conversion to glass was rejected for that reason. Use of sodium hydroxide solution at elevated temperature likely would dissolve our particulate $\mathrm{GeO}_{2}$ to produce a sodium germanate solution. However, laser-induced fluorescence analysis for uranyl requires acidic to near-neutral $\mathrm{pH}$ depending on the luminescence enhancer used. Neutralization or acidification as an aqueous soluticn of sodium germanate would result in formation of a gel of hydroxo or hydrated $\mathrm{GeO}_{2}$ that would be both highly light scattering and capable of sequestering uranyl ion from an added luminescence enhancing agent such as pyrophosphate. For these reasons, solubilization of our particulate $\mathrm{GeO}_{2}$ by dissolution in sodium hydroxide solution at elevated temperature was rejected. Based on these considerations, we carried out a concerted experimental effort to achieve an acceptable rate of chemical reaction of our particulate $\mathrm{GeO}_{2}$ with aqueous $\mathrm{HCl}$ solutions to generate volatile $\mathrm{GeCl}_{4}$.

\section{Our Experimental Tests}

We established that reaction of our particulate $\mathrm{GeO}_{2}$ with concentrated $\mathrm{HCl}$ (ACS reagent grade) did not occur over a period of weeks at ambient temperature and was not observably enhanced by elevated temperature over periods of time extending up to two days and at temperatures that included the boiling point of concentrated $\mathrm{HCl}$. These tests culminated in a series of experiments in which particulate $\mathrm{GeO}_{2}$ was held in the refluxing vapor above constant boiling point hydrochloric acid and in the refluxing vapor above concentrated hydrochloric acid. In none of these tests was any observable conversion our particulate $\mathrm{GeO}_{2}$ to $\mathrm{GeCl}_{4}$ found. These tests used the PFA Teflon apparatus that we created for steam hydrolysis of hydrolyzed $\mathrm{GeF}_{4}$. Instead of charging the apparatus with water, it was charged with an $\mathrm{HCl}$ solution. Reflux was achieved using an 18 inch length of 0.25 inch outer diameter FEP Teflon tubing that extended above the PFA vessel and served as an air-cooled condenser. Portions of the refluxing vapor were collected for analysis and no evidence of $\mathrm{GeCl}_{4}$ was found. In a separate test series, to maximize the 
solution acidity, a stream of dry hydrogen chloride gas was passed through a stirred slurry of particulate $\mathrm{GeO}_{2}$ in concentrated aqueous $\mathrm{HCl}$ at ambient temperature in a fused silica tube the bottom end of which had been flame-sealed to the shape of a cone. High purity Matheson $\mathrm{HCl}$ gas was passed through a two-stage pressure regulator and a Matheson particulate filter prior to the gas stream coming in contact with the aqueous $\mathrm{HCl}$ solution in the fused silica tube. No formation of liquid $\mathrm{GeCl}_{4}$ was observed in the fused silica tube. No reduction in the amount of particulate $\mathrm{GeO}_{2}$ in the aqueous $\mathrm{HCl}$ solution was evident visually after 26 hours. The vapor exiting the reaction vessel was passed through a trap held at $273 \mathrm{~K}$. Analysis of the trap contents did not reveal any $\mathrm{GeCl}_{4}$. We conclude that our particulate $\mathrm{GeO}_{2}$, although of the hexagonal structure type based on its infrared absorption spectrum, exhibited a negligible reaction rate with hydrochloric acid under our experimental test conditions. For this reason, our proposed "chloride volatility" process is not suitable for high sensitivity analysis for the presence of uranium in hydrolyzed $\mathrm{GeF}_{4}$ gas. Reaction of particulate $\mathrm{GeO}_{2}$ with dry $\mathrm{HCl}$ gas at moderately high temperature (e.g., $400^{\circ} \mathrm{C}$ ) was not attempted due to concern about chemical reduction (due to the presence of small amounts of hydrogen gas in $\mathrm{HCl}$ ). Such reduction of trace levels of uranyl would result in lower valent uranium chlorides whose volatility likely would compromise analytical accuracy.

\section{Laser-induced Fluorescence on $\mathrm{GeO}_{2}$ Dissolved in Hydrofluoric Acid Solution}

In a final effort to quantify uranium in hydrolyzed $\mathrm{GeF}_{4}$ gas, we contacted an aliquot of particulate $\mathrm{GeO}_{2}$ with $22 \%$ hydrofluoric acid solution and found that the particulate $\mathrm{GeO}_{2}$ readily dissolved to give a clear, colorless solution. This solution was transferred to a single crystal aluminum oxide cell that consisted of a single crystal aluminum oxide rod into which a hole that had been drilled coaxial with the cylinder axis of the rod to create a flat-bottomed "test tube" shape. A polished disk of single crystal aluminum oxide capped the cavity in the rod and prevented escape of significant amounts of HF vapor from the contained solution. Laser-induced fluorescence analysis of the solution in this cell was carried out using $355 \mathrm{~nm}$ excitation with the apparatus described in our March 12, 2001 progress report. Luminescence from the solution was observed 
throughout the visible spectral range and exhibited complex, non-exponential decay. The luminescence initially peaked in the blue. With increasing time following a laser excitation pulse, the peak luminescence intensity wavelength shifted to longer wavelength. An aliquot of a solution of uranyl ion in dilute nitric acid was added to the solution in the cell in an amount sufficient to give approximately 6 parts per million of uranyl on a weight basis. The characteristic luminescence emission bands of uranyl ion could not be discerned in the recorded emission spectra due to the much more intense broadband, complex luminescence of the solution. This interfering luminescence likely arises from low molecular weight polymers that had leached from the Kel-F and perfluoroalkoxy (PFA) Teflon containers that we used to generate the particulate $\mathrm{GeO}_{2}$. Such luminescence was not observed from our HF stock solution nor was it present in solutions of commercial $\mathrm{GeO}_{2}$ dissolved in our $\mathrm{HF}$ stock solution. We conclude that the sensitivity of luminescence analysis for uranyl in hydrofluoric acid solutions of particulate $\mathrm{GeO}_{2}$ was significantly hindered by the presence of interfering luminescing species that likely are low molecular weight polymers that leached from the walls of Kel$\mathrm{F}$ and Teflon containers.

\section{Recommendations for Possible Future Studies}

The most promising analysis method that we investigated for ultratrace analysis of uranium in $\mathrm{GeF}_{4}$ gas consisted of four major steps:

1) Hydrolysis of $\mathrm{GeF}_{4}$ gas to a slurry of $\mathrm{GeO}_{2}$ and $\mathrm{H}_{2} \mathrm{GeF}_{6}$

2) Steam hydrolysis of the mixture of $\mathrm{GeO}_{2}+\mathrm{H}_{2} \mathrm{GeF}_{6}$ to produce hexagonal $\mathrm{GeO}_{2}$

3) Fusion of hexagonal $\mathrm{GeO}_{2}$ to produce glassy $\mathrm{GeO}_{2}$

4) Laser-induced fluorescence analysis for uranyl ion luminescence in the produced glassy $\mathrm{GeO}_{2}$.

This method failed at the third step because a luminescing impurity (or impurities) grew in at the temperatures needed to produce glassy $\mathrm{GeO}_{2}$ that was free of bubbles and crystalline inclusions. Based on a literature report[5], it seems likely that the luminescing impurity was an oxygen atom deficient site in $\mathrm{GeO}_{2}$. Prolonged heating of the glassy 
$\mathrm{GeO}_{2}$ in a oxygen gas atmosphere is reported to eliminate the $245 \mathrm{~nm}$ optical absorption band that has been attributed to an oxygen atom deficient site in glassy $\mathrm{GeO}_{2}$. [6] Unfortunately, our high temperature furnaces were not designed for heating samples in a pure oxygen atmosphere. In consequence, we could not confirm the reported influence of an oxygen gas atmosphere on suppression of the $245 \mathrm{~nm}$ defect absorption band and, presumably, suppression of interfering luminescence. If the literature reports concerning oxygen atom defects in glassy $\mathrm{GeO}_{2}$ are correct, then the above method, modified in step 3 to include fusion in a pure oxygen gas atmosphere, likely would meet a prime objective of our project, namely a limit of detection of a few parts per trillion of uranium in $\mathrm{GeF}_{4}$ gas.

Due to the growth of a luminescing impurity at step 3 of the above process, we turned to conversion of $\mathrm{GeO}_{2}$ to volatile $\mathrm{GeCl}_{4}$ as a method of removing the light scattering interference of particulate $\mathrm{GeO}_{2}$ and the potential sequestering of uranyl ions by $\mathrm{GeO}_{2}$ prior to use of laser-induced fluorescence to quantify uranium as uranyl ion. As detailed in this progress report, our efforts to convert $\mathrm{GeO}_{2}$ to $\mathrm{GeCl}_{4}$ failed due to the extremely slow rate of reaction of aqueous $\mathrm{HCl}$ with hexagonal $\mathrm{GeO}_{2}$ produced by steam hydrolysis (step 2 of the above process). During the writing of this report, we found an abstract for a literature report on a method for recovery of germanium from solid wastes. That methods is suggestive that a superior alternative to the use of pure $\mathrm{HCl}$ solutions may exist for conversion of $\mathrm{GeO}_{2}$ to $\mathrm{GeCl}_{4}$. Based on the abstract for that literature report, germanium from waste waters co-precipitated with basic iron carbonate and hydroxide, when treated with 6 mole/liter $\mathrm{HCl}$ in the presence of phosphoric acid, is converted to $\mathrm{GeCl}_{4}$ that can be separated by distillation at $108^{\circ} \mathrm{C}$.[7] It seems likely that the co-precipitated germanium is either $\mathrm{GeO}_{2}$ or a hydrate of $\mathrm{GeO}_{2}$. The additional acidity due to added phosphoric acid might enhance dissolution and reaction of our hexagonal $\mathrm{GeO}_{2}$. Because 10 weight $\%$ phosphoric acid is a good uranyl ion luminescence enhancing medium, the presence of residual phosphoric acid after volatilization of the resulting $\mathrm{GeCl} 4$ would be beneficial. In addition, phosphoric acid strongly complexes uranyl ion which would ensure retention of it in the distillation vessel. However, due to the added chemical complexity and attendant possibilities for 
interference from ultratrace impurities in the reagents used, the limit of detection for uranium in $\mathrm{GeF}_{4}$, if volatilizing $\mathrm{GeO}_{2}$ via conversion of it to $\mathrm{GeCl}_{4}$, seems likely to be inferior to that of the four step process outlined in the above paragraph.

\section{Acknowledgements}

Teflon is a registered trademark of the E.I. du Pont de Nemours and Company. The able experimental assistance of C. W. Williams is gratefully acknowledged. Helpful discussions with J. B. Bulko (Starmet Corporation) concerning the properties of $\mathrm{GeF}_{4}$ are gratefully acknowledged. This research was carried out as a subcontract to a DOE Phase II SBIR grant to Starmet Corporation (Concord; MA). 


\section{Literature References}

1. The Chemistry of Germanium, F. Glocking, Academic Press, London, 1969.

2. Kinetics of dissolution of germanium oxide at $\mathbf{2 5}^{\circ} \quad$ I. A. Kakovskii, E. A. Knyazev, S. V. Ponomareva, Ural. Nauchno-Issled. Proektn. Inst. Mednoi Prom-sti. (1966). This is Chemical Abstract number 67:6081.

3. Determination of traces of impurities in pure germanium tetrachloride and germanium dioxide. E. Wunderlich, E. Goehring, Z. Erzbergbau Metallhuettenw.18, 121-124 (1965).

4. Reaction chemistry of crystalline allotropes of germania. L. Seibles, J. W. Mitchell, L. D. Blitzer, J. Am. Ceram. Soc. 72, 1430-1433 (1989).

5. Prospects of using germanium dioxide-based glasses for optics. A. Margaryan and W. M. Liu. Optical Engineering 32, 1995-1996 (1993)

6. Photoluminescence of intrinsic defects in glassy germanium dioxide. Twofold coordinated germanium and nonbridging oxygen. L. Skuja, Physica Status Solidi A: Applied Research 114, 731-737 (1989).

7. Recovery of germanium from solid wastes and neutralizing liquors from production of blanks for quartz optical fibers. V. G. Amelin, Izvestiya Vysshikh Uchebnykh Zavedenii, Khimiya i Khimicheskaya Tekhnologiya, 36, 99-102 (1993). 